\title{
ESTUDIO EXPERIMENTAL Y NUMÉRICO DEL COMPORTAMIENTO DE EXCAVACIONES EJECUTADAS MEDIANTE LA TÉCNICA DE SUELO CLAVETEADO (SOIL NAILING) EN SUELOS DE LA CIUDAD DE QUITO (ECUADOR)
}

\section{Vicente Eduardo Capa Guachón}

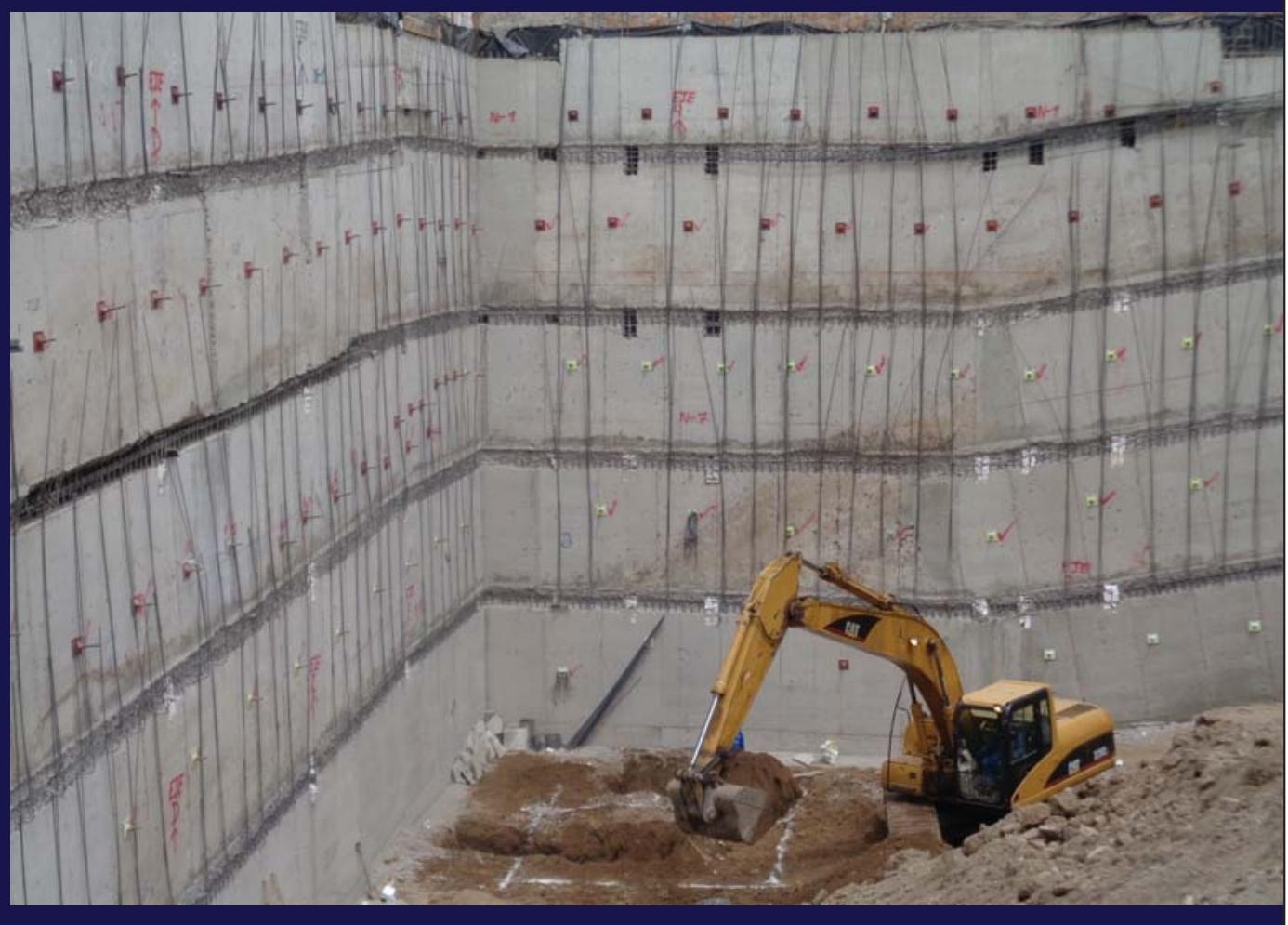

Directores:

Dr. Pedro A. Calderón García Dr. F. Javier Torrijo Echarri 



\section{UNIVERSITAT POLITÈCNICA DE VALÈNCIA}

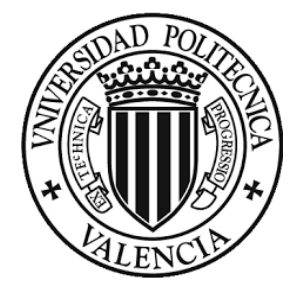

Departamento de Ingeniería de la Construcción y Proyectos de Ingeniería Civil

$\&$

Departamento de Ingeniería del Terreno

ESTUDIO EXPERIMENTAL Y NUMÉRICO DEL COMPORTAMIENTO DE EXCAVACIONES EJECUTADAS MEDIANTE LA TÉCNICA DE SUELO CLAVETEADO (SOIL NAILING) EN SUELOS DE LA CIUDAD DE QUITO (ECUADOR)

TESIS DOCTORAL

Autor

Vicente Eduardo Capa Guachón

\section{Directores}

Dr. Pedro A. Calderón García

Dr. F. Javier Torrijo Echarri

Valencia, enero de 2021 

A mis padres

A mi familia 



\section{AGRADECIMIENTOS}

El desarrollo de esta Tesis Doctoral ha representado para mi, una larga travesía, en cuyo camino y en el momento oportuno conté con el apoyo valioso y desinteresado de muchas personas y amigos, a los que quiero manifestar a través de estas líneas mis más profundos reconocimientos.

Quiero empezar expresando mi eterno agradecimiento a mis directores de tesis: Pedro A. Calderón y F. Javier Torrijo, quienes con su solvencia investigadora y profesional y además con su orientación científico-académica supieron guiar este estudio por el más alto nivel. Gracias por depositar en mi, su confianza desde el primer momento y por brindarme su amistad. En esta parte, también quiero agradecer la confianza de Ignacio Payá, quien fue parte inicial de este proyecto.

Esta investigación se llevó a cabo por varios meses en el Departamento de Ingeniería del Terreno de la Universitat Politècnica de València, especialmente en el Laboratorio de Mecánica de Suelos, en donde, en la ejecución de ensayos geotécnicos siempre conté con el apoyo clave de Carlos Hidalgo Signes, a quien expreso de manera especial mi profundo y eterno agradecimiento. De igual manera, el apoyo de Ángel Morilla fue clave en la realización de los ensayos de laboratorio, y las sugerencias de Elvira Garrido, siempre fueron muy oportunas, para ustedes mis sinceros agradecimientos. Sin lugar a duda, las facilidades brindadas por Rafael Cortés Gimeno, director del Departamento de Ingeniería del Terreno fueron fundamentales para poder realizar el estudio de caracterización geotécnica, por lo que dejo constancia de mi eterna gratitud. Mi reconocimiento también dentro de este Departamento para Asunta Cabanes y Juan Botella, de quienes siempre tuve su constante apoyo.

No puedo olvidar, la ocasión de asistir a las clases de Modelos Predictivos y de Optimización de Estructuras de Hormigón de Víctor Yepes Piqueras, a quien agradezco la oportunidad para asistir a las mismas. De igual manera agradezco a Julio Garzón Roca, por todas sus sugerencias, aportes investigativos, largas pláticas, amistad y apoyo recibido durante mis estancias en Valencia.

Mi agradecimiento para mis amigos del ICITECH de la Universitat Politècnica de València, especialmente a Daniel Tasquer, quien me ayudó con los temas electrónicos y la calibración del equipo de adquisición de datos para el estudio experimental. También el apoyo, aporte técnico y sugerencias de Manuel Buitrago Moreno siempre fueron bien recibidos y aportaron mucho para el desarrollo de la Tesis Doctoral, para ustedes mi infinita gratitud. 
Tuve las facilidades para poder realizar los ensayos de difracción de rayos $\mathrm{X}$ del estudio de caracterización geotécnica en el Laboratorio de Geología de la Universitat de València, por lo que la tutoría de Joaquín Bastida fue de vital importancia en la realización de estos ensayos. Expreso mi gratitud por todo el soporte recibido.

Durante mi estancia investigativa en el Laboratorio de Geotecnia del Departamento de Ingeniería del Terreno de la Universidad Politécnica de Cataluña, tuve la fortuna de contar con la tutoría de investigadores de prestigio: Antonio Gens y Enrique Romero, a quienes agradezco las facilidades brindadas y sus sugerencias que aportaron mucho para el desarrollo de mi investigación. Dentro de este Departamento tuve la invaluable ayuda de Rodrigo Gómez en la realización de todos los ensayos de laboratorio, para quien expreso mi gratitud. También, mi agradecimiento para Alessandro Fraccica, con quien tuve la oportunidad de compartir y coincidir en el laboratorio y supo responder mis inquietudes en el momento oportuno. Y claro, tuve la suerte de conocer a gente del Departamento que me brindaron su amistad: Rodrigo, Clara, Mauricio, Tere y Dani, gracias para todos.

Agradezco a Dennis Waterman de Plaxis BV, quien aportó importantes recomendaciones en la fase de análisis numérico con Plaxis 2D. Sus sugerencias fueron bien recibidas y sumaron en el desarrollo de esta investigación.

Sin lugar a duda, la Empresa Constructora Álvarez Bravo de la ciudad de Quito me dio todas las facilidades para poder realizar las tareas de instrumentación y monitorización del estudio experimental en sus proyectos de edificación durante todo el proceso constructivo, valoro mucho su ayuda y manifiesto mi agradecimiento. Mi gratitud también para la Empresa Pública Metropolitana Metro de Quito $(E P M M Q)$ que me facilitó importante información para complementar el estudio de caracterización geotécnica de la zona centro-norte de la ciudad de Quito.

A propósito dejé para esta instancia, para denotar mi gratitud eterna para F. Javier Torrijo (Javi), Estefanía Bona (Fanny) y su familia por todo el apoyo, acogida y amistad durante esta etapa. La vida siempre da la oportunidad de cosechar invaluables amigos.

Mi profundo agradecimiento a mi familia, siempre conté con su incondicional apoyo, especialmente a mis padres que estuvieron pendientes de esta larga travesía investigadora de varios años, por mi emprendida. Gracias por darme ánimos y por saber comprender mis aspiraciones y propósitos. Su motivación fue clave para poder terminar esta etapa y su apoyo ha sido fundamental en todos mis logros.

Gracias a la Universitat Politècnica de València por acogerme en sus instalaciones de élite para poder realizar mis Estudios de Doctorado y llevar mi investigación por los niveles más altos. Tuve la fortuna de vivir en Valencia, sus calles, paisajes, costumbres y su entorno ilustraron mi retina y fueron mis compañeros durante toda esta etapa, me llevo los mejores recuerdos de su gente y de mi estancia. 


\section{RESUMEN}

La técnica de "Soil Nailing" es un procedimiento de refuerzo del terreno utilizado continuamente en la estabilización de taludes y cortes del terreno en proyectos de ingeniería geotécnica. Esta técnica se aplica con frecuencia en la ciudad de Quito (Ecuador) para el refuerzo del terreno, mejorando la estabilidad de los taludes, durante el proceso de excavación de varios niveles de sótanos. Estas excavaciones de gran profundidad son habituales en proyectos inmobiliarios importantes de la ciudad, en los que el "Soil Nailing" se emplea con algunas variantes que la ajusten a los recursos constructivos disponibles en el medio.

Pese a lo extendido de su uso, esta técnica, que ha resultado ser efectiva para estabilizar las excavaciones durante los procesos constructivos de estructuras de sótano en los suelos de la ciudad de Quito, actualmente dispone de pocas investigaciones locales, ya sean teóricas, numéricas o experimentales, basadas en las propiedades geotécnicas de los suelos volcánicos característicos de la ciudad.

Esta Tesis Doctoral que contó con el soporte del Laboratorio de Ingeniería Geotécnica y el Laboratorio de Estructuras del Instituto de Ciencia y Tecnología del Hormigón (ICITECH) de la Universitat Politècnica de València presenta un estudio experimental y numérico del comportamiento de dos excavaciones reforzadas con la técnica de "Soil Nailing" para la construcción de las estructuras de sótano de dos importantes edificios ubicados en la zona centro-norte de la ciudad de Quito.

Tanto el estudio experimental como el numérico se enfocan principalmente en la evolución de las fuerzas de tensión en las barras de acero de los "Soil Nails", el análisis de desplazamientos horizontales de las pantallas y el análisis de asentamientos en el terreno que se encuentra detrás de las pantallas y que fueron inferidos por la construcción de cada nivel de sótano. Como parte del análisis numérico a través de elementos finitos se han considerado diferentes modelos constitutivos de suelo, cuyos parámetros se determinaron detalladamente de acuerdo a los ensayos de laboratorio del estudio de caracterización geotécnica de esta investigación.

Por tanto, esta Tesis Doctoral constituye una de las primeras investigaciones completas de la región encaminada a explicar el comportamiento experimental y numérico de excavaciones mediante la técnica de "Soil Nailing" y respaldada con un completo trabajo de caracterización geotécnica, llevado a cabo a propósito como parte de este estudio. 
Palabras clave: Suelo claveteado, muro claveteado, excavación, sótano, estudio numérico, elementos finitos, estudio experimental, instrumentación, monitorización, caracterización geotécnica, modelo constitutivo de suelo, suelo volcánico. 


\section{ABSTRACT}

The "Soil Nailing" technique is a ground reinforcement procedure used consistently to stabilize slopes and land sections in geotechnical engineering projects. This technique is frequently used in the city of Quito (Ecuador) to reinforce the ground and improve slope stability during the excavation process for various underground parking levels. Such deep excavations are common in the city's most important real estate projects, in which "Soil Nailing" is used with different variations that are adjusted in accordance with the construction resources available in the particular environment.

Despite its widespread use, this technique which has proven to be so effective in stabilizing excavations during the construction of underground structures in the soils of the city of Quito, currently suffers from a lack of local theoretical, numerical or experimental research based on the geotechnical properties of the city's characteristic soils.

This Doctoral Thesis was supported by the Geotechnical Engineering Laboratory and the Structures Laboratory of the Concrete Science and Technology Institute (ICITECH) of the Universitat Politècnica de València. It presents an experimental and numerical study of the behavior of two excavations reinforced with the Soil Nailing technique for the construction of the basement structures of two important buildings located in the north-central area of the city of Quito.

Both the experimental and the numerical study focus mainly on the stress of tension forces exerted on the steel bars of the "Soil Nails", analysis of horizontal wall displacements and analysis of settlements of the ground behind the walls, which were induced by the construction of each underground level. As part of the numerical analysis through finite elements, different constitutive soil models were considered, the parameters of which were determined in detail in accordance with laboratory testing from the geotechnical characterization study for this research.

This Doctoral Thesis, therefore, constitutes one of the first complete studies in the region aimed at explaining the experimental and numerical behavior of excavations through the Soil Nailing technique, supported by complete geotechnical characterization work which was carried out for the purpose of forming part of this study. 
Keywords: Soil nailing, soil nail wall, excavation, underground parking, underground levels, numerical study, finite elements, experimental study, instrumentation, monitoring, geotechnical characterization, constitutive soil model, volcanic soil. 


\section{RESUM}

La tècnica de "Soil Nailing" és un procediment de reforç del terreny utilitzat contínuament en l'estabilització de talussos i talls del terreny en projectes d'enginyeria geotècnica. Esta tècnica s'aplica ben sovint en la ciutat de Quito (Equador) per al reforç del terreny, millorant l'estabilitat dels talussos, durant el procés d'excavació de diversos nivells de soterranis. Estes excavacions de gran profunditat són habituals en projectes immobiliaris importants de la ciutat, en els que el "Soil Nailing" s'empra amb algunes variants que l'ajusten als recursos constructius disponibles en el mig.

A pesar d'allò que s'ha estés del seu ús, esta tècnica que ha resultat ser efectiva per a estabilitzar les excavacions durant els processos constructius d'estructures de soterrani en els sòls de la ciutat de Quito, actualment disposa de poques investigacions locals, ja siguen teòriques, numèriques o experimentals basades en les propietats geotècniques dels sòls volcànics característics de la ciutat.

Esta Tesi Doctoral que va comptar amb el suport del Laboratori d'Enginyeria Geotècnica i el Laboratori d'Estructures de l'Institut de Ciència i Tecnologia del Formigó (ICITECH) de la Universitat Politècnica de València presenta un estudi experimental i numèric del comportament de dos excavacions reforçades amb la tècnica del "Soil Nailing" per a la construcció de les estructures de soterrani de dos importants edificis ubicats en la zona centre-nord de la ciutat de Quito.

Tant l'estudi experimental com el numèric s'enfoquen principalment en l'evolució de les forces de tensió en les barres d'acer dels "Soil Nailing", l'anàlisi de desplaçaments horitzontals de les pantalles i l'anàlisi d'assentaments en el terreny que es troba darrere de les pantalles i que van ser inferits per la construcció de cada nivell de soterrani. Com a part de l'anàlisi numèrica a través d'elements finits s'han considerat diferents models constitutius de sòl, els paràmetres de la qual es van determinar detalladament d'acord amb els assajos de laboratori de l'estudi de caracterització geotècnica d'esta investigació.

Per tant, esta Tesi Doctoral constituïx una de les primeres investigacions completes de la regió encaminada a explicar el comportament experimental i numèric d'excavacions per mitjà de la tècnica del "Soil Nailing" i protegida amb un complet treball de caracterització geotècnica, dut a terme a propòsit com a part d'este estudi. 
Paraules clau: Sòl clavetejat, mur clavetejat, excavació, soterrani, estudi numèric, elements finits, estudi experimental, instrumentació, monitorització, caracterització geotècnica, model constitutiu de sòl, sòl volcànic. 


\section{ÍNDICE GENERAL}

\section{Capítulo 1. INTRODUCCIÓN Y OBJETIVOS....................................1}

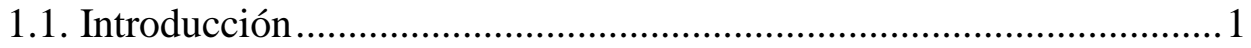

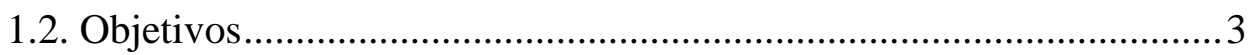

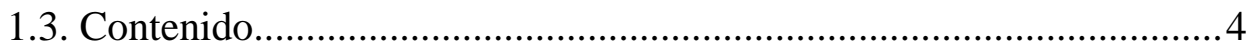

2. Capítulo 2. ESTADO DEL ARTE .................................................7

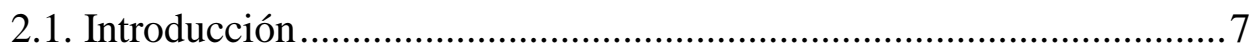

2.2. Caracterización geotécnica de suelos volcánicos .............................. 7

2.2.1. Estudios de suelos volcánicos en la ciudad de Quito .............................12

2.2.2. Estudio geotécnico para la Línea 1 de Metro Quito ................................15

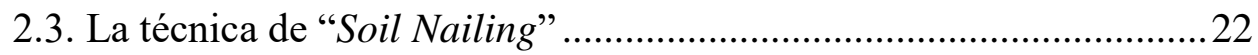

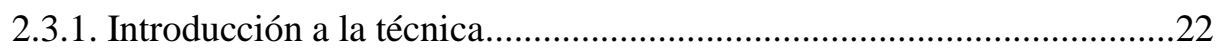

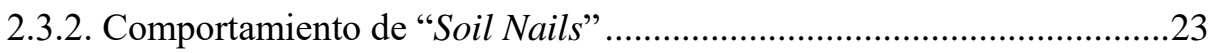

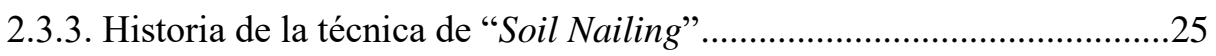

2.3.4. Componentes de un sistema de "Soil Nailing" .....................................26

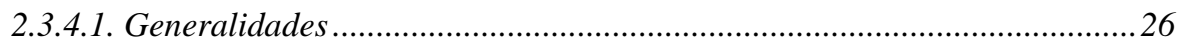

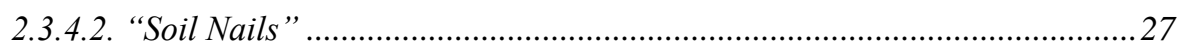

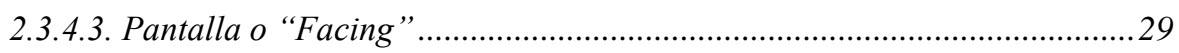

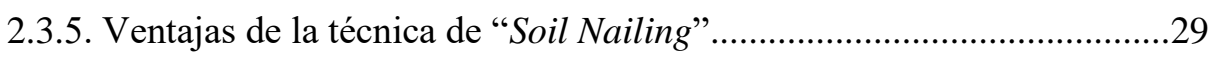

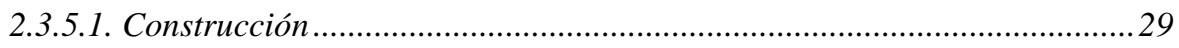

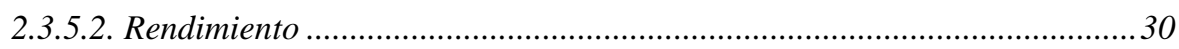

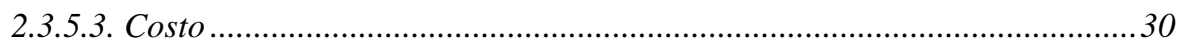

2.3.6. Limitaciones de la técnica de "Soil Nailing"...........................................30

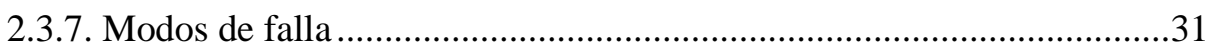

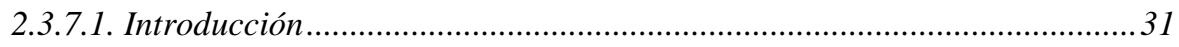

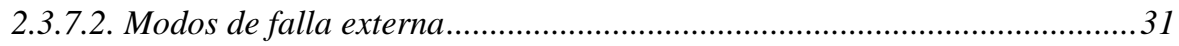

2.3.7.3. Modos de falla interna ………...................................................................... 32

2.3.8. Parámetros equivalentes para "Soil Nails".............................................32

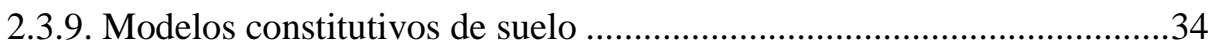

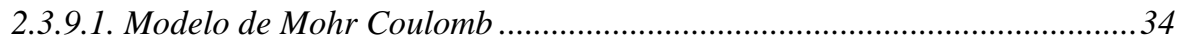




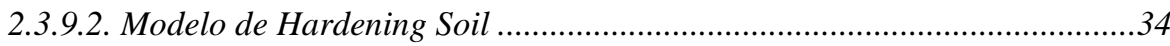

2.3.9.3. Modelo de Hardening Soil with Small-Strain Stiffness .............................37

2.4. Métodos de análisis de sistemas de "Soil Nailing" ......................... 38

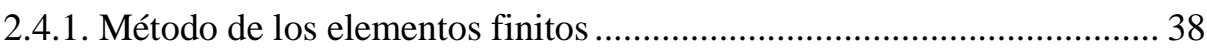

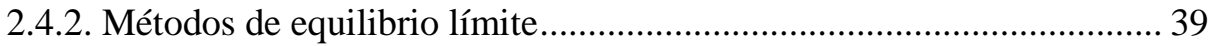

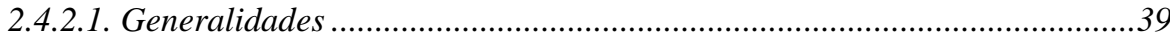

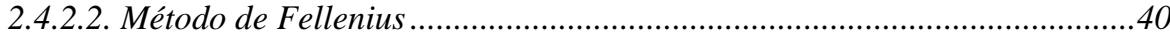

2.4.2.3. Método de Bishop simplificado ..................................................................40

2.4.2.4. Método de Janbu simplificado .....................................................................40

2.4.2.5. Método de Spencer .........................................................................................41

2.4.2.6. Método de Morgenstern-Price ..................................................................41

2.5. Resultados empíricos de excavaciones realizadas mediante la técnica

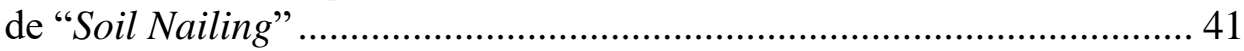

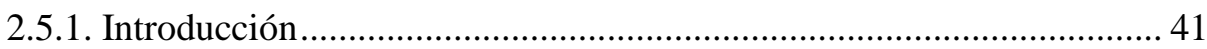

2.5.2. "Soil Nail Wall" en Manhattan (Estados Unidos).................................. 41

2.5.3. "Soil Nailing” en Dublín (Irlanda)............................................................. 43

2.6. La práctica de "Soil Nailing" en la ciudad de Quito ......................... 45

2.7. Conclusiones relativas al estado del arte........................................ 46

\section{Capítulo 3. CARACTERIZACIÓN GEOTÉCNICA DE LA ZONA}

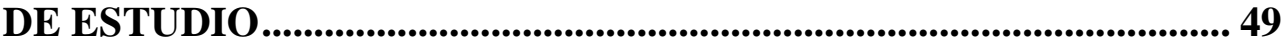

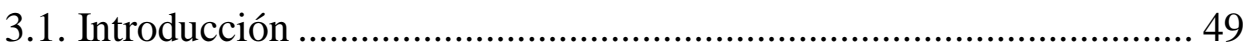

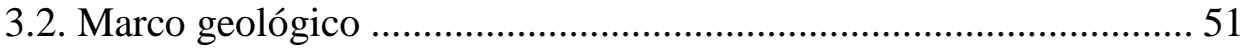

3.3. Investigaciones geotécnicas "in situ" ............................................. 54

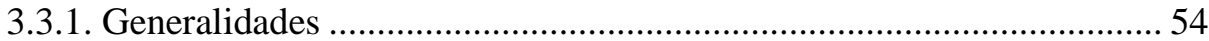

3.3.2. Ensayo de Penetración Estándar (SPT) ................................................. 55

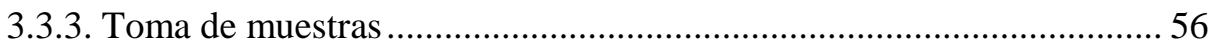

3.4. Propiedades índice y composición del suelo..................................... 56

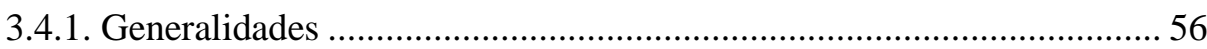

3.4.2. Contenido natural de agua y Límites de Atterberg ................................ 56

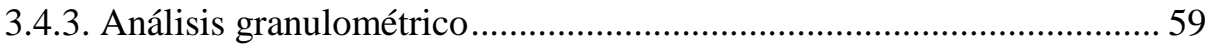




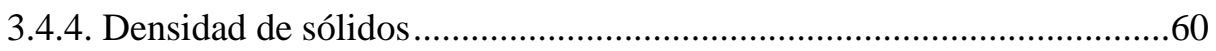

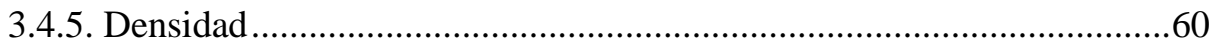

3.4.6. Relación de vacíos..............................................................................61

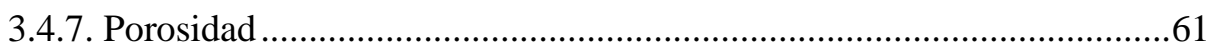

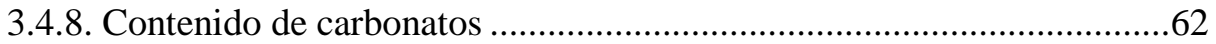

3.4.9. Contenido de materia orgánica .............................................................62

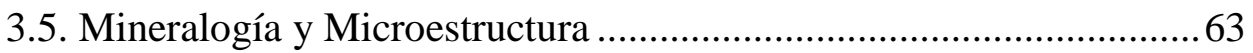

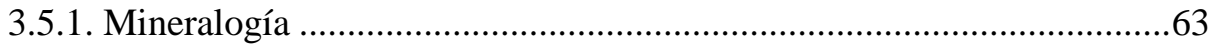

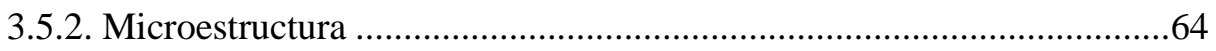

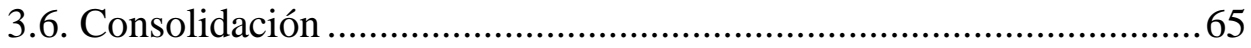

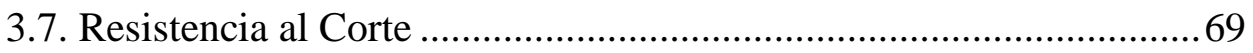

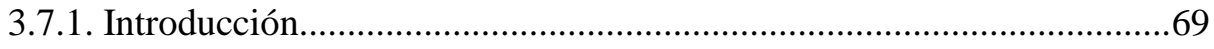

3.7.2. Resistencia al Corte No Drenada........................................................69

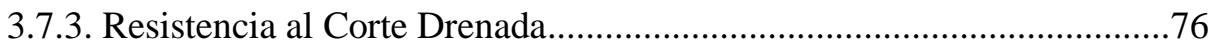

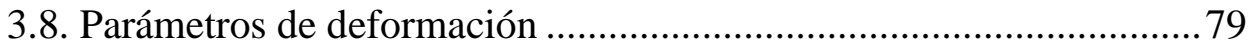

3.9. Conclusiones relativas a la caracterización geotécnica de la zona de

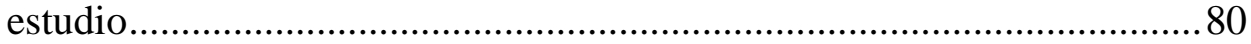

\section{Capítulo 4. PLANTEAMIENTO DEL ESTUDIO

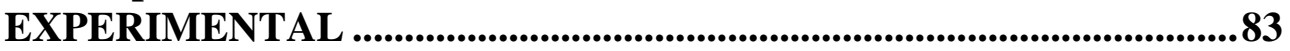

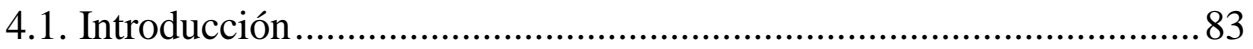

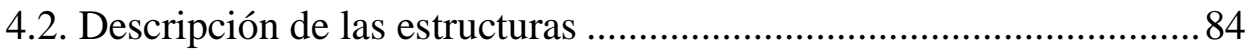

4.3. Proceso constructivo de muros de sótanos en la ciudad de Quito .....87

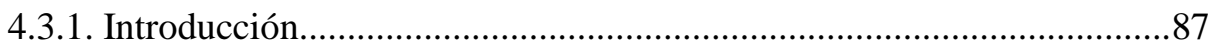

4.3.2. Secuencia constructiva de muros anclados de Torre Centre ..................88

4.3.3. Secuencia constructiva de muros anclados de Zaigen .............................93

4.3.4. Construcción de muros anclados de Torre Centre y Zaigen ................100

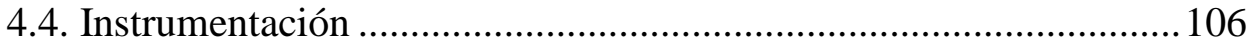

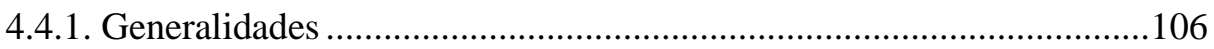

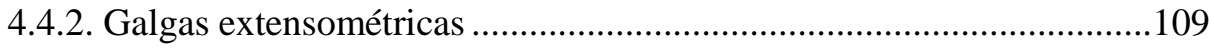

4.4.3. Bases de nivelación ..........................................................................112 
4.4.4. Proceso de instrumentación .................................................................... 113

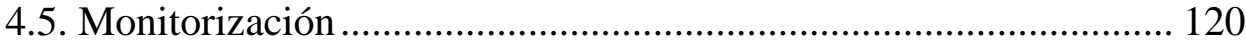

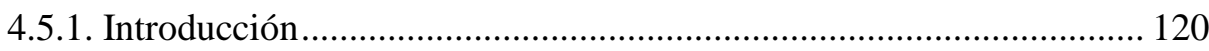

4.5.2. Instrumentos para monitorización ..................................................... 120

4.5.3. Plan de monitorización ................................................................. 122

4.6. Conclusiones relativas al planteamiento del estudio experimental. 123

\section{Capítulo 5. ANÁLISIS MEDIANTE ELEMENTOS FINITOS Y EQUILIBRIO LÍMITE ................................................................................ 125}

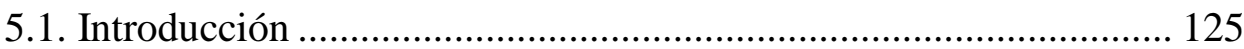

5.2. Parámetros geotécnicos para análisis ............................................ 125

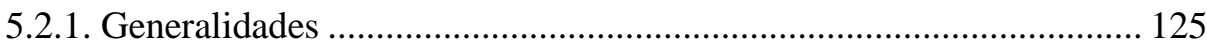

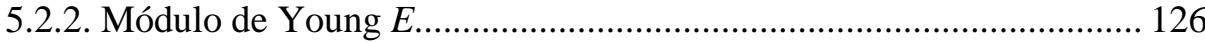

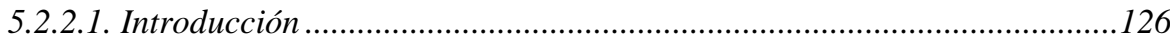

5.2.2.2. Módulo de Young E para el proyecto Torre Centre ...................................126

5.2.2.3. Módulo de Young E para el proyecto Zaigen .............................................127

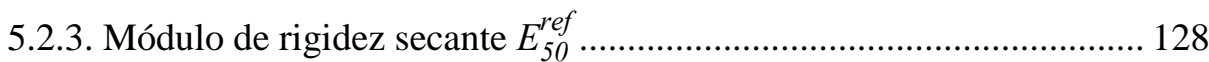

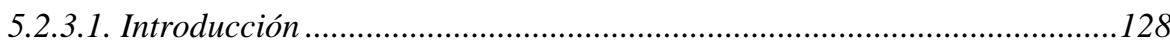

5.2.3.2. Módulo de rigidez secante $E_{50}^{r e f}$ para el proyecto Torre Centre..................128

5.2.3.3. Módulo de rigidez secante $E_{50}^{\text {ref }}$ para el proyecto Zaigen............................130

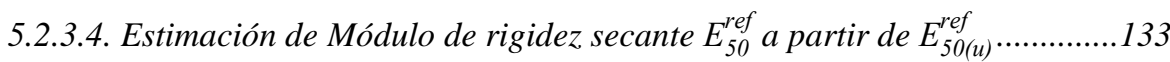

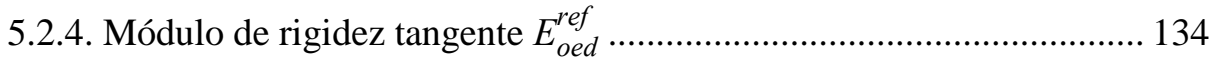

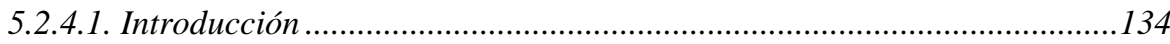

5.2.4.2. Módulo de rigidez, tangente $E_{\text {oed }}^{\text {ref }}$ para el proyecto Torre Centre ..............134

5.2.4.3. Módulo de rigidez tangente $E_{\text {oed }}^{\text {ref }}$ para el proyecto Zaigen .........................136

5.2.5. Módulo de rigidez descarga/recarga $E_{u r}^{\text {ref }}$.............................................. 138

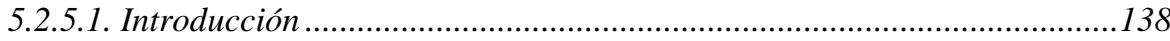

5.2.5.2. Módulo de rigidez descarga/recarga $E_{u r}^{\text {ref }}$ para el proyecto Torre Centre 138

5.2.5.3. Módulo de rigidez descarga/recarga $E_{u r}^{\text {ref }}$ para el proyecto Zaigen ..........139 
5.2.6. Módulo inicial de corte de referencia en pequeñas deformaciones $G_{0}^{r e f}$

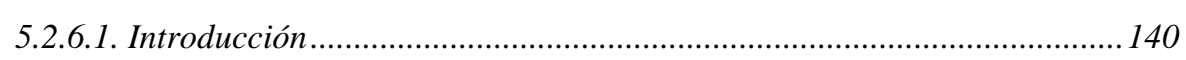

5.2.6.2. Módulo de corte de referencia $G_{0}^{\text {ref }}$ para el proyecto Torre Centre .......... 140

5.2.6.3. Módulo de corte de referencia $G_{0}^{\text {ref }}$ para el proyecto Zaigen..................... 141

5.2.7. Nivel de deformación por corte, donde $G=0.7 G_{0}, \gamma_{0.7} \ldots \ldots \ldots \ldots \ldots \ldots \ldots . . . . .143$

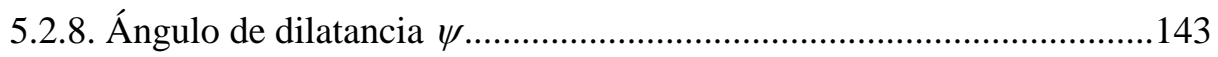

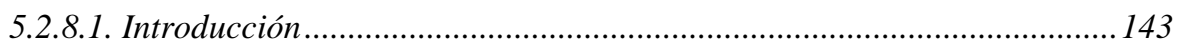

5.2.8.2. Ángulo de dilatancia $\psi$ para el proyecto Torre Centre ............................. 144

5.2.8.3. Ángulo de dilatancia $\psi$ para el proyecto Zaigen ........................................ 144

5.2.9. Resumen de parámetros geotécnicos...................................................145

5.2.9.1. Resumen de parámetros para el modelo de Mohr Coulomb (MC) .......... 145

5.2.9.2. Resumen de parámetros para los modelos de Hardening Soil (HS) y Hardening Soil with Small-Strain Stiffness (HSsmall)......................................... 146

5.3. Características de pantallas y "Soil Nails” para análisis................... 148

5.4. Estudio por el método de los elementos finitos ............................... 150

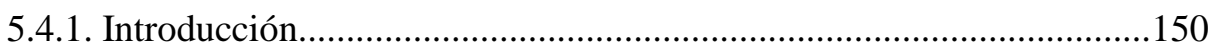

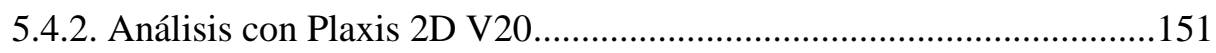

5.4.3. Análisis de estructura de proyecto Torre Centre ..................................151

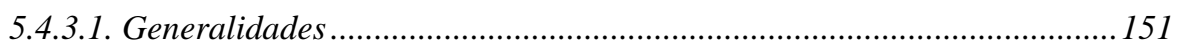

5.4.3.2. Diagramas de fuerza axial de tensión en "Soil Nails" de Torre Centre.. 155

5.4.3.3. Desplazamientos horizontales y verticales inducidos en Torre Centre ... 164

5.4.4. Análisis de estructura de proyecto Zaigen..........................................169

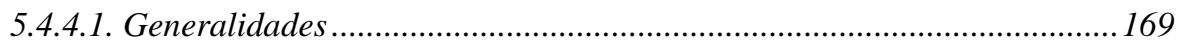

5.4.4.2. Diagramas de fuerza axial de tensión en "Soil Nails" de Zaigen ............173

5.4.4.3. Desplazamientos horizontales y verticales inducidos en Zaigen .............. 182

5.5. Análisis de estabilidad global de estructuras de "Soil Nailing" ...... 187

5.5.1. Generalidades .................................................................................... 187

5.5.2. Análisis de estabilidad global de estructura de proyecto Torre Centre 188

5.5.3. Análisis de estabilidad global de estructura de proyecto Zaigen 189 
5.6. Conclusiones relativas al análisis mediante elementos finitos y

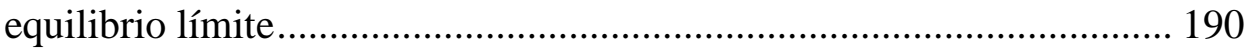

\section{Capítulo 6. RESULTADOS DEL ESTUDIO EXPERIMENTAL 193}

6.1. Introducción 193

6.2. Resultados experimentales por fases constructivas ....................... 194

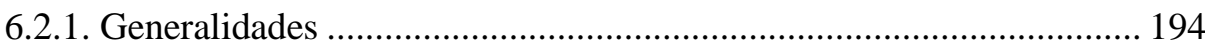

6.2.2. Fuerza axial en barras de acero de "Soil Nails".................................. 194

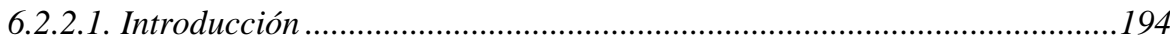

6.2.2.2. Fuerza axial en barras de acero de "Soil Nails" de Torre Centre ...........194

6.2.2.3. Fuerza axial en barras de acero de "Soil Nails" de Zaigen ......................203

6.2.2.4. Efectos de la temperatura en las lecturas de "Strain".............................212

6.2.3. Desplazamientos horizontales y verticales medidos en excavaciones 212

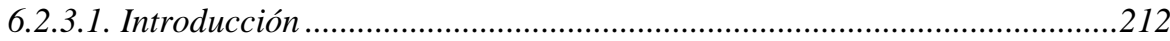

6.2.3.2. Desplazamientos horizontales y verticales medidos en Torre Centre ......213

6.2.3.3. Desplazamientos horizontales y verticales medidos en Zaigen.................218

6.3. Comparación de resultados experimentales y numéricos ............... 224

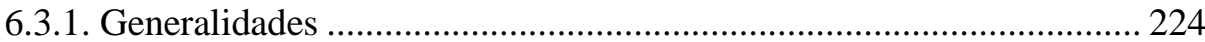

6.3.2. Comparación de fuerza axial en barras de acero de "Soil Nails" ....... 224

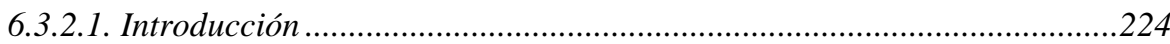

6.3.2.2. Comparación de fuerza axial en barras de acero de "Soil Nails" de Torre

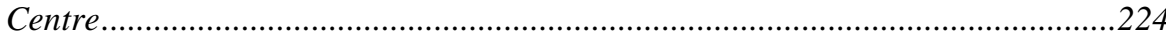

6.3.2.3. Comparación de fuerza axial en barras de acero de "Soil Nails" de Zaigen

6.3.3. Comparación de desplazamientos horizontales en pantallas ............... 239

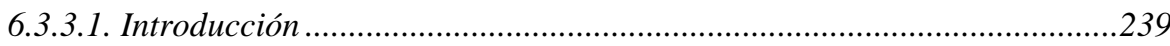

6.3.3.2. Comparación de desplazamientos horizontales en pantalla de Torre Centre .239

6.3.3.3. Comparación de desplazamientos horizontales en pantalla de Zaigen....241

6.3.4. Comparación de asentamientos en el terreno detrás de pantallas ....... 244

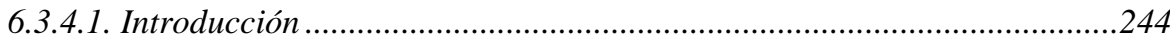

6.3.4.2. Comparación de asentamientos en el terreno detrás de pantalla de Torre Centre. 244 
6.3.4.3. Comparación de asentamientos en el terreno detrás de pantalla de Zaigen .246

6.4. Conclusiones relativas a los resultados del estudio experimental ...249

7. Capítulo 7. CONCLUSIONES Y FUTURAS LÍNEAS DE INVESTIGACIÓN .........................................................................251

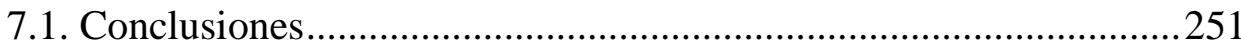

7.2. Futuras líneas de investigación.................................................255

REFERENCIAS .......................................................................................257

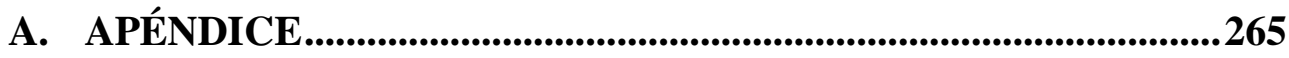

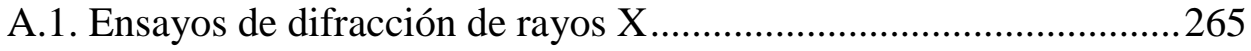

A.2. Ensayos de consolidación unidimensional ...................................2270

A.3. Trayectorias de tensiones efectivas en ensayos triaxiales tipo $C U .275$ 
Estudio experimental y numérico del comportamiento de excavaciones ejecutadas mediante la técnica de suelo claveteado (Soil Nailing) en suelos de la ciudad de Quito (Ecuador) 


\section{ÍNDICE DE FIGURAS}

Fig. 1.1 Estructura de "Soil Nailing" en sótanos de edificios en la ciudad de Quito.1

Fig. 2.1 Ubicación de perforaciones de estudio de Metro Quito en zona centro-norte.

Fig. 2.2 Perfil geológico - geotécnico de Línea 1 de Metro Quito, pk 27+600 y pk

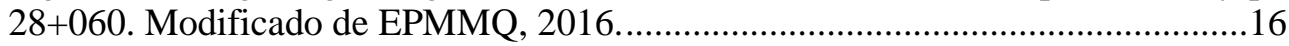

Fig. 2.3 Perfil geológico - geotécnico de Línea 1 de Metro Quito, pk 28+060 y pk

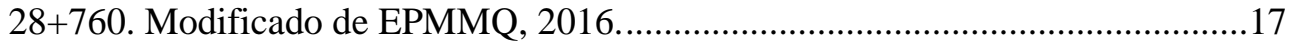

Fig. 2.4 Perfil geológico - geotécnico de Línea 1 de Metro Quito, pk 28+760 y pk 29+460. Modificado de EPMMQ, 2016.............................................................18

Fig. 2.5 Perfil geológico - geotécnico de Línea 1 de Metro Quito, pk 29+460 y pk 30+160. Modificado de EPMMQ, 2016

Fig. 2.6 Aplicaciones típicas de técnica de "Soil Nailing": (a) en talud existente, y (b) en excavación.

Fig. 2.7 Localización de máximas fuerzas de tracción en "Nails". Modificado de

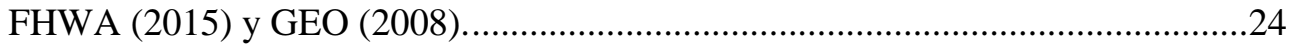

Fig. 2.8 Componentes principales de un sistema de "Soil Nailing". .27

Fig. 2.9 Barras de acero utilizadas en "Soil Nailing". .28

Fig. 2.10 Centrador típico de PVC (FHWA, 2015). La separación indicada es sólo esquemática.

Fig. 2.11 Cabezas de "Nail": (a) "Soil Nail" temporal, (b) "Soil Nail" permanente, y (c) "Soil Nail" con doblez de barra de acero (Ortigao y Sayao, 2004).

Fig. 2.12 Modos potenciales de falla externa en sistemas "Soil Nailing": (a) Falla de estabilidad global, (b) Falla de estabilidad al deslizamiento, y (c) Falla de capacidad de carga. Modificado de GEO (2008). .31

Fig. 2.13 Idea básica de un modelo elástico perfectamente plástico (Plaxis, 2020). 
Fig. 2.14 Definición de $E_{50}^{r e f}$ y $E_{u r}^{r e f}$ para resultados de ensayo triaxial drenado (Plaxis, 2020). 35

Fig. 2.15 Definición de $E_{\text {oed }}^{\text {ref }}$ para resultados de ensayo edométrico (Plaxis, 2020).

Fig. 2.16 Muro claveteado en Manhattan: (a) Vista en planta de geometría de excavación y ubicación de secciones de muro instrumentadas, (b) Sección instrumentada IN-1, y (c) Secciones instrumentadas IN-2 e IN-3 (Holman y Tuozzolo, 2009).

Fig. 2.17 "Soil Nailing” en Dublín: (a) Sección transversal típica (Menkiti y Long, 2008), y (b) Construcción de "Soil Nails" y "Shotcrete" (Menkiti et al., 2013). ... 44

Fig. 2.18 Tensiones [kN] en "Soil Nails" en ubicación de "Strain Gauges" y posible superficie de deslizamiento, que fue controlada (Menkiti et al., 2013).................. 44

Fig. 2.19 Variación de potenciales superficies de deslizamiento y fuerzas de tensión en "Soil Nails". Modificado de (FHWA, 2015). 45

Fig. 2.20 Construcción de niveles de sótano en edificaciones en la zona centro-norte de la ciudad de Quito: (a) Edificio Sense (enero 2020), y (b) Edificio Narelo (diciembre 2019) 46

Fig. 3.1 Mapa de Ecuador y ubicación de la zona de estudio. 50

Fig. 3.2 (a) Mapa tectónico de Ecuador, y (b) Sección tectónica esquemática hacia el norte de Ecuador. Modificado de Martin-Gombojav y Winkler (2008) y Ruiz et al. (2007).

Fig. 3.3 (a) Depósito sedimentario tipo coluvión en zona de sondeo AMA1. Gravas y bloques de roca embebidos en matriz limo arenosa a $7.10 \mathrm{~m}$ de profundidad, y (b) Perfil de suelo residual entre 0.0 y $3.0 \mathrm{~m}$ de profundidad en zona de sondeo JAP1. Descripción de columna estratigráfica in situ.......................................................... 53

Fig. 3.4 Ubicación de los 3 sondeos de perforación: AMA1, JAP1 y AUS1........... 54

Fig. 3.5 (a) Ensayos tipo SPT en función de la profundidad, y (b) $O C R$ en función de

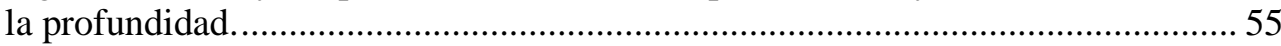

Fig. 3.6 Contenido natural de agua, límite líquido y límite plástico: (a) perforación JAP1, (b) perforación AMA1, y (c) perforación AUS1. ........................................ 57 
Fig. 3.7 Índice de liquidez versus profundidad para perforaciones JAP1, AMAl y AUS1.....

Fig. 3.8 Plasticidad de los suelos: (a) perforación $J A P 1$, (b) perforación AMA1, y (c) perforación AUS1. .58

Fig. 3.9 Distribución del tamaño de partículas: (a) perforación $J A P 1$, (b) perforación AMA1, y (c) perforación AUS1.

Fig. 3.10 (a) Densidad de sólidos versus profundidad para muestras de JAP1, AMA1 y $A U S 1$, y (b) Densidad versus profundidad para especímenes de JAP1, AMAl y AUS1. .60

Fig. 3.11 (a) Relación de vacíos versus profundidad para muestras de JAP1 y AMAl, y (b) Porosidad versus profundidad para especímenes de JAPl y AMAl. .61

Fig. 3.12 (a) Contenido de carbonato versus profundidad para muestras de JAP1 y $A M A 1$, y (b) Contenido de materia orgánica versus profundidad para muestras de JAP1 y AMA1. .62

Fig. 3.13 Análisis de difracción de rayos X para las muestras de JAP1 y AMA1. ..64

Fig. 3.14 Micrografías de ensayos SEM: (a) JAPl: $3.50 \mathrm{~m}$ de profundidad, (b) JAPl: $7.50 \mathrm{~m}$ de profundidad, (c) JAPl: $9.00 \mathrm{~m}$ de profundidad, (d) $J A P 1: 11.00 \mathrm{~m}$ de profundidad, (e) AMAl: $1.80 \mathrm{~m}$ de profundidad, y (f) AMAl: $8.00 \mathrm{~m}$ de profundidad.

Fig. 3.15 Ensayos de consolidación unidimensional de las muestras de las perforaciones JAP1 y AMA1. .66

Fig. 3.16 Correlación del (a) índice de compresión $\left(C_{c}\right)$ y (b) índice de expansión $\left(C_{s}\right)$ con el contenido natural de agua $\left(w_{n a t}\right)$ y el límite líquido $(L L)$, y (c) Correlación de índices de compresión $\left(C_{c}\right)$ y expansión $\left(C_{s}\right)$ con la relación inicial de vacíos $\left(e_{0}\right)$.

Fig. 3.17 Comportamiento del suelo según el concepto de Burland (1990). .68

Fig. 3.18 Célula triaxial del Laboratorio de Mecánica de Suelos (Departamento de Ingeniería del Terreno) de la Universitat Politècnica de València.

Fig. 3.19 Curvas esfuerzo-deformación unitaria-presión de poros para muestras de JAP1 y AMA1. .71 
Fig. 3.20 (a) Variación de la relación de esfuerzos $\sigma_{1}^{\prime} / \sigma_{3}^{\prime}$ para muestras de las perforaciones $J A P l$ y $A M A 1$, y (b) Variación de la relación de esfuerzos $q / p$ ' para muestras de los sondeos JAPl y AMAl.

Fig. 3.21 Ángulo de fricción efectivo secante para muestras de perforaciones JAPI y AMA1.

Fig. 3.22 Trayectoria de tensiones efectivas: (a) y (b) muestras de perforación JAPl, y (c) muestras de perforación AMA1. 74

Fig. 3.23 Ángulos de fricción pico estimados en pruebas triaxiales para muestras de perforaciones JAP1 y AMA1. 75

Fig. 3.24 Correlación entre valores de $N_{S P T}$ y el ángulo de fricción $(\varnothing)$. 76

Fig. 3.25 Curvas esfuerzo-deformación unitaria-variación de volumen para muestras de JAPl y AMAl. 77

Fig. 3.26 Gráficos de esfuerzo cortante versus esfuerzo normal para el criterio de falla asumido en ensayos de compresión triaxial consolidados drenados: (a) espécimen $J A P 1$, profundidad $13.50 \mathrm{~m}$, y (b) espécimen $A M A 1$, profundidad $8.00 \mathrm{~m}$. 78

Fig. 4.1 Ubicación de estructuras para instrumentación y monitorización. 84

Fig. 4.2 Edificio Torre Centre: (a) Implantación - vista en planta, y (b) Elevación principal 85

Fig. 4.3 Edificio Zaigen: (a) Implantación - vista en planta, y (b) Corte principal. 86

Fig. 4.4 Construcción de sótano 1 en Torre Centre: (a) Excavación, (b) Perforaciones para anclajes, (c) Construcción de anclajes, conformación vertical de talud, instalación de acero de refuerzo y hormigonado de pantalla, y (d) Instalación de placas de acero en barras de anclaje. 88

Fig. 4.5 Construcción de sótano 2 en Torre Centre: (a) Excavación, (b) Perforaciones para anclajes, (c) Construcción de anclajes, conformación vertical de talud, instalación de acero de refuerzo y hormigonado de pantalla, y (d) Instalación de placas de acero en barras de anclaje. 89

Fig. 4.6 Construcción de sótano 3 en Torre Centre: (a) Excavación, (b) Perforaciones para anclajes, (c) Construcción de anclajes, conformación vertical de talud, 
instalación de acero de refuerzo y hormigonado de pantalla, y (d) Instalación de placas de acero en barras de anclaje.

Fig. 4.7 Construcción de sótano 4 en Torre Centre: (a) Excavación, (b) Perforaciones para anclajes, (c) Construcción de anclajes, conformación vertical de talud, instalación de acero de refuerzo y hormigonado de pantalla, y (d) Instalación de placas de acero en barras de anclaje.

Fig. 4.8 Construcción de sótano 5 en Torre Centre: (a) Excavación, (b) Perforaciones para anclajes, y (c) Construcción de anclajes, conformación vertical de talud, instalación de acero de refuerzo y hormigonado de pantalla. .92

Fig. 4.9 Construcción de sótano 5 en Torre Centre: Instalación de placas de acero en barras de anclaje.

Fig. 4.10 Construcción de sótano 1 en Zaigen: (a) Excavación, (b) Perforaciones para anclajes, (c) Construcción de anclajes, conformación vertical de talud, instalación de acero de refuerzo y hormigonado de pantalla, y (d) Instalación de placas de acero en barras de anclaje. .94

Fig. 4.11 Construcción de sótano 2 en Zaigen: (a) Excavación, (b) Perforaciones para anclajes, (c) Construcción de anclajes, conformación vertical de talud, instalación de acero de refuerzo y hormigonado de pantalla, y (d) Instalación de placas de acero en barras de anclaje. .95

Fig. 4.12 Construcción de sótano 3 en Zaigen: (a) Excavación, (b) Perforaciones para anclajes, (c) Construcción de anclajes, conformación vertical de talud, instalación de acero de refuerzo y hormigonado de pantalla, y (d) Instalación de placas de acero en barras de anclaje. . .96

Fig. 4.13 Construcción de sótano 4 en Zaigen: (a) Excavación, (b) Perforaciones para anclajes, (c) Construcción de anclajes, conformación vertical de talud, instalación de acero de refuerzo y hormigonado de pantalla

Fig. 4.14 Construcción de sótano 4 en Zaigen: Instalación de placas de acero en barras de anclaje. .98

Fig. 4.15 Construcción de sótano 5 en Zaigen: Excavación. .98

Fig. 4.16 Construcción de sótano 5 en Zaigen: (a) Perforaciones para anclajes, y (b) Construcción de anclajes, conformación vertical de talud, instalación de acero de refuerzo y hormigonado de pantalla. .99 
Fig. 4.17 Construcción de sótano 5 en Zaigen: Instalación de placas de acero en barras de anclaje. 100

Fig. 4.18 Excavaciones para primer nivel de sótanos de edificios: (a) y (b) Torre Centre, y (c) y (d) Zaigen. 101

Fig. 4.19 Perforaciones para "Soil Nails" de muros de edificios: (a) y (b) Torre Centre, y (c) y (d) Zaigen. 102

Fig. 4.20 Construcción de "Soil Nails" para muros: (a) centrador de barras de acero, (b) ingreso de barra de acero en perforación, (c) barra de acero en perforaciones para anclajes de muros de Torre Centre, (d) barra de acero en perforaciones para anclajes de muros de Zaigen, (e) inyección de "Grout" en anclajes para muros de Torre Centre, y (f) inyección de "Grout" en anclajes para muros de Zaigen. 103

Fig. 4.21 Colocación de acero de refuerzo para muro de Torre Centre, y (b) Colocación de acero de refuerzo para muro de Zaigen. 104

Fig. 4.22 (a) Hormigonado de muro de Torre Centre mediante sistema de encofrados, y (b) Hormigonado de muro de Zaigen mediante "Shotcrete". 104

Fig. 4.23 (a) y (b) Colocación de placas de acero en barras de anclajes de muro de Torre Centre, y (c) y (d) Colocación de placas de acero en barras de anclajes de muro de Zaigen. 105

Fig. 4.24 (a) Muros anclados para sótanos de 5 niveles mediante la técnica de "Soil Nailing" para los edificios: (a) Torre Centre, y (b) Zaigen. 105

Fig. 4.25 Pantalla anclada de sótanos de Torre Centre para estudio experimental: (a) Ubicación de sección transversal de pantalla anclada, y (b) Sección transversal de pantalla anclada. 107

Fig. 4.26 Pantalla anclada de sótanos de Zaigen para estudio experimental: (a) Ubicación de sección transversal de pantalla anclada, y (b) Sección transversal de pantalla anclada. 108

Fig. 4.27 Galgas extensométricas utilizadas en la instrumentación: (a) Galgas extensométricas precableadas, y (b) Diagrama de galga extensométrica. 109

Fig. 4.28 (a) Preparación de superficie de la barra, (b) Uso de adhesivo HBM Z70 en contacto de superficie - galga, (c) y (d) Instalación de galga extensométrica en barra de acero 110 
Fig. 4.29 (a) y (b) Protección de galgas extensométricas con masilla AK22, y (c) y (d) Protección de galgas extensométricas con lámina ABM75.

Fig. 4.30 (a) y (b) Barras de acero instrumentadas para anclajes tipo "Soil Nails". 111

Fig. 4.31 (a) y (b) Instalación de bases de nivelación en proyecto Torre Centre, (c) y (d) Instalación de bases de nivelación en proyecto Zaigen.

Fig. 4.32 (a) y (b) Puntos de control de deformaciones en pantalla de Torre Centre, y (c) y (d) Puntos de control de deformaciones en pantalla de Zaigen. 113

Fig. 4.33 Instrumentación de pantalla de Torre Centre: (a) Instrumentación de "Soil Nail" de sótano 1, y (b) Instrumentación de "Soil Nail" de sótano 2 .....................114

Fig. 4.34 Instrumentación de pantalla de Torre Centre: (a) Instrumentación de "Soil Nail" de sótano 3, y (b) Instrumentación de "Soil Nail" de sótano 4. .115

Fig. 4.35 Instrumentación de pantalla de Torre Centre: Instrumentación de "Soil Nail" de sótano 5 . 116

Fig. 4.36 Instrumentación de pantalla de Zaigen: (a) Instrumentación de "Soil Nail" de sótano 1, y (b) Instrumentación de "Soil Nail" de sótano 2.

Fig. 4.37 Instrumentación de pantalla de Zaigen: (a) Instrumentación de "Soil Nail" de sótano 3, y (b) Instrumentación de "Soil Nails" de sótano 4. 118

Fig. 4.38 Instrumentación de pantalla de Zaigen: Instrumentación de "Soil Nail" de sótano 5 .

Fig. 4.39 (a) y (b) Monitorización de anclajes de pantalla de Torre Centre, y (c) y (d) Monitorización de anclajes de pantalla de Zaigen.

Fig. 4.40 (a) y (b) Control de deformaciones en proyecto Torre Centre, y (c) y (d) Control de deformaciones en proyecto Zaigen.

Fig. 5.1 Determinación de módulo de elasticidad tangente $E$ de ensayo triaxial $C D$ en sondeo AMAl $8.00 \mathrm{~m}$ con presión de confinamiento $\sigma_{3}^{\prime}=100 \mathrm{kPa}$.

Fig. 5.2 Determinación de módulo de elasticidad tangente $E$ de ensayo triaxial $C D$ en sondeo JAP1 $13.50 \mathrm{~m}$ con presión de confinamiento $\sigma_{3}{ }_{3}=100 \mathrm{kPa}$. 
Fig. 5.3 Determinación de módulo de rigidez secante $E_{50}$ de ensayo triaxial $C D$ en sondeo AMAl $8.00 \mathrm{~m}$ con presión de confinamiento $\sigma_{3}^{\prime}=100 \mathrm{kPa}$.

128

Fig. 5.4 Determinación de módulo de rigidez secante $E_{50}$ de ensayo triaxial $C D$ en sondeo AMA1 $8.00 \mathrm{~m}$ con presión de confinamiento $\sigma_{3}^{\prime}=200 \mathrm{kPa}$ 129

Fig. 5.5 Determinación de módulo de rigidez secante $E_{50}$ de ensayo triaxial $C D$ en sondeo AMA1 $8.00 \mathrm{~m}$ con presión de confinamiento $\sigma_{3}^{\prime}=300 \mathrm{kPa}$ 129

Fig. 5.6 Determinación del módulo de rigidez $E_{50}^{r e f}$ para AMA1 $8.00 \mathrm{~m}$ de Torre Centre. 130

Fig. 5.7 Determinación de módulo de rigidez secante $E_{50}$ de ensayo triaxial $C D$ en sondeo JAP1 $13.50 \mathrm{~m}$ con presión de confinamiento $\sigma_{3}^{\prime}=50 \mathrm{kPa}$.

Fig. 5.8 Determinación de módulo de rigidez secante $E_{50}$ de ensayo triaxial $C D$ en sondeo JAP1 $13.50 \mathrm{~m}$ con presión de confinamiento $\sigma_{3}^{\prime}=100 \mathrm{kPa}$

Fig. 5.9 Determinación de módulo de rigidez secante $E_{50}$ de ensayo triaxial $C D$ en sondeo JAPl $13.50 \mathrm{~m}$ con presión de confinamiento $\sigma_{3}^{\prime}=200 \mathrm{kPa}$. 132

Fig. 5.10 Determinación de módulo de rigidez secante $E_{50}$ de ensayo triaxial $C D$ en sondeo JAP1 $13.50 \mathrm{~m}$ con presión de confinamiento $\sigma_{3}^{\prime}=300 \mathrm{kPa}$ 132

Fig. 5.11 Determinación del módulo de rigidez $E_{50}^{\text {ref }}$ para JAP1 $13.50 \mathrm{~m}$ de Zaigen. 133

Fig. 5.12 Determinación de módulo de rigidez tangente $E_{\text {oed }}$ de ensayo edométrico en sondeo AMAl $1.50 \mathrm{~m}$. 135

Fig. 5.13 Determinación de módulo de rigidez tangente $E_{\text {oed }}$ de ensayo edométrico en sondeo AMA1 $7.50 \mathrm{~m}$. 135

Fig. 5.14 Determinación de módulo de rigidez tangente $E_{\text {oed }}$ de ensayo edométrico en sondeo JAPl $6.50 \mathrm{~m}$. 137

Fig. 5.15 Determinación de módulo de rigidez tangente $E_{\text {oed }}$ de ensayo edométrico en sondeo JAPl $14.50 \mathrm{~m}$. 137

Fig. 5.16 Determinación de módulo de rigidez descarga/recarga $E_{u r}$ de ensayo triaxial $C D$ en sondeo JAP1 $13.50 \mathrm{~m}$ con presión de confinamiento $\sigma_{3}{ }_{3}=250 \mathrm{kPa}$. 
Fig. 5.17 Deformación unitaria volumétrica, $\varepsilon_{v}$ - Deformación unitaria axial, $\varepsilon_{s}$ de ensayo triaxial $C D$ en sondeo $A M A 18.00 \mathrm{~m}$ con presión de confinamiento $\sigma^{\prime}{ }_{3}=100$ $\mathrm{kPa}$. 144

Fig. 5.18 Deformación unitaria volumétrica, $\varepsilon_{v}$ - Deformación unitaria axial, $\varepsilon_{s}$ de ensayo triaxial $C D$ en sondeo JAPl $13.50 \mathrm{~m}$ con presión de confinamiento $\sigma_{3}{ }_{3}=100$ $\mathrm{kPa}$. 144

Fig. 5.19 Modelo inicial con Plaxis 2D de estructura de "Soil Nailing" de proyecto Torre Centre. 152

Fig. 5.20 Modelo final con Plaxis 2D de estructura de "Soil Nailing" de proyecto Torre Centre. 152

Fig. 5.21 Fases constructivas simuladas con Plaxis 2D para estructura de proyecto Torre Centre. 153

Fig. 5.22 Desplazamientos totales $|\mathrm{u}|$ con modelo de Mohr Coulomb por construcción de sótano 5 .

Fig. 5.23 Desplazamientos totales $|\mathrm{u}|$ con modelo de Hardening Soil por construcción de sótano 5 .

Fig. 5.24 Desplazamientos totales $|\mathrm{u}|$ con modelo de HSsmall por construcción de sótano 5 . 155

Fig. 5.25 Distribución de fuerzas axiales de tensión en "Soil Nails" por construcción de sótano 1 de Torre Centre. 155

Fig. 5.26 Distribución de fuerzas axiales de tensión en "Soil Nails" por construcción de sótano 2 de Torre Centre. .156

Fig. 5.27 Distribución de fuerzas axiales de tensión en "Soil Nails" por construcción de sótano 3 de Torre Centre.

Fig. 5.28 Distribución de fuerzas axiales de tensión en "Soil Nails" por construcción de sótano 4 de Torre Centre. .158

Fig. 5.29 Distribución de fuerzas axiales de tensión en "Soil Nails" por construcción de sótano 5 de Torre Centre. 159

Fig. 5.30 Análisis sísmico pseudoestático: Distribución de fuerzas axiales de tensión en "Soil Nails" para la altura total de $13.55 \mathrm{~m}$ en estructura de Torre Centre......160 
Fig. 5.31 Evolución de fuerzas de tensión en los "Soil Nails" con las fases constructivas según modelo constitutivo de Mohr Coulomb para estructura de Torre Centre.

Fig. 5.32 Evolución de fuerzas de tensión en los "Soil Nails" con las fases constructivas según modelo constitutivo de Hardening Soil para estructura de Torre Centre. 162

Fig. 5.33 Evolución de fuerzas de tensión en los "Soil Nails" con las fases constructivas según modelo constitutivo de HSsmall para estructura de Torre Centre.

Fig. 5.34 Desplazamientos inducidos por construcción de sótano 1 de Torre Centre: (a) desplazamientos horizontales en pantalla, y (b) asentamientos del terreno detrás de la pantalla. 164

Fig. 5.35 Desplazamientos inducidos por construcción de sótano 2 de Torre Centre: (a) desplazamientos horizontales en pantalla, y (b) asentamientos del terreno detrás de la pantalla. 165

Fig. 5.36 Desplazamientos inducidos por construcción de sótano 3 de Torre Centre: (a) desplazamientos horizontales en pantalla, y (b) asentamientos del terreno detrás de la pantalla. 165

Fig. 5.37 Desplazamientos inducidos por construcción de sótano 4 de Torre Centre: (a) desplazamientos horizontales en pantalla, y (b) asentamientos del terreno detrás de la pantalla. 166

Fig. 5.38 Desplazamientos inducidos por construcción de sótano 5 de Torre Centre: (a) desplazamientos horizontales en pantalla, y (b) asentamientos del terreno detrás de la pantalla. 166

Fig. 5.39 Desplazamientos en Torre Centre $(\mathrm{H}=13.55 \mathrm{~m})$ por análisis sísmico pseudoestático: (a) desplazamientos horizontales en pantalla, y (b) asentamientos del terreno detrás de la pantalla. 167

Fig. 5.40 Desplazamientos en Torre Centre por construcción de sótanos (modelo de Mohr Coulomb): (a) desplazamientos horizontales en pantalla, y (b) asentamientos del terreno detrás de la pantalla. 168

Fig. 5.41 Desplazamientos en Torre Centre por construcción de sótanos (modelo de Hardening Soil): (a) desplazamientos horizontales en pantalla, y (b) asentamientos del terreno detrás de la pantalla. 168 
Fig. 5.42 Desplazamientos en Torre Centre por construcción de sótanos (modelo de HSsmall): (a) desplazamientos horizontales en pantalla, y (b) asentamientos del terreno detrás de la pantalla.

Fig. 5.43 Modelo inicial con Plaxis 2D de estructura de "Soil Nailing" de proyecto Zaigen. 170

Fig. 5.44 Modelo final con Plaxis 2D de estructura de "Soil Nailing" de proyecto Zaigen 170

Fig. 5.45 Fases constructivas simuladas con Plaxis 2D para estructura de proyecto Zaigen.

Fig. 5.46 Desplazamientos totales $|\mathrm{u}|$ con modelo de Mohr Coulomb por construcción de sótano 5. 172

Fig. 5.47 Desplazamientos totales $|\mathrm{u}|$ con modelo de Hardening Soil por construcción de sótano 5 . 172

Fig. 5.48 Desplazamientos totales $|\mathrm{u}|$ con modelo de HSsmall por construcción de sótano 5 . 173

Fig. 5.49 Distribución de fuerzas axiales de tensión en "Soil Nails" inducidas por construcción de sótano 1 de Zaigen. 173

Fig. 5.50 Distribución de fuerzas axiales de tensión en "Soil Nails" inducidas por construcción de sótano 2 de Zaigen. 174

Fig. 5.51 Distribución de fuerzas axiales de tensión en "Soil Nails" inducidas por construcción de sótano 3 de Zaigen. 175

Fig. 5.52 Distribución de fuerzas axiales de tensión en "Soil Nails" inducidas por construcción de sótano 4 de Zaigen. 176

Fig. 5.53 Distribución de fuerzas axiales de tensión en "Soil Nails" inducidas por construcción de sótano 5 de Zaigen. 177

Fig. 5.54 Análisis sísmico pseudoestático: Distribución de fuerzas axiales de tensión en "Soil Nails" para la altura total de $15.50 \mathrm{~m}$ en estructura de Zaigen. 178

Fig. 5.55 Evolución de fuerzas de tensión en los "Soil Nails" con las fases constructivas según modelo constitutivo de Mohr Coulomb para estructura de Zaigen. 179 
Fig. 5.56 Evolución de fuerzas de tensión en los "Soil Nails" con las fases constructivas según modelo constitutivo de Hardening Soil para estructura de Zaigen. 180

Fig. 5.57 Evolución de fuerzas de tensión en los "Soil Nails" con las fases constructivas según modelo constitutivo de HSsmall para estructura de Zaigen. 181

Fig. 5.58 Desplazamientos inducidos por construcción de sótano 1 de Zaigen: (a) desplazamientos horizontales en pantalla, y (b) asentamientos del terreno detrás de la pantalla. 182

Fig. 5.59 Desplazamientos inducidos por construcción de sótano 2 de Zaigen: (a) desplazamientos horizontales en pantalla, y (b) asentamientos del terreno detrás de la pantalla

Fig. 5.60 Desplazamientos inducidos por construcción de sótano 3 de Zaigen: (a) desplazamientos horizontales en pantalla, y (b) asentamientos del terreno detrás de la pantalla 183

Fig. 5.61 Desplazamientos inducidos por construcción de sótano 4 de Zaigen: (a) desplazamientos horizontales en pantalla, y (b) asentamientos del terreno detrás de la pantalla. 184

Fig. 5.62 Desplazamientos inducidos por construcción de sótano 5 de Zaigen: (a) desplazamientos horizontales en pantalla, y (b) asentamientos del terreno detrás de la pantalla. 184

Fig. 5.63 Desplazamientos en Zaigen $(H=15.50 \mathrm{~m})$ por análisis sísmico pseudoestático: (a) desplazamientos horizontales en pantalla, y (b) asentamientos del terreno detrás de la pantalla. 185

Fig. 5.64 Desplazamientos en Zaigen por construcción de sótanos (modelo de Mohr Coulomb): (a) desplazamientos horizontales en pantalla, y (b) asentamientos del terreno detrás de la pantalla. 186

Fig. 5.65 Desplazamientos en Zaigen por construcción de sótanos (modelo de Hardening Soil): (a) desplazamientos horizontales en pantalla, y (b) asentamientos del terreno detrás de la pantalla. 186

Fig. 5.66 Desplazamientos en Zaigen por construcción de sótanos (modelo de HSsmall): (a) desplazamientos horizontales en pantalla, y (b) asentamientos del terreno detrás de la pantalla. 
Fig. 5.67 Variación de factor de seguridad (FS) con avance constructivo de sótanos de Torre Centre: (a) Método de elementos finitos (PLAXIS 2D), y (b) Métodos de equilibrio límite (SLIDE2). 188

Fig. 5.68 Determinación de factor de seguridad (FS) de análisis sísmico pseudoestático en Torre Centre cuando H=13.55 m: (a) HSsmall - PLAXIS 2D, y (b) Bishop simplificado - SLIDE2. 189

Fig. 5.69 Variación de factor de seguridad (FS) con avance constructivo de sótanos de Zaigen: (a) Método de elementos finitos (PLAXIS 2D), y (b) Métodos de equilibrio límite (SLIDE2). 189

Fig. 5.70 Determinación de factor de seguridad (FS) de análisis sísmico pseudoestático en Zaigen cuando H=15.50 m: (a) HSsmall - PLAXIS 2D, y (b) Janbu simplificado - SLIDE2.

Fig. 6.1 Instrumentación completa de estructura de "Soil Nailing" de Torre Centre. 195

Fig. 6.2 Fuerzas axiales de tensión inducidas por construcción de sótano 1 de Torre Centre determinadas de lecturas en "Strain Gauges". Comparación con resultados de los modelos numéricos. 195

Fig. 6.3 Fuerzas axiales de tensión inducidas por construcción de sótano 2 de Torre Centre determinadas de lecturas en "Strain Gauges". Comparación con resultados de los modelos numéricos. 196

Fig. 6.4 Fuerzas axiales de tensión inducidas por construcción de sótano 3 de Torre Centre determinadas de lecturas en "Strain Gauges". Comparación con resultados de los modelos numéricos. 197

Fig. 6.5 Fuerzas axiales de tensión inducidas por construcción de sótano 4 de Torre Centre determinadas de lecturas en "Strain Gauges". Comparación con resultados de los modelos numéricos. 199

Fig. 6.6 Fuerzas axiales de tensión inducidas por construcción de sótano 5 de Torre Centre determinadas de lecturas en "Strain Gauges". Comparación con resultados de los modelos numéricos. 201

Fig. 6.7 Instrumentación completa de estructura de "Soil Nailing" de Zaigen.....203 
Fig. 6.8 Fuerzas axiales de tensión inducidas por construcción de sótano 1 de Zaigen determinadas de lecturas en "Strain Gauges". Comparación con resultados de los modelos numéricos 204

Fig. 6.9 Fuerzas axiales de tensión inducidas por construcción de sótano 2 de Zaigen determinadas de lecturas en "Strain Gauges". Comparación con resultados de los modelos numéricos. 205

Fig. 6.10 Fuerzas axiales de tensión inducidas por construcción de sótano 3 de Zaigen determinadas de lecturas en "Strain Gauges". Comparación con resultados de los modelos numéricos. 206

Fig. 6.11 Fuerzas axiales de tensión inducidas por construcción de sótano 4 de Zaigen determinadas de lecturas en "Strain Gauges". Comparación con resultados de los modelos numéricos. 208

Fig. 6.12 Fuerzas axiales de tensión inducidas por construcción de sótano 5 de Zaigen determinadas de lecturas en "Strain Gauges". Comparación con resultados de los modelos numéricos. 210

Fig. 6.13 Medidas topográficas de desplazamientos por construcción de sótano 1 de Torre Centre: (a) desplazamientos horizontales en pantalla, y (b) asentamientos del terreno detrás de la pantalla. Comparación con resultados de los modelos numéricos.

Fig. 6.14 Medidas topográficas de desplazamientos por construcción de sótano 2 de Torre Centre: (a) desplazamientos horizontales en pantalla, y (b) asentamientos del terreno detrás de la pantalla. Comparación con resultados de los modelos numéricos.

Fig. 6.15 Medidas topográficas de desplazamientos por construcción de sótano 3 de Torre Centre: (a) desplazamientos horizontales en pantalla, y (b) asentamientos del terreno detrás de la pantalla. Comparación con resultados de los modelos numéricos.

Fig. 6.16 Medidas topográficas de desplazamientos por construcción de sótano 4 de Torre Centre: (a) desplazamientos horizontales en pantalla, y (b) asentamientos del terreno detrás de la pantalla. Comparación con resultados de los modelos numéricos.

Fig. 6.17 Medidas topográficas de desplazamientos por construcción de sótano 5 de Torre Centre: (a) desplazamientos horizontales en pantalla, y (b) asentamientos del 
terreno detrás de la pantalla. Comparación con resultados de los modelos numéricos.

Fig. 6.18 Medidas topográficas de desplazamientos por construcción de sótano 1 de Zaigen: (a) desplazamientos horizontales en pantalla, y (b) asentamientos del terreno detrás de la pantalla. Comparación con resultados de los modelos numéricos. ....218

Fig. 6.19 Medidas topográficas de desplazamientos por construcción de sótano 2 de Zaigen: (a) desplazamientos horizontales en pantalla, y (b) asentamientos del terreno detrás de la pantalla. Comparación con resultados de los modelos numéricos. ....219

Fig. 6.20 Medidas topográficas de desplazamientos por construcción de sótano 3 de Zaigen: (a) desplazamientos horizontales en pantalla, y (b) asentamientos del terreno detrás de la pantalla. Comparación con resultados de los modelos numéricos. ....220

Fig. 6.21 Medidas topográficas de desplazamientos por construcción de sótano 4 de Zaigen: (a) desplazamientos horizontales en pantalla, y (b) asentamientos del terreno detrás de la pantalla. Comparación con resultados de los modelos numéricos. ....221

Fig. 6.22 Medidas topográficas de desplazamientos por construcción de sótano 5 de Zaigen: (a) desplazamientos horizontales en pantalla, y (b) asentamientos del terreno detrás de la pantalla. Comparación con resultados de los modelos numéricos. ....223

Fig. A.1 Difractogramas de ensayos de difracción de rayos X: (a) JAP1 $3.50 \mathrm{~m}$, (b) JAP1 $7.50 \mathrm{~m}$. .266

Fig. A.2 Difractogramas de ensayos de difracción de rayos X: (a) JAPl $9.00 \mathrm{~m}$, (b) JAP1 $11.00 \mathrm{~m}$. .267

Fig. A.3 Difractogramas de ensayos de difracción de rayos X: (a) JAP1 14.50 m, (b) AMA1 $1.80 \mathrm{~m}$. .268

Fig. A.4 Difractogramas de ensayos de difracción de rayos X: (a) AMA1 4.50 m, (b) AMA1 $8.00 \mathrm{~m}$.

Fig. A.5 Curva relación de vacíos-esfuerzo efectivo vertical, de ensayo de consolidación unidimensional realizado en muestra JAP1 3.50 m. .....................270

Fig. A.6 Curva relación de vacíos-esfuerzo efectivo vertical, de ensayo de consolidación unidimensional realizado en muestra JAP1 6.50 m. ......................271

Fig. A.7 Curva relación de vacíos-esfuerzo efectivo vertical, de ensayo de consolidación unidimensional realizado en muestra JAP1 $9.00 \mathrm{~m}$. .271 
Fig. A.8 Curva relación de vacíos-esfuerzo efectivo vertical, de ensayo de consolidación unidimensional realizado en muestra JAP1 $11.00 \mathrm{~m}$. 272

Fig. A.9 Curva relación de vacíos-esfuerzo efectivo vertical, de ensayo de consolidación unidimensional realizado en muestra JAP1 $14.50 \mathrm{~m}$. 272

Fig. A.10 Curva relación de vacíos-esfuerzo efectivo vertical, de ensayo de consolidación unidimensional realizado en muestra AMA1 $1.50 \mathrm{~m}$. 273

Fig. A.11 Curva relación de vacíos-esfuerzo efectivo vertical, de ensayo de consolidación unidimensional realizado en muestra AMA1 $2.00 \mathrm{~m}$. 273

Fig. A.12 Curva relación de vacíos-esfuerzo efectivo vertical, de ensayo de consolidación unidimensional realizado en muestra AMAl $6.00 \mathrm{~m}$. .274

Fig. A.13 Curva relación de vacíos-esfuerzo efectivo vertical, de ensayo de consolidación unidimensional realizado en muestra AMA1 $7.50 \mathrm{~m}$. 274

Fig. A.14 Trayectorias de tensiones efectivas de ensayo triaxial tipo $C U$ realizado en muestra JAP1 $3.50 \mathrm{~m}$. 275

Fig. A.15 Trayectorias de tensiones efectivas de ensayo triaxial tipo $C U$ realizado en muestra JAP1 $7.50 \mathrm{~m}$. 275

Fig. A.16 Trayectorias de tensiones efectivas de ensayo triaxial tipo $C U$ realizado en muestra JAPl $9.00 \mathrm{~m}$. 276

Fig. A.17 Trayectorias de tensiones efectivas de ensayo triaxial tipo $C U$ realizado en muestra JAP1 $11.00 \mathrm{~m}$. 276

Fig. A.18 Trayectorias de tensiones efectivas de ensayo triaxial tipo $C U$ realizado en muestra JAP1 $14.50 \mathrm{~m}$. 277

Fig. A.19 Trayectorias de tensiones efectivas de ensayo triaxial tipo $C U$ realizado en muestra AMA1 $4.50 \mathrm{~m}$. 277

Fig. A.20 Trayectorias de tensiones efectivas de ensayo triaxial tipo $C U$ realizado en muestra AMAl $6.00 \mathrm{~m}$. 278 


\section{ÍNDICE DE TABLAS}

Tabla 2.1 Características de suelos volcánicos estudiados por Belloni y Morris (1991).

Tabla 2.2 Características de suelos volcánicos estudiados por Hürlimann et al. (2001).

Tabla 2.3 Características de suelos volcánicos estudiados por Bommer et al. (2002).

Tabla 2.4 Características de suelos volcánicos estudiados por Crosta et al. (2005).

Tabla 2.5 Características de suelos volcánicos estudiados por González de Vallejo et al. (2008). 11

Tabla 2.6 Características de suelos volcánicos estudiados por Avşar et al. (2015).11

Tabla 2.7 Características de materiales volcánicos estudiados por Vezzoli et al. (2017).

Tabla 2.8 Propiedades índice de suelos volcánicos estudiados por O'Rourke y Crespo (1988).

Tabla 2.9 Resistencia a la compresión uniaxial de suelos estudiados por O'Rourke y Crespo (1988).

Tabla 2.10 Resistencia a la tensión brasileña de suelos estudiados por O'Rourke y Crespo (1988).

Tabla 2.11 Resistencia al corte de suelos volcánicos estudiados por O'Rourke y Crespo (1988).

Tabla 2.12 Índices de compresión $\left(C_{c}\right)$ e hinchamiento $\left(C_{s}\right)$ obtenidos en muestras de los sondeos del estudio de Metro Quito.

Tabla 2.13 Parámetros de resistencia al corte de ensayos triaxiales tipo $U U$ obtenidos en muestras de los sondeos del estudio de Metro Quito. .21

Tabla 2.14 Comparación de esfuerzos predichos y medidos en "Nails" (Holman y Tuozzolo, 2009). 
Tabla 3.1 Análisis semi-cuantitativo de difracción de rayos X. 63

Tabla 3.2 Parámetros de resistencia al corte no drenado para muestras de perforaciones $J A P 1$ y AMAl. 75

Tabla 3.3 Parámetros de resistencia al corte drenado para muestras de perforaciones JAP1 y AMA1. 78

Tabla 3.4 Parámetros de deformación de trayectorias de tensiones controladas de ensayos triaxiales tipo $C U$ de muestras de sondeos JAPl y $A M A 1$. 79

Tabla 3.5 Parámetros de deformación de ensayos triaxiales tipo $C D$ de muestras de sondeos JAP1 y AMA1. 80

Tabla 3.6 Comparación de las propiedades geotécnicas con las de estudios de otros investigadores.

Tabla 4.1 Características de "Soil Nails" y elementos de instrumentación en Torre Centre. 116

Tabla 4.2 Características de "Soil Nails" y elementos de instrumentación en Zaigen.

Tabla 4.3 Resumen de construcción, instrumentación y monitorización de pantalla para sótanos de Edificio Torre Centre.

Tabla 4.4 Resumen de construcción, instrumentación y monitorización de pantalla para sótanos de Edificio Zaigen

Tabla 5.1 Parámetros requeridos para los modelos de Mohr Coulomb, Hardening Soil y HSsmall 126

Tabla 5.2 Resumen de valores de $E_{50}$ para determinación de $E_{50}^{\text {ref }}$ de muestra AMAI $8.00 \mathrm{~m}$. 130

Tabla 5.3 Resumen de valores de $E_{50}$ para determinación de $E_{50}^{\text {ref }}$ de muestra JAPI $13.50 \mathrm{~m}$. 133

Tabla 5.4 Estimación de módulo de rigidez secante $E_{50}^{r e f}$ para estratos superficiales. 134 
Tabla 5.5 Módulo de rigidez descarga/recarga $E_{u r}^{r e f}$ para ensayos de proyecto Torre Centre.

Tabla 5.6 Módulo de rigidez descarga/recarga $E_{u r}^{r e f}$ para estrato superficial de proyecto Zaigen. 140

Tabla 5.7 Obtención de deformación límite por corte $\gamma_{0.7}$, donde $G=0.7 G_{0 . \ldots . . .143}$

Tabla 5.8 Parámetros geotécnicos para modelo de Mohr Coulomb en Torre Centre y Zaigen.

Tabla 5.9 Parámetros para los modelos de Hardening Soil y HSsmall en Proyecto Torre Centre. .146

Tabla 5.10 Parámetros para los modelos de Hardening Soil y HSsmall en Proyecto Zaigen. 147

Tabla 5.11 Datos de pantallas y "Soil Nails" para proyectos Torre Centre y Zaigen. 148

Tabla 5.12 Parámetros de rigidez axial EA, rigidez a flexión $E I$ y peso unitario w para pantallas.

Tabla 5.13 Rigidez axial EA, rigidez a flexión EI y peso unitario w para "Soil Nails" de Torre Centre.

Tabla 5.14 Rigidez axial EA, rigidez a flexión EI y peso unitario $w$ para "Soil Nails" de Zaigen.

Tabla 5.15 Fuerzas de tensión máxima en "Soil Nails" por construcción de sótano 1 de Torre Centre. 156

Tabla 5.16 Fuerzas de tensión máxima en "Soil Nails" por construcción de sótano 2 de Torre Centre. 156

Tabla 5.17 Fuerzas de tensión máxima en "Soil Nails" por construcción de sótano 3 de Torre Centre.

Tabla 5.18 Fuerzas de tensión máxima en "Soil Nails" por construcción de sótano 4 de Torre Centre. 158

Tabla 5.19 Fuerzas de tensión máxima en "Soil Nails" por construcción de sótano 5 de Torre Centre. 
Tabla 5.20 Fuerzas de tensión máxima en "Soil Nails" por enfoque sísmico pseudoestático en estructura de Torre Centre. 161

Tabla 5.21 Evolución de fuerzas de tensión máxima en "Soil Nails" según modelo de Mohr Coulomb. 162

Tabla 5.22 Evolución de fuerzas de tensión máxima en "Soil Nails" según modelo de Hardening Soil. 163

Tabla 5.23 Evolución de fuerzas de tensión máxima en "Soil Nails" según modelo de HSsmall. 164

Tabla 5.24 Desplazamientos máximos generados por construcción de sótanos de Torre Centre. 167

Tabla 5.25 Fuerzas de tensión máxima en "Soil Nails" por construcción de sótano 1 de Zaigen. 174

Tabla 5.26 Fuerzas de tensión máxima en "Soil Nails" por construcción de sótano 2 de Zaigen. 174

Tabla 5.27 Fuerzas de tensión máxima en "Soil Nails" por construcción de sótano 3 de Zaigen. 175

Tabla 5.28 Fuerzas de tensión máxima en "Soil Nails" por construcción de sótano 4 de Zaigen. 176

Tabla 5.29 Fuerzas de tensión máxima en "Soil Nails" por construcción de sótano 5 de Zaigen. 177

Tabla 5.30 Fuerzas de tensión máxima en "Soil Nails" por enfoque sísmico pseudoestático en estructura de Zaigen. 179

Tabla 5.31 Evolución de fuerzas de tensión máxima en "Soil Nails" según modelo de Mohr Coulomb. 180

Tabla 5.32 Evolución de fuerzas de tensión máxima en "Soil Nails" según modelo de Hardening Soil. 181

Tabla 5.33 Evolución de fuerzas de tensión máxima en "Soil Nails" según modelo de HSsmall. 182 
Tabla 5.34 Desplazamientos máximos generados por construcción de sótanos de Zaigen. 185

Tabla 5.35 Variación de factor de seguridad (FS) con avance constructivo de sótanos en Torre Centre. 188

Tabla 5.36 Variación de factor de seguridad (FS) con el avance constructivo de sótanos en Zaigen. 190

Tabla 6.1 Fuerzas axiales de tensión en "Soil Nails" por construcción de sótano 1 de Torre Centre. 196

Tabla 6.2 Fuerzas axiales de tensión en "Soil Nails" por construcción de sótano 2 de Torre Centre. 197

Tabla 6.3 Fuerzas axiales de tensión en "Soil Nails" por construcción de sótano 3 de Torre Centre. 198

Tabla 6.4 Fuerzas axiales de tensión en "Soil Nails" por construcción de sótano 4 de Torre Centre. .200

Tabla 6.5 Fuerzas axiales de tensión en "Soil Nails" por construcción de sótano 5 de Torre Centre. .202

Tabla 6.6 Fuerzas axiales de tensión en "Soil Nails" por construcción de sótano 1 de Zaigen 204

Tabla 6.7 Fuerzas axiales de tensión en "Soil Nails" por construcción de sótano 2 de Zaigen .205

Tabla 6.8 Fuerzas axiales de tensión en "Soil Nails" por construcción de sótano 3 de Zaigen 207

Tabla 6.9 Fuerzas axiales de tensión en "Soil Nails" por construcción de sótano 4 de Zaigen .209

Tabla 6.10 Fuerzas axiales de tensión en "Soil Nails" por construcción de sótano 5 de Zaigen. 211

Tabla 6.11 Desplazamientos horizontales en pantalla por construcción de sótano 1 de Torre Centre. 213 
Tabla 6.12 Asentamientos en terreno detrás de pantalla por construcción de sótano 1 de Torre Centre.

Tabla 6.13 Desplazamientos horizontales en pantalla por construcción de sótano 2 de Torre Centre. 214

Tabla 6.14 Asentamientos en terreno detrás de pantalla por construcción de sótano 2 de Torre Centre. 214

Tabla 6.15 Desplazamientos horizontales en pantalla por construcción de sótano 3 de Torre Centre. 215

Tabla 6.16 Asentamientos en terreno detrás de pantalla por construcción de sótano 3 de Torre Centre. 215

Tabla 6.17 Desplazamientos horizontales en pantalla por construcción de sótano 4 de Torre Centre. 216

Tabla 6.18 Asentamientos en terreno detrás de pantalla por construcción de sótano 4 de Torre Centre. 216

Tabla 6.19 Desplazamientos horizontales en pantalla por construcción de sótano 5 de Torre Centre.

Tabla 6.20 Asentamientos en terreno detrás de pantalla por construcción de sótano 5 de Torre Centre. 218

Tabla 6.21 Desplazamientos horizontales en pantalla por construcción de sótano 1 de Zaigen.

Tabla 6.22 Asentamientos en terreno detrás de pantalla por construcción de sótano 1 de Zaigen. 219

Tabla 6.23 Desplazamientos horizontales en pantalla por construcción de sótano 2 de Zaigen. 220

Tabla 6.24 Asentamientos en terreno detrás de pantalla por construcción de sótano 2 de Zaigen. 220

Tabla 6.25 Desplazamientos horizontales en pantalla por construcción de sótano 3 de Zaigen. 
Tabla 6.26 Asentamientos en terreno detrás de pantalla por construcción de sótano 3 de Zaigen. .221

Tabla 6.27 Desplazamientos horizontales en pantalla por construcción de sótano 4 de Zaigen. 222

Tabla 6.28 Asentamientos en terreno detrás de pantalla por construcción de sótano 4 de Zaigen. 222

Tabla 6.29 Desplazamientos horizontales en pantalla por construcción de sótano 5 de Zaigen. .222

Tabla 6.30 Asentamientos en terreno detrás de pantalla por construcción de sótano 5 de Zaigen. .223

Tabla 6.31 Comparación de tensiones en "Soil Nails" por construcción de sótano 1 de Torre Centre. 224

Tabla 6.32 Comparación de tensiones en "Soil Nails" por construcción de sótano 2 de Torre Centre. .225

Tabla 6.33 Comparación de tensiones en "Soil Nails" por construcción de sótano 3 de Torre Centre. .226

Tabla 6.34 Comparación de tensiones en "Soil Nails" por construcción de sótano 4 de Torre Centre. 227

Tabla 6.35 Comparación de tensiones en "Soil Nails" por construcción de sótano 5 de Torre Centre. .228

Tabla 6.36 Comparación de tensiones en "Soil Nails" por construcción de sótano 1 de Zaigen. 231

Tabla 6.37 Comparación de tensiones en "Soil Nails" por construcción de sótano 2 de Zaigen. .232

Tabla 6.38 Comparación de tensiones en "Soil Nails" por construcción de sótano 3 de Zaigen. .233

Tabla 6.39 Comparación de tensiones en "Soil Nails" por construcción de sótano 4 de Zaigen. 234 
Tabla 6.40 Comparación de tensiones en "Soil Nails" por construcción de sótano 5 de Zaigen. 236

Tabla 6.41 Comparación de desplazamientos horizontales por construcción de sótanos de Torre Centre

239

Tabla 6.42 Comparación de desplazamientos horizontales por construcción de sótanos de Zaigen.

242

Tabla 6.43 Comparación de asentamientos por construcción de sótanos de Torre Centre. 244

Tabla 6.44 Comparación de asentamientos por construcción de sótanos de Zaigen. 247 


\section{Capítulo 1}

\section{INTRODUCCIÓN Y OBJETIVOS}

\subsection{Introducción}

La zona centro-norte de la ciudad de Quito (Ecuador) conocido como el sector económico y financiero de la capital ecuatoriana se caracteriza por la presencia de edificaciones de altura y por la planificación frecuente de modernos proyectos inmobiliarios generalmente comprendidos entre 16 y 32 niveles de altura. Como parte de su funcionalidad y planificación arquitectónica, cada edificación incluye su respectiva estructura subterránea de sótanos para aparcamiento vehicular, en donde su número de niveles está en función de la altura de la edificación y de la demanda del proyecto arquitectónico, pero generalmente suele estar entre 4 y 7 niveles.

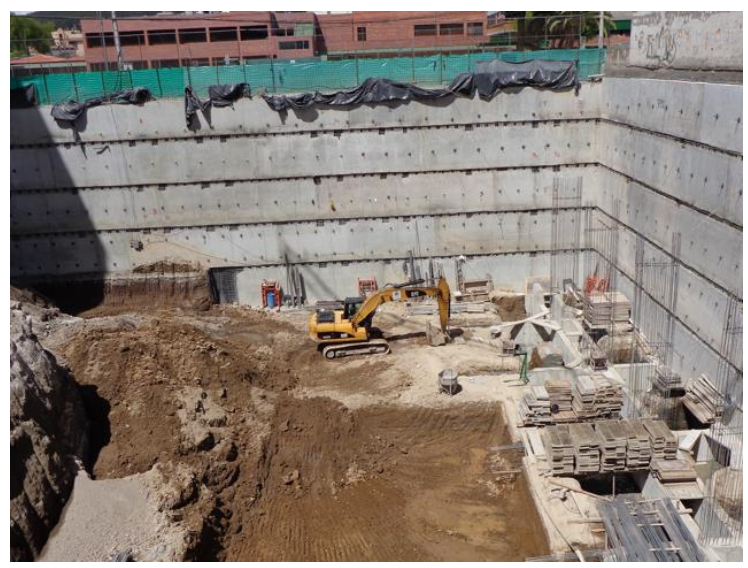

Fig. 1.1 Estructura de "Soil Nailing" en sótanos de edificios en la ciudad de Quito. 
Para la construcción de la mayoría de estructuras de sótano en la capital ecuatoriana es de aplicación frecuente en el proceso de excavación la técnica de "Soil Nailing", o suelo claveteado, con algunas variantes constructivas de acuerdo a los equipos disponibles en el medio y las características de cada proyecto. Sin embargo, esta técnica que ha resultado ser efectiva para el manejo de excavaciones en suelos de la ciudad de Quito, cuenta actualmente con pocas investigaciones locales, ya sean teóricas, numéricas y experimentales basadas en las propiedades geotécnicas de los suelos volcánicos característicos de la zona.

A nivel mundial la técnica de "Soil Nailing" se ha aplicado en diversos proyectos de ingeniería en países como: Estados Unidos (Turner y Jensen, 2005), Chile (Villalobos et al., 2013), China (Zhu et al., 2013), Irlanda (Menkiti et al., 2013), Brasil (Ehrlich y Silva, 2015), entre otros. De igual manera, se han realizado varios estudios numéricos del comportamiento de este tipo de estructuras, como los presentados por Fan y Luo (2008), Singh y Sivakumar Babu (2009), Wei y Cheng (2010), Rabie (2016), Rawat y Gupta (2016), entre otros.

Por otra parte, varios investigadores han presentado determinados estudios experimentales del comportamiento de estructuras de "Soil Nailing". Dentro de estos estudios destacan el proyecto de investigación francés Clouterre que inició en 1986 y contempló ensayos a gran escala, monitorización de muros claveteados y simulaciones numéricas (Clouterre, 1991). Por otro lado, en 1996 comenzó el proyecto experimental denominado "Amherst Test Wall" en University of Massachusetts Amherst, Massachusetts (Estados Unidos), que consistió en un muro a gran escala e instrumentado para investigar su modo de falla (Sheahan, 2000). Por su parte, Garzón et al. (2019) presentaron un estudio comparativo de la conveniencia del uso de los métodos de equilibrio límite y elementos finitos para el diseño de estructuras claveteadas basado en el proyecto "Amherst Test Wall". En tanto que, Holman y Tuozzolo (2009) presentaron un estudio de un muro claveteado temporal "Soil Nail Wall" construido en Manhattan (Estados Unidos) y siendo el objetivo principal investigar la distribución de las fuerzas de tensión en las barras de anclaje.

La investigación planteada en esta Tesis Doctoral estudiará el comportamiento de 2 excavaciones ejecutadas con la técnica de "Soil Nailing" para la construcción de las estructuras de sótano de 5 niveles de 2 importantes edificaciones reales que fueron construidas en la zona centro de norte de la ciudad de Quito. La investigación contempla un enfoque experimental y un análisis numérico mediante elementos finitos donde se considera la aplicación de los modelos constitutivos de suelo de Mohr Coulomb, Hardening Soil y Hardening Soil with Small-Strain Stiffness (HSsmall). Tanto el estudio experimental como el numérico se concentrarán en la evolución de las fuerzas de tensión en las barras de anclaje y el análisis de desplazamientos horizontales de las pantallas y asentamientos en el terreno inferidos por la construcción de cada nivel de sótano. Adicionalmente, la obtención de los parámetros geotécnicos, para cada uno de los modelos de suelo a utilizarse en el 
análisis numérico está respaldada, por una completa campaña de caracterización geotécnica con sondeos de campo y ensayos especializados de laboratorio, ejecutados a propósito como parte de este estudio. En definitiva, esta Tesis Doctoral constituye uno de los primeros estudios completos de la región encaminado a explicar el comportamiento experimental y numérico de excavaciones mediante la técnica de "Soil Nailing" y respaldado con un completo estudio de caracterización geotécnica.

Las diversas actividades de esta investigación fueron realizadas con el soporte del Laboratorio de Mecánica de Suelos del Departamento de Ingeniería del Terreno y el Laboratorio de Estructuras del Instituto de Ciencia y Tecnología del Hormigón (ICITECH) de la Universitat Politècnica de València, distinguidos por contar con grupos de investigadores de larga trayectoria. Este estudio fue realizado con exclusivo financiamiento del autor, por lo que todas las labores investigativas, instrumentación, monitorización y demás actividades se ajustaron al presupuesto y logística disponibles, pero siempre manteniendo especial cuidado en cada procedimiento de adquisición de información.

\subsection{Objetivos}

El objetivo principal de esta investigación es estudiar el comportamiento de excavaciones ejecutadas mediante la técnica de suelo claveteado o "Soil Nailing" en los suelos volcánicos de la ciudad de Quito. Pero para lograr este objetivo principal se tienen los siguientes objetivos específicos:

- Realizar un estudio de caracterización geotécnica de la zona centro norte de la ciudad de Quito, respaldado en sondeos de campo y ensayos especializados de laboratorio, principalmente de identificación, estado y tenso-deformacionales. Las estructuras que son parte del estudio experimental se ubican en el sector centro norte de la capital ecuatoriana.

- Llevar a cabo un estudio experimental del comportamiento de las excavaciones mediante la técnica de "Soil Nailing" para estructuras de sótanos de 2 importantes edificaciones, basado en procedimientos de instrumentación y monitorización oportunos durante las diferentes etapas constructivas.

- Desarrollar una guia detallada de obtención de los parámetros geotécnicos para los diferentes modelos constitutivos de suelo utilizados en el análisis numérico, fundamentada en los ensayos de laboratorio del estudio de caracterización geotécnica.

- Realizar un estudio numérico especializado del comportamiento de las 2 estructuras de "Soil Nailing" del estudio experimental con los diferentes modelos constitutivos de suelo, enfocado principalmente en la evolución de las fuerzas axiales de tensión en las barras de anclaje, los desplazamientos 
horizontales en las pantallas claveteadas y los asentamientos del terreno existente detrás de las pantallas.

- Validar los resultados del modelo numérico y los parámetros procedentes de la caracterización geotécnica con los resultados obtenidos del estudio experimental.

\subsection{Contenido}

La Tesis Doctoral se ha organizado en 7 capítulos, según se indica a continuación:

- Capítulo 1: Introducción y objetivos.

- Capítulo 2: Estado del arte.

- Capítulo 3: Caracterización geotécnica de la zona de estudio.

- Capítulo 4: Planteamiento del estudio experimental.

- Capítulo 5: Análisis mediante elementos finitos y equilibrio límite.

- Capítulo 6: Resultados del estudio experimental.

- Capítulo 7: Conclusiones y futuras líneas de investigación.

El Capítulo 1 presenta una introducción general del uso de la técnica de "Soil Nailing" en proyectos de ingeniería geotécnica y su aplicación frecuente en el reforzamiento de excavaciones para estructuras de sótano en la ciudad de Quito. Por otra parte, en este capítulo se exponen además los objetivos de esta investigación.

El Capítulo 2 presenta el estado del arte relativo a los temas de la Tesis Doctoral. La primera parte menciona estudios generales de caracterización geotécnica de suelos volcánicos, y luego trata de manera específica sobre estudios geotécnicos en la ciudad de Quito. En tanto, la segunda parte trata sobre los aspectos relativos a la técnica de "Soil Nailing", historia, componentes, comportamiento y sus aplicaciones.

El Capítulo 3 expone un estudio completo de caracterización geotécnica de la zona centro norte de la ciudad de Quito. Se detallan los resultados de los diferentes ensayos de laboratorio realizados en esta investigación con una comparación con estudios de suelos volcánicos de otros investigadores y de otros países.

El Capítulo 4 detalla la parte experimental de la investigación. El capítulo describe los recursos utilizados y los procedimientos de instrumentación y monitorización considerados para las fases constructivas de cada estructura de "Soil Nailing".

El Capítulo 5 presenta el análisis numérico de las estructuras de "Soil Nailing". La primera parte expone de manera detallada la obtención de los parámetros geotécnicos para los diferentes modelos constitutivos de suelo. En cambio, en la segunda parte, se presentan de manera gráfica y tabulada los resultados del análisis numérico.

El Capítulo 6 muestra y analiza los resultados del estudio experimental de manera gráfica y tabulada. Estos resultados se obtuvieron durante todas las tareas de 
monitorización a través de las diferentes fases constructivas. Para efectos de comparación, los resultados se presentan superpuestos a los del análisis numérico.

El Capítulo 7 recopila las conclusiones de la Tesis Doctoral y plantea futuras líneas de investigación.

Finalmente, el Apéndice A resume gráficamente los resultados de los principales ensayos del estudio de caracterización geotécnica. 
Estudio experimental y numérico del comportamiento de excavaciones ejecutadas mediante la técnica de suelo claveteado (Soil Nailing) en suelos de la ciudad de Quito (Ecuador) 


\section{Capítulo 2}

\section{ESTADO DEL ARTE}

\subsection{Introducción}

En la ciudad de Quito (Ecuador) es de aplicación frecuente la técnica de suelo claveteado o "Soil Nailing" en el proceso de excavación para la construcción de sótanos de aparcamiento vehicular de varios niveles en edificios. Además, es notorio que en la zona norte de la capital ecuatoriana se proyectan los más importantes proyectos inmobiliarios y modernos de la ciudad. En virtud de ello, la investigación experimental de este estudio se desarrolló en 2 proyectos de edificación reales con estructuras de sótanos de varios niveles localizados en la zona centro-norte de la ciudad de Quito. En dichas estructuras se nos proporcionaron las facilidades necesarias para las labores de monitorización de su proceso constructivo. El subsuelo de esta zona está compuesto principalmente por suelos volcánicos, como se mostrará en el Capítulo 3. En este capítulo se comentarán los estudios de suelos volcánicos realizados por diferentes investigadores y el desarrollo y evolución de la técnica de "Soil Nailing".

\subsection{Caracterización geotécnica de suelos volcánicos}

Los materiales volcánicos se dividen en 4 unidades geotécnicas principales: lavas, brechas autoclásticas, rocas piroclásticas y suelos volcánicos, que se subdividen en función de la alteración hidrotermal, la conexión o soldadura y el enclavamiento (del Potro y Hürlimann, 2008). Según estos autores, la unidad de suelo volcánico agrupa una gran variedad de materiales granulares que van desde brechas volcánicas no 
entrelazadas, piroclastos sueltos, material epiclástico y coluviones hasta suelos alterados hidrotermalmente, consolidados y ricos en arcilla residual.

Una clase particular de material, que está bastante extendido, pero para el cual se han publicado relativamente pocos datos experimentales útiles, es el suelo volcánico. Los suelos volcánicos pueden diferir considerablemente en su mineralogía y propiedades físicas de las arcillas y limos sedimentarios convencionales (Brandes y Nakayama, 2010). Los datos publicados en la literatura muestran 2 grupos geotécnicos distintos de suelos volcánicos: suelos cohesivos y sin cohesión, independiente de su origen (del Potro y Hürlimann, 2008).

En general, en relación con la alta plasticidad, el tamaño de las partículas finas y la composición mineralógica activa, los suelos volcánicos tienen una resistencia al corte relativamente alta, mientras que su compresibilidad es bastante baja para incrementos de esfuerzo relativamente bajos (González de Vallejo et al., 1981).

Según las características y el historial de erupciones, los depósitos de suelos volcánicos pueden ser estratificados o macizos, de grano grueso o de grano fino, adheridos o no adheridos y fisurados o no fisurados. Dichos materiales cubren áreas planas o con pendiente, alcanzando espesores de hasta varias decenas de metros (Avşar et al., 2015).

Por lo tanto, los suelos volcánicos constituyen uno de los grupos de suelos más ampliamente distribuidos en el mundo, especialmente en zonas de América Central y del Sur, islas del Océano Pacífico y del Caribe, África e Indonesia (Bommer et al., 2002). En definitiva, los suelos volcánicos cubren partes importantes de la superficie del mundo, incluidas áreas ocupadas por asentamientos urbanos, estructuras e infraestructuras, y pueden causar problemas de geoingeniería. Algunos suelos volcánicos pueden con frecuencia soportar pendientes casi verticales, cuya ventaja se toma para taludes de carreteras (Avşar et al., 2015). Pero otros suelos volcánicos en regiones tropicales como Hawái (Estados Unidos) tienen los efectos de una meteorización extensa y profunda que puede afectar notablemente las propiedades de ingeniería (Brandes y Nakayama, 2010).

Wesley (1973) realizó un estudio de caracterización de los suelos de Java (Indonesia), principalmente en las arcillas de alta plasticidad, color rojo, derivadas del desgaste de depósitos volcánicos, tales como tobas y cenizas y de las arcillas limosas de alta plasticidad, color café amarillento, derivadas del desgaste de la ceniza volcánica y que pertenece al grupo de suelos denominados como Andosol. Este estudio consistió en la obtención de las propiedades básicas, particularmente los límites de Atterberg, gravedad específica y características de compactación. Posteriormente Wesley (1990) complementa este estudio y esta vez en su investigación incluye resultados de ensayos de consolidación y ensayos triaxiales consolidados no drenados (CU). 
Belloni y Morris (1991) realizaron un estudio para investigar como el comportamiento de escombros de suelos volcánicos afectan en la estabilidad de las laderas en la zona del volcán Reventador, ubicado al noreste de Ecuador, en donde los suelos corresponden parcialmente al producto de varias erupciones volcánicas y comprenden una serie de arcillas, piroclastos, arenas de cuarzo, lahares y aglomerados con cenizas y lapillitas. Algunas de las propiedades índice determinadas en este estudio se presentan en la tabla 2.1.

Tabla 2.1 Características de suelos volcánicos estudiados por Belloni y Morris (1991).

\begin{tabular}{lccc}
\hline \multicolumn{1}{c}{ Propiedad } & Máximo & Mínimo & Media \\
\hline Contenido de humedad [\%] & 215 & 58 & 122 \\
Gravedad específica Gs & 2.79 & 2.32 & 2.49 \\
Densidad $\gamma\left[\mathrm{kN} / \mathrm{m}^{3}\right]$ & 17.4 & 11.6 & 13.8 \\
Densidad seca $\gamma_{\mathrm{d}}\left[\mathrm{kN} / \mathrm{m}^{3}\right]$ & 9.1 & 3.7 & 6.9 \\
Límite Líquido LL [\%] & 293 & 34 & 111 \\
Límite Plástico LP [\%] & 165 & 25 & 65 \\
Índice de Plasticidad IP & 139 & 7 & 46 \\
\hline
\end{tabular}

Por otra parte, Hürlimann et al. (2001) realizaron un estudio de caracterización de un suelo volcánico residual en Tenerife (Islas Canarias, España) y sus implicaciones para grandes fenómenos de deslizamientos de tierra. El análisis granulométrico determinó que estos suelos tienen características arenosas y limosas con algunos componentes de grava y una pequeña fracción de arcilla. En tanto que los límites de Atterberg determinaron que estos suelos no tienen plasticidad. En la tabla 2.2 se muestran los parámetros geotécnicos principales determinados en el estudio de estos autores.

Tabla 2.2 Características de suelos volcánicos estudiados por Hürlimann et al. (2001).

\begin{tabular}{lcccccc}
\hline $\begin{array}{l}\text { Descripción del } \\
\text { suelo }\end{array}$ & $\begin{array}{c}\text { Gravedad } \\
\text { específica } \\
\mathrm{G}_{\mathrm{s}}\end{array}$ & $\begin{array}{c}\text { Densidad } \\
\gamma\end{array}$ & $\begin{array}{c}\text { Relación de } \\
\text { vacíos } \\
\mathrm{e}\end{array}$ & $\begin{array}{c}\text { Porosidad } \\
\mathrm{n}\end{array}$ & $\begin{array}{c}\text { Resistencia al corte máxima } \\
\text { (Ensayos de corte directo tipo } C D \text { ) }\end{array}$ \\
\hline $\begin{array}{l}\text { Suelo volcánico } \\
\text { residual }\end{array}$ & $2.70\left(^{*}\right)$ & 15.0 & $1.20-1.60$ & $54-60$ & 0 & $30-45$ \\
\hline
\end{tabular}

(*) Valor tomado de Avşar et al. (2015).

Bommer et al. (2002) presentaron un estudio de un suelo volcánico identificado como ceniza dacítica de piedra de pómez compuesto de piroclastos ácidos y depósitos epliclásticos mal consolidados denominado como Tierra Blanca, que cubre la mayor parte de la zona superior de San Salvador (El Salvador). Estos depósitos se originaron del producto de múltiples erupciones volcánicas. Tierra Blanca puede ser clasificada como un limo arenoso o arena limosa con contenidos 
de humedad que varían entre $7.5 \%$ y $30 \%$ y un grado de saturación en el orden del $23 \%$ y que puede llegar al $80 \%$ en temporadas lluviosas. En la tabla 2.3 se presentan las principales propiedades geotécnicas obtenidas del estudio de estos autores.

Tabla 2.3 Características de suelos volcánicos estudiados por Bommer et al. (2002).

\begin{tabular}{lcccccc}
\hline $\begin{array}{l}\text { Descripción del } \\
\text { suelo }\end{array}$ & $\begin{array}{c}\text { Gravedad } \\
\text { específica } \\
\mathrm{G}_{\mathrm{s}}\end{array}$ & $\begin{array}{c}\text { Densidad } \\
{\left[\mathrm{kN} / \mathrm{m}^{3}\right]}\end{array}$ & $\begin{array}{c}\text { Relación de } \\
\text { vacíos } \\
{[-]}\end{array}$ & $\begin{array}{c}\text { Porosidad } \\
\mathrm{n}\end{array}$ & $\begin{array}{c}\text { Resistencia al corte máxima } \\
\text { (Ensayos de corte directo y } \\
\text { triaxiales tipo } U U \text { ) }\end{array}$ \\
\hline $\begin{array}{l}\text { Suelo volcánico } \\
\text { (depósito } \\
\text { piroclástico y } \\
\text { epiclástico) }\end{array}$ & $2.25-2.50$ & $13.0-15.0$ & $0.80-1.14$ & $51\left(^{*}\right)$ & $25-30$ & $6\left[{ }^{\circ}\right]$ \\
\hline
\end{tabular}

(*) Valor medio.

Por su parte, Crosta et al. (2005) presentaron un estudio de un suelo volcánico, débil a moderadamente cementado, localizado en la zona de Santa Tecla (El Salvador) compuesto principalmente por limo y arena bien clasificada. Este estudio fue parte del análisis de estabilidad de taludes bajo condiciones estáticas y dinámicas del deslizamiento denominado como "Las Colinas" en la Cordillera del Bálsamo. En este estudio la secuencia volcánica se subdivide en 2 grupos principales: piroclástico y epiclástico, de los cuales el primero es más superficial y alcanza $11 \mathrm{~m}$ a $37 \mathrm{~m}$ de profundidad. De acuerdo al Sistema Unificado de Clasificación de Suelos (SUCS), los suelos de esta investigación corresponden a SW, SM, ML, MH y CL para los depósitos piroclásticos y SM, ML, MH y CL para los depósitos epiclásticos. Los materiales piroclásticos son usualmente más gruesos (37 - 70\% más fino que 0.075 $\mathrm{mm})$ que los epiclásticos (64 - 92\% más fino que $0.075 \mathrm{~mm}$ ). Las propiedades geotécnicas principales de los suelos volcánicos estudiados por estos autores se muestran en la tabla 2.4.

Tabla 2.4 Características de suelos volcánicos estudiados por Crosta et al. (2005).

\begin{tabular}{lcccccc}
\hline $\begin{array}{l}\text { Descripción del } \\
\text { suelo }\end{array}$ & $\begin{array}{c}\text { Gravedad } \\
\text { específica } \\
\mathrm{G}_{\mathrm{s}}\end{array}$ & $\begin{array}{c}\text { Densidad } \\
\gamma\end{array}$ & $\begin{array}{c}\text { Relación de } \\
\text { vacíos } \\
{\left[\mathrm{kN} / \mathrm{m}^{3}\right]}\end{array}$ & $\begin{array}{c}\text { Porosidad } \\
\mathrm{n}\end{array}$ & $\begin{array}{c}\text { Resistencia al corte máxima } \\
\text { (Ensayos de corte directo y } \\
\text { triaxiales tipo } U U \text { ) }\end{array}$ \\
\hline $\begin{array}{l}\text { Depósito } \\
\text { piroclástico }\end{array}$ & $1.90-2.70$ & 14.9 & - & - & $7-950$ & $0.2-39.6$ \\
$\begin{array}{l}\text { Depósito } \\
\text { epiclástico }\end{array}$ & $2.20-2.70$ & 15.2 & - & - & $6-200$ & $9.9-45$ \\
\hline
\end{tabular}

González de Vallejo et al. (2008) publicaron una investigación de características geotécnicas de suelos volcánicos de Islas Canarias (España), en donde las propiedades de estos suelos dependen mucho del estado de depósito y del tamaño de las partículas. El estudio presenta básicamente características de suelos volcánicos 
residuales, que son el producto de la meteorización in situ de materiales piroclásticos con abundantes proporciones de limo y arena y con menos frecuencia arcillas limosas. En este estudio, el contenido natural de agua de los suelos estuvo entre $12 \%$ y $180 \%$, en tanto que los valores de límite líquido oscilaron entre $52 \%$ y $102 \%$, mientras que el límite plástico estuvo entre $15 \%$ y $95 \%$. La tabla 2.5 muestra las características principales de los suelos volcánicos estudiados por estos autores.

Tabla 2.5 Características de suelos volcánicos estudiados por González de Vallejo et al. (2008).

\begin{tabular}{|c|c|c|c|c|c|c|}
\hline \multirow{2}{*}{$\begin{array}{l}\text { Descripción del } \\
\text { suelo }\end{array}$} & \multirow{2}{*}{$\begin{array}{c}\text { Gravedad } \\
\text { específica } \\
\mathrm{G}_{\mathrm{s}}\end{array}$} & \multirow{2}{*}{$\begin{array}{c}\text { Densidad } \\
\text { seca } \\
\gamma_{\mathrm{d}} \\
{\left[\mathrm{kN} / \mathrm{m}^{3}\right]}\end{array}$} & \multirow{2}{*}{$\begin{array}{c}\text { Relación de } \\
\text { vacíos } \\
\text { e } \\
{[-]}\end{array}$} & \multirow{2}{*}{$\begin{array}{c}\text { Porosidad } \\
n \\
\\
{[\%]}\end{array}$} & \multicolumn{2}{|c|}{ Resistencia al corte máxima } \\
\hline & & & & & $\mathrm{c}[\mathrm{kPa}]$ & $\varnothing\left[^{\circ}\right]$ \\
\hline $\begin{array}{l}\text { Suelo volcánico } \\
\text { residual }\end{array}$ & $2.20-3.00$ & $12.0-13.0$ & $1.60-2.88$ & $62-74(*)$ & $\leq 100$ & $23-40$ \\
\hline
\end{tabular}

(*) Valores calculados según los valores de relación de vacíos.

Avşar et al. (2015) presentaron su estudio realizado sobre los suelos volcánicos de la ciudad de Isparta, ubicada al oeste de Turquía y caracterizados por ser débilmente adheridos e integrados fundamentalmente por arenas limosas. El análisis mineralógico a través de difracción de rayos $\mathrm{X}(X R D)$ determinó que este suelo volcánico está compuesto principalmente por minerales de mica y feldespato con una cantidad menor de minerales arcillosos, cuarzo y dolomita. Los minerales de mica y feldespato están representados por biotitas y plagioclasas, respectivamente. Además, observaciones a través de microscopía electrónica (SEM) mostraron picos marcados de Sílice en los límites intergranulares, lo cual sugiere que el material de unión es vidrio volcánico degradado. El suelo está compuesto principalmente por arena $(53 \%$ - 67\%), limo (18\% - 33\%) y pequeñas cantidades de grava $(6 \%-14 \%)$ y partículas del tamaño de arcilla $(2 \%-8 \%)$. Por otra parte, el contenido natural de agua estuvo en el orden de $9 \%$ y 14\%. Según el Sistema Unificado de Clasificación de Suelos (SUCS) este suelo volcánico puede clasificarse como un suelo no plástico o arena limosa porosa, del tipo SM. La tabla 2.6 muestra las principales propiedades geotécnicas del suelo volcánico estudiado por estos investigadores.

Tabla 2.6 Características de suelos volcánicos estudiados por Avşar et al. (2015).

\begin{tabular}{lcccccc}
\hline $\begin{array}{l}\text { Descripción del } \\
\text { suelo }\end{array}$ & $\begin{array}{c}\text { Gravedad } \\
\text { específica } \\
\mathrm{G}_{\mathrm{s}}\end{array}$ & $\begin{array}{c}\text { Densidad } \\
\gamma\end{array}$ & $\begin{array}{c}\text { Relación de } \\
\text { vacíos } \\
\mathrm{e}\end{array}$ & $\begin{array}{c}\text { Porosidad } \\
\mathrm{n}\end{array}$ & $\begin{array}{c}\text { Resistencia al corte máxima } \\
\text { (Ensayos de corte directo) }\end{array}$ \\
& & {$\left[\mathrm{kN} / \mathrm{m}^{3}\right]$} & {$[-]$} & {$[\%]$} & $\mathrm{c}[\mathrm{kPa}]$ & $\varnothing\left[{ }^{\circ}\right]$ \\
\hline Suelo volcánico & $2.35-2.65$ & $14.0-16.7$ & $0.49-0.85\left(^{*}\right)$ & $33-46$ & $0-52$ & $41-59$ \\
\hline
\end{tabular}

(*) Valores calculados según los valores de porosidad

Por su parte, Vezzoli et al. (2017) presentaron su estudio de caracterización geológico - geotécnico de la avalancha de escombros y depósitos piroclásticos del volcán Cotopaxi (Ecuador), que se ubica a unos $75 \mathrm{~km}$ al sureste de la ciudad de 
Quito. El análisis granulométrico realizado sobre muestras de tamaño inferior a 75 $\mathrm{mm}$, determinó que los depósitos de la avalancha de escombros están integrados principalmente por elementos tamaño grava $(31 \%-58 \%)$, arena $(37 \%-57 \%)$ y finos (6\% - 12\%), que de acuerdo al Sistema Unificado de Clasificación de Suelos (SUCS) se clasifican como SP-SM y GP-GM. En tanto que el análisis granulométrico sobre muestras de depósitos piroclásticos determinó una composición de: grava $(0 \%$ $81 \%)$, arena (18\% - 77\%) y finos (1\% - 23\%), que clasifican a estos depósitos como SP-SM, GP-GM, SM y GW. El análisis mineralógico con difracción de rayos X $(X R D)$ a ciertas muestras del depósito piroclástico determinó la presencia de vermiculita, albita, cuarzo y hornblenda. En la tabla 2.7 se muestra un resumen de los principales parámetros de este estudio.

Tabla 2.7 Características de materiales volcánicos estudiados por Vezzoli et al. (2017).

\begin{tabular}{|c|c|c|c|c|c|c|}
\hline \multirow[t]{2}{*}{$\begin{array}{l}\text { Descripción del } \\
\text { suelo }\end{array}$} & \multirow{2}{*}{$\begin{array}{c}\text { Gravedad } \\
\text { específica } \\
\mathrm{G}_{\mathrm{s}}\end{array}$} & \multirow{2}{*}{$\begin{array}{c}\text { Densidad } \\
\gamma \\
{\left[\mathrm{kN} / \mathrm{m}^{3}\right]}\end{array}$} & \multirow{2}{*}{$\begin{array}{c}\text { Relación de } \\
\text { vacíos } \\
\text { e } \\
{[-]}\end{array}$} & \multirow{2}{*}{$\begin{array}{c}\text { Porosidad } \\
\text { n } \\
\text { [\%] }\end{array}$} & \multicolumn{2}{|c|}{$\begin{array}{l}\text { Resistencia al corte máxima } \\
\text { (Ensayos triaxiales tipo } C D \text { ) }\end{array}$} \\
\hline & & & & & $c^{\prime}[\mathrm{kPa}]$ & $\varnothing^{\prime}\left[{ }^{\circ}\right]$ \\
\hline $\begin{array}{l}\text { Depósito de } \\
\text { avalancha de } \\
\text { escombros }\end{array}$ & $1.63-2.25$ & $24.5-25.9$ & $0.06-0.61$ & $6-38$ & 0 & $47-56$ \\
\hline $\begin{array}{l}\text { Depósitos } \\
\text { piroclásticos }\end{array}$ & 2.52 & $10.1-17.9$ & $0.22-0.79$ & $18-44$ & 0 & $42-53$ \\
\hline
\end{tabular}

\subsubsection{Estudios de suelos volcánicos en la ciudad de Quito}

La Formación Cangahua se distribuye en gran parte de la Depresión Interandina, en cuyos depósitos se localiza la ciudad de Quito. La Depresión Interandina es un valle estructural entre 2 cadenas montañosas paralelas a los Andes de Ecuador, la Cordillera Occidental y la Cordillera Real.

Cangahua es un material que tiene alta porosidad, típicamente entre $40 \%$ y $50 \%$ y un peso unitario seco bajo, típico entre $11 \mathrm{kN} / \mathrm{m}^{3}$ y $14 \mathrm{kN} / \mathrm{m}^{3}$. Su resistencia a la compresión uniaxial puede oscilar entre $200 \mathrm{kPa}$ y $600 \mathrm{kPa}$. Cangahua posee características distintivas de roca, como un tejido cementado y una resistencia a la tensión y resistencia a la fractura relativamente altas (O'Rourke y Crespo, 1988). Aunque según Pilecki (1990) este material no pertenece necesariamente a un suelo particulado ni a una roca homogénea, sino que se asemeja a una entidad intermedia de "roca blanda" o de "material suelto cementado".

O'Rourke y Crespo (1988) presentaron un estudio completo sobre propiedades geotécnicas de suelos volcánicos cementados de una zona localizada entre Tumbaco y el Valle de Los Chillos, que se ubica al este de la ciudad de Quito. Para ello se recolectaron 5 bloques cúbicos inalterados de suelo y se transportaron cuidadosamente al Laboratorio de Geotecnia de Cornell University (Estados Unidos) para su análisis. 
El análisis a través de difracción de rayos $\mathrm{X}$ determinó que los bloques de Cangahua recuperados de la zona este de la ciudad de Quito, estuvieron compuestos principalmente de plagioclasa y hornblenda y con menores cantidades de augita, hiperstena y cuarzo. Aunque también no se descartó una mínima presencia de montmorillonita y haloysita poco cristalizadas. Por otra parte, ensayos de microscopía electrónica $(S E M)$ mostraron picos marcados de Sílice en los límites intergranulares, que sugieren que la Sílice amorfa es un agente de cementación dominante.

Luego de los análisis respectivos, se determinó que este depósito está compuesto de arena fina cementada y partículas del tamaño de limo, con un contenido en humedad natural variable entre $15 \%$ y $20 \%$. Las propiedades índice promedio determinadas en este estudio se muestran en la tabla 2.8 .

Tabla 2.8 Propiedades índice de suelos volcánicos estudiados por O’Rourke y Crespo (1988).

\begin{tabular}{ccccccc}
\hline $\begin{array}{c}\text { Código } \\
\text { de } \\
\text { muestra }\end{array}$ & $\begin{array}{c}\text { Peso unitario } \\
\text { parcialmente } \\
\text { saturado } \gamma \\
{\left[\mathrm{kN} / \mathrm{m}^{3}\right]}\end{array}$ & $\begin{array}{c}\text { Peso } \\
\text { unitario } \\
\text { seco } \gamma_{\mathrm{d}} \\
{\left[\mathrm{kN} / \mathrm{m}^{3}\right]}\end{array}$ & $\begin{array}{c}\text { Gravedad } \\
\text { específica } \\
\mathrm{G}_{\mathrm{s}}\end{array}$ & $\begin{array}{c}\text { Relación de } \\
\text { vacíos } \\
\mathrm{e}\end{array}$ & $\begin{array}{c}\text { Porosidad } \\
\mathrm{n}\end{array}$ & $\begin{array}{c}\text { Grado de } \\
\text { saturación } \\
\mathrm{S}_{\mathrm{r}}\end{array}$ \\
\hline 4 & 12.8 & 11.0 & 2.58 & 1.30 & 56 & 32 \\
{$[\%]$}
\end{tabular}

Para determinar la resistencia a la compresión uniaxial los investigadores realizaron 3 ensayos de cada uno de los 5 bloques de suelo. En la tabla 2.9 se presentan los resultados de estos ensayos, destacándose la resistencia media a la compresión, rango de resistencias y los coeficientes de variación.

Tabla 2.9 Resistencia a la compresión uniaxial de suelos estudiados por O’Rourke y Crespo (1988).

\begin{tabular}{|c|c|c|c|c|}
\hline \multirow[t]{2}{*}{$\begin{array}{l}\text { Código de } \\
\text { muestra }\end{array}$} & \multirow{2}{*}{$\begin{array}{c}\text { Peso unitario } \\
\text { seco } \gamma_{\mathrm{d}} \\
{\left[\mathrm{kN} / \mathrm{m}^{3}\right]}\end{array}$} & \multicolumn{3}{|c|}{$\begin{array}{l}\text { Resistencia a la compresión uniaxial qu } \\
{[\mathrm{kPa}]}\end{array}$} \\
\hline & & $\operatorname{Media}(*)$ & Rango & Coeficiente de variación \\
\hline 4 & 11.0 & 360 & $314-437$ & 0.18 \\
\hline 5 & 13.1 & 495 & $462-559$ & 0.11 \\
\hline 7 & 14.4 & 664 & $648-694$ & 0.04 \\
\hline 8 & 13.5 & 535 & $496-594$ & 0.10 \\
\hline 10 & 12.5 & 452 & $442-472$ & 0.04 \\
\hline
\end{tabular}

(*) Valor medio de los 3 ensayos. 
Por otro lado, la tabla 2.10 resume los resultados de ensayos de tracción indirecta (ensayo "brasileño"), realizados sobre 3 muestras de cada bloque inalterado de suelo. Los autores utilizaron el ensayo de tensión brasileña para proporcionar una medida indirecta de la resistencia a la tracción uniaxial.

Tabla 2.10 Resistencia a la tensión brasileña de suelos estudiados por O'Rourke y Crespo (1988).

\begin{tabular}{ccccc}
\hline $\begin{array}{c}\text { Código de } \\
\text { muestra }\end{array}$ & $\begin{array}{c}\text { Peso unitario } \\
\text { seco } \gamma_{\mathrm{d}}\end{array}$ & \multicolumn{3}{c}{$\begin{array}{c}\text { Resistencia a la tensión brasileña qt } \\
{[\mathrm{kPa}]}\end{array}$} \\
\cline { 2 - 5 }$\left[\mathrm{kN} / \mathrm{m}^{3}\right]$ & Media(*) & Rango & Coeficiente de variación \\
\hline 4 & 11.0 & 68 & $55-93$ & 0.31 \\
5 & 13.1 & 110 & $93-136$ & 0.21 \\
7 & 14.4 & 207 & $107-255$ & 0.20 \\
8 & 13.5 & 127 & $104-168$ & 0.28 \\
10 & 12.5 & 101 & $90-121$ & 0.17 \\
\hline
\end{tabular}

(*) Valor medio de los 3 ensayos.

Para determinar la resistencia al corte de estos suelos volcánicos, O'Rourke y Crespo (1988) incluyeron en su estudio ensayos triaxiales consolidados drenados $(C D)$ con medida de cambio de volumen, realizados sobre probetas de $35 \mathrm{~mm}$ de diámetro y $87 \mathrm{~mm}$ de altura y con presiones de confinamiento de $0,60,120,200$ y $300 \mathrm{kPa}$. La tabla 2.11 resume los resultados de resistencia al corte obtenidos en este estudio.

Tabla 2.11 Resistencia al corte de suelos volcánicos estudiados por O'Rourke y Crespo (1988).

\begin{tabular}{|c|c|c|c|c|c|c|c|c|}
\hline \multirow{2}{*}{ 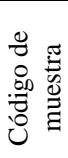 } & \multirow[t]{2}{*}{$\begin{array}{c}\text { Presión de célula } \\
{[\mathrm{kPa}]}\end{array}$} & \multirow{2}{*}{ 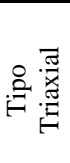 } & \multirow{2}{*}{$\begin{array}{c}\text { Densidad } \\
\gamma / \gamma_{\mathrm{d}} \\
{\left[\mathrm{kN} / \mathrm{m}^{3}\right]}\end{array}$} & \multirow{2}{*}{$\begin{array}{c}\text { Relación } \\
\text { de vacíos } \\
\text { e } \\
{[-]}\end{array}$} & \multicolumn{2}{|c|}{$\begin{array}{l}\text { Resistencia al corte } \\
\text { máxima }\end{array}$} & \multicolumn{2}{|c|}{$\begin{array}{l}\text { Resistencia al corte } \\
\text { residual }\end{array}$} \\
\hline & & & & & $\mathrm{c}^{\prime}[\mathrm{kPa}]$ & $\varnothing^{\prime}\left[{ }^{\circ}\right]$ & $\mathrm{c}^{\prime}[\mathrm{kPa}]$ & $\varnothing^{\prime}\left[{ }^{\circ}\right]$ \\
\hline 7 & $0,60,120,200$ & $C D$ & $16.6 / 14.4$ & 0.76 & 201 & 39 & 111 & 40 \\
\hline 10 & $0,60,120,200,300$ & $C D$ & $14.9 / 12.5$ & 1.03 & 111 & 40 & 88 & 36 \\
\hline
\end{tabular}

Según los ensayos triaxiales realizados, O'Rourke y Crespo (1988) concluyeron que este suelo volcánico exhibe un modo de falla frágil en presiones de confinamiento bajas con una transición a falla dúctil en presiones de confinamiento más altas.

De los ensayos realizados, los autores concluyen que la falla en taludes de Cangahua es causada por la formación y propagación de fracturas, que a menudo se inician en lugares de erosión y socavación cerca del pie del talud. Entonces, debido a que la falla de un talud de este material depende de la propagación de las grietas, resulta importante probar las propiedades que controlan la formación de fracturas y su crecimiento en el material intacto. Por otra parte, las fallas en taludes de Cangahua ocurren con mayor frecuencia durante o después de periodos de lluvia intensa y en periodos de clima inusualmente seco y ventoso (O'Rourke y Crespo, 1988). 


\subsubsection{Estudio geotécnico para la Línea 1 de Metro Quito}

Como parte de las investigaciones geotécnicas para el diseño de las estructuras de la Línea 1 del Metro de la ciudad de Quito, la Empresa Pública Metropolitana Metro de Quito $(E P M M Q)$ llevó a cabo una campaña completa de trabajos de campo y laboratorio, de donde se obtuvieron los diferentes parámetros y perfiles geológicogeotécnicos para toda la longitud del túnel y obras subterráneas.

Los parámetros obtenidos en este estudio fueron facilitados por la Empresa Pública Metropolitana Metro de Quito para complementar esta investigación.

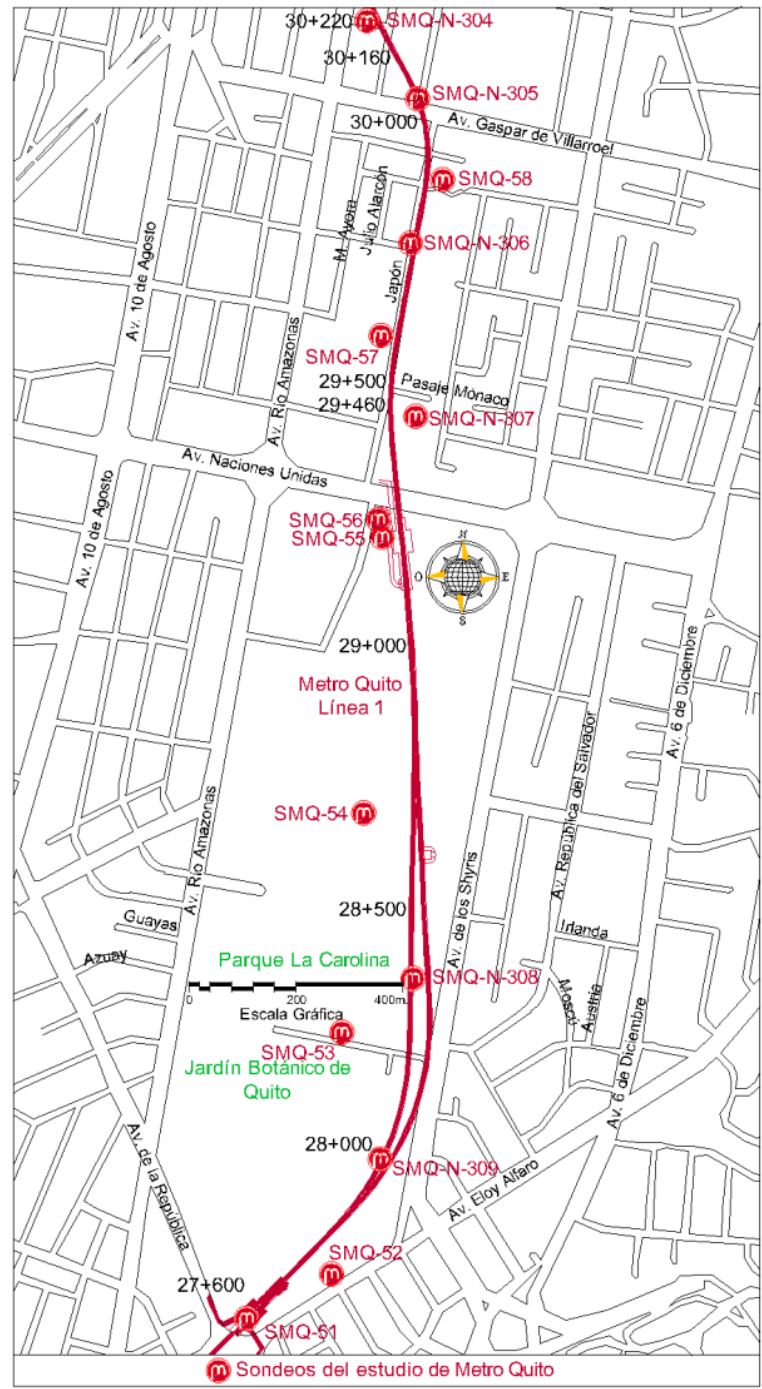

Fig. 2.1 Ubicación de perforaciones de estudio de Metro Quito en zona centro-norte. 


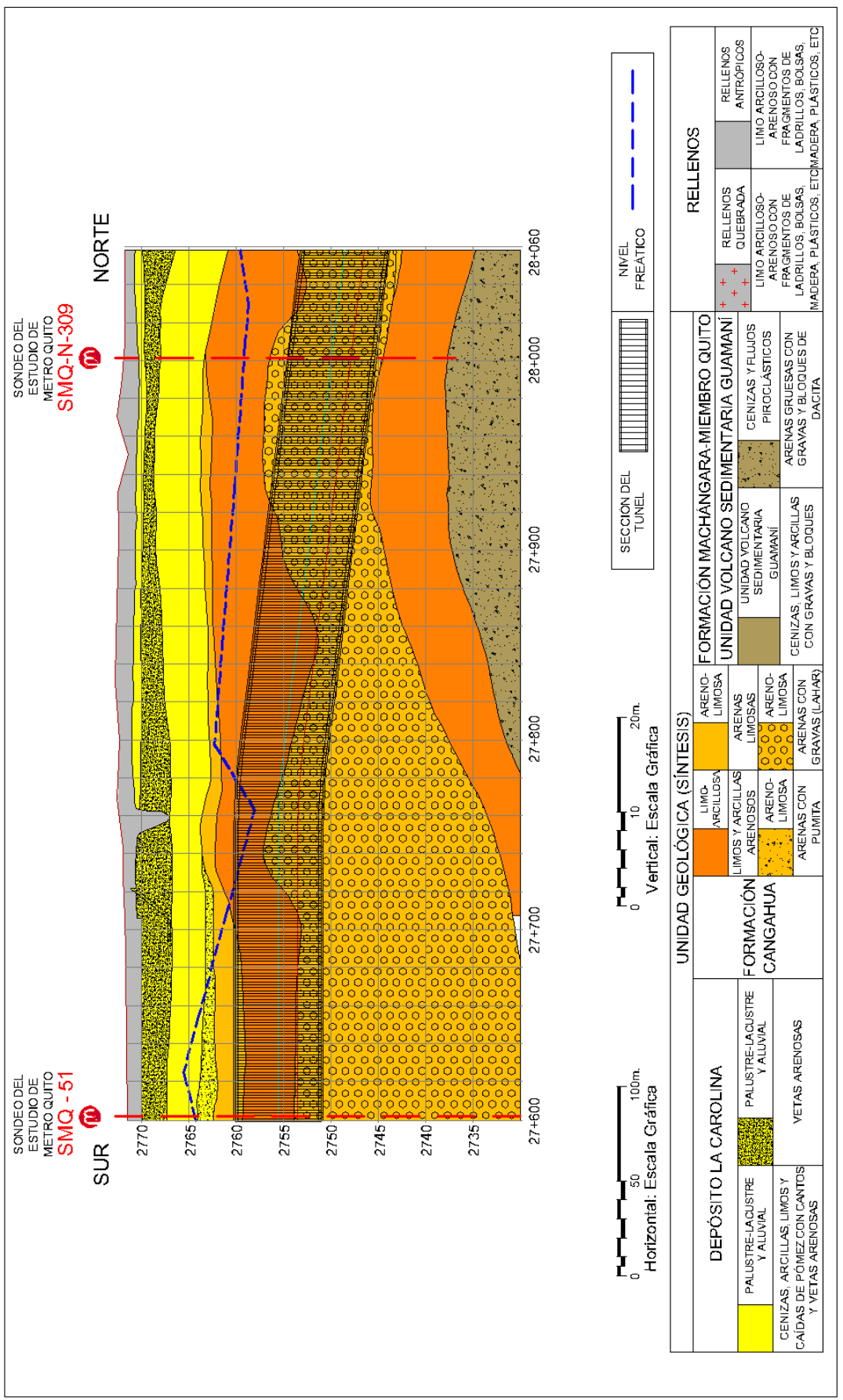

Fig. 2.2 Perfil geológico - geotécnico de Línea 1 de Metro Quito, pk 27+600 y pk 28+060. Modificado de EPMMQ, 2016. 


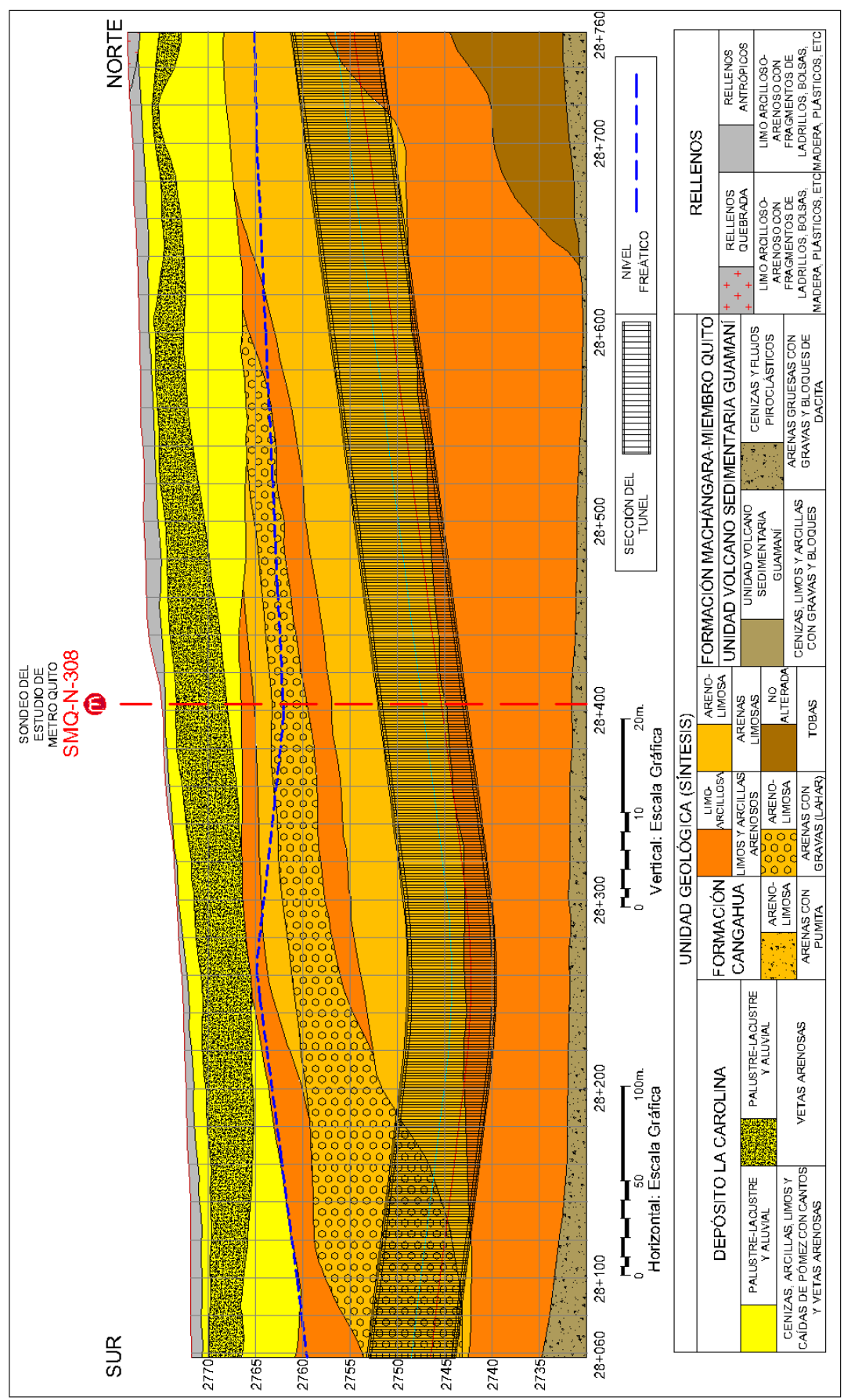

Fig. 2.3 Perfil geológico - geotécnico de Línea 1 de Metro Quito, pk 28+060 y pk 28+760. Modificado de EPMMQ, 2016. 


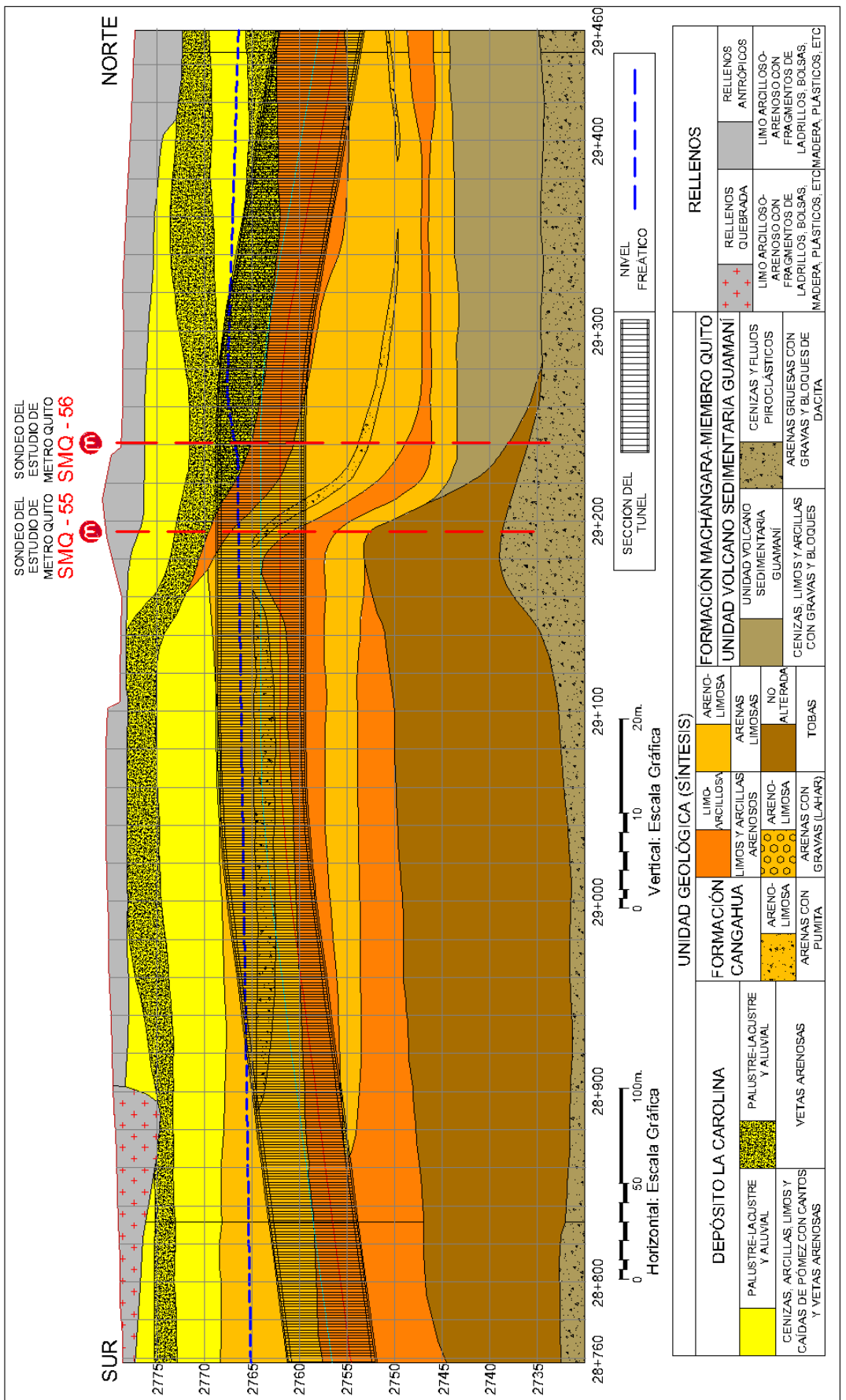

Fig. 2.4 Perfil geológico - geotécnico de Línea 1 de Metro Quito, pk 28+760 y pk 29+460. Modificado de EPMMQ, 2016. 


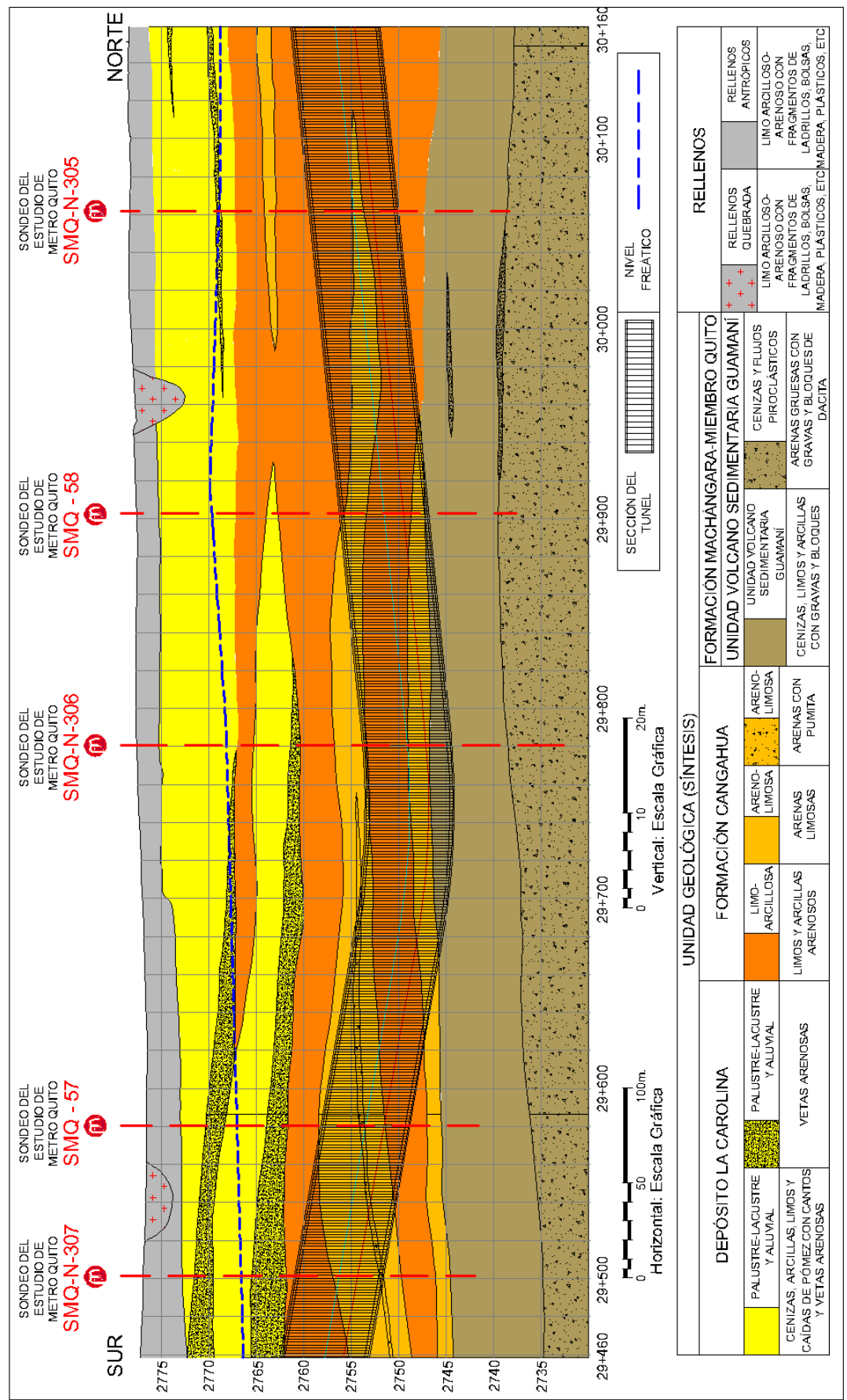

Fig. 2.5 Perfil geológico - geotécnico de Línea 1 de Metro Quito, pk 29+460 y pk 30+160. Modificado de EPMMQ, 2016. 
Este estudio inicialmente contempló las investigaciones geotécnicas para el proyecto original (año 2012) y después incluyó un estudio complementario (año 2016) (EPMMQ, 2016). La totalidad de trabajos de campo entre las 2 etapas, exclusivamente en el sector centro-norte comprendido entre el parque La Carolina y la Av. Gaspar de Villarroel consistió de 14 sondeos de perforación de profundidades comprendidas entre $30 \mathrm{~m}$ y $45 \mathrm{~m}$. La Fig. 2.1 muestra el trazado de la Línea 1 de Metro Quito en el tramo que coincide con la zona centro-norte de la ciudad y la ubicación de sondeos de perforación entre los puntos kilométricos (pk) 27+600 y $30+220$.

Las Fig. 2.2, 2.3, 2.4 y 2.5 muestran los perfiles geológico - geotécnicos obtenidos del estudio geotécnico de Metro Quito comprendidos entre los puntos kilométricos (pk) $27+600$ y $30+160$. En estos perfiles se han incluido y se han superpuesto los sondeos de perforación que fueron parte de este estudio.

Según el estudio geotécnico para la Línea 1 del Sistema de Metro Quito (EPMMQ, 2016) estos depósitos corresponden a suelos volcánicos que incluyen limos arenosos de baja a alta plasticidad, arcillas arenosas de baja a media plasticidad y arenas limosas. De acuerdo al Sistema Unificado de Clasificación de Suelos (SUCS) y en concordancia a la norma ASTM D2487 (ASTM D2487, 2011) estos estratos corresponden a los tipos de suelo: ML, MH, CL, CL-ML y SM. El contenido natural de agua en limos y arcillas osciló entre $16 \%$ y 64\%, mientras que en arenas estuvo entre $7 \%$ y $49 \%$. La gravedad específica de estos suelos volcánicos estuvo en el rango de 2.40 y 2.69 , en tanto que los valores de densidad oscilaron entre $14.7 \mathrm{kN} / \mathrm{m}^{3}$ y $20.9 \mathrm{kN} / \mathrm{m}^{3}$.

Por otra parte, para determinar las propiedades de compresión de estos suelos se realizaron ensayos de consolidación unidimensional con doble drenaje en muestras inalteradas y cuidadosamente insertadas en anillos edométricos de acero inoxidable de $50 \mathrm{~mm}$ de diámetro y $20 \mathrm{~mm}$ de altura, de acuerdo con las especificaciones ASTM D2435 (ASTM D2435, 2011). En estas pruebas el esfuerzo de sobrecarga se incrementó desde $25 \mathrm{kPa}$ hasta $816 \mathrm{kPa}$ y cada escalón de carga se mantuvo durante 24 h (EPMMQ, 2016). Las curvas edométricas resultantes fueron utilizadas para determinar los parámetros de compresión. La tabla 2.12 muestra los valores de índice de compresión $\left(C_{c}\right)$ e índice de hinchamiento $\left(C_{s}\right)$ para las muestras obtenidas de las perforaciones distribuidas en esta zona como parte de este estudio. De acuerdo a los valores de la tabla 2.12 se tiene que $C_{s}$ oscila entre 0.09 y 0.66 , mientras que $C_{s}$ varía entre 0.01 y 0.05 .

Para determinar las propiedades de resistencia al corte de estos suelos, el estudio de Metro Quito incluye ensayos de compresión triaxial no consolidados no drenados $(U U)$, realizados de acuerdo a la especificación ASTM D2850 (ASTM D2850, 2015). La tabla 2.13 muestra un resumen de los parámetros obtenidos en estos ensayos, en donde el ángulo de fricción oscila entre $3.3^{\circ}$ y $45.0^{\circ}$ y la cohesión varía entre $10 \mathrm{kPa}$ y $300 \mathrm{kPa}$. 
Tabla 2.12 Índices de compresión $\left(C_{c}\right)$ e hinchamiento $\left(C_{s}\right)$ obtenidos en muestras de los sondeos del estudio de Metro Quito.

\begin{tabular}{|c|c|c|c|c|}
\hline & \multicolumn{2}{|c|}{ Ensayo } & \multirow{2}{*}{$C_{c}$} & \multirow{2}{*}{$C_{s}$} \\
\hline \multirow{9}{*}{ 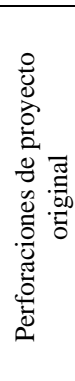 } & Perforación & Prof. [m] & & \\
\hline & SMQ-51 & 6.00 & 0.664 & 0.041 \\
\hline & SMQ-52 & 6.00 & 0.199 & 0.045 \\
\hline & SMQ-53 & 3.00 & 0.113 & 0.013 \\
\hline & SMQ-54 & 6.00 & 0.116 & 0.012 \\
\hline & SMQ-55 & 13.13 & 0.103 & 0.008 \\
\hline & SMQ-56 & 12.00 & 0.090 & 0.011 \\
\hline & SMQ-57 & 16.56 & 0.126 & 0.023 \\
\hline & SMQ-58 & 9.00 & 0.203 & 0.017 \\
\hline
\end{tabular}

Tabla 2.13 Parámetros de resistencia al corte de ensayos triaxiales tipo $U U$ obtenidos en muestras de los sondeos del estudio de Metro Quito.

\begin{tabular}{|c|c|c|c|c|c|c|c|c|}
\hline \multirow{2}{*}{ 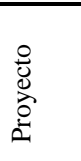 } & \multicolumn{2}{|c|}{ Ensayo } & $\begin{array}{l}\text { Presión de } \\
\text { célula }\end{array}$ & \multirow{2}{*}{ 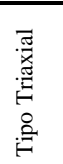 } & \multirow{2}{*}{$\begin{array}{c}W_{\text {nat }} \\
{[\%]}\end{array}$} & \multirow{2}{*}{$\begin{array}{l}\gamma / \gamma_{\mathrm{d}} \\
{\left[\mathrm{kN} / \mathrm{m}^{3}\right]}\end{array}$} & \multirow{2}{*}{$\begin{array}{c}\mathrm{c} \\
{[\mathrm{kPa}]}\end{array}$} & \multirow{2}{*}{$\begin{array}{l}\varnothing \\
\left.{ }^{\circ}\right]\end{array}$} \\
\hline & Sondeo & $\begin{array}{l}\text { Prof. } \\
\text { [m] }\end{array}$ & {$[\mathrm{kPa}]$} & & & & & \\
\hline \multirow{18}{*}{ 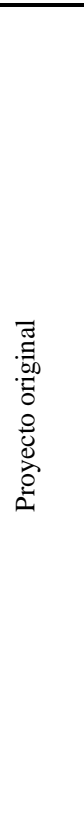 } & SMQ-51 & 6.00 & $70,141,281$ & $\overline{U U}$ & 56 & $16.3 / 10.4$ & 45 & 5.7 \\
\hline & \multirow{4}{*}{ SMQ-52 } & 4.20 & $70,141,281$ & $U U$ & 45 & $15.8 / 10.9$ & 15 & 11.8 \\
\hline & & 10.00 & $70,141,281$ & $U U$ & 25 & $19.1 / 15.3$ & 60 & 29.7 \\
\hline & & 25.43 & $70,141,281$ & $U U$ & 35 & $17.4 / 12.9$ & 50 & 36.9 \\
\hline & & 36.42 & $700,141,281$ & $U U$ & 31 & $19.0 / 14.5$ & 300 & 19.5 \\
\hline & SMQ-53 & 28.55 & $70,141,281$ & $U U$ & 26 & $17.5 / 13.9$ & 30 & 45.0 \\
\hline & SMQ-54 & 6.00 & $70,141,281$ & $U U$ & 26 & $17.6 / 13.9$ & 20 & 27.4 \\
\hline & \multirow{5}{*}{ SMQ-55 } & 2.45 & $70,141,281$ & $U U$ & 24 & $18.0 / 14.5$ & 10 & 30.6 \\
\hline & & 8.00 & $70,141,281$ & $U U$ & 24 & $17.2 / 13.9$ & 20 & 35.0 \\
\hline & & 16.09 & $70,141,281$ & $U U$ & 25 & $17.8 / 14.2$ & 50 & 25.3 \\
\hline & & 25.45 & $70,141,281$ & $U U$ & 18 & $18.7 / 15.8$ & 50 & 32.8 \\
\hline & & 31.63 & $70,141,281$ & $U U$ & 28 & $17.5 / 13.7$ & 35 & 35.5 \\
\hline & SMQ-56 & 9.45 & $70,141,281$ & $U U$ & 31 & $17.6 / 13.5$ & 20 & 8.8 \\
\hline & & 6.00 & $70,141,281$ & $U U$ & 45 & $14.7 / 10.1$ & 25 & 12.2 \\
\hline & & 14.53 & $70,141.281$ & $U U$ & 32 & $17.8 / 13.4$ & 70 & 3.3 \\
\hline & & 25.46 & 70. 141.281 & $U U$ & 28 & $17.6 / 13.8$ & 40 & 44.4 \\
\hline & SMQ-57 & 31.57 & $70,141,281$ & $U U$ & 37 & $17.0 / 12.4$ & 60 & 12.2 \\
\hline & SMQ-58 & 4.00 & $70,141,281$ & $U U$ & 49 & $15.5 / 10.4$ & 65 & 11.8 \\
\hline \multirow{5}{*}{ 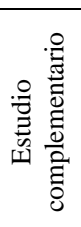 } & SMQ-N-304 & 21.00 & $50,100,200$ & $U U$ & 25 & $18.5 / 14.8$ & 122 & 40.5 \\
\hline & SMQ-N-305 & 25.35 & $50,100.200$ & $U U$ & 24 & $19.9 / 16.0$ & 53 & 23.3 \\
\hline & SMQ-N-306 & 27.55 & $50,100,200$ & $U U$ & 21 & $19.2 / 15.8$ & 93 & 36.1 \\
\hline & SMQ-N-308 & 28.00 & $50,100,200$ & $U U$ & 31 & $18.7 / 14.3$ & 137 & 43.0 \\
\hline & SMQ-N-309 & 27.55 & $50,100,200$ & $U U$ & 33 & 18.4 / 13.9 & 104 & 36.0 \\
\hline
\end{tabular}




\subsection{La técnica de "Soil Nailing"}

\subsubsection{Introducción a la técnica}

"Soil Nailing" es una técnica de refuerzo del terreno que se ha aplicado con mucha frecuencia en la estabilización de taludes, terraplenes, cortes del terreno en la construcción de carreteras y ferrocarriles, en túneles y en estructuras de contención. Esta técnica consiste en reforzar la masa de suelo mediante la introducción de una serie de elementos de refuerzo pasivos, delgados o barras de acero para resistir los esfuerzos de tensión, flexión y corte (Ortigao y Sayao, 2004). Las barras de acero se instalan sub-horizontalmente y espaciadas estrechamente en la masa de suelo o roca suave erosionada en agujeros previamente perforados, para luego ser llenados con mortero fluido o "Grout". La Fig. 2.6 muestra ejemplos de aplicaciones típicas de esta técnica.

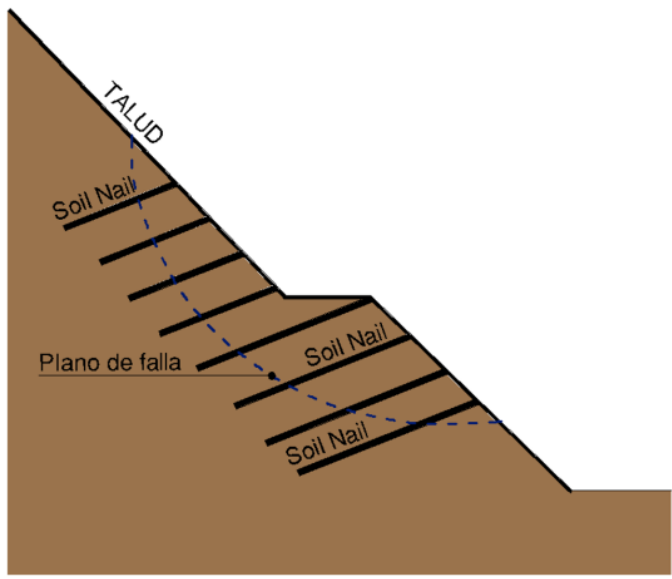

(a)

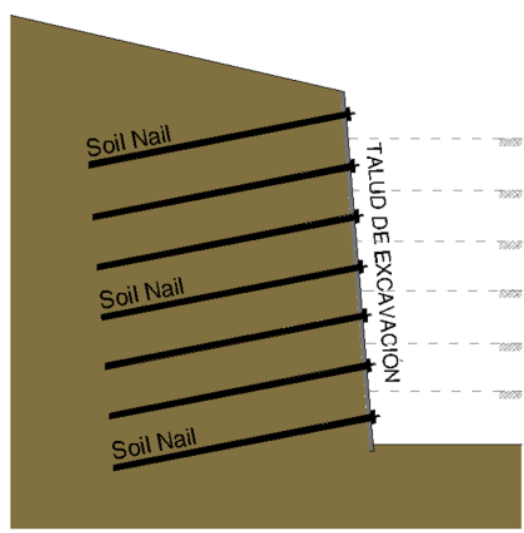

(b)

Fig. 2.6 Aplicaciones típicas de técnica de "Soil Nailing": (a) en talud existente, y (b) en excavación.

Generalmente, los "Soil Nails" son distribuidos e instalados con separaciones horizontales y verticales comprendidas entre $1.00 \mathrm{~m}$ y $1.50 \mathrm{~m}$, y con inclinaciones entre $10^{\circ}$ y $20^{\circ}$ con respecto a la horizontal. Mientras que el diámetro de las barras de acero de los "Soil Nails" suele estar entre $25 \mathrm{~mm}$ a $40 \mathrm{~mm}$ y con una longitud usualmente en el rango de 4 m - 20 m (Pradhan et al., 2019). Según Ortigao y Sayao (2004) la longitud de los "Soil Nails" suele ser del 60\% al 120\% de la altura de una excavación vertical. En cambio, según ICE (2012) la longitud de los "Soil Nails" suele ser de 1.0 a 1.5 veces la altura del talud, dependiendo de las condiciones del terreno.

Para el recubrimiento del talud (Pantalla o "Facing"), el tipo estándar de revestimiento es el hormigón proyectado, a diferencia del resto de pantallas en estructuras de contención en donde se usa el concreto estándar (Ortigao y Sayao, 2004). Por otra parte, el "Grout" mejora la unión entre el suelo y los "Soil Nails" y 
los protege contra la corrosión. La relación agua-cemento del mortero fluido o "Grout" para los "Soil Nails" generalmente varía entre 0.40 y 0.45 (Pradhan et al., 2019). El conjunto de "Soil Nails" y la pantalla o "Facing" contribuyen a la estabilidad general del talud o excavación.

En la práctica a menudo se realizan simulaciones numéricas de muros claveteados o "Soil Nail Walls" para evaluar su rendimiento y estabilidad (Singh y Sivakumar Babu, 2009). Una estructura de "Soil Nailing" debe cumplir con ciertos requerimientos fundamentales de estabilidad, uso y durabilidad, durante su construcción y en su periodo de diseño (GEO, 2008). Otras cuestiones como el costo y el impacto ambiental también son aspectos a tener en cuenta en la planificación. El diseño de estructuras claveteadas se realiza con mayor frecuencia utilizando un análisis de estado límite y un programa de estabilidad de taludes (ICE, 2012). Por otra parte, la heterogeneidad de las condiciones del suelo y la posible presencia de agua subterránea hacen que el planteamiento de modelos apropiados de análisis y diseño sea una tarea difícil. Un modelo del terreno se debe basar en el modelo geológico y debe incorporar el rango de parámetros de ingeniería y las condiciones del terreno (GEO, 2008).

El diseño de estructuras de "Soil Nailing" se basa actualmente en el Método de Diseño por Esfuerzos Admisibles o "Allowable Stress Design (ASD)" porque el Método de Diseño por Factores de Carga y Resistencia o "Load and Resistance Factor Design (LRFD)" no está del todo disponible (FHWA, 2015; Lin y Liu, 2016). Sin embargo, Lin y Liu (2016) presentaron un estudio de análisis de factores de resistencia para el método LRFD en estructuras de "Soil Nailing" contra fallas de estabilidad externa, siendo este enfoque uno de los primeros para el desarrollo de esta metodología. En el método $A S D$ se asignan factores de seguridad (FS) para controlar los niveles de seguridad de una estructura contra varios potenciales modos de falla (Lin y Liu, 2016). El factor de seguridad es un factor único que considera toda la incertidumbre del diseño, los materiales y la construcción (FHWA, 2015). En definitiva, el $F S$ se puede definir como la relación de la resistencia general disponible de un sistema a las cargas totales aplicadas al mismo. Con frecuencia, un solo $F S$ es inadecuado para garantizar un nivel de seguridad consistente y uniforme para una estructura, ya que puede implicar diversos grados de incertidumbre (Duncan, 2000; Lin y Liu, 2016).

\subsubsection{Comportamiento de "Soil Nails"}

Los "Soil Nails" pueden trabajar sometidos a esfuerzos de tensión y corte. Sin embargo, con los ángulos de instalación normales comprendidos entre $10^{\circ}$ y $20^{\circ}$ el componente de corte es insignificante y por lo general se desprecia, por lo que los "Nails" son diseñados para trabajar sólo en tensión (ICE, 2012).

Los "Soil Nails" deben ser diseñados para penetrar a través de la zona activa de movimiento y suficientemente más allá de cualquier potencial superficie de 
deslizamiento, hacia una zona de suelo resistente (ICE, 2012). Considerando un tramo de masa de suelo reforzado con un sistema de "Soil Nails", las cargas en los mismos sólo pueden ser inducidas por el movimiento del talud, pantalla o muro de contención, siendo la sección del "Nail" más alejado de la superficie la primera en ser esforzada por el movimiento del terreno (ICE, 2012).

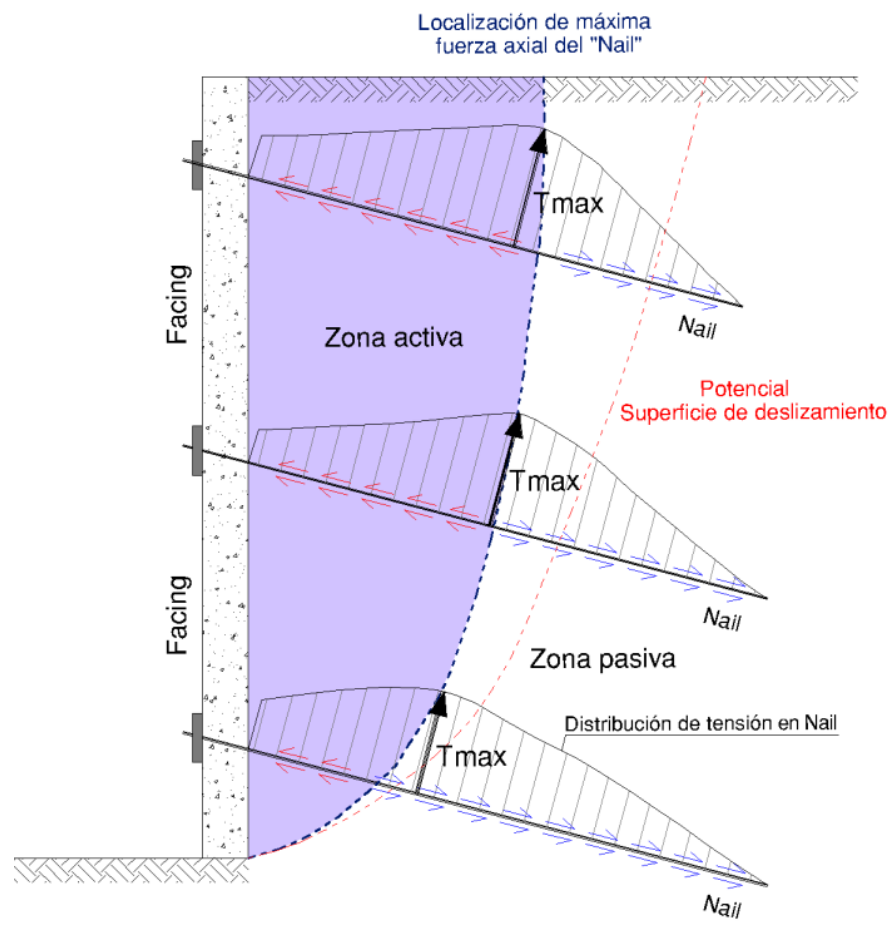

Fig. 2.7 Localización de máximas fuerzas de tracción en "Nails". Modificado de FHWA (2015) y GEO (2008).

A medida que la perforación con la barra de acero o "Nail" ya instalada es rellenada de "Grout" en toda su longitud, se desarrollan tensiones a lo largo de toda la longitud del "Nail" (Pradhan et al., 2019). La transferencia de carga hacia y desde el suelo circundante se desarrolla a través de esfuerzos de corte que actúan a lo largo de la interface del "Grout" del "Soil Nail". Durante un corte del terreno, el suelo retenido se deforma hacia la excavación, por tanto, los "Soil Nails" se extienden dando como resultado fuerzas axiales de tensión en las barras de acero de los mismos. La carga de tensión axial en las barras de acero o "Nails" aumenta desde la cabeza de la barra hasta un valor máximo, luego disminuye a medida que el "Soil Nail" transfiere la carga al suelo circundante (Ver Fig. 2.7). La resistencia a la tensión de la barra de acero del "Soil Nail" y la resistencia a la extracción (pull-out) del "Soil Nail" son los principales mecanismos de resistencia de este sistema (FHWA, 2015). 


\subsubsection{Historia de la técnica de "Soil Nailing"}

El origen del "Soil Nailing" se remonta a la década de 1960, cuando se introdujo el Nuevo Método Austriaco de Túneles para el soporte de excavación de rocas (Rabcewicz, 1964a, 1964b, 1965). La introducción de barras de acero en perforaciones en el terreno y la inyección del mortero fluido o "Grout" en dichas perforaciones, en combinación con el uso de revestimiento de hormigón proyectado o "Shotcrete" fueron utilizados para proveer soporte a las excavaciones (FHWA, 2015).

Las barras pasivas de acero se conocen como pernos de roca o bulones en la industria de túneles. Posteriormente el concepto de combinar el refuerzo pasivo de acero y el hormigón proyectado se difundió a proyectos de estabilización de pendientes rocosas (Lang, 1961). La aplicación de esta técnica se expandió más tarde en trabajos de estabilización de taludes y excavaciones en suelo (FHWA, 2015).

En 1970 constructores de túneles utilizaron por primera vez esta técnica en Brasil. Sin embargo, esta experiencia no se reportó adecuadamente (Ortigao y Sayao, 2004). En 1972 se usaron "Soil Nails" para estabilizar un talud de corte en arena de aproximadamente 60 pies de altura para un proyecto de ampliación de ferrocarril cerca de Versalles, Francia (Rabejac y Toudic, 1974). El método resultó ser rentable y la construcción más rápida que otros métodos de soporte convencionales, por lo que a partir de este proyecto la técnica de "Soil Nailing" se hizo de uso común en Francia y otros países europeos. En 1975 se realizó en Alemania la primera investigación de "Soil Nailing" con ensayos de modelos de laboratorio y pruebas a gran escala de muros claveteados (Stocker et al., 1979).

Por otra parte, el programa de investigación francés Clouterre con el aporte de participantes públicos y privados inició en 1986. Este estudio incluyó pruebas a gran escala, monitorización de muros claveteados, pruebas de campo y simulaciones numéricas (Clouterre, 1991). El objetivo era promover la aplicación de la técnica de "Soil Nailing" para estructuras a corto y largo plazo a partir de las recomendaciones emitidas. Pero, en definitiva, se orientó esta investigación principalmente a entender mejor el comportamiento de los muros claveteados, a establecer las limitaciones del proceso, a mejorar los métodos para el diseño de estas estructuras y a cómo usar el "Soil Nailing" para estructuras a largo plazo. La originalidad del proyecto Clouterre radicó en el hecho en que tres modelos experimentales de estructuras claveteadas "Soil Nail Walls" completamente instrumentadas fueron construidas y monitorizadas desde su construcción hasta los ensayos que las llevaron a la falla (Clouterre, 1991).

En 1996, el grupo de la industria de la geo-construcción denominado como ADSC inició discusiones sobre un proyecto relacionado con "Soil Nailing". Para ello en 1997 construyeron el denominado "Amherst Test Wall" en University of Massachusetts Amherst (UMass Amherst) National Geotechnical Experimentation Site (NGES), cerca del poblado de Amherst, Massachusetts (Estados Unidos). Este 
fue un muro a gran escala construido en suelo arcilloso como una prueba experimental realizada para ampliar el conocimiento sobre la técnica de "Soil Nailing". El muro fue instrumentado para examinar su modo de falla, y la UMass $N G E S$ fue seleccionada por las características del suelo y el soporte proporcionado en este organismo para llevar a cabo los trabajos investigativos de campo (Sheahan, 2000). Por su lado, Garzón et al. (2019) presentaron un estudio comparativo de la conveniencia de la aplicación de los métodos de elementos finitos y equilibrio límite para el diseño de estructuras claveteadas a partir del proyecto experimental "Amherst Test Wall"

Holman y Tuozzolo (2009) presentaron un estudio experimental de un muro claveteado temporal "Soil Nail Wall" construido en Manhattan, Ciudad de New York (Estados Unidos) en 2007. Se cree que este proyecto ubicado en un campo universitario cerca de East River constituye el primer "Soil Nail Wall" en Manhattan. El proyecto fue instrumentado durante su ejecución y de igual manera monitorizado durante y después de su construcción. El principal objetivo de este estudio radicó en investigar la distribución de tensiones en las barras de los "Soil Nails".

Ehrlich y Silva (2015) presentaron una investigación del comportamiento de una excavación de $31 \mathrm{~m}$ de altura soportada por un sistema combinado de anclajes y de "Soil Nailing" en suelo residual de gneis y ejecutada en 2005. Esta excavación fue parte de la construcción de un edificio en Niterói, Río de Janeiro, Brasil. Cuando la construcción del muro superior estaba casi terminada, surgió una grieta paralela a la dirección del muro en la cima del talud. Por lo que se decidió paralizar los trabajos de construcción para realizar estudios adicionales. Se detectó que la inclinación de los estratos de suelo variaba a lo largo de la excavación y tenían una orientación que era desfavorable para la estabilidad del corte. Entonces esta investigación resalta la importancia de la correcta definición de las condiciones geológicas y geotécnicas para la comprensión del mecanismo de colapso, con la finalidad de lograr un análisis de estabilidad más realista.

\subsubsection{Componentes de un sistema de "Soil Nailing"}

\subsubsection{Generalidades}

El uso de la técnica de "Soil Nailing" implica reforzar el terreno a medida que se excava. Este procedimiento es utilizado en estructuras de contención temporales y permanentes. La técnica utiliza barras de acero pasivas, resistentes a la tensión que son incrustadas dentro de una perforación de diámetro comprendido entre $5 \mathrm{~cm}$ y 15 $\mathrm{cm}$, que luego será rellenada con "Grout". El sistema incluye un revestimiento del talud (Pantalla o "Facing") con un espesor que puede variar entre $5 \mathrm{~cm}$ y $15 \mathrm{~cm}$, con una o dos capas de mallas de acero embebidas en el "Shotcrete". Los revestimientos más delgados se aplican generalmente en pendientes inclinadas y los revestimientos más gruesos en excavaciones verticales permanentes (Ortigao y Sayao, 2004). La 
cabeza de cada "Soil Nail" incluye una pequeña placa de acero que se ajusta perfectamente a la pantalla. Para el caso de estructuras permanentes dicha placa por lo general queda embebida dentro de un dado de concreto. En la Fig. 2.8 se muestran los componentes principales de una estructura de "Soil Nailing" y en definitiva en esta sección se mencionan los elementos principales de este tipo de estructuras.

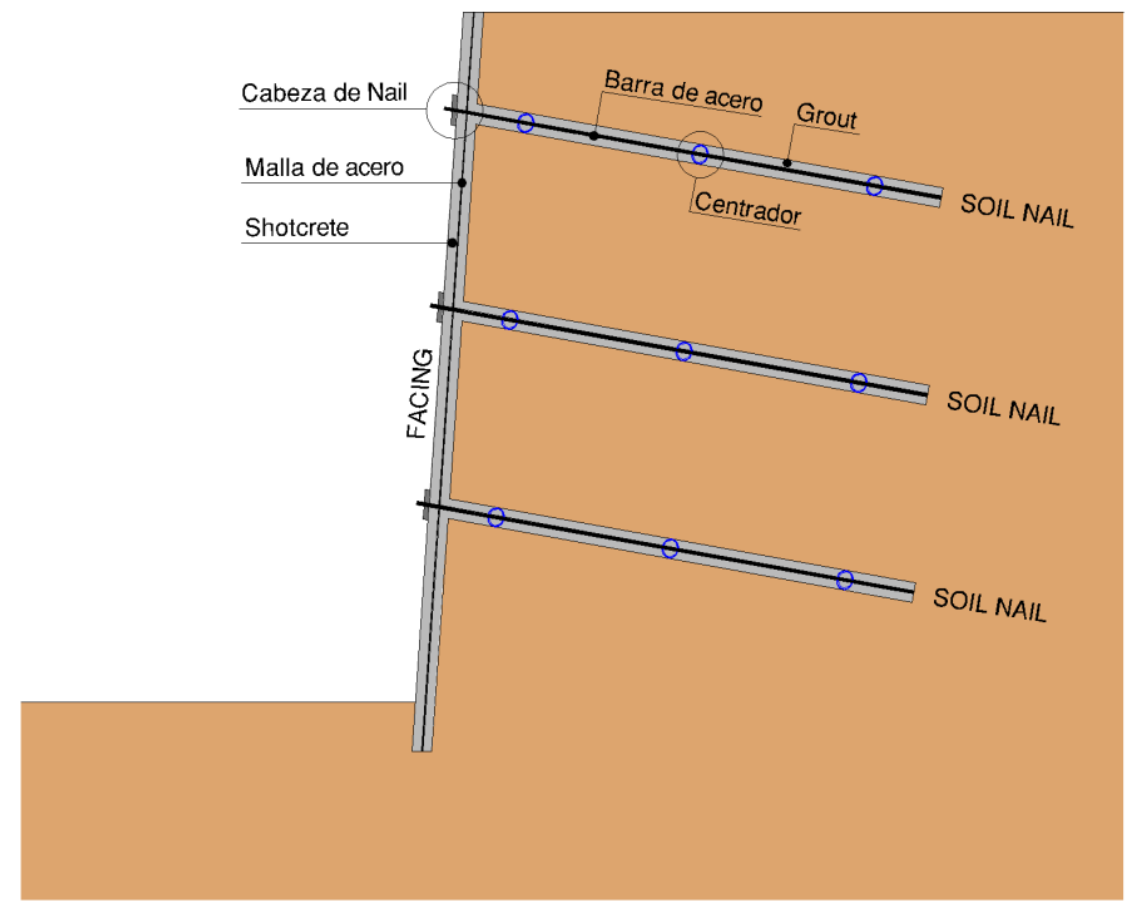

Fig. 2.8 Componentes principales de un sistema de "Soil Nailing".

\subsubsection{2. "Soil Nails"}

- Barras de acero o bulones: Constituyen los elementos clave de una estructura de "Soil Nailing". Proporcionan de manera fundamental la resistencia a la tensión en respuesta al movimiento lateral y la deformación de la masa inestable de suelo retenido en la estructura de muro claveteada (Pradhan et al., 2019). El movimiento del terreno puede ocurrir durante la excavación, después de la excavación en ausencia de cargas externas (como resultado de deformaciones dependientes del tiempo), o después de la excavación cuando se aplican cargas externas como sobrecargas o cargas de tráfico (FHWA, 2015). Con frecuencia, son instaladas dentro de un agujero pre-taladrado que luego será rellenado con mortero fluido o "Grout". Por otra parte, los bulones generalmente tienen una resistencia nominal a la tensión de 60 ksi (Grado 60) o 75 ksi (Grado 75) (FHWA, 
2015). En la Fig. 2.9 se muestran las barras de acero que con frecuencia son utilizadas en sistemas de "Soil Nailing".

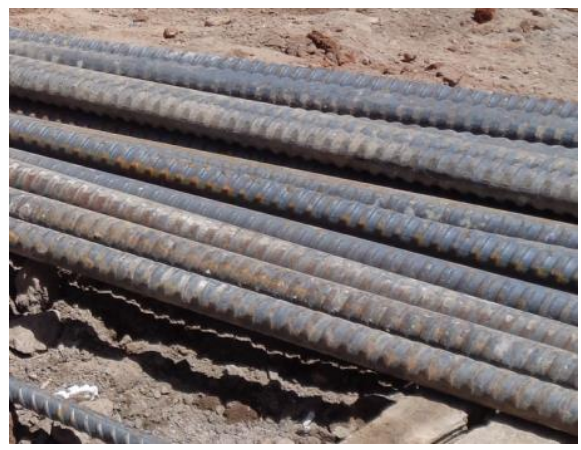

Fig. 2.9 Barras de acero utilizadas en "Soil Nailing".

- "Grout" o mortero fluido: Generalmente consiste de una mezcla de cemento Portland y agua. El "Grout" se inyecta en la perforación después de instalar el refuerzo principal y puede ser por gravedad o aplicando una pequeña presión. El "Grout" transfiere los esfuerzos cortantes de la masa inestable de suelo a la barra de acero o refuerzo del "Soil Nail" (GEO, 2008) y luego transfiere los esfuerzos axiales del "Soil Nail" a la masa estable del suelo (Pradhan et al., 2019; FHWA, 2015). La resistencia mínima a la compresión para el "Grout" debe ser de 1500 $\mathrm{lb} / \mathrm{pul}^{2}$ (10.4 MPa) a los 3 días, y de $3000 \mathrm{lb} / \mathrm{pulg}^{2}(20.8 \mathrm{MPa})$ a $4000 \mathrm{lb} / \mathrm{pulg}^{2}$ (27.6 MPa) a los 28 días (FHWA, 2015).

- Centradores y acoples: Los centradores son utilizados para garantizar que la barra de acero o "Nail" quede más o menos centrada en la perforación, previo a la inyección del mortero fluido. En la Fig. 2.10 se muestra un tipo de centrador de PVC mencionado en FHWA (2015). Por otra parte, los acoples se usan para unir barras de acero y ampliar su longitud (GEO, 2008).

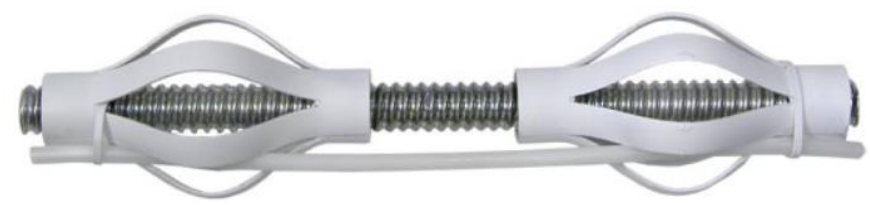

Fig. 2.10 Centrador típico de PVC (FHWA, 2015). La separación indicada es sólo esquemática.

- Cabeza del "Nail": Se compone de una placa de acero, la misma que es ajustada al extremo roscado del "Nail" a través de una tuerca. Para el caso de estructuras de "Soil Nailing" permanentes es recomendable construir un dado de revestimiento de sección cuadrada de concreto armado. La Fig. 2.11 presenta esquemas de cabeza de "Nail" típicos usados en estructuras de contención o muros con "Soil Nailing". 


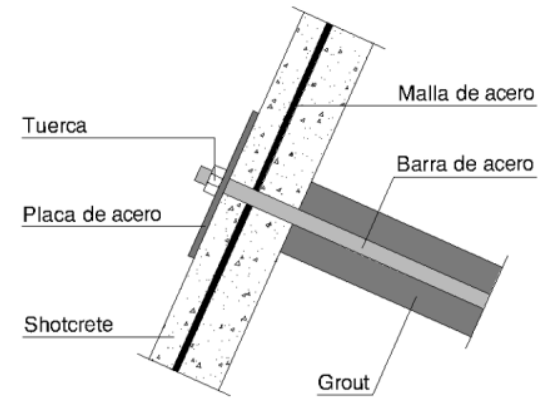

(a)

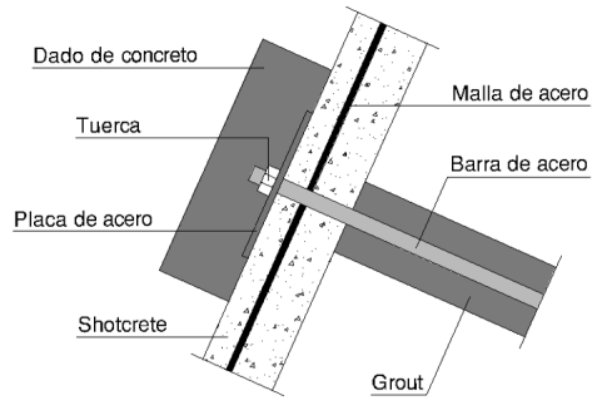

(b)

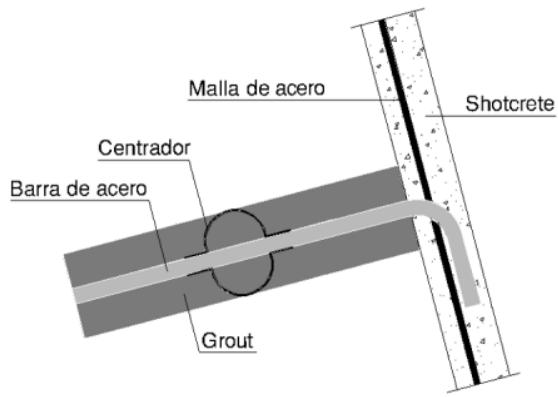

(c)

Fig. 2.11 Cabezas de "Nail": (a) "Soil Nail" temporal, (b) "Soil Nail" permanente, y (c) "Soil Nail" con doblez de barra de acero (Ortigao y Sayao, 2004).

\subsubsection{Pantalla o "Facing"}

Generalmente este revestimiento se compone de una capa inicial y de una capa final. Inmediatamente después de la excavación se aplica el revestimiento inicial sobre el suelo expuesto para proporcionar estabilidad temporal. En tanto que la capa o revestimiento final se construye sobre el revestimiento inicial y proporciona continuidad estructural a lo largo del periodo de diseño.

\subsubsection{Ventajas de la técnica de "Soil Nailing"}

De acuerdo a FHWA (2015), las ventajas de la técnica de "Soil Nailing" se dividen en 3 principales categorías: construcción, rendimiento y costo.

\subsubsection{Construcción}

- El proceso de construcción de muros claveteados es rápido y causa menos congestión e impacto ambiental, en comparación con otras técnicas constructivas como pozos perforados o muros de pilotes soldados que requieren equipos relativamente grandes (FHWA, 2015; GEO, 2008). 
- La limitación aérea en espacio no es mayor inconveniente para la construcción de "Soil Nails", por lo que su aplicación se puede dar sin mayores complicaciones debajo de estructuras existentes.

- Los parámetros de diseño de muros claveteados, tales como la longitud, ángulo de inclinación y ubicación de los "Soil Nails" se pueden ajustar fácilmente a las limitaciones del sitio debido a las variaciones en las condiciones del terreno cuando se encuentren rocas, pilas u otras estructuras subterráneas (FHWA, 2015; Pradhan et al., 2019).

- La técnica de "Soil Nailing" resulta más rentable en proyectos de difícil acceso, ya que al ser los equipos más pequeños su movilización e instalación es más fácil.

\subsubsection{Rendimiento}

- Los muros claveteados son relativamente flexibles, por lo que se pueden ajustar de manera comparable a grandes asentamientos y por tanto funcionan mejor en condiciones sísmicas. Además su modo de falla es dúctil y proporcionan señales tempranas de advertencia (Pradhan et al., 2019).

- Las deflexiones medidas en muros claveteados por lo general están dentro de los límites tolerables en proyectos de carreteras, cuando la construcción se controla adecuadamente (FHWA, 2015).

\subsubsection{Costo}

- Los muros claveteados convencionales "Soil Nail Walls" tienden a ser más económicos que los muros de concreto convencionales más altos que 12 pies (3.7 m) a 15 pies (4.6 m) (FHWA, 2015). Por otra parte, la aplicación de estructuras de "Soil Nailing" da como resultado un ahorro comprendido entre $10 \%$ y $30 \%$ en comparación con los muros anclados o "Tieback Walls" (Pradhan et al., 2019). Sin embargo, de acuerdo a FHWA (2015), los muros claveteados "Soil Nail Walls" son típicamente equivalentes en costo o más rentables que los muros anclados, cuando se utilizan procedimientos convencionales de construcción.

\subsubsection{Limitaciones de la técnica de "Soil Nailing"}

Se pueden mencionar las siguientes desventajas o limitaciones relativas a esta técnica:

- En proyectos donde se requiera el control estricto de deformaciones, los "Soil Nails" no resultan ser la opción más confiable. Para controlar dichas deformaciones puede ser necesario la aplicación de técnicas de reforzamiento adicionales que incrementarán el costo de construcción (FHWA, 2015).

- Esta técnica puede resultar inadecuada en proyectos con presencia de nivel freático, debido a las dificultades para la excavación, perforación e inyección de "Grout" (Pradhan et al., 2019; GEO, 2008). La construcción de muros 
claveteados requiere mantener temporalmente el talud de la excavación sin elementos de soporte adicionales (FHWA, 2015).

- La construcción de los "Soil Nails" presenta elevada dificultad en arenas y en general en suelos sin cohesión, ya que la perforación puede colapsar incluso en el mismo proceso constructivo (Pradhan et al., 2019).

- Este procedimiento resulta ineficaz en taludes o deslizamientos muy altos, por la dificultad para instalar refuerzos de "Soil Nail" de gran longitud (Pradhan et al., 2019; GEO, 2008).

- Las barras de acero de los "Soil Nails" son propensas a la corrosión (especialmente en terrenos con elevada humedad o con otros agentes agresores), por lo tanto se debe incluir una medida preventiva para controlar estos agentes, procedimiento que significa un costo adicional en la instalación.

\subsubsection{Modos de falla}

\subsubsection{Introducción}

Una estructura de "Soil Nailing" debe ser diseñada para satisfacer las comprobaciones de seguridad requeridas contra todos los modos potenciales de falla, incluidos los modos de falla externa e interna.

\subsubsection{Modos de falla externa}

Las fallas externas se refieren a las fallas en la estabilidad global, estabilidad al deslizamiento y la capacidad de carga (Ver Fig. 2.12). La estabilidad global se refiere a la pérdida de estabilidad general de la masa de suelo reforzada, que puede ocurrir cuando las cargas totales superan las resistencias proporcionadas por el suelo a lo largo de la superficie crítica de falla y por los "Soil Nails" que se extienden a través de ella (Lin y Liu, 2016). La estabilidad global se realiza de manera más adecuada utilizando programas computacionales generales de estabilidad de taludes que con aquellos paquetes informáticos dedicados al diseño de este tipo de estructuras (FWHA, 2015).

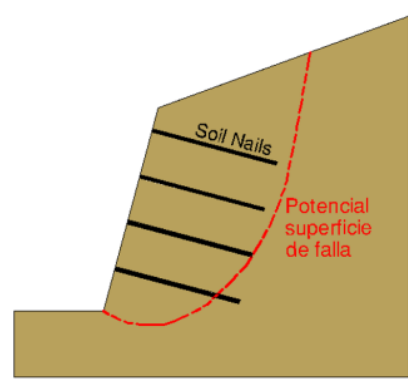

(a)

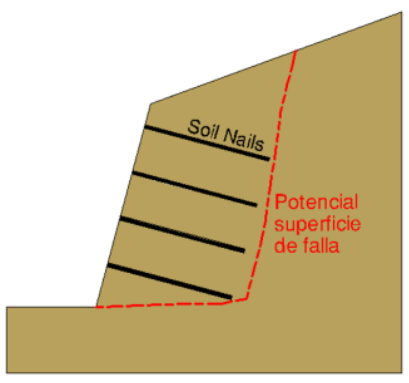

(b)

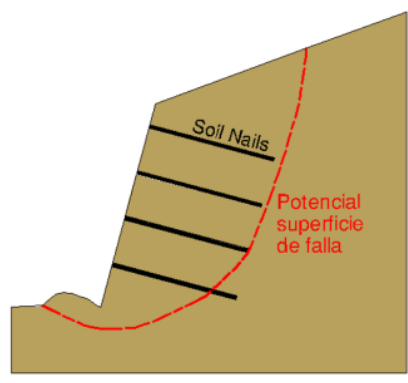

(c)

Fig. 2.12 Modos potenciales de falla externa en sistemas "Soil Nailing": (a) Falla de estabilidad global, (b) Falla de estabilidad al deslizamiento, y (c) Falla de capacidad de carga. Modificado de GEO (2008). 
La estabilidad al deslizamiento se refiere al movimiento horizontal de toda la masa de suelo claveteada a lo largo de su base. Mientras que la falla de la capacidad de carga sólo puede ocurrir cuando un muro claveteado se construye sobre suelos de grano fino muy blandos, aún en este escenario este modo de falla es raro o poco frecuente, por lo que generalmente se excluye en los estudios (Lin y Liu, 2016).

\subsubsection{Modos de falla interna}

Las fallas internas se refieren a fallas dentro de la masa de suelo claveteada (GEO, 2008). La estabilidad interna de los muros claveteados debe considerarse para potenciales superficies de deslizamiento que se extienden a través del suelo y a algunos o todos los "Soil Nails" (FHWA, 2015). Entonces, en un sistema de "Soil Nailing" las fallas internas pueden ocurrir en la zona activa, la zona pasiva o en ambas zonas (GEO, 2008).

Según GEO (2008), los modos de falla interna en la zona activa contemplan lo siguiente:

- Falla de la masa de suelo. El suelo se desintegra y fluye alrededor de los "Soil Nails" y las cabezas de los "Nails".

- Falla del soporte debajo de las cabezas de los "Nails".

- Falla estructural de los "Soil Nails" bajo acciones combinadas de tracción, corte y flexión.

- Falla estructural de las cabezas de "Nails" o en la pantalla. Puede ser falla de flexión, punzonamiento o falla en la conexión de la pantalla con la cabeza del "Nail".

- Falla superficial en las cabezas de "Nails". Puede ser por erosión o falla local por deslizamiento.

En tanto, que los modos de falla interna en la zona pasiva contemplan la falla a la extracción (pull-out) en la interfaz del suelo con el "Grout" o en el contacto "Grout" con la barra de acero (GEO, 2008). La resistencia a la extracción o "pull-out" de la interfaz suelo-"Soil Nail" es un parámetro crítico que depende de una serie de factores influyentes, como las condiciones del suelo, el método de perforación, la sobrecarga/presión del suelo y el método de inyección del "Grout" o mortero fluido, ya sea bajo gravedad o presión (Hong et. al., 2013).

\subsubsection{Parámetros equivalentes para "Soil Nails"}

En la simulación de muros claveteados o "Soil Nail Walls", por lo general se utilizan elementos estructurales rectangulares para modelar los "Soil Nails" y la pantalla o "Facing". Los parámetros de entrada más importantes para los elementos tipo placa son la rigidez a flexión EI y la rigidez axial EA (Sivakumar Babu y Singh, 2009). 
Dado que los "Soil Nails" son de sección transversal circular y se colocan con determinadas separaciones horizontales, es necesario determinar rigideces axiales y a flexión equivalentes para la correcta simulación de los "Soil Nails" circulares como elementos de placa rectangulares (Sivakumar Babu y Singh, 2009; Rawat y Gupta, 2016).

Para los "Soil Nails" con bulbo de "Grout", el módulo de elasticidad equivalente $E_{e q}$ se determinará considerando la contribución de la rigidez elástica del "Grout" y de la barra de acero de refuerzo. Entonces de los fundamentos de resistencia de materiales, $E_{e q}$ se puede determinar de acuerdo a la expresión 2.1 (Singh y Sivakumar Babu, 2009; Ardakani et al., 2014).

$$
E_{e q}=E_{n}\left(\frac{A_{n}}{A}\right)+E_{g}\left(\frac{A_{g}}{A}\right)
$$

Donde:

$E_{n} \quad$ módulo de elasticidad de la barra de acero o "Nail"

$E_{g} \quad$ módulo de elasticidad del "Grout"

$A$ área de la perforación, siendo $A=\pi D_{p}^{2} / 4$, en donde $D_{p}$ es el diámetro de la perforación

$A_{n} \quad$ área de la barra de acero o "Nail"

$A_{g} \quad$ área de la sección de "Grout", siendo $A_{g}=A-A_{n}$

Entonces, una vez determinado el módulo de rigidez equivalente $E_{e q}$ y siendo $S_{h}$ la separación horizontal entre cada uno de los "Soil Nails", la rigidez axial EA y a flexión $E I$ puede ser determinada por las expresiones 2.2 y 2.3, respectivamente (Singh y Sivakumar Babu, 2009).

Rigidez axial: $E A=\frac{E_{e q}}{S_{h}}\left(\frac{\pi D_{p}^{2}}{4}\right) \quad[\mathrm{kN} / \mathrm{m}]$

Rigidez a flexión: $E I=\frac{E_{e q}}{S_{h}}\left(\frac{\pi D_{p}^{4}}{64}\right) \quad\left[\mathrm{kN} \mathrm{m}^{2} / \mathrm{m}\right]$

Por otra parte, el espesor de placa equivalente $d_{e q}$ en función de los parámetros de rigidez axial y a flexión se puede calcular con la expresión 2.4 (Plaxis, 2020).

$$
d_{e q}=\sqrt{12 \frac{E I}{E A}} \quad[\mathrm{~m}]
$$




\subsubsection{Modelos constitutivos de suelo}

\subsubsection{Modelo de Mohr Coulomb}

El modelo de Mohr Coulomb (MC) es un modelo elástico perfectamente plástico, que se puede utilizar como una primera aproximación del comportamiento del suelo (Plaxis, 2020) (Ver Fig. 2.13). La parte lineal elástica del modelo de Mohr Coulomb está basada en la ley de elasticidad de Hooke (Plaxis, 2020; Singh y Sivakumar Babu, 2009). La parte perfectamente plástica está basada en el criterio de falla de Coulomb, formulado en un marco de plasticidad no asociado (Plaxis, 2020). Este modelo requiere el ingreso de 5 parámetros básicos, los cuales son generalmente familiares para la mayoría de ingenieros geotécnicos y pueden ser obtenidos de ensayos básicos en muestras de suelo (Plaxis, 2020). Los parámetros requeridos son: módulo de Young $E$, relación de Poisson $v$, cohesión $c$, ángulo de fricción $\varnothing$ y el ángulo de dilatancia del suelo $\psi$ (Plaxis, 2020; Singh y Sivakumar Babu, 2009).

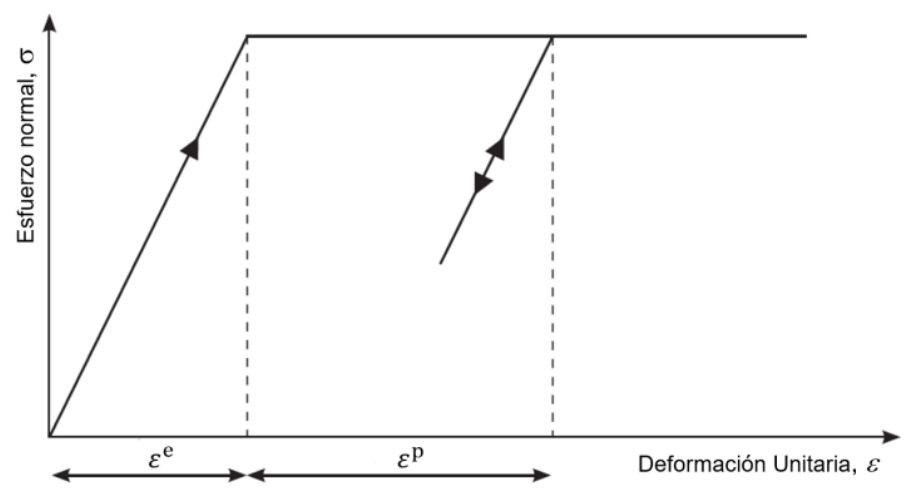

Fig. 2.13 Idea básica de un modelo elástico perfectamente plástico (Plaxis, 2020).

El principio básico de elastoplasticidad es que las deformaciones y las relaciones de deformación se descomponen en una parte elástica $\varepsilon^{\mathrm{e}} \mathrm{y}$ en otra parte plástica $\varepsilon^{\mathrm{p}}$ (Plaxis, 2020), según se puede ver en la Fig. 2.13.

En este modelo, para cada capa se estima una rigidez constante promedio o una rigidez que aumenta linealmente con la profundidad. Debido a esta rigidez constante, los cálculos tienden a ser relativamente rápidos y se obtiene una primera estimación de las deformaciones (Plaxis, 2020).

\subsubsection{Modelo de Hardening Soil}

El modelo de Hardening Soil (HS) o de suelo con endurecimiento isotrópico es un modelo avanzado para simular el comportamiento de diferentes tipos de suelo, ya sean blandos o rígidos. En primera instancia este modelo se calibró para arena en 
base a los resultados de ensayos de compresión triaxial y ensayos edométricos (Schanz et al, 1999).

De manera similar al modelo de $M C$, la falla en el modelo de Hardening Soil se define mediante el criterio de falla de Mohr Coulomb. Por otra parte, a diferencia del modelo de $M C$, el modelo de Hardening Soil considera el aumento de rigidez con la presión (Singh y Sivakumar Babu, 2009), es decir este modelo considera la dependencia de esfuerzos de los módulos de rigidez. El modelo utiliza una formulación de ley de potencia para la rigidez dependiente del esfuerzo, similar a la utilizada en el modelo hiperbólico de Duncan Chang (Duncan y Chang, 1970). Entonces, la idea básica para la formulación del modelo de Hardening Soil es la relación hiperbólica entre la deformación axial y el esfuerzo desviador en carga primaria.

La superficie de fluencia de un modelo tipo de Hardening Soil no está fija en el espacio de tensión principal, por el contrario, puede expandirse debido a la deformación plástica. Este modelo incluye 2 tipos de endurecimiento, denominados endurecimiento por corte y endurecimiento por compresión. El endurecimiento por corte es usado para modelar deformaciones irreversibles debidas a carga desviadora primaria. El endurecimiento por compresión es utilizado para modelar deformaciones plásticas irreversibles debidas a compresión primaria en carga edométrica e isótropa (Plaxis, 2020).

En el modelo de Hardening Soil, se requieren resultados de ensayos edométricos y ensayos triaxiales (Surarak et al., 2012). La Fig. 2.14 muestra la obtención de los módulos de rigidez en carga primaria en un ensayo triaxial drenado estándar. En tanto, que en la Fig. 2.15 se muestra la obtención del módulo de rigidez tangente en un ensayo edométrico.

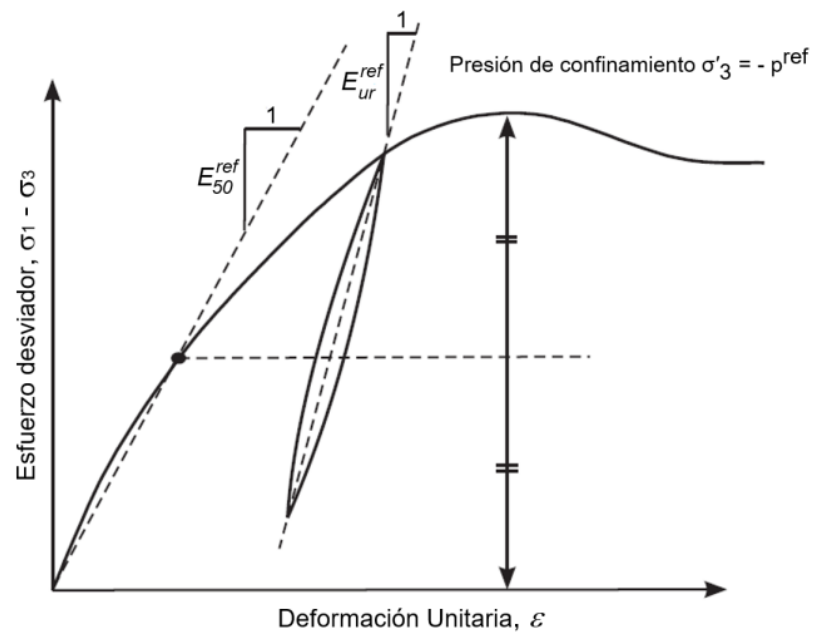

Fig. 2.14 Definición de $E_{50}^{r e f}$ y $E_{u r}^{r e f}$ para resultados de ensayo triaxial drenado (Plaxis, 2020). 


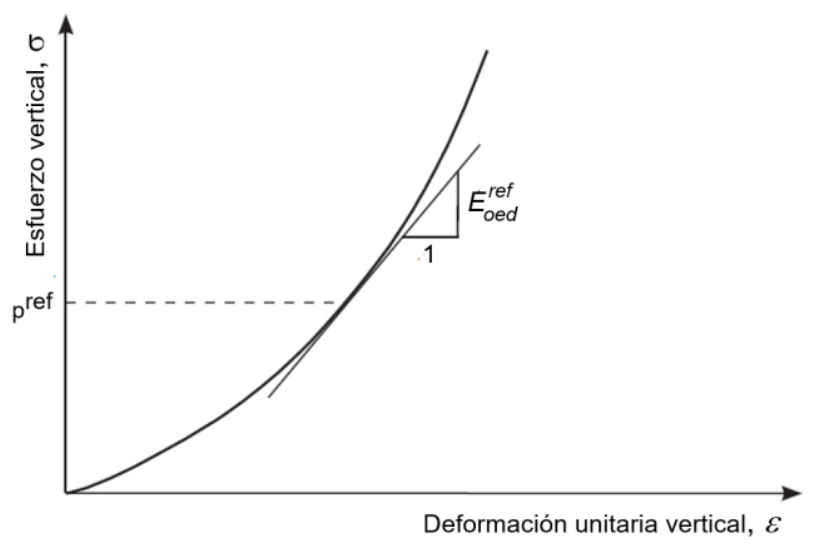

Fig. 2.15 Definición de $E_{\text {oed }}^{\text {ref }}$ para resultados de ensayo edométrico (Plaxis, 2020).

Los parámetros de falla del modelo de Hardening Soil, tales como: cohesión $c$, ángulo de fricción $\emptyset \mathrm{y}$ el ángulo de dilatancia $\psi$ coinciden con aquellos del modelo de Mohr Coulomb.

El resto de parámetros requeridos en este modelo de suelo son principalmente: la presión de referencia $p^{\text {ref }}$ (se considera por defecto $100 \mathrm{kPa}$ ), módulo de rigidez secante de ensayo triaxial drenado a la presión de referencia $\left(E_{50}^{\text {ref }}\right)$, módulo de rigidez tangente de carga primaria de ensayo edométrico a la presión de referencia $\left(E_{\text {oed }}^{\text {ref }}\right)$, módulo de rigidez descarga/recarga de ensayo triaxial drenado a la presión de referencia $\left(E_{u r}^{r e f}\right)$, relación de dependencia de esfuerzos en el comportamiento de rigidez $(\mathrm{m})$, y la relación de Poisson en descarga/recarga $\left(v_{u r}\right)$ (se considera por defecto 0.20).

El parámetro $E_{50}$, es el módulo de rigidez dependiente del esfuerzo de confinamiento para carga primaria y se obtiene, por la expresión 2.5 (Plaxis, 2020).

$$
E_{50}=E_{50}^{r e f}\left(\frac{c \cos \emptyset-\sigma_{3}^{\prime} \operatorname{sen} \emptyset}{c \cos \emptyset+p^{r e f} \operatorname{sen} \varnothing}\right)^{m}
$$

La rigidez edométrica $E_{\text {oed }}$ dependiente del esfuerzo, está dada por la expresión 2.6 (Plaxis, 2020).

$$
E_{\text {oed }}=E_{\text {oed }}^{r e f}\left(\frac{c \cos \emptyset-\sigma_{y}^{\prime} \operatorname{sen} \emptyset}{c \cos \varnothing+p^{r e f} \operatorname{sen} \varnothing}\right)^{m}
$$

Para las trayectorias de tensión de descarga/recarga, se utiliza otro módulo de rigidez $E_{u r}$ dependiente del esfuerzo, y está dado por la expresión 2.7 (Plaxis, 2020).

$$
E_{u r}=E_{u r}^{r e f}\left(\frac{c \cos \emptyset-\sigma_{3}^{\prime} \operatorname{sen} \emptyset}{c \cos \varnothing+p^{r e f} \operatorname{sen} \varnothing}\right)^{m}
$$


En estas expresiones $\sigma_{3}^{\prime}$ es la presión de confinamiento en el ensayo triaxial y es usualmente negativa. Por su parte, $\sigma_{y}^{\prime}$ es el esfuerzo efectivo vertical en el ensayo edométrico.

El modelo de Hardening Soil (HS) genera un perfil de asentamientos más realista en comparación al modelo de Mohr Coulomb. La consideración de la rigidez no-lineal e inelástica en el modelo de $H S$ permite una mejor predicción de asentamientos cerca de una excavación (Teo y Wong, 2012).

\subsubsection{Modelo de Hardening Soil with Small-Strain Stiffness}

El rango de deformación en el cual los suelos pueden considerarse verdaderamente elásticos es muy pequeño. Con el aumento de la amplitud de deformación, la rigidez del suelo decae de forma no-lineal (Benz, 2007). Entonces el modelo de Hardening Soil with Small-Strain Stiffness (HSsmall) es una modificación del modelo de Hardening Soil $(H S)$ que considera el incremento de rigidez de los suelos a pequeñas deformaciones. A bajos niveles de deformación, la mayoría de suelos presentan una mayor rigidez que los niveles de deformación en ingeniería. Esta rigidez varía nolinealmente con la deformación (Singh y Sivakumar Babu, 2009).

El modelo de Hardening Soil with Small-Strain Stiffness se basa en el modelo de Hardening Soil y utiliza casi por completo los mismos parámetros. De hecho, sólo se necesitan 2 parámetros adicionales para describir la variación de la rigidez con la deformación (Plaxis, 2020). Estos parámetros son: el módulo de corte inicial o de pequeñas deformaciones $\left(G_{0}\right)$ y el nivel de deformación por corte $\left(\gamma_{0.7}\right)$ en el que el módulo secante de corte $G_{S}$ se reduce a aproximadamente al $70 \%$ de $G_{0}$.

Varios factores actúan en los parámetros de pequeñas deformaciones $G_{0}$ y $\gamma_{0.7}$. Principalmente están influenciados por el estado real de esfuerzos y la relación de vacíos del suelo (e). En el modelo HSsmall, la dependencia de esfuerzos del módulo de corte $G_{0}$ es tomada en cuenta con la ley de potencia de acuerdo a la expresión 2.8, en donde, $\sigma_{3}^{\prime}$ es el esfuerzo efectivo horizontal. El umbral de deformación de corte $\gamma_{0.7}$ se toma independientemente del esfuerzo medio (Plaxis, 2020).

$$
G_{0}=G_{0}^{r e f}\left(\frac{c \cos \varnothing-\sigma_{3}^{\prime} \operatorname{sen} \varnothing}{c \cos \varnothing+p^{r e f} \operatorname{sen} \varnothing}\right)^{m}
$$

Una buena correlación para estimar el $G_{0}$ de muchos suelos es por ejemplo la expresión 2.9 dada por Hardin y Black (1969). Sin embargo, existen otras correlaciones en la literatura de este campo (Benz, 2007) y el conocimiento de la relación de vacíos inicial de un material puede ser muy útil para derivar su módulo inicial de corte en pequeñas deformaciones (Plaxis, 2020).

$$
G_{0}^{r e f}=33 \frac{(2.97-e)^{2}}{1+e} \quad[\mathrm{Mpa}] \quad \text { para: } p^{r e f}=100 \mathrm{kPa}
$$




\subsection{Métodos de análisis de sistemas de "Soil Nailing"}

\subsubsection{Método de los elementos finitos}

Con frecuencia se usan rigurosas técnicas computacionales basadas en los métodos de los elementos finitos o de las diferencias finitas para estudiar la compleja interacción suelo - estructura y evaluar el rendimiento y la estabilidad de las estructuras de "Soil Nailing" (Sivakumar Babu y Singh, 2009). El método de los elementos finitos es una popular y poderosa herramienta que se ha utilizado para analizar taludes reforzados por anclajes al terreno (Wu et al., 2017). En ingeniería práctica, la estabilidad global de un sistema de "Soil Nailing" es la principal preocupación en lugar del comportamiento mecánico de un solo elemento o "Soil Nail" en la masa de suelo (Fan y Luo, 2008).

El uso creciente de geometrías complejas y de varios materiales ha hecho que el análisis no-lineal sea interactivo por naturaleza. El método de los elementos finitos es usado para analizar la zona de falla, la no-linealidad del suelo y los efectos de las etapas constructivas para predecir las condiciones reales del sitio (Rawat y Gupta, 2016).

El análisis de taludes por elementos finitos es un problema complejo que requiere de la definición de las condiciones iniciales, condiciones de contorno, propiedades tenso-deformacionales de los suelos del talud y las secuencias de carga (Tan y Sarma, 2008). Entonces, el hecho de que estos procedimientos requieran de una gran cantidad de datos de cálculo y de tiempo justifica el uso de paquetes informáticos basados en el método de los elementos finitos. Además, con la ventaja de no suponer de antemano la ubicación y la forma de la superficie de falla, el método de los elementos finitos ha sido ampliamente aceptado para el análisis de estabilidad de taludes (Griffiths y Lane, 1999; Rabie, 2014). Por otra parte, si se dispone de datos reales de compresibilidad del suelo, las soluciones a través de elementos finitos proporcionarán información de las deformaciones en los diferentes niveles de esfuerzo (Griffiths y Lane, 1999).

La simulación numérica de sistemas de "Soil Nailing" a través del método de los elementos finitos ha demostrado ser muy útil en la predicción de deformaciones de taludes, análisis de esfuerzos, resistencia a la extracción o "pull-out" de anclajes, distribución de fuerzas a lo largo de la longitud de los "Soil Nails", análisis de la variación de fuerzas en los "Soil Nails" con la cohesión, ángulo de fricción y el movimiento lateral del talud. Además, con el método de los elementos finitos es posible el cálculo del factor de seguridad (FS) aplicando el método de reducción de resistencia, el cual consiste en la reducción de los parámetros resistentes ( $c$ y $\emptyset$ ) por un factor de seguridad que interviene mientras las cargas debidas al peso del suelo y otras fuerzas externas sean aplicadas y hasta que el sistema no pueda mantener una condición estable (Rawat y Gupta, 2016). Esta técnica ha sido adoptada en 
reconocidos programas geotécnicos computacionales fundamentados en los métodos de los elementos finitos y diferencias finitas, tales como PLAXIS 2D, ANSYS y FLAC 2D.

Sin lugar a dudas, en los últimos años el uso de PLAXIS 2D ha despertado el interés de expertos dedicados a la Geotecnia para el análisis de variadas estructuras de "Soil Nailing". Este paquete computacional es una herramienta bidimensional basada en el método de los elementos finitos, de uso comercial y enfocado para análisis de deformación y estabilidad dentro de un extenso campo de problemas de Ingeniería Geotécnica. En problemas de estabilidad de taludes en PLAXIS 2D, el factor de seguridad $(F S)$ se obtiene mediante un procedimiento de reducción denominado "phi/c reduction", en donde los parámetros de resistencia al corte del suelo (tan $\emptyset$ ) $y(c)$, como también la resistencia a la tensión se reducen sucesivamente hasta que se produce el fallo de la estructura. El ángulo de dilatancia $\psi$ en principio no es afectado por el procedimiento de reducción. Sin embargo, el ángulo de dilatancia $\psi$ nunca puede ser mayor al ángulo de fricción $\varnothing$. Entonces cuando el ángulo de fricción $\emptyset$ se ha reducido bastante que se vuelve igual al ángulo de dilatancia $\psi$, cualquier reducción adicional del ángulo de fricción $\varnothing$ conducirá a la misma reducción en el ángulo de dilatancia $\psi$.

En definitiva, el factor de seguridad global de una estructura está dado por la expresión 2.10.

$$
F S=\frac{\text { Resistencia disponible }}{\text { Resistencia a la falla }}
$$

\subsubsection{Métodos de equilibrio límite}

\subsubsection{Generalidades}

Existen diferentes métodos analíticos disponibles para evaluar la estabilidad de un sistema de "Soil Nailing". La mayoría de estos métodos son de análisis de equilibrio límite basados en el método de las rebanadas (GEO, 2008). Los métodos de equilibrio límite generalmente analizan discretizando la masa del talud de falla en pequeñas rebanadas y tratando cada rebanada individual como un único bloque deslizante (Rabie, 2014).

La elección del método depende en que el mismo cumpla a satisfacción con todas las condiciones de equilibrio. Los factores de seguridad $(F S)$ calculados por métodos que consideran sólo equilibrio de fuerzas o sólo equilibrio de momentos no podrían dar resultados correctos. Por lo tanto, deben usarse en el análisis sólo los métodos que satisfagan tanto el equilibrio de fuerzas como el equilibrio de momentos (Shiu et al., 2007). Los métodos que satisfagan todas las condiciones de equilibrio dan como resultado en esencia el mismo factor de seguridad, independientemente de los supuestos que puedan asumir (Wright y Duncan, 1991). 
El análisis de estabilidad por métodos de equilibrio límite en primera instancia corresponde a un problema indeterminado. Para convertir el problema a una solución estáticamente determinada el número de incógnitas debe ser igual al número de ecuaciones (Wright y Duncan, 1991; Rawat y Gupta, 2016). Entonces, los métodos disponibles asumen diferentes suposiciones hechas con respecto a las fuerzas entre rebanadas y la forma en que se satisfacen las ecuaciones de equilibrio global de fuerza y momento (Duncan y Wright, 2005). El hecho de incluir en los modelos, elementos de refuerzo adicionales como "Soil Nails" contribuye a la estabilidad general del sistema y por otra parte no generan incógnitas adicionales en las ecuaciones de equilibrio (Wright y Duncan, 1991). Los métodos de equilibrio límite utilizan los métodos de prueba "trial" de superficie de deslizamiento para localizar la superficie de deslizamiento más óptima que tenga el menor factor de seguridad. Las superficies de deslizamiento consideradas en estos métodos pueden ser circulares, lineales o una combinación de ambas formas (Rawat y Gupta, 2016). Estos métodos de análisis han sido adoptados en reconocidos paquetes computacionales como SLIDE y SLOPE/W.

\subsubsection{Método de Fellenius}

Este método es el más simple de todos, pues involucra suposiciones crudas y fuertes con respecto a las fuerzas entre rebanadas. En el método ordinario de Fellenius las fuerzas entre rebanadas se desprecian al derivar la tensión normal en la superficie de deslizamiento (Zhu et al., 2003). Este método satisface el equilibrio de momentos para una superficie de deslizamiento circular, pero desprecia las fuerzas normales y las de corte entre rebanadas. El método se aplica de manera convencional a superficies de deslizamiento circular y considera el equilibrio de momento alrededor del centro del círculo.

\subsubsection{Método de Bishop simplificado}

El método de Bishop simplificado se basa en el equilibrio de momentos en el centro de una superficie de corte circular y el equilibrio de fuerzas en la dirección vertical. El equilibrio de momentos se considera sólo para todo el cuerpo libre compuesto por todas las rebanadas. El equilibrio de fuerzas verticales se considera para cada rebanada individual (Wright y Duncan, 1991). El método de Bishop simplificado no considera las fuerzas de corte entre rebanadas (Rabie, 2014).

\subsubsection{Método de Janbu simplificado}

El método de Janbu simplificado supone que no hay fuerzas de corte entre rebanadas. Además este método satisface el equilibrio de fuerzas verticales para cada rebanada y el equilibrio global de fuerza horizontal para la masa entera de suelo (Rabie, 2014). 


\subsubsection{Método de Spencer}

El método de Spencer supone que las fuerzas laterales son paralelas, es decir todas las fuerzas laterales tienen la misma inclinación (Wright y Duncan, 1991; Zhu et al., 2003). El método satisface el equilibrio estático completo de fuerzas y momentos. La solución implica evaluar el factor de seguridad, la inclinación de las fuerzas laterales y las otras fuerzas desconocidas y sus ubicaciones (Wright y Duncan, 1991).

\subsubsection{Método de Morgenstern-Price}

El método de Morgenstern-Price satisface los equilibrios de fuerza y momento. Considera las fuerzas normales y de corte entre rebanadas y asume funciones de relación de fuerzas entre las mismas. El método sugiere asumir cualquier tipo de función de fuerza pudiendo ser trapezoidal, de medio seno o alguna otra definida por el usuario.

\subsection{Resultados empíricos de excavaciones realizadas mediante la técnica de "Soil Nailing"}

\subsubsection{Introducción}

La técnica de "Soil Nailing" a raíz de su primera aplicación ha sido difundida con éxito en varios países. Como parte del desarrollo de esta técnica algunos investigadores instrumentaron algunas estructuras reales e implementaron procedimientos de monitorización del proceso constructivo y del comportamiento de este tipo de estructuras.

\subsection{2. "Soil Nail Wall" en Manhattan (Estados Unidos)}

Holman y Tuozzolo (2009) presentaron un estudio experimental de un muro tipo "Soil Nail Wall" que fue construido en un campo universitario cerca de East River en Manhattan (Estados Unidos) en el año 2007. En este proyecto, los "Soil Nails" de 3 secciones de muro fueron instrumentadas con "Strain Gauges" o galgas extensométricas (Ver Fig. 2.16). El programa de monitorización se ejecutó durante los 1.5 meses de la construcción del muro claveteado y se extendió durante 4 meses adicionales y posteriores, dando un total de tiempo de monitorización de 5.5 meses. En el perfil de suelo se identificó un estrato de relleno superficial de $2.10 \mathrm{~m}$ compuesto de arena y ángulo de fricción $\emptyset$ de $30^{\circ}$ y luego un estrato de arena limosa con ángulo de fricción $\emptyset$ de $38^{\circ}$. El espaciamiento vertical de los "Soil Nails" estuvo entre $1.22 \mathrm{~m}$ y $1.83 \mathrm{~m}$, en tanto que el espaciamiento horizontal fue de $1.83 \mathrm{~m}$. La longitud de los "Soil Nails" con barra de acero de refuerzo No. 25, grado 520 varió desde $5.8 \mathrm{~m}$ en los niveles superiores a $2.7 \mathrm{~m}$ en la base de la excavación.

Para el análisis teórico de las estructuras se utilizó el programa computacional SNAILZ (Caltrans, 1991), el mismo que se basa en el equilibrio de fuerzas y en procedimientos de esfuerzos admisibles. De acuerdo al diseño original, el factor de 
seguridad para la excavación completa fue de 1.35. Pero en base a los parámetros reales de entrada los factores de seguridad calculados para la condición final fueron de 1.43 a 1.51 .

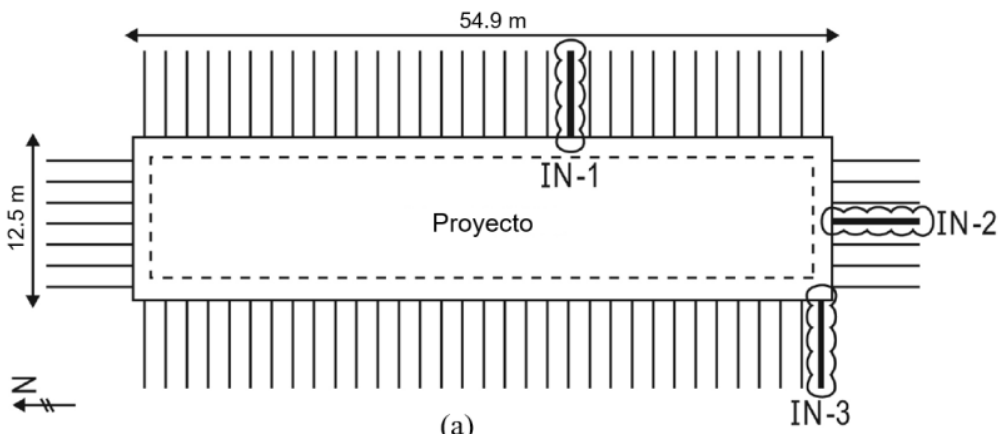

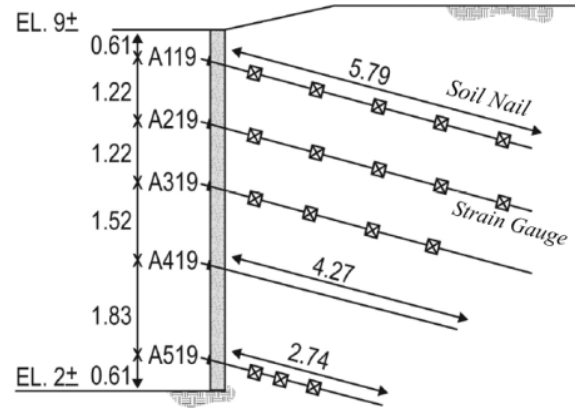

(b)

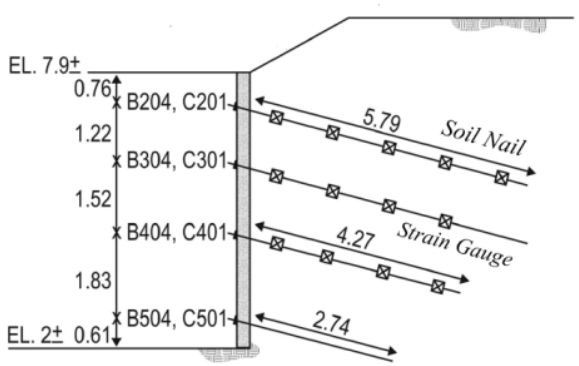

(c)

Fig. 2.16 Muro claveteado en Manhattan: (a) Vista en planta de geometría de excavación y ubicación de secciones de muro instrumentadas, (b) Sección instrumentada IN-1, y (c) Secciones instrumentadas IN-2 e IN-3 (Holman y Tuozzolo, 2009).

Las secciones de prueba con galgas extensométricas proporcionaron los datos relacionados con el desarrollo de las cargas en los "Soil Nails". Las cargas y esfuerzos máximos desarrollados y medidos en los "Soil Nails" fueron comparados con aquellos esfuerzos teóricos predichos con el programa SNAILZ (Ver Tabla 2.14). Las relaciones entre los esfuerzos predichos y medidos en los "Soil Nails" fueron muy significativas, con valores generales que se aproximan a la media de 2.10. El esfuerzo de diseño más alejado del valor medido en campo se verificó en el "Soil Nail" A519 de la sección de prueba IN-1, donde la relación fue de 6.81.

Las cargas en los "Soil Nails" de un muro se desarrollan y evolucionan como función del tiempo, y no necesariamente son constantes durante o después de un proceso de construcción. Para las secciones de prueba instrumentadas en este proyecto, las cargas en los "Soil Nails" continuaron incrementándose durante todo el tiempo después de alcanzar la profundidad total de excavación y hasta el final de la monitorización 127 días después (Holman y Tuozzolo, 2009). 
Tabla 2.14 Comparación de esfuerzos predichos y medidos en "Nails" (Holman y Tuozzolo, 2009).

\begin{tabular}{|c|c|c|c|c|c|c|}
\hline \multirow[b]{2}{*}{$\begin{array}{c}\text { Sección } \\
\text { de } \\
\text { prueba }\end{array}$} & \multirow[b]{2}{*}{$\begin{array}{c}\text { No. de } \\
\text { "Soil Nail" }\end{array}$} & \multicolumn{3}{|c|}{ Esfuerzos máximos de tensión [MPa] } & \multirow[b]{2}{*}{$\begin{array}{l}\text { Relación } \\
\text { (1) /(3) }\end{array}$} & \multirow[b]{2}{*}{$\begin{array}{l}\text { Relación } \\
\text { promedio }\end{array}$} \\
\hline & & $\begin{array}{l}\text { Análisis } \\
\text { con } \\
\text { SNAILZ } \\
\text { (1) }\end{array}$ & $\begin{array}{c}\text { Lectura } \\
\text { in situ } \\
10 / 4 / 2007 \\
\text { (2) }\end{array}$ & $\begin{array}{c}\text { Lectura } \\
\text { in situ } \\
2 / 4 / 2008 \\
\text { (3) }\end{array}$ & & \\
\hline \multirow{4}{*}{ IN-1 } & A119 & 64.9 & 46.3 & 76.1 & 0.85 & \multirow{4}{*}{2.50} \\
\hline & A219 & 114.5 & 65.3 & 116.4 & 0.98 & \\
\hline & A319 & 197.7 & 73.5 & 145.4 & 1.36 & \\
\hline & A519 & 334.8 & 27.7 & 49.2 & 6.81 & \\
\hline \multirow{3}{*}{ IN-2 } & B204 & 104.2 & 27.8 & 61.9 & 1.68 & \multirow{3}{*}{1.63} \\
\hline & B304 & 181.1 & 66.7 & 99.0 & 1.83 & \\
\hline & B404 & 122.0 & 31.0 & 87.8 & 1.39 & \\
\hline \multirow{3}{*}{ IN-3 } & C201 & 104.2 & 39.4 & 43.8 & 2.38 & \multirow[b]{3}{*}{2.03} \\
\hline & C301 & 181.1 & 25.0 & 90.7 & 2.00 & \\
\hline & \multirow[t]{3}{*}{ C401 } & 122.0 & 25.7 & 70.9 & 1.72 & \\
\hline & & & & Media & 2.10 & \\
\hline & & & & Desv. Estándar & 1.62 & \\
\hline
\end{tabular}

La diferencia principal entre los esfuerzos máximos predichos y los medidos en los "Soil Nails" resultó ser de casi el 40\%, el cual resulta un valor sustancial que sugiere que los métodos actuales de análisis y diseño de equilibrio límite pueden no ser lo suficientemente rigurosos y suficientes para describir el comportamiento interno de la estructura de "Soil Nailing".

\subsection{3. “Soil Nailing” en Dublín (Irlanda)}

Menkiti et al. (2013) presentaron un estudio de una estructura de "Soil Nailing" construida en arcilla de roca "boulder clay", el cual es un material de baja plasticidad, muy rígido a duro, con gravilla y arcilla arenosa, con presencia ocasional de lentes permeables y otras zonas sin cohesión. Esta investigación presentó los datos del proyecto del túnel del Puerto de Dublín para un gran conjunto de pruebas de extracción "pull-out" a corto plazo y con datos adicionales de monitorización realizadas en "Soil Nails" de un talud de unos $12 \mathrm{~m}$ de altura. Las fuerzas de tensión en los "Soil Nails" del talud reforzado se monitorizaron utilizando "Strain Gauges". La Fig. 2.17 muestra los taludes reforzados mediante la técnica de "Soil Nailing" y los procedimientos realizados.

Los valores de fuerza más grandes ocurrieron al final de la construcción del talud, con cargas máximas de $47 \mathrm{kPa}$. El análisis de los picos de los perfiles de fuerza de tracción sugiere que una potencial superficie de falla que hubiera cruzado la autopista posterior fue controlada con éxito, según se puede ver en la Fig. 2.18 (Menkiti et al., 2013). 

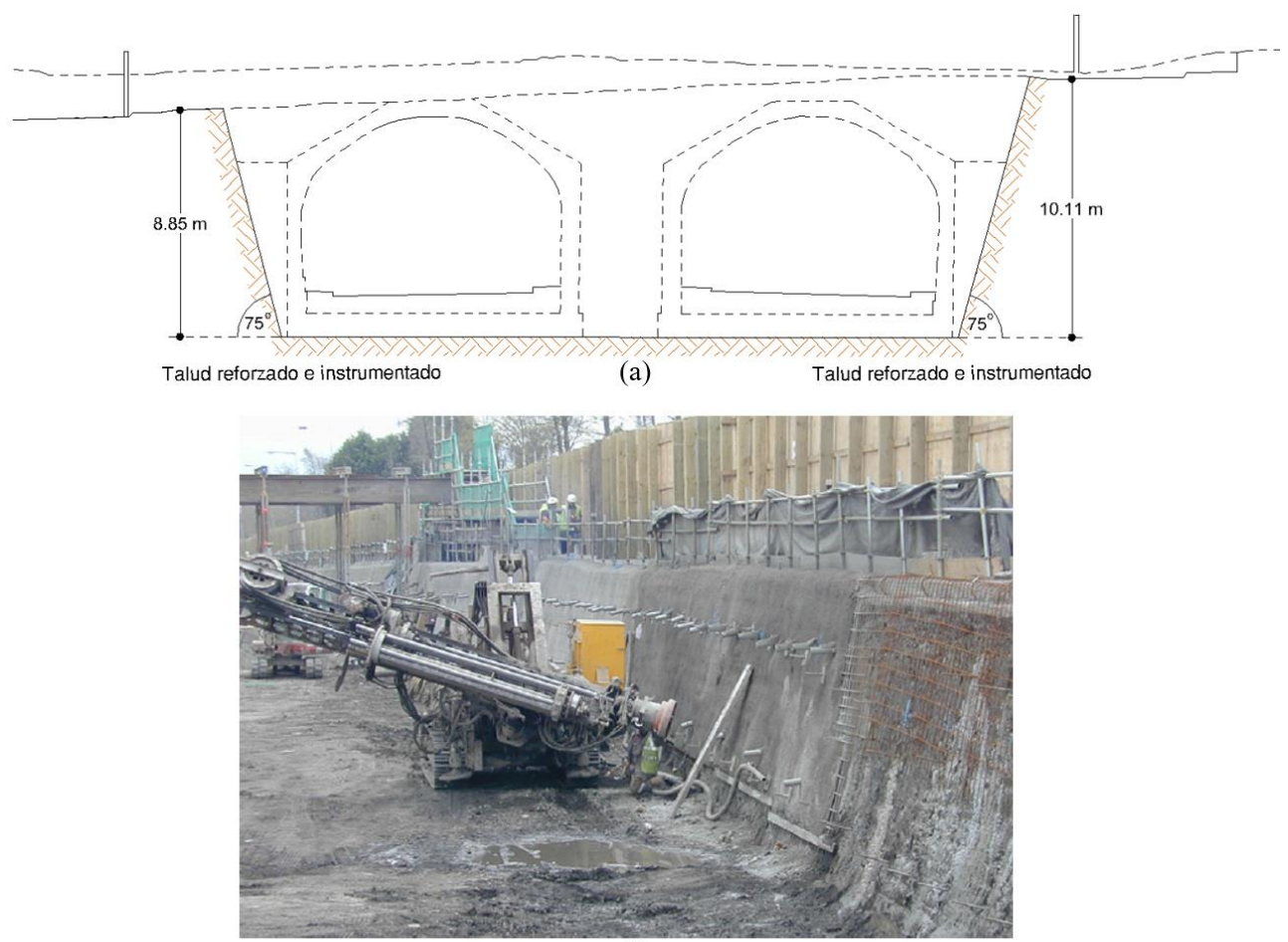

(b)

Fig. 2.17 "Soil Nailing” en Dublín: (a) Sección transversal típica (Menkiti y Long, 2008), y (b) Construcción de "Soil Nails" y "Shotcrete" (Menkiti et al., 2013).

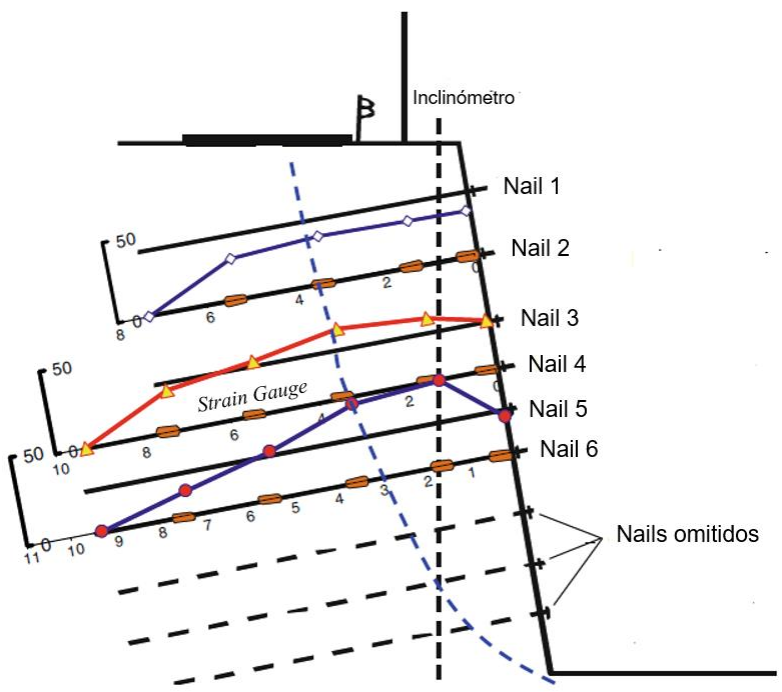

Fig. 2.18 Tensiones [kN] en "Soil Nails" en ubicación de "Strain Gauges" y posible superficie de deslizamiento, que fue controlada (Menkiti et al., 2013). 


\subsection{La práctica de "Soil Nailing" en la ciudad de Quito}

En la zona norte de la ciudad de Quito se planifican y construyen los más importantes proyectos inmobiliarios de la capital ecuatoriana. Es así que en el sector de "La Carolina", parroquia Iñaquito, zona centro-norte de la ciudad en los últimos años se han edificado importantes proyectos de 16, 18, 22, 25 o 32 niveles principales y con 5 a 7 niveles de sótano.

Para la construcción de los niveles de sótano es práctica común en la ciudad de Quito, realizar excavaciones parciales, por lo general cada excavación equivale a la altura de un nivel de sótano. Cada altura excavada es reforzada con "Soil Nails" y con la respectiva pantalla que puede ser construida mediante hormigonado clásico dentro de un sistema de encofrado o a través de concreto proyectado o "Shotcrete". En la Fig. 2.19 se indica la variación de las fuerzas de tracción y de las potenciales superficies de deslizamiento con el avance de las fases de excavación (FHWA, 2015).

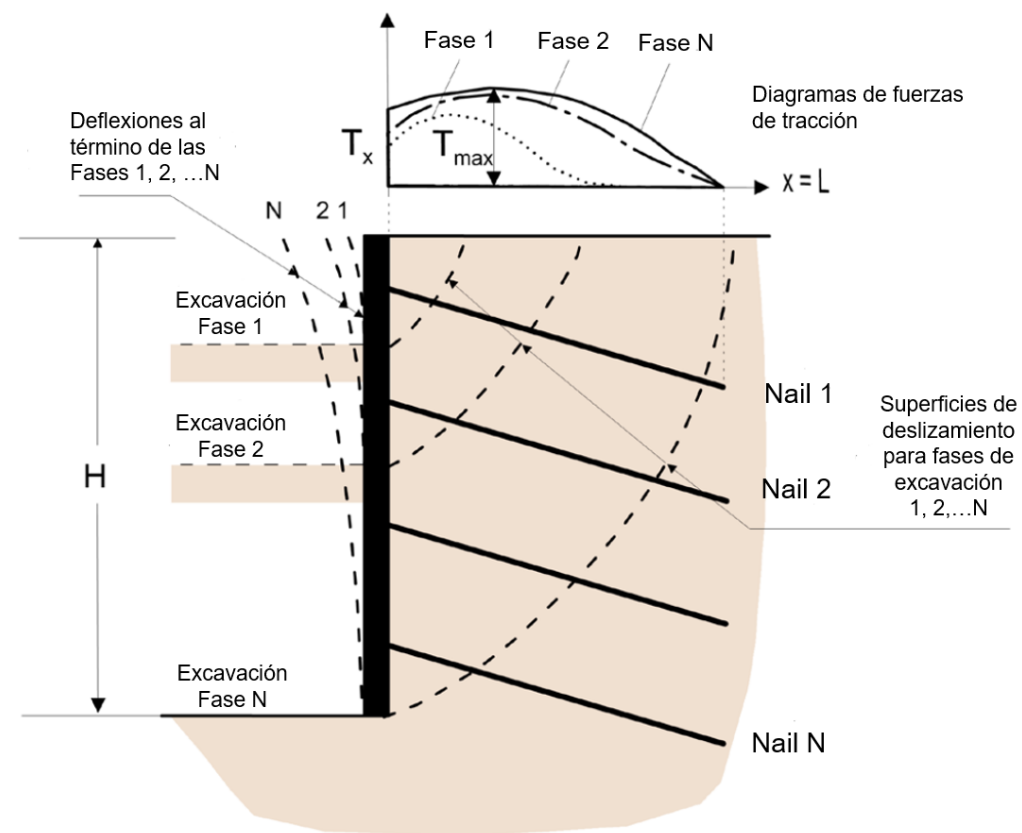

Fig. 2.19 Variación de potenciales superficies de deslizamiento y fuerzas de tensión en "Soil Nails". Modificado de (FHWA, 2015).

Las estructuras de muro construidas para todos los niveles de sótano no dejan de ser estructuras o sistemas de "Soil Nailing" con ligeros ajustes realizados a conveniencia. Las estructuras de muro claveteado para sótanos de edificios de gran altura comúnmente incluyen pantallas de concreto armado con espesores que pueden variar entre $20 \mathrm{~cm}$ y $25 \mathrm{~cm}$ (a diferencia del espesor acostumbrado en la técnica de 
"Soil Nailing" clásica de $5 \mathrm{~cm}$ a $15 \mathrm{~cm}$ ) y con acero de refuerzo en 2 capas. Los calculistas de estructuras de edificios acostumbran incluir esta estructura de muro perimetral de concreto armado de los sótanos en su modelo de elementos finitos, incluso como parte del sistema sismo-resistente. Sin embargo, los "Soil Nails" que fueron parte del proceso constructivo por lo general cumplen una función temporal, validando el factor de seguridad global durante el proceso de excavación ante cargas estáticas y efectos sísmicos. La Fig. 2.20 muestra la aplicación de la técnica de "Soil Nailing" en edificaciones de la ciudad de Quito.

Respecto a la cabeza del "Nail" en la unión del bulón o barra de acero con la pantalla de concreto o "Facing" es acostumbrado hacerlo mediante una placa de acero, la cual es fijada a través de una tuerca instalada de manera adecuada en el extremo roscado de la barra de acero (Ver Fig. 2.11(a) en sección 2.3.4.2). En otros casos la unión de la barra de acero con la pantalla se hace a través de un doblez de la barra del "Soil Nail", el cual queda embebido adecuadamente dentro de la pantalla de concreto (Ver Fig. 2.11(c) en sección 2.3.4.2).

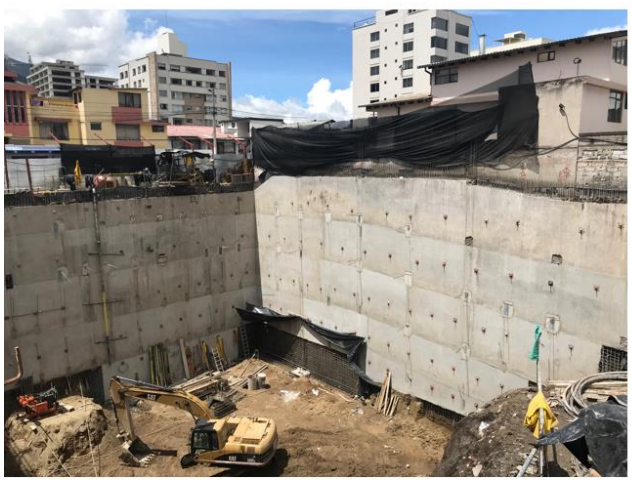

(a)

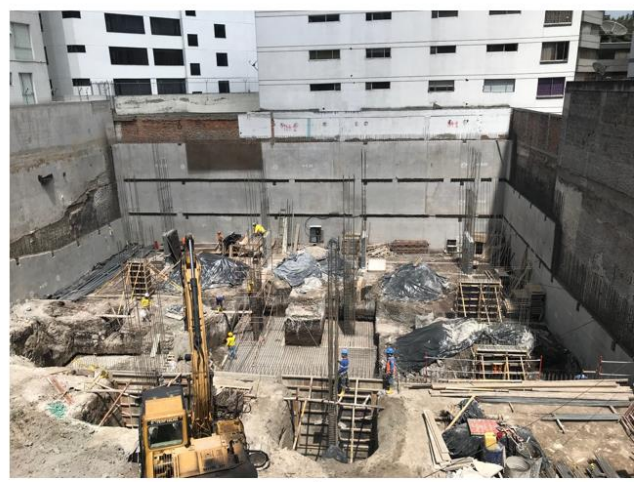

(b)

Fig. 2.20 Construcción de niveles de sótano en edificaciones en la zona centro-norte de la ciudad de Quito: (a) Edificio Sense (enero 2020), y (b) Edificio Narelo (diciembre 2019).

\subsection{Conclusiones relativas al estado del arte}

En este capítulo se ha presentado un recuento de importantes estudios geotécnicos realizados a nivel internacional y local sobre caracterización de suelos volcánicos. De investigaciones internacionales se han destacado los parámetros de estudios realizados en Tenerife (España), San Salvador (El Salvador) e Isparta (Turquía). En tanto que de estudios de territorio ecuatoriano se han detallado los parámetros de investigaciones realizadas en la zona del volcán Reventador (zona noreste de Ecuador), zona del volcán Cotopaxi (sureste de la ciudad de Quito) y de las zonas norte y este de la ciudad de Quito. A pesar de toda la información recopilada de investigaciones indexadas y oficiales de estudios de suelos volcánicos en la ciudad de Quito, se identificaron muy pocos estudios detallados. 
En general, se identificaron de manera clara en varios parámetros, valores bajos de densidad y gravedad específica o densidad de partículas sólidas. De igual manera fueron muy notorios los parámetros altos de relación de vacíos y de porosidad, propiedades que caracterizan generalmente a los suelos volcánicos analizados por varios investigadores.

Investigaciones realizadas mediante microscopía electrónica (SEM) establecieron la presencia de picos marcados de Sílice en los límites intergranulares, lo cual podría establecer que el material de unión es vidrio volcánico degradado. Además, la Sílice amorfa resultaría ser un agente de cementación dominante.

Del análisis a través de difracción de rayos $\mathrm{X}$ de los suelos de la zona este de la ciudad de Quito, se determinó principalmente la presencia de plagioclasa y hornblenda y con menores proporciones de augita, hiperstena y cuarzo. Aunque también no se descartó una mínima presencia de montmorillonita y haloysita poco cristalizadas.

De los estudios realizados en taludes de suelos volcánicos, se ha notado que la falla es causada por la formación y propagación de fracturas, que con frecuencia se inician en lugares de erosión y socavación cerca del pie del talud. Las fallas en taludes de suelos volcánicos ocurren con mayor frecuencia durante o después de periodos de lluvia intensa y en temporadas de clima seco y con viento.

Por otra parte, la técnica de "Soil Nailing" es un procedimiento simple y económico de estabilización de taludes, utilizado con frecuencia para reforzar taludes existentes y particularmente como método de refuerzo del terreno durante procesos de excavación. Es fundamental que los anclajes o "Soil Nails" sean diseñados para penetrar a través de la zona activa de movimiento y suficientemente más allá de cualquier potencial superficie de deslizamiento y hacia una zona resistente del terreno.

Para el análisis de estructuras de "Soil Nailing" se dispone de los métodos de equilibrio límite y del método de los elementos finitos. Ambos procedimientos analizan de manera satisfactoria la estabilidad global de taludes reforzados. Sin embargo, el método de los elementos finitos con aplicación especialmente de los modelos constitutivos de suelo de Hardening Soil (HS) y Hardening Soil with SmallStrain Stiffness (HSsmall) es más riguroso al momento de describir el comportamiento interno de la estructura de "Soil Nailing", pues resulta ser muy práctico en la predicción de desplazamientos y deformaciones en taludes, en análisis de esfuerzos y resistencia a la extracción o "pull-out" de los "Soil Nails", pero particularmente ha resultado ser muy útil en la predicción de la distribución y variación de fuerzas a lo largo de la longitud de los anclajes.

De estudios experimentales sobre el comportamiento de muros claveteados del tipo "Soil Nail Walls" se ha verificado que las fuerzas de tracción en las barras de anclaje de los "Soil Nails" evolucionan a través del tiempo, manifestándose incrementos 

la técnica de suelo claveteado (Soil Nailing) en suelos de la ciudad de Quito (Ecuador)

durante cada fase constructiva y aún después de alcanzar la profundidad total de excavación. 


\section{Capítulo 3 \\ CARACTERIZACIÓN GEOTÉCNICA \\ DE LA ZONA DE ESTUDIO}

\subsection{Introducción}

Actualmente existe muy poca información disponible de caracterización geotécnica de los suelos volcánicos de la ciudad de Quito, especialmente de zonas en donde se ha emprendido la construcción de importantes proyectos inmobiliarios. Y justamente los 2 proyectos seleccionados para el estudio numérico y experimental de esta investigación se ubican en la zona de "La Carolina", sector centro-norte (Ver Fig. 3.1), de importante desarrollo económico, financiero y de arquitectura moderna de la capital ecuatoriana.

El principal objetivo de esta caracterización es proporcionar a los ingenieros involucrados en proyectos de la ingeniería geotécnica y civil importantes parámetros del suelo basados en los resultados obtenidos de una campaña completa de investigaciones de campo y laboratorio. Muy pocos estudios de esta naturaleza se han realizado hasta la fecha en esta ciudad por lo que este estudio será de gran ayuda en la planificación de estructuras para ingenieros de la construcción y arquitectos.

Como parte de este estudio de caracterización geotécnica se distribuyeron adecuadamente y realizaron en la zona centro-norte de la ciudad 3 sondeos de $25 \mathrm{~m}$ de profundidad, los cuales se denominaron como AMA1, JAP1 y AUS1. En cada perforación se realizaron medidas a cada metro del ensayo de penetración estándar $(S P T)$. La ubicación de estos sondeos se detalla en la sección 3.3 de este estudio. 

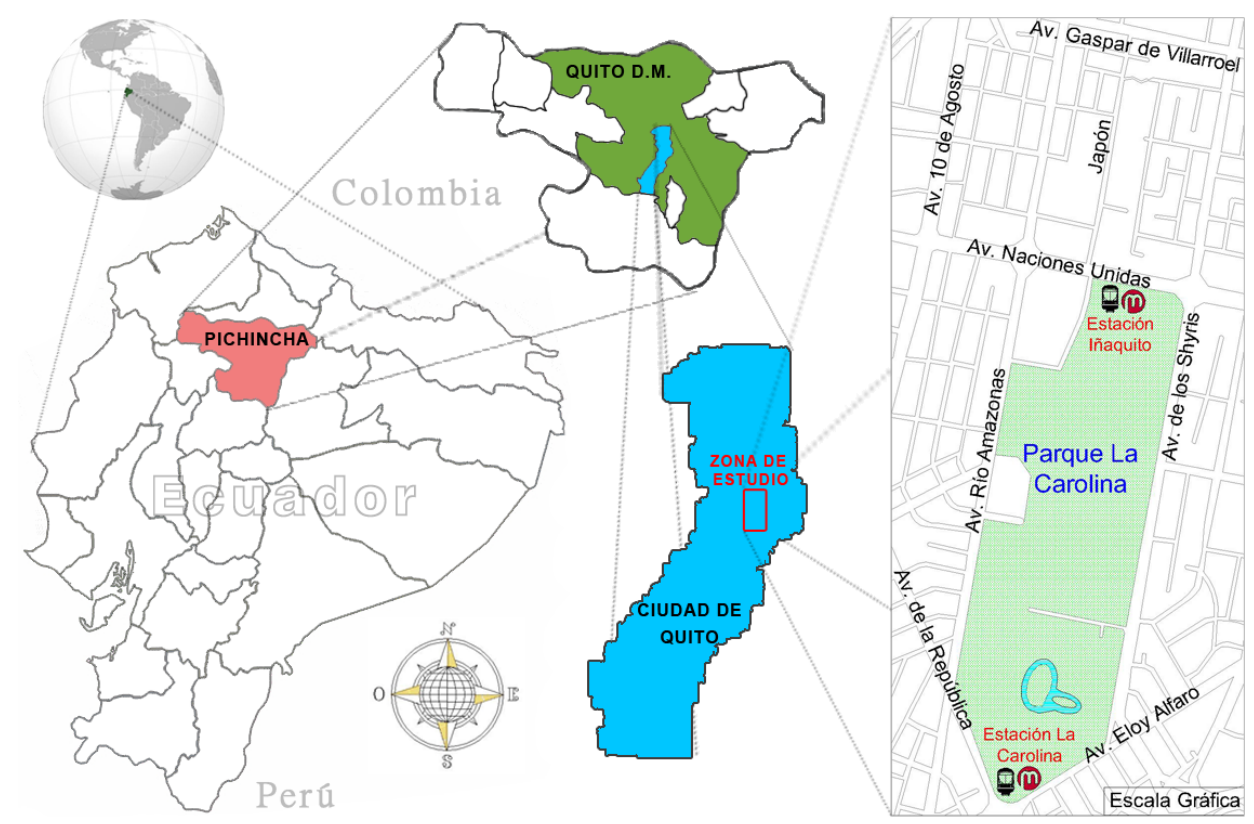

Fig. 3.1 Mapa de Ecuador y ubicación de la zona de estudio.

Los ensayos de laboratorio se realizaron en el Laboratorio de Mecánica de Suelos de la Universitat Politècnica de València en muestras alteradas e inalteradas extraídas de los sondeos ejecutados en la zona de estudio. Dichas muestras fueron adecuadamente recuperadas, selladas y empaquetadas en cada sondeo y enviadas como paquete con categoría de frágil a la ciudad de Valencia (España).

Los ensayos de laboratorio se basaron en 4 características principales: propiedades índice, compresibilidad, resistencia al corte y parámetros de deformación bajo esfuerzo desviador. Las propiedades índice fueron combinadas con ensayos convencionales de consolidación con doble drenaje (superior e inferior) y ensayos triaxiales $C U$ y $C D$ para evaluar la compresibilidad, rigidez y resistencia.

De acuerdo a los ensayos realizados se determinó que el subsuelo está parcialmente compuesto por suelos volcánicos ligeramente sobreconsolidados con un contenido promedio de materia orgánica superficial cercano al $4 \%$. Para complementar la investigación se realizaron ensayos de difracción de rayos $\mathrm{X}(X R D)$ y de microscopía electrónica $(S E M)$ enfocados a determinar las características mineralógicas y de microestructura y evaluar su influencia en el comportamiento mecánico de los suelos volcánicos.

Los parámetros geotécnicos obtenidos en este estudio de caracterización serán utilizados en la fase de estudio teórico y numérico del comportamiento de muros anclados que son parte de esta investigación. 


\subsection{Marco geológico}

Ecuador está ubicado en la parte noroccidental de América del Sur, atravesada de sur a norte por la Cordillera de los Andes con $600 \mathrm{~km}$ de largo y una dirección preferente de NNE-SSO, la cual comienza a desarrollarse a finales del Cretácico por el movimiento de subducción de la placa de Nazca y Carnegie Ridge (cadena montañosa submarina situada en la Placa de Nazca) bajo la placa Sudamericana, generando un régimen tectónico compresivo E-O dominante hasta la actualidad (Rodríguez-Peces y Gordón-Pérez, 2015; Hall et al., 2008; Coltorti y Ollier, 1999). Carnegie Ridge es emergente en el hot-spot activo de Galápagos (Spikings y Simpsom, 2014). La Cordillera de los Andes se divide en dos ramales denominados Cordillera Occidental (formada por rocas volcano-sedimentarias cretácicas y terciarias) y la Cordillera Oriental o Real (formada por rocas metamórficas jurásicas), separadas por una depresión tectónica intermedia conocida como el Valle Interandino (fosa tectónica rellena por materiales volcánicos plio-cuaternarios) (Rodríguez-Peces y Gordón-Pérez, 2015). Durante el desarrollo de la Depresión Interandina varias cuencas se formaron progresivamente (Winkler et al., 2005), el origen y la forma se atribuyen a las fallas complejas durante el Cuaternario (Hall et al., 2008). El valle interandino es el hogar de grandes ciudades, entre ellas la ciudad de Quito, asentada sobre una cuenca sedimentaria intramontañosa con forma alargada en dirección N-S (Ver Fig. 3.2).

Estratigráficamente el área de interés (centro-norte de Quito) corresponde a depósitos que descansan sobre la Formación Cangahua (toba y ceniza volcánica correspondiente al periodo cuaternario). Hacia su parte oeste (zona de sondeo geotécnico AMAl) se definen depósitos coluviales (DGGM, 1980), la estructura de este depósito no tiene secuencia de depositación y de manera general se encuentran materiales de todos los tamaños granulométricos. Durante las evaluaciones de los testigos de perforación se detallan básicamente limos, arcillas y arenas limosas de colores café oscuro, café claro y gris, con presencia de gravas y bloques de roca (Ver Fig. 3.3(a)).

Hacia la parte este de la zona de estudio (zona de sondeo geotécnico JAPl) se identifican depósitos sedimentarios lacustres (DGGM, 1980) compuestos por capas bien estratificadas de limos, arcillas y arenas limosas de colores café claro, café amarillento y gris amarillento que exhiben lapilli de pómez y superficialmente con presencia de materia orgánica en descomposición, esto corresponde a un depósito lagunar de ceniza (Ver Fig. 3.3(b)). 


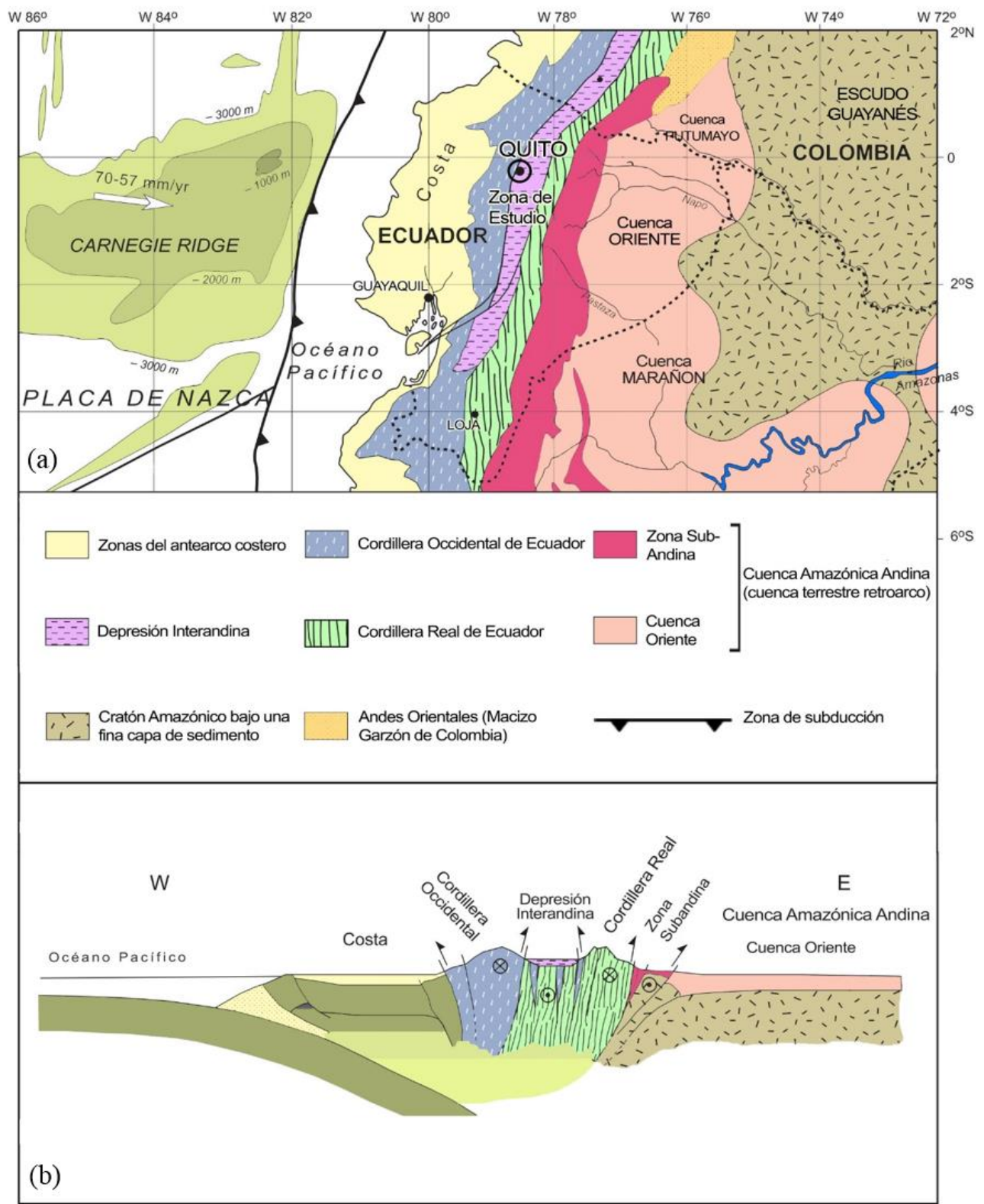

Fig. 3.2 (a) Mapa tectónico de Ecuador, y (b) Sección tectónica esquemática hacia el norte de Ecuador. Modificado de Martin-Gombojav y Winkler (2008) y Ruiz et al. (2007). 


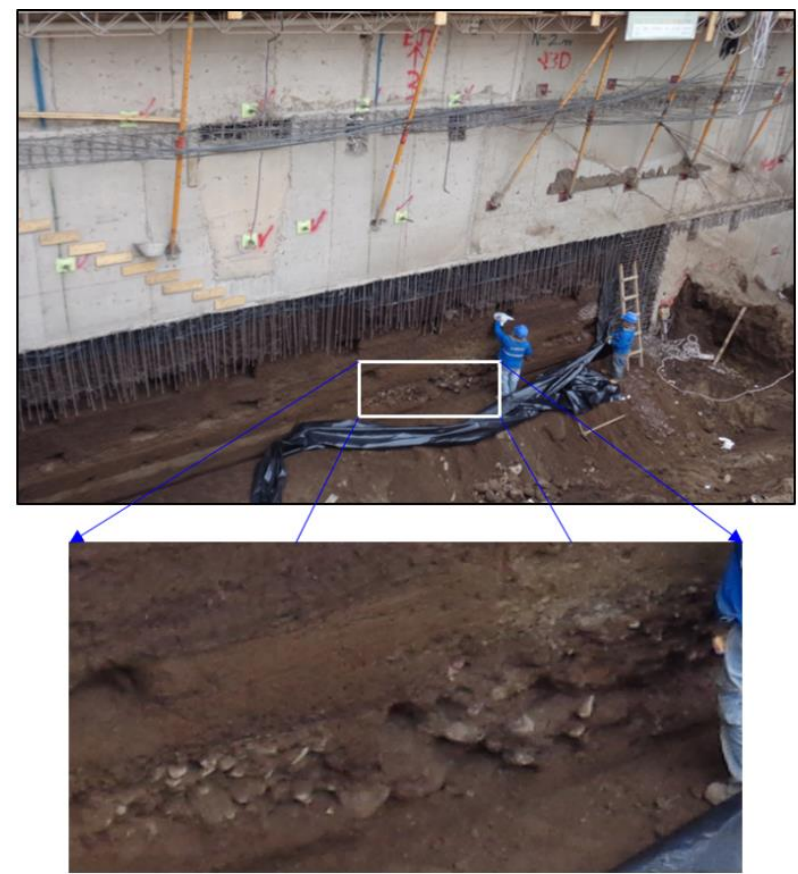

(a)

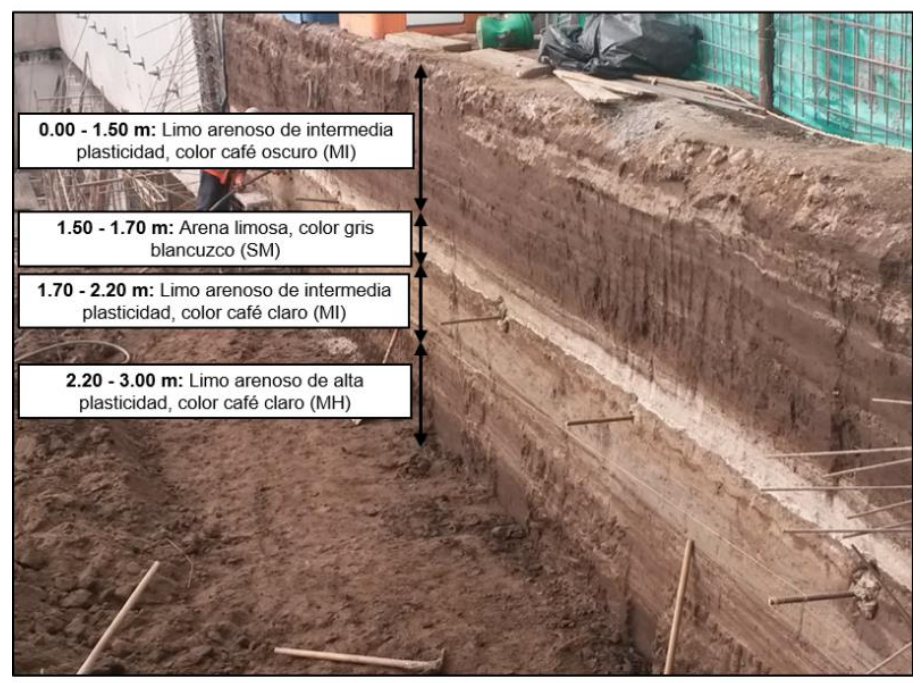

(b)

Fig. 3.3 (a) Depósito sedimentario tipo coluvión en zona de sondeo AMA1. Gravas y bloques de roca embebidos en matriz limo arenosa a $7.10 \mathrm{~m}$ de profundidad, y (b) Perfil de suelo residual entre $0.0 \mathrm{y}$ $3.0 \mathrm{~m}$ de profundidad en zona de sondeo JAP1. Descripción de columna estratigráfica in situ. 


\subsection{Investigaciones geotécnicas "in situ"}

\subsubsection{Generalidades}

Los trabajos de campo consistieron de 3 perforaciones de $25 \mathrm{~m}$ de profundidad, con ensayos de penetración estándar (SPT) cada metro, en la zona centro-norte de la ciudad. Estas perforaciones se designaron como AMAl (Av. Río Amazonas y Guayas), JAPl (Calle Japón y Agustín Guerrero) y AUS1 (Calle Austria e Irlanda). La ubicación de estos 3 sondeos de perforación se indica a detalle en la Fig. 3.4.

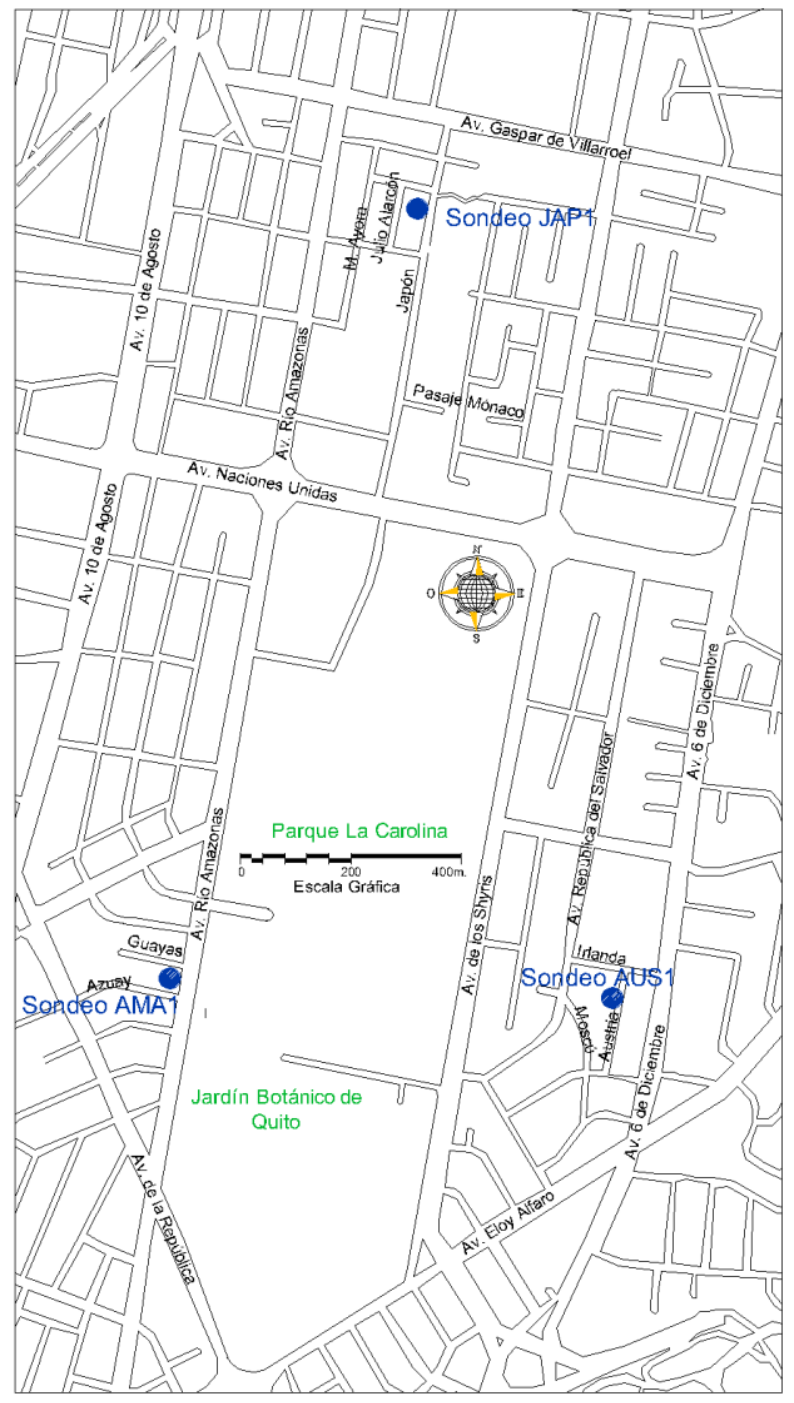

Fig. 3.4 Ubicación de los 3 sondeos de perforación: AMA1, JAP1 y AUS1. 


\subsubsection{Ensayo de Penetración Estándar (SPT)}

El ensayo "in situ" más usado y económico es el de penetración estándar (Standard Penetration Test o SPT), el cual mide la resistencia del suelo a la penetración a determinada profundidad. También puede ser usado para estimar las propiedades de suelos granulares (Mujtaba et al., 2017), correlacionar la resistencia al corte no drenada de suelos cohesivos, calcular la capacidad del suelo de soporte y estimar los asentamientos.

En este estudio los ensayos de penetración estándar (SPT) se realizaron de acuerdo a la norma ASTM D1586 (ASTM D1586, 2011). La Fig. 3.5(a) muestra la profundidad de perforación versus el número de golpes del SPT para cada uno de los 3 sondeos principales.

Por otra parte, el esfuerzo de preconsolidación fue estimado a partir de los ensayos de consolidación. La Fig. 3.5(b) muestra las respectivas relaciones de sobreconsolidación $(O C R)$ a diferentes profundidades. Se puede observar que los valores de $O C R$ varían de 1.62 a la profundidad de $3.50 \mathrm{~m}$ hasta 1.30 a la profundidad de $14.50 \mathrm{~m}$.

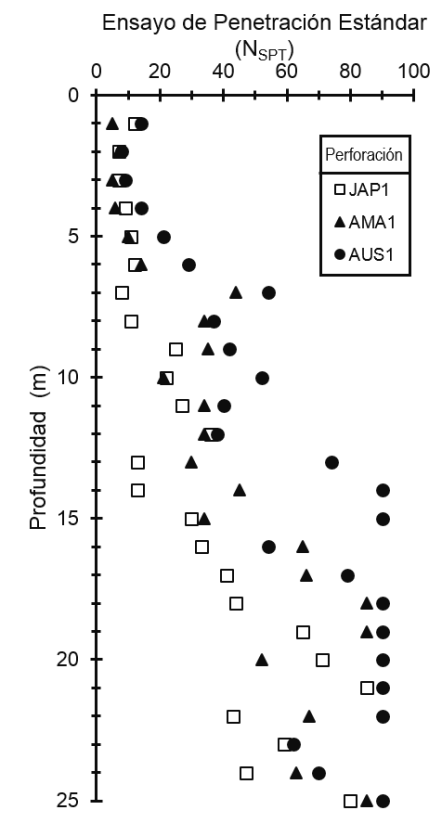

(a)

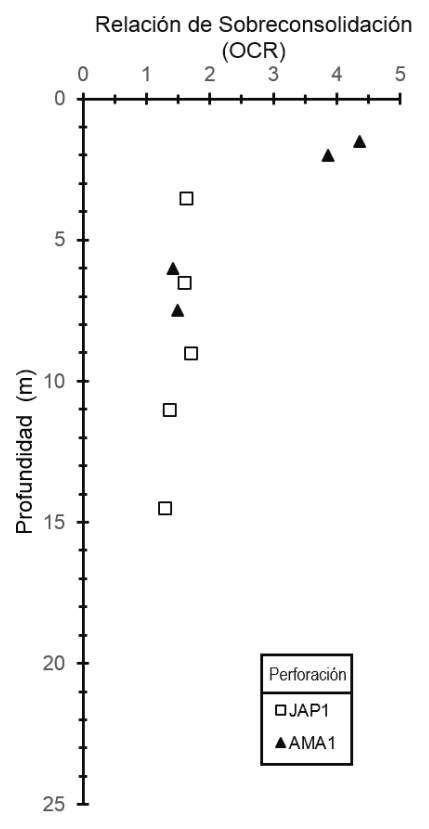

(b)

Fig. 3.5 (a) Ensayos tipo SPT en función de la profundidad, y (b) $O C R$ en función de la profundidad. 


\subsubsection{Toma de muestras}

La investigación geotécnica "in situ" es el proceso de caracterización del suelo que requiere de muestras inalteradas de alta calidad. La recuperación de muestras a través de tubos de pared delgada es la manera más fácil y económica de muestreo, aunque en varias ocasiones este procedimiento es asociado con alteración del suelo. En este estudio se utilizaron tubos de acero inoxidable de $600 \mathrm{~mm}$ de longitud, $78 \mathrm{~mm}$ de diámetro exterior y $1.50 \mathrm{~mm}$ de espesor de pared, para recuperar muestras de los sondeos JAP1 y AMA1. La relación entre diámetro exterior y espesor de pared, De/t fue de 50.7, cuyo valor es mayor al mínimo De/t recomendado por Ladd y DeGroot (2003).

\subsection{Propiedades índice y composición del suelo}

\subsubsection{Generalidades}

En esta sección se describen las propiedades índice de los materiales en función de las respectivas pruebas ejecutadas. Todos los ensayos de laboratorio fueron realizados de acuerdo a las especificaciones ASTM y UNE (ASTM, 2011; AENOR, 1999).

\subsubsection{Contenido natural de agua y Límites de Atterberg}

La variación de valores del contenido natural de agua $\left(w_{n a t}\right)$, límite líquido $(L L)$ y límite plástico $(L P)$ se muestra en la Fig. 3.6. Se puede distinguir que el contenido natural de agua en el sondeo JAPl varía entre el $13 \%$ y el $50 \%$ y decrece normalmente con la profundidad a partir de los $16.00 \mathrm{~m}$. En AMAl, se encontró un rango uniforme de valores comprendidos entre el $12 \%$ y el $26 \%$. Mientras que en AUS1, la distribución del contenido natural de agua estuvo entre el $9 \%$ y el $33 \%$.

En general, el límite plástico $(L P)$ varía de $16 \%$ a $34 \%$ (promedio $25 \%$ ), mientras que los valores de límite líquido $(L L)$ oscilan entre el $18 \%$ y el $64 \%$ (promedio $\sim 35 \%$ ). Por otra parte, la Fig. 3.7 muestra el índice de liquidez (IL) en función de la profundidad, el cual varía entre -2.0 y 1.0 .

La Fig. 3.8 muestra la carta de plasticidad de Casagrande para las respectivas muestras de los sondeos JAP1, AMA1 y AUS1. Es evidente que todas las muestras se ubican cercanas a la línea-A. La mayoría de especímenes de $J A P l$ son clasificados como limos y arcillas con plasticidad variable entre baja y alta. Mientras que la mayoría de muestras de AMAl y AUSI fueron identificados como limos y arcillas de baja a intermedia plasticidad. 


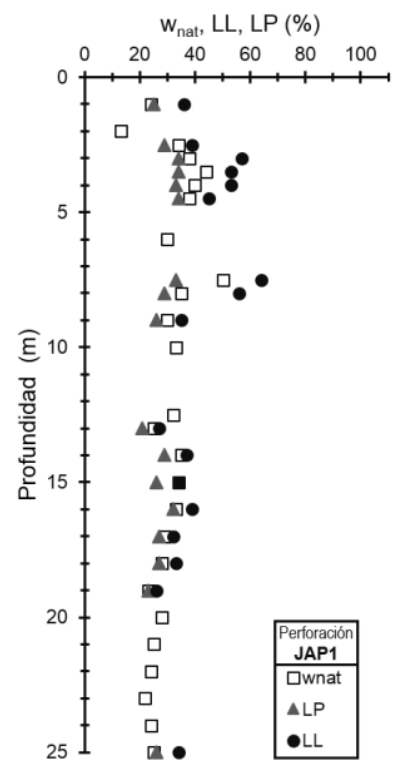

(a)

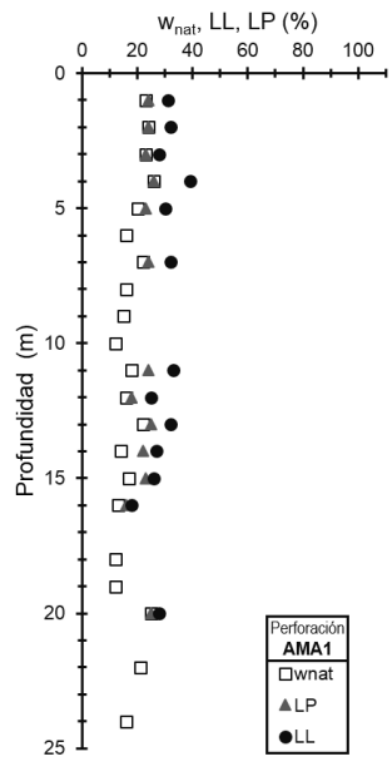

(b)

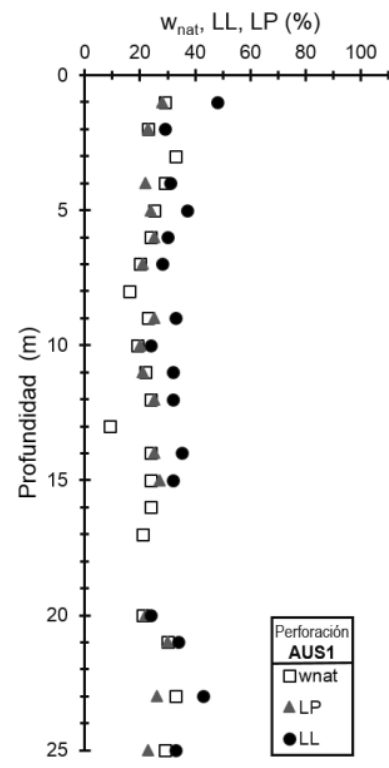

(c)

Fig. 3.6 Contenido natural de agua, límite líquido y límite plástico: (a) perforación JAP1, (b) perforación AMAl, y (c) perforación AUS1.

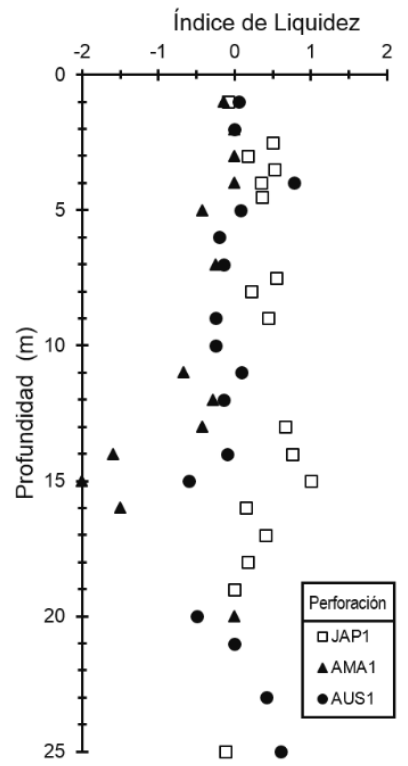

Fig. 3.7 Índice de liquidez versus profundidad para perforaciones JAP1, AMA1 y AUS1. 


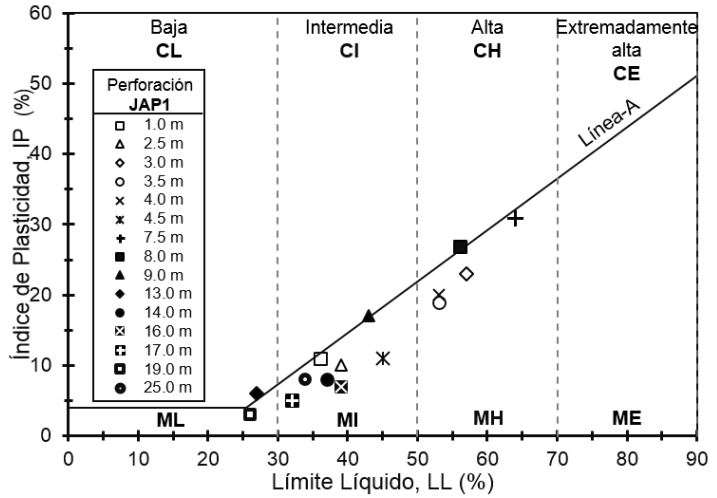

(a)

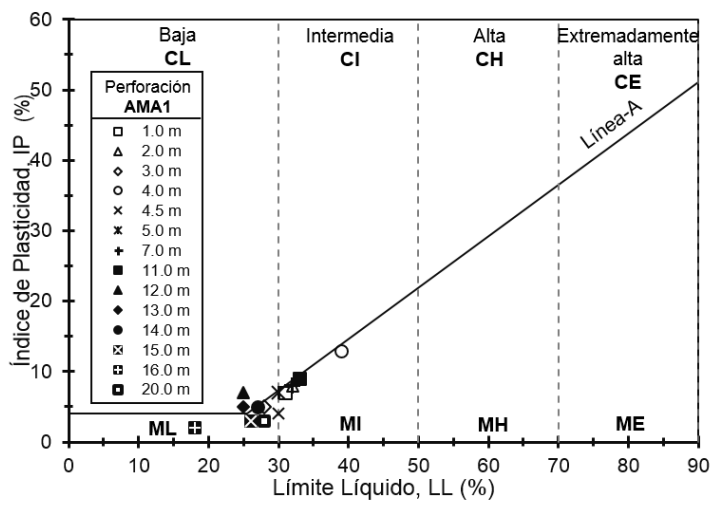

(b)

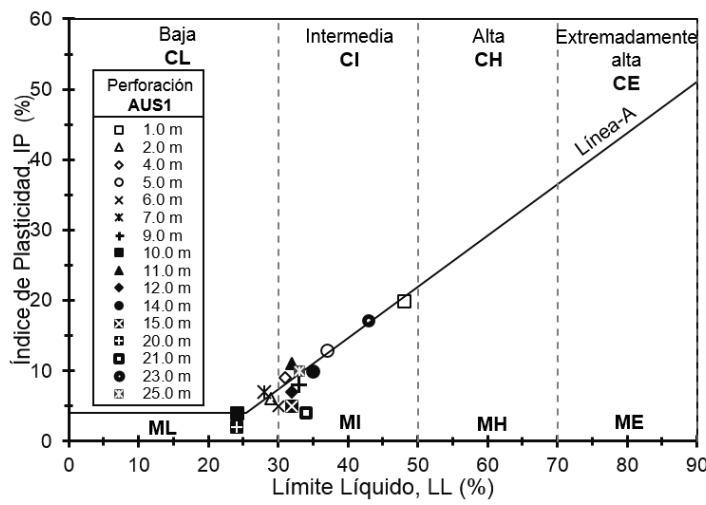

(c)

Fig. 3.8 Plasticidad de los suelos: (a) perforación JAP1, (b) perforación AMA1, y (c) perforación AUS1. 


\subsubsection{Análisis granulométrico}

La Fig. 3.9(a) muestra el perfil de distribución granulométrica para especímenes de la perforación JAP1. En este sondeo, el contenido de limo varía de $37 \%$ a $64 \%$ (promedio 53\%) entre las profundidades de $1.00 \mathrm{~m}$ y $14.50 \mathrm{~m}$. De todas maneras el contenido de arena es predominante por debajo del nivel de $14.50 \mathrm{~m}$ y con valores máximos hasta el 71\%. Por otro lado, la Fig. 3.9(b) demuestra que la distribución granulométrica para especímenes de $A M A l$ es más o menos constante a través de la profundidad, con un contenido de arena que oscila entre el $28 \%$ y $75 \%$ (promedio $\sim 52 \%$ ). Finalmente, la Fig. 3.9(c) muestra la distribución del tamaño de las partículas para especímenes de AUS1, en donde el contenido de finos es predominante a través de la profundidad ( $42 \%$ a $84 \%)$.

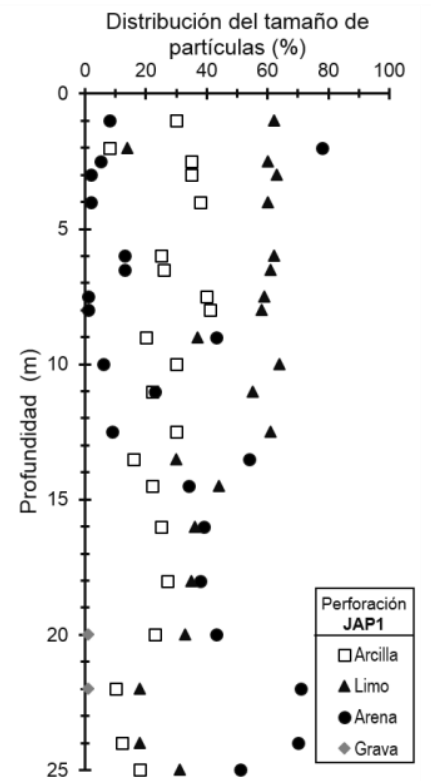

(a)

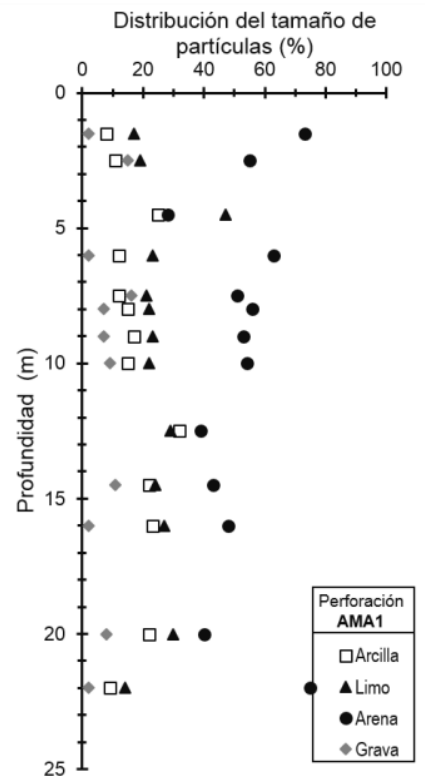

(b)

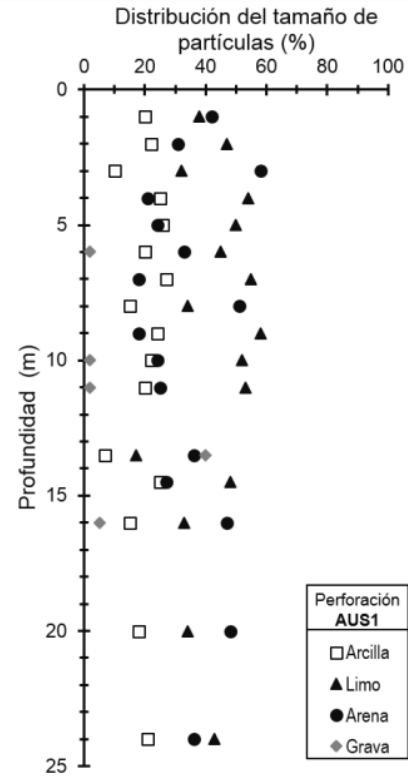

(c)

Fig. 3.9 Distribución del tamaño de partículas: (a) perforación $J A P 1$, (b) perforación $A M A 1$, y (c) perforación AUS1.

Por otra parte, los suelos volcánicos de la zona este de la ciudad de Quito estudiados por O'Rourke y Crespo (1988) marcaron una composición en peso de 60\% a 65\% de arena fina y de $10 \%$ a $15 \%$ de arcilla y la fracción restante correspondiendo a limo. 


\subsubsection{Densidad de sólidos}

Los valores de densidad de sólidos obtenidos se reportan en la Fig. 3.10(a). En general, estos valores se sitúan entre 2.35 y $2.65 \mathrm{Mg} / \mathrm{m}^{3}$ en el sondeo $J A P 1$. Las muestras de AMAl oscilan entre 2.61 y $2.70 \mathrm{Mg} / \mathrm{m}^{3}$ y los especímenes de AUSI varían entre 2.50 y $2.55 \mathrm{Mg} / \mathrm{m}^{3}$.

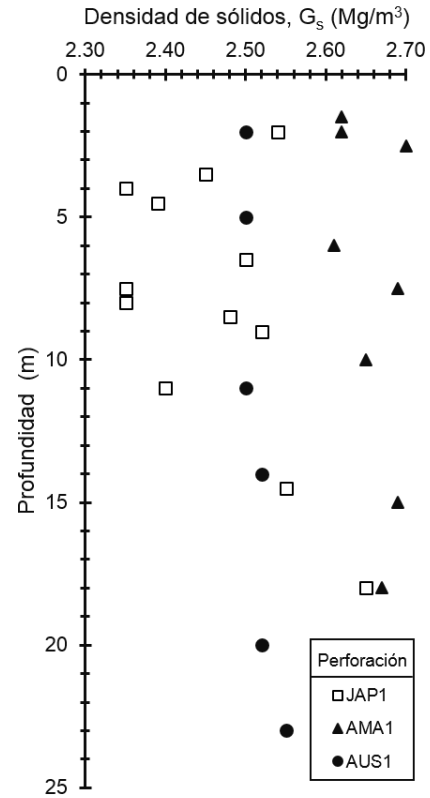

(a)

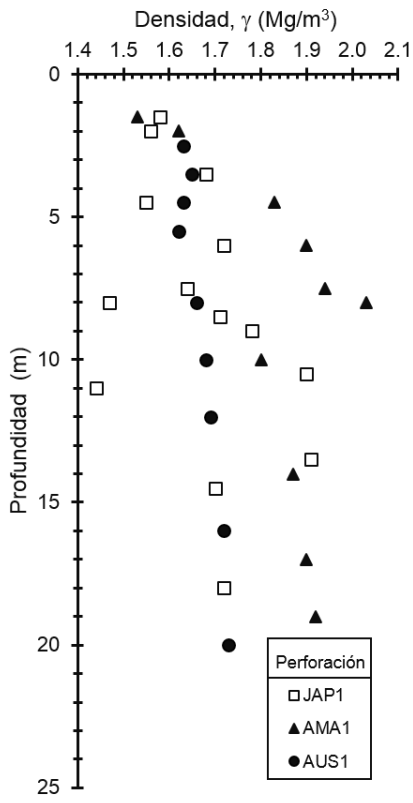

(b)

Fig. 3.10 (a) Densidad de sólidos versus profundidad para muestras de JAP1, AMA1 y AUS1, y (b) Densidad versus profundidad para especímenes de JAPl, AMAl y AUS1.

Determinados suelos estudiados presentaron valores de densidad de sólidos bajos, en concordancia con aquellos valores de los suelos volcánicos investigados por O’Rourke y Crespo (1988), Bommer et al. (2002) y Avşar et al. (2015).

\subsubsection{Densidad}

La Fig. 3.10(b) muestra los valores de densidad obtenidos en los ensayos realizados. En el sondeo JAPl estos valores están en el rango de 1.44 y $1.91 \mathrm{Mg} / \mathrm{m}^{3}$, entre 1.80 y $2.03 \mathrm{Mg} / \mathrm{m}^{3}$ en $A M A 1$ y oscilan entre 1.62 y $1.73 \mathrm{Mg} / \mathrm{m}^{3}$ en $A U S I$.

Los valores de densidad encontrados en este estudio fueron bajos, así como aquellos valores de los suelos volcánicos analizados por O'Rourke y Crespo (1988), Hürlimann et al. (2001), Bommer et al. (2002) y Avşar et al. (2015). 


\subsubsection{Relación de vacíos}

Los valores de relación de vacíos se muestran en la Fig. 3.11(a). En el sondeo JAP1 varían entre 0.88 y 1.92 y entre 0.49 y 0.99 en $A M A 1$.

Los valores de relación de vacíos de este estudio están dentro del rango de valores de los suelos volcánicos investigados por O'Rourke y Crespo (1988), Hürlimann et al. (2001) y Bommer et al. (2002).

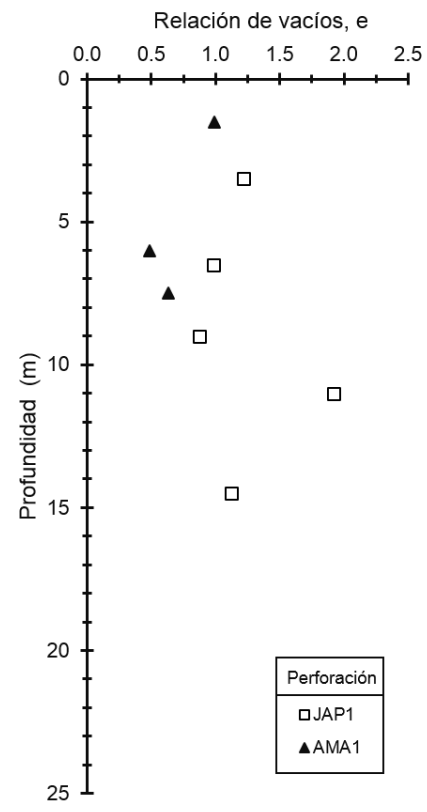

(a)

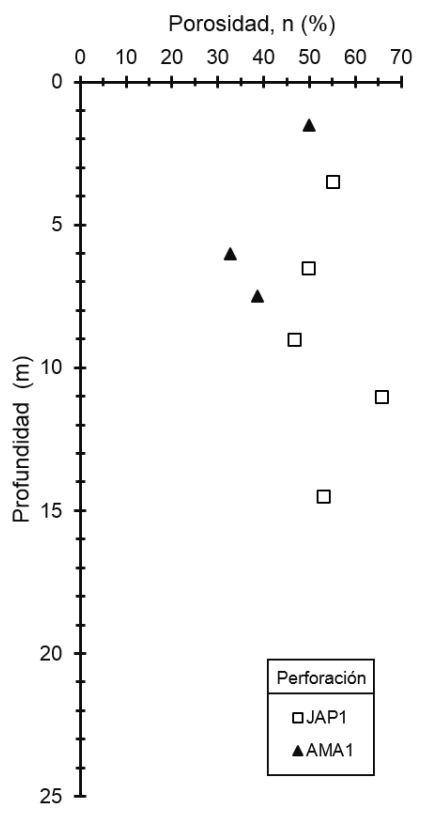

(b)

Fig. 3.11 (a) Relación de vacíos versus profundidad para muestras de JAP1 y AMA1, y (b) Porosidad versus profundidad para especímenes de JAP1 y AMA1.

\subsubsection{Porosidad}

La Fig. 3.11(b) muestra los valores de porosidad obtenidos. En JAP1 varían en el rango de $47 \%$ y $66 \%$ y oscilan entre $33 \%$ y $50 \%$ en los especímenes de AMAl.

Los suelos investigados presentan alta porosidad en concordancia con los valores obtenidos en los suelos volcánicos estudiados por O’Rourke y Crespo (1988), Hürlimann et al. (2001), Bommer et al. (2002) y Avşar et al. (2015). 


\subsubsection{Contenido de carbonatos}

Se aplicó el método del Calcímetro de Bernard para determinar el contenido de carbonato de calcio de las muestras de los sondeos JAP1 y AMA1. La variación del contenido de carbonato con la profundidad se indica en la Fig. 3.12(a). Los valores para las muestras de $J A P I$ oscilan entre $4.0 \%$ y $5.7 \%$ y entre $3.7 \%$ y $6.2 \%$ para los especímenes de $A M A 1$.

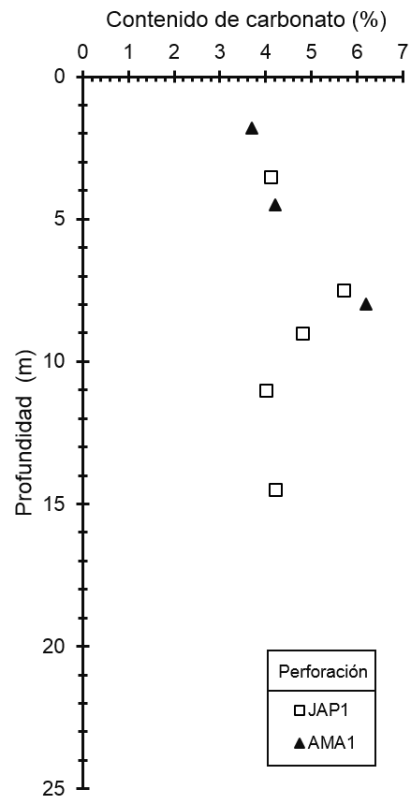

(a)

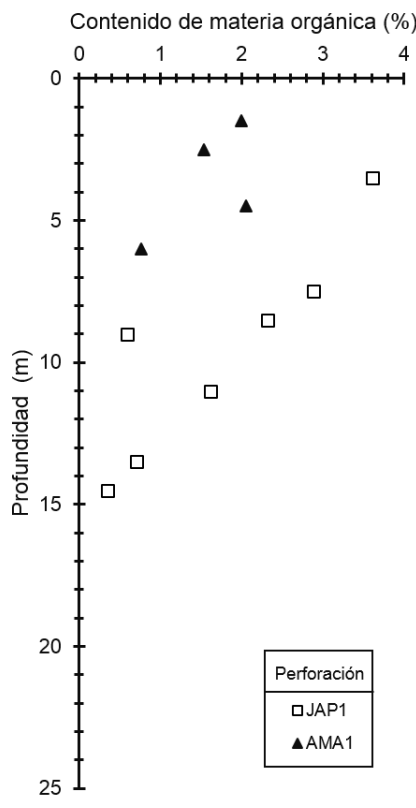

(b)

Fig. 3.12 (a) Contenido de carbonato versus profundidad para muestras de JAP1 y AMA1, y (b) Contenido de materia orgánica versus profundidad para muestras de JAP1 y AMAl.

\subsubsection{Contenido de materia orgánica}

Se utilizó el método del permanganato de potasio para determinar el contenido de materia orgánica $(O C)$ de las muestras de JAPl y AMA1. La Fig. 3.12(b) muestra la variación del contenido de materia orgánica con la profundidad, el cual se sitúa entre $0.35 \%$ y $3.61 \%$ para los especímenes de $J A P 1$ y entre $0.76 \%$ y $2.05 \%$ para las muestras de AMA1. En ambos casos, los valores de materia orgánica muestran una clara tendencia a disminuir con la profundidad. 


\subsection{Mineralogía y Microestructura}

\subsubsection{Mineralogía}

Se realizaron análisis semi-cuantitativos de difracción de rayos $\mathrm{X}(X R D)$ en las muestras de los sondeos JAPl y AMAl para determinar su composición mineralógica. Estos ensayos se llevaron a cabo en el Laboratorio de Geología de la Universitat de València (Valencia, España). Previo al análisis XRD, las muestras fueron secadas para eliminar el contenido de agua y pulverizadas para que sus partículas granulares pasen el tamiz de $80 \mu \mathrm{m}$. La composición mineralógica de los suelos fue determinada por análisis XRD mediante polvo orientado al azar y agregados orientados (El Howayek et al., 2016). El detalle del análisis semicuantitativo de difracción de rayos X se indica en la Tabla 3.1 y en la Fig. 3.13.

Tabla 3.1 Análisis semi-cuantitativo de difracción de rayos X.

\begin{tabular}{|c|c|c|c|c|c|c|c|c|}
\hline \multirow{4}{*}{$\begin{array}{l}\text { NOMBRE } \\
\text { COMPUESTO }\end{array}$} & \multicolumn{8}{|c|}{ PERFORACIÓN } \\
\hline & \multicolumn{5}{|c|}{ JAP1 } & \multicolumn{3}{|c|}{ AMA1 } \\
\hline & $3.50 \mathrm{~m}$ & $7.50 \mathrm{~m}$ & $9.00 \mathrm{~m}$ & $11.00 \mathrm{~m}$ & $14.50 \mathrm{~m}$ & $1.80 \mathrm{~m}$ & $4.50 \mathrm{~m}$ & $8.00 \mathrm{~m}$ \\
\hline & \multicolumn{8}{|c|}{$(\%)$} \\
\hline Albita & 14.4 & 15.0 & 11.6 & 13.7 & 23.1 & 7.5 & 17.3 & 15.8 \\
\hline Cristobalita & 8.1 & 9.5 & 7.4 & 8.7 & 6.4 & 4.2 & 6.9 & 5.6 \\
\hline Cuarzo & 7.3 & 7.9 & 8.2 & 0.9 & 1.9 & 1.4 & 4.1 & 5.7 \\
\hline Diópsido & 9.0 & 6.9 & 4.2 & 5.0 & 5.7 & 1.4 & 6.6 & 9.4 \\
\hline Augita & 12.1 & 5.8 & 8.1 & 9.5 & 32.3 & - & 5.7 & 10.3 \\
\hline Pirita & 1.5 & 2.1 & 1.6 & 1.9 & 2.6 & 2.2 & 1.2 & 1.1 \\
\hline Tremolita & 7.7 & 15.8 & 10.2 & 7.0 & 17.8 & 9.4 & 21.8 & 27.9 \\
\hline Calcita & 2.0 & 1.5 & 1.4 & 2.3 & 1.7 & 0.6 & 0.5 & 0.9 \\
\hline Clorita & 4.8 & 3.2 & 1.6 & 2.9 & 3.9 & 0.9 & 3.0 & - \\
\hline Biotita & 1.8 & 2.4 & 0.4 & 0.7 & 1.3 & 0.5 & 0.7 & 1.3 \\
\hline Clinoenstatita & 3.6 & 3.6 & 2.1 & 3.2 & 0.6 & 2.7 & 2.7 & 4.6 \\
\hline Anortita & 25.2 & 26.2 & 40.8 & 44.2 & 2.6 & 69.2 & 27.1 & 14.2 \\
\hline Montmorillonita & 2.6 & - & 2.2 & - & - & - & 2.1 & 1.6 \\
\hline Caolinita & - & - & - & - & - & - & - & 1.5 \\
\hline
\end{tabular}

En resumen, las muestras analizadas estuvieron compuestas de plagioclasas (7.5 $69.2 \%)$, piroxenos $(1.4-32.3 \%)$, anfíboles (7.0 - 27.9\%), filosilicatos $(0.0-4.8 \%)$, inosilicatos $(0.6-4.6 \%)$, sílice $(0.9-9.5 \%)$, sulfuros $(1.1-2.6 \%)$ y carbonatos $(0.5$ $-2.3 \%)$. 


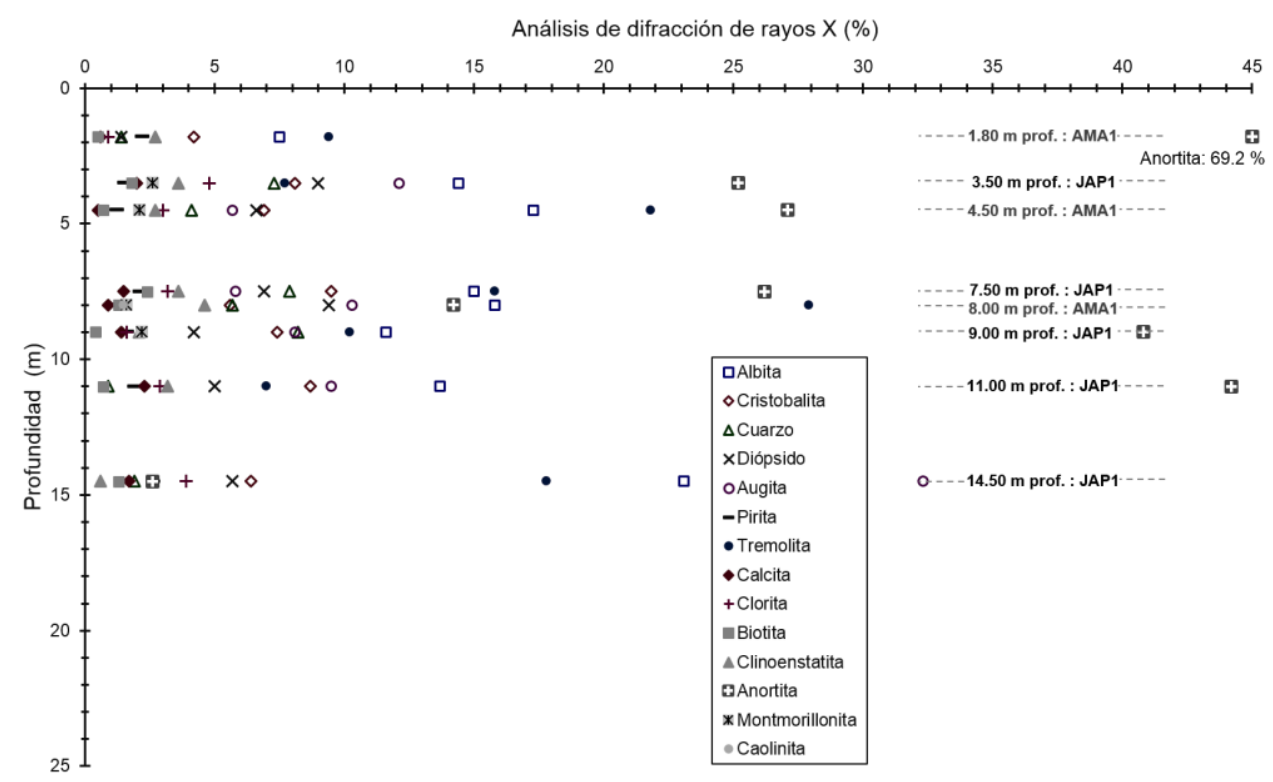

Fig. 3.13 Análisis de difracción de rayos X para las muestras de JAP1 y AMA1.

\subsubsection{Microestructura}

Se realizaron ensayos de microscopía electrónica (SEM) con ayuda de un microscopio de barrido modelo JSM 6300 utilizando muestras intactas secadas al horno. En este caso se analizaron muestras de la misma procedencia de las que se estudiaron en los ensayos de difracción de rayos X. En cada espécimen se identificó de manera predominante la presencia de plagioclasa, augita, tremolita, diópsido y cristobalita-cuarzo, que es consistente con los valores obtenidos del análisis mineralógico de la sección 3.5.1. En la Fig. 3.14 se muestran imágenes capturadas de los ensayos de microscopía electrónica realizados en las muestras de los sondeos $J A P 1$ y $A M A 1$, en donde se puede identificar de manera clara en la Fig. 3.14(d) la presencia de burbujas de gas y materia orgánica. 


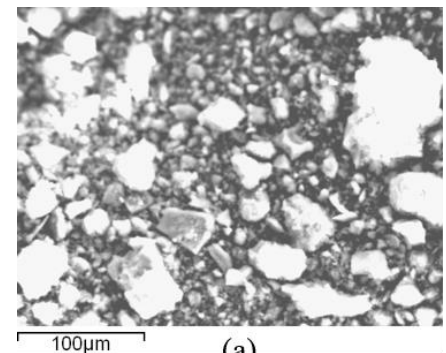

(a)

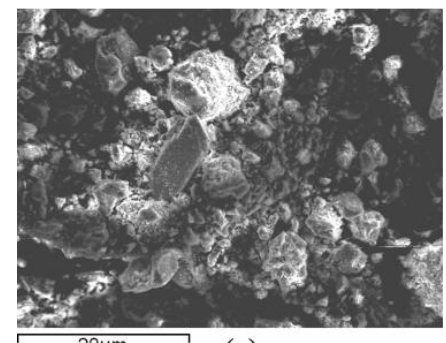

(c)

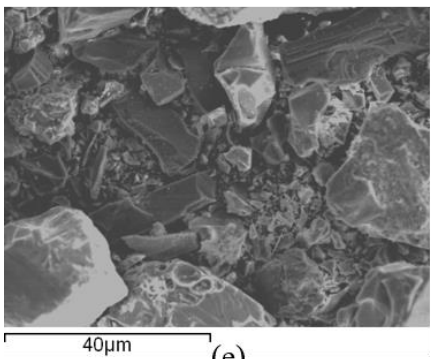

(e)

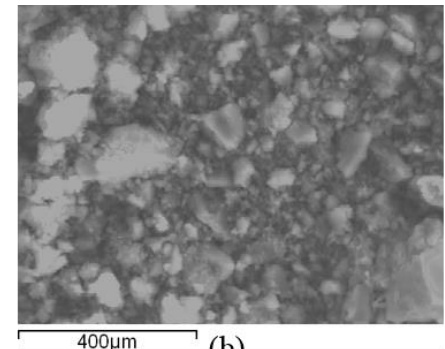

(b)
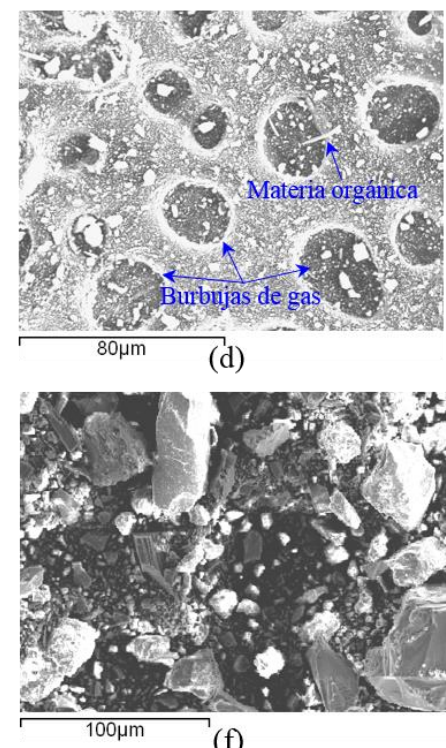

(f)

Fig. 3.14 Micrografías de ensayos SEM: (a) JAP1: $3.50 \mathrm{~m}$ de profundidad, (b) JAP1: $7.50 \mathrm{~m}$ de profundidad, (c) JAP1: $9.00 \mathrm{~m}$ de profundidad, (d) JAPl: $11.00 \mathrm{~m}$ de profundidad, (e) AMA1: $1.80 \mathrm{~m}$ de profundidad, y (f) $A M A 1: 8.00 \mathrm{~m}$ de profundidad.

\subsection{Consolidación}

Aplicando las normas ASTM D2435 (ASTM D2435, 2011) y UNE 103-405 (AENOR, 1999), se realizaron ensayos convencionales de consolidación unidimensional con doble drenaje (superior e inferior) sobre especímenes inalterados para evaluar los parámetros de compresión de los suelos. Los diámetros de los anillos edométricos de acero inoxidable fueron $45 \mathrm{~mm}, 50 \mathrm{~mm}$ y $70 \mathrm{~mm}$, en tanto que su altura fue de $20 \mathrm{~mm}$. Cada escalón de incremento de carga se mantuvo durante 24 horas. Los esfuerzos de sobrecarga fueron incrementados de $5 \mathrm{kPa}$ hasta $1000 \mathrm{kPa}$, aunque algunos especímenes fueron cargados hasta $2000 \mathrm{kPa}$.

La Fig. 3.15 muestra los resultados de los ensayos de consolidación unidimensional de los especímenes de las perforaciones JAPl y AMAl en términos del esfuerzo efectivo vertical y la respectiva relación de vacíos. 

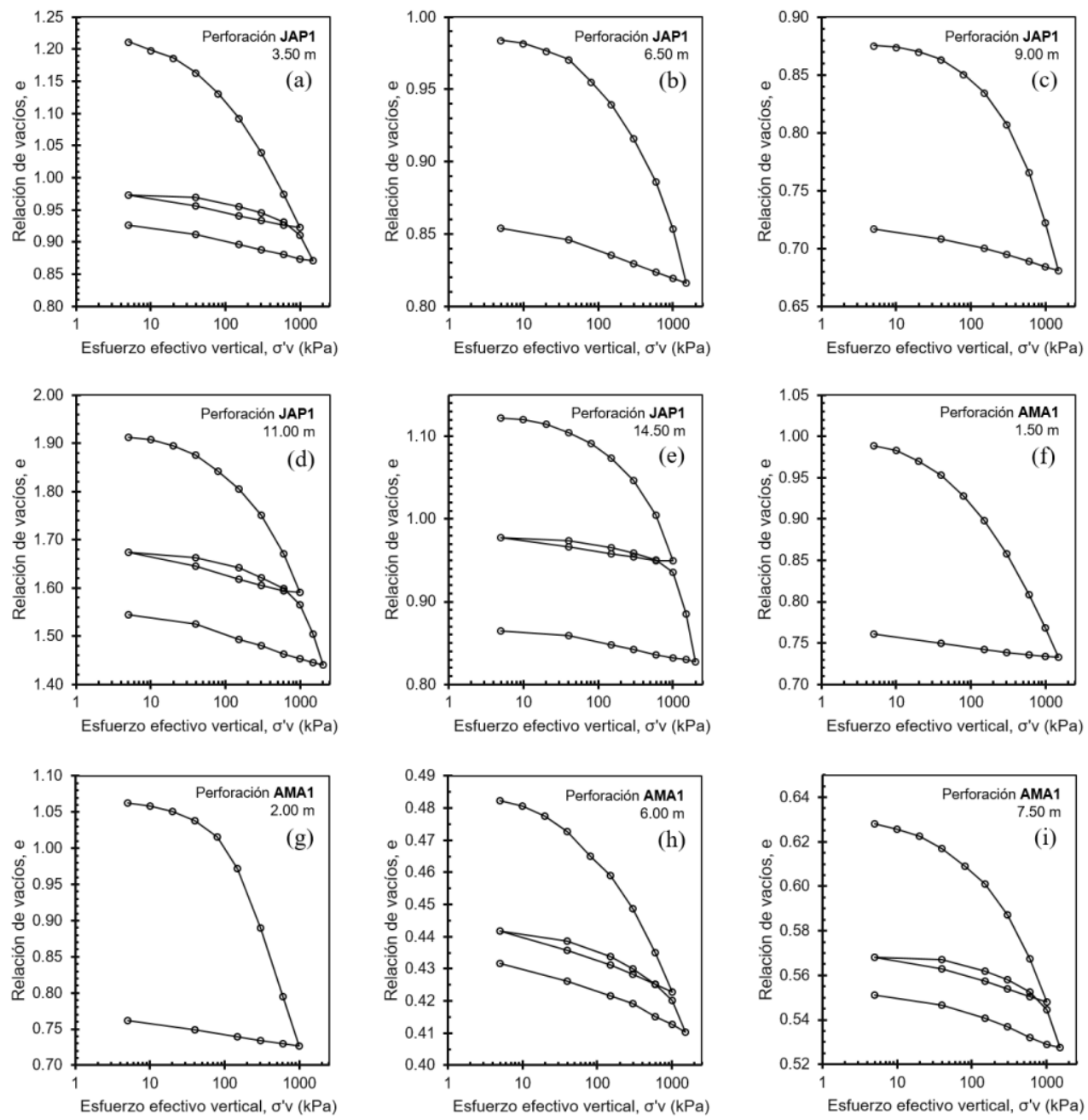

Fig. 3.15 Ensayos de consolidación unidimensional de las muestras de las perforaciones JAP1 y AMA1.

En las muestras de la perforación $J A P l$, el índice de compresión $C_{c}$ varía entre 0.15 y 0.36 y el índice de expansión $C_{s}$ está en el rango de 0.02 y 0.05 . En tanto que en $A M A 1, C_{c}$ tiene valores entre 0.06 y 0.30 y $C_{s}$ presenta valores entre 0.01 y 0.02 . Los valores de $C_{c}$ de este estudio están dentro del rango de aquellos de los suelos volcánicos investigados por Hürlimann et al. (2001).

La Fig. 3.16(a) muestra la relación entre el índice de compresión $\left(C_{c}\right)$ con el contenido natural de agua $\left(w_{\text {nat }}\right)$ y límite líquido $(L L)$ para los especímenes de JAP1 y $A M A 1$. Por otra parte la Fig 3.16(b) presenta la correlación entre el índice de expansión $\left(C_{s}\right)$ con el contenido natural de agua $\left(w_{n a t}\right)$ y el límite líquido $(L L)$. En tanto que la Fig. 3.16(c) muestra la relación entre los índices de compresión $\left(C_{c}\right)$ y 
expansión $\left(C_{s}\right)$ con la relación inicial de vacíos $\left(e_{0}\right)$. Generalmente $C_{c}$ presenta una buena correlación con $e_{0}$ y $w_{\text {nat }}$ para la mayoría de los tipos de arcilla (Leroueil et al., 1990).

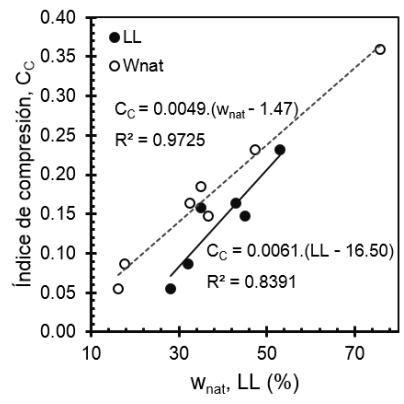

(a)

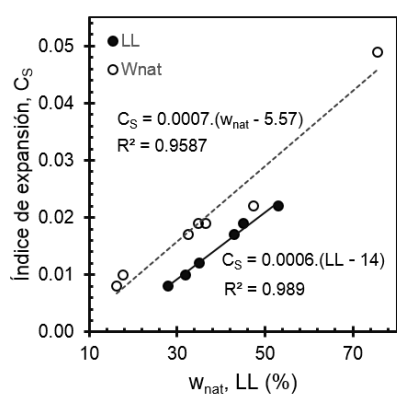

(b)

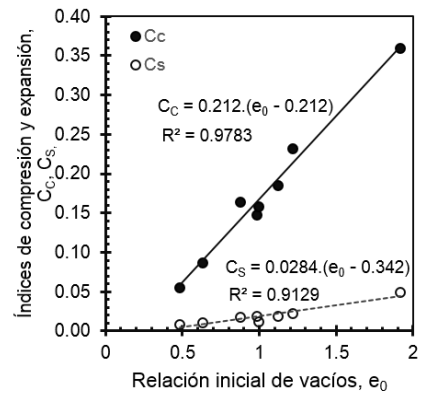

(c)

Fig. 3.16 Correlación del (a) índice de compresión $\left(C_{c}\right)$ y (b) índice de expansión $\left(C_{s}\right)$ con el contenido natural de agua $\left(w_{n a t}\right)$ y el límite líquido $(L L)$ y (c) Correlación de índices de compresión $\left(C_{c}\right)$ y expansión $\left(C_{s}\right)$ con la relación inicial de vacíos $\left(e_{0}\right)$.

De acuerdo a la Fig. 3.16, se pueden obtener las siguientes fórmulas empíricas para los suelos de la zona en estudio:

$$
\begin{aligned}
& C_{c}=0.0049\left(w_{\text {nat }}-1.47\right) \\
& C_{c}=0.0061(L L-16.50) \\
& C_{c}=0.212\left(e_{0}-0.212\right) \\
& C_{s}=0.0007\left(w_{\text {nat }}-5.57\right) \\
& C_{s}=0.0006(L L-14) \\
& C_{s}=0.0284\left(e_{0}-0.342\right)
\end{aligned}
$$

La relación $C_{d} / C_{s}$ es un valor constante y en los casos de este estudio varía entre 6 y 10.

De acuerdo a Burland (1990), las curvas de compresión pueden ser normalizadas usando el concepto de índice de vacíos, el cual se define como:

$$
I_{v}=\frac{e-e_{100}^{*}}{e_{100}^{*}-e_{1000}^{*}}=\frac{e-e_{100}^{*}}{C_{c}^{*}}
$$

\section{Donde:}

$I_{v} \quad$ índice de vacíos

e relación de vacíos

$e_{100}^{*}$ relación de vacíos al esfuerzo de sobrecarga efectiva de $100 \mathrm{kPa}$ 
$e_{1000}^{*} \quad$ relación de vacíos al esfuerzo de sobrecarga efectiva de $1000 \mathrm{kPa}$

$C_{c} \quad$ índice de compresión intrínseca de Burland

El concepto de índice de vacíos es útil para comparar la compresibilidad de una muestra de suelo en todo el perfil. El índice de vacíos in situ puede ser usado para estudiar la historia de esfuerzos y la estructura del suelo (Gylland et al., 2013). En este estudio para los suelos obtenidos del norte de la ciudad de Quito, $e_{100}^{*}$ y $C_{c}^{*}$ fueron estimados de la relación de vacíos al límite líquido $\left(e_{L}\right)$ usando las correlaciones empíricas de Burland (Low et al., 2011).

$$
\begin{aligned}
& e_{100}^{*}=0.109+0.679 e_{L}-0.089 e_{L}^{2}+0.016 e_{L}^{3} \\
& C_{c}^{*}=0.256 e_{L}-0.04
\end{aligned}
$$

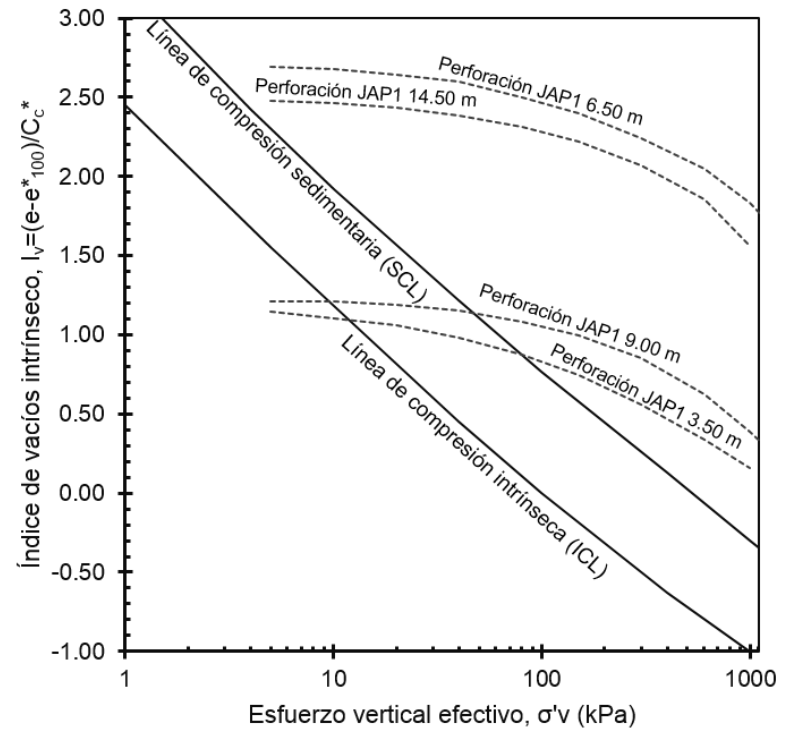

Fig. 3.17 Comportamiento del suelo según el concepto de Burland (1990).

La Fig. 3.17 indica las curvas de compresión normalizadas para las muestras de la perforación $J A P 1$, donde la línea de compresión intrínseca $(I C L)$ y la línea de compresión sedimentaria (SCL) establecidas por Burland (1990) son incluidas como referencia.

Además la Fig. 3.17 muestra que las curvas $I_{v}-\log \sigma_{v}^{\prime}$ para los especímenes JAPI $3.50 \mathrm{~m}$ y $J A P 19.00 \mathrm{~m}$ cruzan la línea de compresión intrínseca $(I C L)$ durante la carga inicial a bajos esfuerzos, lo que significa que el suelo in situ ha adquirido una estructura post-depósito. Mientras que los valores para las muestras JAP1 $6.50 \mathrm{~m}$ y JAPl 14.50 m están muy por encima de la línea de compresión sedimentaria (SCL), lo que indica un alto grado de estructura del suelo (Burland, 1990). 


\subsection{Resistencia al Corte}

\subsubsection{Introducción}

La resistencia al corte del suelo es la propiedad que presenta un suelo para resistir la falla y el desplazamiento entre sus partículas cuando actúa una fuerza externa. Este concepto es fundamental al momento de estimar la presión lateral del suelo sobre estructuras de contención y en análisis de estabilidad de taludes.

Existen varios ensayos de laboratorio para obtener la resistencia al corte de los suelos, en este estudio se realizaron ensayos triaxiales consolidados no drenados $(C U)$ y ensayos triaxiales consolidados drenados $(C D)$, los cuales se llevaron a cabo en la célula de trayectoria de esfuerzos hidráulicos del Laboratorio de Mecánica de Suelos (Departamento de Ingeniería del Terreno) de la Universitat Politècnica de València (Ver Fig. 3.18), sobre muestras inalteradas, recuperadas de la zona de estudio, transportadas adecuadamente y almacenadas en el cuarto húmedo del laboratorio y controlando constantemente la humedad relativa del $100 \%$.

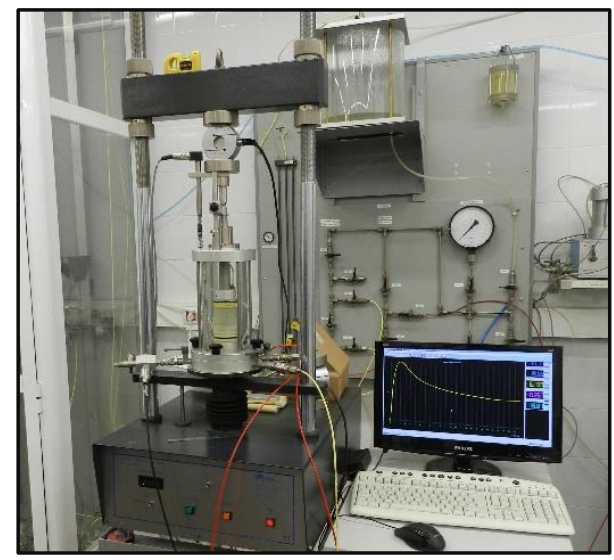

Fig. 3.18 Célula triaxial del Laboratorio de Mecánica de Suelos (Departamento de Ingeniería del

Terreno) de la Universitat Politècnica de València.

Estos análisis son los únicos que se han realizado hasta la fecha en esta región específica y se constituirán en una fuente valiosa de información que será útil para futuras investigaciones.

\subsubsection{Resistencia al Corte No Drenada}

La resistencia al corte no drenada del suelo juega un papel fundamental en Ingeniería Geotécnica, ya que proporciona importante información para calcular las presiones de tierra ejercidas por los suelos en condiciones no drenadas (estabilidad a corto plazo) y la capacidad de carga, por ejemplo en suelos que soportan cimentaciones de 
muros a gravedad. Además, es un indicador del comportamiento del suelo en asociación con otras propiedades de la ingeniería.

La resistencia al corte no drenada de un suelo es generalmente determinada en laboratorio utilizando ensayos triaxiales no consolidados no drenados $(U U)$ y ensayos triaxiales consolidados no drenados $(C U)$.

En este estudio se realizaron ensayos triaxiales consolidados no drenados $(C U)$ con medida de presión de poros, aplicando las normas ASTM D4767 (ASTM D4767, 2011) y UNE 103-402 (AENOR, 2011), para el efecto se consideraron probetas de suelo de $38 \mathrm{~mm}$ de diámetro y altura $76 \mathrm{~mm}$ y para tallar las mismas se utilizó un torno tallador y una sierra de alambre muy fino. Cada prueba triaxial comprendió tres etapas diferentes: (1) saturación, (2) consolidación, y (3) rotura bajo condiciones no drenadas (Pineda et al., 2016). Se utilizó una rampa de saturación controlada por esfuerzos hasta el punto en que la presión de celda y la presión de cola alcanzaron $610 \mathrm{kPa}$ y $600 \mathrm{kPa}$, respectivamente. Estos valores se mantuvieron por aproximadamente 24 horas, después de lo cual se revisó el parámetro B de Skempton y encontrando que los valores fueron superiores a 0.96 en cada instancia (Pineda et al., 2016). Todos los especímenes fueron sometidos a consolidación isotrópica, ubicándose el drenaje del agua de poros en la parte superior de cada muestra. Al mismo tiempo, el exceso de presión de agua de poros fue medido con un transductor de presión de poros conectado a la línea de drenaje inferior. Finalmente, cada espécimen fue sometido a rotura sin drenaje bajo una velocidad de desplazamiento vertical de $0.03 \mathrm{~mm} / \mathrm{min}$.

Para representar los resultados de cada uno de los ensayos se utilizó el plano $q-p$ ' de Cambridge, con: $p^{\prime}=\left(\sigma_{1}^{\prime}+2 . \sigma^{\prime}{ }_{3}\right) / 3$ y $q=\sigma_{l}^{\prime}-\sigma_{3}^{\prime}$, en donde: $\sigma_{l}^{\prime}$ es el esfuerzo aplicado al espécimen de prueba en dirección vertical (axial) y $\sigma_{3}^{\prime}$ es la presión general aplicada a la muestra de prueba en la cámara triaxial.

La Fig. 3.19 muestra las curvas esfuerzo - deformación unitaria axial, $q-\varepsilon_{s}$, con la evolución de la presión de poros, $u$, para cada una de los especímenes de las perforaciones $J A P 1$ y $A M A l$. 


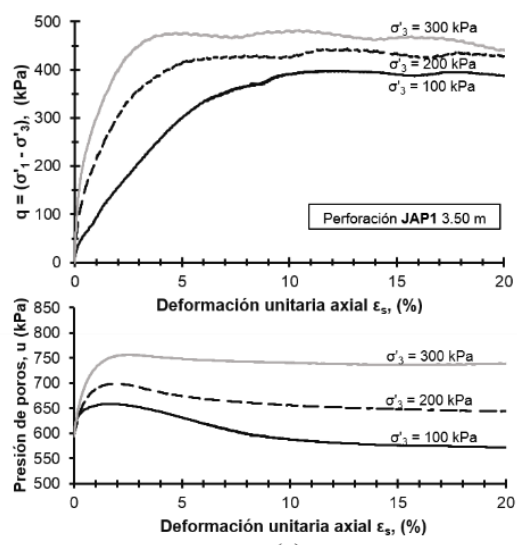

(a)

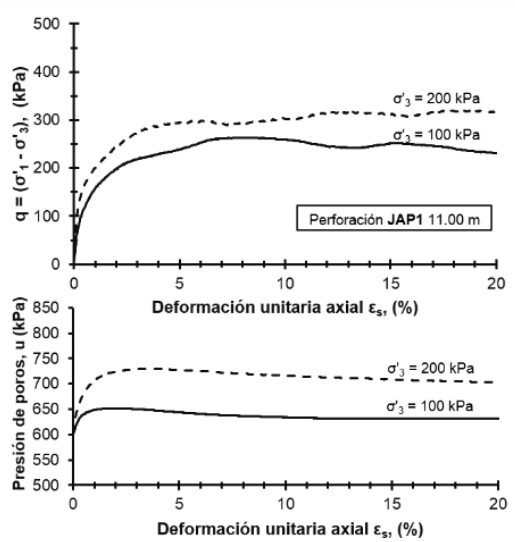

(c)
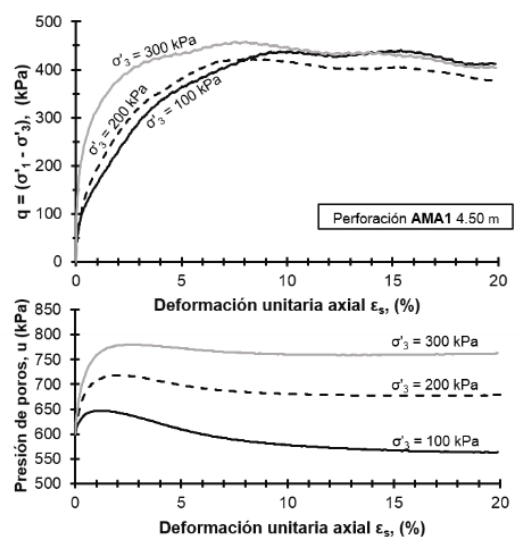

(e)

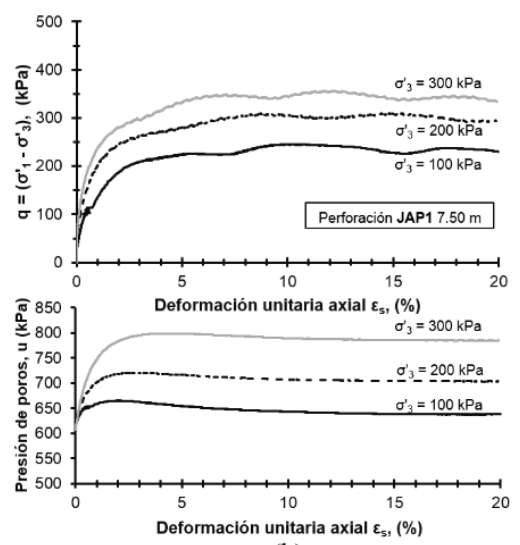

(b)
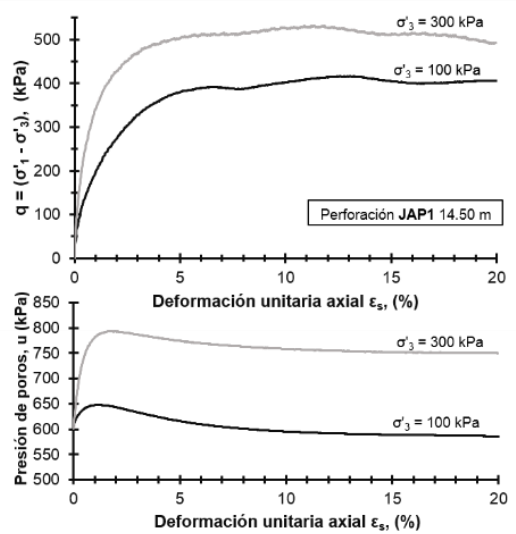

(d)
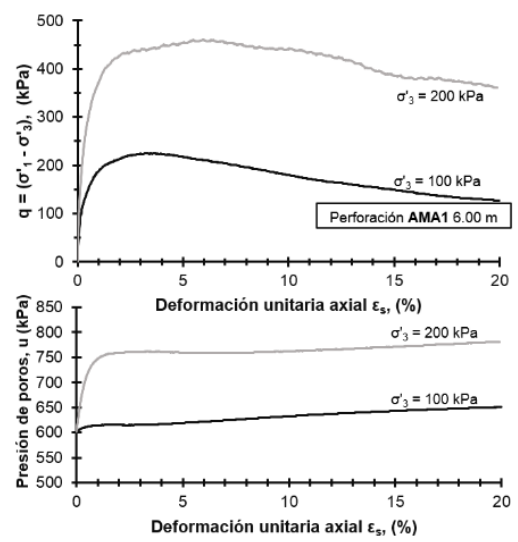

(f)

Fig. 3.19 Curvas esfuerzo-deformación unitaria-presión de poros para muestras de JAP1 y AMA1. 
Se consideraron diferentes criterios de falla para determinar la resistencia al corte de un espécimen de suelo a partir de un ensayo triaxial, tales como: esfuerzo desviador máximo, relación de esfuerzos principales máxima, deformación unitaria límite, estado crítico y esfuerzo residual. En este estudio se adoptó como criterio de falla, la relación máxima de esfuerzos $\sigma_{1}^{\prime} / \sigma_{3}^{\prime}$, a partir de la cual se determinó la resistencia al corte del suelo. Esta relación proporciona una mejor correlación entre el esfuerzo cortante y el esfuerzo normal al momento de representar en los círculos de esfuerzos de Mohr. La relación es igual a 1 al inicio del ensayo, porque en esta etapa $\sigma_{1}^{\prime}=\sigma_{3}^{\prime}$. El máximo valor de $\sigma_{l}^{\prime} / \sigma_{3}^{\prime}$ no necesariamente ocurre a la misma deformación unitaria axial del máximo esfuerzo desviador. Los valores máximos de la relación de esfuerzos $\sigma_{l}^{\prime} / \sigma_{3}^{\prime}$ varían entre 4.00 y 5.35 , con $\varepsilon_{\mathrm{s}}$ oscilando entre $3.75 \%$ y $6.00 \%$, mientras que los valores post-pico de esta relación de esfuerzos están en el rango de 3.55 hasta aproximadamente 4.65. La Fig. 3.20(a) muestra la variación de la relación de esfuerzos, $\sigma_{l}^{\prime} / \sigma_{3}^{\prime}$, con la deformación unitaria axial, $\varepsilon_{\mathrm{s}}$, para las muestras de las perforaciones $J A P 1$ y $A M A 1$. Mientras que, la variación de la relación de esfuerzos, $q / p^{\prime}$, con la deformación unitaria axial, $\varepsilon_{s}$, se indica en la Fig. 3.20(b). En este caso, los valores post-pico de la relación de esfuerzos varían entre 1.35 y 1.65.

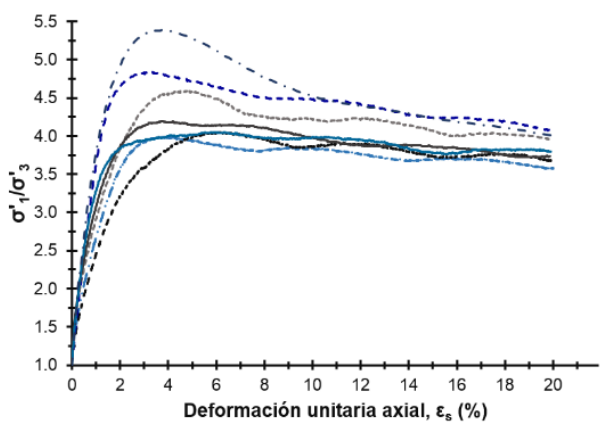

(a)

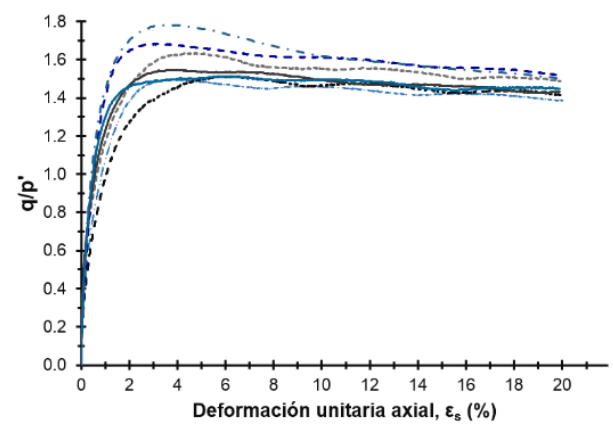

(b)

Fig. 3.20 (a) Variación de la relación de esfuerzos $\sigma_{l}^{\prime} / \sigma_{3}^{\prime}$ para muestras de las perforaciones $J A P 1$ y $A M A 1$, y (b) Variación de la relación de esfuerzos q/p' para muestras de los sondeos JAPl y AMA1.

El comportamiento de la relación de esfuerzos, $q / p$ ', se clasificó en dos grupos principales como se puede ver en la Fig. 3.21, la cual muestra que la resistencia no drenada en compresión fue determinada usando el concepto de la mecánica crítica del suelo. La pendiente $(M)$ de la línea de estado crítico en compresión (Kempfert y Gebreselassie, 2006; Konkol et al., 2019) se obtiene mediante la expresión:

$$
M=\frac{6 \operatorname{sen} \varnothing^{\prime}}{3-\operatorname{sen} \emptyset^{\prime}}
$$




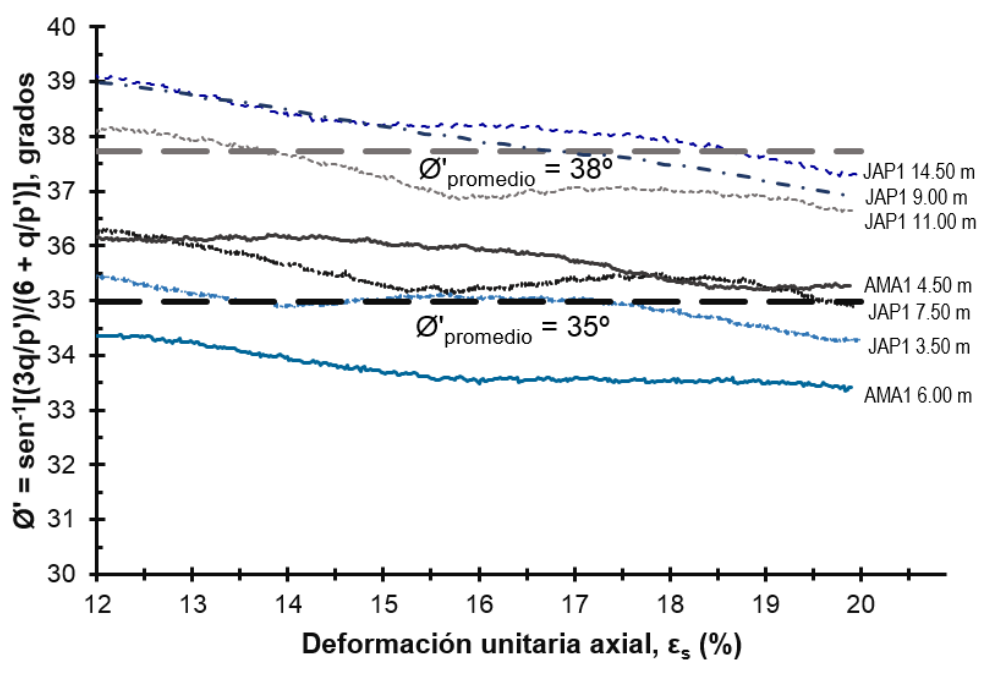

Fig. 3.21 Ángulo de fricción efectivo secante para muestras de perforaciones JAP1 y AMA1.

El ángulo de fricción secante, $\emptyset_{\text {sec }}^{\prime}$, fue estimado para deformaciones unitarias axiales superiores al $12 \%$. Los ángulos de fricción promedio de $35^{\circ}$ (especímenes de $3.50 \mathrm{~m}$ a $7.50 \mathrm{~m}$ de profundidad) y $38^{\circ}$ (especímenes de $9.00 \mathrm{~m}$ a $14.50 \mathrm{~m}$ de profundidad) constituyen la respuesta post-pico de los especímenes de JAPl y $A M A 1$. Sin embargo, esta relación entre $\emptyset_{\text {sec }}^{\prime}$ y la profundidad de la muestra no es definitiva, dado que algunos factores (forma de las partículas, distribución y configuración del tamaño, mineralogía de los granos, relación de vacíos, contenido de agua y el historial de esfuerzos anteriores) (Head y Epps, 2014) pueden afectar la resistencia del suelo medida en un ensayo de laboratorio.

La Fig. 3.22 muestra las trayectorias de tensiones en el plano $q$ - $p$ ' para las muestras de JAPl y $A M A 1$ en condiciones triaxiales. El comportamiento del suelo sometido a la rotura es fácilmente observado en las trayectorias de tensiones efectivas indicadas en esta figura. Por tanto, los ángulos de fricción pico entre $34^{\circ}$ y $38^{\circ}$ fueron estimados en compresión triaxial para las muestras de estas dos perforaciones.

La Tabla 3.2 proporciona un resumen de los parámetros de resistencia obtenidos de los ensayos de compresión triaxial consolidados no drenados $(C U)$ de las muestras de JAPl y AMA1. Los especímenes superficiales muestran un ángulo de fricción pico de $\emptyset_{\text {peak }}^{\prime} \approx 35^{\circ}$ y una cohesión efectiva $\left(c^{\prime}\right)$ comprendida entre $5 \mathrm{kPa}$ y $26 \mathrm{kPa}$, mientras que las muestras más profundas presentan un ángulo de fricción pico de $\emptyset_{\text {peak }}^{\prime} \approx 38^{\circ}$ y una cohesión efectiva ( $c^{\prime}$ ) entre $10 \mathrm{kPa}$ y $20 \mathrm{kPa}$. 

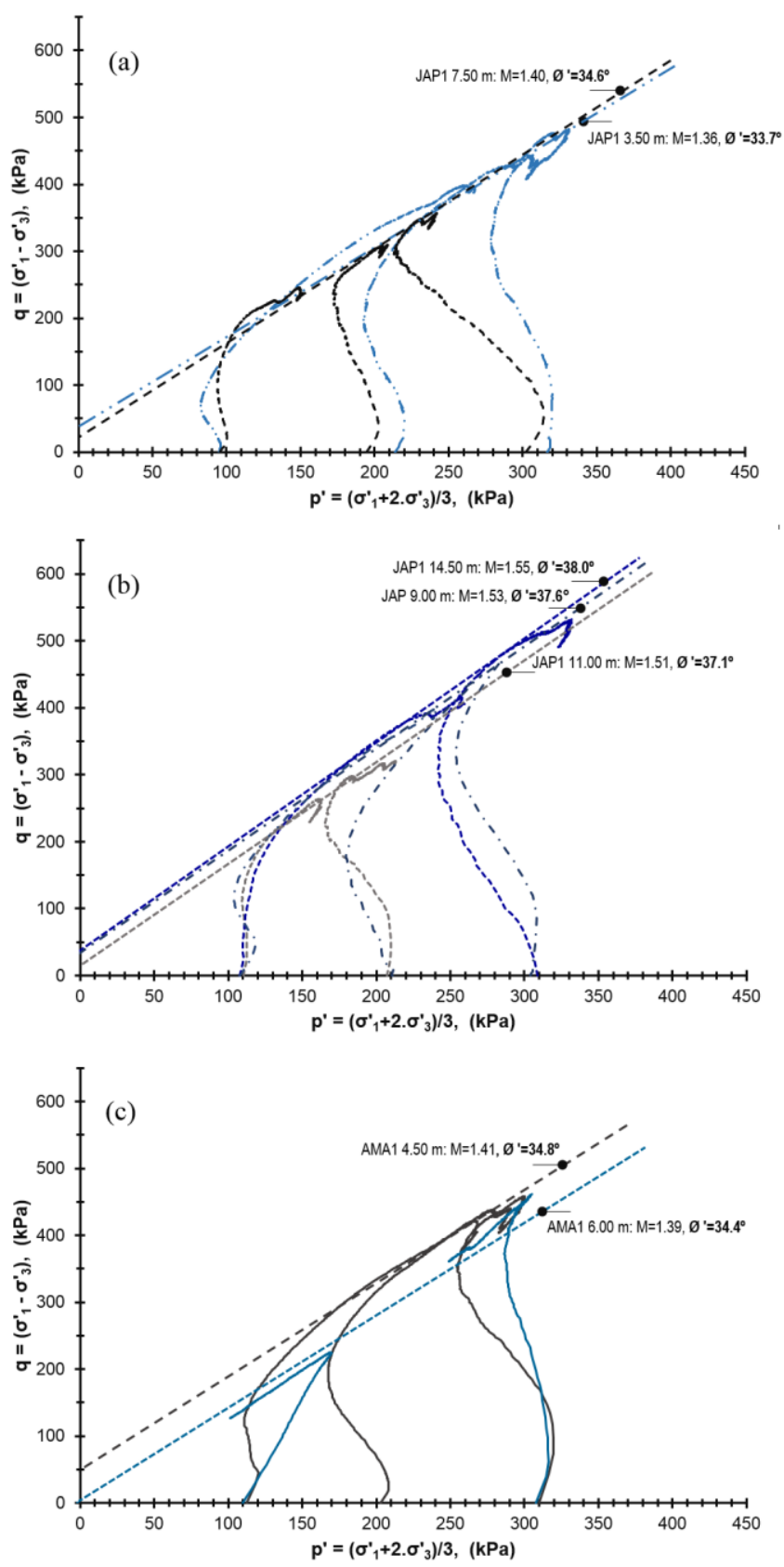

Fig. 3.22 Trayectoria de tensiones efectivas: (a) y (b) muestras de perforación JAP1, y (c) muestras de perforación AMA1. 
Tabla 3.2 Parámetros de resistencia al corte no drenado para muestras de perforaciones JAP1 y AMA1.

\begin{tabular}{|c|c|c|c|c|c|c|c|}
\hline \multicolumn{2}{|c|}{ Ensayo } & \multirow{2}{*}{$\begin{array}{c}\text { Presión de célula } \\
{[\mathrm{kPa}]}\end{array}$} & \multirow{2}{*}{ 总高 } & \multirow{2}{*}{$\begin{array}{l}\mathrm{W}_{\text {nat }} \\
{[\%]}\end{array}$} & \multirow{2}{*}{$\begin{array}{c}\gamma / \gamma_{\mathrm{d}} \\
{\left[\mathrm{kN} / \mathrm{m}^{3}\right]}\end{array}$} & \multirow{2}{*}{$\begin{array}{c}\mathrm{c}^{\prime} \\
{[\mathrm{kPa}]}\end{array}$} & \multirow{2}{*}{$\begin{array}{l}\varnothing^{\prime} \\
{\left[{ }^{\circ}\right]}\end{array}$} \\
\hline Perforación & Prof. [m] & & & & & & \\
\hline$J A P 1$ & 3.50 & $100,200,300$ & $C U$ & 43 & $16.8 / 11.7$ & 21 & 33.7 \\
\hline$A M A 1$ & 4.50 & $100,200,300$ & $C U$ & 25 & $18.3 / 14.6$ & 26 & 34.8 \\
\hline$A M A 1$ & 6.00 & 100,300 & $C U$ & 16 & $19.0 / 16.4$ & 5 & 34.4 \\
\hline$J A P 1$ & 7.50 & $100,200,300$ & $C U$ & 50 & $16.4 / 10.9$ & 14 & 34.6 \\
\hline$J A P 1$ & 9.00 & 100,300 & $C U$ & 30 & $17.8 / 13.7$ & 17 & 37.6 \\
\hline$J A P 1$ & 11.00 & 100,200 & $C U$ & 32 & $14.4 / 10.9$ & 10 & 37.1 \\
\hline$J A P 1$ & 14.50 & 100,300 & $C U$ & 34 & $17.0 / 12.7$ & 20 & 38.0 \\
\hline
\end{tabular}

La Fig. 3.23 muestra el perfil de variación del ángulo de fricción pico $\left(\varnothing_{\text {peak }}^{\prime}\right)$ con la profundidad para las perforaciones JAP1 y AMAl de acuerdo a los valores dados en la Tabla 3.2. Se puede distinguir de manera clara la tendencia a aumentar el valor del ángulo de fricción con la profundidad.

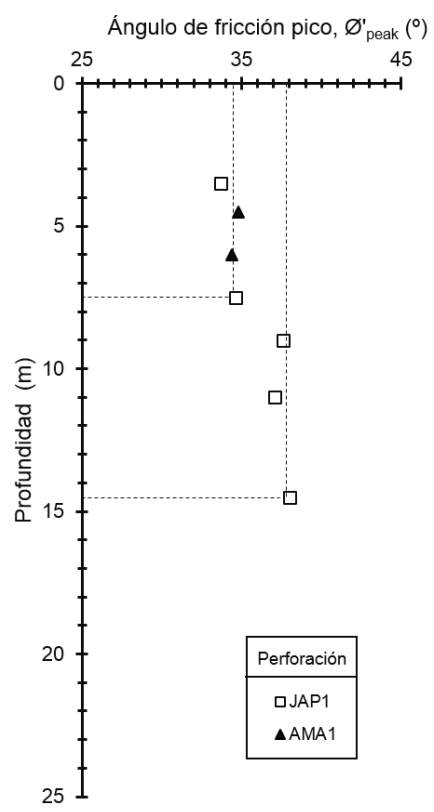

Fig. 3.23 Ángulos de fricción pico estimados en pruebas triaxiales para muestras de perforaciones JAPI y AMA1. 
Los suelos estudiados presentan valores del ángulo de fricción $\left(\varnothing^{\prime}\right)$ ligeramente más bajos y valores de cohesión ( $\left.c^{\prime}\right)$ mucho más bajos que aquellos de los suelos volcánicos investigados por O'Rourke y Crespo (1988). Esto se justifica en cierto grado, dado que presentan una estructura similar, sin embargo son de una formación diferente. Los suelos examinados por O'Rourke y Crespo (1988) se ubicaron en un área entre los sectores de Tumbaco y el Valle de Los Chillos, al este de Quito, mientras que los del presente estudio son de la región centro-norte de la ciudad.

Se correlacionaron los valores de los ensayos de penetración estándar $\left(N_{S P T}\right)$ con los valores del ángulo de fricción, con la consecuente aplicación de la técnica de análisis de regresión lineal para obtener esta relación. Finalmente, la relación con el mejor ajuste logrado en este proceso se muestra en la Fig. 3.24 y en la ecuación 3.11.

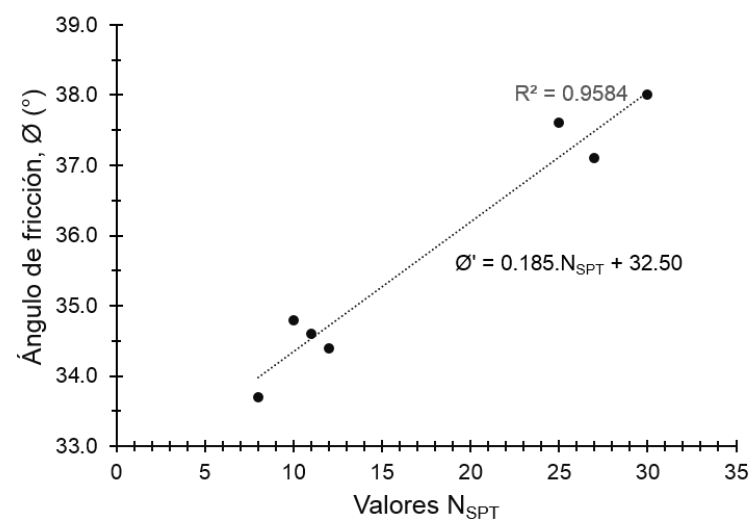

Fig. 3.24 Correlación entre valores de $N_{S P T}$ y el ángulo de fricción $(\varnothing)$.

$$
\varnothing=0.185 N_{S P T}+32.50
$$

Los resultados obtenidos con esta correlación resultan entre un $6 \%$ y $15 \%$ mayores a los obtenidos con la estimación y ecuación de Kumar et al. (2016):

$$
\varnothing=27.12+0.2857 N_{S P T}
$$

\subsubsection{Resistencia al Corte Drenada}

La resistencia drenada de un suelo es representada por los parámetros cohesión efectiva $\left(c^{\prime}\right)$ y ángulo de fricción efectivo $\left(\varnothing^{\prime}\right)$ y se usa para un análisis a largo plazo (Kempfert y Gebreselassie, 2006). Como parte de esta investigación, se realizaron además ensayos triaxiales consolidados drenados $(C D)$ con medida de cambio de volumen, sobre probetas talladas de $38 \mathrm{~mm}$ de diámetro y $76 \mathrm{~mm}$ de atura y bajo las recomendaciones de las especificaciones ASTM D7181 (ASTM D7181, 2011) y UNE 103-402 (AENOR, 1999). En este tipo de ensayo triaxial, durante la fase de 
rotura a compresión del espécimen, se mantiene constante la presión externa de la célula y se deja el drenaje libre de la probeta a una velocidad constante de deformación, según la norma UNE 103-402 (AENOR, 1999).

Cada ensayo triaxial cumplió con las 3 etapas sucesivas: (1) saturación, (2) consolidación, y (3) rotura bajo condiciones drenadas. La etapa de saturación de cada espécimen fue llevaba a cabo durante 24 horas y al final de la misma se verificó que el parámetro $B$ de Skempton sea mayor a 0.96. La etapa de consolidación se realizó bajo condiciones isotrópicas, con el drenaje de agua de poros en la parte superior del espécimen. Finalmente la etapa de rotura se realizó bajo condiciones drenadas y con una velocidad de desplazamiento vertical de $0.01 \mathrm{~mm} / \mathrm{min}$.

La Fig. 3.25 expone las curvas esfuerzo - deformación unitaria axial, $q-\varepsilon_{s}$, con la variación del cambio de volumen, para cada una de las muestras de las perforaciones JAP1 y AMA1.
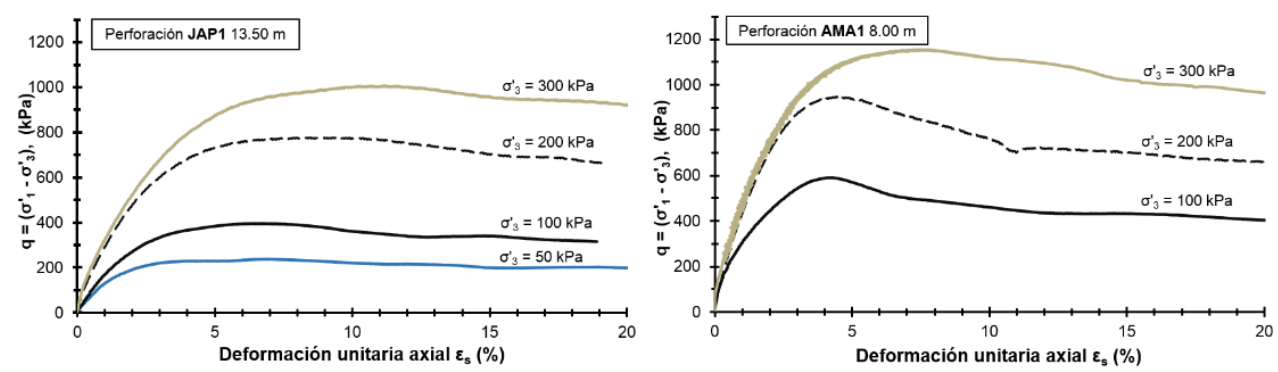

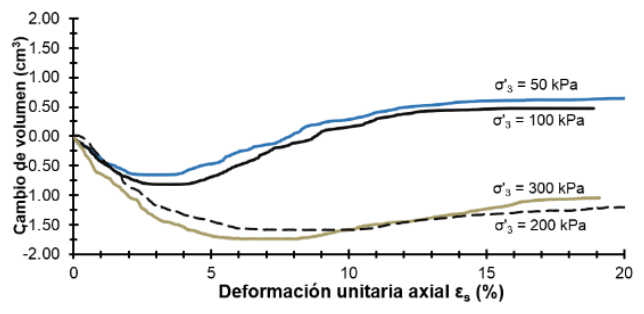

(a)

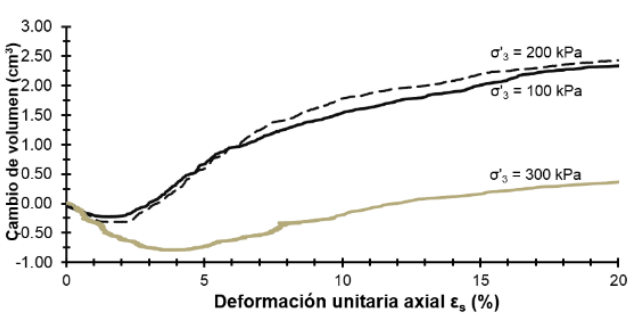

(b)

Fig. 3.25 Curvas esfuerzo-deformación unitaria-variación de volumen para muestras de JAP1 y AMA1.

La Fig. 3.26 muestra los gráficos de esfuerzo cortante $\tau^{\prime}$ versus esfuerzo normal $\sigma$ ' para cada una de las muestras de JAPl y AMAl y los respectivos círculos de esfuerzos de Mohr para el criterio de falla adoptado (máximo valor de $\sigma_{l}^{\prime} / \sigma_{3}^{\prime}$ ) para los ensayos de compresión triaxial consolidados drenados. 


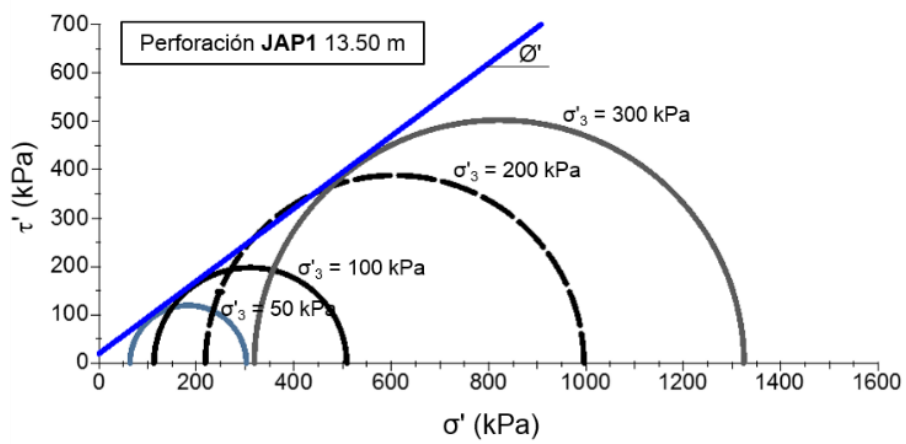

(a)

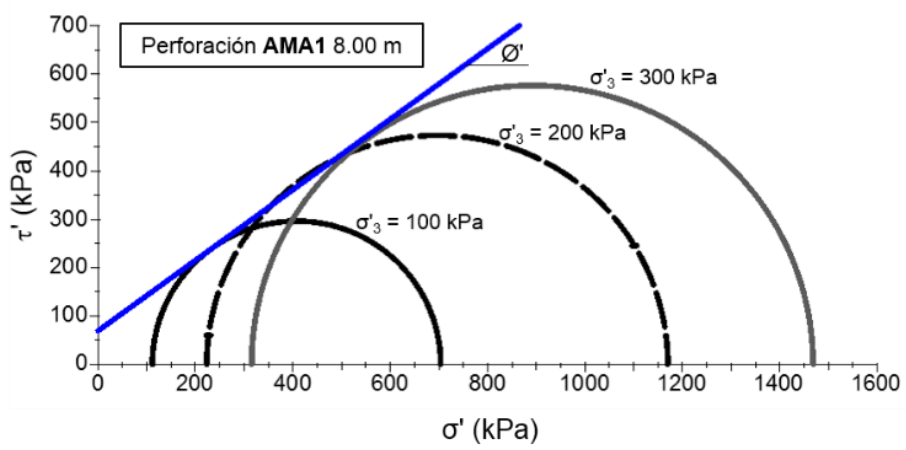

(b)

Fig. 3.26 Gráficos de esfuerzo cortante versus esfuerzo normal para el criterio de falla asumido en ensayos de compresión triaxial consolidados drenados: (a) espécimen $J A P 1$, profundidad $13.50 \mathrm{~m}, \mathrm{y}$ (b) espécimen AMA1, profundidad $8.00 \mathrm{~m}$.

En la Tabla 3.3 se presenta un resumen de los parámetros de resistencia obtenidos de los ensayos de compresión triaxial consolidados drenados $(C D)$ de los especímenes de JAPl y $A M A 1$. Las pruebas realizadas muestran un ángulo de fricción pico de $\emptyset_{\text {peak }}^{\prime} \approx 37^{\circ}$ y una cohesión efectiva $\left(c^{\prime}\right)$ comprendida entre $20 \mathrm{kPa}$ y $69 \mathrm{kPa}$.

Tabla 3.3 Parámetros de resistencia al corte drenado para muestras de perforaciones JAP1 y AMA1.

\begin{tabular}{|c|c|c|c|c|c|c|c|}
\hline \multicolumn{2}{|c|}{ Ensayo } & Presión de célula & .. $\bar{\sigma}$ & $\mathrm{W}_{\text {nat }}$ & $\gamma / \gamma_{\mathrm{d}}$ & & \\
\hline Perforación & Prof. [m] & {$[\mathrm{kPa}]$} & $\stackrel{\tilde{g}}{\vec{E}}$ & {$[\%]$} & {$\left[\mathrm{kN} / \mathrm{m}^{3}\right]$} & {$[\mathrm{kPa}]$} & {$\left[{ }^{\circ}\right]$} \\
\hline$A M A 1$ & 8.00 & $100,200,300$ & $C D$ & 16 & $20.3 / 17.5$ & 69 & 36.1 \\
\hline JAP1 & 13.50 & $50,100,200,300$ & $C D$ & 31 & $19.1 / 14.6$ & 20 & 36.9 \\
\hline
\end{tabular}




\subsection{Parámetros de deformación}

Los parámetros básicos de deformación se pueden derivar de las curvas esfuerzo deformación unitaria axial, $q-\varepsilon_{s}$, así como los módulos de elasticidad drenado, $E_{i}$, y no drenado, $E_{u i}$, y el módulo secante al $50 \%$ del esfuerzo de falla, $E_{50}$. Duncan y Chang (1970) introdujeron una relación de esfuerzos de falla de $R_{f}=\left(\sigma_{1}-\sigma_{3}\right)_{f} /\left(\sigma_{1}\right.$ $\left.\sigma_{3}\right)_{u l t}$, porque $\left(\sigma_{1}-\sigma_{3}\right)_{f}$ es generalmente menor que $\left(\sigma_{l}-\sigma_{3}\right)_{u l t}$, donde $\left(\sigma_{l}-\sigma_{3}\right)_{f}$ es el esfuerzo desviador a la falla, y $\left(\sigma_{l}-\sigma_{3}\right)_{u l t}$ es el último valor asintótico del esfuerzo desviador en la prueba triaxial.

La relación entre estos diferentes parámetros se puede ver en Plaxis (2020). A modo de ejemplo, el parámetro $E_{50}$, es el módulo de rigidez secante dependiente del esfuerzo de confinamiento, para carga primaria y se obtiene, por:

$$
E_{50}=E_{50}^{r e f}\left(\frac{c^{\prime} \cos \emptyset^{\prime}-\sigma_{3}^{\prime} \operatorname{sen} \emptyset^{\prime}}{c^{\prime} \cos \emptyset^{\prime}+p^{r e f} \operatorname{sen} \emptyset^{\prime}}\right)^{m}
$$

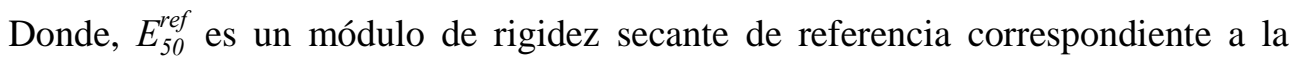
presión de confinamiento de referencia $p^{r e f}$ y $m$ es la relación de dependencia de esfuerzos en el comportamiento de rigidez, mientras que $E_{i}^{r e f}$ es una referencia para el módulo de rigidez drenado y $E_{u i}^{r e f}$ es una referencia para el módulo de rigidez no drenado.

Los parámetros de deformación obtenidos de las trayectorias de tensiones para una presión de referencia $p^{r e f}$ de $100 \mathrm{kPa}$ para los ensayos de compresión triaxial consolidados no drenados $(C U)$ se proporcionan en la Tabla 3.4. Mientras que en la Tabla 3.5 se muestran los parámetros de deformación para los ensayos de compresión triaxial consolidados drenados $(C D)$.

Tabla 3.4 Parámetros de deformación de trayectorias de tensiones controladas de ensayos triaxiales tipo $C U$ de muestras de sondeos JAPl y $A M A 1$.

\begin{tabular}{|c|c|c|c|c|c|c|c|c|}
\hline \multicolumn{2}{|c|}{ Ensayo } & \multicolumn{3}{|c|}{ Módulo Tangente } & \multicolumn{2}{|c|}{ Módulo Secante } & \multirow{3}{*}{$E_{u i}^{r e f} / E_{50(u)}^{r e f}$} & \multirow{3}{*}{$\begin{array}{l}R_{f} \\
{[-]}\end{array}$} \\
\hline Perforación & Prof. & $p^{r e f}$ & $E_{u i}^{r e f}$ & $m$ & $E_{50(u)}^{r e f}$ & $m$ & & \\
\hline & {$[\mathrm{m}]$} & {$[\mathrm{kPa}]$} & {$[\mathrm{kPa}]$} & {$[-]$} & {$[\mathrm{kPa}]$} & {$[-]$} & & \\
\hline JAPI & 3.50 & 100 & 20000 & 1.20 & 7353 & 1.54 & 2.72 & 0.98 \\
\hline$A M A 1$ & 4.50 & 100 & 41667 & 0.81 & 11364 & 1.27 & 3.67 & 0.92 \\
\hline$A M A 1$ & 6.00 & 100 & 55556 & 1.05 & 45455 & 1.11 & 1.22 & 0.99 \\
\hline$J A P 1$ & 7.50 & 100 & 32258 & 0.73 & 14085 & 1.11 & 2.29 & 0.97 \\
\hline$J A P 1$ & 9.00 & 100 & 51020 & 0.90 & 12500 & 0.80 & 4.08 & 0.75 \\
\hline$J A P 1$ & 11.00 & 100 & 52632 & 1.21 & 21277 & 0.93 & 2.47 & 0.92 \\
\hline JAPI & 14.50 & 100 & 41379 & 0.73 & 18462 & 0.96 & 2.24 & 0.91 \\
\hline
\end{tabular}


La Tabla 3.4 muestra que $E_{u i}^{r e f}$ varía de $20000 \mathrm{kPa}$ a $55556 \mathrm{kPa}$. Los valores de $m$ correspondientes a $E_{u i}^{r e f}$ oscilan entre 0.73 a 1.21 . En contraste, $E_{50(u)}^{r e f}$ varía de 7353 $\mathrm{kPa}$ a $45455 \mathrm{kPa}$, y los correspondientes valores de $m$ oscilan entre 0.80 a 1.54 . Las relaciones de $E_{u i}^{r e f} / E_{50(u)}^{r e f}$ están en el rango de 1.22 a 4.08 , con un valor promedio de 2.67. Finalmente, los valores de $R_{f}$ varían entre 0.75 a 0.99 .

Tabla 3.5 Parámetros de deformación de ensayos triaxiales tipo $C D$ de muestras de sondeos JAPl y AMA1.

\begin{tabular}{|c|c|c|c|c|c|c|c|c|}
\hline Ens & & & Módulo & gente & Módul & ecante & & \\
\hline \multirow{2}{*}{ Perforación } & Prof. & $p^{r e f}$ & $E_{i}^{r e f}$ & $m$ & $E_{50}^{r e f}$ & $m$ & \multirow{2}{*}{$E_{i}^{r e f} / E_{50}^{r e f}$} & \multirow{2}{*}{$\begin{array}{l}R_{f} \\
{[-]}\end{array}$} \\
\hline & {$[\mathrm{m}]$} & {$[\mathrm{kPa}]$} & {$[\mathrm{kPa}]$} & {$[-]$} & {$[\mathrm{kPa}]$} & {$[-]$} & & \\
\hline JAP1 & 13.50 & 100 & 25000 & 0.60 & 16815 & 0.59 & 1.49 & 0.99 \\
\hline$A M A 1$ & 8.00 & 100 & 85714 & 0.60 & 32370 & 0.60 & 2.65 & 0.99 \\
\hline
\end{tabular}

La Tabla 3.5 muestra que $E_{i}^{r e f}$ varía de $25000 \mathrm{kPa}$ a $85714 \mathrm{kPa}$. El valor de $m$

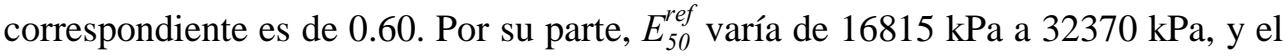
valor respectivo de $m$ oscila entre 0.59 y 0.60 . La relación de $E_{i}^{r e f} / E_{50}^{\text {ref }}$ está en el rango de 1.49 a 2.65 , con un valor promedio de 2.07 . Finalmente, el valor de $R_{f}$ está en el rango de 0.99 .

\subsection{Conclusiones relativas a la caracterización geotécnica de la zona de estudio}

En este capítulo se ha realizado un estudio de caracterización geotécnica de la zona centro-norte de la ciudad de Quito, basado en ensayos de campo, con la consecuente recuperación de muestras alteradas e inalteradas y una campaña completa de ensayos de laboratorio realizados principalmente en el Laboratorio de Mecánica de Suelos del Departamento de Ingeniería del Terreno de la Universitat Politècnica de València. Los parámetros geotécnicos obtenidos en este estudio serán utilizados posteriormente en la fase de modelación numérica de las estructuras de contención objeto del estudio experimental y numérico de esta investigación.

En función de los ensayos realizados se pueden mencionar las siguientes conclusiones:

El subsuelo en la zona norte de la ciudad de Quito está constituido por suelos volcánicos que contienen limos y acillas de baja a alta plasticidad y un contenido de materia orgánica que varía entre $0.35 \%$ y $3.61 \%$. Está compuesto principalmente por anortita, augita, tremolita, cristobalita, albita, diópsido, cuarzo, clinoenstatita y clorita; sin embargo, también se identificaron en menores proporciones pirita, calcita, biotita, montmorillonita y caolinita. 


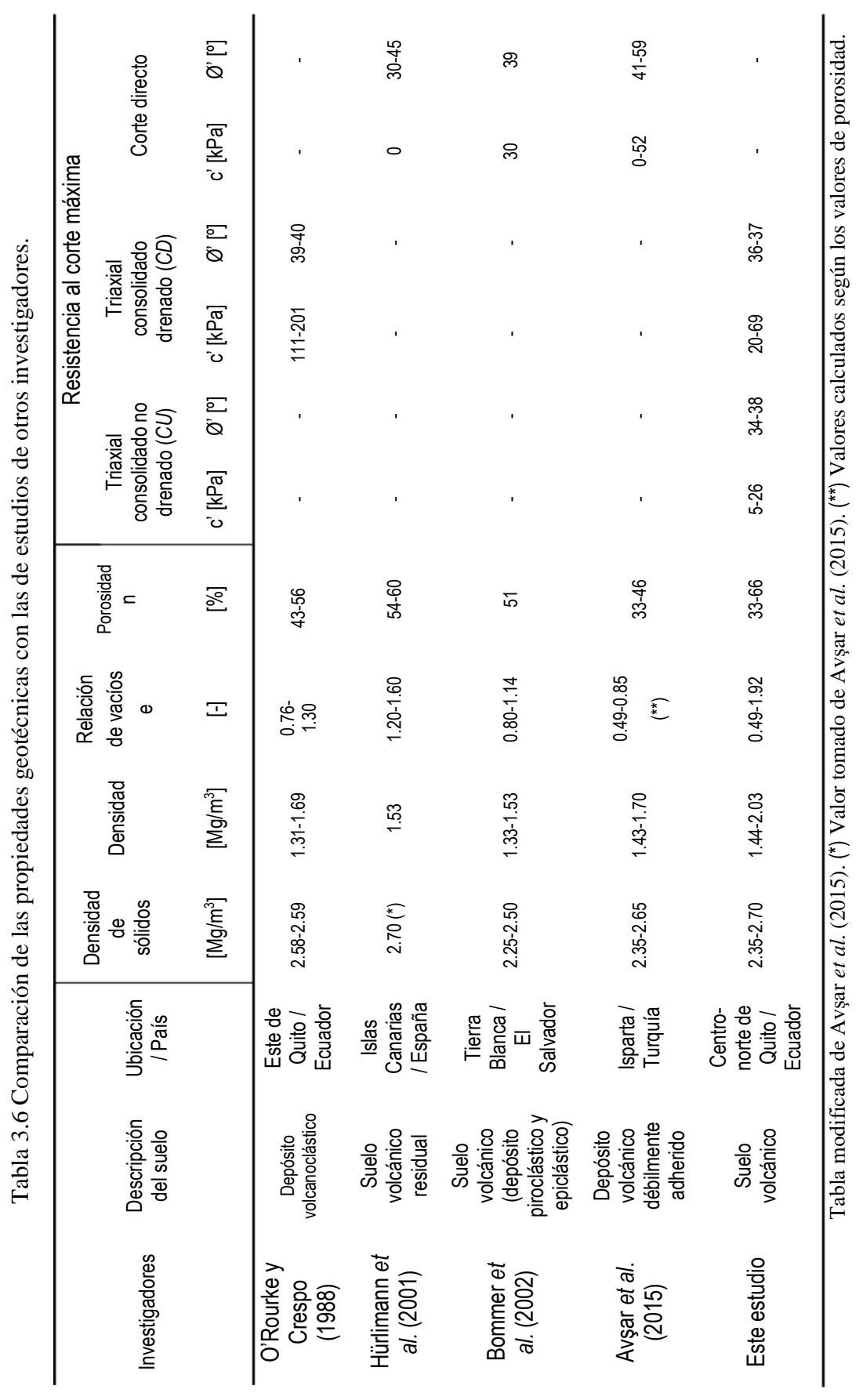


En general, se han podido identificar de manera clara en determinados especímenes valores bajos de densidad y densidad de partículas sólidas. Algunas imágenes de los ensayos de microscopía electrónica (SEM) muestran la presencia de burbujas de gas y materia orgánica, lo cual podría ser la principal razón de dichos valores bajos de densidad. Adicionalmente Crosta et al. (2005) explica estos valores bajos por la presencia de pómez y elementos vesiculares con poros no comunicantes o por la presencia de cenizas o fragmentos de vidrio. Por otra parte, de manera general se determinaron valores altos de relación de vacíos y de porosidad, los cuales están dentro del rango de valores de aquellos suelos volcánicos estudiados por O'Rourke y Crespo (1988), Hürlimann et al. (2001), Bommer et al. (2002) y Avşar et al. (2015). La Tabla 3.6 muestra los rangos de valores obtenidos y su similitud con los datos establecidos en los estudios anteriores.

Se determinó que los suelos estudiados son ligeramente sobreconsolidados con relaciones de sobreconsolidación $(O C R)$ oscilando entre 1.29 y 1.69 a profundidades comprendidas entre $3.0 \mathrm{~m}$ y $15.0 \mathrm{~m}$.

La resistencia al corte drenada y no drenada obtenidas de los ensayos de laboratorio, en realidad podría ser menor a los verdaderos valores in situ, ya que la alteración del suelo causada por el proceso de muestreo con tubos de pared delgada no puede ser completamente evitada. Y la razón principal de esta alteración es el alivio de tensiones totales durante el proceso de muestreo.

En los ensayos de compresión triaxial, la máxima relación de esfuerzos $\sigma_{1}^{\prime} / \sigma_{3}^{\prime}$, como criterio de falla proporciona una mejor correlación en el momento de la falla entre el esfuerzo de corte y el esfuerzo normal en los círculos de esfuerzos de Mohr, para estimar la resistencia al corte de los suelos.

En general, el ángulo de fricción pico $\left(\varnothing^{\prime}{ }_{\text {peak }}\right)$ obtenido en los ensayos de compresión triaxial consolidados no drenados muestra un valor mínimo de $33.7^{\circ}$ a la profundidad de $3.5 \mathrm{~m}$ y aumenta gradualmente con la profundidad a $38.0^{\circ}$ a $14.5 \mathrm{~m}$. Por tanto, se han identificado claramente dos grupos con parámetros de resistencia al corte no drenada. Entre $3.5 \mathrm{~m}$ y $7.5 \mathrm{~m}$ los valores de $\emptyset_{\text {peak }}^{\prime}$ medidos varían entre $33.7^{\circ}$ a $34.8^{\circ}$ y con valor promediado de $35.0^{\circ}$. A profundidades entre $9.0 \mathrm{~m}$ y $14.5 \mathrm{~m}$ los valores de $\emptyset_{\text {peak }}^{\prime}$ medidos se encuentran en el rango de $37.1^{\circ}$ y $38.0^{\circ}$ y con un valor promedio de $38.0^{\circ}$. Por otra parte, el ángulo de fricción pico $\left(\varnothing_{\text {peak }}^{\prime}\right)$ obtenido en los ensayos de compresión triaxial consolidados drenados presenta valores comprendidos entre $36.1^{\circ}$ y $36.9^{\circ}$ para profundidades entre $8.0 \mathrm{~m}$ y $13.5 \mathrm{~m}$. Los valores del ángulo de fricción coinciden con aquellos de los suelos volcánicos investigados por O'Rourke y Crespo (1988) y Hürlimann et al. (2001). Los valores de cohesión obtenidos en el presente estudio demuestran estar en el rango de los correspondientes a los suelos volcánicos estudiados por Avşar et al. (2015), como puede verse en la Tabla 3.6. 


\section{Capítulo 4}

\section{PLANTEAMIENTO DEL ESTUDIO EXPERIMENTAL}

\subsection{Introducción}

En este capítulo se detalla el programa de la parte experimental de esta investigación. Esta etapa inicia con el proceso de búsqueda y selección de 2 proyectos de construcción de edificaciones reales en el centro-norte de la ciudad de Quito (Ecuador) y que incluyan muros de sótano de 5 niveles, puesto que al tratarse de estructuras de contención de tierras de más de $13 \mathrm{~m}$ de altura en su fase más crítica requieren necesariamente de un sistema de anclajes al terreno. Y por otra parte las características de este tipo de estructuras seleccionadas para este estudio reúnen las condiciones apropiadas para ser consideradas como objeto de esta investigación.

Por tanto, en este capítulo se describe el proceso de instrumentación y monitorización implementados en cada estructura de muro de anclado durante sus fases constructivas, empezando por el primer sótano superficial hasta llegar al quinto nivel subterráneo, procedimientos que debieron ejecutarse de manera simultánea a los avances de la empresa constructora propietaria de los proyectos de edificación y que dio las facilidades para implementar estos procedimientos de investigación.

En la primera parte se detalla la ubicación, características y tipo de estructuras seleccionadas para este estudio. Luego se identifican las variables o parámetros que caracterizan al comportamiento de este tipo de estructuras de muro anclado, para seguidamente pasar a describir el tipo de ensayos, actividades necesarias y metodología aplicada en el programa experimental. Para el proceso de 
instrumentación y monitorización se adoptaron las recomendaciones de la guía "Soil Nail Walls - Reference Manual" de la Federal Highway Administration (FHWA, 2015). Todo proceso de instrumentación y monitorización en obras de ingeniería geotécnica y estructural requiere el uso de accesorios y equipos y sistemas de adquisición de datos. Esta investigación no es la excepción. Por tanto, en este capítulo se describen las características de los sensores y equipos electrónicos utilizados en esta parte experimental. Los resultados obtenidos para cada una de las variables en esta etapa experimental, serán expuestos en el Capítulo 6 y comparados con diferentes procedimientos teóricos de cálculo expuestos en el Capítulo 5.

\subsection{Descripción de las estructuras}

Para los procesos de instrumentación y monitorización en el estudio experimental del comportamiento de muros anclados, se tuvo las facilidades para acceder a la fase de construcción de sótanos de 2 importantes y modernos proyectos de edificación localizados en la zona centro-norte de la ciudad de Quito.

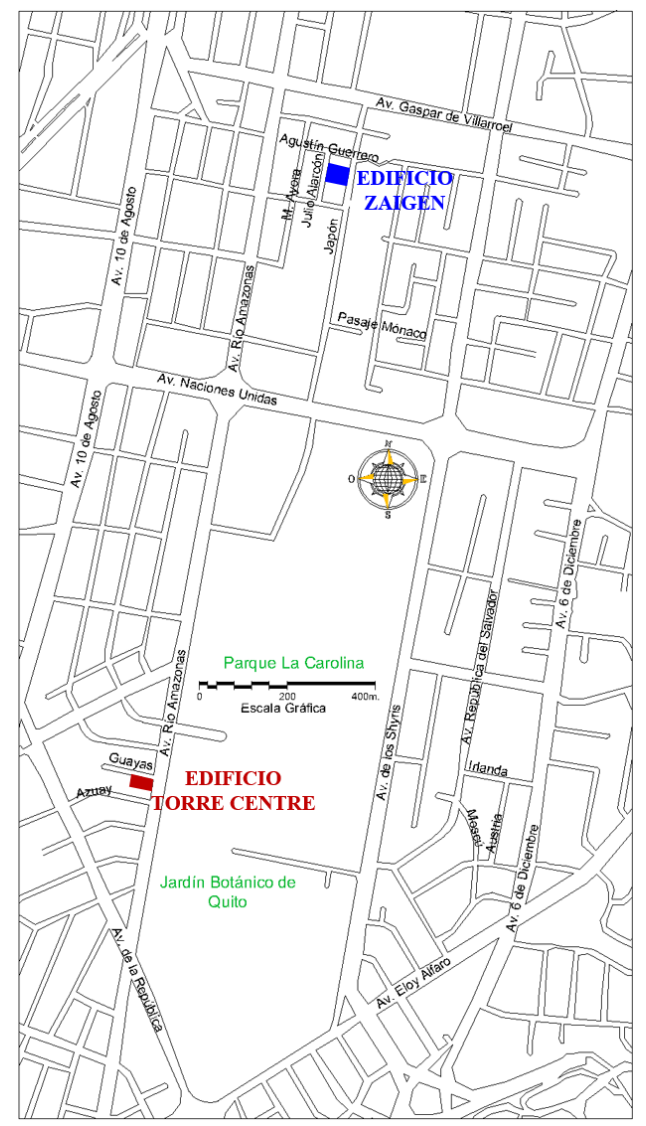

Fig. 4.1 Ubicación de estructuras para instrumentación y monitorización. 

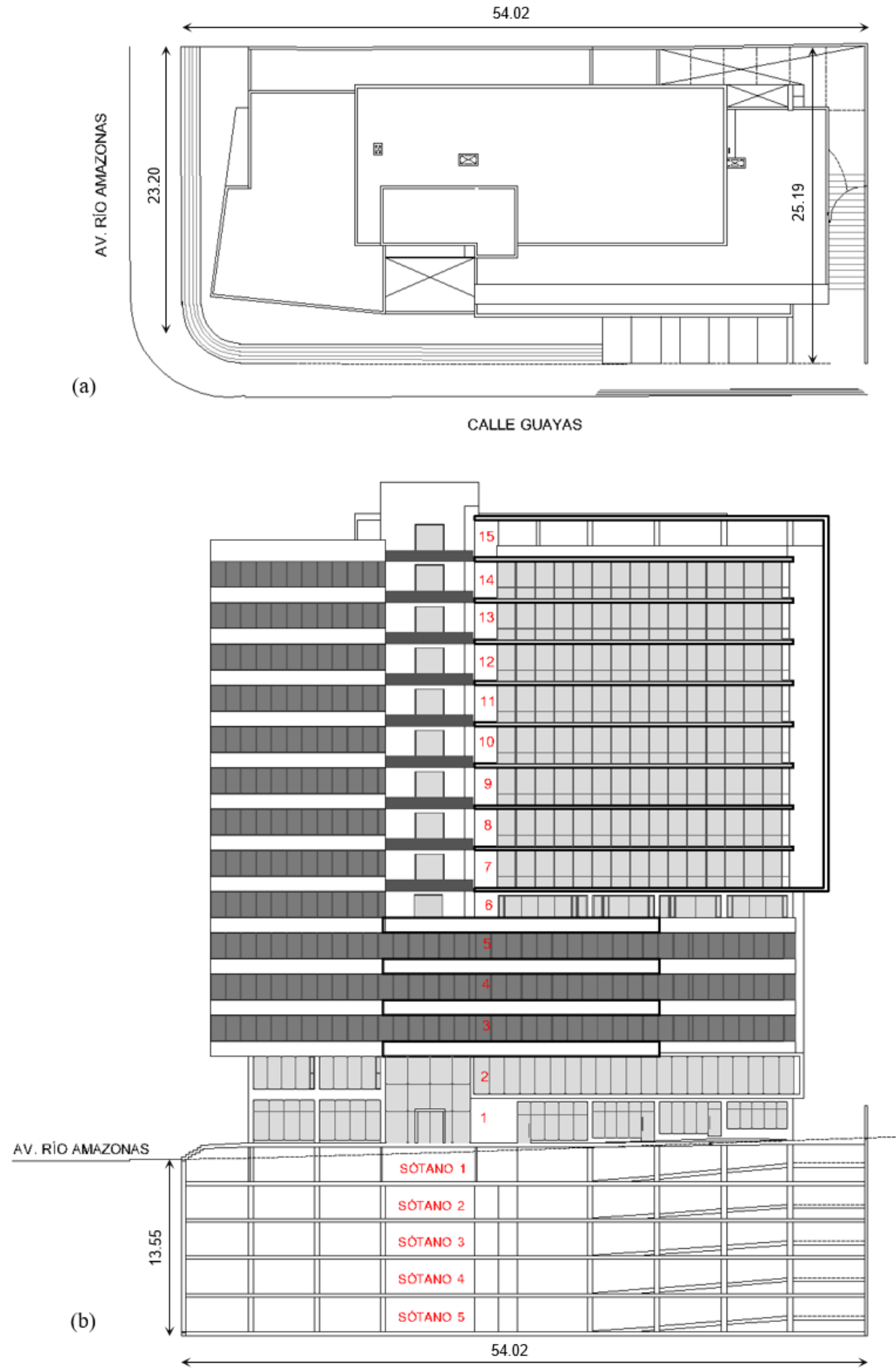

Fig. 4.2 Edificio Torre Centre: (a) Implantación - vista en planta, y (b) Elevación principal. 
(a)
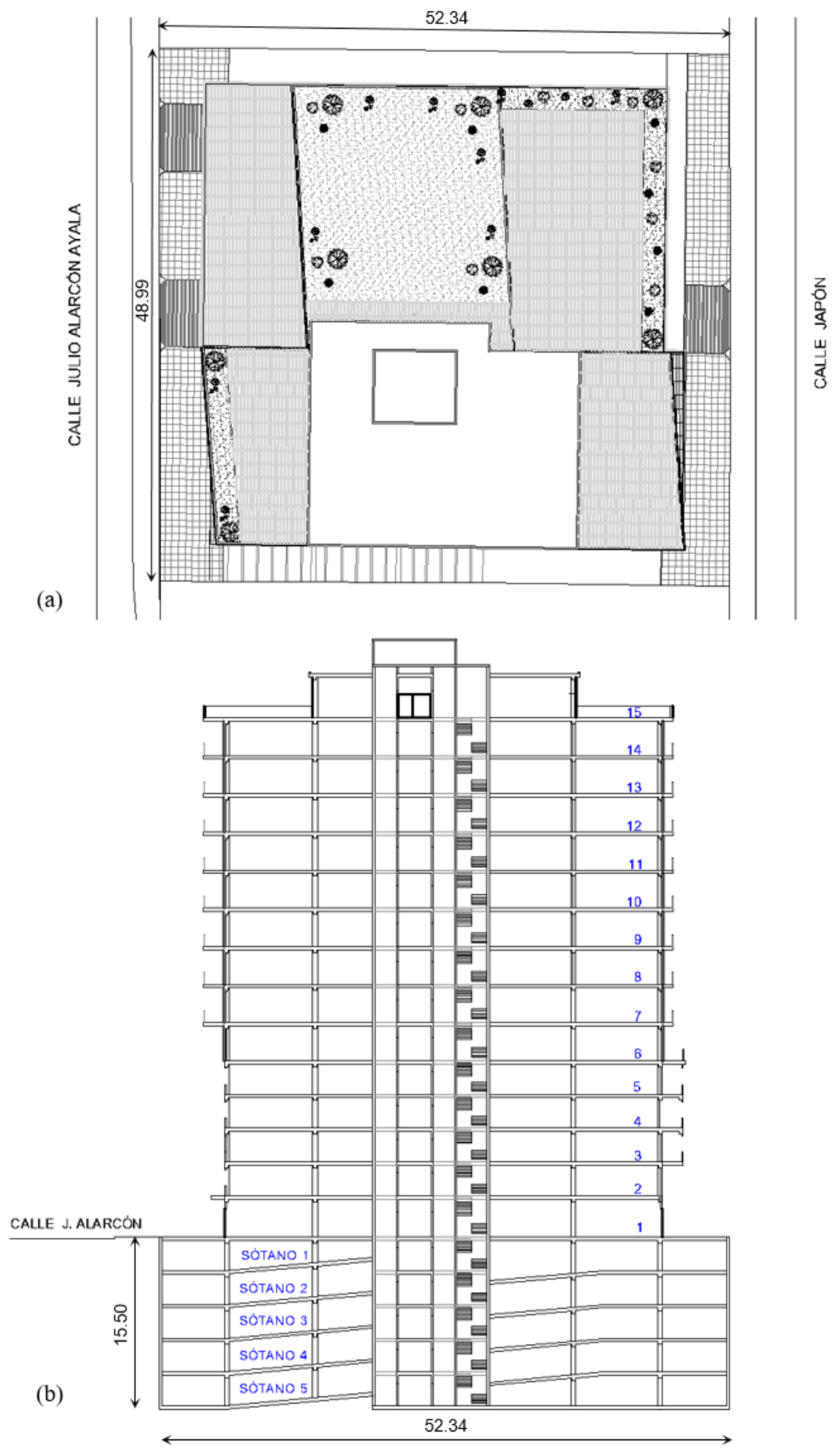

Fig. 4.3 Edificio Zaigen: (a) Implantación - vista en planta, y (b) Corte principal. 
El primer proyecto seleccionado y al que se tuvo acceso se denomina Torre Centre y se ubica en la Av. Río Amazonas y calle Guayas (Ver ubicación en Fig. 4.1). Este edificio de estructura principal de hormigón armado se caracteriza por tener 15 pisos principales destinados a oficinas y 5 niveles de sótanos para aparcamiento vehicular, llegando a alcanzar una profundidad total de excavación de $13.55 \mathrm{~m}$, medidos desde el nivel de acera (Ver Fig. 4.2). La construcción de este proyecto se llevó a cabo entre los años 2016 y 2018. La ubicación de Torre Centre coincide con el sondeo de perforación $A M A 1$ que se realizó previamente y de manera planificada como parte del estudio de caracterización geotécnica de esta investigación (Capítulo 3).

Por otra parte, el segundo proyecto se denomina Zaigen y se localiza en las calles Julio Alarcón y Agustín Guerrero (Ver ubicación en Fig. 4.1). De manera similar este proyecto también de estructura de hormigón armado incluye 15 pisos principales con uso destinado a oficinas y 5 niveles de sótanos, cuya altura de excavación total es de $15.50 \mathrm{~m}$, medidos desde la cota de la acera (Ver Fig. 4.3). La construcción de Zaigen se llevó a cabo durante los años 2017 y 2020. En este caso, la implantación de esta edificación coincide con el sondeo de perforación $J A P 1$, que se realizó inicialmente y de manera simultánea como parte del estudio geotécnico para este proyecto de construcción y del estudio de caracterización geotécnica de esta investigación (Capítulo 3).

De esta manera, y gracias a los estudios geotécnicos detallados que se realizaron en esta investigación, en ambos proyectos Torre Centre y Zaigen se disponen de parámetros geotécnicos específicos de estas zonas en particular (Capítulo 3) y que serán utilizados en el estudio del comportamiento de los respectivos muros anclados mediante diferentes procedimientos teóricos en el Capítulo 5.

\subsection{Proceso constructivo de muros de sótanos en la ciudad de Quito}

\subsubsection{Introducción}

Los muros anclados para sótanos de edificios mediante "Soil Nails" es un método de refuerzo del terreno comúnmente llamado como "Soil Nailing" que consiste básicamente en la instalación de barras de acero o "bulones" en posición subhorizontal a una determinada profundidad en los estratos de suelo y que nacen de una pantalla frontal perfectamente vertical de hormigón armado, conocida frecuentemente como "Muro" o "Facing", contribuyendo de esta manera a aumentar la estabilidad de la estructura de contención.

En la construcción de las estructuras de sótano de los edificios Torre Centre y Zaigen se aplicó la secuencia constructiva típica de los muros anclados conocidos como "Soil Nail Walls" (FHWA, 2015) adaptada a las excavaciones frecuentes para muros de sótano de varios niveles de edificaciones en la ciudad de Quito. Estos procedimientos constructivos se detallan en las secciones 4.3.2 y 4.3.3. 


\subsubsection{Secuencia constructiva de muros anclados de Torre Centre}

En esta parte se definen de manera secuencial y esquemática las diferentes fases que fueron aplicadas en la construcción de los sótanos de 5 niveles del edificio Torre Centre. Estos procesos serán modelados en el Capítulo 5 mediante diferentes procedimientos teóricos y numéricos. En el caso del edificio Torre Centre, los 5 niveles de sótano cubren una excavación total de $13.55 \mathrm{~m}$ con un muro o pantalla de concreto armado, reforzada en toda su altura con 5 filas de anclajes al terreno tipo "Soil Nails", según el diseño original de este proyecto. Por tanto, la profundidad total de corte del terreno fue lograda mediante excavaciones parciales que representan a la altura de un nivel de sótano. En este proyecto, para el hormigonado de las pantallas se utilizó un sistema de encofrados tradicionales. Por otra parte, en todos los niveles la construcción de anclajes comprende la introducción de la barra de acero en la perforación y la inyección del mortero fluido o "Grout". El proceso inicia con la excavación para la construcción del primer nivel de sótano, el cual incluye una fila de anclajes. La Fig. 4.4 muestra el proceso de construcción del muro de sótano 1.
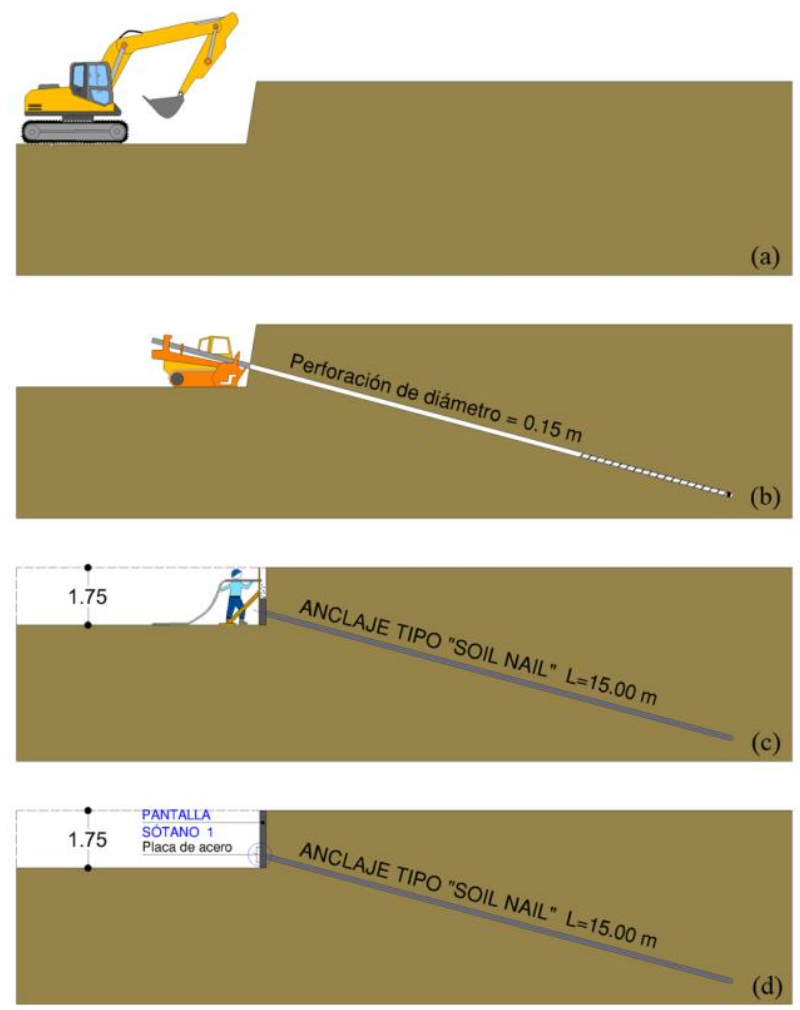

Fig. 4.4 Construcción de sótano 1 en Torre Centre: (a) Excavación, (b) Perforaciones para anclajes, (c) Construcción de anclajes, conformación vertical de talud, instalación de acero de refuerzo y hormigonado de pantalla, y (d) Instalación de placas de acero en barras de anclaje. 
Una vez terminada la construcción del muro de sótano del primer nivel con su respectiva fila de anclajes al terreno, para la construcción del sótano del segundo nivel se aplica un procedimiento similar al ejecutado anteriormente. El segundo nivel de sótano también incluye una fila de anclajes al terreno tipo "Soil Nails". La Fig. 4.5 expone el proceso de construcción del muro de sótano 2.
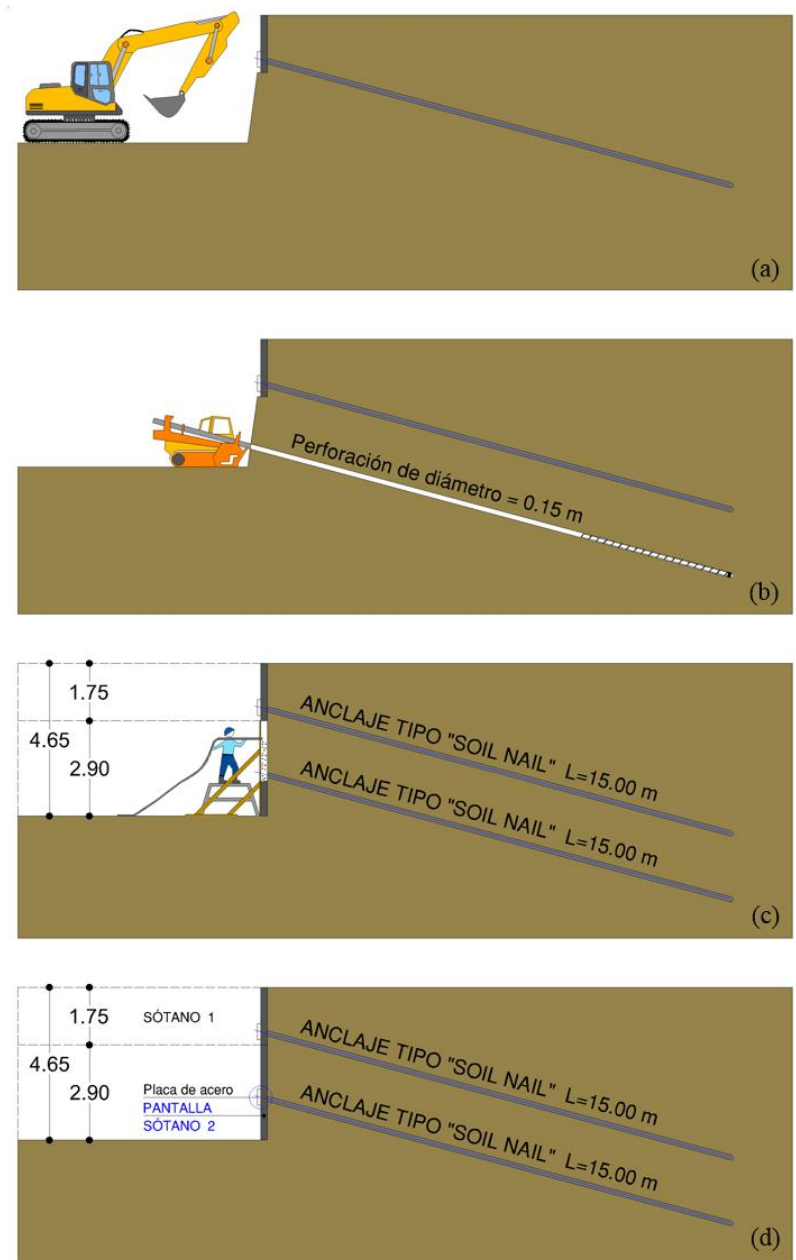

Fig. 4.5 Construcción de sótano 2 en Torre Centre: (a) Excavación, (b) Perforaciones para anclajes, (c) Construcción de anclajes, conformación vertical de talud, instalación de acero de refuerzo y hormigonado de pantalla, y (d) Instalación de placas de acero en barras de anclaje.

De igual manera, el procedimiento de construcción del tercer nivel de sótanos es similar a los 2 sótanos anteriores, en donde el tercer nivel de sótanos también incluye una fila de anclajes al terreno tipo "Soil Nails". La Fig. 4.6 muestra el proceso de construcción del sótano 3. 

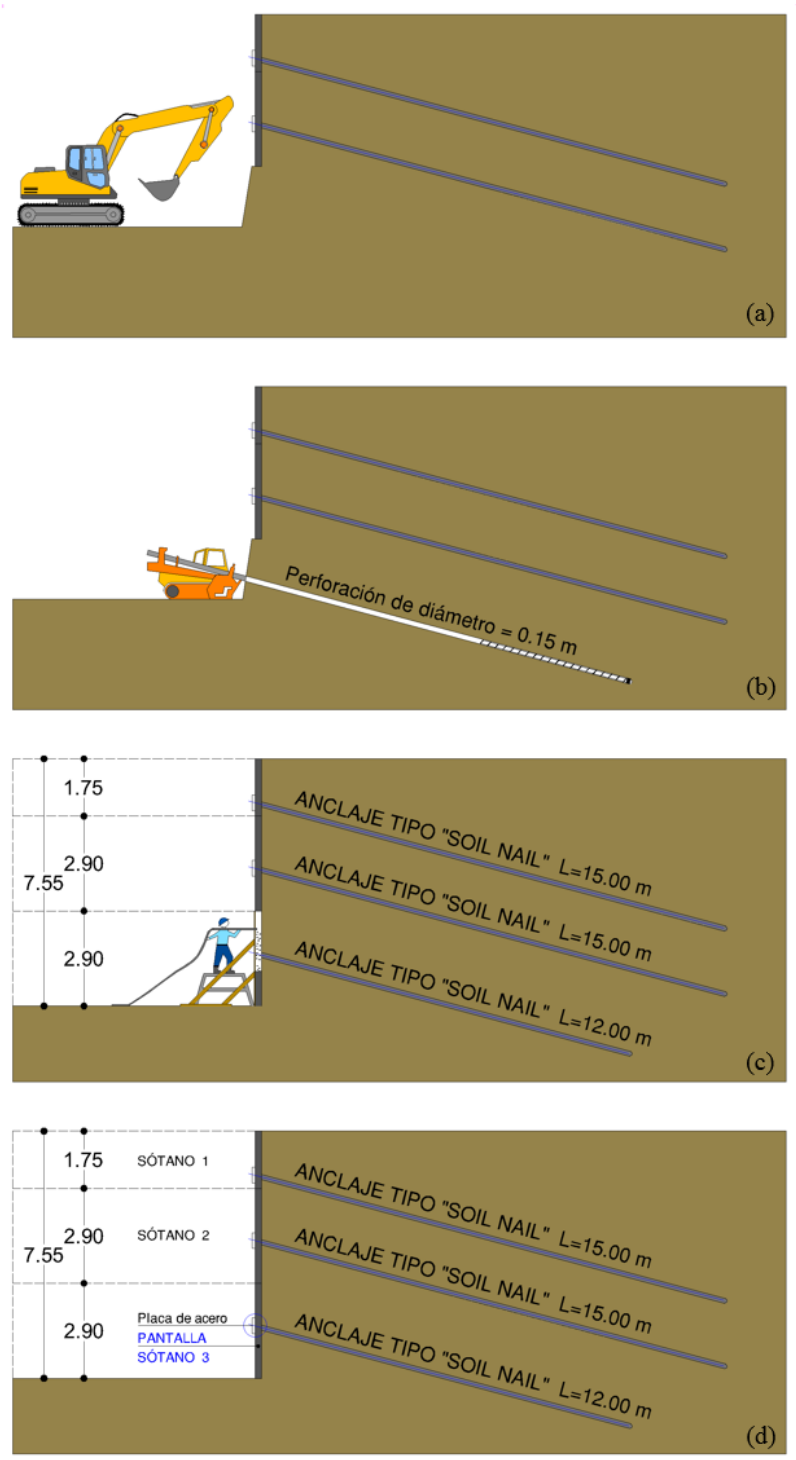

Fig. 4.6 Construcción de sótano 3 en Torre Centre: (a) Excavación, (b) Perforaciones para anclajes, (c) Construcción de anclajes, conformación vertical de talud, instalación de acero de refuerzo y hormigonado de pantalla, y (d) Instalación de placas de acero en barras de anclaje.

Posteriormente, en la construcción del cuarto nivel de sótanos, también se incluye una fila de anclajes al terreno tipo "Soil Nails" y el procedimiento constructivo es similar a los sótanos anteriores. La Fig. 4.7 indica el proceso de construcción del muro de sótano 4. 

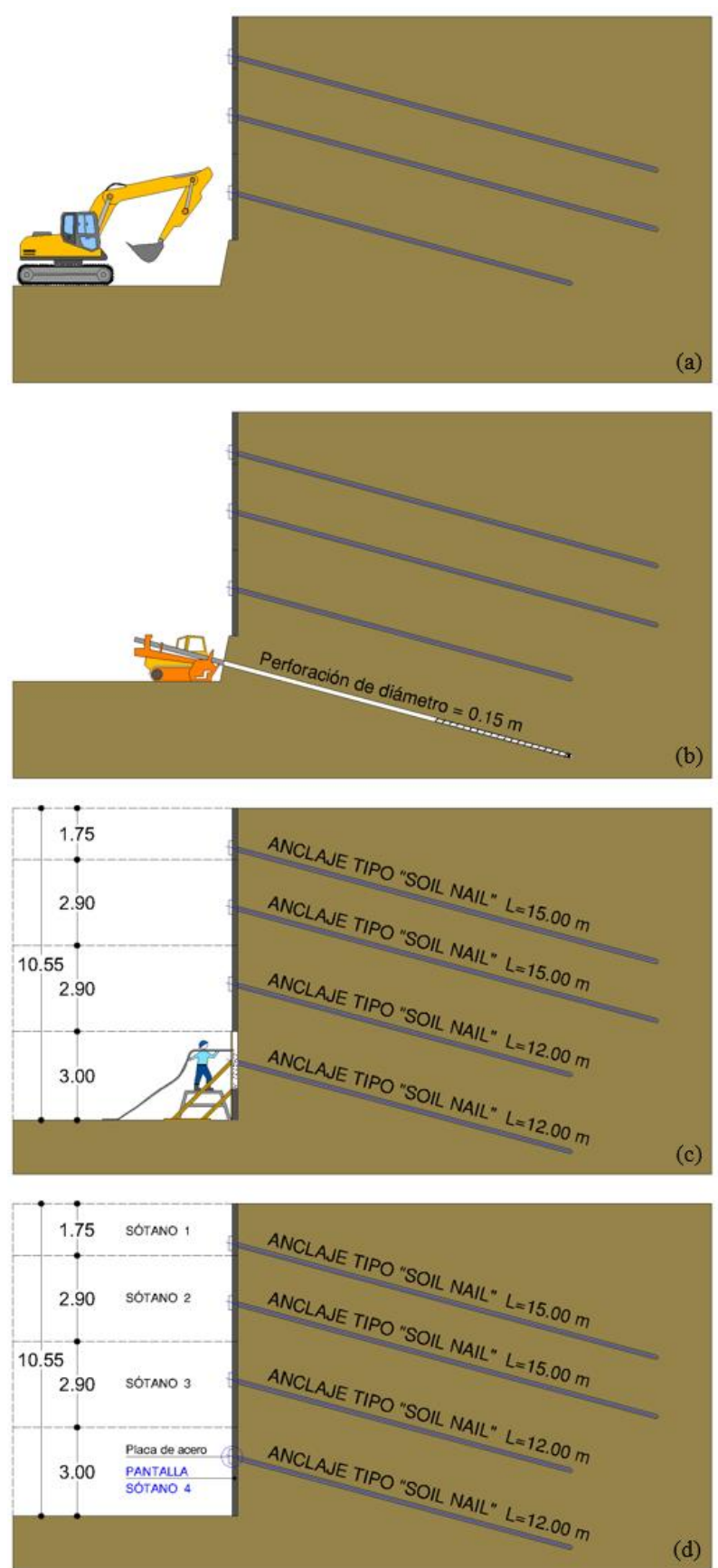

Fig. 4.7 Construcción de sótano 4 en Torre Centre: (a) Excavación, (b) Perforaciones para anclajes, (c) Construcción de anclajes, conformación vertical de talud, instalación de acero de refuerzo y hormigonado de pantalla, y (d) Instalación de placas de acero en barras de anclaje. 
El quinto nivel de sótanos también incluye una fila de anclajes y su construcción es similar. Las Fig. 4.8 y 4.9 muestran el proceso constructivo del sótano 5.
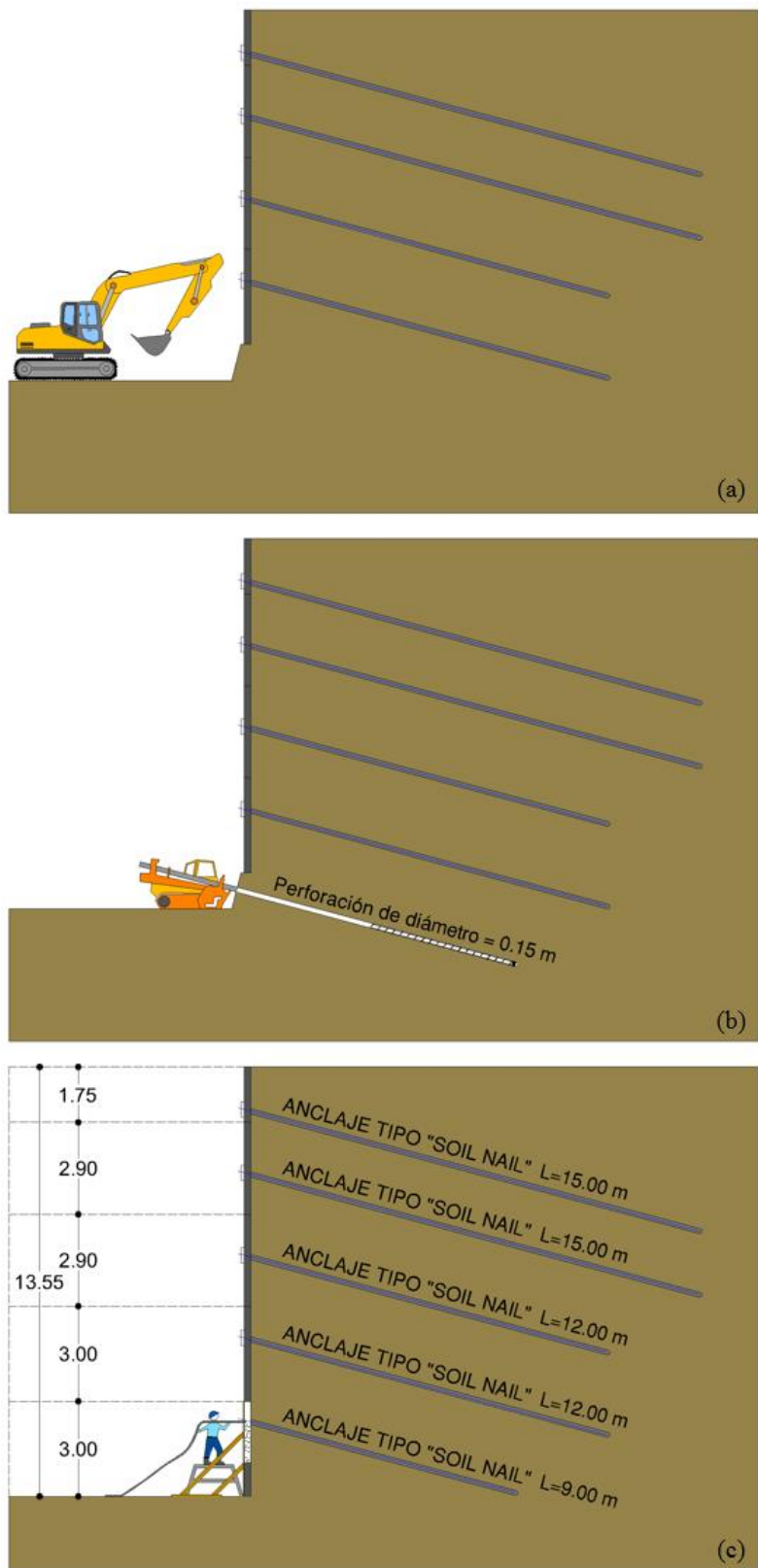

Fig. 4.8 Construcción de sótano 5 en Torre Centre: (a) Excavación, (b) Perforaciones para anclajes, y (c) Construcción de anclajes, conformación vertical de talud, instalación de acero de refuerzo y hormigonado de pantalla. 


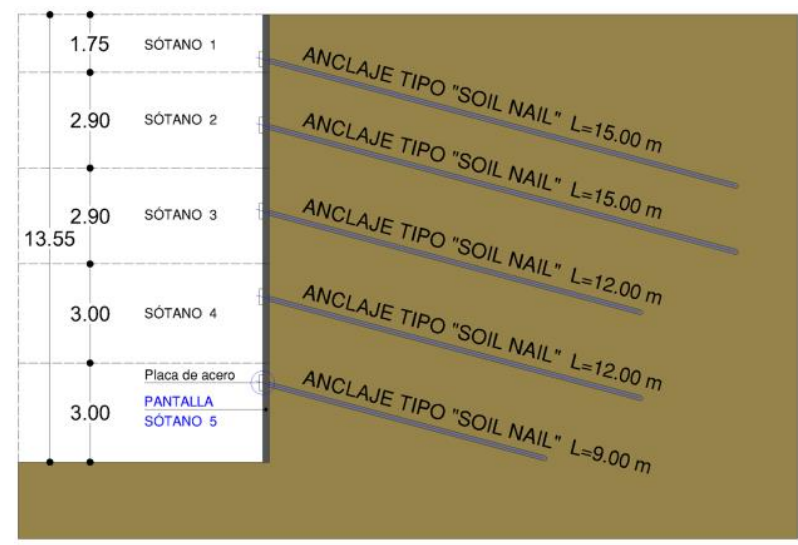

Fig. 4.9 Construcción de sótano 5 en Torre Centre: Instalación de placas de acero en barras de anclaje.

Con la construcción del sótano 5, la pantalla o muro de Torre Centre alcanza una altura acumulada de $13.55 \mathrm{~m}$, siendo esta la fase constructiva más crítica. Esta altura total posteriormente irá disminuyendo conforme se van construyendo desde abajo hacia arriba los respectivos forjados de piso, hasta llegar con el forjado final al nivel de acera. En esta instancia, se puede decir que los anclajes al terreno han terminado su función temporal, ya que las pantallas o muros quedarán perfectamente apuntaladas por los forjados de cada nivel.

\subsubsection{Secuencia constructiva de muros anclados de Zaigen}

En esta sección se identifican las fases que fueron parte de la construcción de los 5 niveles de sótanos del edificio Zaigen, las cuales se presentan de manera secuencial y gráfica. Estas fases constructivas serán modeladas luego en el Capítulo 5 mediante diferentes análisis teóricos y numéricos.

La profundidad total de corte del terreno fue alcanzada mediante excavaciones parciales, cada una de las cuales representa a la altura de un nivel de sótano, así como en el caso de los sótanos del proyecto Torre Centre. En todos los niveles de muros, la construcción de anclajes al terreno comprende la introducción del bulón o barra de acero en la perforación y la inyección del mortero fluido o "Grout". En este proyecto, para el hormigonado de cada pantalla se utilizó hormigón proyectado o "Shotcrete".

Por otra parte, todos los niveles de muros de sótanos incluyen una fila de anclajes, a excepción del cuarto nivel que contempla 2 filas. Es decir, en este caso el muro o pantalla de concreto armado incluye en toda su altura 6 filas de anclajes al terreno tipo "Soil Nails", según el diseño original de este proyecto.

Cada nivel de sótano de Zaigen implica una altura parcial de $3.10 \mathrm{~m}$, por lo que los 5 niveles de sótano representan una excavación total de $15.50 \mathrm{~m}$. 
La secuencia constructiva de muros del edificio Zaigen inicia con la excavación para la construcción del primer nivel de sótanos, el cual incluye una fila de anclajes al terreno tipo "Soil Nails". La Fig. 4.10 expone el proceso de construcción del muro de sótano 1, el cual cubre una excavación inicial de $3.10 \mathrm{~m}$, que representa a la altura del primer nivel.
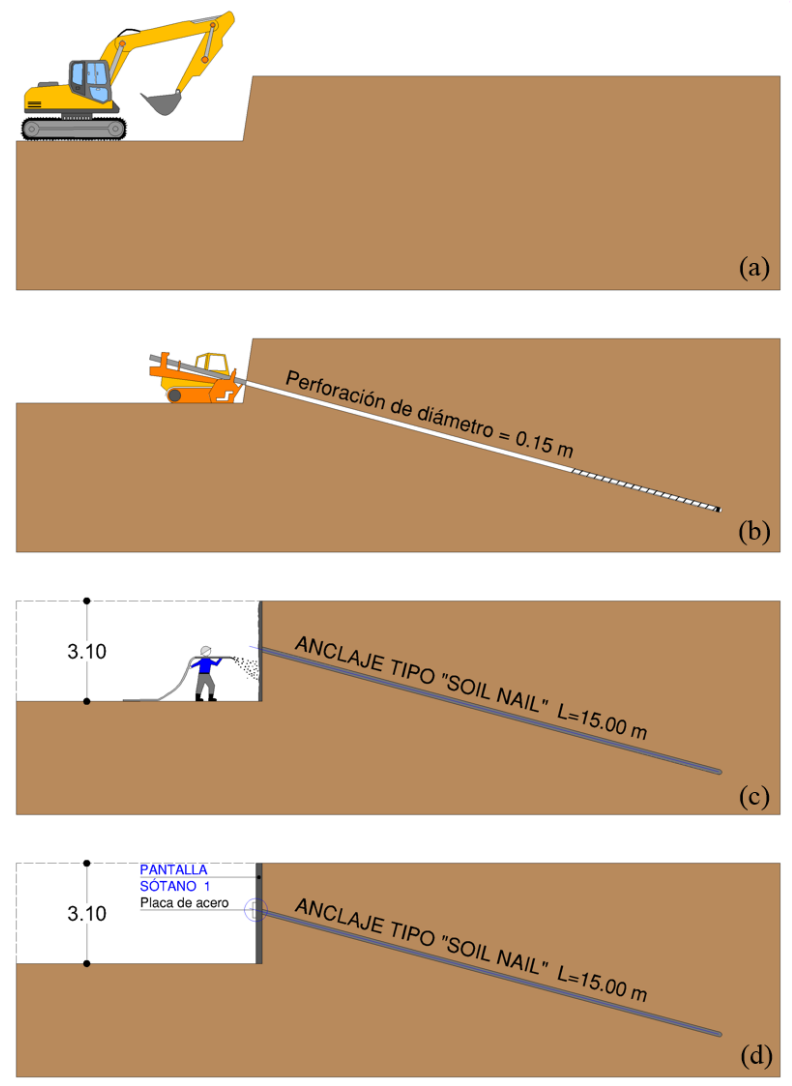

Fig. 4.10 Construcción de sótano 1 en Zaigen: (a) Excavación, (b) Perforaciones para anclajes, (c) Construcción de anclajes, conformación vertical de talud, instalación de acero de refuerzo y hormigonado de pantalla, y (d) Instalación de placas de acero en barras de anclaje.

Posterior a la construcción del primer nivel de sótano con su respectiva fila de anclajes al terreno, se aplica un procedimiento similar al anterior para la construcción del sótano del segundo nivel y el resto de niveles. El segundo nivel de sótano también incluye una fila de anclajes al terreno tipo "Soil Nails". Terminada la construcción de este nivel de sótano, la altura de la pantalla es de 6.20 m. La Fig. 4.11 muestra el proceso de construcción del muro de sótano 2. 

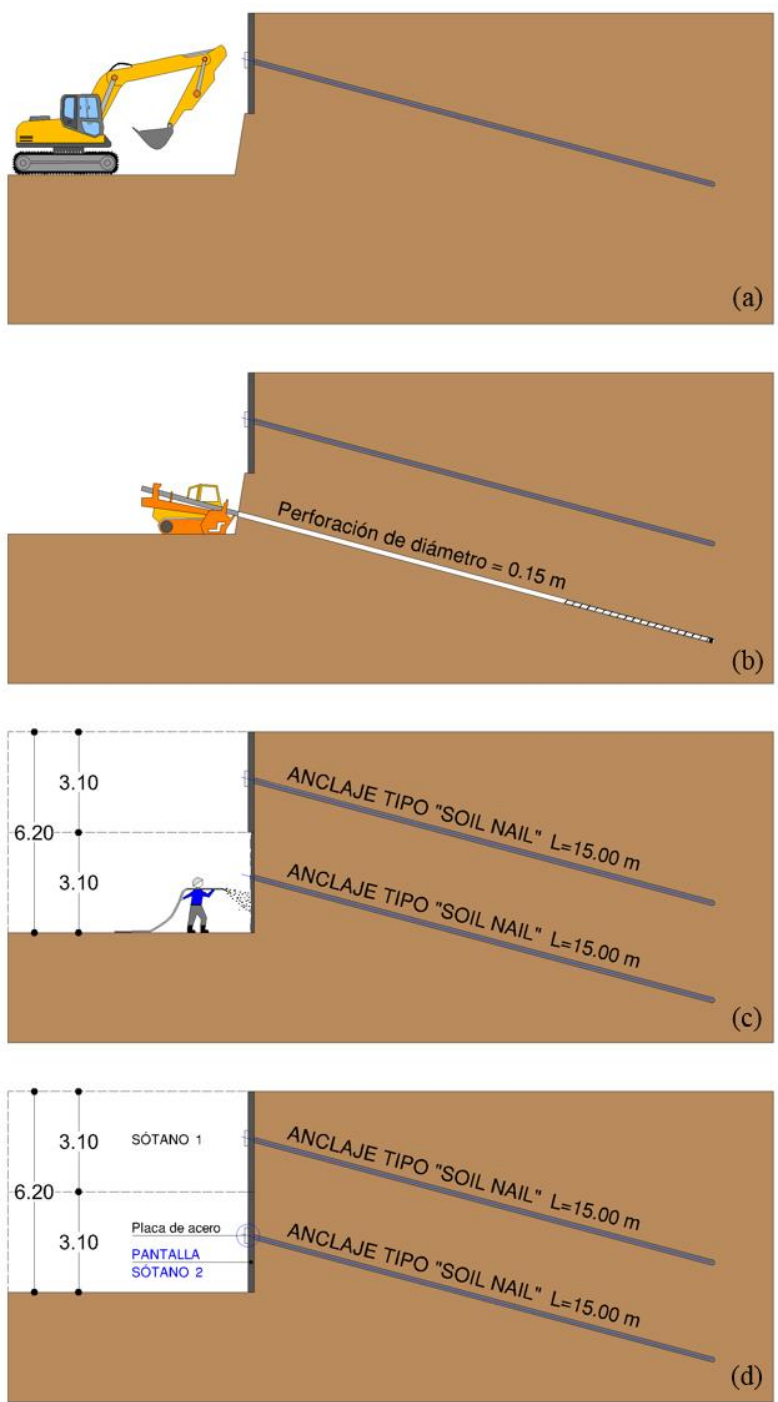

Fig. 4.11 Construcción de sótano 2 en Zaigen: (a) Excavación, (b) Perforaciones para anclajes, (c) Construcción de anclajes, conformación vertical de talud, instalación de acero de refuerzo y hormigonado de pantalla, y (d) Instalación de placas de acero en barras de anclaje.

El proceso constructivo del tercer nivel de sótanos es similar a los 2 sótanos anteriores, este nivel también incluye una fila de anclajes al terreno tipo "Soil Nails". Con la construcción de este nivel de sótano, la altura de la pantalla es de $9.30 \mathrm{~m}$. La Fig. 4.12 muestra el proceso de construcción del sótano 3. 

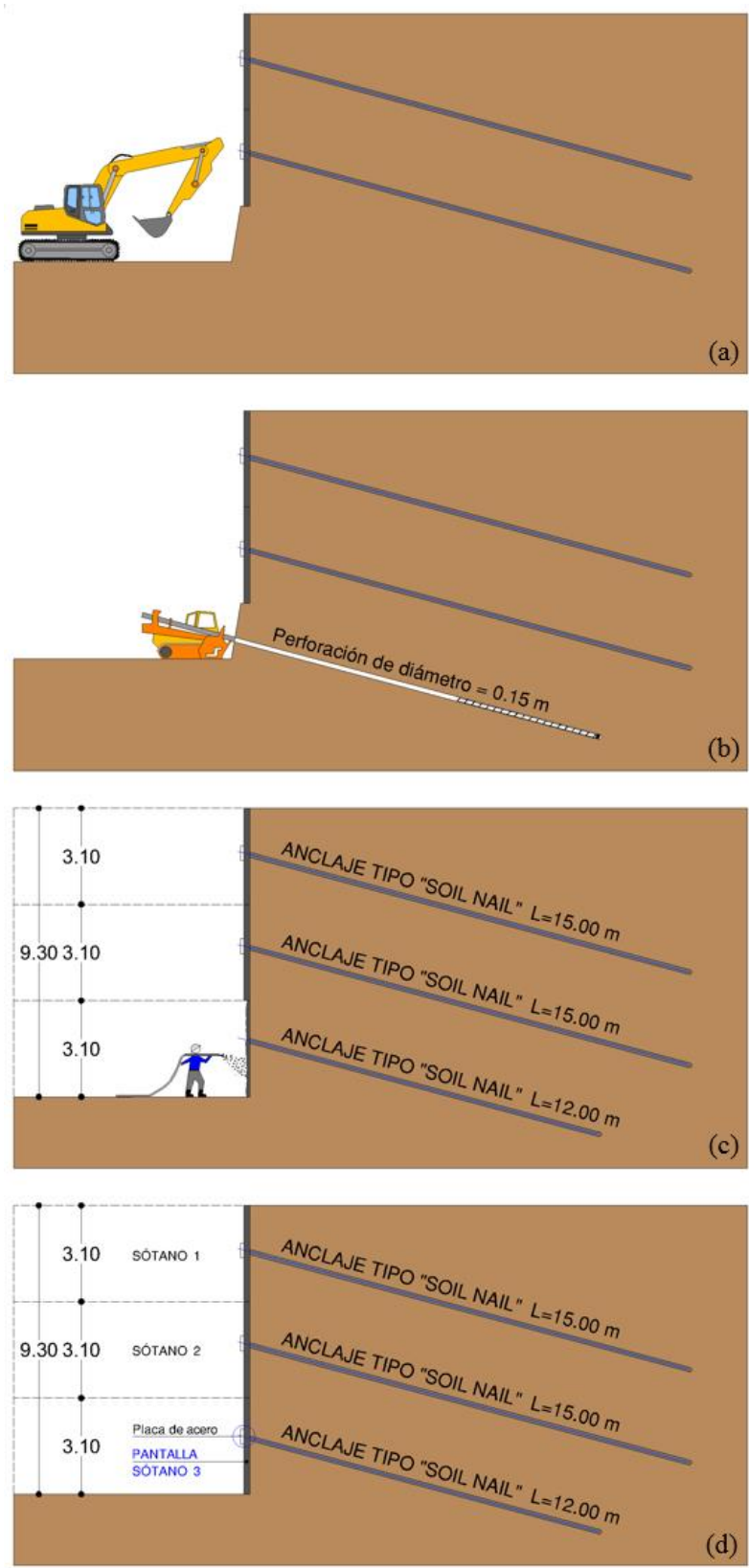

Fig. 4.12 Construcción de sótano 3 en Zaigen: (a) Excavación, (b) Perforaciones para anclajes, (c) Construcción de anclajes, conformación vertical de talud, instalación de acero de refuerzo y hormigonado de pantalla, y (d) Instalación de placas de acero en barras de anclaje.

Por otra parte, el cuarto nivel de sótanos incluye dos filas de anclajes al terreno. Las Fig. 4.13 y 4.14 muestran el proceso de construcción del sótano 4. 

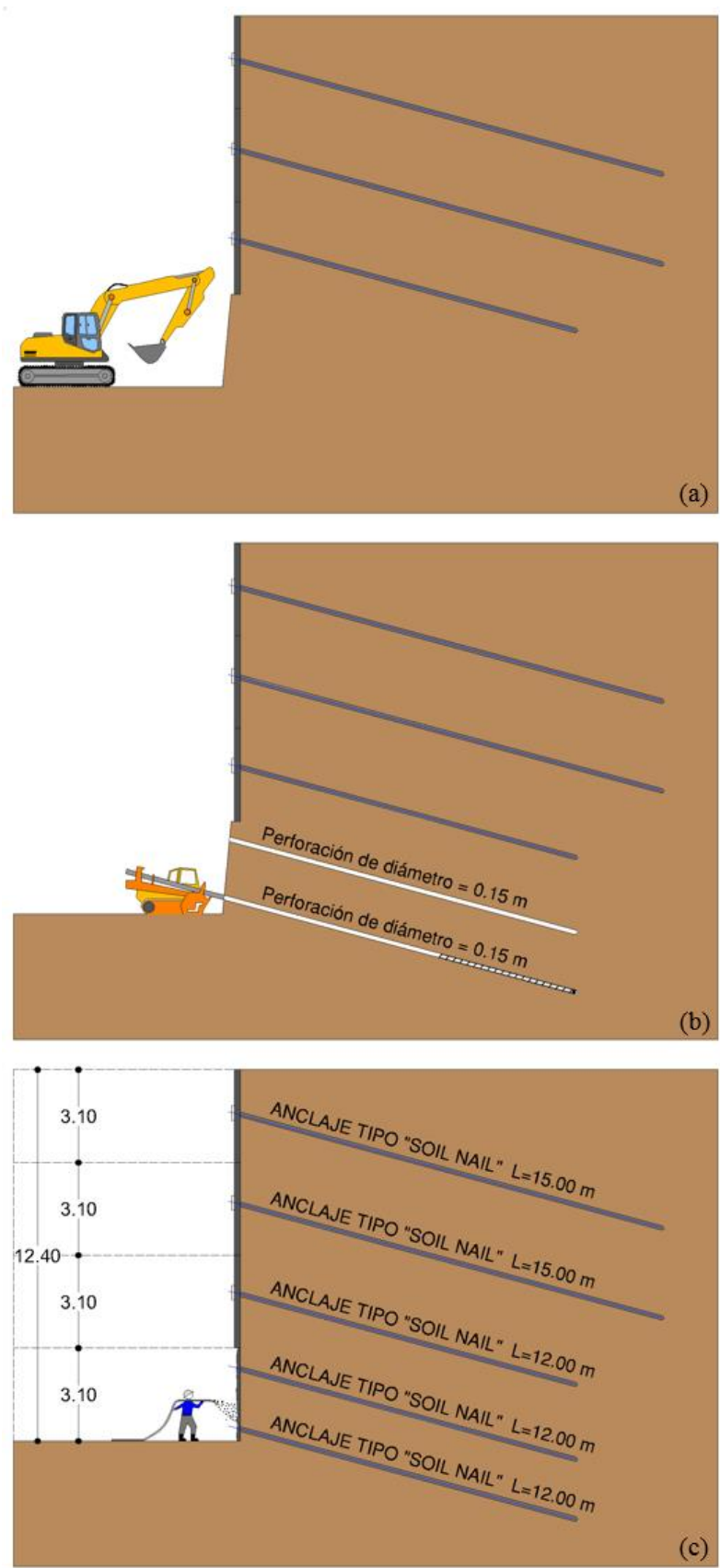

Fig. 4.13 Construcción de sótano 4 en Zaigen: (a) Excavación, (b) Perforaciones para anclajes, (c) Construcción de anclajes, conformación vertical de talud, instalación de acero de refuerzo y hormigonado de pantalla. 


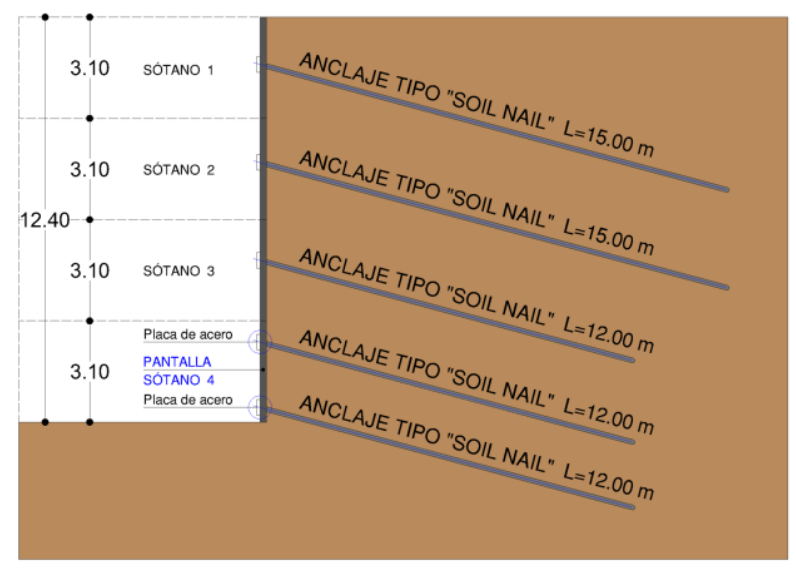

Fig. 4.14 Construcción de sótano 4 en Zaigen: Instalación de placas de acero en barras de anclaje.

Finalmente, con la construcción del muro de $3.10 \mathrm{~m}$ del quinto nivel de sótanos, se logra la altura de pantalla máxima en este proyecto y su proceso constructivo es similar a los cuatro niveles de sótano anteriores. De igual manera, este nivel incluye una fila de anclajes al terreno tipo "Soil Nails".

Por otra parte, con la construcción del muro de sótano 5, la pantalla o muro del edificio Zaigen alcanza una altura total de $15.50 \mathrm{~m}$, siendo esta la fase constructiva más crítica, por la altura que cubre y el consecuente y notable incremento de esfuerzos axiales en las barras de anclaje de los "Soil Nails", como se podrá verificar posteriormente en los resultados del análisis experimental expuestos en el Capítulo 6 y en el análisis con métodos teóricos y numéricos en el Capítulo 5. Las Fig. 4.15, 4.16 y 4.17 indican el proceso constructivo del muro de sótano 5.

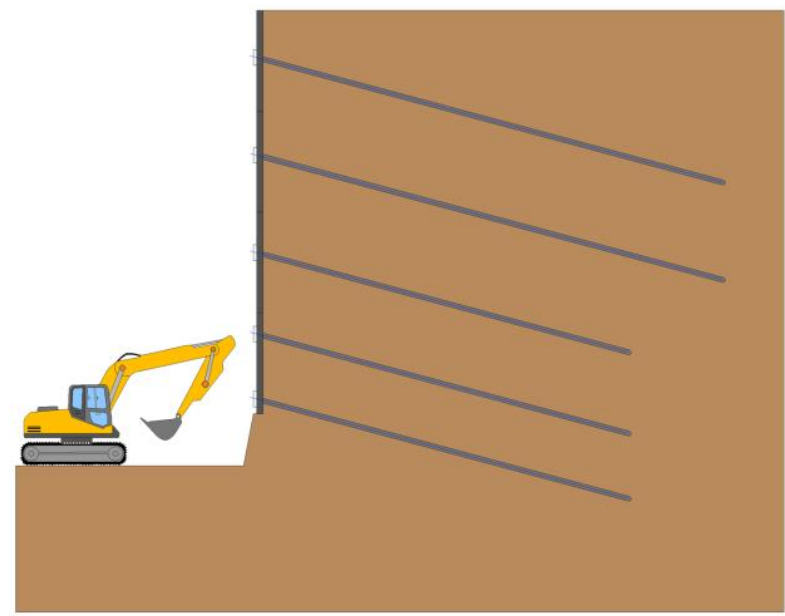

Fig. 4.15 Construcción de sótano 5 en Zaigen: Excavación. 


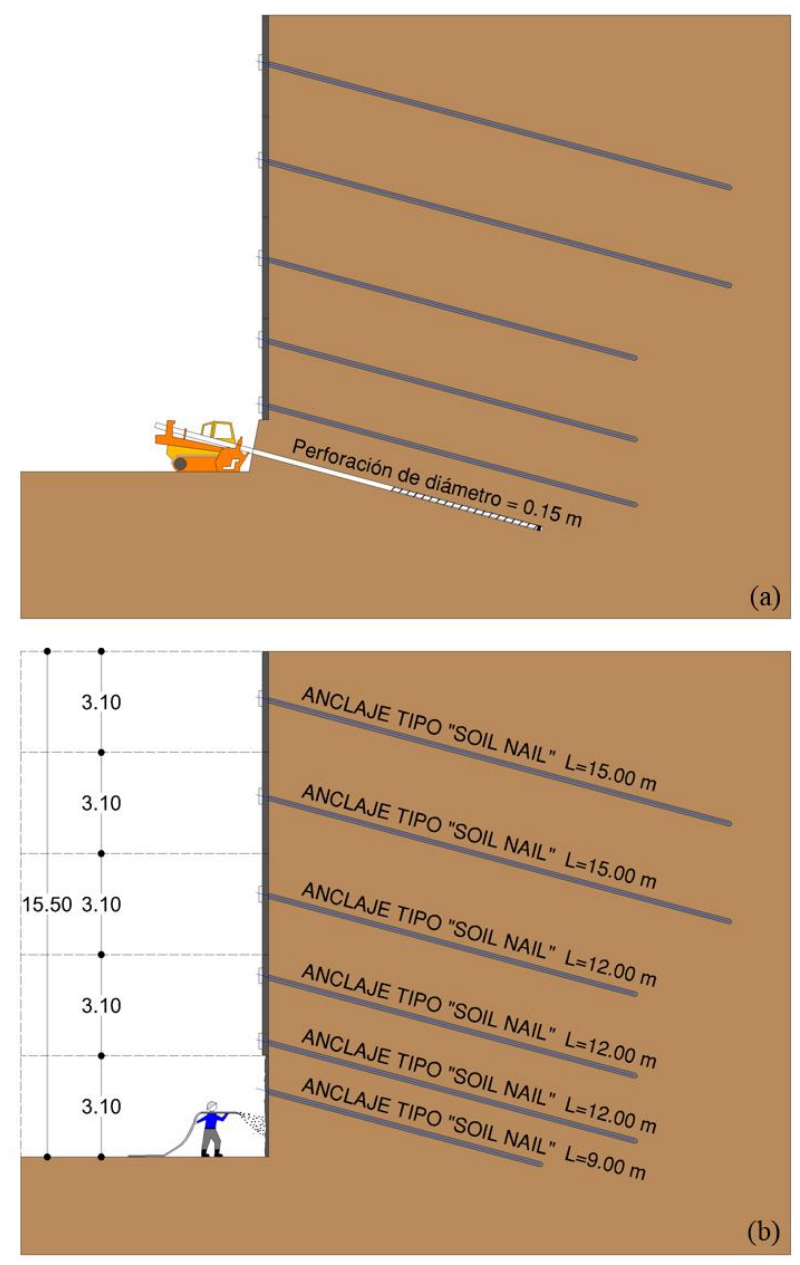

Fig. 4.16 Construcción de sótano 5 en Zaigen: (a) Perforaciones para anclajes, y (b) Construcción de anclajes, conformación vertical de talud, instalación de acero de refuerzo y hormigonado de pantalla.

Como se puede ver en la Fig. 4.16(b), en esta fase constructiva se tiene la fila final de anclajes en el quinto nivel de muro de sótano y por consiguiente se han logrado las 6 filas de anclajes al terreno tipo "Soil Nails" distribuidas en la altura total de $15.50 \mathrm{~m}$.

Finaliza la construcción de este muro con el hormigonado del último nivel de pantalla mediante la técnica de "Shotcrete", como se puede ver en la Fig. 4.16(b) y la instalación de las placas de acero en la respectiva fila de anclaje, según se muestra en la Fig. 4.17. 


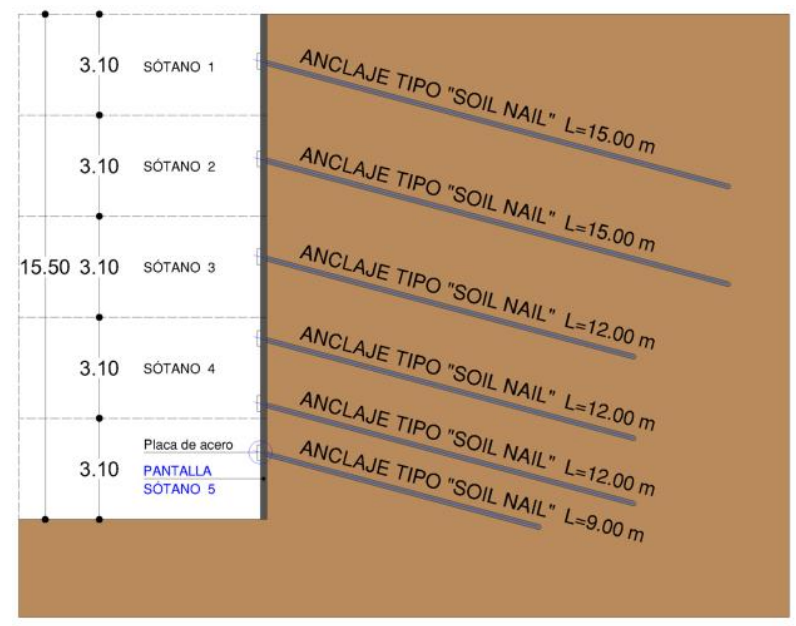

Fig. 4.17 Construcción de sótano 5 en Zaigen: Instalación de placas de acero en barras de anclaje.

La altura acumulada de $15.50 \mathrm{~m}$ de la pantalla anclada posteriormente irá disminuyendo según se vayan construyendo desde abajo hacia arriba los respectivos forjados de cada piso, hasta llegar con el forjado final al nivel de acera. Luego de esta parte, los anclajes al terreno tipo "Soil Nails" han terminado su función temporal, puesto que las pantallas o muros quedarán perfectamente apuntaladas por los forjados de cada nivel.

En síntesis, los procedimientos para construcción de las estructuras de muros de sótano de los edificios Torre Centre y Zaigen son similares. La única diferencia radica en que para el hormigonado de las pantallas en Torre Centre se utilizaron sistemas de encofrado tradicionales, en tanto que en Zaigen se utilizó hormigón proyectado o "Shotcrete".

\subsubsection{Construcción de muros anclados de Torre Centre y Zaigen}

La construcción de los muros de los sótanos para aparcamiento vehicular de los edificios Torre Centre y Zaigen, se ejecutó de acuerdo a la guía esquemática de procesos constructivos detallados en las secciones 4.3.2 y 4.3.3, siendo en ambos casos similares. Por otra parte, en esta sección se expone una síntesis de la construcción de cada una de los elementos integrantes de estas estructuras de muros de sótano en sus respectivas fases constructivas.

1. Excavación del terreno para el primer nivel de sótano (Ver Fig. 4.18). La factibilidad de este paso podría resultar crítica en algunas ocasiones, porque el talud generado por el corte del terreno debe tener la capacidad de permanecer estable preferentemente sin elementos de soporte adicionales (independiente del nivel de excavación en el que se esté trabajando), hasta que los anclajes o "Soil Nails" y la pantalla o "Facing" sean construidos. En 
el caso de Torre Centre y Zaigen no fue necesario el uso de apuntalamientos adicionales durante las fases de excavación. En estas etapas es recomendable adoptar como práctica frecuente, trabajar con tramos de excavación cortos y no realizar de inicio cortes del terreno verticales (más bien dejar temporalmente pequeños contrafuertes de suelo o bataches) hasta que se construyan los anclajes al terreno. Por tanto, el corte vertical definitivo o conformación del talud se ejecuta exclusivamente para iniciar el proceso de instalación del acero de refuerzo de la pantalla y su consecuente fundición u hormigonado, procedimientos que suelen tardar entre uno o dos días como máximo, como en los casos de los muros de los edificios Torre Centre y Zaigen.

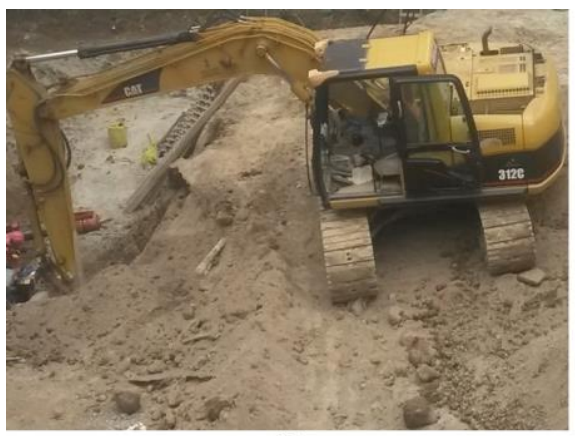

(a)

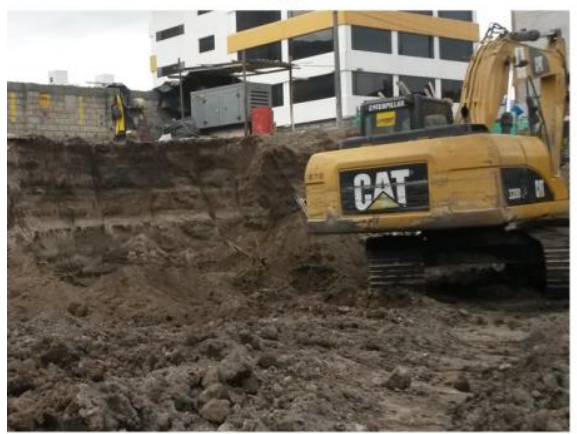

(c)

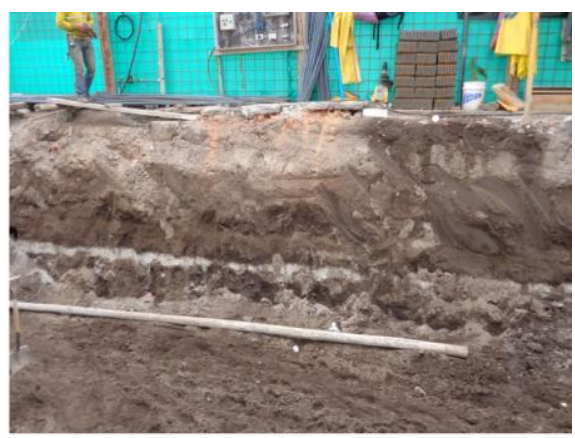

(b)

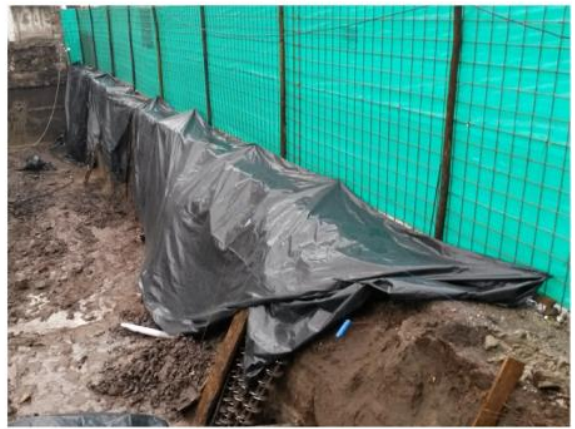

(d)

Fig. 4.18 Excavaciones para primer nivel de sótanos de edificios: (a) y (b) Torre Centre, y (c) y (d) Zaigen.

2. Perforaciones para anclajes al terreno o "Soil Nails" en muros de Torre Centre y Zaigen (Ver Fig. 4.19). Utilizando equipo de perforación especializado y apoyado sobre la plataforma excavada se realizaron los agujeros o perforaciones en los taludes generados por el corte del terreno, para la construcción de los anclajes según las profundidades requeridas en los diseños originales. El diámetro promedio de las perforaciones para los anclajes de los muros de los 2 proyectos Torre Centre y Zaigen fue de 0.15 
$\mathrm{m}$ y la inclinación en ambos casos de $15^{\circ}$ con respecto a la horizontal. Generalmente, los agujeros o perforaciones realizadas se mantienen estables y no requieren revestimiento, como sucedió en los 2 proyectos de este estudio.

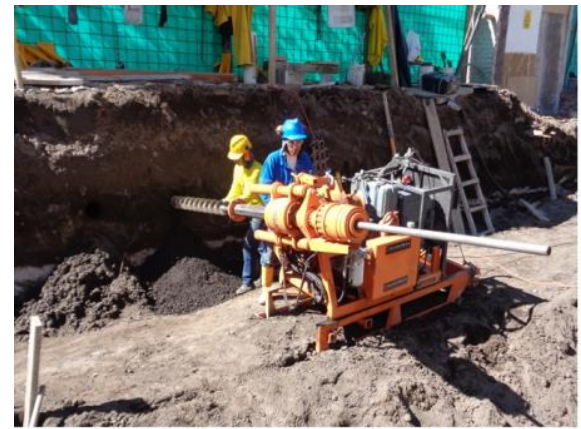

(a)

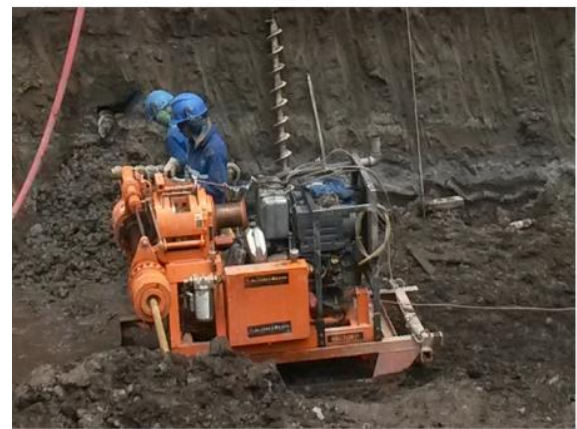

(c)

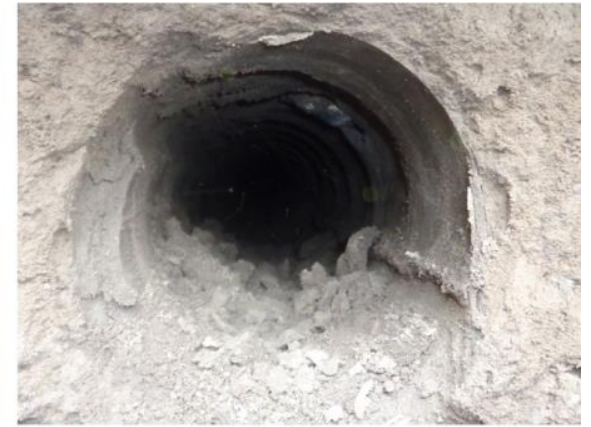

(b)

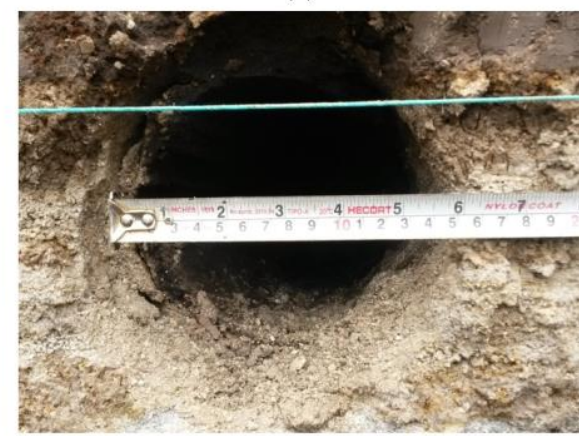

(d)

Fig. 4.19 Perforaciones para "Soil Nails" de muros de edificios: (a) y (b) Torre Centre, y (c) y (d) Zaigen .

3. Instalación de barras de acero y fundición de anclajes o "Grouting" (Ver Fig. 4.20). Se introdujeron las barras de acero en las perforaciones ejecutadas, procurando que cada barra o bulón quede más o menos centrado en los agujeros con la ayuda de centradores metálicos o plásticos instalados alternadamente en la longitud del bulón. Para los anclajes de los muros de ambas estructuras, Torre Centre y Zaigen se utilizaron barras de acero de 25 $\mathrm{mm}$. Seguidamente se procedió a la fundición de los anclajes con mortero fluido o "Grout", el cual fue transportado a toda la profundidad de las perforaciones con ayuda de un "Tubo Tremie" y un sistema de inyección preferentemente a presión nominal baja. Sin embargo, en pocos casos se aplicó un sistema de inyección a gravedad, siempre garantizando que los agujeros sean llenados en su totalidad 


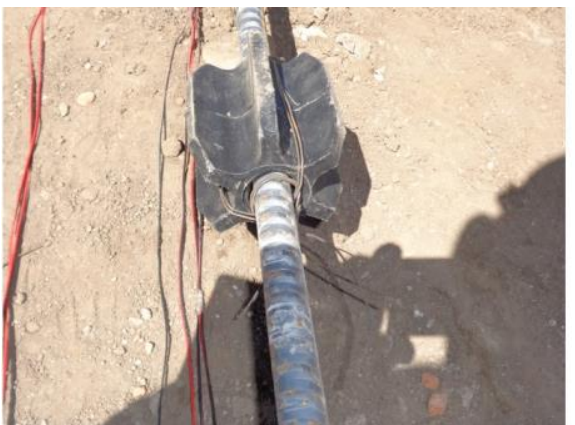

(a)

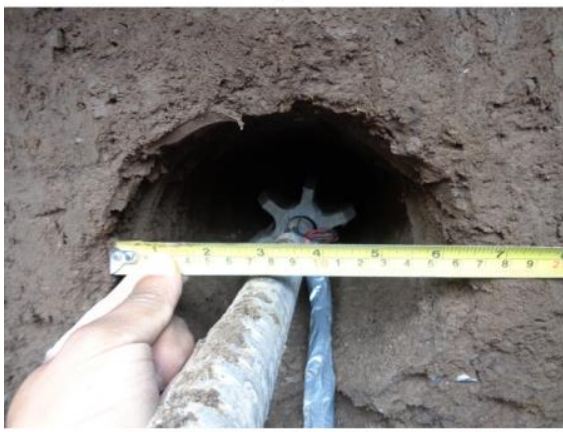

(c)

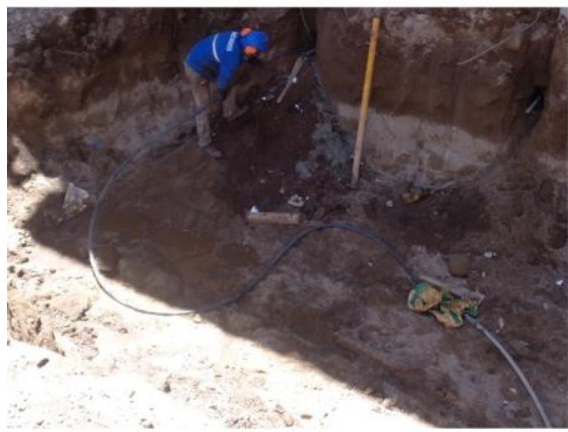

(e)

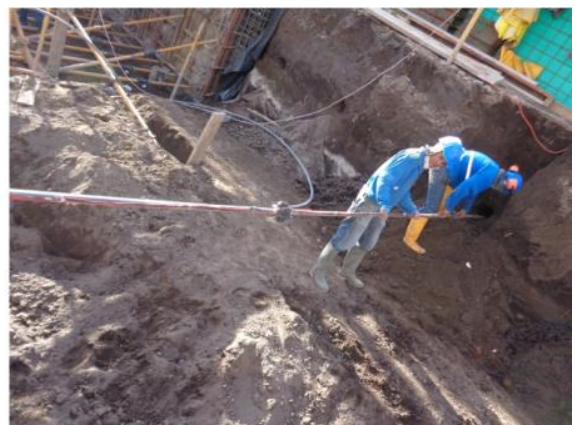

(b)

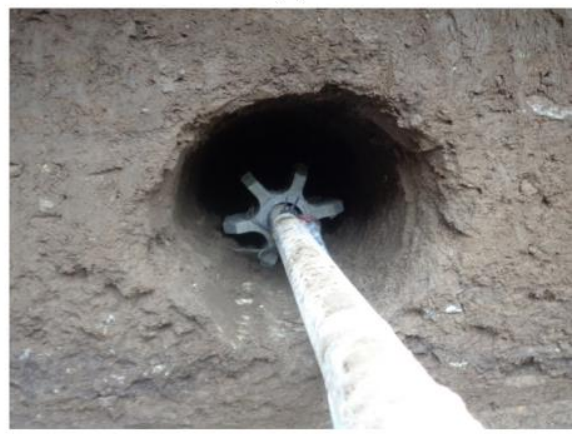

(d)

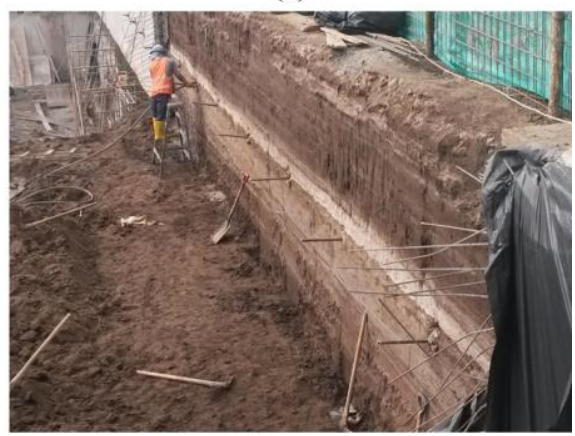

(f)

Fig. 4.20 Construcción de "Soil Nails" para muros: (a) centrador de barras de acero, (b) ingreso de barra de acero en perforación, (c) barra de acero en perforaciones para anclajes de muros de Torre Centre, (d) barra de acero en perforaciones para anclajes de muros de Zaigen, (e) inyección de "Grout" en anclajes para muros de Torre Centre, y (f) inyección de "Grout" en anclajes para muros de Zaigen.

4. Construcción de pantalla, "Muro" o "Facing". Posterior a la construcción de los "Soil Nails" y la conformación vertical del talud, se procedió a la colocación inmediata del acero de refuerzo en distribución horizontal y vertical (Ver Fig. 4.21). Para el caso de los muros de sótanos de las estructuras de Torre Centre y Zaigen se consideraron pantallas de $0.25 \mathrm{~m}$ de 
espesor con doble armadura de acero de refuerzo, según las especificaciones del diseño estructural de estos proyectos.

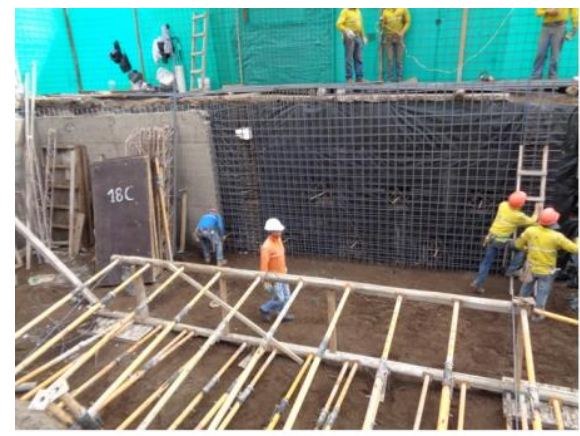

(a)

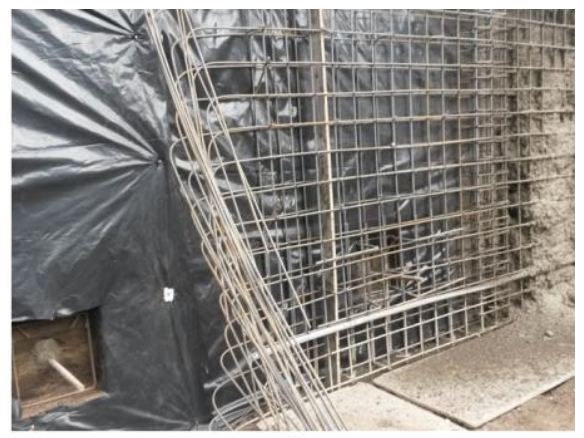

(b)

Fig. 4.21 Colocación de acero de refuerzo para muro de Torre Centre, y (b) Colocación de acero de refuerzo para muro de Zaigen.

Seguidamente se procedió al hormigonado de la pantalla (Ver Fig. 4.22). En Torre Centre se utilizó un sistema de encofrados tradicionales para el hormigonado, en tanto que en Zaigen se utilizó hormigón proyectado o "Shotcrete".

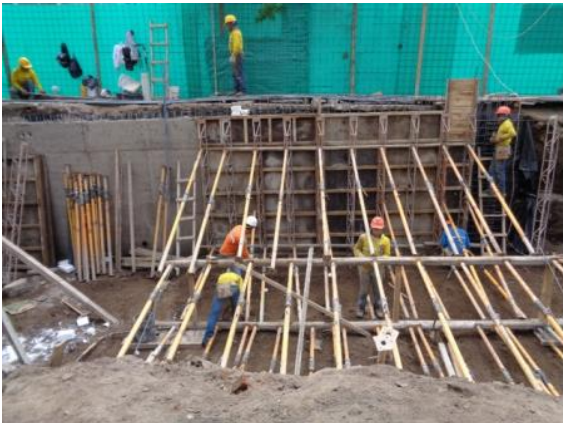

(a)

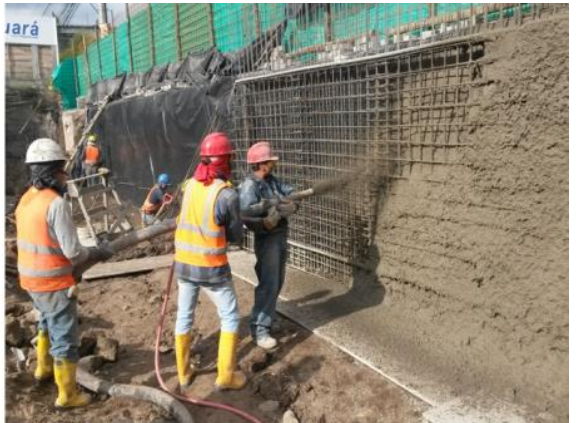

(b)

Fig. 4.22 (a) Hormigonado de muro de Torre Centre mediante sistema de encofrados, y (b) Hormigonado de muro de Zaigen mediante "Shotcrete".

Finalmente, después de construidas las pantallas y a medida que el concreto empieza a curarse, se procedió a instalar las placas de acero sobre las barras de anclaje que sobresalen de los anclajes o "Soil Nails" (Ver Fig. 4.23). 


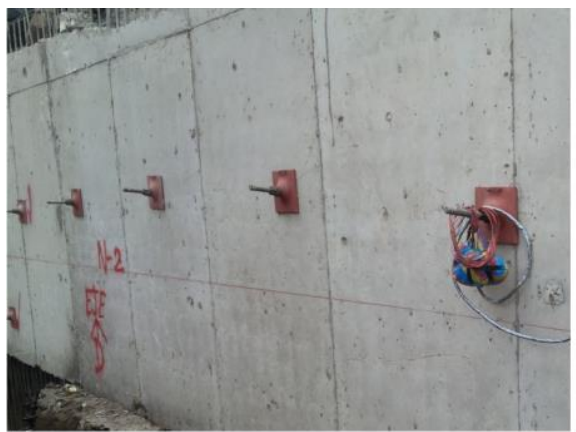

(a)

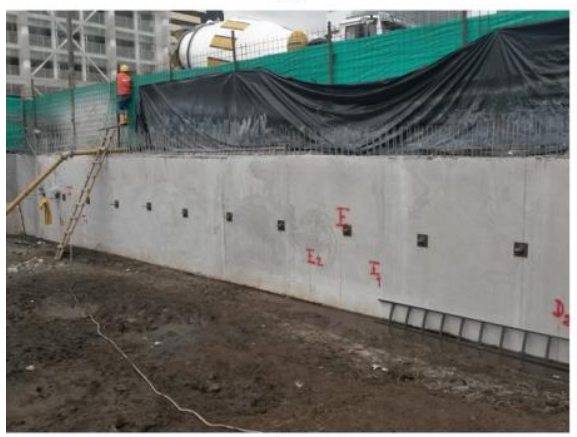

(c)

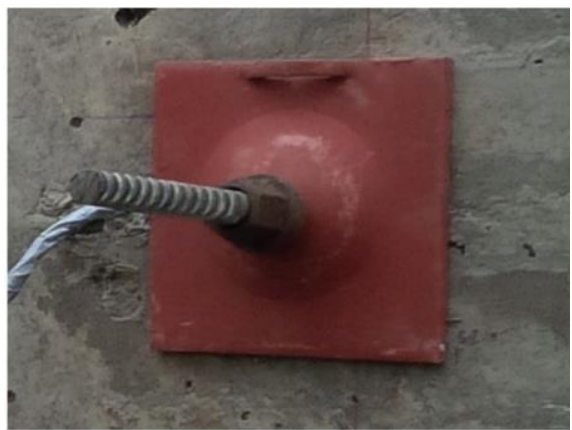

(b)

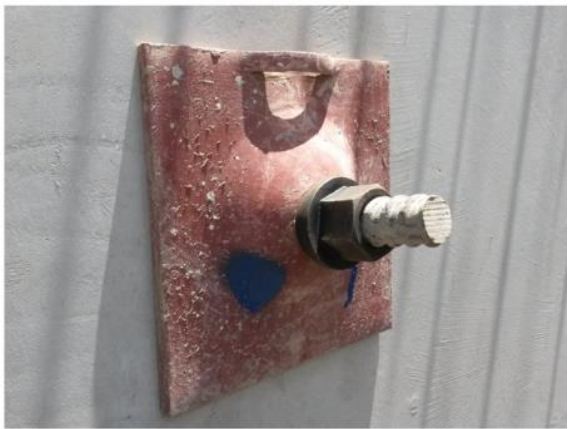

(d)

Fig. 4.23 (a) y (b) Colocación de placas de acero en barras de anclajes de muro de Torre Centre, y (c) y (d) Colocación de placas de acero en barras de anclajes de muro de Zaigen.

5. Construcción de niveles inferiores de muros. Para el resto de niveles de muros de sótanos de Torre Centre y Zaigen, se repiten la totalidad de los 4 pasos anteriormente mencionados, hasta completar todos los niveles y lograr la altura total de las pantallas en cada proyecto (Ver Fig. 4.24).

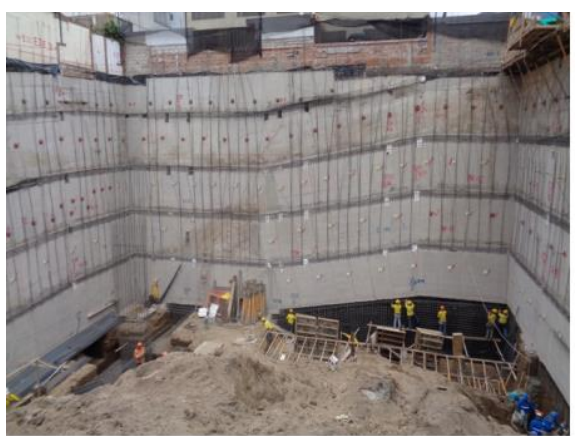

(a)

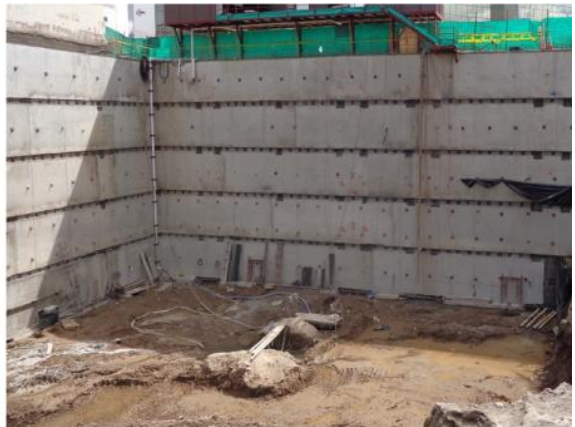

(b)

Fig. 4.24 (a) Muros anclados para sótanos de 5 niveles mediante la técnica de "Soil Nailing" para los edificios: (a) Torre Centre, y (b) Zaigen. 


\subsection{Instrumentación}

\subsubsection{Generalidades}

Como parte del estudio experimental del comportamiento de muros anclados tipo "Soil Nail Walls" con el ajuste para las construcciones de sótanos de edificios en la ciudad de Quito, previamente se deben identificar las variables que caracterizan su desempeño. Al respecto la guía "Soil Nail Walls - Reference Manual" de la Federal Highway Administration (FHWA, 2015), menciona que el indicador más significativo que identifica a estos muros es la cantidad de deformación de la pantalla durante y después de la construcción.

Por otra parte, de manera más explícita la mencionada guía dentro de las actividades de monitorización sugiere realizar mediciones a los siguientes parámetros:

- Desplazamientos horizontales y verticales en la cara de la pantalla.

- Desplazamientos horizontales y verticales de la superficie del terreno que se encuentra detrás de la pantalla. Adicionalmente, en esta parte es recomendable verificar la existencia de grietas en la superficie del suelo mediante inspecciones visuales diarias.

- Determinación de la magnitud y ubicación de la carga de tensión máxima a lo largo de la longitud de los anclajes o "Soil Nails".

Con estos antecedentes, se procedió a diseñar procedimientos de instrumentación para conocer posteriormente el comportamiento de estas variables durante las diferentes fases constructivas a través de un plan periódico de monitorización.

La presente investigación fue realizada exclusivamente con financiamiento propio del autor, por lo que todas las actividades de instrumentación y posterior monitorización se ajustaron a los términos económicos y logísticos disponibles, pero siempre manteniendo especial cuidado en cada procedimiento ejecutado para obtener resultados confiables.

Entonces, para el estudio experimental del comportamiento tanto en Torre Centre como en Zaigen se seleccionaron los muros anclados más representativos, según las facilidades ofrecidas para esta investigación en la construcción de cada proyecto.

Dentro de cada muro anclado se seleccionó una sección transversal completa de pantalla con sus respectivas filas de anclajes al terreno tipo "Soil Nails" para instrumentar el sistema completo. Estas secciones transversales elegidas, coinciden en el punto medio de la longitud total de los tramos de pantalla, para trabajar posteriormente con problemas de deformación plana, en lugar de problemas tridimensionales. La Fig. 4.25 muestra la ubicación y características de la sección transversal de pantalla anclada de Torre Centre que fue estudiada en esta investigación experimental. En tanto que la Fig. 4.26 presenta la ubicación y características de la pantalla anclada de Zaigen. 


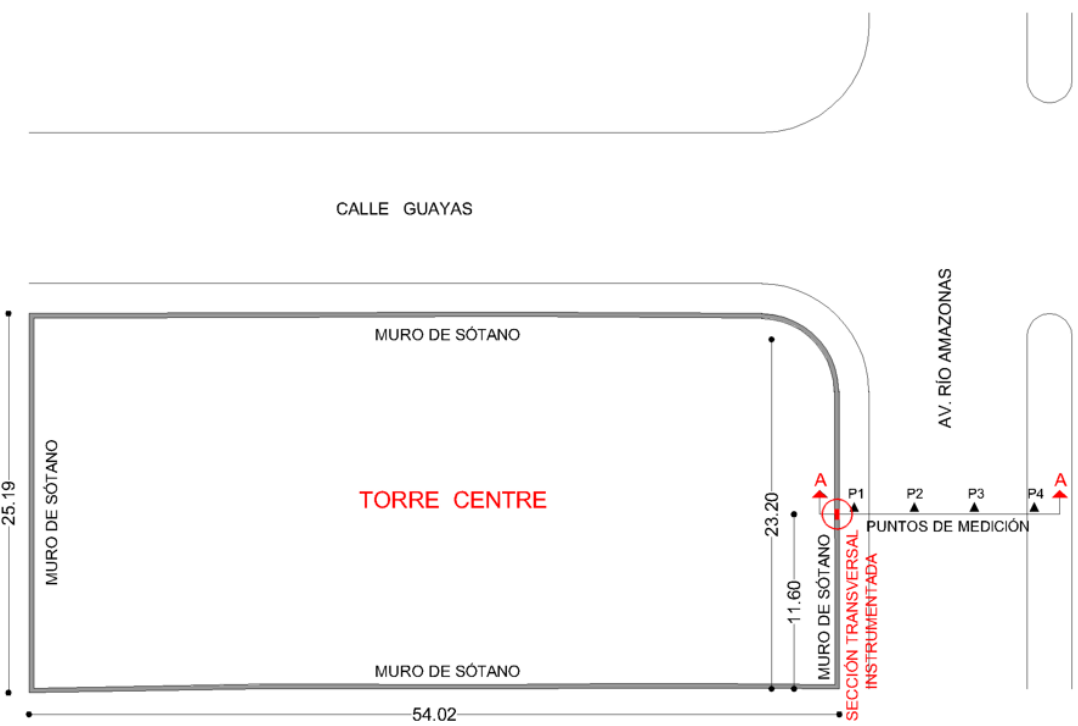

(a)

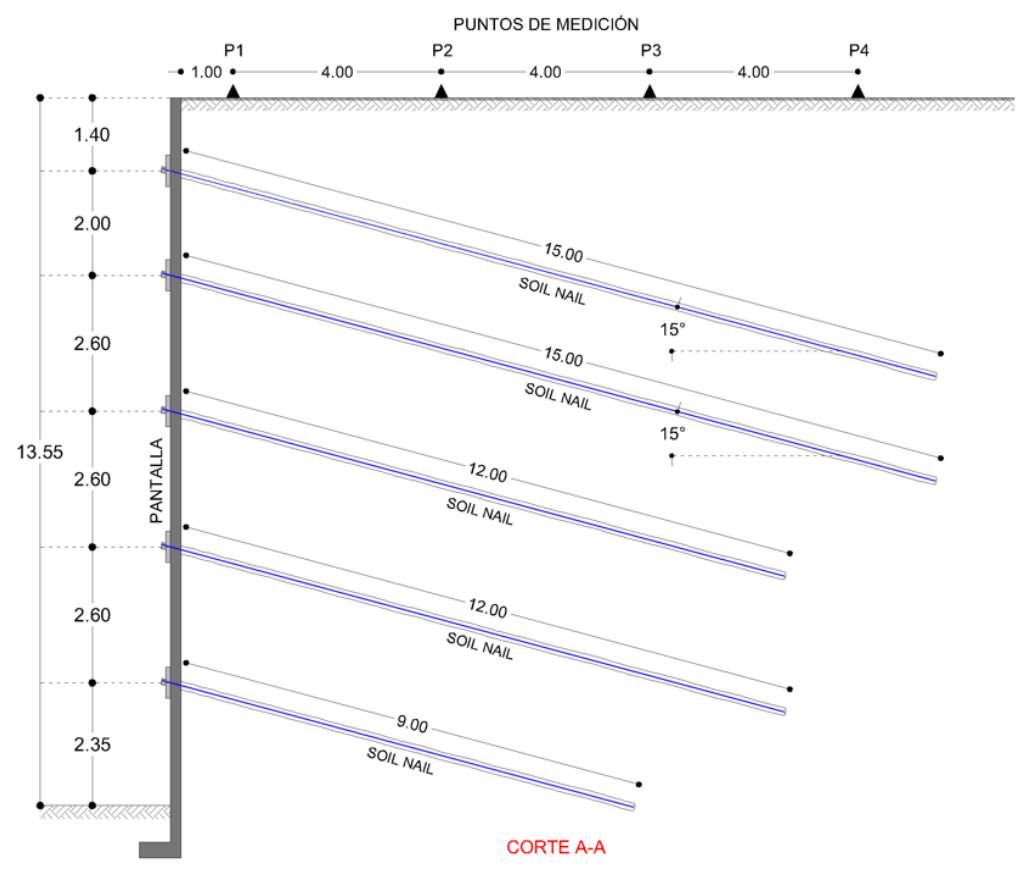

(b)

Fig. 4.25 Pantalla anclada de sótanos de Torre Centre para estudio experimental: (a) Ubicación de sección transversal de pantalla anclada, y (b) Sección transversal de pantalla anclada. 


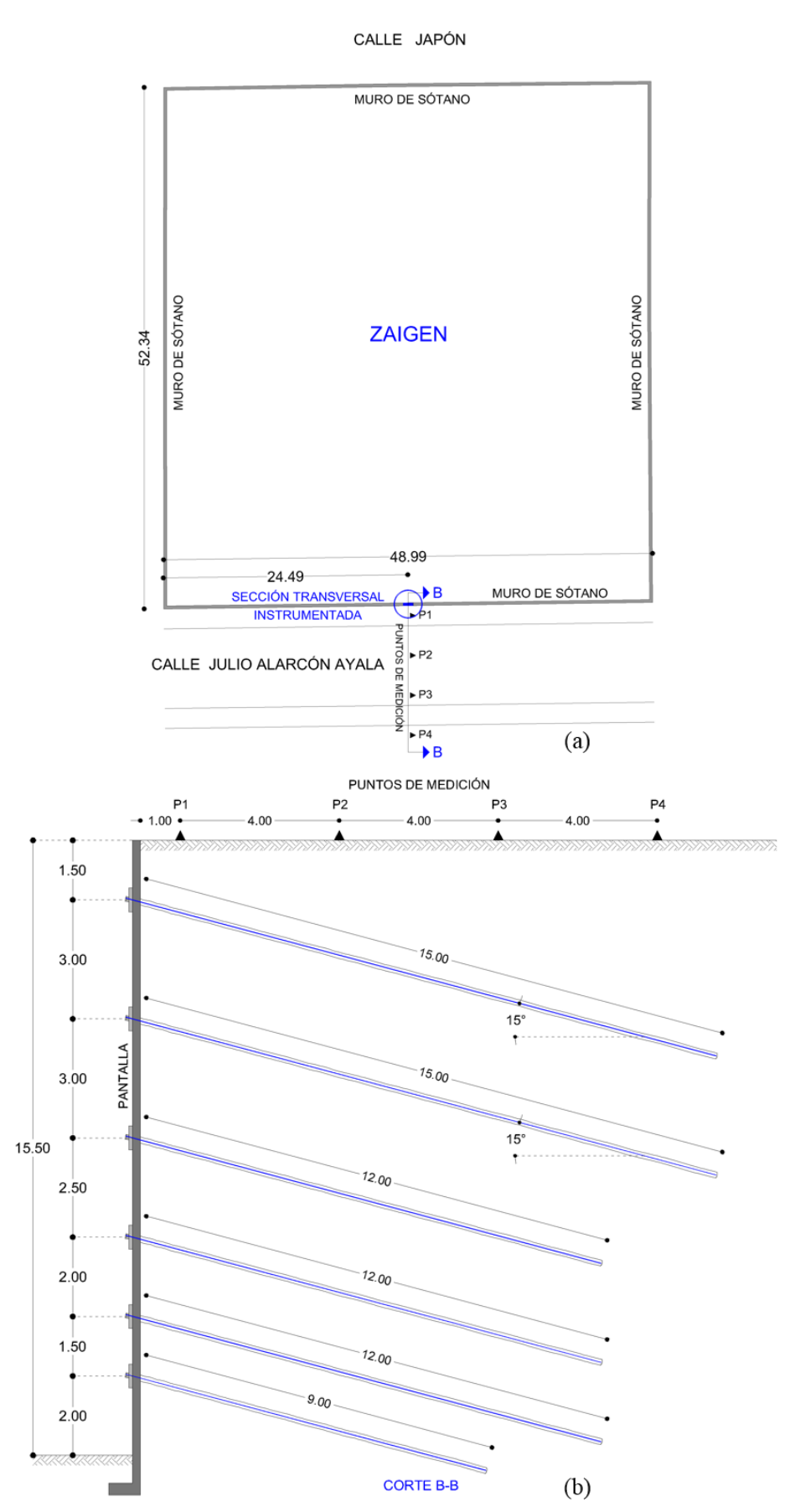

Fig. 4.26 Pantalla anclada de sótanos de Zaigen para estudio experimental: (a) Ubicación de sección transversal de pantalla anclada, y (b) Sección transversal de pantalla anclada. 
Por tanto, como parte del estudio experimental para estimar los parámetros que caracterizan a este tipo de estructuras ancladas, se instalaron galgas extensométricas en las barras de anclaje cada cierta distancia, para determinar la magnitud de la fuerza axial en las mismas. Por otra parte, se construyeron bases de nivelación en los puntos de medición detrás de la sección transversal de cada pantalla anclada, según se indica en las Fig. 4.25 y 4.26, para el control de las deformaciones del terreno. Adicionalmente, para la medición de las deformaciones de la pantalla se instalaron en la misma pequeñas marcas metálicas fijas y permanentes, junto a las placas de los anclajes.

\subsubsection{Galgas extensométricas}

Se instalaron y distribuyeron "Strain Gauges" o galgas extensométricas en la longitud de cada barra de acero de los anclajes o "Soil Nails", para determinar la magnitud y ubicación de la fuerza máxima y la posible distribución de la fuerza axial en toda la longitud. Para el efecto, se utilizaron galgas extensométricas precableadas de la marca HBM y del tipo K-LY4, de longitud de rejilla $3 \mathrm{~mm}$ y resistencia 120 Ohm. La Fig. 4.27 muestra el tipo de galgas extensométricas utilizadas en el estudio experimental.

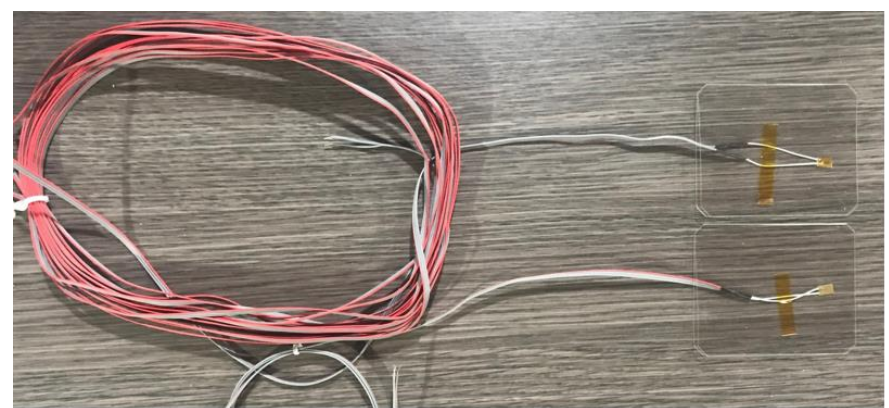

(a)

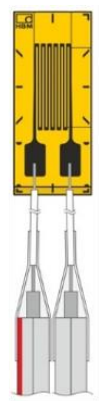

(b)

Fig. 4.27 Galgas extensométricas utilizadas en la instrumentación: (a) Galgas extensométricas precableadas, y (b) Diagrama de galga extensométrica.

Por otra parte, en resumen, el proceso de instalación de las galgas extensométricas en los bulones o barras de acero incluyó los siguientes pasos:

- Preparación de la superficie de instalación, para ello se generó una superficie lisa en la barra de acero. Además, para obtener mejores resultados con los sensores, la limpieza de la superficie fue fundamental, ya que cualquier partícula que exista en el contacto superficie - sensor puede alterar los resultados. En la Fig. 4.28(a) se muestra el proceso de preparación de la superficie de la barra de acero.

- Para adherir el sensor o galga extensométrica a la superficie lisa de la barra de acero se utilizó el adhesivo Z70 de la marca HBM, el cual tarda un minuto 
en polimerizar a $20^{\circ} \mathrm{C}$ y aplicando presión con el dedo pulgar durante ese lapso mínimo de tiempo. En la Fig. 4.28(b) se muestra el uso del adhesivo en la superficie lisa - limpia de la barra de acero. Las Fig. 4.28(c) y 4.28(d) muestran la instalación de la galga en la barra de acero.

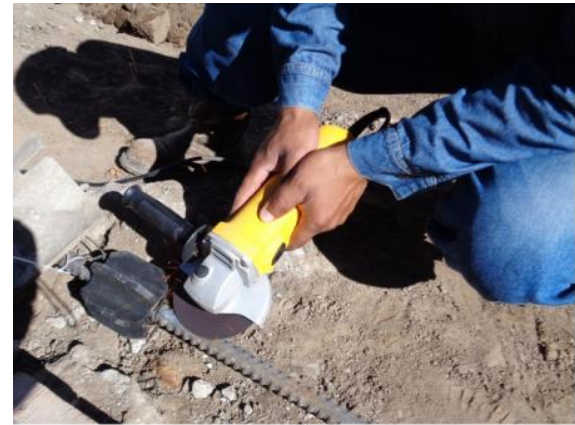

(a)

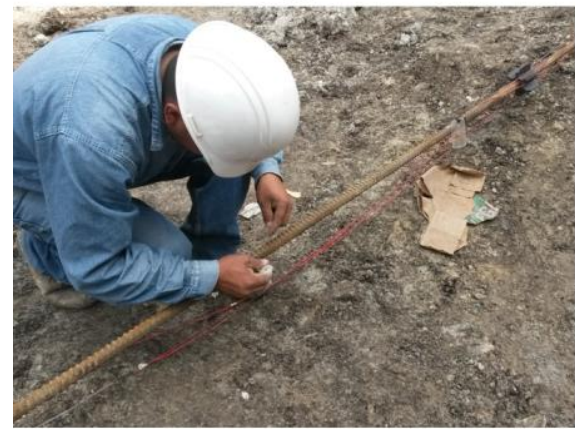

(c)

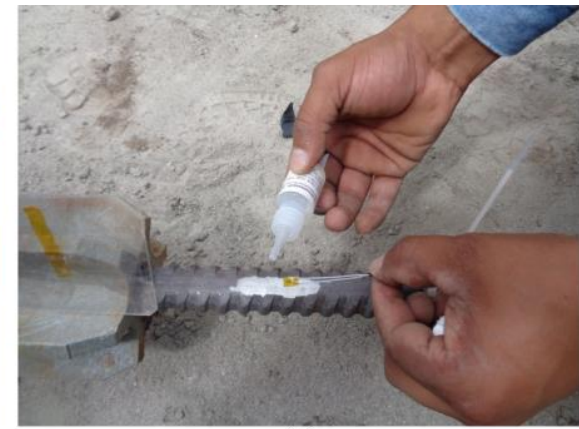

(b)

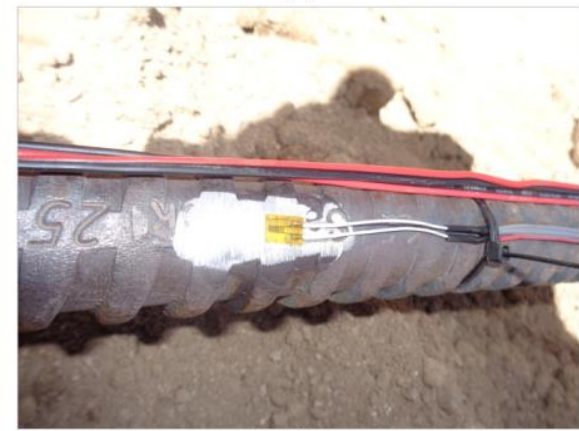

(d)

Fig. 4.28 (a) Preparación de superficie de la barra, (b) Uso de adhesivo HBM Z70 en contacto de superficie - galga, (c) y (d) Instalación de galga extensométrica en barra de acero.

- Inmediatamente después de la instalación del "Strain Gauge" o sensor en la barra de acero, el mismo fue protegido de los agentes externos y ambientales, principalmente de la humedad y de los efectos del proceso de inyección del "Grout". Entonces, para el recubrimiento de todas las galgas extensométricas se utilizó la masilla plástica de adhesión fuerte AK22 de la marca HBM, la cual se aplicó moldeándola con la mano en el punto de la galga o de medición. Las Fig. 4.29(a) y 4.29(b) muestran el uso de la masilla AK22. Por otra parte, para la protección de los sensores también se utilizaron las láminas de aluminio con masilla plástica ABM75 de la marca HBM, las cuales se aplicaron presionándolas con la mano en el punto de medición o de la galga. Las Fig. 4.29(c) y 4.29(d) exponen la aplicación de la lámina ABM75. Finalmente, en la Fig. 4.30 se muestran barras de acero instrumentadas con galgas extensométricas en toda su longitud y listas para ser introducidas en las perforaciones. 


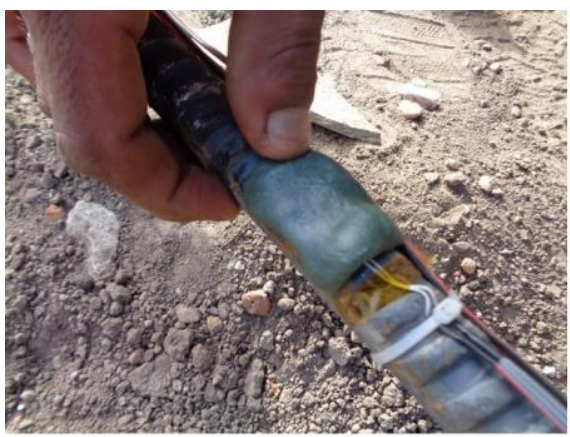

(a)

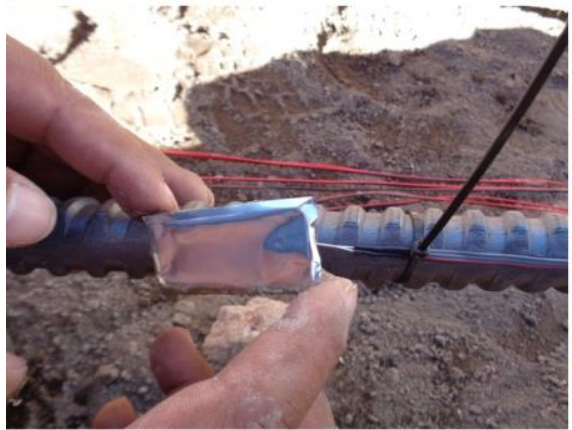

(c)

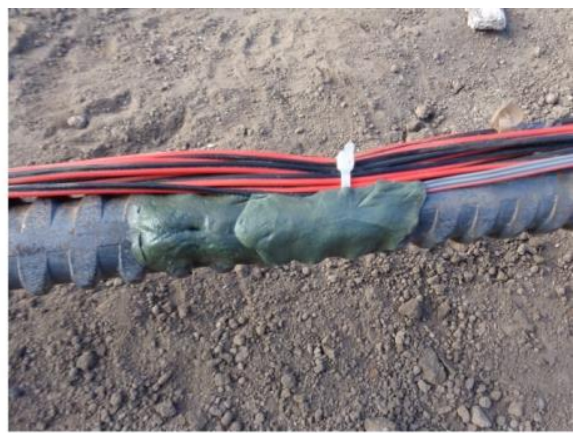

(b)

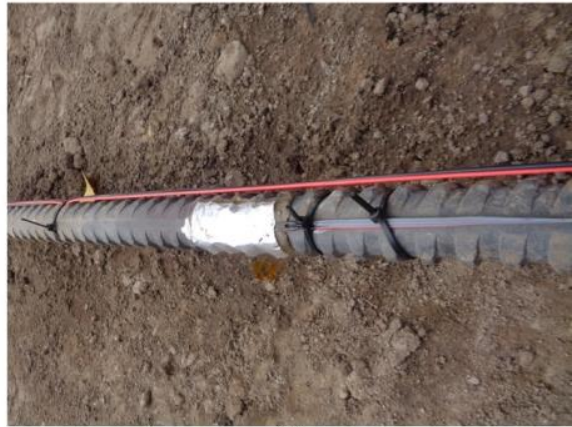

(d)

Fig. 4.29 (a) y (b) Protección de galgas extensométricas con masilla AK22, y (c) y (d) Protección de galgas extensométricas con lámina ABM75.

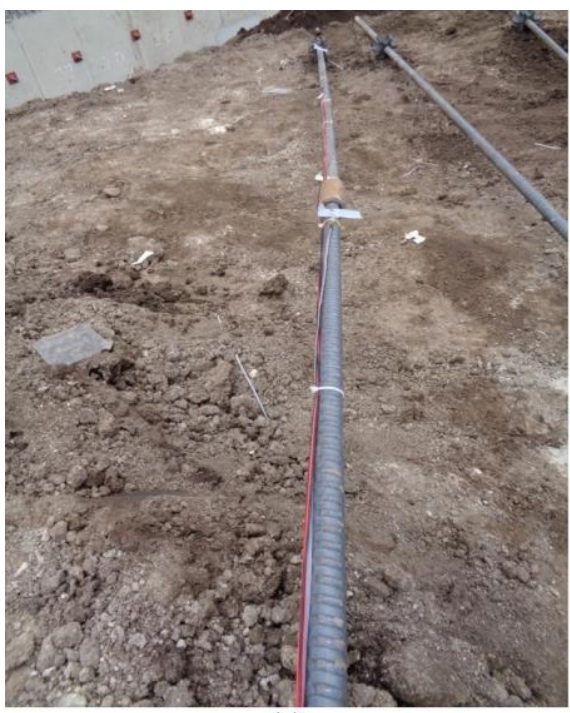

(a)

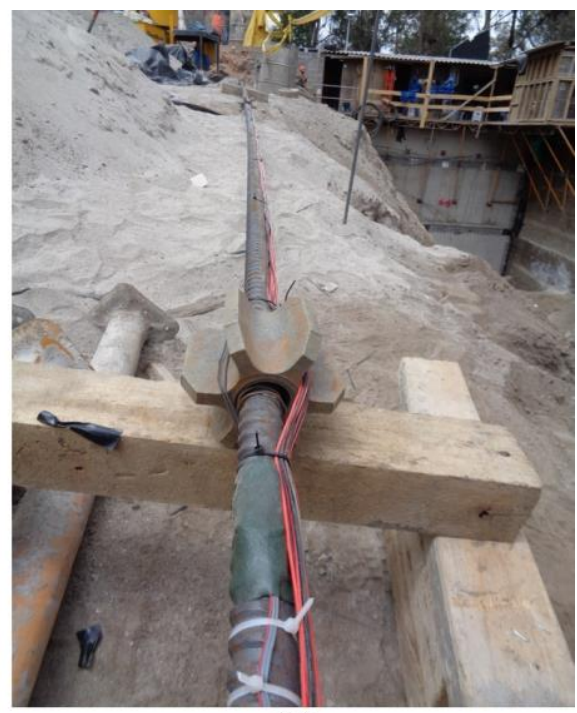

(b)

Fig. 4.30 (a) y (b) Barras de acero instrumentadas para anclajes tipo "Soil Nails". 


\subsubsection{Bases de nivelación}

Como parte del proceso de instrumentación de las estructuras ancladas tipo "Soil Nailing" de este estudio experimental y para su posterior monitorización, se construyeron puntos de control o bases de nivelación en la alineación perpendicular que se encuentra detrás de la pantalla y que coincide con la orientación de las filas de anclajes o "Soil Nails", para el control de las deformaciones durante cada fase de excavación para los diferentes niveles de sótano y en general durante todo el proceso constructivo. La posición de los puntos de medición se realizó de acuerdo a las facilidades que se dieron para su ubicación, dado que coincidieron con vías de alto tráfico vehicular. Las Fig. 4.25 y 4.26 muestran la ubicación de estos puntos de medición para los proyectos Torre Centre y Zaigen, respectivamente.

Por otra parte, la Fig. 4.31 muestra la construcción de los puntos de medición durante la etapa de instrumentación, los cuales consisten básicamente de una barra de acero embebida dentro de una masa de concreto en una pequeña perforación en el terreno. La separación de estos puntos de medición se indica en las Fig. 4.25 y 4.26.

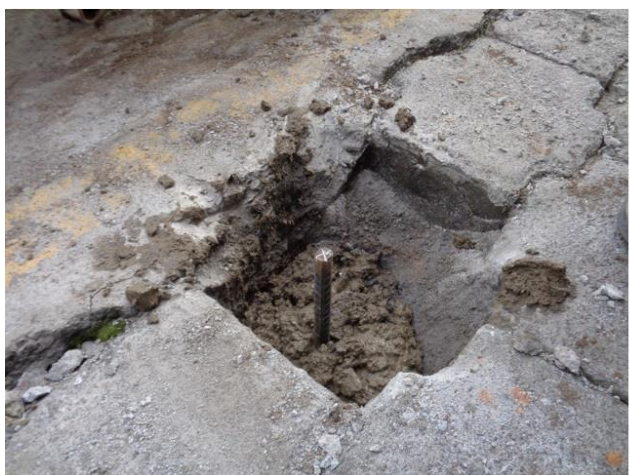

(a)

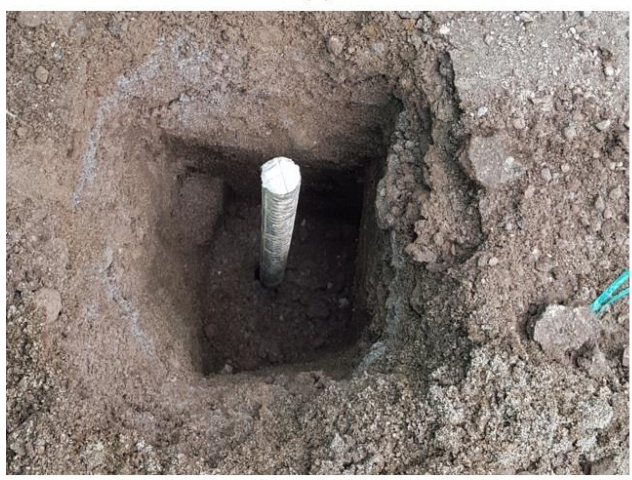

(c)

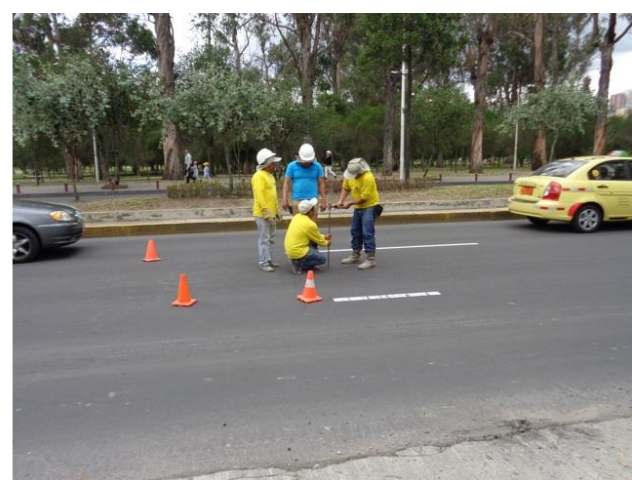

(b)

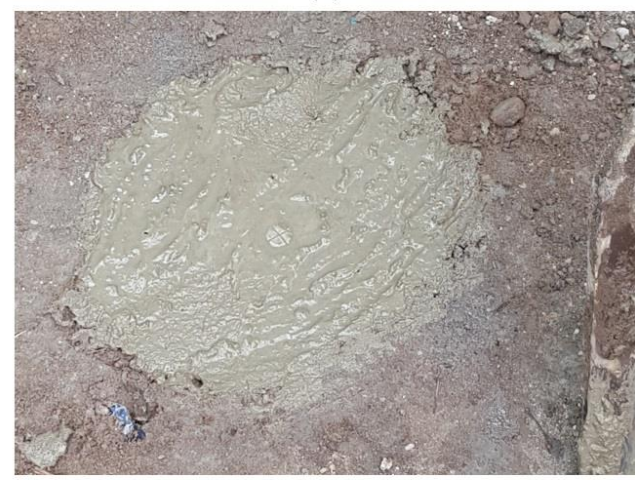

(d)

Fig. 4.31 (a) y (b) Instalación de bases de nivelación en proyecto Torre Centre, (c) y (d) Instalación de bases de nivelación en proyecto Zaigen. 
De igual manera, en la Fig. 4.32 se muestra las marcas metálicas en la pantalla, junto a las placas de acero de los anclajes, las mismas que fueron utilizadas para el control de deformaciones en la pantalla. Nótese también la salida de los terminales de los cables de todas las galgas extensométricas instaladas en la longitud de las barras de los anclajes, a utilizarse durante el proceso de monitorización.

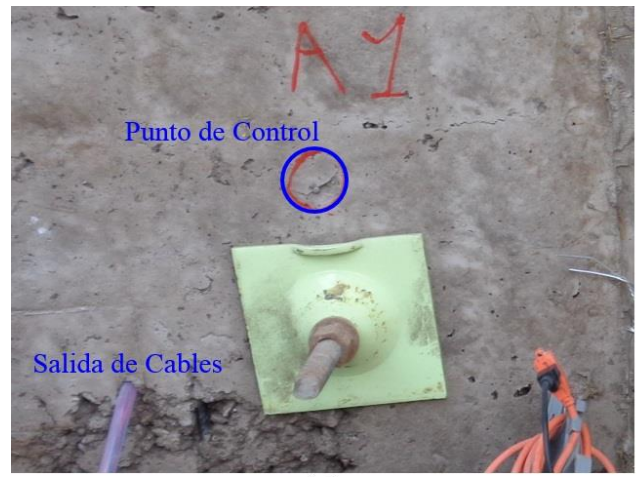

(a)

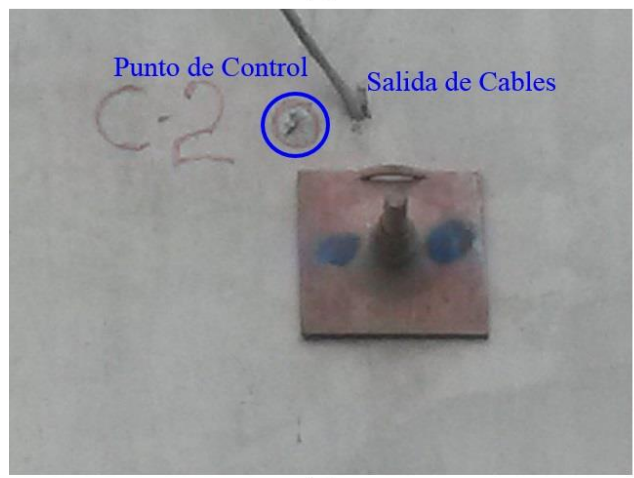

(c)

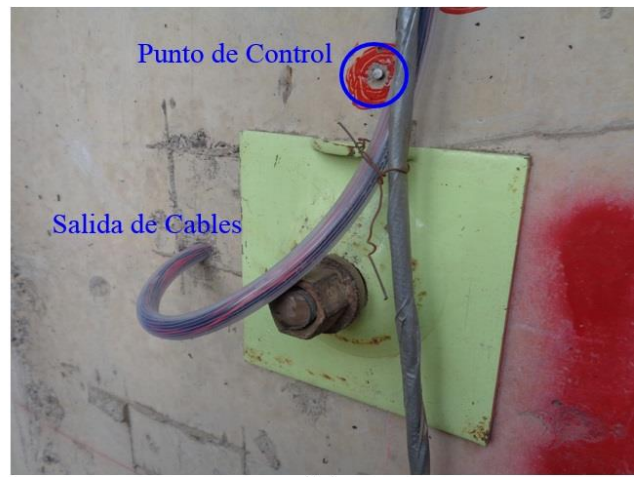

(b)

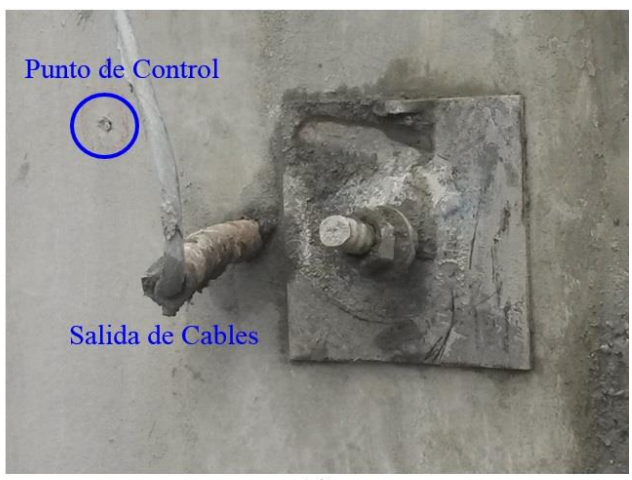

(d)

Fig. 4.32 (a) y (b) Puntos de control de deformaciones en pantalla de Torre Centre, y (c) y (d) Puntos de control de deformaciones en pantalla de Zaigen.

\subsubsection{Proceso de instrumentación}

El proceso de instrumentación se realizó de manera paralela al avance de la construcción. Las bases de nivelación fueron construidas al inicio de cada proyecto y obligatoriamente previo al arranque de la excavación para el primer nivel de sótano, con la finalidad de referenciar los niveles iniciales y en base a ellos determinar las afectaciones y deformaciones con el proceso constructivo.

La colocación de galgas extensométricas en las barras de acero y su instalación en las perforaciones se realizó conforme al avance constructivo. Las Fig. 4.33, 4.34 y 4.35 muestran el proceso de instrumentación de los "Soil Nails" de Torre Centre. 
Estudio experimental y numérico del comportamiento de excavaciones ejecutadas mediante la técnica de suelo claveteado (Soil Nailing) en suelos de la ciudad de Quito (Ecuador)

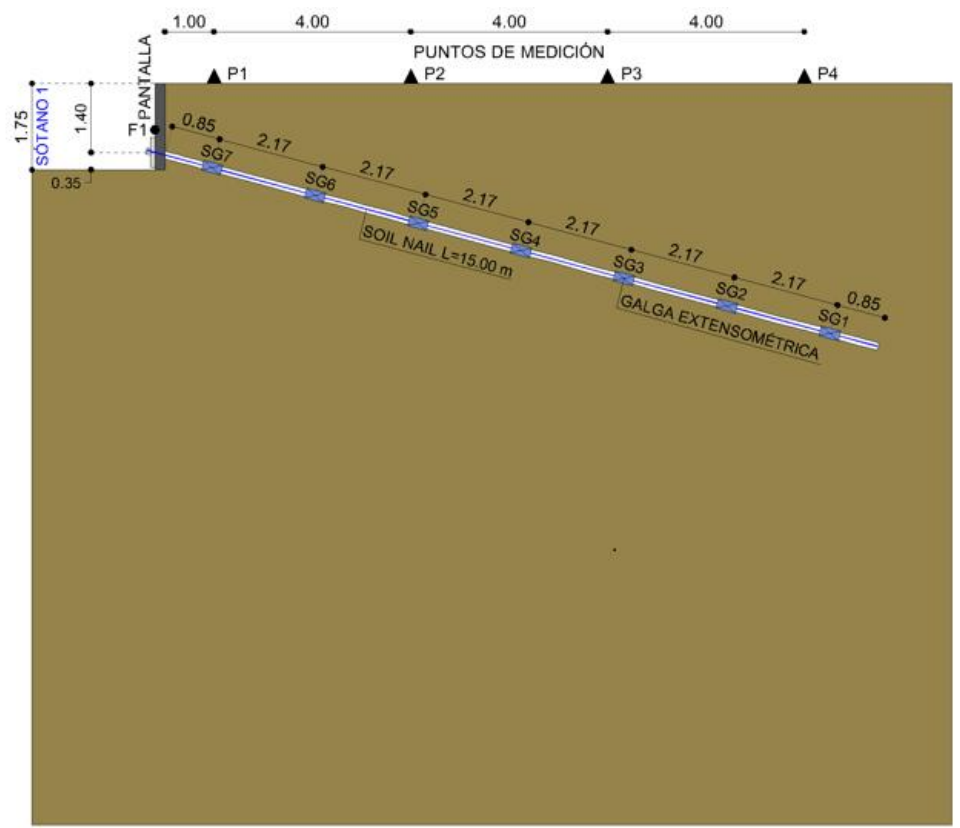

(a)

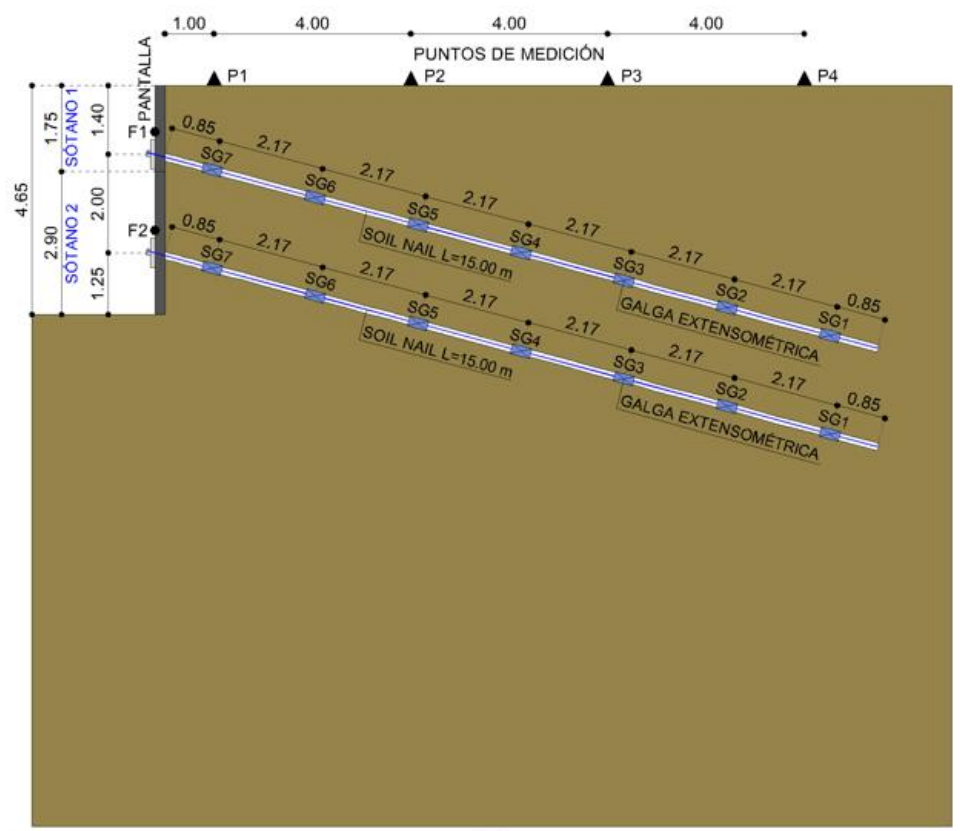

(b)

Fig. 4.33 Instrumentación de pantalla de Torre Centre: (a) Instrumentación de "Soil Nail" de sótano 1, y (b) Instrumentación de "Soil Nail" de sótano 2. 


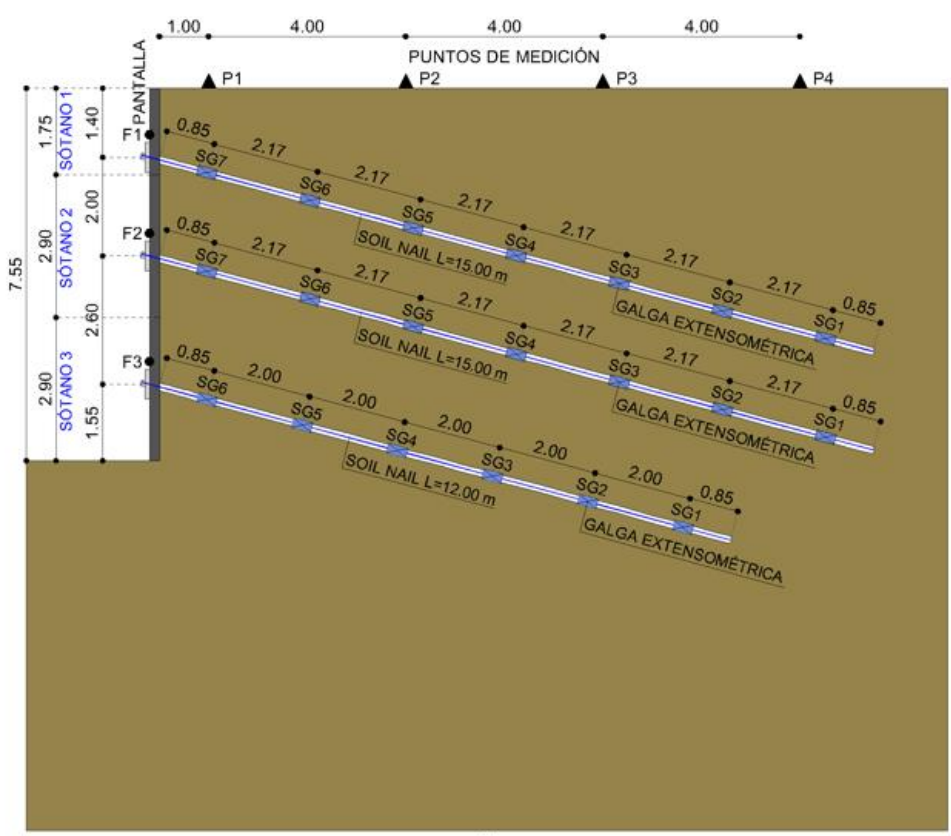

(a)

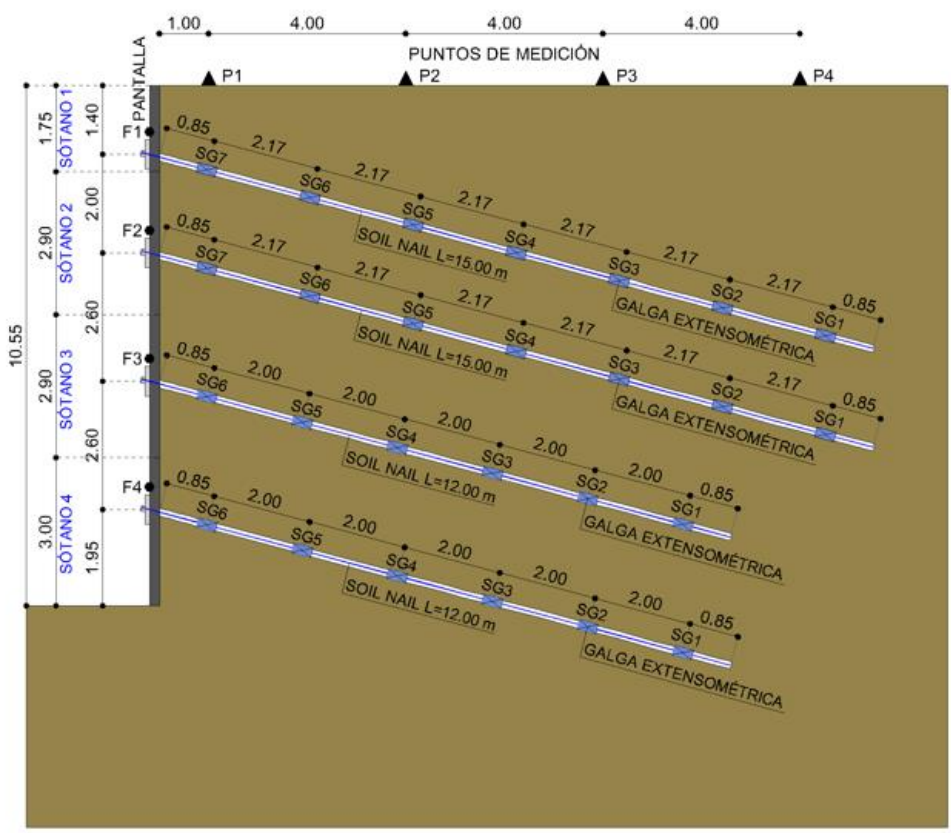

(b)

Fig. 4.34 Instrumentación de pantalla de Torre Centre: (a) Instrumentación de "Soil Nail" de sótano 3, y (b) Instrumentación de "Soil Nail" de sótano 4. 


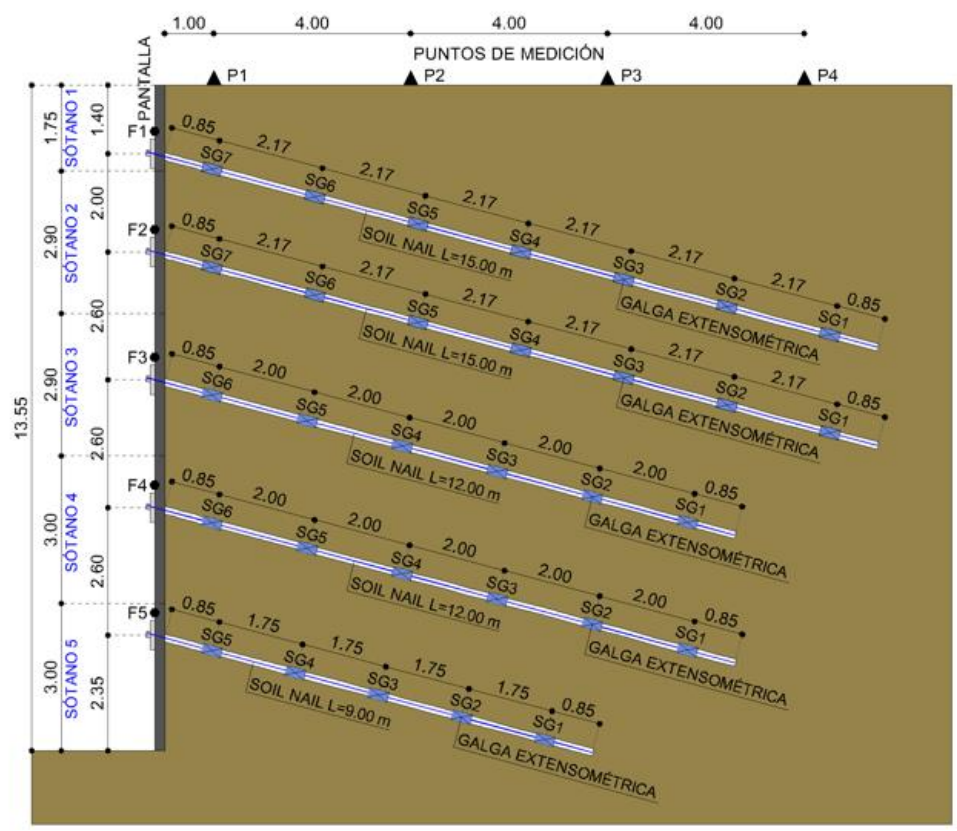

Fig. 4.35 Instrumentación de pantalla de Torre Centre: Instrumentación de "Soil Nail" de sótano 5.

Como se puede distinguir en las Fig. 4.33, 4.34 y 4.35, cada nivel de sótano de Torre Centre tiene una fila de "Soil Nails" y por tanto, cada fila de anclajes fue instrumentada con galgas extensométricas. En la Tabla 4.1 se muestra las características de los anclajes y la distribución de los mismos con sus respectivos elementos de instrumentación.

Tabla 4.1 Características de "Soil Nails" y elementos de instrumentación en Torre Centre.

\begin{tabular}{ccccccccc}
\hline \multicolumn{2}{c}{ SÓTANO } & \multicolumn{2}{c}{ "SOIL NAILS" } & \multicolumn{5}{c}{ INSTRUMENTACIÓN } \\
\hline $\begin{array}{c}\text { Nivel de } \\
\text { sótano }\end{array}$ & $\begin{array}{c}\text { Fila de } \\
\text { anclaje }\end{array}$ & $\begin{array}{c}\text { Longitud } \\
\text { de "Soil } \\
\text { Nails" } \\
{[\mathrm{m}]}\end{array}$ & $\begin{array}{c}\text { Separación } \\
\text { horizontal de } \\
\text { "Soil Nails" } \\
{[\mathrm{m}]}\end{array}$ & $\begin{array}{c}\text { Número } \\
\text { de } \\
\text { galgas }\end{array}$ & $\begin{array}{c}\text { Separación } \\
\text { de galgas }\end{array}$ & $\begin{array}{c}\text { Nombre de } \\
\text { galgas } \\
{[\mathrm{m}]}\end{array}$ & $\begin{array}{c}\text { Punto de } \\
\text { medición } \\
\text { en pantalla }\end{array}$ & $\begin{array}{c}\text { Punto de } \\
\text { medición } \\
\text { detrás de } \\
\text { pantalla }\end{array}$ \\
\hline 1 & 1 & 15 & 1.50 & 7 & 2.17 & SG1 a SG7 & F1 & F2 \\
2 & 2 & 15 & 1.50 & 7 & 2.17 & SG1 a SG7 & P1, P2, \\
3 & 3 & 12 & 1.50 & 6 & 2.00 & SG1 a SG6 & F3 & P3 y P4 \\
4 & 4 & 12 & 2.00 & 6 & 2.00 & SG1 a SG6 & F4 & F5 \\
5 & 5 & 9 & 2.00 & 5 & 1.75 & SG1 a SG5 & & \\
\hline
\end{tabular}

Por otra parte, en las Fig. 4.36, 4.37 y 4.38 se indica el proceso de instrumentación de los anclajes de los sótanos del proyecto Zaigen. En este caso la pantalla incluye 6 filas, por tanto, en cada "Soil Nail" se instalaron galgas extensométricas. 


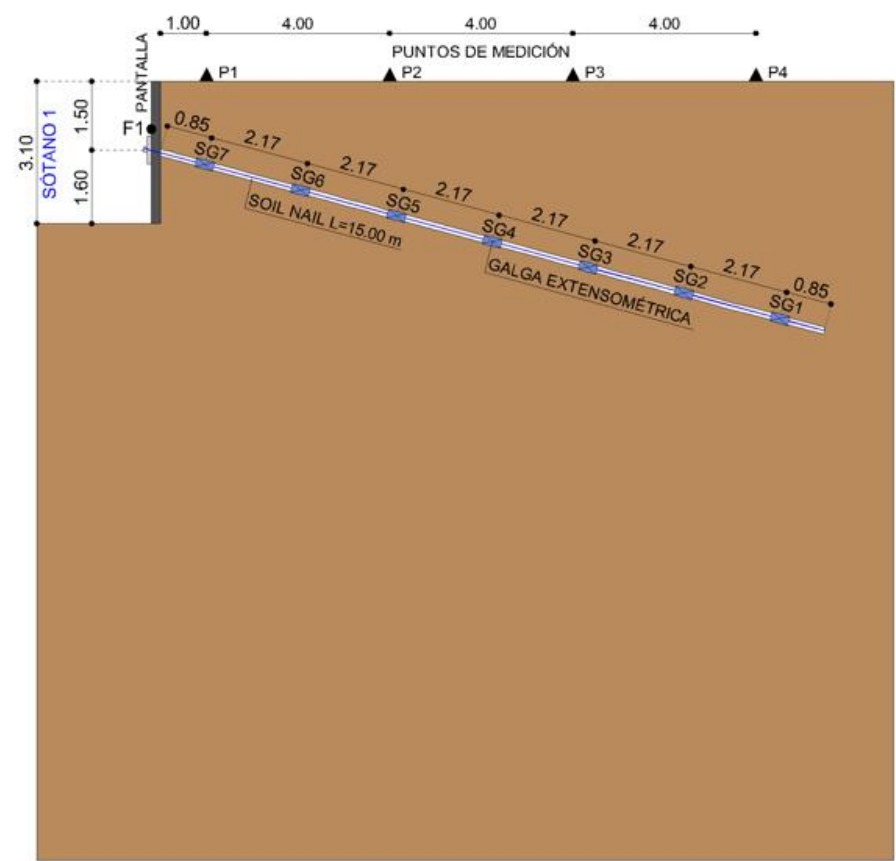

(a)

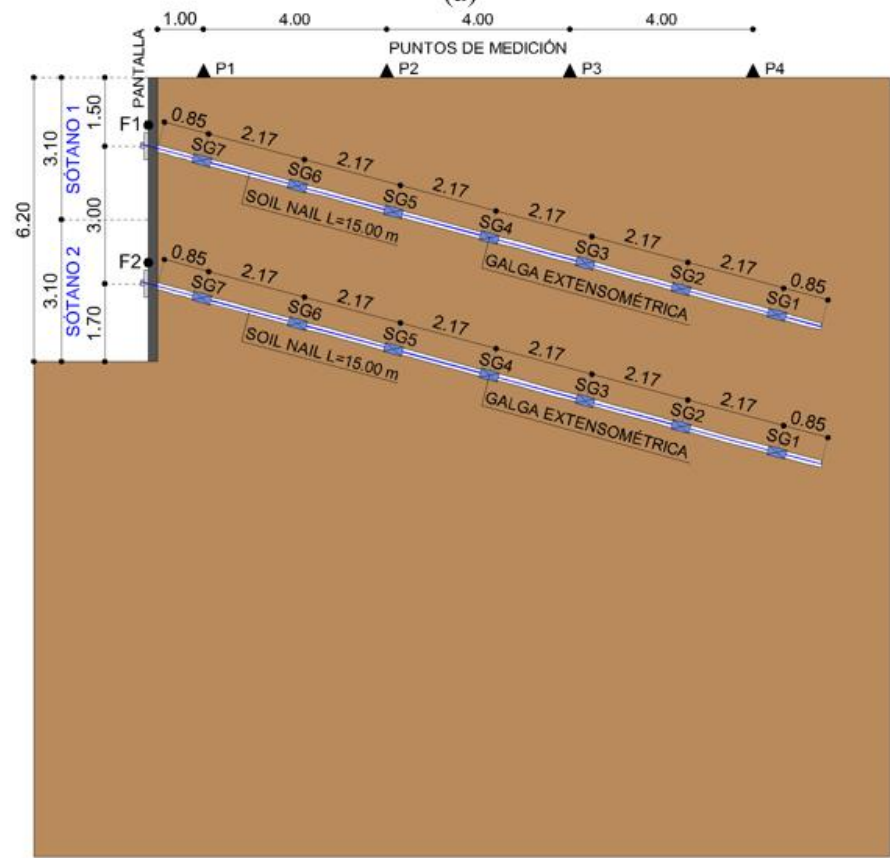

(b)

Fig. 4.36 Instrumentación de pantalla de Zaigen: (a) Instrumentación de "Soil Nail" de sótano 1, y (b) Instrumentación de "Soil Nail" de sótano 2. 


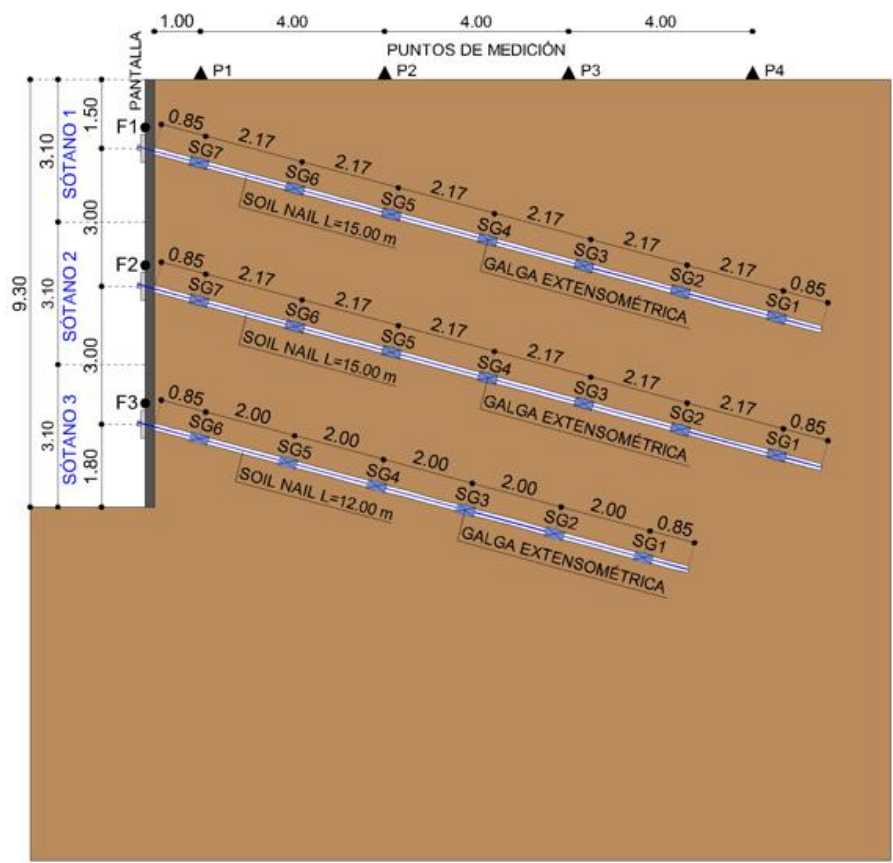

(a)

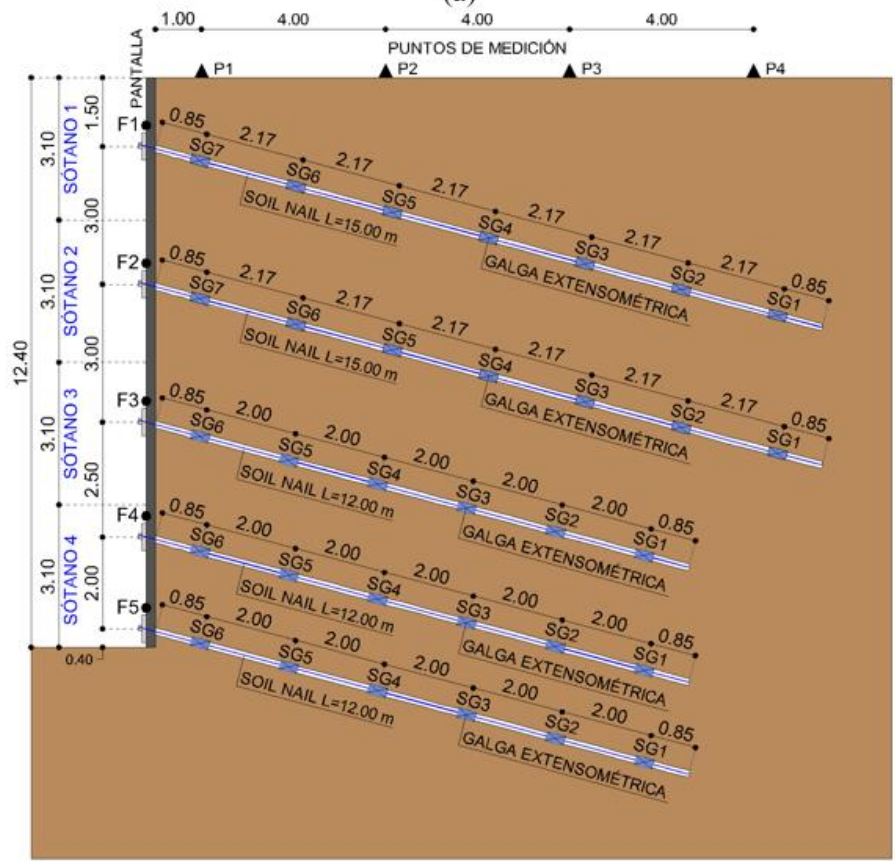

(b)

Fig. 4.37 Instrumentación de pantalla de Zaigen: (a) Instrumentación de "Soil Nail" de sótano 3, y (b) Instrumentación de "Soil Nails" de sótano 4. 


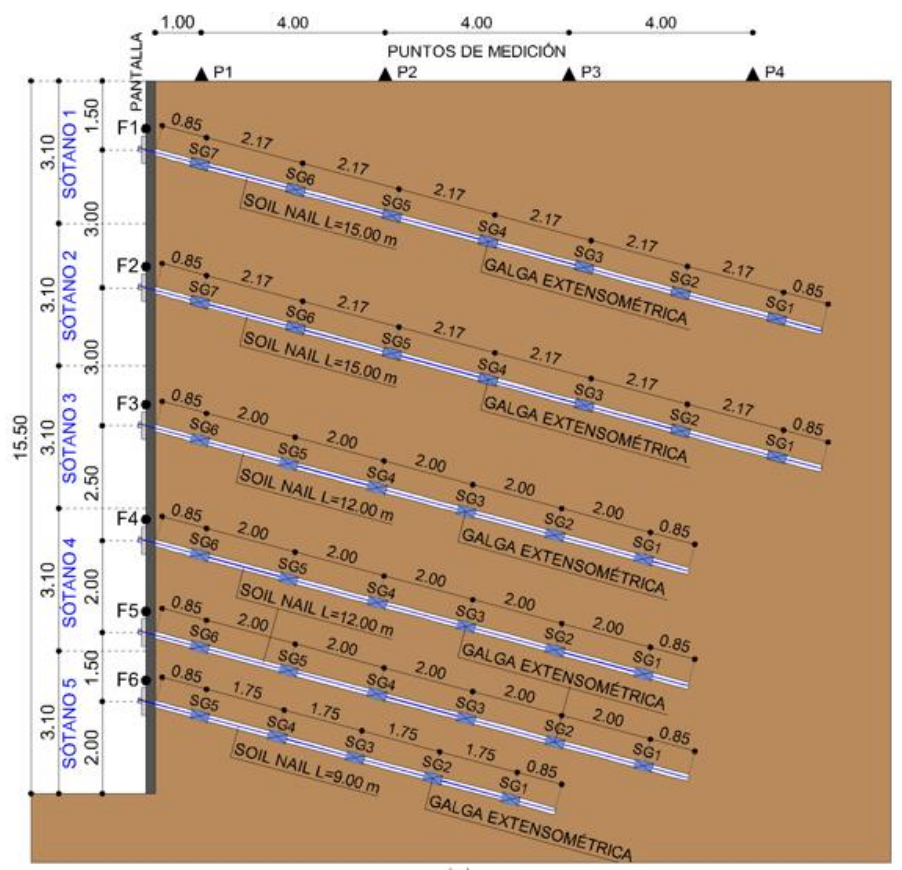

Fig. 4.38 Instrumentación de pantalla de Zaigen: Instrumentación de "Soil Nail" de sótano 5.

De acuerdo a las Fig. 4.36, 4.37 y 4.38, cada nivel de sótano de Zaigen tiene una fila de "Soil Nails", a excepción del cuarto nivel que incluye 2 filas. De igual manera, cada fila de anclajes fue instrumentada con galgas extensométricas. En la Tabla 4.2 se indican las características de los anclajes y la distribución de los mismos con sus respectivos elementos de instrumentación.

Tabla 4.2 Características de "Soil Nails" y elementos de instrumentación en Zaigen.

\begin{tabular}{|c|c|c|c|c|c|c|c|c|}
\hline \multicolumn{2}{|c|}{ SÓTANO } & \multicolumn{2}{|c|}{ "SOIL NAILS" } & \multicolumn{5}{|c|}{ INSTRUMENTACIÓN } \\
\hline $\begin{array}{c}\text { Nivel de } \\
\text { sótano }\end{array}$ & $\begin{array}{l}\text { Fila de } \\
\text { anclaje }\end{array}$ & $\begin{array}{c}\text { Longitud } \\
\text { de "Soil } \\
\text { Nails" } \\
\text { [m] }\end{array}$ & $\begin{array}{c}\text { Separación } \\
\text { horizontal de } \\
\text { "Soil Nails" } \\
{[\mathrm{m}]}\end{array}$ & $\begin{array}{c}\text { Número } \\
\text { de } \\
\text { galgas }\end{array}$ & $\begin{array}{c}\text { Separación } \\
\text { de galgas } \\
{[\mathrm{m}]}\end{array}$ & $\begin{array}{c}\text { Nombre de } \\
\text { galgas }\end{array}$ & $\begin{array}{c}\text { Punto de } \\
\text { medición } \\
\text { en pantalla }\end{array}$ & $\begin{array}{c}\text { Punto de } \\
\text { medición } \\
\text { detrás de } \\
\text { pantalla }\end{array}$ \\
\hline 1 & 1 & 15 & 2.00 & 7 & 2.17 & SG1 a SG7 & $\mathrm{F} 1$ & \\
\hline 2 & 2 & 15 & 1.70 & 7 & 2.17 & SG1 a SG7 & $\mathrm{F} 2$ & \\
\hline 3 & 3 & 12 & 1.60 & 6 & 2.00 & SG1 a SG6 & F3 & P1, P2, \\
\hline 4 & 4 & 12 & 1.60 & 6 & 2.00 & SG1 a SG6 & F4 & P3 y P4 \\
\hline & 5 & 12 & 1.60 & 6 & 2.00 & SG1 a SG6 & F5 & \\
\hline 5 & 6 & 9 & 1.60 & 5 & 1.75 & SG1 a SG5 & F6 & \\
\hline
\end{tabular}

Los procedimientos de instrumentación de Torre Centre y Zaigen fueron similares. 


\subsection{Monitorización}

\subsubsection{Introducción}

El proceso de monitorización inició seguidamente a la instalación de los puntos de medición en el terreno que se encuentran detrás de cada pantalla anclada. Destacándose que la monitorización estuvo continuamente ligada al proceso de instrumentación de cada fase constructiva y en general periódicamente durante el tiempo que tomó la construcción de todos los niveles de sótano.

\subsubsection{Instrumentos para monitorización}

Durante las diferentes fases de monitorización se utilizó principalmente un equipo electrónico de adquisición de datos INET-555 de la marca Omega, previamente calibrado para realizar este tipo de lecturas en el Laboratorio de Estructuras del Instituto de Ciencia y Tecnología del Hormigón (ICITECH) de la Universitat Politècnica de València.

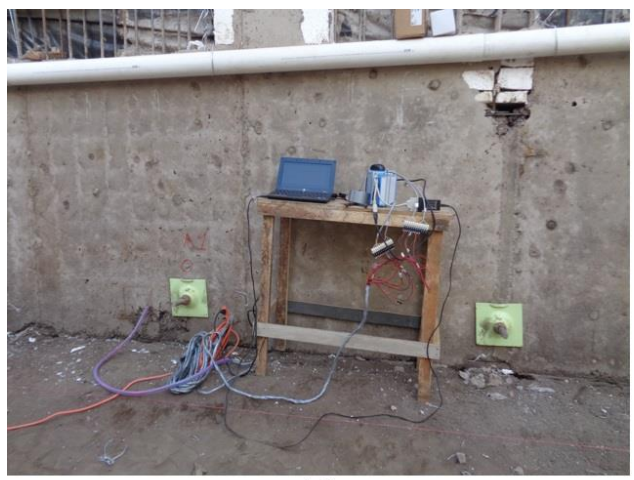

(a)

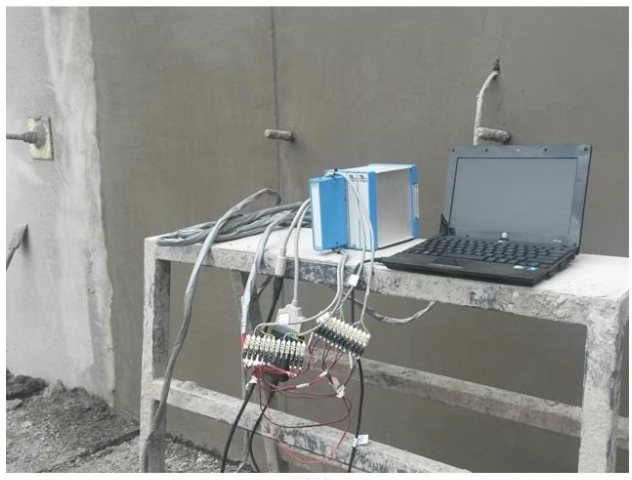

(c)

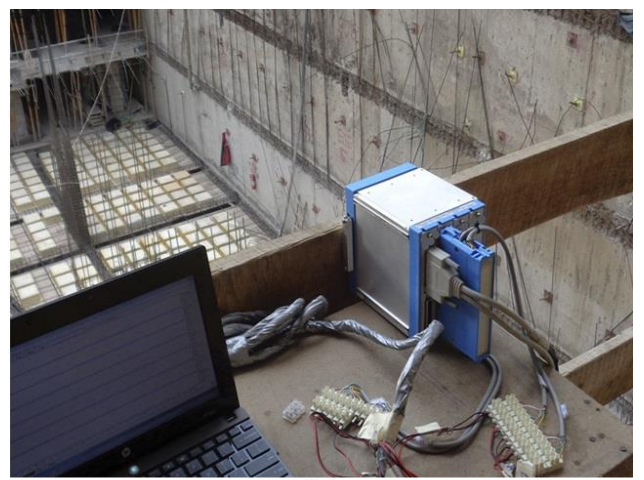

(b)

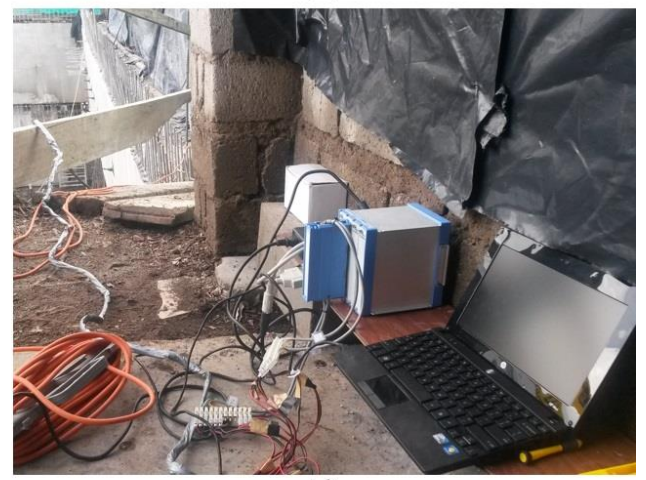

(d)

Fig. 4.39 (a) y (b) Monitorización de anclajes de pantalla de Torre Centre, y (c) y (d) Monitorización de anclajes de pantalla de Zaigen. 
Para las diferentes lecturas, en el momento apropiado los terminales de todas las galgas extensométricas de cada fila de "Soil Nails" fueron conectados al equipo de adquisición de datos, el cual trabaja en interface con un computador portátil y registra las lecturas de "Strain" o deformación unitaria en el sentido longitudinal en los diferentes puntos en que se encuentren instaladas las galgas extensométricas. El tiempo de adquisición de datos en cada anclaje fue de 15 minutos. La Fig. 4.39 muestra el proceso de monitorización de los "Soil Nails" de las pantallas de los proyectos Torre Centre y Zaigen.

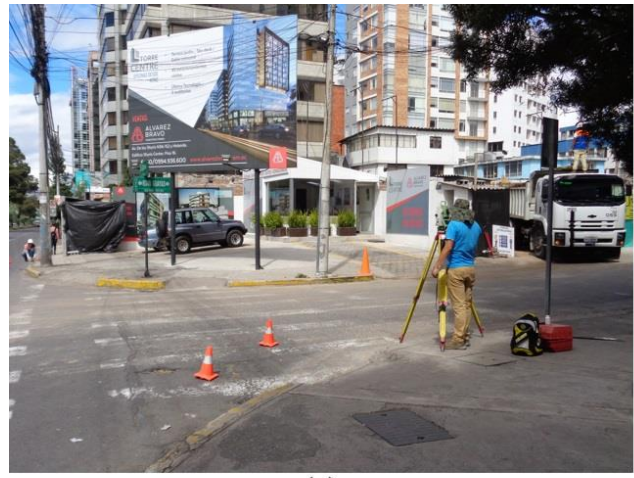

(a)

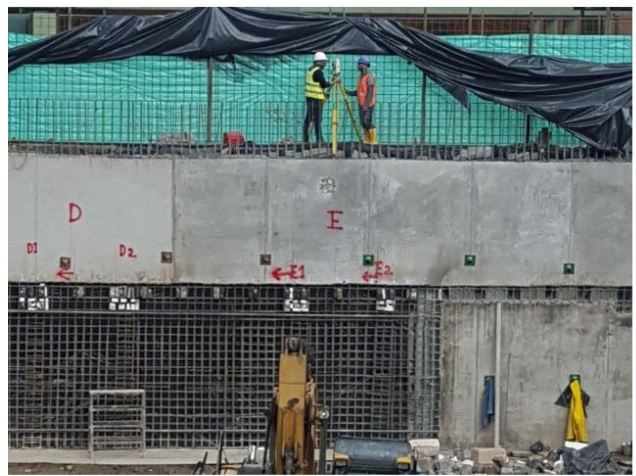

(c)

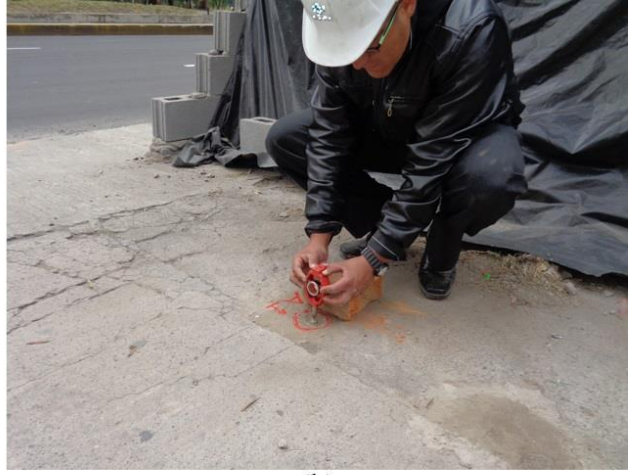

(b)

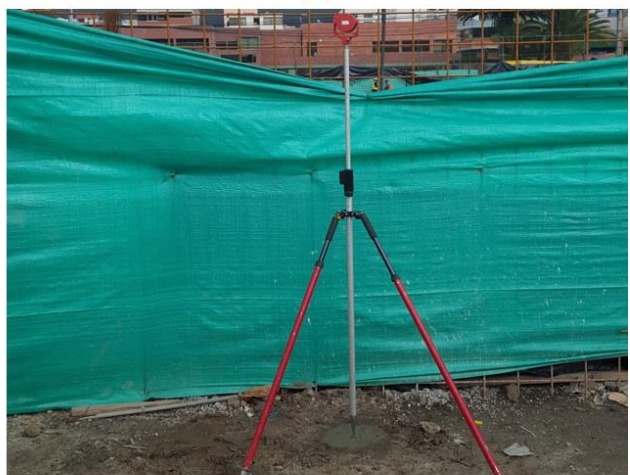

(d)

Fig. 4.40 (a) y (b) Control de deformaciones en proyecto Torre Centre, y (c) y (d) Control de deformaciones en proyecto Zaigen.

Por otra parte, el control de deformaciones en las bases de nivelación ubicadas en el terreno de la parte posterior de las pantallas ancladas y en los puntos de medición localizados en las pantallas se realizó con equipo de topografía. La Fig. 4.40 muestra el proceso de monitorización con equipo topográfico en los proyectos Torre Centre y Zaigen. 


\subsubsection{Plan de monitorización}

Resultó de suma importancia establecer los niveles iniciales del terreno previo al inicio de la primera excavación, puesto que en función de ellos se determinó las deformaciones inferidas por la excavación de cada nivel de sótano y por el proceso constructivo.

Por otra parte, inmediatamente después de la construcción de cada fila de anclajes correctamente instrumentados, se realizó la lectura de valores de partida de "Strain" con el equipo de adquisición de datos, siendo estos valores de gran importancia, puesto que, con el aumento valor de "Strain". Por lo que se requirió de lecturas periódicas de los valores de deformación unitaria reportados por las galgas extensométricas instaladas en los bulones de la altura de corte del terreno para la construcción del siguiente nivel de sótano, las tensiones de las barras de anclaje crecen, y por tanto se necesita conocer ese incremento del o barras de acero. Entonces, como parte de este estudio experimental y de acuerdo a la conveniencia se realizaron lecturas semanales.

Tabla 4.3 Resumen de construcción, instrumentación y monitorización de pantalla para sótanos de Edificio Torre Centre.

\begin{tabular}{|c|c|c|c|c|c|c|}
\hline \multirow[b]{2}{*}{$\begin{array}{l}\text { SÓTANO } \\
\text { No. }\end{array}$} & \multirow{2}{*}{$\begin{array}{c}\text { FASE } \\
\text { Excavación / } \\
\text { Construcción }\end{array}$} & \multirow[b]{2}{*}{$\begin{array}{l}\text { INSTRUMENTACIÓN } \\
\text { (Instalación) }\end{array}$} & \multicolumn{3}{|c|}{ MEDICIÓN } & \multirow[b]{2}{*}{ FECHA } \\
\hline & & & $\begin{array}{l}\text { STRAIN } \\
\text { GAUGES }\end{array}$ & $\begin{array}{l}\text { BASES DE } \\
\text { NIVELACIÓN } \\
\text { (TERRENO) }\end{array}$ & $\begin{array}{l}\text { PUNTOS DE } \\
\text { MEDICIÓN } \\
\text { (PANTALLA) }\end{array}$ & \\
\hline- & - & Bases de nivelación & & $*$ & & $19 / 07 / 2016$ \\
\hline $0.00 \mathrm{~m}$ & Excavación & & & & & $22 / 07 / 2016$ \\
\hline 1 & Const. "Soil Nails" & Strain Gauges & $*$ & & & $23 / 07 / 2016$ \\
\hline$-1.75 \mathrm{~m}$ & Constr. pantalla & Punto metálico & $*$ & $*$ & $*$ & $25 / 07 / 2016$ \\
\hline$-1.75 \mathrm{~m}$ & Excavación & & & & & $02 / 08 / 2016$ \\
\hline 2 & Const. "Soil Nails" & Strain Gauges & $*$ & & & $02 / 08 / 2016$ \\
\hline$-4.65 \mathrm{~m}$ & Constr. pantalla & Punto metálico & $*$ & $*$ & $*$ & 03/08/2016 \\
\hline$-4.65 \mathrm{~m}$ & Excavación & & & & & $12 / 09 / 2016$ \\
\hline 3 & Const. "Soil Nails" & Strain Gauges & $*$ & & & $12 / 09 / 2016$ \\
\hline$-7.55 \mathrm{~m}$ & Constr. pantalla & Punto metálico & $*$ & $*$ & $*$ & $13 / 09 / 2016$ \\
\hline$-7.55 \mathrm{~m}$ & Excavación & & & & & $13 / 12 / 2016$ \\
\hline 4 & Const. "Soil Nails" & Strain Gauges & $*$ & & & $13 / 12 / 2016$ \\
\hline$-10.55 \mathrm{~m}$ & Constr. pantalla & Punto metálico & $*$ & $*$ & $*$ & $14 / 12 / 2016$ \\
\hline$-10.55 \mathrm{~m}$ & Excavación & & & & & $16 / 01 / 2017$ \\
\hline 5 & Const. "Soil Nails" & Strain Gauges & $*$ & & & $17 / 01 / 2017$ \\
\hline$-13.55 \mathrm{~m}$ & Constr. pantalla & Punto metálico & $*$ & $*$ & $*$ & $18 / 01 / 2017$ \\
\hline
\end{tabular}


La construcción de un nuevo nivel de sótano implicaba hacer lecturas en las galgas extensométricas del nuevo anclaje y adicionalmente revisar el comportamiento y almacenar los nuevos valores de "Strain" de los anclajes de los niveles de sótano superiores, puesto que siempre existirá variación por efectos del proceso constructivo.

De manera paralela a todos los procesos de monitorización antes mencionados, se realizó el control de deformaciones en las bases de nivelación y los puntos de medición de la pantalla. En las Tablas 4.3 y 4.4 se muestran resúmenes del proceso constructivo, instrumentación y monitorización de los muros claveteados de Torre Centre y Zaigen, respectivamente.

Tabla 4.4 Resumen de construcción, instrumentación y monitorización de pantalla para sótanos de Edificio Zaigen.

\begin{tabular}{|c|c|c|c|c|c|c|}
\hline \multirow[b]{2}{*}{$\begin{array}{l}\text { SÓTANO } \\
\text { No. }\end{array}$} & \multirow{2}{*}{$\begin{array}{c}\text { FASE } \\
\text { Excavación / } \\
\text { Construcción }\end{array}$} & \multirow[b]{2}{*}{$\begin{array}{l}\text { INSTRUMENTACIÓN } \\
\text { (Instalación) }\end{array}$} & \multicolumn{3}{|c|}{ MEDICIÓN } & \multirow[b]{2}{*}{ FECHA } \\
\hline & & & $\begin{array}{c}\text { STRAIN } \\
\text { GAUGES }\end{array}$ & $\begin{array}{c}\text { BASES DE } \\
\text { NIVELACIÓN } \\
\text { (TERRENO) }\end{array}$ & $\begin{array}{l}\text { PUNTOS DE } \\
\text { MEDICIÓN } \\
\text { (PANTALLA) }\end{array}$ & \\
\hline- & - & Bases de nivelación & & * & & $16 / 03 / 2017$ \\
\hline $0.00 \mathrm{~m}$ & Excavación & & & & & $21 / 03 / 2017$ \\
\hline 1 & Const. "Soil Nails" & Strain Gauges & $*$ & & & $22 / 03 / 2017$ \\
\hline$-3.10 \mathrm{~m}$ & Constr. pantalla & Punto metálico & $*$ & $*$ & $*$ & $23 / 03 / 2017$ \\
\hline$-3.10 \mathrm{~m}$ & Excavación & & & & & $06 / 04 / 2017$ \\
\hline 2 & Const. "Soil Nails" & Strain Gauges & $*$ & & & 07/04/2017 \\
\hline$-6.20 \mathrm{~m}$ & Constr. pantalla & Punto metálico & $*$ & $*$ & $*$ & 08/04/2017 \\
\hline$-6.20 \mathrm{~m}$ & Excavación & & & & & $20 / 04 / 2017$ \\
\hline 3 & Const. "Soil Nails" & Strain Gauges & $*$ & & & $21 / 04 / 2017$ \\
\hline$-9.30 \mathrm{~m}$ & Constr. pantalla & Punto metálico & $*$ & $*$ & $*$ & $22 / 04 / 2017$ \\
\hline$-9.30 \mathrm{~m}$ & Excavación & & & & & $11 / 05 / 2017$ \\
\hline 4 & Const. "Soil Nails" & Strain Gauges & $*$ & & & $12 / 05 / 2017$ \\
\hline$-12.40 \mathrm{~m}$ & Constr. pantalla & Punto metálico & $*$ & $*$ & $*$ & $13 / 05 / 2017$ \\
\hline$-12.40 \mathrm{~m}$ & Excavación & & & & & $18 / 05 / 2017$ \\
\hline 5 & Const. "Soil Nails" & Strain Gauges & $*$ & & & $19 / 05 / 2017$ \\
\hline$-15.50 \mathrm{~m}$ & Constr. pantalla & Punto metálico & $*$ & $*$ & $*$ & $20 / 05 / 2017$ \\
\hline
\end{tabular}

\subsection{Conclusiones relativas al planteamiento del estudio experimental}

En este capítulo se han mencionado las actividades que se realizaron como parte de la instrumentación y monitorización para el estudio del comportamiento de las pantallas ancladas durante sus fases constructivas. 
Para la instrumentación, en cada proyecto se seleccionó la pantalla más representativa, y en la misma se optó por hacer la investigación experimental en la sección transversal de muro ubicada en el punto medio del tramo, incluyéndose en el corte transversal la sección de pantalla con sus respectivos anclajes o "Soil Nails" Para el cometido se utilizaron galgas extensométricas o "Strain Guages", las mismas que fueron instaladas en el sentido longitudinal de las barras de anclaje a determinada distancia de separación.

Se completa la instrumentación con la construcción de bases de nivelación en el terreno que se encuentra en la zona posterior de cada muro y la instalación de puntos metálicos fijos en la pantalla.

Todos los elementos de medición y control de la fase de instrumentación quedaron acordes para ser parte del proceso de monitorización y así obtener la variación de las deformaciones del terreno y la pantalla y principalmente estimar las fuerzas axiales y su distribución en la longitud de cada barra de anclaje. 


\section{Capítulo 5}

\section{ANÁLISIS MEDIANTE ELEMENTOS FINITOS Y EQUILIBRIO LÍMITE}

\subsection{Introducción}

Este capítulo presenta un análisis teórico completo de las 2 estructuras tipo "Soil Nailing" que fueron parte del estudio experimental. Se utilizará principalmente el método de los elementos finitos con la aplicación del programa PLAXIS 2D V20, y métodos de equilibrio límite a través del programa SLIDE2. En cada análisis se utilizarán las características geométricas y estructurales de las pantallas según los proyectos originales. Se completará la información con los parámetros del terreno obtenidos de los ensayos del estudio de caracterización geotécnica del Capítulo 3 de esta investigación. Posteriormente, los factores de seguridad globales obtenidos con estos métodos teóricos serán contrastados y comparados.

\subsection{Parámetros geotécnicos para análisis}

\subsubsection{Generalidades}

En esta sección se definen los parámetros geotécnicos para el análisis de cada estructura, para ello se establecerán los requeridos para la aplicación de los modelos constitutivos de suelo de Mohr Coulomb (MC), Hardening Soil (HS) y Hardening Soil with Small-Strain Stiffness (HSsmall). Por tanto, se determinarán los valores de resistencia y rigidez a utilizar en cada modelo constitutivo. Los parámetros básicos requeridos para estos tres modelos constitutivos de suelo se indican en la Tabla 5.1. 
Tabla 5.1 Parámetros requeridos para los modelos de Mohr Coulomb, Hardening Soil y HSsmall.

\begin{tabular}{|c|c|c|c|c|}
\hline \multirow{2}{*}{ PARÁMETRO } & & \multicolumn{3}{|c|}{ MODELO CONSTITUTIVO } \\
\hline & & $\begin{array}{c}\text { MOHR } \\
\text { COULOMB }\end{array}$ & $\begin{array}{l}\text { HARDENING } \\
\text { SOIL }\end{array}$ & HSsmall \\
\hline Cohesión & $c^{\prime}$ & $\bullet$ & $\bullet$ & $\bullet$ \\
\hline Ángulo de fricción & $\varnothing^{\prime}$ & $\bullet$ & $\bullet$ & $\bullet$ \\
\hline Ángulo de dilatancia & $\psi$ & $\bullet$ & $\bullet$ & • \\
\hline Módulo de Young & $E$ & • & & \\
\hline Relación de Poisson & $v$ & $\bullet$ & & \\
\hline $\begin{array}{l}\text { Módulo de rigidez secante de ensayo triaxial drenado a la } \\
\text { presión de referencia } \mathrm{p}^{\text {ref }}\end{array}$ & $E_{50}^{r e f}$ & & $\bullet$ & • \\
\hline $\begin{array}{l}\text { Módulo de rigidez tangente de carga primaria de ensayo } \\
\text { edométrico a la presión de referencia } \mathrm{p}^{\text {ref }}\end{array}$ & $E_{\text {oed }}^{\text {ref }}$ & & $\bullet$ & $\bullet$ \\
\hline $\begin{array}{l}\text { Módulo de rigidez descarga/recarga a la presión de } \\
\text { referencia } \mathrm{p}^{\text {ref }}\end{array}$ & $E_{u r}^{r e f}$ & & $\bullet$ & $\bullet$ \\
\hline Presión de referencia & $p^{r e f}$ & & $\bullet$ & $\bullet$ \\
\hline $\begin{array}{l}\text { Relación de dependencia de esfuerzos en el comportamiento } \\
\text { de rigidez }\end{array}$ & $m$ & & $\bullet$ & $\bullet$ \\
\hline Relación de Poisson en descarga/recarga & $v_{\mathrm{ur}}$ & & $\bullet$ & $\bullet$ \\
\hline Módulo de corte de referencia en pequeñas deformaciones & $G_{0}^{\text {ef }}$ & & & $\bullet$ \\
\hline Deformación límite por corte, donde $G=0.7 G_{0}$ & $\gamma_{0.7}$ & & & $\bullet$ \\
\hline
\end{tabular}

En ambos proyectos Torre Centre y Zaigen se han identificado 2 estratos principales de suelo, de los cuales se establecerán los parámetros necesarios para cada modelo constitutivo. Los valores para los parámetros de resistencia al corte (cohesión $c^{\prime}$ y ángulo de fricción $\varnothing^{\prime}$ ) son tomados directamente de los ensayos triaxiales consolidados no drenados $(C U)$ y consolidados drenados $(C D)$ analizados en el Capítulo 3 de este estudio.

\subsubsection{Módulo de Young $E$}

\subsubsection{Introducción}

Para el cálculo del módulo de Young $E$ se utilizarán las curvas $q-\varepsilon_{s}$ de los ensayos triaxiales consolidados drenados $C D$ realizados con la presión de confinamiento $\sigma_{3}^{\prime}$ de $100 \mathrm{kPa}$.

\subsubsection{Módulo de Young E para el proyecto Torre Centre}

De la curva esfuerzo $q$ - deformación $\varepsilon_{s}$ de la Fig. 5.1, se puede determinar el módulo de elasticidad tangente $E$ para la muestra $A M A 18.00$ m con presión de confinamiento $\sigma_{3}^{\prime}=100 \mathrm{kPa}$. 


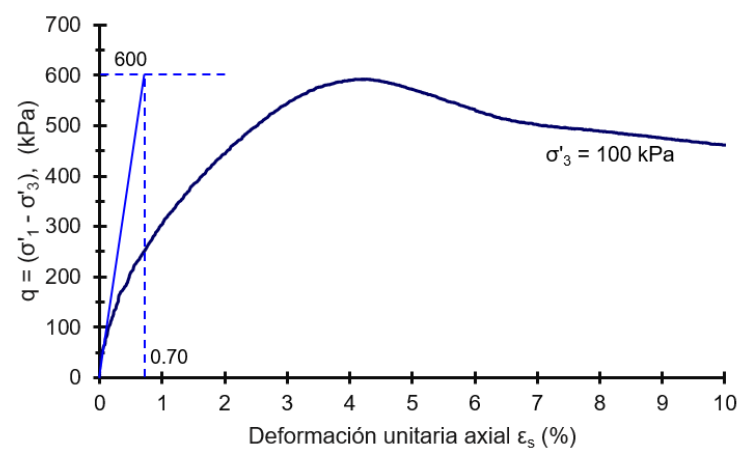

Fig. 5.1 Determinación de módulo de elasticidad tangente $E$ de ensayo triaxial $C D$ en sondeo $A M A 1$ $8.00 \mathrm{~m}$ con presión de confinamiento $\sigma_{3}^{\prime}=100 \mathrm{kPa}$.

Entonces de la Fig. 5.1 se tiene:

$$
E=\frac{600}{0.007}=85714 \mathrm{kPa}
$$

\subsubsection{Módulo de Young E para el proyecto Zaigen}

De la curva esfuerzo $q$ - deformación $\varepsilon_{s}$ de la Fig. 5.2, se puede calcular el módulo de elasticidad tangente $E$ para $J A P 113.50 \mathrm{~m}$ con presión de confinamiento $\sigma_{3}{ }_{3}=100$ $\mathrm{kPa}$.

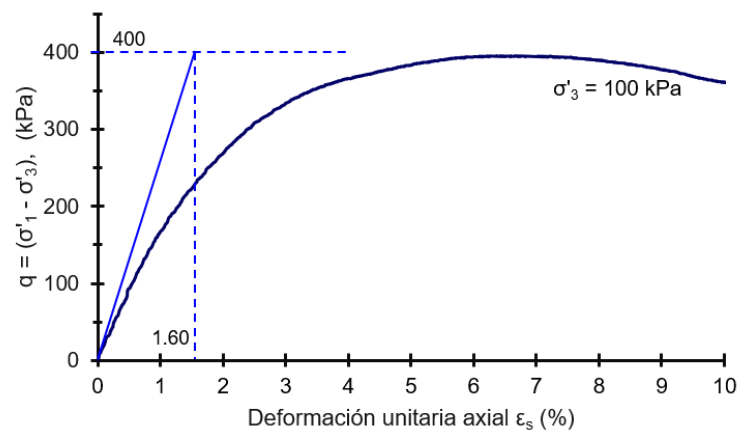

Fig. 5.2 Determinación de módulo de elasticidad tangente $E$ de ensayo triaxial $C D$ en sondeo JAPI $13.50 \mathrm{~m}$ con presión de confinamiento $\sigma_{3}^{\prime}=100 \mathrm{kPa}$.

Entonces de la Fig. 5.2 se tiene:

$$
E=\frac{400}{0.016}=25000 \mathrm{kPa}
$$




\subsubsection{Módulo de rigidez secante $E_{50}^{r e f}$}

\subsubsection{Introducción}

Para el cálculo del módulo de rigidez secante $E_{50}^{r e f}$ se utilizarán las curvas $q-\varepsilon_{s}$ de los ensayos triaxiales $C D$ disponibles, con diferentes presiones de confinamiento $\sigma_{3}^{\prime}$. Del proyecto Torre Centre se dispone del ensayo triaxial $C D$ de la perforación $A M A I$ $8.00 \mathrm{~m}$ con las presiones de confinamiento $\sigma_{3}^{\prime}$ de $100 \mathrm{kPa}, 200 \mathrm{kPa}$ y $300 \mathrm{kPa}$. En tanto, del proyecto Zaigen se dispone del ensayo triaxial $C D$ del sondeo JAP1 13.50 $\mathrm{m}$ con presiones de confinamiento $\sigma_{3}^{\prime}$ de $50 \mathrm{kPa}, 100 \mathrm{kPa}, 200 \mathrm{kPa}$ y $300 \mathrm{kPa}$. Por defecto el módulo de rigidez $E_{50}^{r e f}$ se calcula para la presión de referencia $p^{r e f}=100$ $\mathrm{kPa}$.

\subsubsection{Módulo de rigidez secante $E_{50}^{\text {ref }}$ para el proyecto Torre Centre}

Del ensayo triaxial consolidado drenado $(C D)$ del sondeo $A M A 18.00 \mathrm{~m}$ se tienen los parámetros de resistencia al corte drenado $c^{\prime}=69 \mathrm{kPa}$ y $\varnothing^{\prime}=36.1^{\circ}($ Ver sección 3.7.3. de Capítulo 3).

De la Fig. 5.3, se puede determinar el módulo de rigidez secante $E_{50}$ para $A M A 18.00$ $\mathrm{m}$ con presión de confinamiento $\sigma_{3}^{\prime}=100 \mathrm{kPa}$.

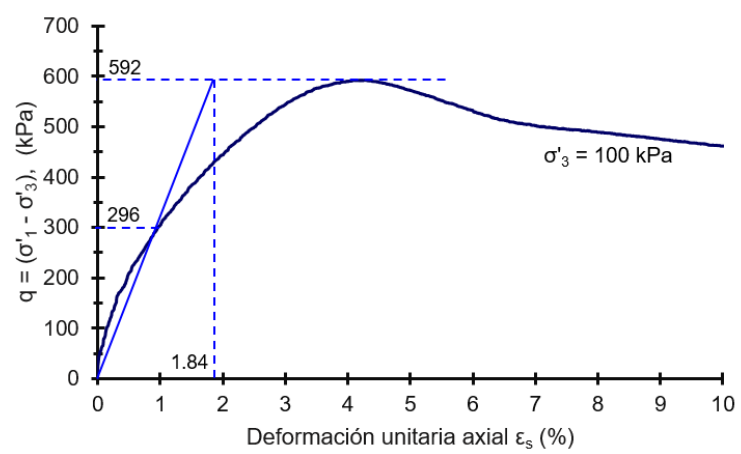

Fig. 5.3 Determinación de módulo de rigidez secante $E_{50}$ de ensayo triaxial $C D$ en sondeo $A M A 18.00$ m con presión de confinamiento $\sigma_{3}^{\prime}=100 \mathrm{kPa}$.

Por tanto, de la Fig. 5.3 se tiene la relación:

$$
E_{50}^{\sigma^{\prime} 3=100 \mathrm{kPa}}=\frac{592}{0.0184}=32174 \mathrm{kPa}
$$

De la Fig. 5.4, se puede determinar el módulo de rigidez secante $E_{50}$ para AMA1 8.00 $\mathrm{m}$ con presión de confinamiento $\sigma_{3}^{\prime}=200 \mathrm{kPa}$. 


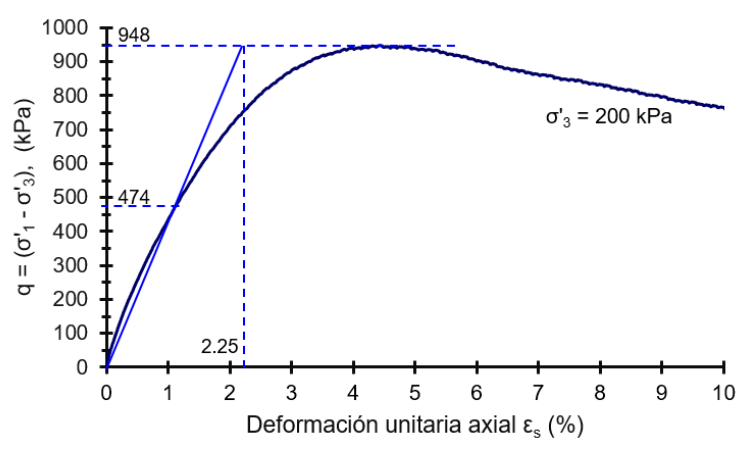

Fig. 5.4 Determinación de módulo de rigidez secante $E_{50}$ de ensayo triaxial $C D$ en sondeo $A M A 18.00$ m con presión de confinamiento $\sigma_{3}^{\prime}=200 \mathrm{kPa}$.

Entonces, de la Fig. 5.4 se tiene la relación:

$$
E_{50}^{\sigma^{\prime} 3=200 \mathrm{kPa}}=\frac{948}{0.0225}=42133 \mathrm{kPa}
$$

De la Fig. 5.5, se puede determinar el módulo de rigidez secante $E_{50}$ para AMA1 8.00 $\mathrm{m}$ con presión de confinamiento $\sigma_{3}^{\prime}=300 \mathrm{kPa}$.

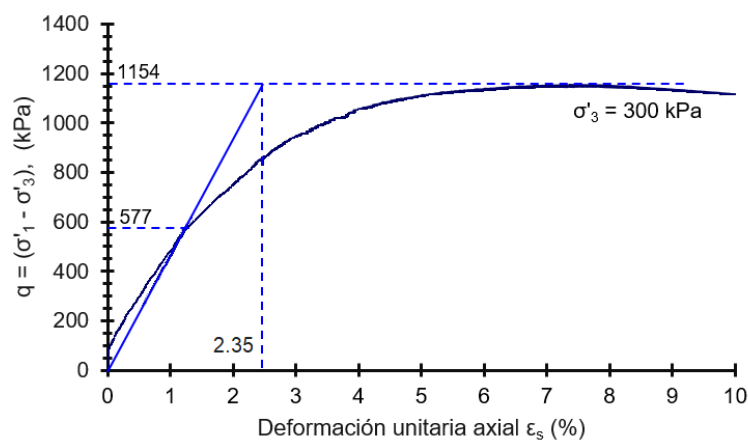

Fig. 5.5 Determinación de módulo de rigidez secante $E_{50}$ de ensayo triaxial $C D$ en sondeo AMA1 8.00 m con presión de confinamiento $\sigma_{3}^{\prime}=300 \mathrm{kPa}$.

Por tanto, de la Fig. 5.5 se tiene la relación:

$$
E_{50}^{\sigma^{\prime} 3=300 \mathrm{kPa}}=\frac{1154}{0.0235}=49106 \mathrm{kPa}
$$

Se grafica $\operatorname{Ln}\left(E_{50}\right)$ versus $\operatorname{Ln}\left(\frac{c^{\prime} \cos \emptyset^{\prime}-\sigma_{3}^{\prime} \operatorname{sen} \emptyset^{\prime}}{c^{\prime} \cos \emptyset^{\prime}+p^{r e f} \operatorname{sen} \emptyset^{\prime}}\right)$ para las 3 muestras ensayadas a diferentes presiones de confinamiento, en escala natural y se traza una línea recta que mejor se ajuste a los 3 puntos. En esta ecuación, $\sigma_{3}^{\prime}$ se considera como negativo. 
La intercepción de la línea de tendencia con el eje vertical $(\mathrm{x}=0)$ proporciona el valor de $\operatorname{Ln}\left(E_{50}^{\text {ref }}\right)$ y la pendiente de esta recta corresponde al valor del parámetro $m$. La Tabla 5.2 y la Fig. 5.6 muestran el resumen de valores y la determinación de $E_{50}^{\text {ref }}$.

Tabla 5.2 Resumen de valores de $E_{50}$ para determinación de $E_{50}^{r e f}$ de muestra $A M A 18.00 \mathrm{~m}$.

\begin{tabular}{|c|c|c|c|c|c|c|c|}
\hline $\begin{array}{c}c^{\prime} \\
{[\mathrm{kPa}]}\end{array}$ & $\begin{array}{l}\emptyset^{\prime} \\
{\left[{ }^{\circ}\right]}\end{array}$ & $\begin{array}{c}\sigma_{3}^{\prime} \\
{[\mathrm{kPa}]}\end{array}$ & $\begin{array}{l}p^{r e f} \\
{[\mathrm{kPa}]}\end{array}$ & $\begin{array}{c}E_{50} \\
{[\mathrm{kPa}]}\end{array}$ & $\operatorname{Ln}\left(E_{50}\right)$ & $\left(\frac{c^{\prime} \cos \emptyset^{\prime}-\sigma_{3}^{\prime} \operatorname{sen} \emptyset^{\prime}}{c^{\prime} \cos \emptyset^{\prime}+p^{r e f} \operatorname{sen} \emptyset^{\prime}}\right)$ & $\operatorname{Ln}\left(\frac{c^{\prime} \cos \emptyset^{\prime}-\sigma^{\prime} 3 \operatorname{sen} \emptyset^{\prime}}{c^{\prime} \cos \emptyset^{\prime}+p^{r e f} \operatorname{sen} \emptyset^{\prime}}\right)$ \\
\hline \multirow{3}{*}{69} & \multirow{3}{*}{36.1} & -100 & \multirow{3}{*}{100} & 32174 & 10.379 & 1.000 & 0.000 \\
\hline & & -200 & & 42133 & 10.649 & 1.514 & 0.415 \\
\hline & & -300 & & 49106 & 10.802 & 2.028 & 0.707 \\
\hline
\end{tabular}

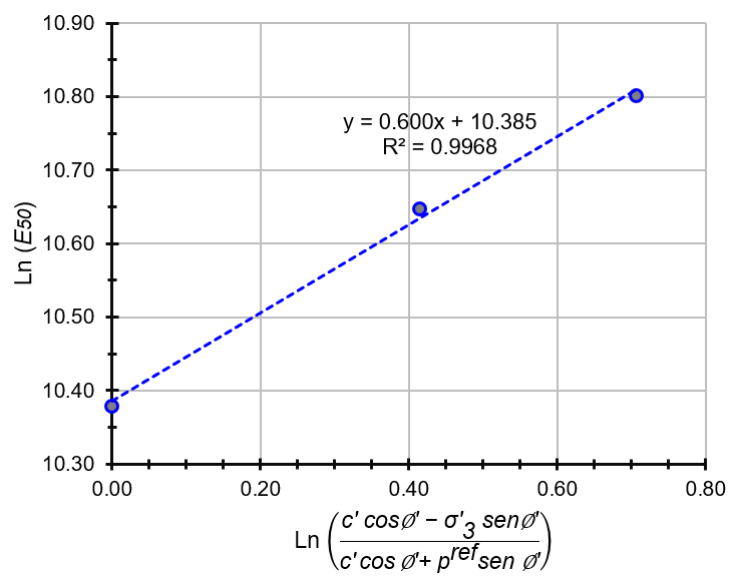

Fig. 5.6 Determinación del módulo de rigidez $E_{50}^{\text {ref }}$ para AMA1 $8.00 \mathrm{~m}$ de Torre Centre.

De la Fig. 5.6 se tiene $\operatorname{Ln}\left(E_{50}^{r e f}\right)=10.385$, de donde automáticamente se deduce el valor para el módulo de rigidez $E_{50}^{\text {ref }}$, entonces:

$$
E_{50}^{r e f}=32370 \mathrm{kPa}
$$

La pendiente de la línea de tendencia es 0.60 , que corresponde al parámetro $m$, entonces:

$$
m=0.60
$$

\subsubsection{Módulo de rigidez secante $E_{50}^{\text {ref }}$ para el proyecto Zaigen}

Del ensayo triaxial consolidado drenado $(C D)$ del sondeo JAP1 $13.50 \mathrm{~m}$ se tienen los parámetros de resistencia al corte drenado $c^{\prime}=20 \mathrm{kPa}$ y $\varnothing^{\prime}=36.9^{\circ}($ Ver sección 3.7.3. de Capítulo 3). 
De la Fig. 5.7, se obtiene el módulo de rigidez secante $E_{50}$ para $J A P 113.50 \mathrm{~m}$ con presión de confinamiento $\sigma_{3}{ }_{3}=50 \mathrm{kPa}$.

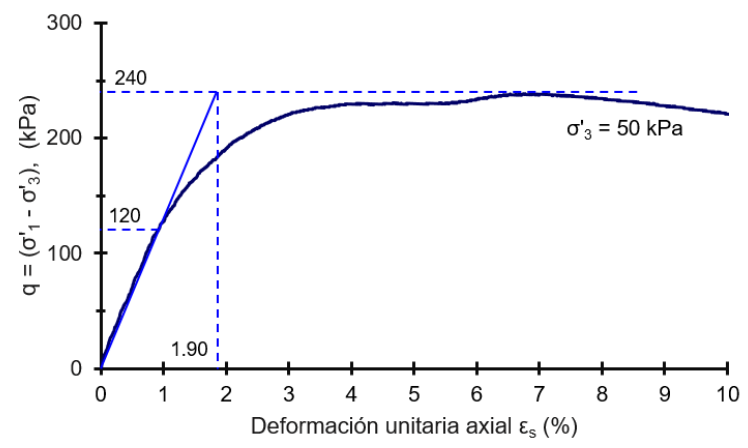

Fig. 5.7 Determinación de módulo de rigidez secante $E_{50}$ de ensayo triaxial $C D$ en sondeo JAPl 13.50 m con presión de confinamiento $\sigma_{3}^{\prime}=50 \mathrm{kPa}$.

Entonces, de la Fig. 5.7 se tiene la relación:

$$
E_{50}^{\sigma_{3}^{\prime}=50 \mathrm{kPa}}=\frac{240}{0.0190}=12632 \mathrm{kPa}
$$

De la Fig. 5.8, se puede determinar el módulo de rigidez secante $E_{50}$ para JAPl 13.50 $\mathrm{m}$ con presión de confinamiento $\sigma_{3}{ }_{3}=100 \mathrm{kPa}$.

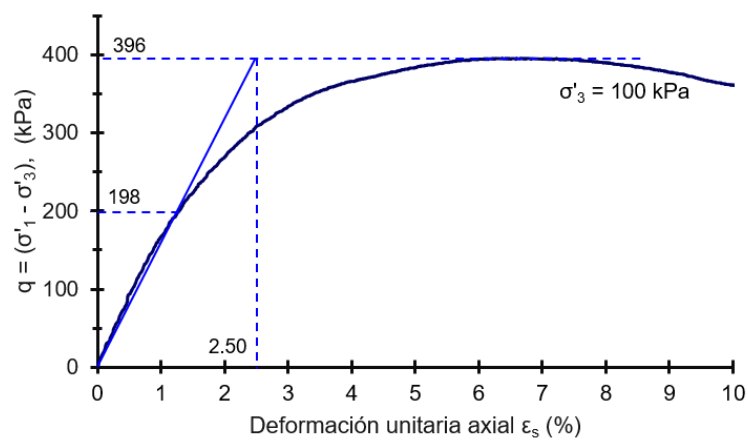

Fig. 5.8 Determinación de módulo de rigidez secante $E_{50}$ de ensayo triaxial $C D$ en sondeo JAP1 13.50 $\mathrm{m}$ con presión de confinamiento $\sigma_{3}^{\prime}=100 \mathrm{kPa}$.

Por tanto, de la Fig. 5.8 se tiene la relación:

$$
E_{50}^{\sigma^{\prime} 3=100 \mathrm{kPa}}=\frac{396}{0.0250}=15840 \mathrm{kPa}
$$

De la Fig. 5.9, se puede determinar el módulo de rigidez secante $E_{50}$ para JAPl 13.50 $\mathrm{m}$ con presión de confinamiento $\sigma_{3}^{\prime}=200 \mathrm{kPa}$. 


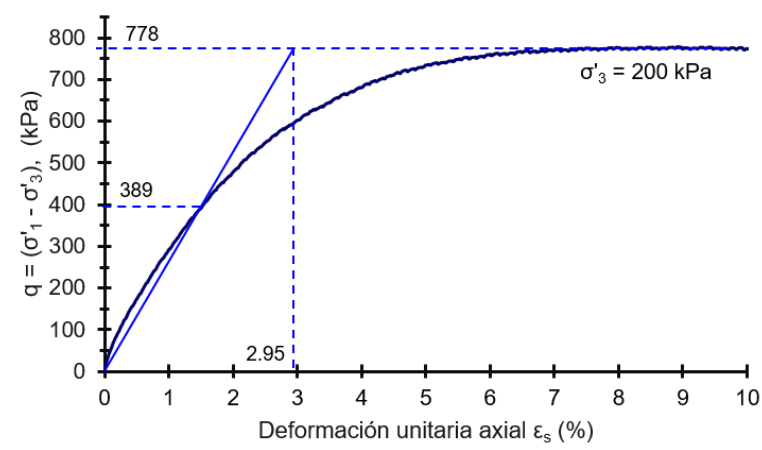

Fig. 5.9 Determinación de módulo de rigidez secante $E_{50}$ de ensayo triaxial $C D$ en sondeo JAP1 13.50 m con presión de confinamiento $\sigma_{3}^{\prime}=200 \mathrm{kPa}$.

Entonces, de la Fig. 5.9 se tiene la relación:

$$
E_{50}^{\sigma^{\prime} 3=200 \mathrm{kPa}}=\frac{778}{0.0295}=26373 \mathrm{kPa}
$$

De la Fig. 5.10, se puede determinar el módulo de rigidez secante $E_{50}$ para JAPI $13.50 \mathrm{~m}$ con presión de confinamiento $\sigma_{3}^{\prime}=300 \mathrm{kPa}$.

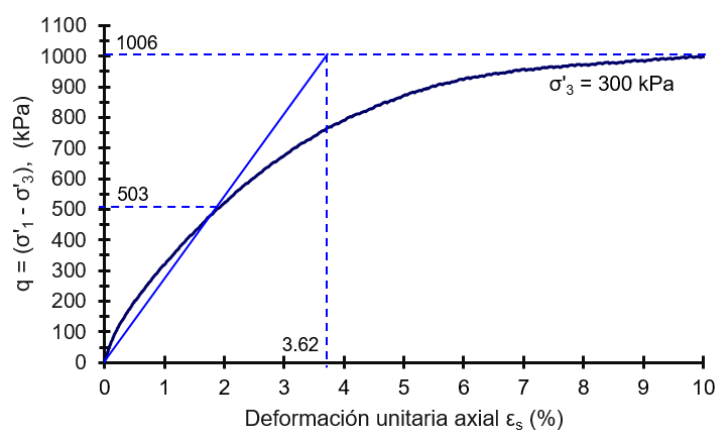

Fig. 5.10 Determinación de módulo de rigidez secante $E_{50}$ de ensayo triaxial $C D$ en sondeo JAP1 13.50 m con presión de confinamiento $\sigma_{3}^{\prime}=300 \mathrm{kPa}$.

Por tanto, de la Fig. 5.10 se tiene la relación:

$$
E_{50}^{\sigma^{\prime} 3=300 \mathrm{kPa}}=\frac{1006}{0.0362}=27790 \mathrm{kPa}
$$

Se grafica $\operatorname{Ln}\left(E_{50}\right)$ versus $\operatorname{Ln}\left(\frac{c^{\prime} \cos \emptyset^{\prime}-\sigma_{3}^{\prime} \operatorname{sen} \emptyset^{\prime}}{c^{\prime} \cos \emptyset^{\prime}+p^{r e f} \operatorname{sen} \emptyset^{\prime}}\right)$ para las 4 muestras ensayadas a diferentes presiones de confinamiento, en escala natural y se traza una línea recta que mejor se ajuste a los 4 puntos. En esta expresión, $\sigma_{3}^{\prime}$ se considera como negativo. 
La intercepción de la línea de tendencia con el eje vertical $(\mathrm{x}=0)$ proporciona el valor de $\operatorname{Ln}\left(E_{50}^{r e f}\right)$ y el valor del parámetro $m$ está dado por la pendiente de esta recta. La Tabla 5.3 y la Fig. 5.11 presentan el resumen de valores y la determinación de $E_{50}^{\text {ref }}$.

Tabla 5.3 Resumen de valores de $E_{50}$ para determinación de $E_{50}^{r e f}$ de muestra JAP1 $13.50 \mathrm{~m}$.

\begin{tabular}{cccccccc}
\hline $\begin{array}{c}c^{\prime} \\
{[\mathrm{kPa}]}\end{array}$ & $\begin{array}{c}\emptyset^{\prime} \\
{\left[{ }^{\circ}\right]}\end{array}$ & $\begin{array}{c}\sigma_{3}^{\prime} \\
{[\mathrm{kPa}]}\end{array}$ & $\begin{array}{c}p^{r e f} \\
{[\mathrm{kPa}]}\end{array}$ & $\begin{array}{c}E_{50} \\
{[\mathrm{kPa}]}\end{array}$ & $\operatorname{Ln}\left(E_{50}\right)$ & $\left(\frac{c^{\prime} \cos \emptyset^{\prime}-\sigma_{3}^{\prime} \operatorname{sen} \emptyset^{\prime}}{c^{\prime} \cos \emptyset^{\prime}+p^{r e f} \operatorname{sen} \emptyset^{\prime}}\right)$ & $\operatorname{Ln}\left(\frac{c^{\prime} \cos \emptyset^{\prime}-\sigma_{3}^{\prime} \operatorname{sen} \emptyset^{\prime}}{c^{\prime} \cos \emptyset^{\prime}+p^{r e} \operatorname{sen} \emptyset^{\prime}}\right)$ \\
\hline \multirow{3}{*}{20} & & -50 & & 12632 & 9.444 & 0.605 & -0.503 \\
& 36.9 & -100 & \multirow{2}{*}{100} & 15840 & 9.670 & 1.000 & 0.000 \\
& -200 & & 26373 & 10.180 & 1.790 & 0.582 \\
& & -300 & & 27790 & 10.232 & 2.579 & 0.947 \\
\hline
\end{tabular}

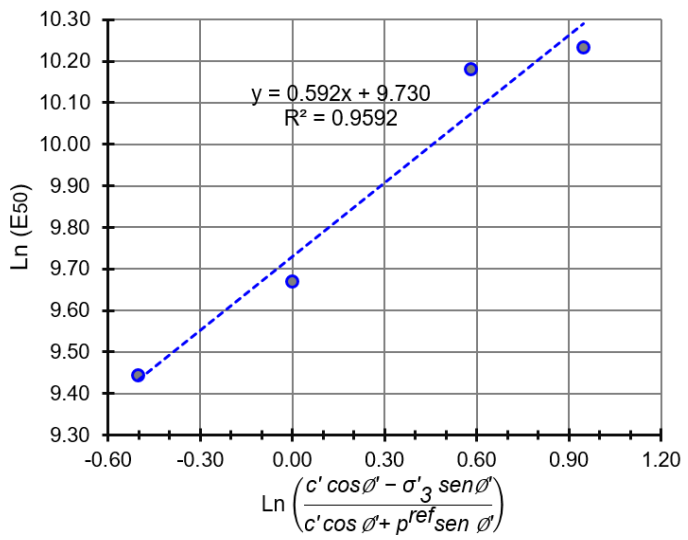

Fig. 5.11 Determinación del módulo de rigidez $E_{50}^{r e f}$ para JAP1 $13.50 \mathrm{~m}$ de Zaigen.

De la Fig. 5.11 se tiene $\operatorname{Ln}\left(E_{50}^{r e f}\right)=9.730$, de donde automáticamente se deduce el valor para el módulo de rigidez $E_{50}^{\text {ref }}$, entonces:

$$
E_{50}^{r e f}=16815 \mathrm{kPa}
$$

La pendiente de la línea de tendencia es 0.59 , que corresponde al parámetro $m$, entonces:

$$
m=0.59
$$

5.2.3.4. Estimación de Módulo de rigidez secante $E_{50}^{r e f}$ a partir de $E_{50(u)}^{r e f}$

Al no disponer de ensayos triaxiales consolidados drenados $(C D)$ en Torre Centre dentro del estrato comprendido entre $0.00 \mathrm{~m}$ y $6.00 \mathrm{~m}$ y en Zaigen dentro del estrato 
comprendido entre $0.00 \mathrm{~m}$ y $7.50 \mathrm{~m}$, el parámetro de rigidez secante drenado $E_{50}^{\text {ref }}$ se estimará a partir de la rigidez no drenada $E_{50(u)}^{r e f}$.

Según Wroth y Houlsby (1985), el factor $f$ de la expresión 5.1 establece la relación entre el comportamiento drenado y no drenado de los suelos.

$$
f=\frac{1+v}{1+v_{u}}
$$

En donde, $v$ es la relación de Poisson en condiciones drenadas y $v_{u}$ es la relación de Poisson en condiciones no drenadas. Para el presente caso $v=0.2$ y para condiciones no drenadas $v_{u}=0.5$ (Wroth y Houlsby, 1985). Por lo tanto, se deduce la relación de la expresión 5.2 para estimar $E_{50}^{\text {ref }}$. Además, con estos parámetros conocidos en el presente caso, se determina $f=0.80$.

$$
E_{50}^{r e f}=f E_{50(u)}^{r e f}
$$

Por otra parte, se conoce la rigidez secante no drenada $E_{50(u)}^{\text {ref }}$ de los ensayos AMAI $4.50 \mathrm{~m}$ y JAP1 $7.50 \mathrm{~m}$, correspondientes a los estratos superficiales de suelo de los proyectos Torre Centre y Zaigen, respectivamente (Ver sección 3.8. de Capítulo 3). En la Tabla 5.4 se presenta la estimación de los valores de rigidez secante $E_{50}^{\text {ref }}$.

Tabla 5.4 Estimación de módulo de rigidez secante $E_{50}^{r e f}$ para estratos superficiales.

\begin{tabular}{cccccc}
\hline Proyecto & Sondeo & $\begin{array}{c}\text { Profundidad } \\
{[\mathrm{m}]}\end{array}$ & $\begin{array}{c}E_{50(u)}^{\text {ref }} \\
{[\mathrm{kPa}]}\end{array}$ & $f$ & $\begin{array}{c}E_{50}^{\text {ref }} \\
{[\mathrm{kPa}]}\end{array}$ \\
\hline $\begin{array}{c}\text { Torre Centre } \\
\text { Zaigen }\end{array}$ & AMA1 & 4.50 & 11364 & 0.80 & 9091 \\
\hline
\end{tabular}

\subsubsection{Módulo de rigidez tangente $E_{o e d}^{\text {ref }}$}

\subsubsection{Introducción}

Para el cálculo del módulo de rigidez tangente $E_{\text {oed }}^{\text {ref }}$ se utilizarán los datos del estado de carga primaria de los ensayos edométricos para construir curvas deformación unitaria vertical, $\varepsilon_{y}$ versus esfuerzo efectivo vertical, $\sigma_{\mathrm{y}}^{\prime}$. Para hacer más simples los cálculos ambos ejes se grafican en escala aritmética. En la determinación de $E_{\text {oed }}$, se tomarán en cuenta los esfuerzos verticales efectivos de $\sigma_{\mathrm{y}}^{\prime}=100 \mathrm{kPa}$ y $\sigma_{\mathrm{y}}^{\prime}=200 \mathrm{kPa}$.

\subsubsection{Módulo de rigidez tangente $E_{\text {oed }}^{\text {ref }}$ para el proyecto Torre Centre}

Para Torre Centre se dispone del ensayo edométrico AMA1 $1.50 \mathrm{~m}$, de donde se obtiene la gráfica $\varepsilon_{y}$ - $\sigma_{\mathrm{y}}^{\prime}$ indicada en la Fig. 5.12, de aquí se determina el módulo de rigidez tangente $E_{\text {oed }}$ para $\sigma_{y}^{\prime}=-100 \mathrm{kPa}$. La compresión se considera negativa. 


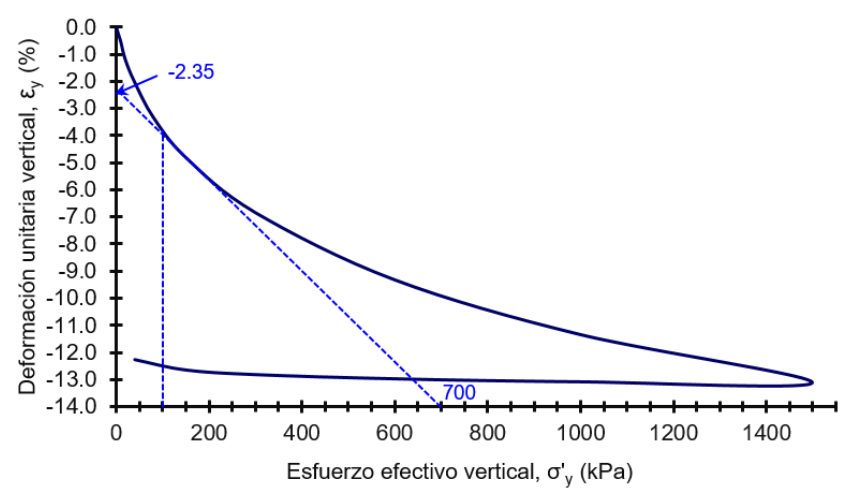

Fig. 5.12 Determinación de módulo de rigidez tangente $E_{\text {oed }}$ de ensayo edométrico en sondeo AMA1 $1.50 \mathrm{~m}$.

De la Fig. 5.12 se tiene la relación:

$$
E_{\text {oed }}^{\text {ref }}=E_{\text {oed }}^{\sigma_{y}^{\prime}=100 \mathrm{kPa}}=\frac{700}{0.14-0.0235}=6009 \mathrm{kPa}
$$

Para Torre Centre se dispone además del ensayo edométrico AMA1 $7.50 \mathrm{~m}$. A partir de los datos de este ensayo se obtiene la gráfica $\varepsilon_{y}-\sigma_{\text {y }}^{\prime}$ indicada en la Fig. 5.13, de donde se puede determinar el módulo de rigidez tangente $E_{\text {oed }}$ para este ensayo.

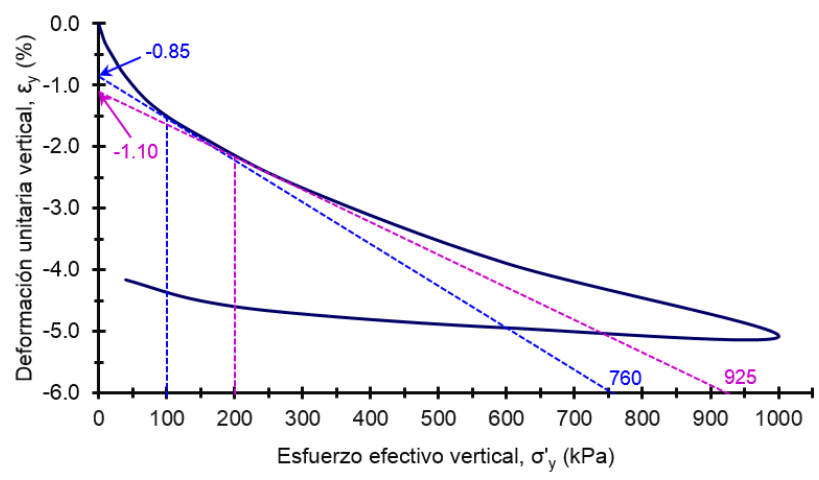

Fig. 5.13 Determinación de módulo de rigidez tangente $E_{\text {oed }}$ de ensayo edométrico en sondeo AMAl $7.50 \mathrm{~m}$.

De la Fig. 5.13 se tiene las relaciones:

$$
\begin{aligned}
& E_{\text {oed }}^{\sigma_{y}^{\prime}=100 \mathrm{kPa}}=\frac{760}{0.06-0.0085}=14757 \mathrm{kPa} \\
& E_{\text {oed }}^{\sigma_{y}^{\prime}=200 \mathrm{kPa}}=\frac{925}{0.06-0.0110}=18878 \mathrm{kPa}
\end{aligned}
$$


En el modelo de Hardening Soil, el módulo de rigidez tangente se define por la expresión 5.3.

$$
E_{\text {oed }}=E_{\text {oed }}^{r e f}\left(\frac{c^{\prime} \cos \varnothing^{\prime}-\sigma_{y}^{\prime} \operatorname{sen} \varnothing^{\prime}}{c^{\prime} \cos \varnothing^{\prime}+p^{r e f} \operatorname{sen} \varnothing^{\prime}}\right)^{m}
$$

Para este caso, se considera $c^{\prime}=69 \mathrm{kPa}$ y $\varnothing^{\prime}=36.1^{\circ}$. Siendo la presión de referencia $p^{r e f}=100 \mathrm{kPa}$ y para $\sigma_{y}^{\prime}=-100 \mathrm{kPa}$, puesto que la compresión se considera como negativa, de la expresión 5.3 se deduce:

$$
\begin{gathered}
E_{\text {oed }}^{\sigma_{y}^{\prime}=100 \mathrm{kPa}}=E_{\text {oed }}^{r e f} \\
E_{\text {oed }}^{\text {ref }}=E_{\text {oed }}^{\sigma_{y}^{\prime}=100 \mathrm{kPa}}=14757 \mathrm{kPa}
\end{gathered}
$$

Por otra parte, para el caso en donde la presión de referencia $p^{r e f}=100 \mathrm{kPa}$ y para $\sigma_{y}^{\prime}=-200 \mathrm{kPa}$, de la expresión 5.3 se deduce:

$$
E_{\text {oed }}^{\sigma_{y=200 k a}^{\prime}}=E_{\text {oed }}^{r e f}\left(\frac{c^{\prime} \cos \emptyset^{\prime}-(-200) \operatorname{sen} \emptyset^{\prime}}{c^{\prime} \cos \emptyset^{\prime}+p^{r e f} \operatorname{sen} \emptyset^{\prime}}\right)^{m}
$$

De donde:

$$
\begin{gathered}
\frac{E_{\text {oed }}^{\sigma_{y}^{\prime}=200 k P a}}{E_{\text {oed }}^{r e f}}=\left[\frac{69 \cos \left(36.1^{\circ}\right)-(-200) \operatorname{sen}\left(36.1^{\circ}\right)}{69 \cos \left(36.1^{\circ}\right)+(100) \operatorname{sen}\left(36.1^{\circ}\right)}\right]^{m} \\
\frac{18878}{14757}=1.51^{m} \\
m=0.60
\end{gathered}
$$

La relación de dependencia de esfuerzos en el comportamiento de rigidez para este caso coincide con el valor de $m=0.60$ determinado a partir del ensayo triaxial drenado $C D$ para la muestra $A M A 18.00 \mathrm{~m}$.

\subsubsection{Módulo de rigidez tangente $E_{\text {oed }}^{r e f}$ para el proyecto Zaigen}

Para Zaigen se dispone del ensayo edométrico JAP1 $6.50 \mathrm{~m}$, de donde se genera la gráfica $\varepsilon_{y}-\sigma_{y}^{\prime}$ indicada en la Fig. 5.14, de aquí se determina el módulo de rigidez tangente $E_{\text {oed }}$ para $\sigma_{y}^{\prime}=-100 \mathrm{kPa}$. La compresión se considera negativa. 


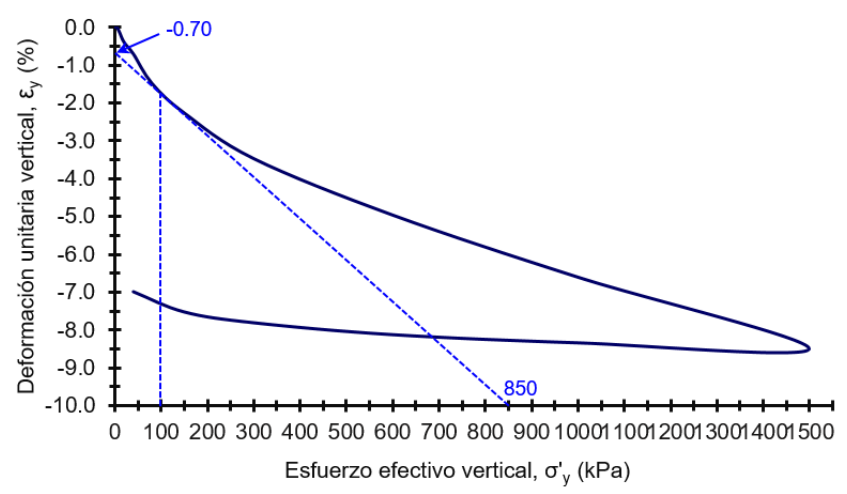

Fig. 5.14 Determinación de módulo de rigidez tangente $E_{\text {oed }}$ de ensayo edométrico en sondeo JAP1 $6.50 \mathrm{~m}$.

De la Fig. 5.14 se tiene la relación:

$$
E_{\text {oed }}^{\text {ref }}=E_{\text {oed }}^{\sigma_{y}^{\prime}=100 \mathrm{kPa}}=\frac{850}{0.10-0.007}=9140 \mathrm{kPa}
$$

Para Zaigen se cuenta además con el ensayo edométrico JAP1 $14.50 \mathrm{~m}$. A partir de los datos de este ensayo se obtiene la gráfica $\varepsilon_{y}-\sigma_{y}^{\prime}$ que se indica en la Fig. 5.15, de donde se puede determinar el módulo de rigidez tangente $E_{\text {oed }}$ para este ensayo.

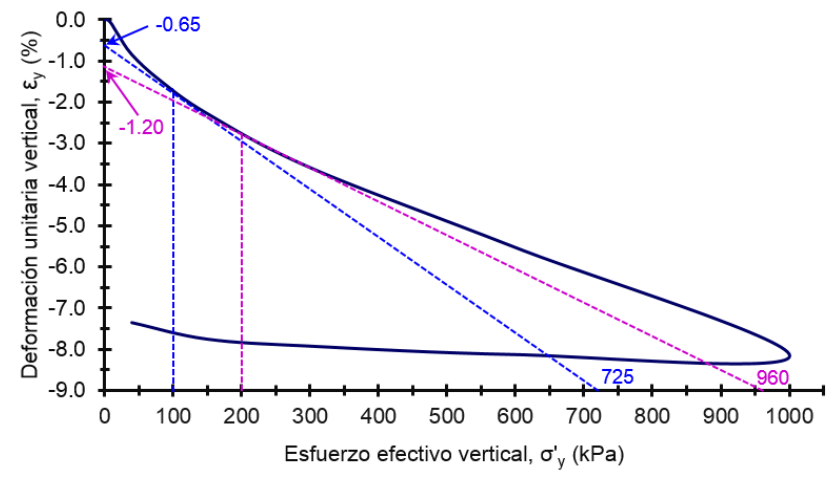

Fig. 5.15 Determinación de módulo de rigidez tangente $E_{\text {oed }}$ de ensayo edométrico en sondeo JAP1 $14.50 \mathrm{~m}$.

De la Fig. 5.15 se tiene las relaciones:

$$
\begin{aligned}
E_{\text {oed }}^{\sigma_{y}^{\prime}=100 \mathrm{kPa}} & =\frac{725}{0.09-0.0065}=8683 \mathrm{kPa} \\
E_{\text {oed }}^{\sigma_{y}^{\prime}=200 \mathrm{kPa}} & =\frac{960}{0.09-0.0120}=12308 \mathrm{kPa}
\end{aligned}
$$


Para este caso, se tiene como datos $c^{\prime}=20 \mathrm{kPa}$ y $\varnothing^{\prime}=38.0^{\circ}$. Considerando la expresión 5.3, para la presión de referencia $p^{r e f}=100 \mathrm{kPa}$ y para $\sigma_{y}^{\prime}=-100 \mathrm{kPa}$, puesto que la compresión se considera como negativa, se deduce:

$$
\begin{gathered}
E_{\text {oed }}^{\sigma_{y}^{\prime}=100 \mathrm{kPa}}=E_{\text {oed }}^{r e f} \\
E_{\text {oed }}^{r e f}=E_{\text {oed }}^{\sigma_{y}^{\prime}=100 \mathrm{kPa}}=8683 \mathrm{kPa}
\end{gathered}
$$

Por otro lado, para el caso en donde la presión de referencia $p^{r e f}=100 \mathrm{kPa}$ y para $\sigma_{y}^{\prime}$ $=-200 \mathrm{kPa}$, de la expresión 5.3 se deduce:

$$
\begin{gathered}
\frac{E_{\text {oed }}^{\sigma_{y}^{\prime}=200 \mathrm{kPa}}}{E_{\text {oed }}^{r e f}}=\left(\frac{c^{\prime} \cos \emptyset^{\prime}-(-200) \operatorname{sen} \emptyset^{\prime}}{c^{\prime} \cos \emptyset^{\prime}+p^{r e f} \operatorname{sen} \emptyset^{\prime}}\right)^{m} \\
\frac{12308}{8683}=\left[\frac{20 \cos \left(38.0^{\circ}\right)-(-200) \operatorname{sen}\left(38.0^{\circ}\right)}{20 \cos \left(38.0^{\circ}\right)+(100) \operatorname{sen}\left(38.0^{\circ}\right)}\right]^{m} \\
1.42=1.80^{m} \\
m=0.60
\end{gathered}
$$

La relación de dependencia de esfuerzos en el comportamiento de rigidez para este caso es similar al valor de $m=0.59$ determinado a partir del ensayo triaxial drenado $C D$ para la muestra JAPl $13.50 \mathrm{~m}$.

\subsubsection{Módulo de rigidez descarga/recarga $E_{u r}^{r e f}$}

\subsubsection{Introducción}

Para el cálculo del módulo de rigidez $E_{u r}^{r e f}$, se requiere de curvas $q-\varepsilon_{s}$ con un escalón intermedio de descarga/recarga de ensayos triaxiales consolidados drenados tipo $(C D)$.

\subsubsection{Módulo de rigidez descarga/recarga $E_{u r}^{\text {ref }}$ para el proyecto Torre Centre}

Para Torre Centre no se dispone de ensayos triaxiales $C D$ con escalones de descarga/recarga. Sin embargo, se adoptará la recomendación de Plaxis (2020), en donde para fines prácticos sugiere utilizar la expresión 5.4.

$$
E_{u r}^{r e f}=3 E_{50}^{r e f}
$$

Por otra parte, en la Tabla 5.5 se presentan los valores estimados para el módulo de rigidez $E_{u r}^{r e f}$ de los estratos de suelo del proyecto Torre Centre. 
Tabla 5.5 Módulo de rigidez descarga/recarga $E_{u r}^{r e f}$ para ensayos de proyecto Torre Centre.

\begin{tabular}{ccccc}
\hline Proyecto & Sondeo & Profundidad $[\mathrm{m}]$ & $E_{50}^{r e f}[\mathrm{kPa}]$ & $E_{u r}^{r e f}[\mathrm{kPa}]$ \\
\hline Torre Centre & AMA1 & 4.50 & 9091 & 27273 \\
Torre Centre & AMA1 & 8.00 & 32370 & 97110 \\
\hline
\end{tabular}

\subsubsection{Módulo de rigidez descarga/recarga $E_{u r}^{\text {ref }}$ para el proyecto Zaigen}

Para Zaigen se dispone de los datos del ensayo triaxial $C D$ con escalón de descarga/recarga y presión de confinamiento $\sigma_{3}^{\prime}$ de $250 \mathrm{kPa}$ para la muestra JAP1 $13.50 \mathrm{~m}$, en donde se conocen los parámetros de resistencia al corte drenado $c^{\prime}=20$ kPa y $\varnothing^{\prime}=36.9^{\circ}$. La Fig. 5.16 muestra la gráfica $q-\varepsilon_{s}$ para este ensayo.

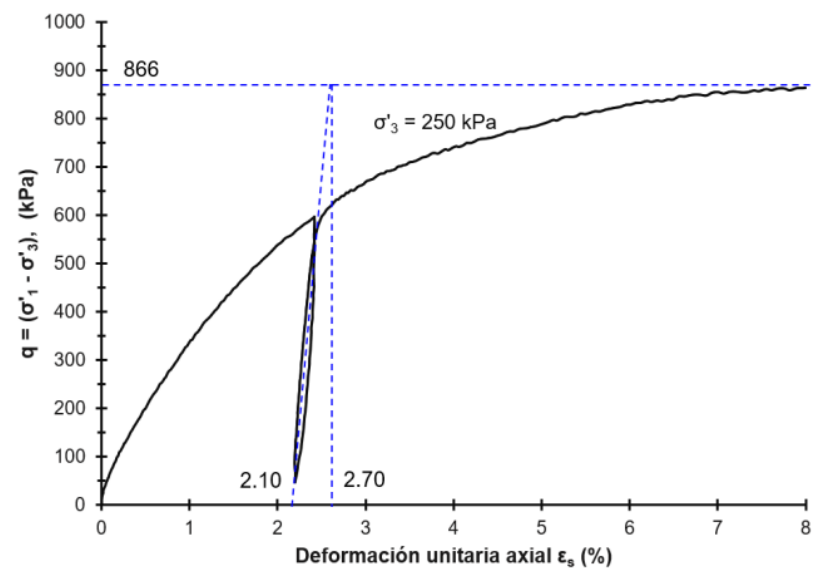

Fig. 5.16 Determinación de módulo de rigidez descarga/recarga $E_{u r}$ de ensayo triaxial $C D$ en sondeo $J A P 113.50 \mathrm{~m}$ con presión de confinamiento $\sigma_{3}^{\prime}=250 \mathrm{kPa}$.

Entonces de la Fig. 5.16 se tiene:

$$
E_{u r}^{\sigma_{3}^{\prime}=250 \mathrm{kPa}}=\frac{866}{0.0270-0.0210}=144333 \mathrm{kPa}
$$

Por lo tanto:

$$
\begin{gathered}
E_{u r}^{\sigma_{3}^{\prime}=250 \mathrm{kPa}}=E_{u r}^{r e f}\left(\frac{c^{\prime} \cos \emptyset^{\prime}-\sigma_{3}^{\prime} \operatorname{sen} \emptyset^{\prime}}{c^{\prime} \cos \emptyset^{\prime}+p^{r e f} \operatorname{sen} \emptyset^{\prime}}\right)^{m} \\
144333=E_{u r}^{r e f}\left[\frac{20 \cos \left(36.9^{\circ}\right)-(-250) \operatorname{sen}\left(36.9^{\circ}\right)}{20 \cos \left(36.9^{\circ}\right)+(100) \operatorname{sen}\left(36.9^{\circ}\right)}\right]^{0.6} \\
E_{u r}^{r e f}=90314 \mathrm{kPa}
\end{gathered}
$$

Por otra parte, en la Tabla 5.6 se presenta el valor estimado para el módulo de rigidez $E_{u r}^{r e f}$ según la expresión 5.4 para el estrato de suelo superficial del proyecto Zaigen. 
Tabla 5.6 Módulo de rigidez descarga/recarga $E_{u r}^{r e f}$ para estrato superficial de proyecto Zaigen.

\begin{tabular}{ccccc}
\hline Proyecto & Sondeo & Profundidad $[\mathrm{m}]$ & $E_{50}^{r e f}[\mathrm{kPa}]$ & $E_{u r}^{r e f}[\mathrm{kPa}]$ \\
\hline Zaigen & JAP1 & 7.50 & 11268 & 33804 \\
\hline
\end{tabular}

\subsubsection{Módulo inicial de corte de referencia en pequeñas deformaciones $G_{0}^{\text {ref }}$}

\subsubsection{Introducción}

Para obtener el módulo inicial de corte en pequeñas deformaciones se aplicará la expresión 2.9 (Ver sección 2.3.9.3. de Capítulo 2) de Hardin y Black (1969), la cual da una buena estimación para varios tipos de suelo. En esta expresión el módulo de corte de referencia $G_{0}^{\text {ref }}$ está definido para la presión de referencia $p^{r e f}$ de $100 \mathrm{kPa}$.

\subsubsection{Módulo de corte de referencia $G_{0}^{\text {ef }}$ para el proyecto Torre Centre}

En Torre Centre se identifican 2 estratos de suelo principales. El primer estrato superficial cubre desde $0.00 \mathrm{~m}$ a $6.00 \mathrm{~m}$ y el segundo estrato se ubica desde $6.00 \mathrm{~m}$ a $13.55 \mathrm{~m}$ de profundidad.

\section{Estrato superficial de $0.00 \mathrm{~m}$ a $6.00 \mathrm{~m}$}

Para el estrato superficial de $0.00 \mathrm{~m}$ a $6.00 \mathrm{~m}$ de Torre Centre se tienen los datos de los ensayos triaxiales AMA1 $4.50 \mathrm{~m}$ y AMA1 $6.00 \mathrm{~m}$, de donde se deducen los valores promedio de $c^{\prime}=15 \mathrm{kPa}$ y $\varnothing^{\prime}=34.6^{\circ}$. El peso unitario promedio de este estrato de suelo es $18.0 \mathrm{kN} / \mathrm{m}^{3}$. La relación promedio de sobreconsolidación $O C R$ es 1.40 .

Por otra parte, del ensayo edométrico AMA1 $2.00 \mathrm{~m}$ se tiene el valor de la relación de vacíos $e=1.069$. Entonces, aplicando la expresión 2.9 de Hardin y Black (1969), se obtiene el módulo de corte de referencia:

$$
G_{0}^{r e f}=33 \frac{(2.97-\mathrm{e})^{2}}{1+\mathrm{e}}=33 \frac{(2.97-1.069)^{2}}{1+1.069}=57.639 \mathrm{MPa}=57639 \mathrm{kPa}
$$

Para este estrato, el coeficiente de empuje al reposo (Mayne y Kulhawy, 1982) es:

$$
K_{0}=\left(1-\operatorname{sen} \emptyset^{\prime}\right) O C R^{\operatorname{sen} \emptyset^{\prime}}=\left[1-\operatorname{sen}\left(34.6^{\circ}\right)\right](1.40)^{\operatorname{sen}\left(34.6^{\circ}\right)}=0.5231
$$

El esfuerzo principal efectivo vertical $\sigma_{1}^{\prime}$, a la mitad del estrato de $6.00 \mathrm{~m}$ es:

$$
{\sigma^{\prime}}_{1}=\left(\frac{6.00 \mathrm{~m}}{2}\right)\left(18.0 \frac{\mathrm{kN}}{\mathrm{m}^{3}}\right)=54.00 \mathrm{kPa}
$$

El esfuerzo principal efectivo horizontal $\sigma_{3}^{\prime}$, entonces es:

$$
\sigma_{3}^{\prime}=K_{0} \sigma_{l}^{\prime}=(0.5231)(54.00 \mathrm{kPa})=28.25 \mathrm{kPa}
$$

De la expresión 2.8 se puede calcular el módulo de corte $G_{0}, \sigma_{3}^{\prime}$ se considera negativo. 


$$
G_{0}=G_{0}^{r e f}\left(\frac{c \cos \emptyset-\sigma_{3}^{\prime} \operatorname{sen} \emptyset}{c \cos \emptyset+p^{r e f} \operatorname{sen} \emptyset}\right)^{m}=(57639)\left[\frac{15 \cos \left(34.6^{\circ}\right)-(-28.25) \operatorname{sen}\left(34.6^{\circ}\right)}{15 \cos \left(34.6^{\circ}\right)+(100) \operatorname{sen}\left(34.6^{\circ}\right)}\right]^{0.6}=33791 \mathrm{kPa}
$$

Estrato de $6.00 \mathrm{~m}$ a $13.55 \mathrm{~m}$

El estrato de $6.00 \mathrm{~m}$ a $13.55 \mathrm{~m}$ de Torre Centre tiene los datos del ensayo triaxial AMA1 $8.00 \mathrm{~m}$, donde $c^{\prime}=69 \mathrm{kPa}$ y $\varnothing^{\prime}=36.1^{\circ}$. El peso unitario promedio del estrato de suelo es $19.0 \mathrm{kN} / \mathrm{m}^{3}$. La relación promedio de sobreconsolidación $O C R$ es 1.50 .

Además, del ensayo edométrico AMA1 $7.50 \mathrm{~m}$ se tiene el valor de la relación de vacíos $e=0.631$. Entonces, aplicando la expresión 2.9 de Hardin y Black (1969), se obtiene el módulo de corte de referencia:

$$
G_{0}^{r e f}=33 \frac{(2.97-\mathrm{e})^{2}}{1+\mathrm{e}}=33 \frac{(2.97-0.631)^{2}}{1+0.631}=110.693 \mathrm{MPa}=110693 \mathrm{kPa}
$$

Para este estrato, el coeficiente de empuje al reposo (Mayne y Kulhawy, 1982) es:

$$
K_{0}=\left(1-\operatorname{sen} \emptyset^{\prime}\right) O C R^{\operatorname{sen} \emptyset^{\prime}}=\left[1-\operatorname{sen}\left(36.1^{\circ}\right)\right](1.50)^{\operatorname{sen}\left(36.1^{\circ}\right)}=0.5217
$$

El esfuerzo principal efectivo vertical $\sigma_{1}^{\prime}$, a la mitad de este estrato es:

$$
\sigma_{1}^{\prime}=(6.00 \mathrm{~m})\left(18.0 \frac{\mathrm{kN}}{\mathrm{m}^{3}}\right)+\left[\frac{(13.55-6.00) \mathrm{m}}{2}\right]\left(19.0 \frac{\mathrm{kN}}{\mathrm{m}^{3}}\right)=179.73 \mathrm{kPa}
$$

El esfuerzo principal efectivo horizontal $\sigma_{3}^{\prime}$, entonces es:

$$
\sigma_{3}^{\prime}=K_{0} \sigma_{1}^{\prime}=(0.5217)(179.73 \mathrm{kPa})=93.77 \mathrm{kPa}
$$

De la expresión 2.8 se puede calcular el módulo de corte $G_{0}$. En esta expresión, $\sigma_{3}^{\prime}$ se considera negativo.

$$
G_{0}=G_{0}^{r e f}\left(\frac{c \cos \emptyset-\sigma_{3}^{\prime} \operatorname{sen} \emptyset}{c \cos \emptyset+p^{r e f} \operatorname{sen} \emptyset}\right)^{m}=(110693)\left[\frac{69 \cos \left(36.1^{\circ}\right)-(-93.77) \operatorname{sen}\left(36.1^{\circ}\right)}{69 \cos \left(36.1^{\circ}\right)+(100) \operatorname{sen}\left(36.1^{\circ}\right)}\right]^{0.6}=108553 \mathrm{kPa}
$$

5.2.6.3. Módulo de corte de referencia $G_{0}^{\text {ef }}$ para el proyecto Zaigen

En Zaigen se identifican 2 estratos de suelo principales. El primer estrato superficial se ubica desde $0.00 \mathrm{~m}$ a $7.50 \mathrm{~m}$ y el segundo estrato cubre desde $7.50 \mathrm{~m}$ a $15.50 \mathrm{~m}$ de profundidad.

Estrato superficial de $0.00 \mathrm{~m}$ a $7.50 \mathrm{~m}$

Para el estrato superficial de $0.00 \mathrm{~m}$ a $7.50 \mathrm{~m}$ de Zaigen se tienen los datos de los ensayos triaxiales $J A P 13.50 \mathrm{~m}$ y $J A P 17.50 \mathrm{~m}$, de donde se determinan los valores promedio de $c^{\prime}=18 \mathrm{kPa}$ y $\varnothing^{\prime}=34.2^{\circ}$. El peso unitario promedio de este estrato de suelo es $17.0 \mathrm{kN} / \mathrm{m}^{3}$. La relación promedio de sobreconsolidación $O C R$ es 1.60 .

Por su parte, del ensayo edométrico JAP1 $3.50 \mathrm{~m}$ se tiene el valor de la relación de vacíos $e=1.219$. Por tanto, aplicando la expresión 2.9 de Hardin y Black (1969), se obtiene el módulo de corte de referencia: 


$$
G_{0}^{r e f}=33 \frac{(2.97-\mathrm{e})^{2}}{1+\mathrm{e}}=33 \frac{(2.97-1.219)^{2}}{1+1.219}=45.596 \mathrm{MPa}=45596 \mathrm{kPa}
$$

Para este estrato, el coeficiente de empuje al reposo (Mayne y Kulhawy, 1982) es:

$$
K_{0}=\left(1-\operatorname{sen} \emptyset^{\prime}\right) O C R^{\operatorname{sen} \emptyset^{\prime}}=\left[1-\operatorname{sen}\left(34.2^{\circ}\right)\right](1.60)^{\operatorname{sen}\left(34.2^{\circ}\right)}=0.5703
$$

El esfuerzo principal efectivo vertical $\sigma_{1}^{\prime}$, a la mitad del estrato de $7.50 \mathrm{~m}$ es:

$$
{\sigma^{\prime}}_{1}=\left(\frac{7.50 \mathrm{~m}}{2}\right)\left(17.0 \frac{\mathrm{kN}}{\mathrm{m}^{3}}\right)=63.75 \mathrm{kPa}
$$

El esfuerzo principal efectivo horizontal $\sigma_{3}^{\prime}$, entonces es:

$$
\sigma_{3}^{\prime}=K_{0} \sigma_{l}^{\prime}=(0.5703)(63.75 \mathrm{kPa})=36.36 \mathrm{kPa}
$$

De la expresión 2.8 se puede calcular el módulo de corte $G_{0}, \sigma_{3}^{\prime}$ se considera negativo.

$$
G_{0}=G_{0}^{r e f}\left(\frac{c \cos \emptyset-\sigma_{3}^{\prime} \operatorname{sen} \emptyset}{c \cos \emptyset+p^{r e f} \operatorname{sen} \emptyset}\right)^{m}=(45596)\left[\frac{18 \cos \left(34.2^{\circ}\right)-(-36.36) \operatorname{sen}\left(34.2^{\circ}\right)}{18 \cos \left(34.2^{\circ}\right)+(100) \operatorname{sen}\left(34.2^{\circ}\right)}\right]^{0.6}=29969 \mathrm{kPa}
$$

Estrato de $7.50 \mathrm{~m}$ a $15.50 \mathrm{~m}$

Para el estrato de $7.50 \mathrm{~m}$ a $15.50 \mathrm{~m}$ de Zaigen se cuenta con los datos de los ensayos triaxiales JAP1 $9.00 \mathrm{~m}$, JAP1 $11.00 \mathrm{~m}$, JAP1 $13.50 \mathrm{~m}$ y JAP1 $14.50 \mathrm{~m}$, de donde se deducen los valores promedio de $c^{\prime}=17 \mathrm{kPa}$ y $\varnothing^{\prime}=37.4^{\circ}$. El peso unitario promedio de este estrato de suelo es $17.5 \mathrm{kN} / \mathrm{m}^{3}$. La relación promedio de sobreconsolidación $O C R$ es 1.30 .

Además, del ensayo edométrico JAP1 $9.00 \mathrm{~m}$ se tiene el valor de la relación de vacíos $e=0.876$. Entonces, aplicando la expresión 2.9 de Hardin y Black (1969), se obtiene el módulo de corte de referencia:

$$
G_{0}^{r e f}=33 \frac{(2.97-\mathrm{e})^{2}}{1+\mathrm{e}}=33 \frac{(2.97-0.876)^{2}}{1+0.876}=77.132 \mathrm{MPa}=77132 \mathrm{kPa}
$$

Para este estrato, el coeficiente de empuje al reposo (Mayne y Kulhawy, 1982) es:

$$
K_{0}=\left(1-\operatorname{sen} \emptyset^{\prime}\right) O C R^{\operatorname{sen} \emptyset^{\prime}}=\left[1-\operatorname{sen}\left(37.4^{\circ}\right)\right](1.30)^{\operatorname{sen}\left(37.4^{\circ}\right)}=0.4605
$$

El esfuerzo principal efectivo vertical $\sigma_{1}^{\prime}$, a la mitad de este estrato es:

$$
\sigma_{1}^{\prime}=(7.50 \mathrm{~m})\left(17.0 \frac{\mathrm{kN}}{\mathrm{m}^{3}}\right)+\left[\frac{(15.50-7.50) \mathrm{m}}{2}\right]\left(17.5 \frac{\mathrm{kN}}{\mathrm{m}^{3}}\right)=197.50 \mathrm{kPa}
$$

El esfuerzo principal efectivo horizontal $\sigma_{3}^{\prime}$, entonces es:

$$
\sigma_{3}^{\prime}=K_{0} \sigma_{1}^{\prime}=(0.4605)(197.50 \mathrm{kPa})=90.95 \mathrm{kPa}
$$

De la expresión 2.8 se puede calcular el módulo de corte $G_{0}$. En esta expresión, $\sigma_{3}^{\prime}$ se considera negativo.

$$
G_{0}=G_{0}^{r e f}\left(\frac{c \cos \emptyset-\sigma_{3}^{\prime} \operatorname{sen} \emptyset}{c \cos \emptyset+p^{r e f} \operatorname{sen} \emptyset}\right)^{m}=(77132)\left[\frac{17 \cos \left(37.4^{\circ}\right)-(-90.95) \operatorname{sen}\left(37.4^{\circ}\right)}{17 \cos \left(37.4^{\circ}\right)+(100) \operatorname{sen}\left(37.4^{\circ}\right)}\right]^{0.6}=73653 \mathrm{kPa}
$$


Los valores de $G_{0}, \sigma_{1}^{\prime}$ y $K_{0}$ obtenidos en esta sección serán utilizados en la determinación de los parámetros de nivel de deformación por corte, cuando $G=0.7$ $G_{0}$, denominados como $\gamma_{0.7}$.

\subsubsection{Nivel de deformación por corte, donde $G=0.7 G_{0}, \gamma_{0.7}$}

Para determinar el nivel de deformación por corte, denominado como $\gamma_{0.7}$, en donde el módulo de corte secante se reduce aproximadamente al $70 \%$ de su valor inicial $G_{0}$, se aplicará la expresión 5.5 (Plaxis, 2020).

$$
\gamma_{0.7} \approx \frac{1}{9 G_{0}}\left[2 c^{\prime}\left(1+\cos \left(2 \emptyset^{\prime}\right)\right)-\sigma_{1}^{\prime}\left(1+K_{0}\right) \operatorname{sen}\left(2 \emptyset^{\prime}\right)\right]
$$

Donde:

$G_{0} \quad$ módulo de corte inicial o de pequeñas deformaciones

$c^{\prime} \quad$ cohesión

$\emptyset^{\prime} \quad$ ángulo de fricción

$\sigma_{1}^{\prime} \quad$ esfuerzo principal efectivo vertical (se considera como negativo en la expresión)

$K_{0} \quad$ coeficiente de empuje al reposo

La Tabla 5.7 presenta los valores de $\gamma_{0.7}$ obtenidos con la aplicación de la expresión 5.5 para los estratos de suelo de los proyectos Torre Centre y Zaigen.

Tabla 5.7 Obtención de deformación límite por corte $\gamma_{0.7}$, donde $G=0.7 G_{0}$.

\begin{tabular}{cccccccc}
\hline Proyecto & Estrato $[\mathrm{m}]$ & $G_{0}[\mathrm{kPa}]$ & $c^{\prime}[\mathrm{kPa}]$ & $\emptyset^{\prime}\left[{ }^{\circ}\right]$ & $\sigma_{1}^{\prime}[\mathrm{kPa}]$ & $K_{0}[-]$ & $\gamma_{0.7}[-]$ \\
\hline \multirow{2}{*}{ Torre Centre } & $0.00-6.00$ & 33791 & 15 & 34.6 & -54.00 & 0.5231 & $3.86 \times 10^{-4}$ \\
& $6.00-13.55$ & 108553 & 69 & 36.1 & -179.73 & 0.5217 & $4.51 \times 10^{-4}$ \\
\hline \multirow{2}{*}{ Zaigen } & $0.00-7.50$ & 29969 & 18 & 34.2 & -63.75 & 0.5703 & $5.28 \times 10^{-4}$ \\
& $7.50-15.50$ & 73653 & 17 & 37.4 & -197.50 & 0.4605 & $4.85 \times 10^{-4}$ \\
\hline
\end{tabular}

\subsection{8. Ángulo de dilatancia $\psi$}

\subsubsection{Introducción}

Para el cálculo del ángulo de dilatancia $\psi$ son necesarias las curvas deformación unitaria volumétrica, $\varepsilon_{v}$ versus deformación unitaria axial, $\varepsilon_{s}$ de ensayos triaxiales consolidados drenados $C D$. 


\subsubsection{2. Ángulo de dilatancia $\psi$ para el proyecto Torre Centre}

De la curva deformación unitaria volumétrica versus deformación unitaria axial ( $\varepsilon_{v^{-}}$ $\varepsilon_{s}$ ) del ensayo AMA1 $8.00 \mathrm{~m}$, se puede determinar el ángulo de dilatancia, $\psi$ para dicho ensayo, según se indica en la Fig. 5.17.

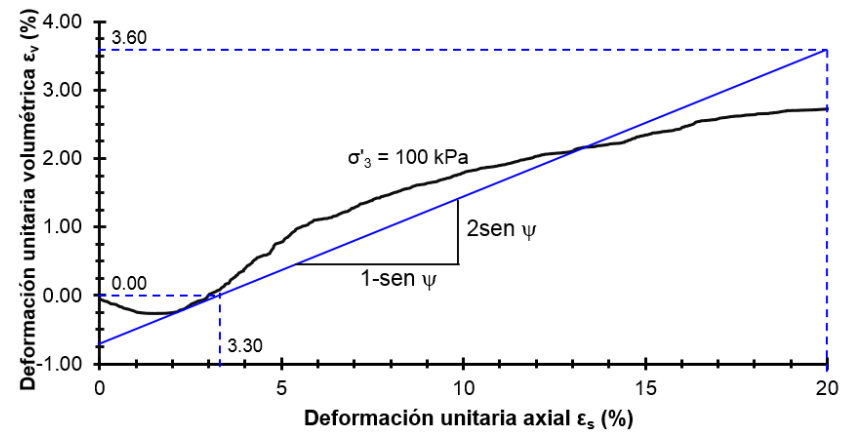

Fig. 5.17 Deformación unitaria volumétrica, $\varepsilon_{v}$ - Deformación unitaria axial, $\varepsilon_{s}$ de ensayo triaxial $C D$ en sondeo AMA1 $8.00 \mathrm{~m}$ con presión de confinamiento $\sigma^{\prime}{ }_{3}=100 \mathrm{kPa}$.

De la Fig. 5.17 se tiene la relación:

$$
\begin{gathered}
\frac{1-\operatorname{sen} \psi}{2 \operatorname{sen} \psi}=\frac{20.00-3.30}{3.60}=4.64 \\
\operatorname{sen} \psi=0.0973 \\
\psi=6^{\circ}
\end{gathered}
$$

\subsubsection{3. Ángulo de dilatancia $\psi$ para el proyecto Zaigen}

De la curva deformación unitaria volumétrica versus deformación unitaria axial $\left(\varepsilon_{v^{-}}\right.$ $\varepsilon_{s}$ ) del ensayo JAP1 $13.50 \mathrm{~m}$, se obtiene el ángulo de dilatancia, según se indica en la Fig. 5.18.

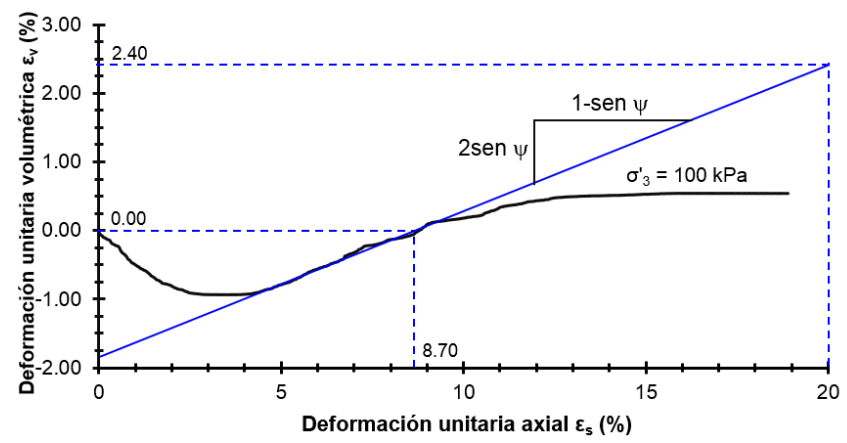

Fig. 5.18 Deformación unitaria volumétrica, $\varepsilon_{v}$ - Deformación unitaria axial, $\varepsilon_{s}$ de ensayo triaxial $C D$ en sondeo JAP1 $13.50 \mathrm{~m}$ con presión de confinamiento $\sigma_{3}^{\prime}=100 \mathrm{kPa}$. 
Por tanto, de la Fig. 5.18 se tiene la relación:

$$
\begin{gathered}
\frac{1-\operatorname{sen} \psi}{2 \operatorname{sen} \psi}=\frac{20.00-8.70}{2.40}=4.71 \\
\operatorname{sen} \psi=0.0960 \\
\psi=6^{\circ}
\end{gathered}
$$

En ambos casos, de acuerdo a los resultados obtenidos se verifica la expresión 5.6, por lo que se aplicará la misma en el resto de ensayos para estimar el ángulo de dilatancia $\psi$.

$$
\psi \approx \emptyset-30 \quad\left[{ }^{\circ}\right]
$$

Esta expresión coincide con la sugerida por Plaxis (2020) para estimar el ángulo de dilatancia, cuando el ángulo de fricción es mayor a $30^{\circ}$.

\subsubsection{Resumen de parámetros geotécnicos}

\subsubsection{Resumen de parámetros para el modelo de Mohr Coulomb (MC)}

En la Tabla 5.8 se presentan los parámetros geotécnicos de los estratos de suelo

\begin{tabular}{|c|c|c|c|c|c|}
\hline \multirow{3}{*}{ PARÁMETRO } & & \multicolumn{4}{|c|}{ MODELO CONSTITUTIVO DE MOHR COULOMB } \\
\hline & & \multicolumn{2}{|c|}{ TORRE CENTRE } & \multicolumn{2}{|c|}{ ZAIGEN } \\
\hline & & $0.00-6.00 \mathrm{~m}$ & $6.00-13.55 \mathrm{~m}$ & $0.00-7.50 \mathrm{~m}$ & $7.50-15.50 \mathrm{~m}$ \\
\hline Tipo & - & Drenado & Drenado & Drenado & Drenado \\
\hline Cohesión $\left[\mathrm{kN} / \mathrm{m}^{2}\right]$ & $c '$ & 15 & 69 & 18 & 17 \\
\hline Ángulo de fricción $\left[{ }^{\circ}\right]$ & $\varnothing$ & 34 & 36 & 34 & 36 \\
\hline Ángulo de dilatancia $\left[^{\circ}\right]$ & $\psi$ & 4 & 6 & 4 & 6 \\
\hline Peso unitario $\left[\mathrm{kN} / \mathrm{m}^{3}\right]$ & $\gamma$ & 18.0 & 19.0 & 17.0 & 17.5 \\
\hline Módulo de Young $\left[\mathrm{kN} / \mathrm{m}^{2}\right]$ & $E$ & 41667 & 85714 & 20000 & 25000 \\
\hline Relación de Poisson [-] & $v$ & 0.3 & 0.3 & 0.3 & 0.3 \\
\hline Rel. de sobreconsolidación [-] & $O C R$ & 1.4 & 1.5 & 1.6 & 1.3 \\
\hline Coef. de empuje al reposo [-] & $K_{0}$ & 0.517 & 0.493 & 0.555 & 0.461 \\
\hline
\end{tabular}
identificados, para aplicación del modelo de Mohr Coulomb en los proyectos Torre Centre y Zaigen.

Tabla 5.8 Parámetros geotécnicos para modelo de Mohr Coulomb en Torre Centre y Zaigen.

En esta tabla se resumen los parámetros geotécnicos determinados en esta sección y se complementan con aquellos obtenidos en el Capítulo 3. Los valores del coeficiente al reposo $K_{0}$ se han determinado según la expresión 5.7 (Plaxis, 2020). 


\subsubsection{Resumen de parámetros para los modelos de Hardening Soil (HS) y Hardening Soil with Small-Strain Stiffness (HSsmall)}

En las Tablas 5.9 y 5.10 se resumen los parámetros geotécnicos obtenidos en esta sección para los estratos de suelo identificados, para la aplicación de los modelos constitutivos de Hardening Soil y Hardening Soil with Small-Strain Stiffness en los proyectos Torre Centre y Zaigen, respectivamente. Se complementan con los determinados en la sección de caracterización geotécnica (Capítulo 3).

Tabla 5.9 Parámetros para los modelos de Hardening Soil y HSsmall en Proyecto Torre Centre.

\begin{tabular}{|c|c|c|c|c|c|}
\hline \multirow{3}{*}{ PARÁMETRO } & & \multicolumn{4}{|c|}{ MODELO CONSTITUTIVO } \\
\hline & & \multicolumn{2}{|c|}{ HARDENING SOIL } & \multicolumn{2}{|c|}{ HSsmall } \\
\hline & & $0.00-6.00 \mathrm{~m}$ & $6.00-13.55 \mathrm{~m}$ & $0.00-6.00 \mathrm{~m}$ & $6.00-13.55 \mathrm{~m}$ \\
\hline Tipo & - & Drenado & Drenado & Drenado & Drenado \\
\hline Cohesión $\left[\mathrm{kN} / \mathrm{m}^{2}\right]$ & $c^{\prime}$ & 15 & 69 & 15 & 69 \\
\hline Ángulo de fricción [ $\left.{ }^{\circ}\right]$ & $\varnothing$ & 34 & 36 & 34 & 36 \\
\hline Ángulo de dilatancia $\left[^{\circ}\right]$ & $\psi$ & 4 & 6 & 4 & 6 \\
\hline Peso unitario $\left[\mathrm{kN} / \mathrm{m}^{3}\right]$ & $\gamma$ & 18.0 & 19.0 & 18.0 & 19.0 \\
\hline $\begin{array}{l}\text { Módulo de rigidez secante de ensayo } \\
\text { triaxial drenado a la presión de } \\
\text { referencia } p^{\text {ref }}\left[\mathrm{kN} / \mathrm{m}^{2}\right]\end{array}$ & $E_{50}^{r e f}$ & 9091 & 32370 & 9091 & 32370 \\
\hline $\begin{array}{l}\text { Módulo de rigidez tangente de carga } \\
\text { primaria de ensayo edométrico a la } \\
\text { presión de referencia } p^{\text {ref }}\left[\mathrm{kN} / \mathrm{m}^{2}\right]\end{array}$ & $E_{\text {oed }}^{\text {ref }}$ & 6009 & 14757 & 6009 & 14757 \\
\hline $\begin{array}{l}\text { Módulo de rigidez descarga/recarga a } \\
\text { la presión de referencia } p^{\text {ref }}\left[\mathrm{kN} / \mathrm{m}^{2}\right]\end{array}$ & $E_{u r}^{r e f}$ & 27273 & 97110 & 27273 & 97110 \\
\hline Presión de referencia $\left[\mathrm{kN} / \mathrm{m}^{2}\right]$ & $p^{r e f}$ & 100 & 100 & 100 & 100 \\
\hline $\begin{array}{l}\text { Relación de dependencia de esfuerzos } \\
\text { en el comportamiento de rigidez [-] }\end{array}$ & $m$ & 0.60 & 0.60 & 0.60 & 0.60 \\
\hline $\begin{array}{l}\text { Relación de Poisson en } \\
\text { descarga/recarga [-] }\end{array}$ & $v_{\mathrm{ur}}$ & 0.2 & 0.2 & 0.2 & 0.2 \\
\hline Coef. de empuje al reposo NC [-] & $K_{0}^{\mathrm{NC}}$ & 0.441 & 0.412 & 0.441 & 0.412 \\
\hline Relación de sobreconsolidación [-] & $O C R$ & 1.40 & 1.50 & 1.40 & 1.50 \\
\hline Coef. de empuje al reposo SC [-] & $K_{0}$ & 0.517 & 0.493 & 0.517 & 0.493 \\
\hline $\begin{array}{l}\text { Módulo de corte de referencia en } \\
\text { pequeñas deformaciones }\left[\mathrm{kN} / \mathrm{m}^{2}\right]\end{array}$ & $G_{0}^{r e f}$ & - & - & 57639 & 110693 \\
\hline $\begin{array}{l}\text { Deformación límite por corte, donde } \\
G=0.7 G_{0}[-]\end{array}$ & $\gamma_{0.7}$ & - & - & $3.86 \times 10^{-4}$ & $4.51 \times 10^{-4}$ \\
\hline
\end{tabular}


Tabla 5.10 Parámetros para los modelos de Hardening Soil y HSsmall en Proyecto Zaigen.

\begin{tabular}{|c|c|c|c|c|c|}
\hline \multirow{3}{*}{ PARÁMETRO } & & \multicolumn{4}{|c|}{ MODELO CONSTITUTIVO } \\
\hline & & \multicolumn{2}{|c|}{ HARDENING SOIL } & \multicolumn{2}{|c|}{ HSsmall } \\
\hline & & $0.00-7.50 \mathrm{~m}$ & $7.50-15.50 \mathrm{~m}$ & $0.00-7.50 \mathrm{~m}$ & $7.50-15.50 \mathrm{~m}$ \\
\hline Tipo & - & Drenado & Drenado & Drenado & Drenado \\
\hline Cohesión $\left[\mathrm{kN} / \mathrm{m}^{2}\right]$ & $c$ ' & 18 & 17 & 18 & 17 \\
\hline Ángulo de fricción $\left[{ }^{\circ}\right]$ & $\varnothing$ & 34 & 36 & 34 & 36 \\
\hline Ángulo de dilatancia $\left[{ }^{\circ}\right]$ & $\psi$ & 4 & 6 & 4 & 6 \\
\hline Peso unitario $\left[\mathrm{kN} / \mathrm{m}^{3}\right]$ & $\gamma$ & 17.0 & 17.5 & 17.0 & 17.5 \\
\hline $\begin{array}{l}\text { Módulo de rigidez secante de ensayo } \\
\text { triaxial drenado a la presión de } \\
\text { referencia } p^{r e f}\left[\mathrm{kN} / \mathrm{m}^{2}\right]\end{array}$ & $E_{50}^{r e f}$ & 11268 & 16815 & 11268 & 16815 \\
\hline $\begin{array}{l}\text { Módulo de rigidez tangente de carga } \\
\text { primaria de ensayo edométrico a la } \\
\text { presión de referencia } p^{r e f}\left[\mathrm{kN} / \mathrm{m}^{2}\right]\end{array}$ & $E_{\text {oed }}^{\text {ref }}$ & 9140 & 8683 & 9140 & 8683 \\
\hline $\begin{array}{l}\text { Módulo de rigidez descarga/recarga a } \\
\text { la presión de referencia } p^{\text {ref }}\left[\mathrm{kN} / \mathrm{m}^{2}\right]\end{array}$ & $E_{u r}^{r e f}$ & 33804 & 90314 & 33804 & 90314 \\
\hline Presión de referencia $\left[\mathrm{kN} / \mathrm{m}^{2}\right]$ & $p^{r e f}$ & 100 & 100 & 100 & 100 \\
\hline $\begin{array}{l}\text { Relación de dependencia de esfuerzos } \\
\text { en el comportamiento de rigidez [-] }\end{array}$ & $m$ & 0.60 & 0.60 & 0.60 & 0.60 \\
\hline $\begin{array}{l}\text { Relación de Poisson en } \\
\text { descarga/recarga [-] }\end{array}$ & $v_{\mathrm{ur}}$ & 0.2 & 0.2 & 0.2 & 0.2 \\
\hline Coef. de empuje al reposo NC [-] & $K_{0}^{\mathrm{NC}}$ & 0.441 & 0.412 & 0.441 & 0.412 \\
\hline Relación de sobreconsolidación [-] & $O C R$ & 1.60 & 1.30 & 1.60 & 1.30 \\
\hline Coef. de empuje al reposo SC [-] & $K_{0}$ & 0.555 & 0.461 & 0.555 & 0.461 \\
\hline $\begin{array}{l}\text { Módulo de corte de referencia en } \\
\text { pequeñas deformaciones }\left[\mathrm{kN} / \mathrm{m}^{2}\right]\end{array}$ & $G_{0}^{e f}$ & - & - & 45596 & 77132 \\
\hline $\begin{array}{l}\text { Deformación límite por corte, donde } \\
G=0.7 G_{0}[-]\end{array}$ & $\gamma_{0.7}$ & - & - & $5.28 \times 10^{-4}$ & $4.85 \times 10^{-4}$ \\
\hline
\end{tabular}

Adicionalmente, se ha adoptado en todos los casos el valor para la relación de Poisson en descarga/recarga $v_{\text {ur }}$ de 0.2 , recomendado y establecido por defecto en Plaxis (2020).

En la determinación del valor del coeficiente de empuje al reposo $K_{0}$ para suelos sobreconsolidados SC se ha utilizado la expresión 5.7, sugerida por Plaxis (2020). 


$$
K_{0}=K_{0}^{\mathrm{NC}} O C R-\frac{v_{u r}}{1-v_{u r}}(O C R-1)
$$

Siendo, OCR la relación de sobreconsolidación, $v_{u r}$ la relación de Poisson en descarga/recarga y $K_{0}^{N C}$ el coeficiente de empuje al reposo para consolidación normal NC y está dado por la expresión 5.8.

$$
K_{0}^{\mathrm{NC}}=1-\operatorname{sen} \emptyset^{\prime}
$$

\subsection{Características de pantallas y "Soil Nails" para análisis}

En esta sección se definen las propiedades de ingreso de cada pantalla o "Facing" y "Soil Nails" para el análisis de cada estructura. Por lo tanto, en la Tabla 5.11 se presentan las características geométricas y de materiales para pantallas y "Soil Nails" de los proyectos Torre Centre y Zaigen.

El módulo de elasticidad del "Grout" y del concreto ha sido estimado de acuerdo a la expresión 5.9 (ACI 318, 2019; NEC, 2015), la cual está en función de su resistencia a la compresión $\mathrm{f}^{\prime}$. Para el presente caso, la resistencia a la compresión del "Grout" es de $210 \mathrm{~kg} / \mathrm{cm}^{2}(20.58 \mathrm{MPa})$, en tanto que la resistencia a la compresión del concreto es de $240 \mathrm{~kg} / \mathrm{cm}^{2}(23.53 \mathrm{MPa})$

$$
E_{g}=4700 \sqrt{\mathrm{f}_{\mathrm{c}}} \quad[\mathrm{MPa}]
$$

Tabla 5.11 Datos de pantallas y "Soil Nails" para proyectos Torre Centre y Zaigen.

\begin{tabular}{lccc}
\hline \multicolumn{1}{c}{ PARÁMETRO } & & TORRE & \multirow{2}{*}{ ZEAIGEN } \\
\hline Altura de la pantalla [m] & $H$ & 13.55 & 15.50 \\
Material & - & Elástico & Elástico \\
Módulo de elasticidad del acero de "Nails" [MPa] & $E_{n}$ & 200000 & 200000 \\
Módulo de elasticidad del concreto [MPa] & $E$ & 22800 & 22800 \\
Módulo de elasticidad del "Grout" de "Nails" [MPa] & $E_{g}$ & 21320 & 21320 \\
Diámetro de la perforación [m] & $D_{p}$ & 0.15 & 0.15 \\
Diámetro de barras de acero de "Nails" [mm] & $d$ & 25 & 25 \\
Inclinación de "Nails" con respecto a la horizontal [] & $i$ & 15 & 15 \\
Espesor de la pantalla o muro [m] & $t$ & 0.25 & 0.25 \\
\hline
\end{tabular}

La Tabla 5.12 detalla la obtención de los parámetros de rigidez axial $E A$, rigidez a flexión EI y peso unitario $w$ para las pantallas de los proyectos Torre Centre y Zaigen. Los parámetros se calculan para una longitud unitaria de $1.00 \mathrm{~m}$ y para un peso unitario del concreto $\gamma_{\mathrm{c}}$ de $24 \mathrm{kN} / \mathrm{m}^{3}$. 
Tabla 5.12 Parámetros de rigidez axial EA, rigidez a flexión $E I$ y peso unitario $w$ para pantallas.

\begin{tabular}{lcccccccccc}
\hline Obra & $\begin{array}{c}L \\
{[\mathrm{~m}]}\end{array}$ & $\begin{array}{c}t \\
{[\mathrm{~m}]}\end{array}$ & $\begin{array}{c}A \\
{\left[\mathrm{~m}^{2}\right]}\end{array}$ & $\begin{array}{c}\text { Eng. } \\
{\left[\mathrm{m}^{4}\right]}\end{array}$ & $\begin{array}{c}E \\
{\left[\mathrm{kN} / \mathrm{m}^{2}\right]}\end{array}$ & $\begin{array}{c}E A \\
{[\mathrm{kN} / \mathrm{m}]}\end{array}$ & $\begin{array}{c}E I \\
{\left[\mathrm{kN} . \mathrm{m}^{2} / \mathrm{m}\right]}\end{array}$ & $\begin{array}{c}\gamma_{c} \\
{\left[\mathrm{kN} / \mathrm{m}^{3}\right]}\end{array}$ & $\begin{array}{c}\text { Unitario } w \\
{[\mathrm{kN} / \mathrm{m} / \mathrm{m}]}\end{array}$ \\
\hline $\begin{array}{l}\text { Torre } \\
\text { Centre }\end{array}$ & 1.00 & 0.25 & 0.25 & $1.302 \times 10^{-3}$ & $2.28 \times 10^{7}$ & 5700000 & 29685 & 24 & 6.00 \\
Zaigen & 1.00 & 0.25 & 0.25 & $1.302 \times 10^{-3}$ & $2.28 \times 10^{7}$ & 5700000 & 29685 & 24 & 6.00 \\
\hline
\end{tabular}

Para determinar la rigidez axial $E A$, rigidez a flexión $E I$ y peso unitario $w$ de los "Soil Nails" de los proyectos Torre Centre y Zaigen se determina el módulo de elasticidad equivalente $E_{e q}$, que es común para ambos proyectos. El diámetro de la perforación $\left(D_{p}\right)$ es $0.15 \mathrm{~m}$ y el diámetro de la barra de acero (d) es de $25 \mathrm{~mm}$. Los pesos unitarios del acero y del "Grout" son $78.50 \mathrm{kN} / \mathrm{m}^{3}$ y $22 \mathrm{kN} / \mathrm{m}^{3}$, respectivamente.

Área (A) de la sección de "Soil Nail":

$$
\mathrm{A}=\pi \frac{D_{p}^{2}}{4}=\pi \frac{(0.15)^{2}}{4}=0.017671 \mathrm{~m}^{2}
$$

Área $\left(\mathrm{A}_{\mathrm{n}}\right)$ de la sección de la barra de acero:

$$
\mathrm{A}_{\mathrm{n}}=\pi \frac{\mathrm{d}^{2}}{4}=\pi \frac{(0.025)^{2}}{4}=0.000491 \mathrm{~m}^{2}
$$

Área $\left(\mathrm{A}_{\mathrm{g}}\right)$ de la sección de "Grout":

$$
\mathrm{A}_{\mathrm{g}}=\mathrm{A}-\mathrm{A}_{\mathrm{n}}=0.017671-0.000491=0.017180 \mathrm{~m}^{2}
$$

Módulo de elasticidad equivalente $\left(E_{e q}\right)$ del "Soil Nail" (Se aplica la expresión 2.1):

$$
E_{\text {eq }}=E_{n}\left(\frac{A_{n}}{A}\right)+E_{g}\left(\frac{A_{g}}{A}\right)=\left(2.00 \times 10^{8}\right)\left[\frac{0.000491}{0.017671}\right]+\left(2.132 \times 10^{7}\right)\left[\frac{0.017180}{0.017671}\right]=2.628 \times 10^{7} \mathrm{kPa}
$$

Para la determinación de la rigidez axial EA y la rigidez a flexión EI de los "Soil Nails" se aplican las expresiones 2.2 y 2.3 , respectivamente. En ambos casos, las rigideces están función de la separación horizontal de los "Soil Nails". En la Tabla 5.13 se presentan los valores de rigidez calculados de acuerdo a cada separación horizontal $S_{h}$ para los "Soil Nails" del proyecto Torre Centre, en tanto que en la Tabla 5.14 se muestran los valores de rigidez para los "Soil Nails" del proyecto Zaigen.

$$
\begin{aligned}
& \text { Rigidez axial: } E A=\frac{E_{e q}}{S_{h}}\left(\frac{\pi D_{p}^{2}}{4}\right)=\frac{2.628 \times 10^{7}}{S_{h}}\left[\frac{\pi(0.15)^{2}}{4}\right]=\frac{464406}{S_{h}} \frac{\mathrm{kN}}{\mathrm{m}} \\
& \text { Rigidez a flexión: } E I=\frac{E_{e q}}{S_{h}}\left(\frac{\pi D_{p}^{4}}{64}\right)=\frac{2.628 \times 10^{7}}{S_{h}}\left[\frac{\pi(0.15)^{4}}{64}\right]=\frac{653}{S_{h}} \frac{\mathrm{kN} \mathrm{m}^{2}}{\mathrm{~m}}
\end{aligned}
$$

El peso unitario para los "Soil Nails" está dado por: 
Peso unitario: $w=\frac{\left(0.000491 \mathrm{~m}^{2}\right)\left(78.50 \frac{\mathrm{kN}}{\mathrm{m}^{3}}\right)+\left(0.017180 \mathrm{~m}^{2}\right)\left(22.00 \frac{\mathrm{kN}}{\mathrm{m}^{3}}\right)}{S_{h}}=\frac{0.4165}{S_{h}} \frac{\frac{\mathrm{kN}}{\mathrm{m}}}{\mathrm{m}}$

Tabla 5.13 Rigidez axial EA, rigidez a flexión EI y peso unitario $w$ para "Soil Nails" de Torre Centre.

\begin{tabular}{|c|c|c|c|c|c|c|}
\hline \multicolumn{2}{|c|}{ SÓTANO } & \multicolumn{5}{|c|}{ "SOIL NAILS" } \\
\hline $\begin{array}{l}\text { Nivel } \\
\text { de } \\
\text { sótano }\end{array}$ & $\begin{array}{l}\text { Fila de } \\
\text { anclaje }\end{array}$ & $\begin{array}{l}\text { Longitud } \\
\text { de "Soil } \\
\text { Nails" }\end{array}$ & $\begin{array}{c}\text { Separación } \\
\text { horizontal de } \\
\text { "Soil Nails" } S_{h}\end{array}$ & $\begin{array}{c}\text { Rigidez Axial } \\
E A\end{array}$ & $\begin{array}{c}\text { Rigidez a Flexión } \\
E I\end{array}$ & $\begin{array}{c}\text { Peso unitario } \\
w\end{array}$ \\
\hline & & {$[\mathrm{m}]$} & [m] & {$[\mathrm{kN} / \mathrm{m}]$} & {$[\mathrm{kN} \mathrm{m} / 2 / \mathrm{m}]$} & {$[\mathrm{kN} / \mathrm{m} / \mathrm{m}]$} \\
\hline 1 & 1 & 15.0 & 1.50 & 309604 & 435 & 0.278 \\
\hline 2 & 2 & 15.0 & 1.50 & 309604 & 435 & 0.278 \\
\hline 3 & 3 & 12.0 & 1.50 & 309604 & 435 & 0.278 \\
\hline 4 & 4 & 12.0 & 2.00 & 232203 & 327 & 0.208 \\
\hline 5 & 5 & 9.0 & 2.00 & 232203 & 327 & 0.208 \\
\hline
\end{tabular}

Tabla 5.14 Rigidez axial EA, rigidez a flexión EI y peso unitario $w$ para "Soil Nails" de Zaigen.

\begin{tabular}{ccccccc}
\hline \multicolumn{2}{c}{ SÓTANO } & \multicolumn{5}{c}{ "SOIL NAILS” } \\
\hline $\begin{array}{c}\text { Nivel } \\
\text { de } \\
\text { sótano }\end{array}$ & $\begin{array}{c}\text { Fila de } \\
\text { anclaje }\end{array}$ & $\begin{array}{c}\text { Longitud } \\
\text { de "Soil } \\
\text { Nails" }\end{array}$ & $\begin{array}{c}\text { Separación } \\
\text { horizontal de } \\
\text { "Soil Nails" } S_{h}\end{array}$ & $\begin{array}{c}\text { Rigidez Axial } \\
E A\end{array}$ & $\begin{array}{c}\text { Rigidez a Flexión } \\
E I\end{array}$ & $\begin{array}{c}\text { Peso unitario } \\
w\end{array}$ \\
\hline 1 & 1 & 15.0 & 2.00 & 232203 & 327 & 0.208 \\
2 & 2 & 15.0 & 1.70 & 273180 & 384 & 0.245 \\
3 & 3 & 12.0 & 1.60 & 290254 & 408 & 0.260 \\
& 4 & 12.0 & 1.60 & 290254 & 408 & 0.260 \\
4 & 5 & 12.0 & 1.60 & 290254 & 408 & 0.260 \\
5 & 6 & 9.0 & 1.60 & 290254 & 408 & 0.260 \\
\hline
\end{tabular}

\subsection{Estudio por el método de los elementos finitos}

\subsubsection{Introducción}

El método de los elementos finitos $(M E F)$ inicialmente fue estudiado por Courant (1943) y es una poderosa técnica numérica asistida por ordenador. Originalmente fue desarrollado para la solución numérica de complejos problemas en ingeniería mecánica, luego fue ampliamente utilizado en ingeniería civil para análisis de estructuras y en problemas de teoría de la elasticidad (Pradhan et al., 2018). Actualmente el $M E F$ es utilizado en ingeniería geotécnica por muchos investigadores en el análisis de estabilidad de taludes y con resultados racionales. 


\subsubsection{Análisis con Plaxis $2 D$ V20}

En ingeniería geotécnica, la estabilidad global de una estructura tipo "Soil Nailing" prevalece antes que conocer el comportamiento de un solo anclaje o "Soil Nail" (Fan y Luo, 2008). En este sentido, el programa Plaxis 2D V20 tiene en cuenta el comportamiento mecánico de la interacción suelo - anclaje y calcula el factor de seguridad $(F S)$ de todo el conjunto. Por otra parte, Plaxis 2D está equipado de varias características para analizar muchos parámetros importantes de complejas estructuras geotécnicas (Wu y Tung, 2019). Por tanto, en este estudio se utilizará Plaxis 2D V20 CONNECT Edition, por ser un programa informático completo para análisis bidimensional de deformaciones y esfuerzos basado en análisis no lineal por el método de los elementos finitos, con inclusión de varios modelos constitutivos de suelo y que además posibilita la modelación de las diferentes fases constructivas.

Las estructuras de los 2 proyectos Torre Centre y Zaigen serán analizadas aplicando los modelos constitutivos de suelo Mohr Coulomb (MC), Hardening Soil (HS) y Hardening Soil with Small-Strain Stiffness (HSsmall). Para generar la malla de elementos finitos con la densidad apropiada se utilizarán elementos de 15 nodos. Para ambas estructuras de "Soil Nailing" se generará una malla de elementos "muy fina" y los esfuerzos iniciales se generarán mediante el procedimiento $K_{0}$. Por otra parte, en cada modelo se incluirán interfaces estándar en los "Soil Nails" para considerar y simular la fricción existente en la interacción suelo - anclaje. El valor considerado para la resistencia de las interfaces es de $R_{\text {inter }}=0.67$.

\subsubsection{Análisis de estructura de proyecto Torre Centre}

\subsubsection{Generalidades}

Torre Centre incluye 5 niveles de sótano con una excavación total de $13.55 \mathrm{~m}$, mediante 5 excavaciones parciales que representan a la altura de un nivel de sótano, según se puede observar en la Fig. 4.35 del Capítulo 4. Este modelo numérico incluye una pequeña sobrecarga superficial de $2 \mathrm{kN} / \mathrm{m}$ en la vía para simular el ligero y esporádico tráfico vehicular durante el proceso constructivo de esta estructura.

La Fig. 5.19 muestra el modelo numérico inicial para la estructura de "Soil Nailing" simulada con Plaxis 2D V20. En este modelo se incluyen dimensiones, elementos estructurales y demás parámetros que caracterizan a esta estructura. Mientras tanto, la Fig. 5.20 presenta el modelo numérico en la quinta fase de excavación, que es cuando se ha construido el sótano 5 y se ha alcanzado una excavación de $13.55 \mathrm{~m}$.

En la Fig. 5.21 se grafican las diferentes fases constructivas para la simulación con Plaxis 2D. La construcción de cada nivel de sótano contempla 4 fases básicas: [1] la excavación inicial de la totalidad del terreno correspondiente al nivel de sótano, dejando un pequeño contrafuerte de suelo, [2] la construcción del "Soil Nail", [3] la conformación vertical del talud, y [4] la construcción de la pantalla de concreto. 


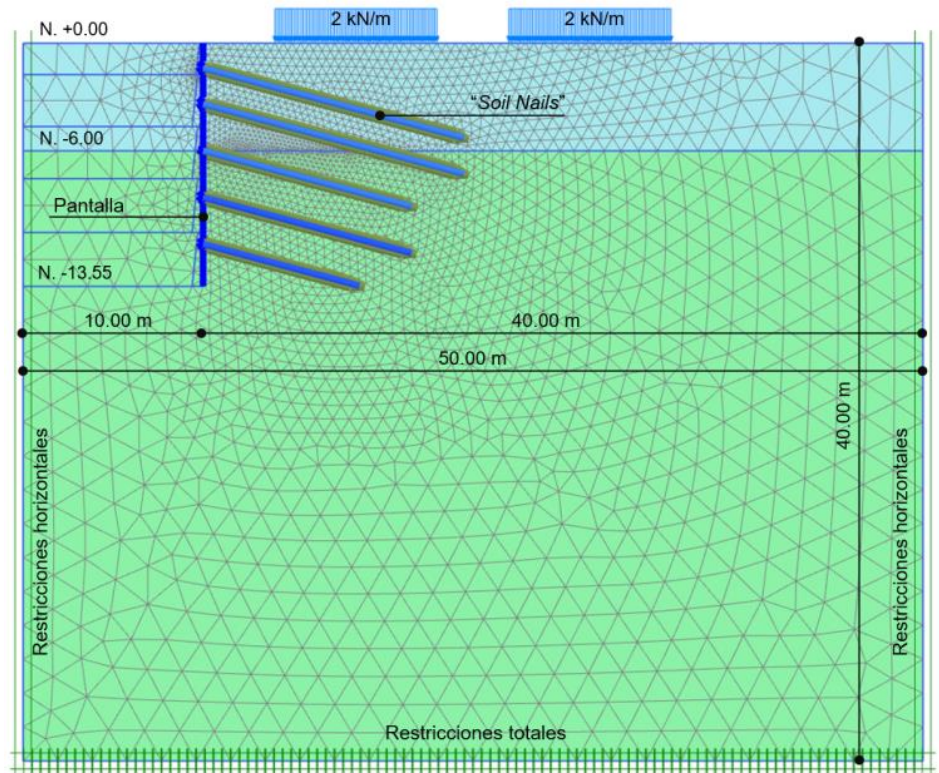

Fig. 5.19 Modelo inicial con Plaxis 2D de estructura de "Soil Nailing" de proyecto Torre Centre.

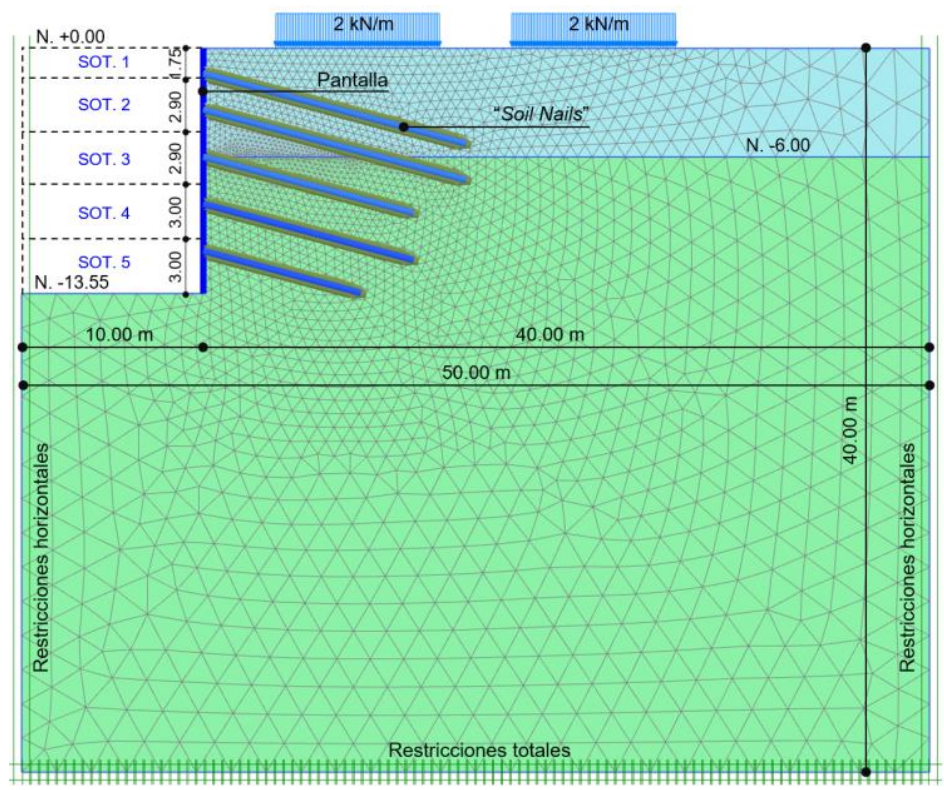

Fig. 5.20 Modelo final con Plaxis 2D de estructura de "Soil Nailing" de proyecto Torre Centre. 


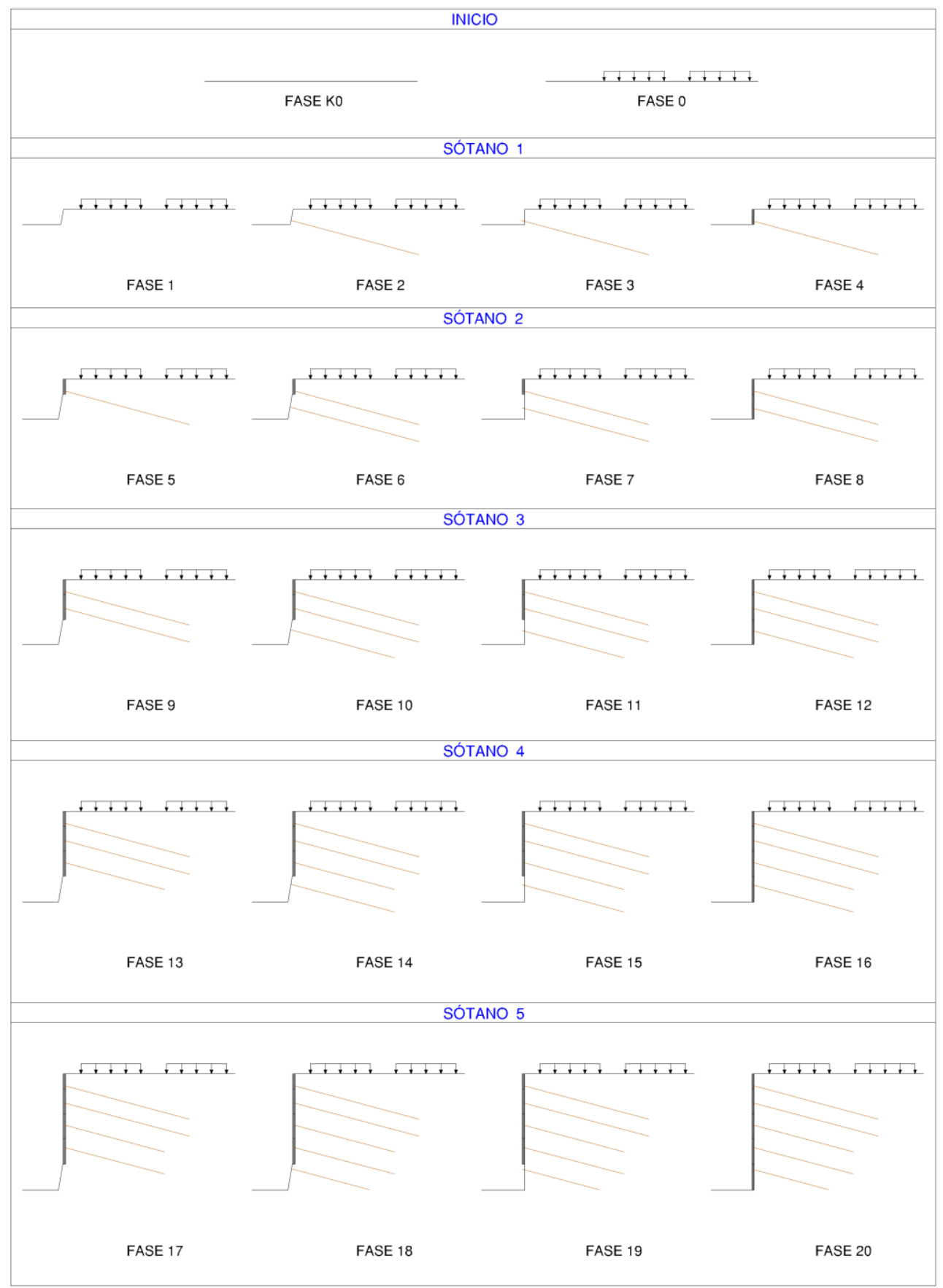

Fig. 5.21 Fases constructivas simuladas con Plaxis 2D para estructura de proyecto Torre Centre. 
Por otra parte, en las Fig. 5.22, 5.23 y 5.24 se presenta el análisis de la estructura de Torre Centre con la construcción del sótano 5, que es la fase de mayores desplazamientos, aplicando los 3 modelos constitutivos de suelo: Mohr Coulomb, Hardening Soil y HSsmall, respectivamente. Se nota en el análisis con el modelo de Mohr Coulomb, valores altos de ascensión del suelo en el fondo de la excavación.

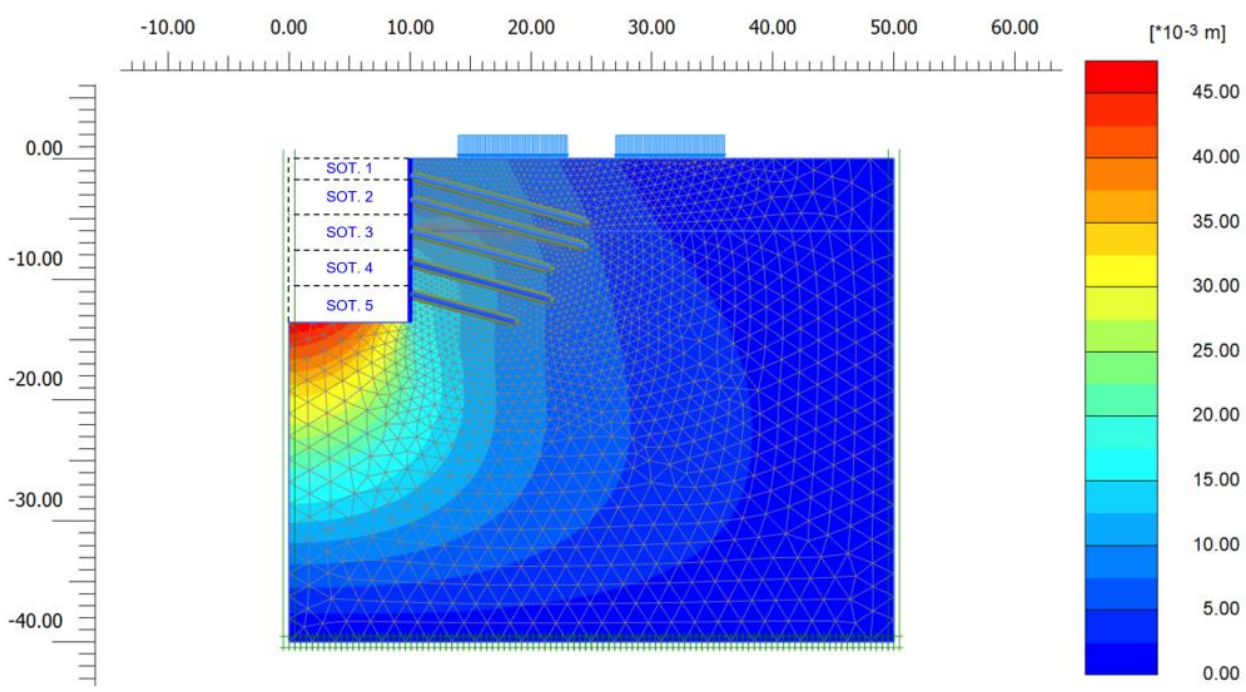

Fig. 5.22 Desplazamientos totales $|\mathrm{u}|$ con modelo de Mohr Coulomb por construcción de sótano 5.

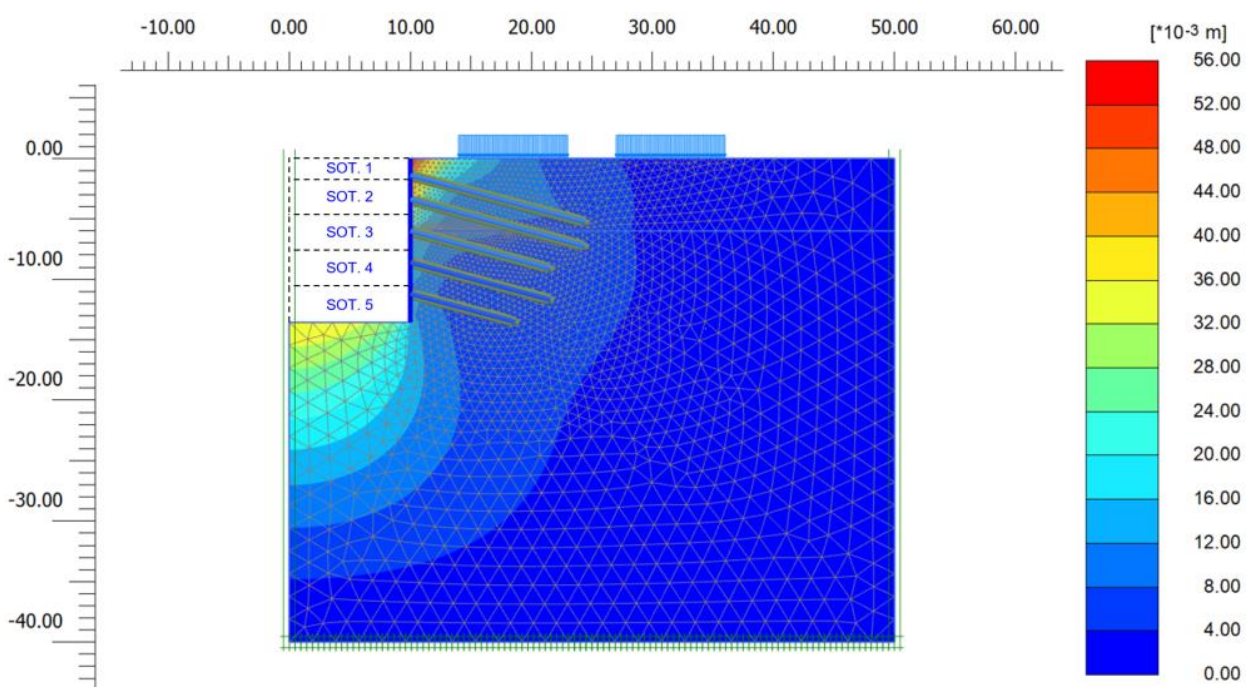

Fig. 5.23 Desplazamientos totales $|\mathbf{u}|$ con modelo de Hardening Soil por construcción de sótano 5. 


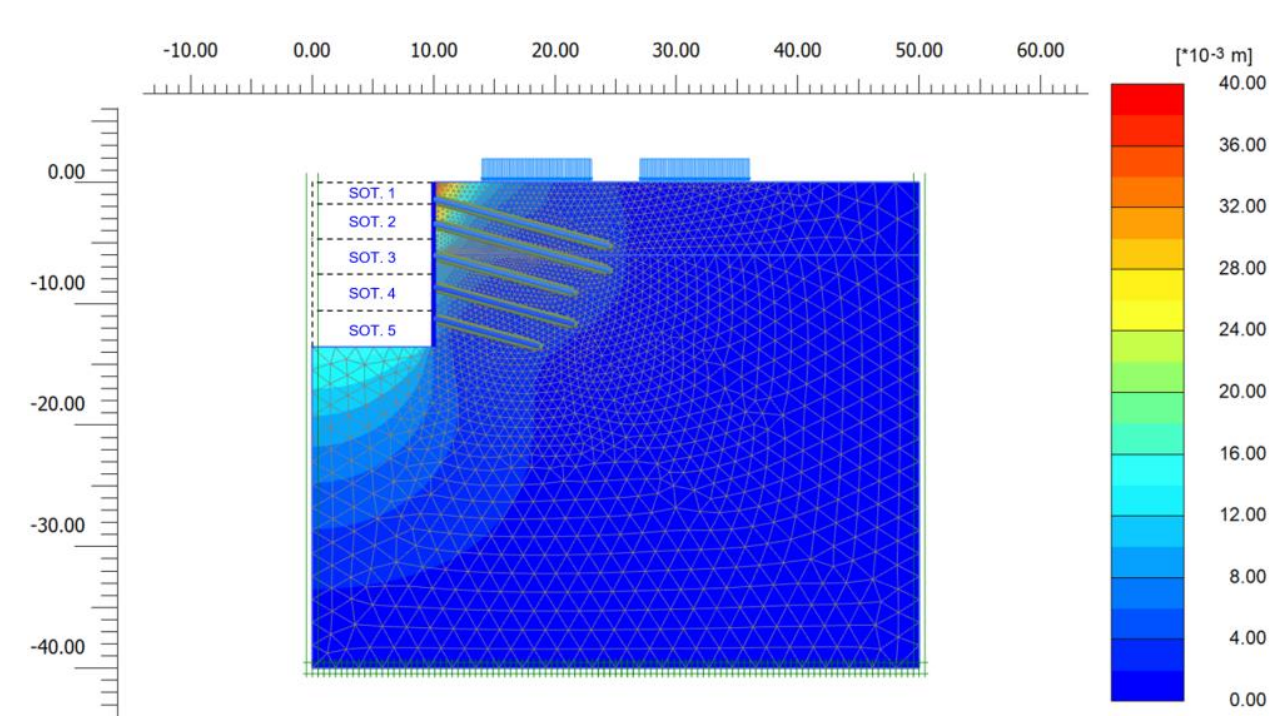

Fig. 5.24 Desplazamientos totales $|\mathrm{u}|$ con modelo de HSsmall por construcción de sótano 5.

\subsubsection{Diagramas de fuerza axial de tensión en "Soil Nails" de Torre Centre}

En esta sección se resumen los diagramas de fuerzas axiales de tensión generadas en los "Soil Nails" por efecto de las excavaciones parciales para la construcción de cada sótano. Inicialmente, para una mejor comparación en cada nivel de sótano se grafica simultáneamente la distribución de fuerzas axiales de tensión obtenidas aplicando los 3 modelos constitutivos de suelo: Mohr Coulomb, Hardening Soil y HSsmall.

Por tanto, en las Fig. 5.25 a 5.29 se presenta de manera secuencial y de acuerdo al proceso constructivo los diagramas de distribución de fuerzas de tensión generados en los "Soil Nails" por efecto de la construcción de los 5 sótanos de Torre Centre.

\section{Excavación 1 - construcción de sótano 1}

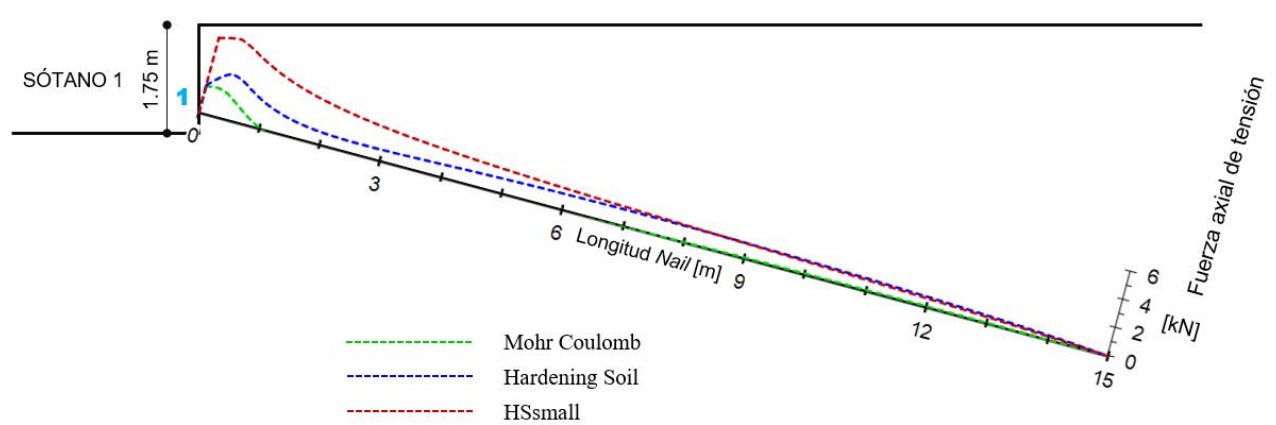

Fig. 5.25 Distribución de fuerzas axiales de tensión en "Soil Nails" por construcción de sótano 1 de Torre Centre. 
En la Tabla 5.15 se resumen los valores de tensiones máximas para los "Soil Nails" del diagrama de la Fig. 5.25, generados por la construcción del sótano 1, para cada uno de los modelos constitutivos de suelo.

Tabla 5.15 Fuerzas de tensión máxima en "Soil Nails" por construcción de sótano 1 de Torre Centre.

\begin{tabular}{|c|c|c|c|c|}
\hline \multirow{3}{*}{ SÓTANO } & \multirow{3}{*}{$\begin{array}{l}\text { "SOIL } \\
\text { NAIL" }\end{array}$} & \multirow{2}{*}{\multicolumn{3}{|c|}{$\frac{\text { FUERZA AXIAL DE TENSIÓN MÁXIMA [kN] }}{\text { MODELO CONSTITUTIVO }}$}} \\
\hline & & & & \\
\hline & & Mohr Coulomb & Hardening Soil & HSsmall \\
\hline \multicolumn{5}{|c|}{ CONSTRUCCIÓN DE SÓTANO 1} \\
\hline 1 & 1 & 1.97 & 3.18 & 5.62 \\
\hline
\end{tabular}

\section{Excavación 2 - construcción de sótano 2}

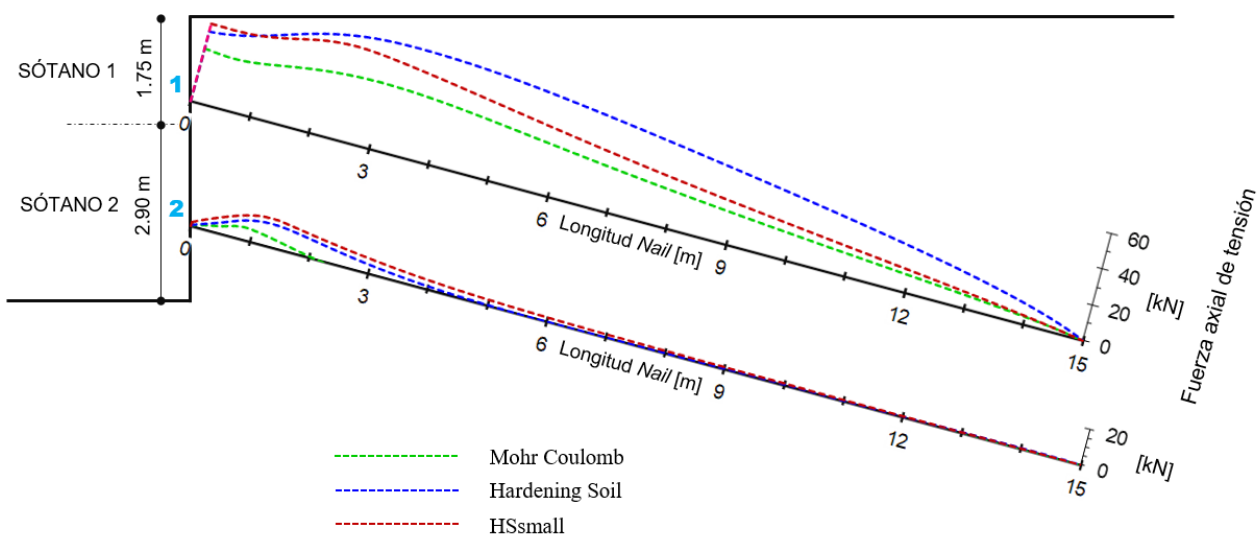

Fig. 5.26 Distribución de fuerzas axiales de tensión en "Soil Nails" por construcción de sótano 2 de Torre Centre.

En la Tabla 5.16 se presentan los valores de tensiones máximas para los "Soil Nails" del diagrama de la Fig. 5.26, generados por la construcción del sótano 2, para cada uno de los modelos constitutivos de suelo.

Tabla 5.16 Fuerzas de tensión máxima en "Soil Nails" por construcción de sótano 2 de Torre Centre.

\begin{tabular}{ccccc}
\hline \multirow{2}{*}{ SÓTANO } & \multirow{2}{*}{ "SOIL } & \multicolumn{4}{c}{ FUERZA AXIAL DE TENSIÓN MÁXIMA [kN] } \\
\cline { 3 - 5 } & NAIL" & \multicolumn{4}{c}{ MODELO CONSTITUTIVO } \\
\cline { 3 - 5 } & \multicolumn{5}{c}{ Mohr Coulomb } & Hardening Soil & HSsmall \\
\hline 1 & 1 & 36.43 & 59.82 & 51.90 \\
2 & 2 & 6.60 & 12.51 & 14.97 \\
\hline
\end{tabular}




\section{Excavación 3 - construcción de sótano 3}

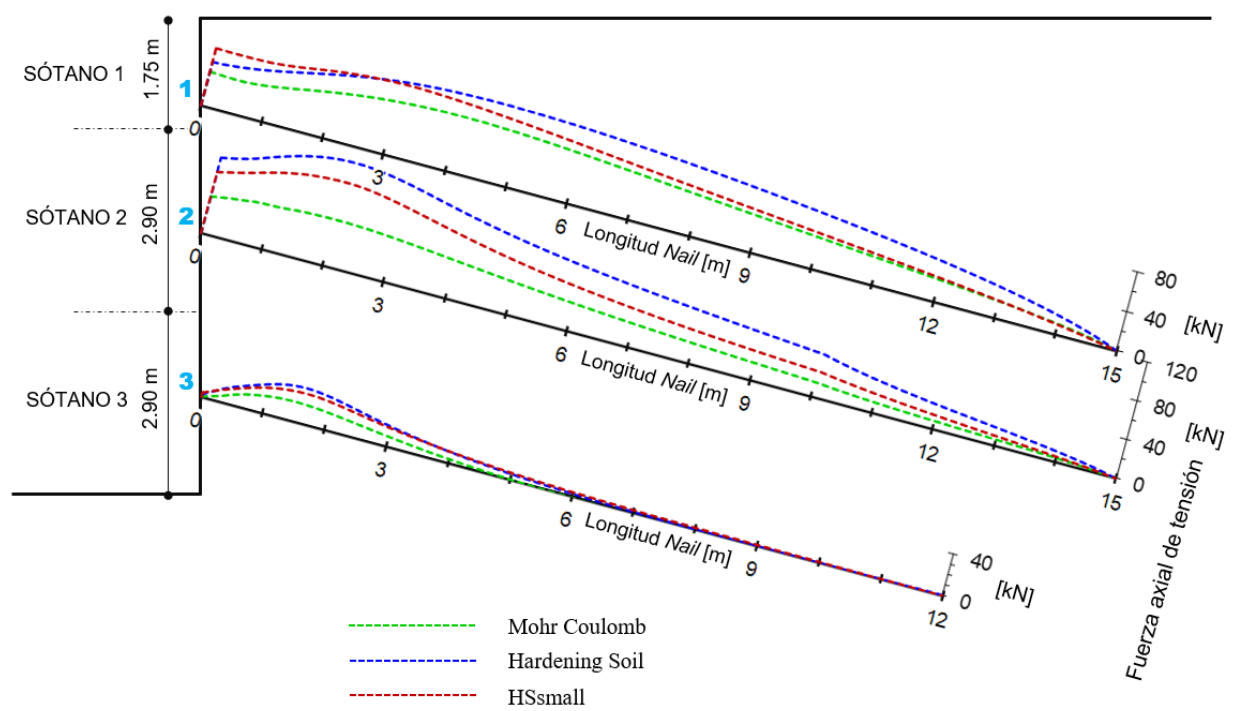

Fig. 5.27 Distribución de fuerzas axiales de tensión en "Soil Nails" por construcción de sótano 3 de Torre Centre.

En la Tabla 5.17 se resumen los valores de tensiones máximas para los "Soil Nails" del diagrama de la Fig. 5.27, inducidos por la construcción del sótano 3, para cada uno de los modelos constitutivos de suelo.

Tabla 5.17 Fuerzas de tensión máxima en "Soil Nails" por construcción de sótano 3 de Torre Centre.

\begin{tabular}{|c|c|c|c|c|}
\hline \multirow{3}{*}{ SÓTANO } & \multirow{3}{*}{$\begin{array}{l}\text { "SOIL } \\
\text { NAIL" }\end{array}$} & \multirow{2}{*}{\multicolumn{3}{|c|}{$\frac{\text { FUERZA AXIAL DE TENSIÓN MÁXIMA [kN] }}{\text { MODELO CONSTITUTIVO }}$}} \\
\hline & & & & \\
\hline & & Mohr Coulomb & Hardening Soil & HSsmall \\
\hline \multicolumn{5}{|c|}{ CONSTRUCCIÓN DE SÓTANO 3} \\
\hline 1 & 1 & 55.63 & 77.44 & 70.75 \\
\hline 2 & 2 & 48.13 & 106.69 & 86.52 \\
\hline 3 & 3 & 18.76 & 32.59 & 28.42 \\
\hline
\end{tabular}




\section{Excavación 4 - construcción de sótano 4}

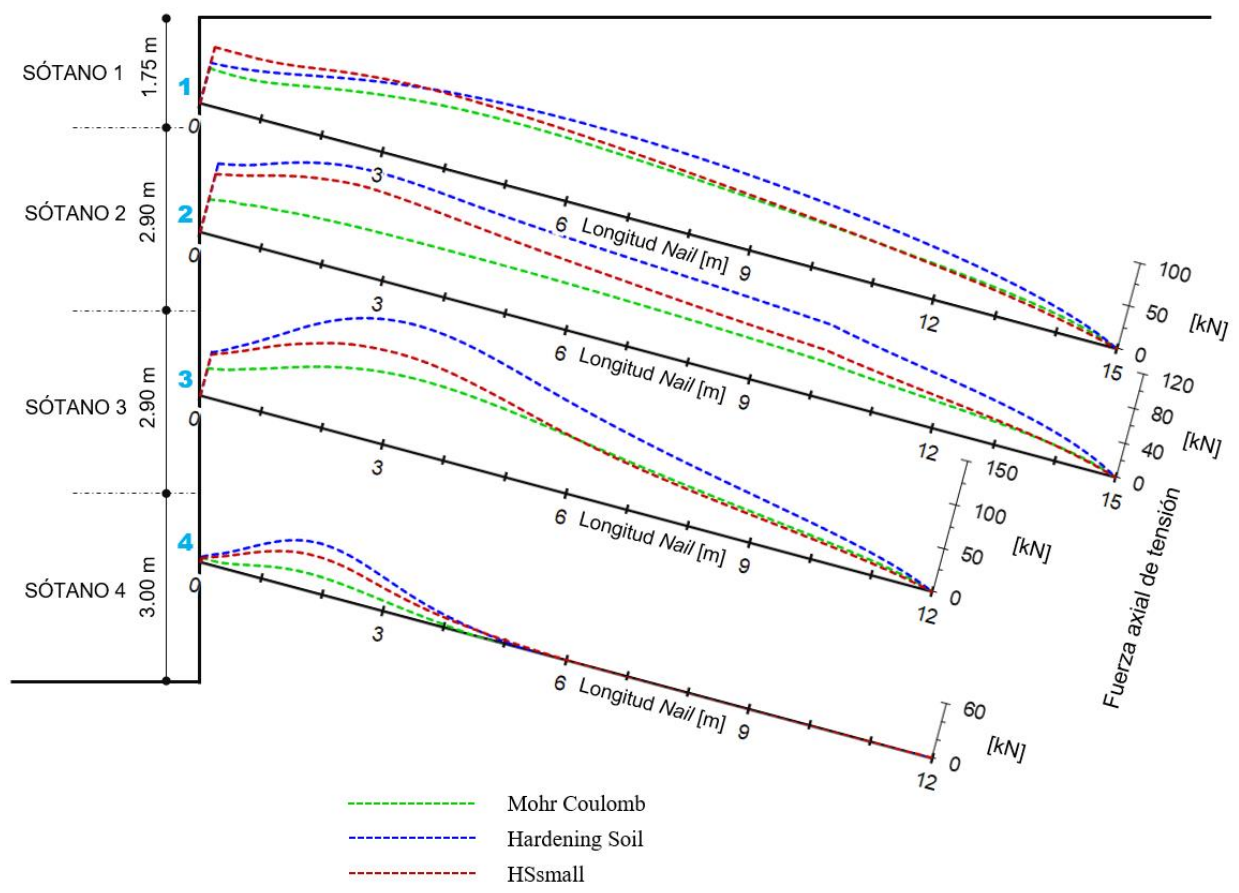

Fig. 5.28 Distribución de fuerzas axiales de tensión en "Soil Nails" por construcción de sótano 4 de Torre Centre.

En la Tabla 5.18 se presentan los valores de tensiones máximas para los "Soil Nails" del diagrama de la Fig. 5.28, generados por la construcción del sótano 4, para cada uno de los modelos constitutivos de suelo.

Tabla 5.18 Fuerzas de tensión máxima en "Soil Nails" por construcción de sótano 4 de Torre Centre.

\begin{tabular}{ccccc}
\hline \multirow{2}{*}{ SÓTANO } & \multirow{2}{*}{$\begin{array}{c}\text { SOIL } \\
\text { NAIL" }\end{array}$} & \multicolumn{3}{c}{ FUERZA AXIAL DE TENSIÓN MÁXIMA [kN] } \\
\cline { 3 - 5 } & & \multicolumn{4}{c}{ Mohr Coulomb } & Hardening Soil & HSsmall \\
\hline & 1 & 70.29 & 90.06 & 82.16 \\
2 & 2 & 52.19 & 115.53 & 96.04 \\
3 & 3 & 80.28 & 137.45 & 102.16 \\
4 & 4 & $17-92$ & 51.41 & 38.02 \\
\hline
\end{tabular}




\section{Excavación 5 - construcción de sótano 5}

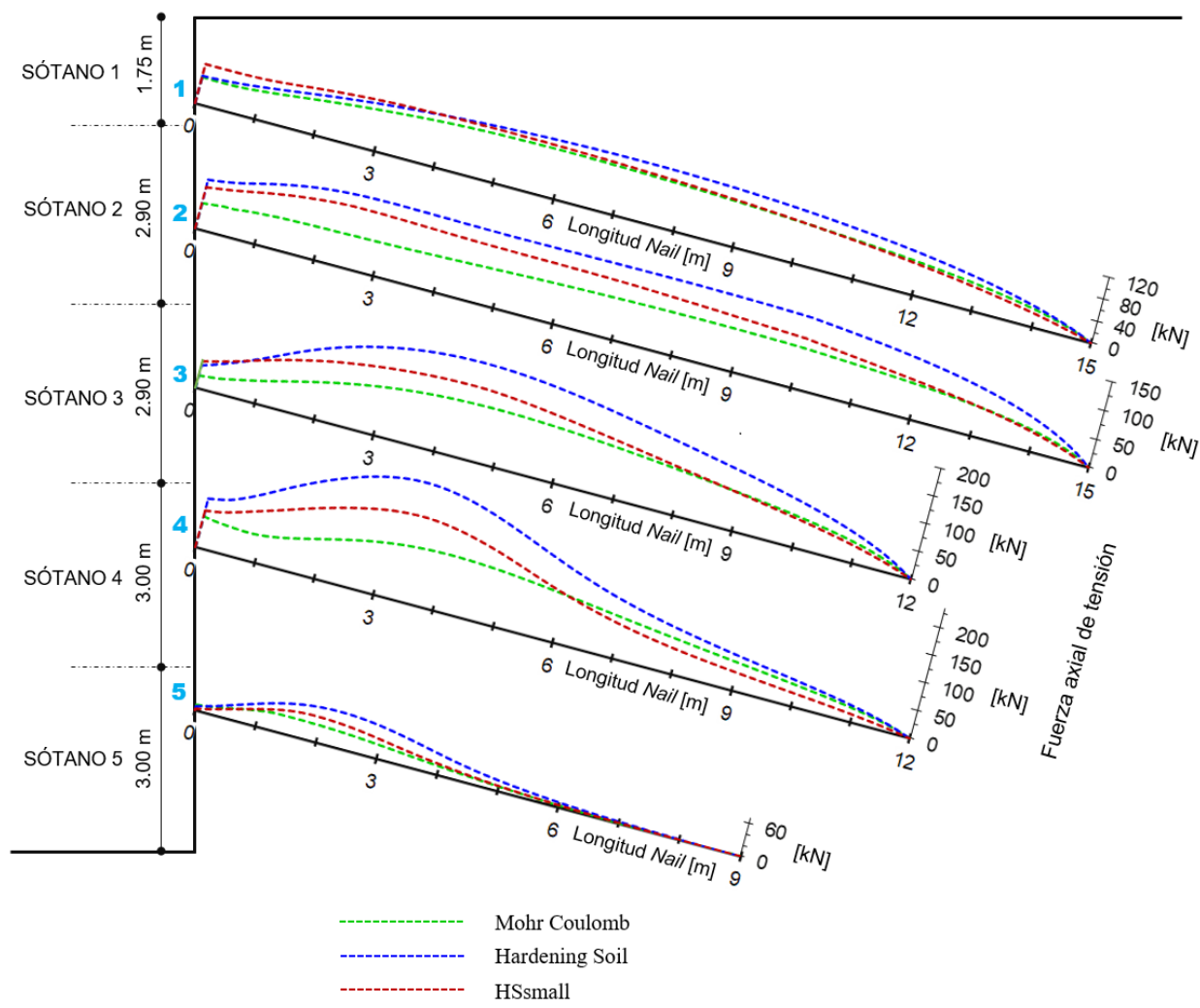

Fig. 5.29 Distribución de fuerzas axiales de tensión en "Soil Nails" por construcción de sótano 5 de Torre Centre.

En la Tabla 5.19 se resumen los valores de tensiones máximas para los "Soil Nails" del diagrama de la Fig. 5.29, inducidos por la construcción del sótano 5.

Tabla 5.19 Fuerzas de tensión máxima en "Soil Nails" por construcción de sótano 5 de Torre Centre.

\begin{tabular}{|c|c|c|c|c|}
\hline \multirow{3}{*}{ SÓTANO } & \multirow{3}{*}{ "SOIL } & \multirow{2}{*}{\multicolumn{3}{|c|}{$\frac{\text { FUERZA AXIAL DE TENSIÓN MÁXIMA [kN] }}{\text { MODELO CONSTITUTIVO }}$}} \\
\hline & & & & \\
\hline & & Mohr Coulomb & Hardening Soil & HSsmall \\
\hline \multicolumn{5}{|c|}{ CONSTRUCCIÓN DE SÓTANO 5} \\
\hline 1 & 1 & 86.51 & 104.14 & 92.83 \\
\hline 2 & 2 & 71.07 & 126.15 & 104.49 \\
\hline 3 & 3 & 98.27 & 172.06 & 129.24 \\
\hline 4 & 4 & 101.16 & 213.07 & 153.16 \\
\hline 5 & 5 & 32.90 & 63.87 & 46.60 \\
\hline
\end{tabular}




\section{Análisis sísmico pseudoestático}

Se ha incluido un análisis sísmico con enfoque pseudoestático para la estructura de "Soil Nailing" de Torre Centre para la altura total de 13.55 m, que representa a los 5 niveles de sótano, y que constituye el caso más crítico.

De acuerdo a la zona sísmica de la ciudad de Quito, en dicho análisis se ha considerado la aceleración horizontal $\mathrm{a}_{\mathrm{h}}=0.20 \mathrm{~g}$ y la aceleración vertical $\mathrm{a}_{\mathrm{v}}=0.10$ g. La Fig. 5.30 muestra los diagramas de distribución de fuerzas de tensión en los "Soil Nails" por efecto del análisis sísmico pseudoestático para el caso de la excavación total para los 5 sótanos.

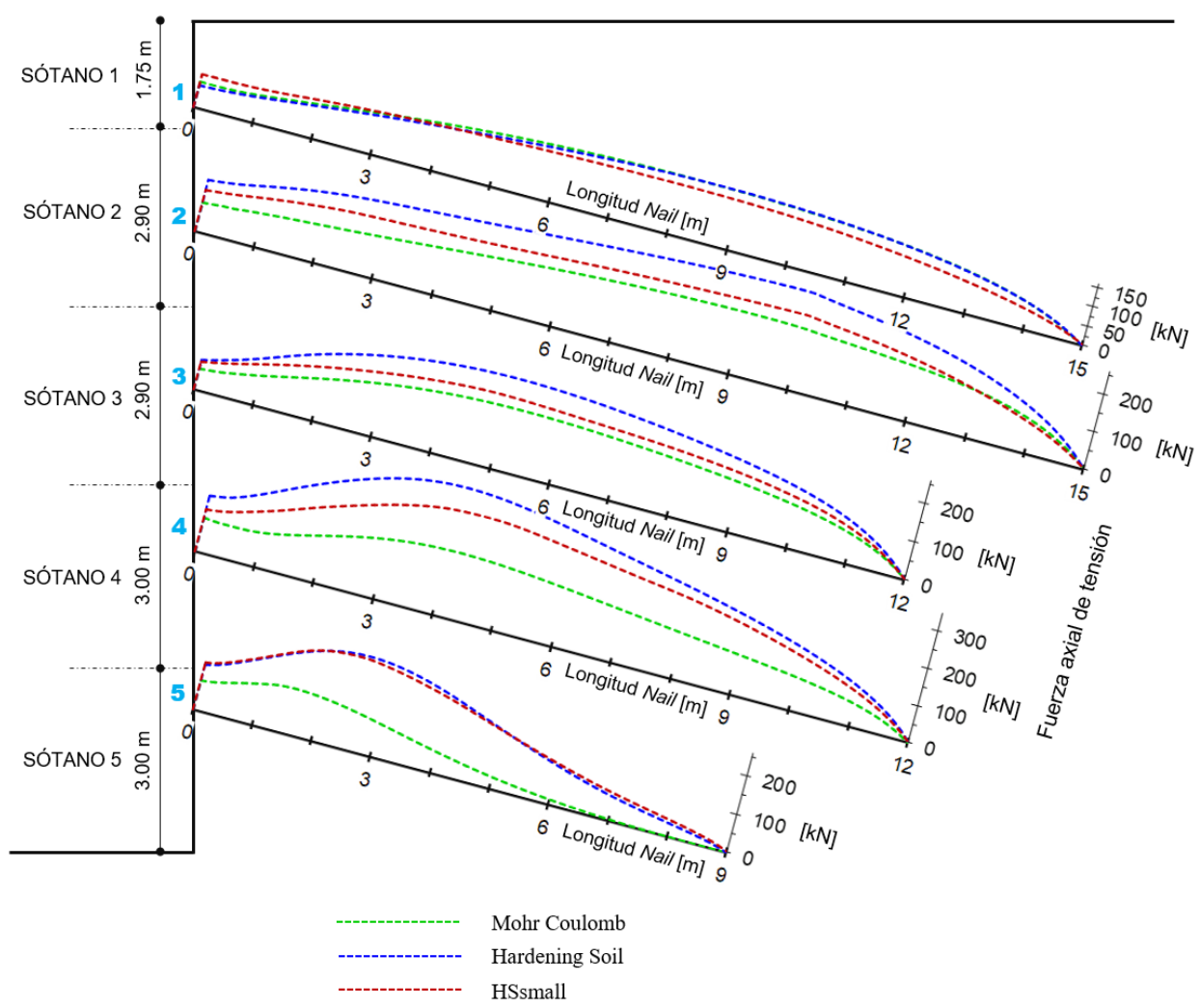

Fig. 5.30 Análisis sísmico pseudoestático: Distribución de fuerzas axiales de tensión en "Soil Nails" para la altura total de $13.55 \mathrm{~m}$ en estructura de Torre Centre.

En la Tabla 5.20 se resumen los valores de tensiones máximas para los "Soil Nails" del diagrama de la Fig. 5.30, generados por el enfoque sísmico pseudoestático, para el análisis con los 3 modelos constitutivos de suelo. 
Tabla 5.20 Fuerzas de tensión máxima en "Soil Nails" por enfoque sísmico pseudoestático en estructura de Torre Centre.

\begin{tabular}{|c|c|c|c|c|}
\hline \multirow{3}{*}{ SÓTANO } & \multirow{3}{*}{$\begin{array}{l}\text { "SOIL } \\
\text { NAIL" }\end{array}$} & \multirow{2}{*}{\multicolumn{3}{|c|}{$\frac{\text { FUERZA AXIAL DE TENSIÓN MÁXIMA [kN] }}{\text { MODELO CONSTITUTIVO }}$}} \\
\hline & & & & \\
\hline & & Mohr Coulomb & Hardening Soil & HSsmall \\
\hline \multicolumn{5}{|c|}{ ANÁLISIS PSEUDOESTÁTICO } \\
\hline 1 & 1 & 149.94 & 152.37 & 128.15 \\
\hline 2 & 2 & 163.81 & 257.00 & 196.72 \\
\hline 3 & 3 & 162.36 & 237.55 & 188.30 \\
\hline 4 & 4 & 175.82 & 343.08 & 283.23 \\
\hline 5 & 5 & 116.33 & 246.08 & 239.29 \\
\hline
\end{tabular}

Evolución de tensiones con las fases constructivas según modelo de Mohr Coulomb

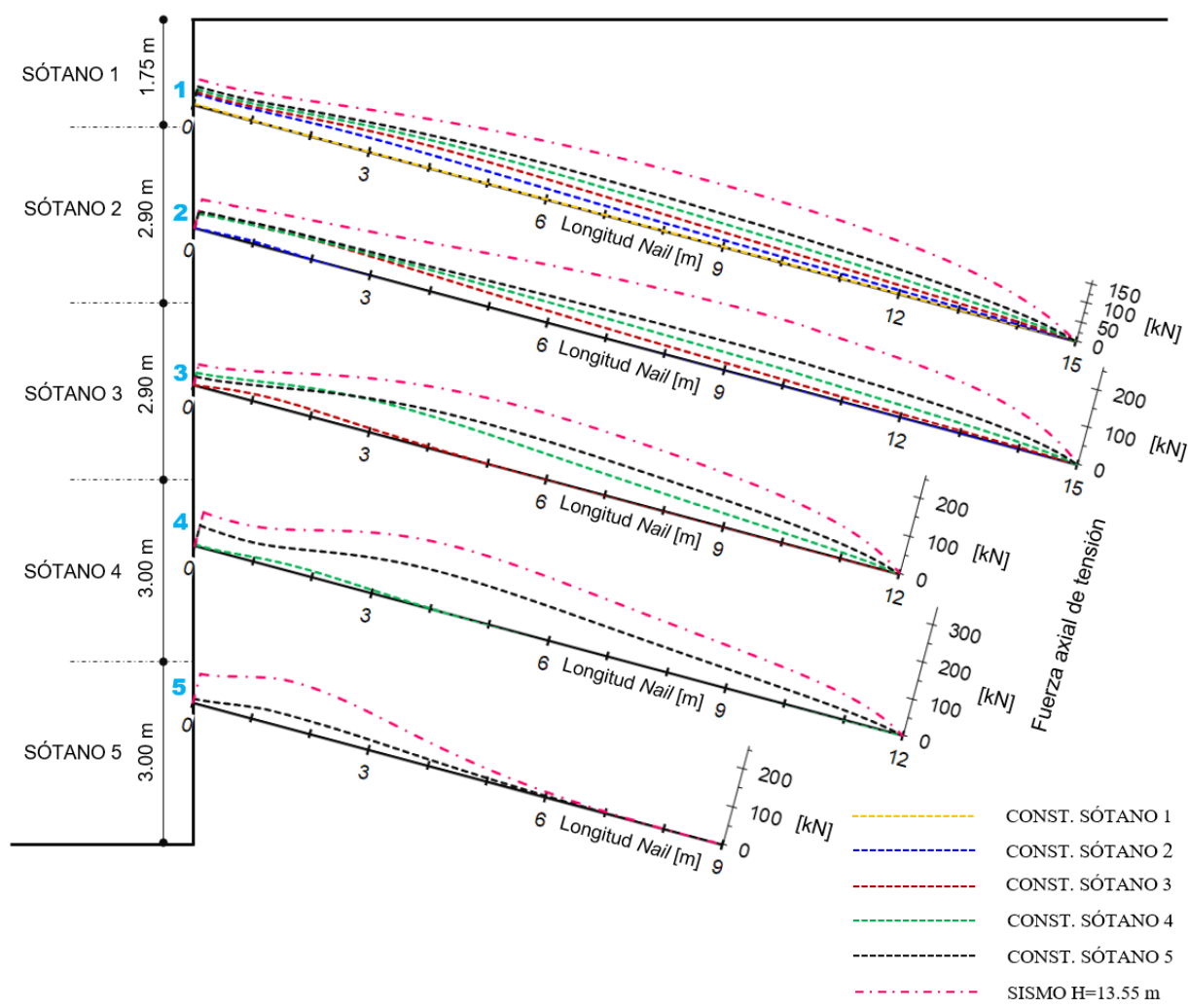

Fig. 5.31 Evolución de fuerzas de tensión en los "Soil Nails" con las fases constructivas según modelo constitutivo de Mohr Coulomb para estructura de Torre Centre. 
La Fig. 5.31 presenta la evolución de las fuerzas de tensión en los "Soil Nails" con las fases constructivas según el modelo constitutivo de Mohr Coulomb. La Tabla 5.21 muestra el resumen de las tensiones máximas de los diagramas de la Fig. 5.31.

Tabla 5.21 Evolución de fuerzas de tensión máxima en "Soil Nails" según modelo de Mohr Coulomb.

\begin{tabular}{cccccc}
\hline \multirow{2}{*}{ FASE } & \multicolumn{5}{c}{ FUERZA AXIAL DE TENSIÓN MÁXIMA [kN] } \\
\cline { 2 - 6 } & 1 & 2 & 3 & 4 & 5 \\
\cline { 2 - 6 } & 1.97 & - & - & - & - \\
\hline CONST. SÓTANO 1 & 36.43 & 6.60 & - & - & - \\
CONST. SÓTANO 2 & 55.63 & 48.13 & 18.76 & - & - \\
CONST. SÓTANO 3 & 70.29 & 52.19 & 80.28 & 17.92 & - \\
CONST. SÓTANO 4 & 86.51 & 71.07 & 98.27 & 101.16 & 32.90 \\
CONST. SÓTANO 5 & 149.94 & 163.81 & 162.36 & 175.82 & 116.33 \\
SISMO H=13.55 m & & & & & \\
\hline
\end{tabular}

\section{Evolución de tensiones con las fases constructivas según modelo de Hardening Soil}

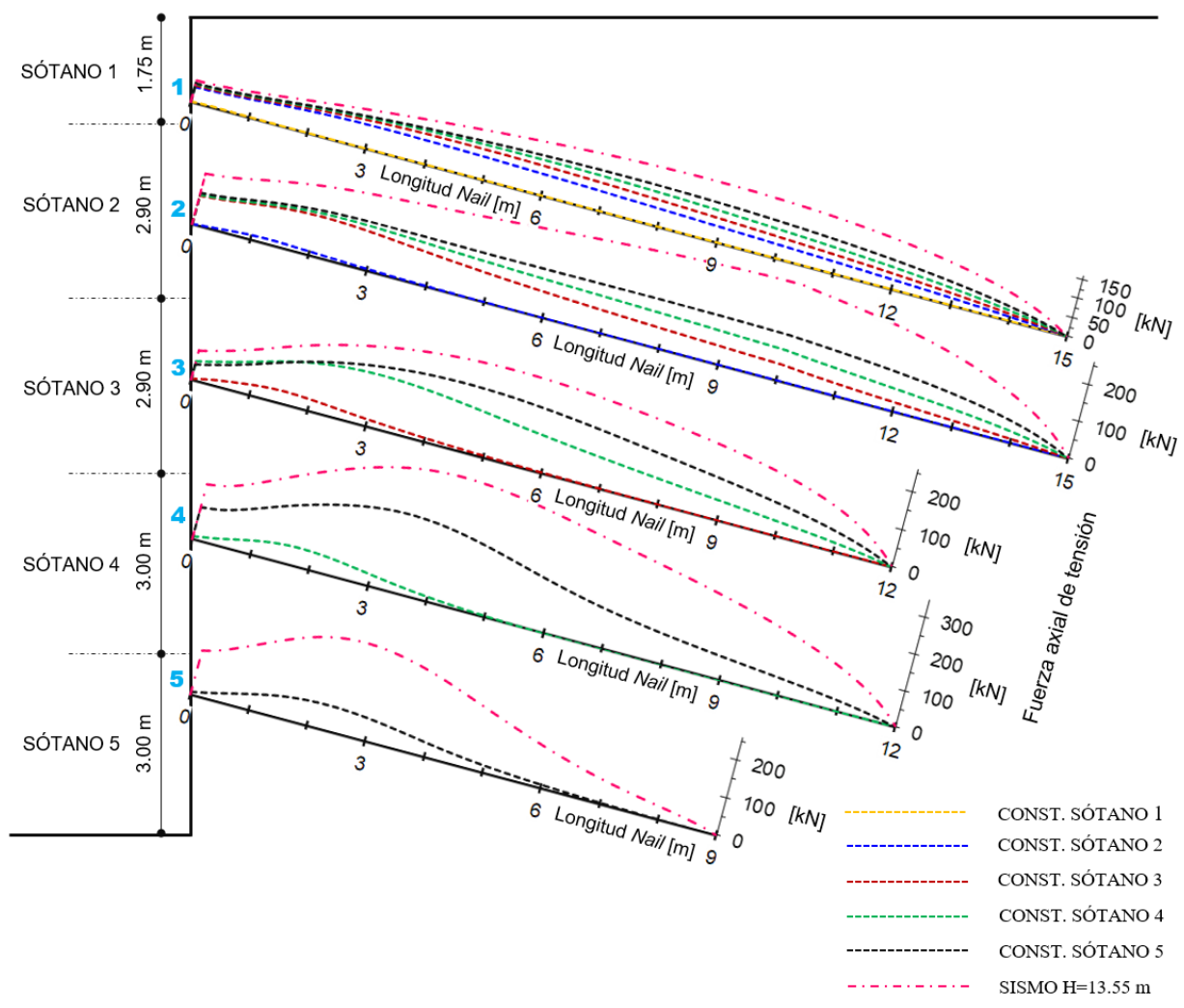

Fig. 5.32 Evolución de fuerzas de tensión en los "Soil Nails" con las fases constructivas según modelo constitutivo de Hardening Soil para estructura de Torre Centre. 
La Fig. 5.32 muestra la evolución de las fuerzas de tensión en los "Soil Nails" con las fases constructivas según el modelo constitutivo de Hardening Soil. La Tabla 5.22 resume los valores de las tensiones máximas de los diagramas de la Fig. 5.32.

Tabla 5.22 Evolución de fuerzas de tensión máxima en "Soil Nails" según modelo de Hardening Soil.

\begin{tabular}{cccccc}
\hline \multirow{2}{*}{ FASE } & \multicolumn{5}{c}{ FUERZA AXIAL DE TENSIÓN MÁXIMA [kN] } \\
\cline { 2 - 6 } & 1 & 2 & 3 & 4 & 5 \\
\cline { 2 - 6 } & 3.18 & - & - & - & - \\
\hline CONST. SÓTANO 1 & 59.82 & 12.51 & - & - & - \\
CONST. SÓTANO 2 & 77.44 & 106.69 & 32.59 & - & - \\
CONST. SÓTANO 3 & 90.06 & 115.53 & 137.45 & 51.41 & - \\
CONST. SÓTANO 4 & 104.14 & 126.15 & 172.06 & 213.07 & 63.87 \\
CONST. SÓTANO 5 & 152.37 & 257.00 & 237.55 & 343.08 & 246.08 \\
SISMO H=13.55 m & 15 . & & &
\end{tabular}

Evolución de tensiones con las fases constructivas según modelo de HSsmall

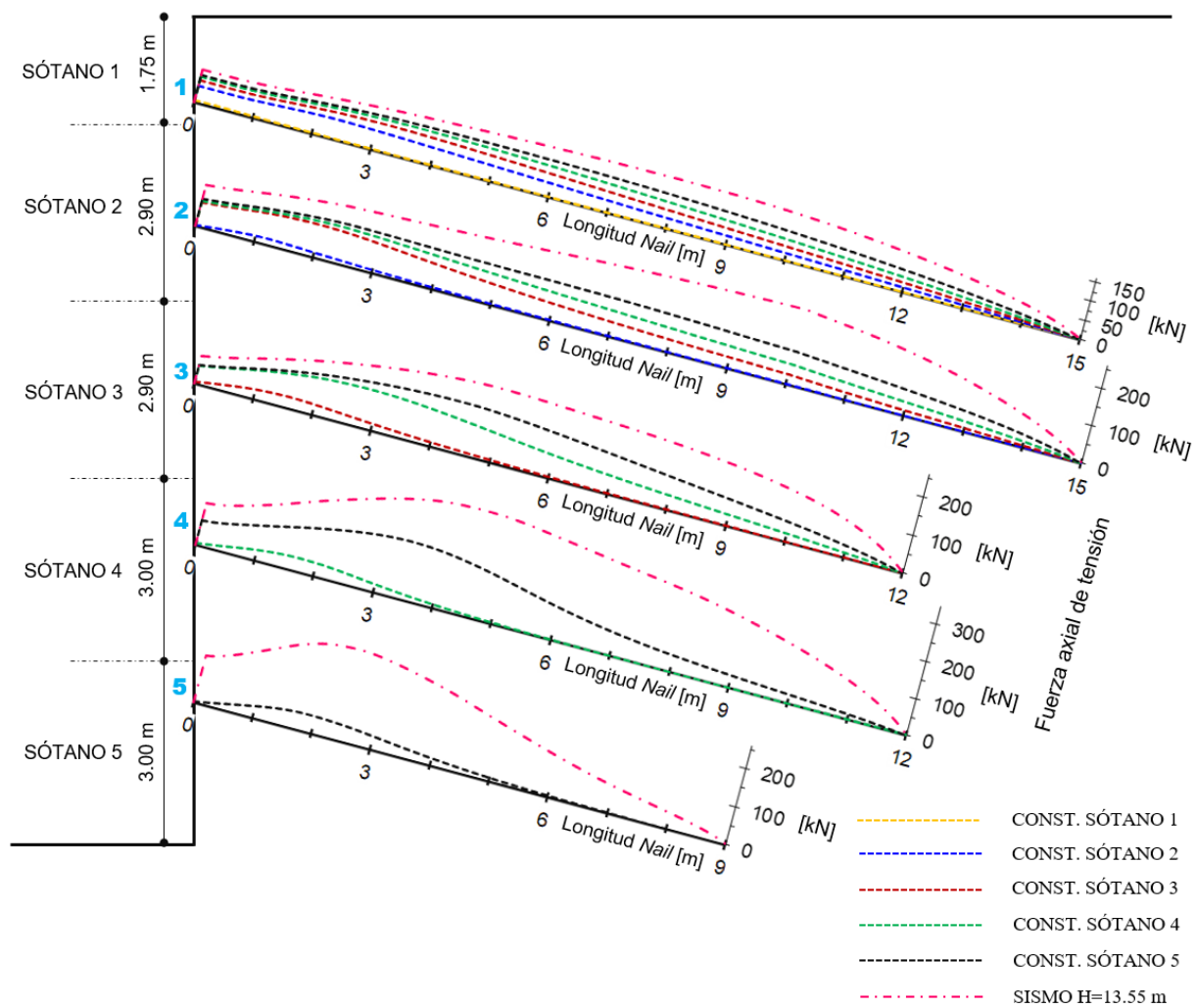

Fig. 5.33 Evolución de fuerzas de tensión en los "Soil Nails" con las fases constructivas según modelo constitutivo de HSsmall para estructura de Torre Centre. 
La Fig. 5.33 detalla la evolución de las fuerzas de tensión en los "Soil Nails" con el avance de las fases constructivas según el modelo constitutivo de HSsmall. Por su parte, la Tabla 5.23 resume los valores de las fuerzas de tensión máximas de los diagramas de la Fig. 5.33.

Tabla 5.23 Evolución de fuerzas de tensión máxima en "Soil Nails" según modelo de HSsmall.

\begin{tabular}{cccccc}
\hline \multirow{2}{*}{ FASE } & \multicolumn{5}{c}{ FUERZA AXIAL DE TENSIÓN MÁXIMA [kN] } \\
\cline { 2 - 6 } & 1 & 2 & 3 & 4 & 5 \\
\cline { 2 - 6 } & 5.62 & - & - & - & - \\
\hline CONST. SÓTANO 1 & 51.90 & 14.97 & - & - & - \\
CONST. SÓTANO 2 & 70.75 & 86.52 & 28.42 & - & - \\
CONST. SÓTANO 3 & 82.16 & 96.04 & 102.16 & 38.02 & - \\
CONST. SÓTANO 4 & 92.83 & 104.49 & 129.24 & 153.16 & 46.60 \\
CONST. SÓTANO 5 & 128.15 & 196.72 & 188.30 & 283.23 & 239.29 \\
SISMO H=13.55 m & & & & & \\
\hline
\end{tabular}

El análisis sísmico pseudoestático con los diferentes modelos constitutivos de suelo se lo realizó exclusivamente para la fase de altura total de la estructura $(\mathrm{H}=13.55 \mathrm{~m})$.

\subsubsection{Desplazamientos horizontales y verticales inducidos en Torre Centre}

En esta sección se presentan los diagramas de desplazamientos horizontales en la pantalla y de desplazamientos verticales o asentamientos del terreno detrás de la pantalla, inducidos por las 5 excavaciones parciales para la construcción de cada sótano del proyecto Torre Centre.

Para una mejor comparación, en cada nivel de sótano se grafica simultáneamente la distribución de desplazamientos obtenidos aplicando los 3 modelos constitutivos de suelo: Mohr Coulomb, Hardening Soil y HSsmall.

En la Fig. 5.34 se muestra la evolución de los desplazamientos horizontales en la pantalla y verticales inducidos en el terreno por efectos de la excavación y construcción del sótano 1.
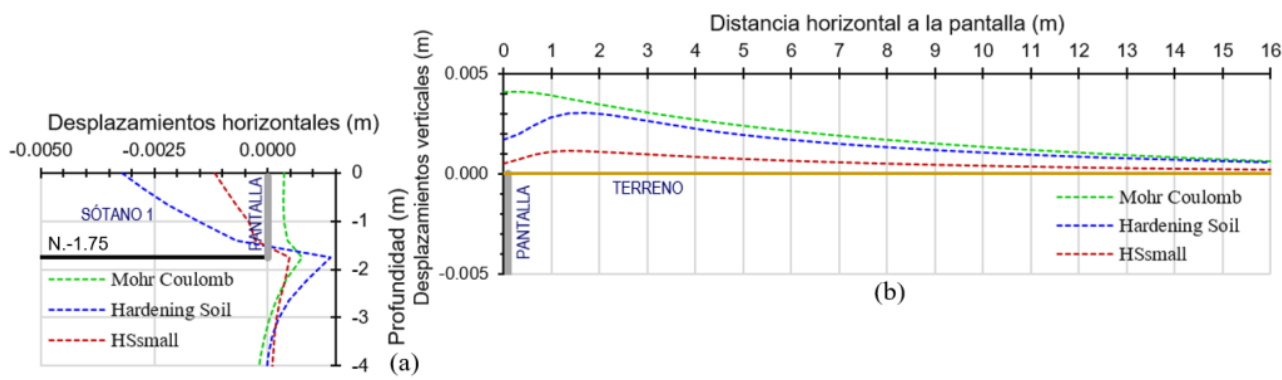

(b)

Fig. 5.34 Desplazamientos inducidos por construcción de sótano 1 de Torre Centre: (a) desplazamientos horizontales en pantalla, y (b) asentamientos del terreno detrás de la pantalla. 
La Fig. 5.35 presenta la evolución de los desplazamientos horizontales en la pantalla y asentamientos inducidos en el terreno por efectos de la excavación y la construcción del sótano 2.
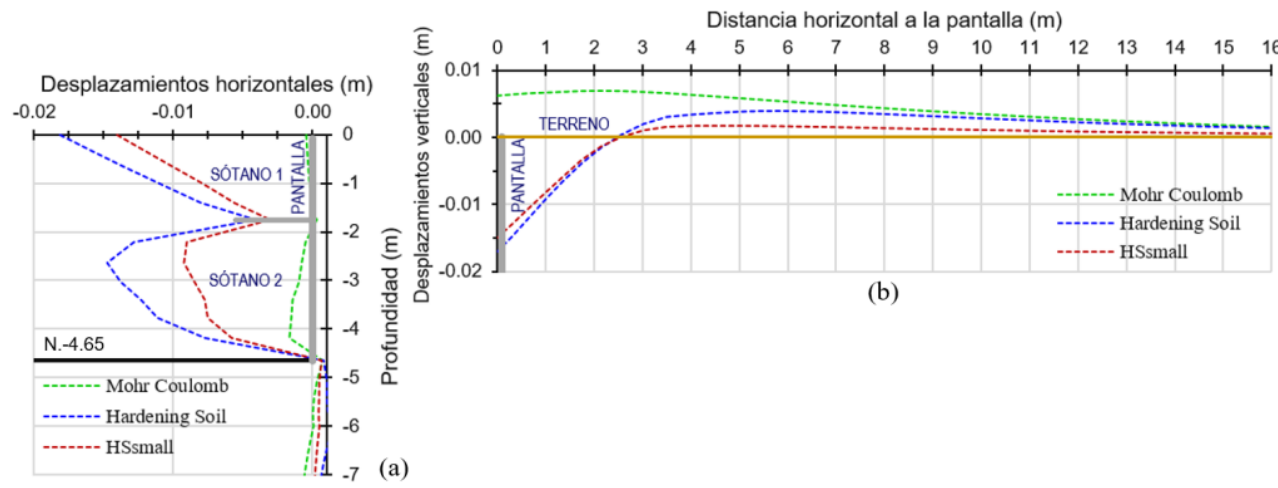

(b)

Fig. 5.35 Desplazamientos inducidos por construcción de sótano 2 de Torre Centre: (a) desplazamientos horizontales en pantalla, y (b) asentamientos del terreno detrás de la pantalla.

En la Fig. 5.36 se muestra la evolución de los desplazamientos horizontales en la pantalla y verticales inducidos en el terreno por efectos de la excavación y construcción del sótano 3.
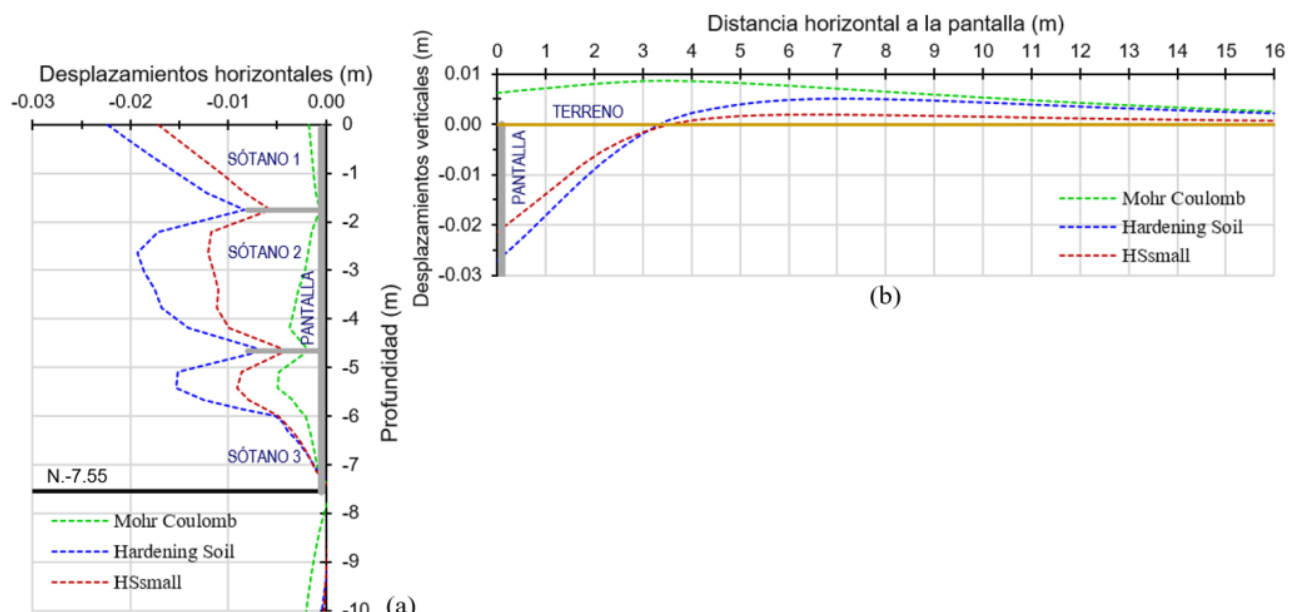

(b)

Fig. 5.36 Desplazamientos inducidos por construcción de sótano 3 de Torre Centre: (a) desplazamientos horizontales en pantalla, y (b) asentamientos del terreno detrás de la pantalla.

Por otra parte, en las Fig. 5.37 y 5.38 se presenta la evolución de los desplazamientos horizontales en la pantalla y verticales inducidos en el terreno por efecto de la construcción de los niveles de sótano 4 y 5 , respectivamente. 


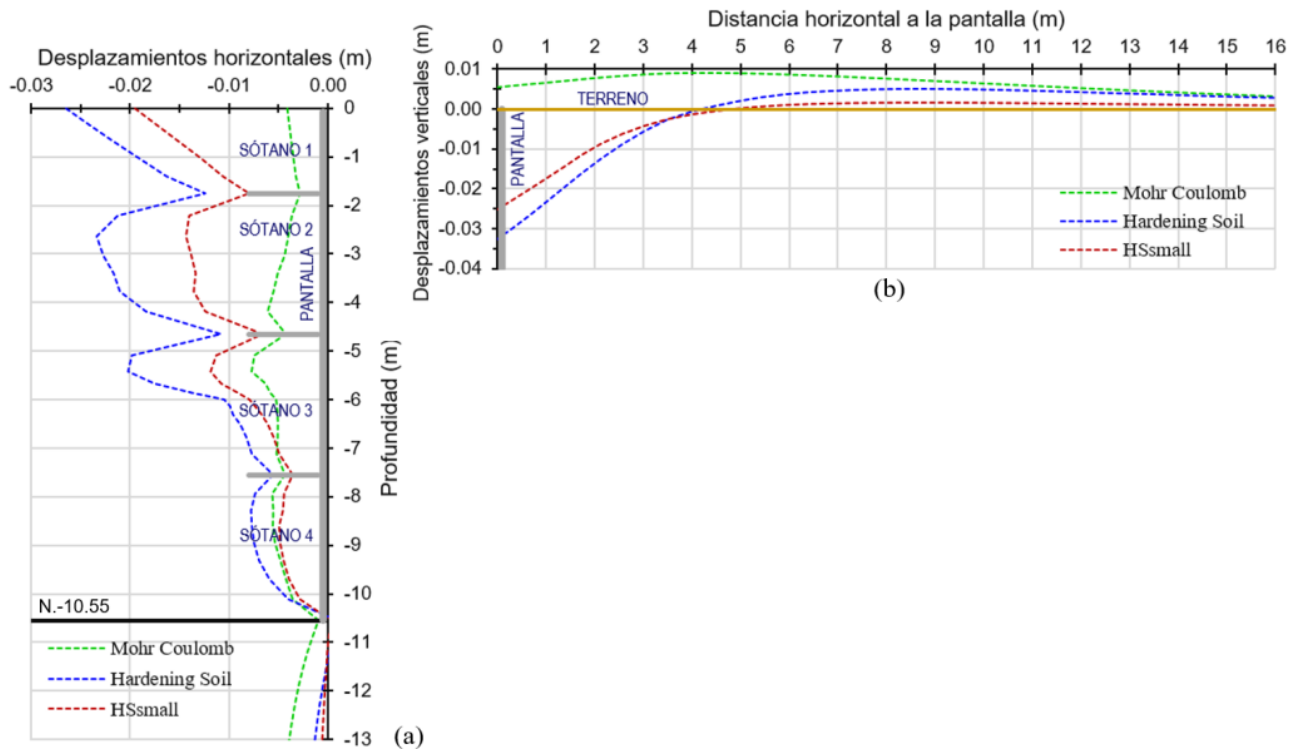

Fig. 5.37 Desplazamientos inducidos por construcción de sótano 4 de Torre Centre: (a) desplazamientos horizontales en pantalla, y (b) asentamientos del terreno detrás de la pantalla.

Desplazamientos horizontales $(\mathrm{m})$

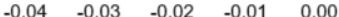
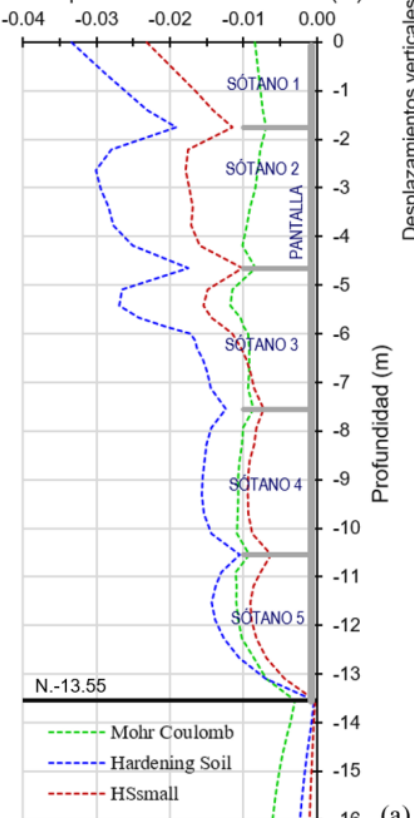

(a)

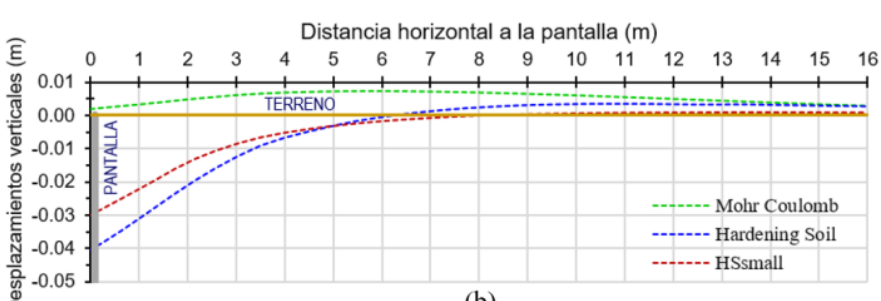

(b)

Fig. 5.38 Desplazamientos inducidos por construcción de sótano 5 de Torre Centre: (a) desplazamientos horizontales en pantalla, y (b) asentamientos del terreno detrás de la pantalla. 
Adicionalmente, en la Fig. 5.39 se muestra los diagramas de desplazamientos horizontales y verticales inducidos en el terreno por efectos del análisis sísmico pseudoestático para el caso de la excavación total para los 5 sótanos $(\mathrm{H}=13.55 \mathrm{~m})$.
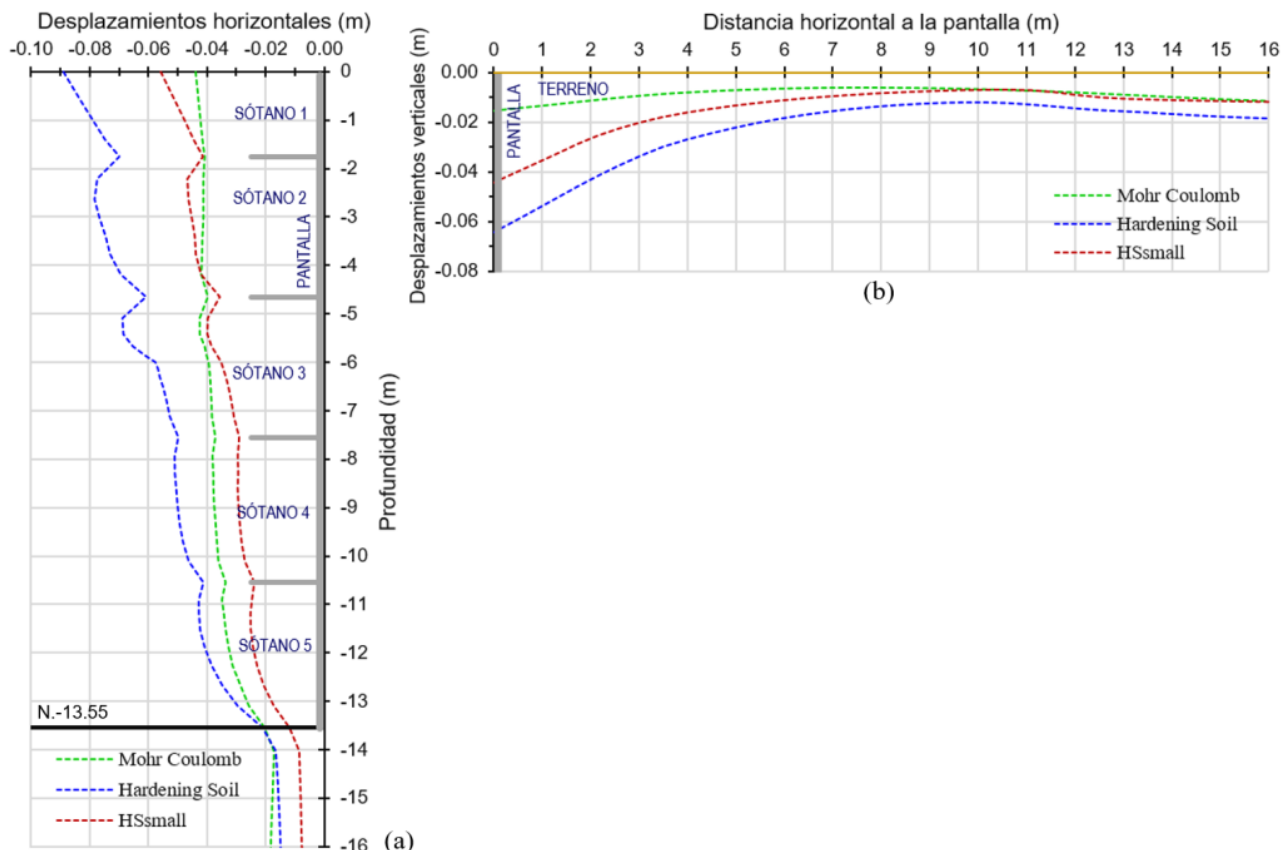

(b)

Fig. 5.39 Desplazamientos en Torre Centre $(\mathrm{H}=13.55 \mathrm{~m})$ por análisis sísmico pseudoestático: (a) desplazamientos horizontales en pantalla, y (b) asentamientos del terreno detrás de la pantalla.

La Tabla 5.24 presenta los valores máximos de desplazamientos horizontales en la pantalla y asentamientos inducidos por la construcción de cada nivel de sótano.

Tabla 5.24 Desplazamientos máximos generados por construcción de sótanos de Torre Centre.

\begin{tabular}{|c|c|c|c|c|c|c|c|c|}
\hline \multirow{4}{*}{ FASE } & \multirow{2}{*}{\multicolumn{2}{|c|}{ SÓTANO }} & \multicolumn{6}{|c|}{ DESPLAZAMIENTOS MÁXIMOS DEL TERRENO [m] } \\
\hline & & & \multicolumn{6}{|c|}{ MODELO CONSTITUTIVO } \\
\hline & \multirow{2}{*}{ No } & \multirow{2}{*}{$\begin{array}{c}\text { PROF. } \\
\text { ACUMULADA } \\
{[\mathrm{m}]}\end{array}$} & \multicolumn{2}{|c|}{ Mohr Coulomb } & \multicolumn{2}{|c|}{ Hardening Soil } & \multicolumn{2}{|c|}{ HSsmall } \\
\hline & & & Hor. & Ver. & Hor. & Ver. & Hor. & Ver. \\
\hline CONST. SÓTANO & 1 & -1.75 & 0.0008 & 0.0041 & -0.0032 & 0.0031 & -0.0012 & 0.0011 \\
\hline CONST. SÓTANO & 2 & -4.65 & -0.0021 & 0.0069 & -0.0181 & -0.0171 & -0.0140 & -0.0150 \\
\hline CONST. SÓTANO & 3 & -7.55 & -0.0050 & 0.0088 & -0.0224 & -0.0271 & -0.0171 & -0.0214 \\
\hline CONST. SÓTANO & 4 & -10.55 & -0.0077 & 0.0091 & -0.0265 & -0.0326 & -0.0195 & -0.0252 \\
\hline CONST. SÓTANO & 5 & -13.55 & -0.0118 & 0.0075 & -0.0334 & -0.0406 & -0.0232 & -0.0301 \\
\hline SISMO H=13.55 m & 5 & -13.55 & -0.0438 & -0.0153 & -0.0891 & -0.0646 & -0.0559 & -0.0444 \\
\hline
\end{tabular}


Desplazamientos horizontales $(\mathrm{m})$ $\begin{array}{llllll}-0.05 & -0.04 & -0.03 & -0.02 & -0.01 & 0.00\end{array}$

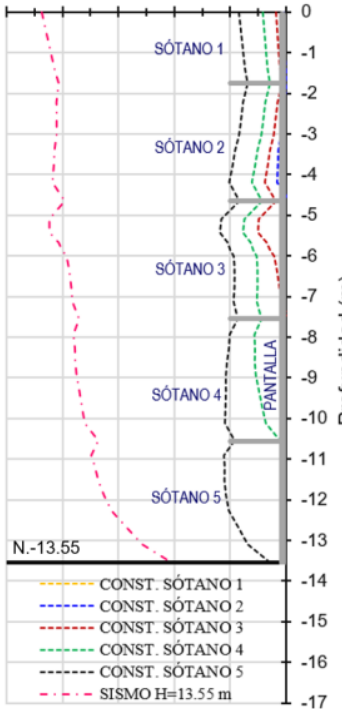

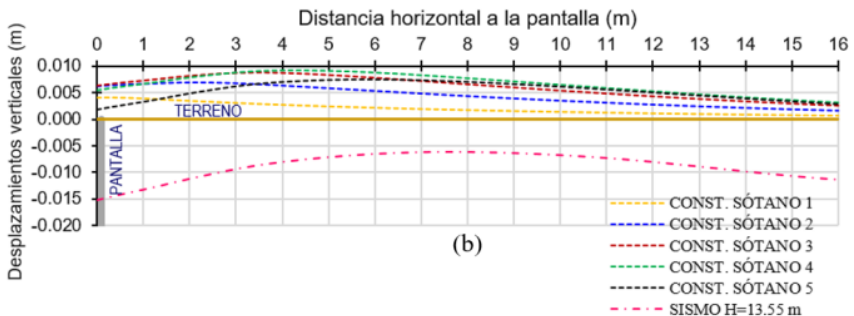

Fig. 5.40 Desplazamientos en Torre Centre por construcción de sótanos (modelo de Mohr Coulomb): (a) desplazamientos horizontales en pantalla, y (b) asentamientos del terreno detrás de la pantalla.

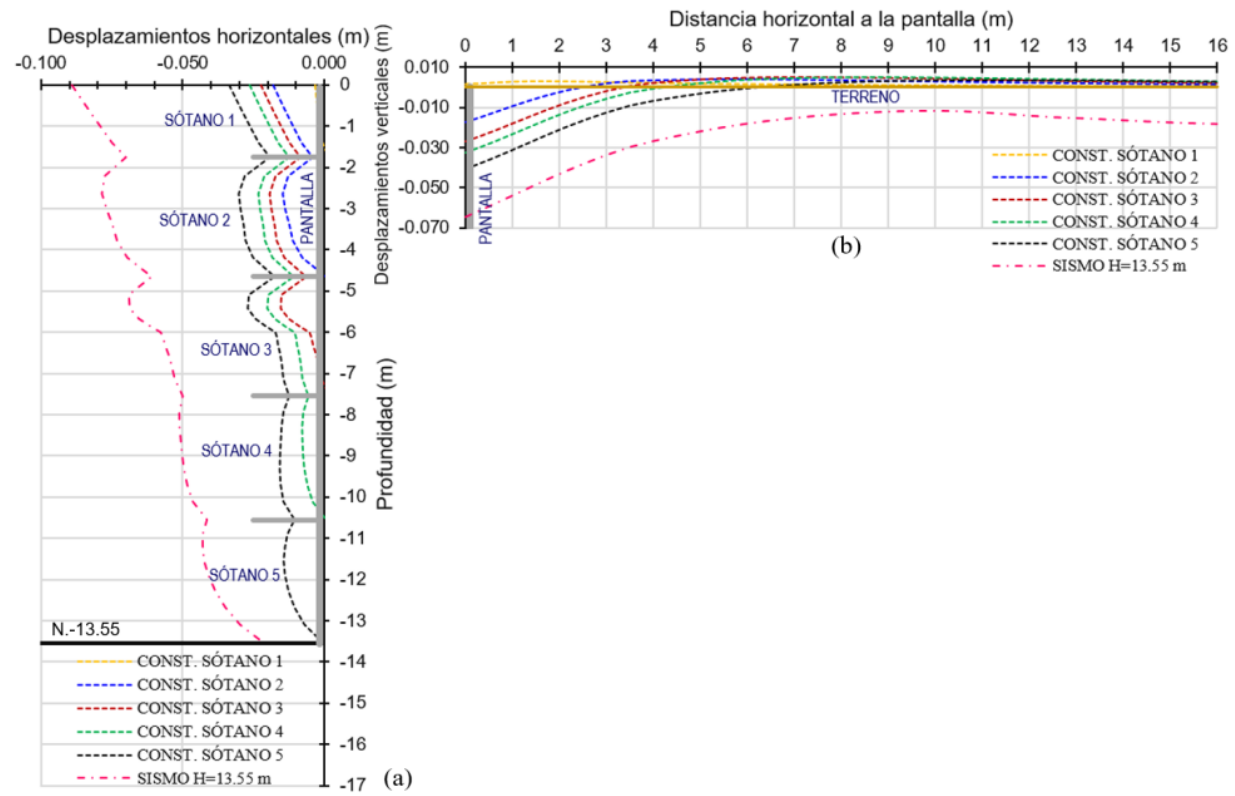

Fig. 5.41 Desplazamientos en Torre Centre por construcción de sótanos (modelo de Hardening Soil): (a) desplazamientos horizontales en pantalla, y (b) asentamientos del terreno detrás de la pantalla. 


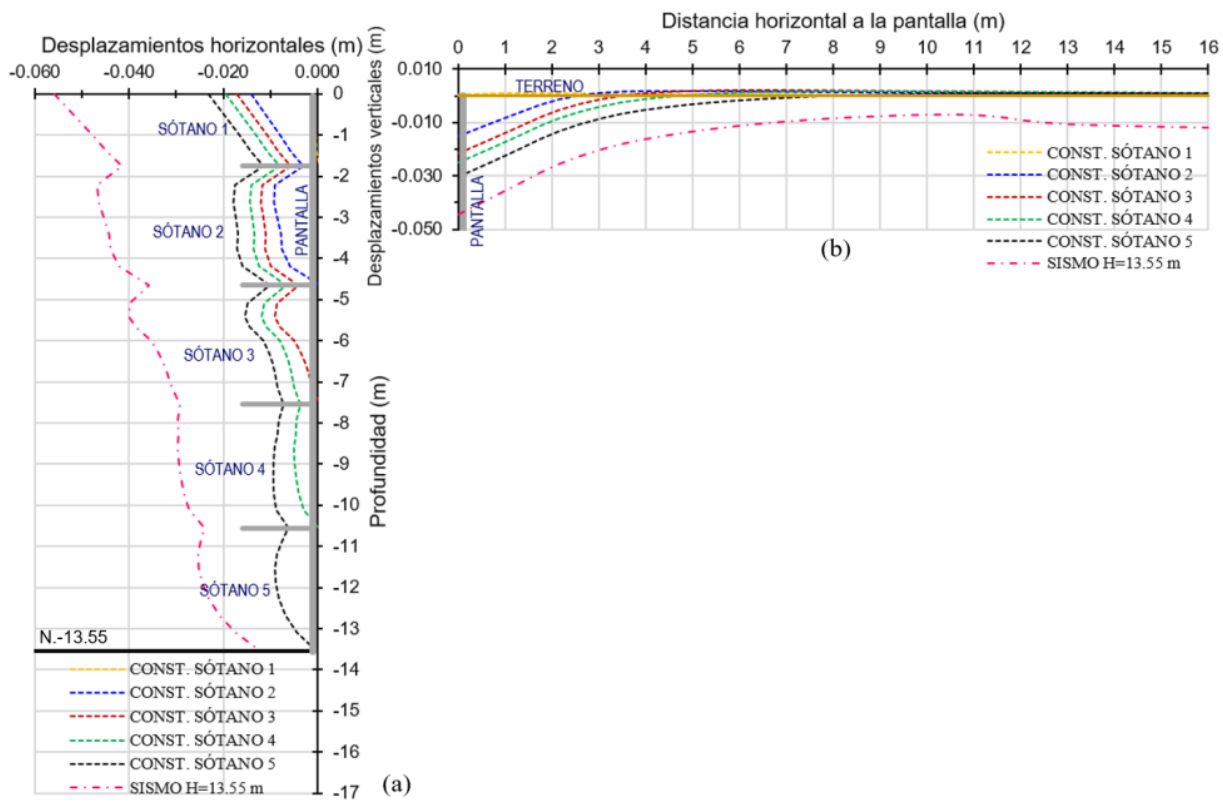

Fig. 5.42 Desplazamientos en Torre Centre por construcción de sótanos (modelo de HSsmall): (a) desplazamientos horizontales en pantalla, y (b) asentamientos del terreno detrás de la pantalla.

Las Fig. 5.40, 5.41 y 5.42 muestran la evolución de desplazamientos horizontales en la pantalla y asentamientos en el terreno, por la construcción de cada nivel de sótano de Torre Centre y aplicando individualmente los modelos constitutivos de suelo.

\subsubsection{Análisis de estructura de proyecto Zaigen}

\subsubsection{Generalidades}

Zaigen contempla 5 niveles de sótano con una excavación total de 15.50 m, mediante 5 excavaciones parciales que representan a la altura de un nivel de sótano, conforme se muestra en la Fig. 4.38 del Capítulo 4. En este modelo numérico se ha incluido una pequeña sobrecarga superficial de $1 \mathrm{kN} / \mathrm{m}$ en la vía para considerar el ligero y esporádico tráfico vehicular que se dio durante el proceso constructivo. La Fig. 5.43 presenta el modelo numérico inicial para la estructura de "Soil Nailing" simulada con Plaxis 2D V20 para el proyecto Zaigen, en donde se incluyen dimensiones, elementos estructurales y demás parámetros que identifican a esta estructura. Por su parte, la Fig. 5.44 muestra el modelo numérico en la quinta fase de excavación, que es cuando se ha construido el sótano 5 y se tiene una excavación de $15.50 \mathrm{~m}$. En la Fig. 5.45 se esquematizan todas las fases constructivas para la simulación con Plaxis 2D. La construcción de cada nivel de sótano incluye 4 fases básicas: [1] la excavación inicial de la totalidad del terreno correspondiente al nivel de sótano, dejando un pequeño contrafuerte de suelo, [2] la construcción del "Soil Nail", [3] la conformación vertical del talud, y [4] la construcción de la pantalla de concreto. 


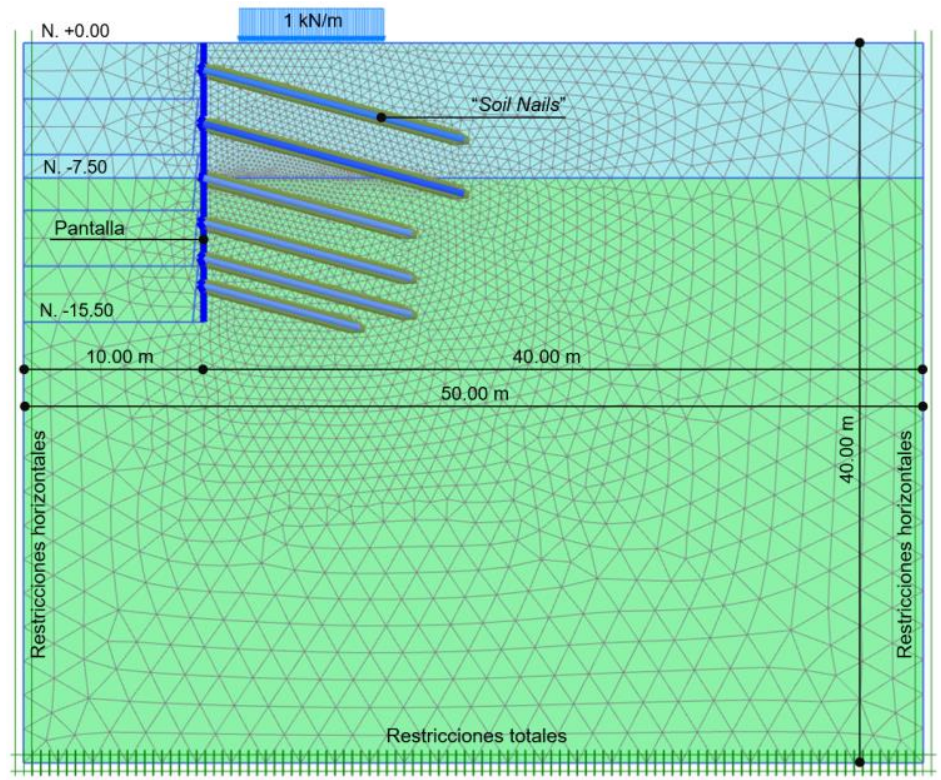

Fig. 5.43 Modelo inicial con Plaxis 2D de estructura de "Soil Nailing" de proyecto Zaigen.

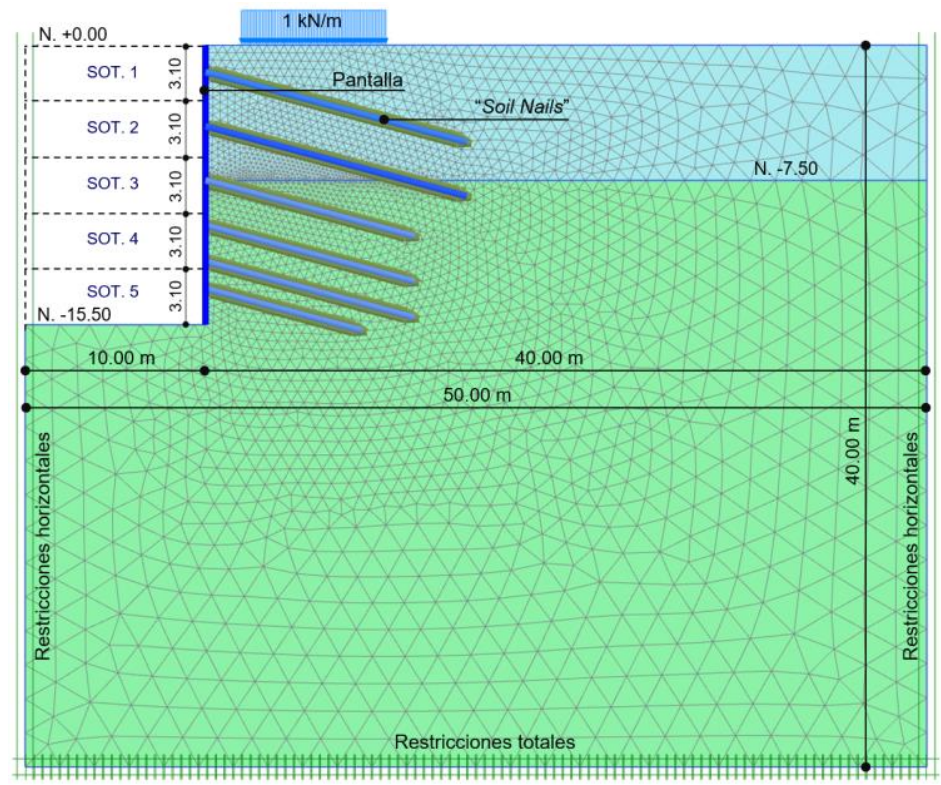

Fig. 5.44 Modelo final con Plaxis 2D de estructura de "Soil Nailing" de proyecto Zaigen. 


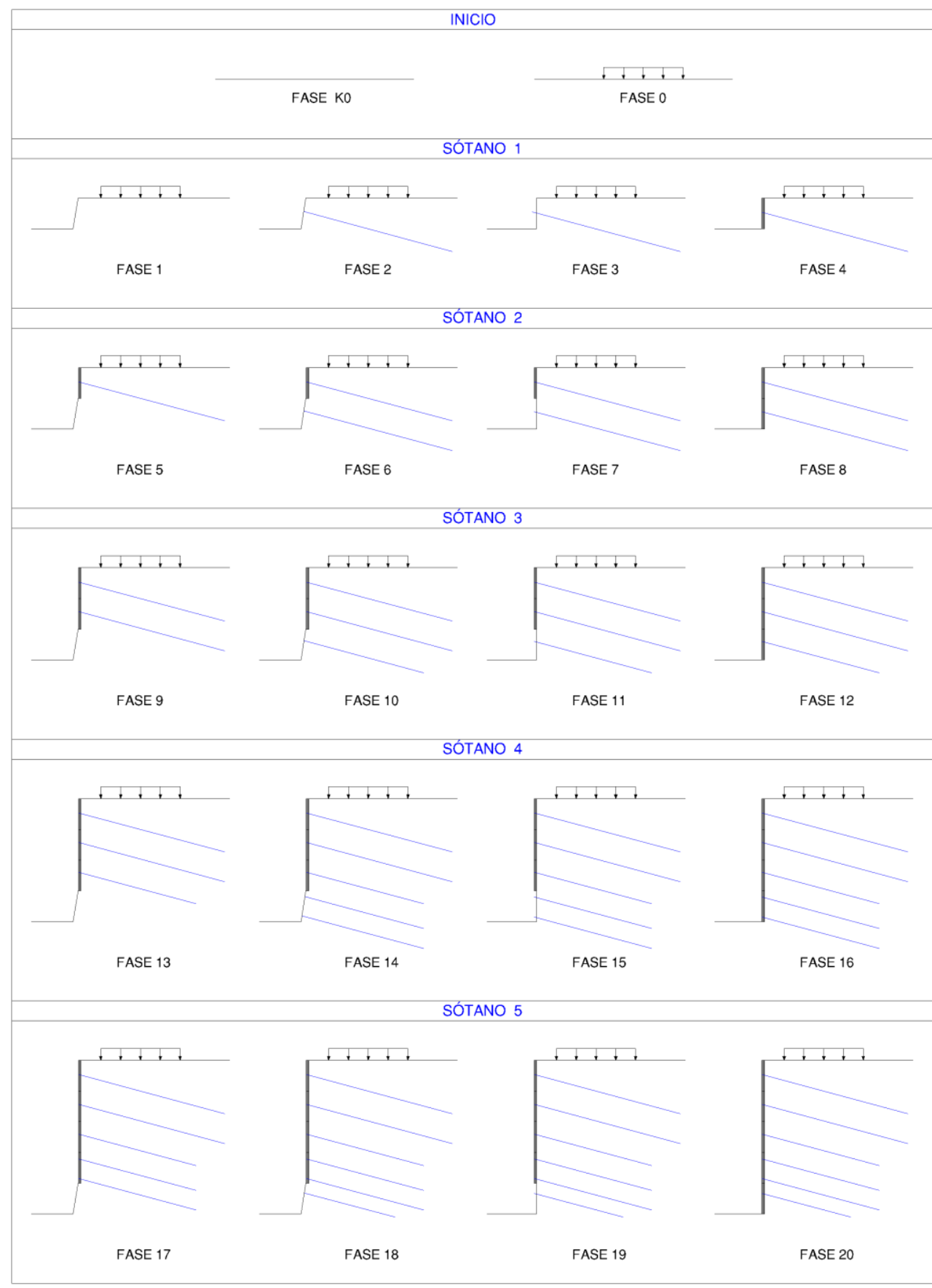

Fig. 5.45 Fases constructivas simuladas con Plaxis 2D para estructura de proyecto Zaigen. 
Por otra parte, las Fig. 5.46, 5.47 y 5.48 presentan el análisis de la estructura de Zaigen con la construcción del sótano 5, que es la fase de mayores desplazamientos, aplicando los 3 modelos constitutivos de suelo: Mohr Coulomb, Hardening Soil y HSsmall, respectivamente. Se nota en el análisis con el modelo de Mohr Coulomb, valores altos de ascensión del suelo en el fondo de la excavación.

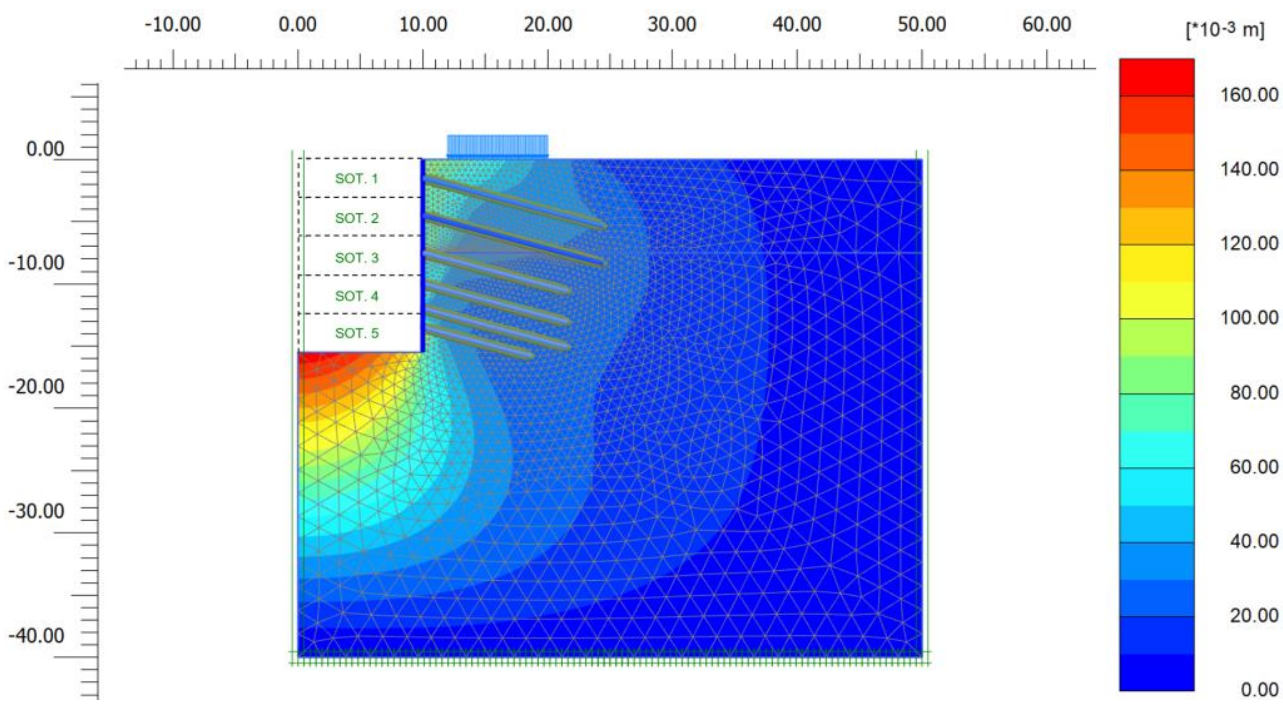

Fig. 5.46 Desplazamientos totales |u| con modelo de Mohr Coulomb por construcción de sótano 5.

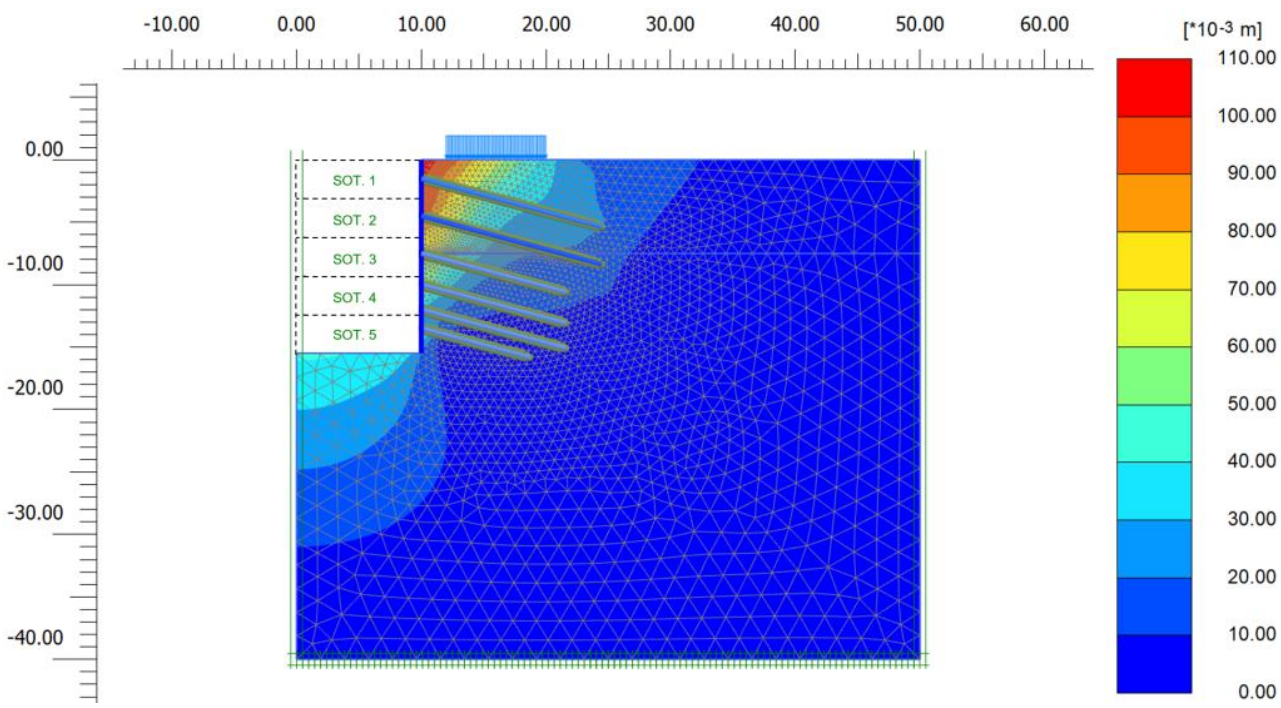

Fig. 5.47 Desplazamientos totales $|\mathrm{u}|$ con modelo de Hardening Soil por construcción de sótano 5. 


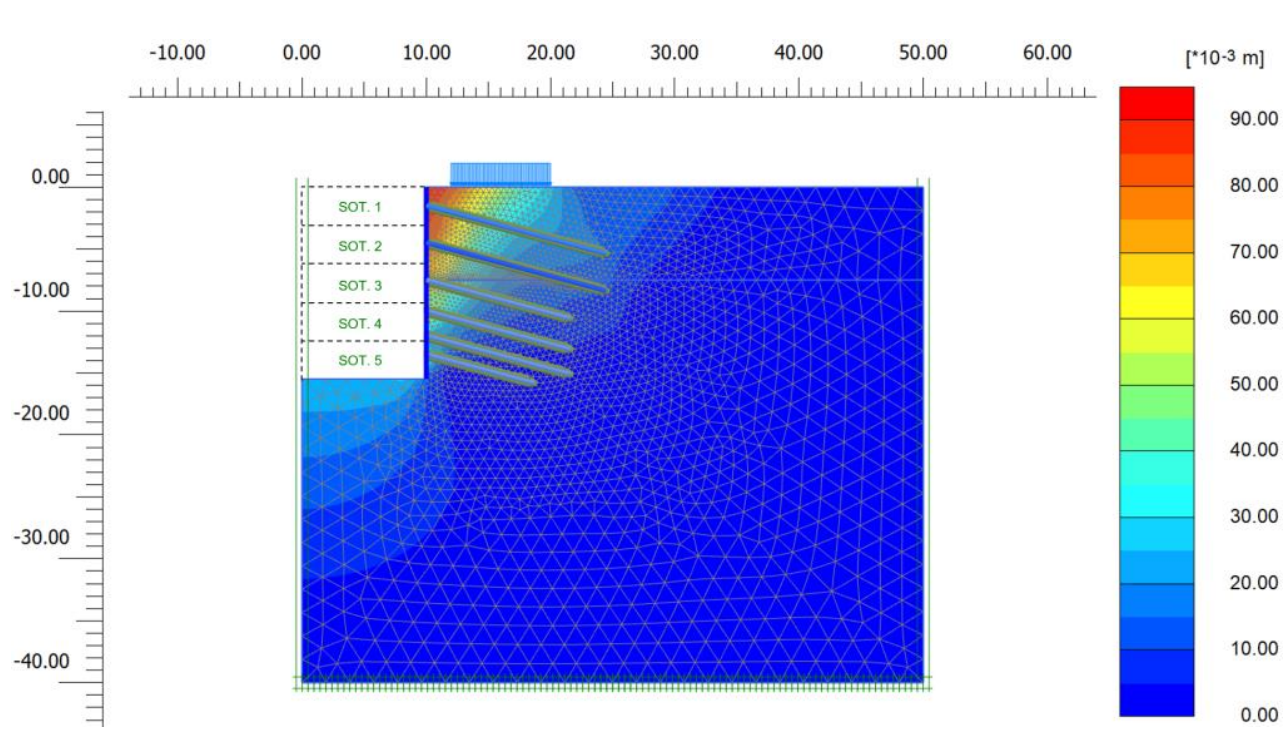

Fig. 5.48 Desplazamientos totales $|\mathrm{u}|$ con modelo de HSsmall por construcción de sótano 5.

\subsubsection{Diagramas de fuerza axial de tensión en "Soil Nails" de Zaigen}

Esta parte resume los diagramas de fuerzas axiales de tensión inducidas en los "Soil Nails" por efecto de las excavaciones parciales para la construcción de cada sótano. Inicialmente, para una mejor comparación en cada nivel de sótano se grafica simultáneamente la distribución de fuerzas axiales de tensión obtenidas aplicando los 3 modelos constitutivos de suelo: Mohr Coulomb, Hardening Soil y HSsmall.

Por tanto, en las Fig. 5.49 a 5.53 se muestra de manera secuencial y de acuerdo al proceso constructivo los diagramas de distribución de fuerzas de tensión inducidos en los "Soil Nails" por efecto de la construcción de los 5 sótanos de Zaigen.

\section{Excavación 1 - construcción de sótano 1}

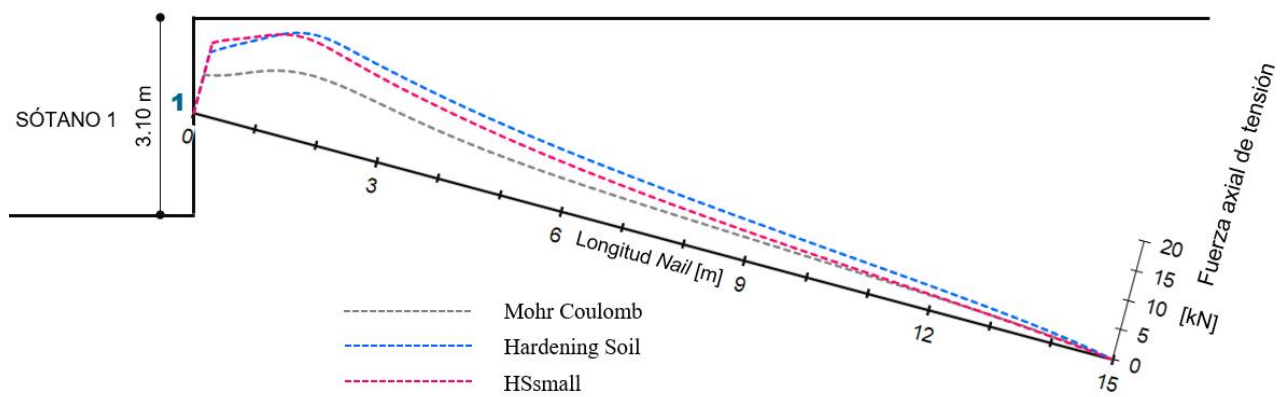

Fig. 5.49 Distribución de fuerzas axiales de tensión en "Soil Nails" inducidas por construcción de sótano 1 de Zaigen. 
La Tabla 5.25 resume los valores de tensiones máximas para los "Soil Nails" del diagrama de la Fig. 5.49, inducidos por la construcción del sótano 1, para cada uno de los modelos constitutivos de suelo.

Tabla 5.25 Fuerzas de tensión máxima en "Soil Nails" por construcción de sótano 1 de Zaigen.

\begin{tabular}{|c|c|c|c|c|}
\hline \multirow{3}{*}{ SÓTANO } & \multirow{3}{*}{$\begin{array}{l}\text { "SOIL } \\
\text { NAIL" }\end{array}$} & \multirow{2}{*}{\multicolumn{3}{|c|}{ FUERZA AXIAL DE TENSIÓN MÁXIMA [kN] }} \\
\hline & & & & \\
\hline & & Mohr Coulomb & Hardening Soil & HSsmall \\
\hline \multicolumn{5}{|c|}{ CONSTRUCCIÓN DE SÓTANO 1} \\
\hline 1 & 1 & 10.86 & 17.39 & 16.67 \\
\hline
\end{tabular}

Excavación 2 - construcción de sótano 2

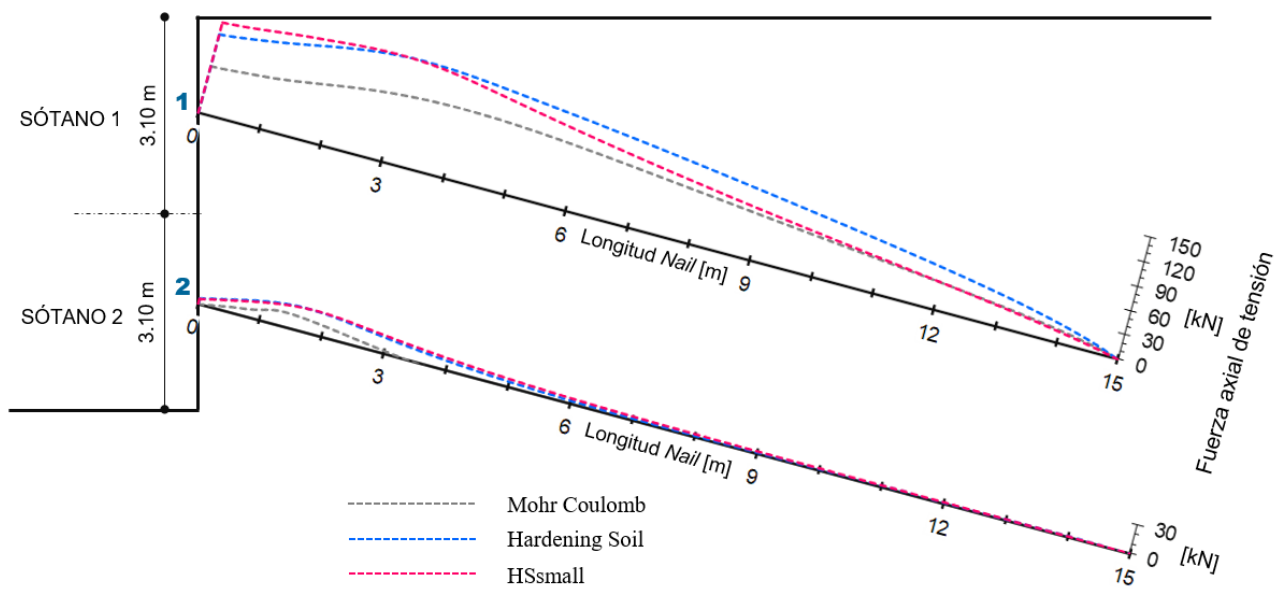

Fig. 5.50 Distribución de fuerzas axiales de tensión en "Soil Nails" inducidas por construcción de sótano 2 de Zaigen.

La Tabla 5.26 presenta los valores de tensiones máximas para los "Soil Nails" del diagrama de la Fig. 5.50, inducidos por la construcción del sótano 2, para cada uno de los modelos constitutivos de suelo.

Tabla 5.26 Fuerzas de tensión máxima en "Soil Nails" por construcción de sótano 2 de Zaigen.

\begin{tabular}{ccccc}
\hline \multirow{2}{*}{ SÓTANO } & "SOIL & \multicolumn{4}{c}{ FUERZA AXIAL DE TENSIÓN MÁXIMA [kN] } \\
\cline { 3 - 5 } & NAIL" & \multicolumn{4}{c}{ MODELO CONSTITUTIVO } \\
\cline { 3 - 5 } & & Mohr Coulomb & Hardening Soil & HSsmall \\
\hline 1 & 1 & 84.78 & 129.03 & 127.76 \\
2 & 2 & 14.60 & 24.44 & 24.27 \\
\hline
\end{tabular}




\section{Excavación 3 - construcción de sótano 3}

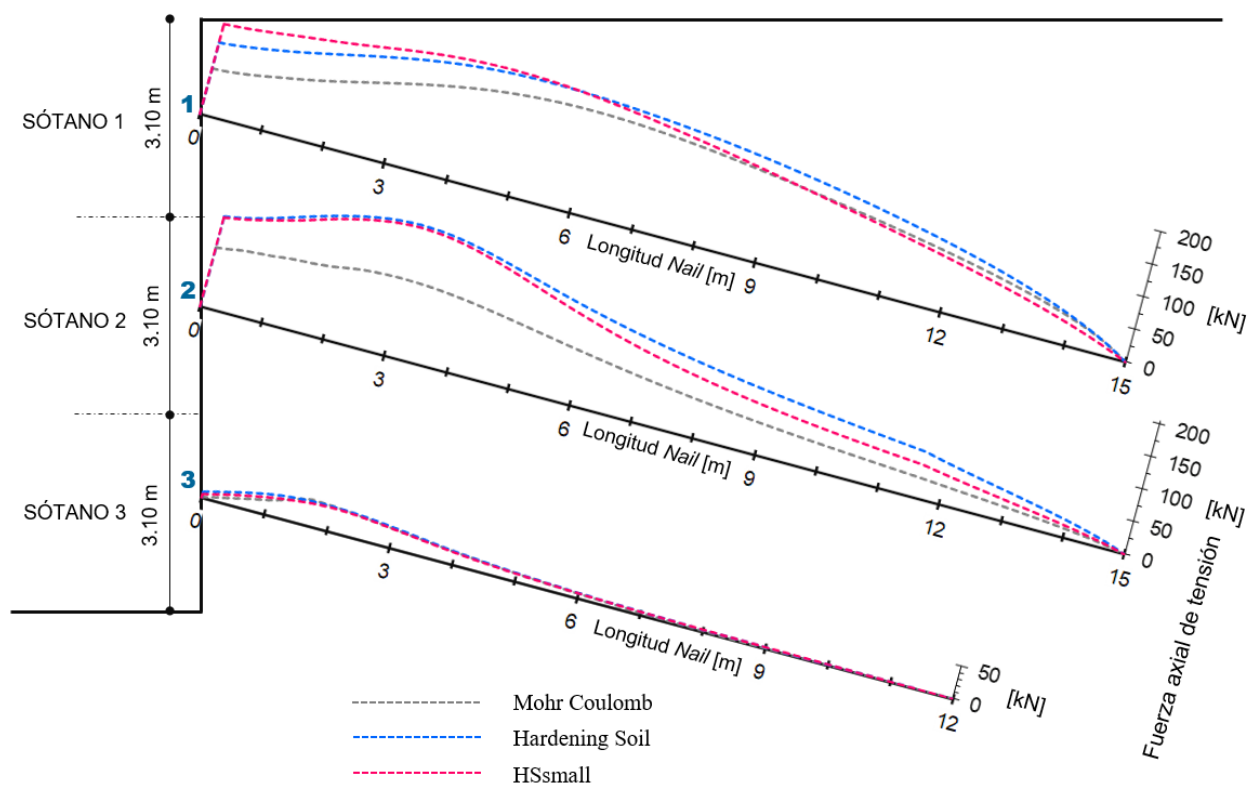

Fig. 5.51 Distribución de fuerzas axiales de tensión en "Soil Nails" inducidas por construcción de sótano 3 de Zaigen.

La Tabla 5.27 resume los valores de tensiones máximas para los "Soil Nails" del diagrama de la Fig. 5.51, inducidos por la construcción del sótano 3, para cada uno de los modelos constitutivos de suelo.

Tabla 5.27 Fuerzas de tensión máxima en "Soil Nails" por construcción de sótano 3 de Zaigen.

\begin{tabular}{|c|c|c|c|c|}
\hline \multirow{3}{*}{ SÓTANO } & \multirow{3}{*}{$\begin{array}{l}\text { "SOIL } \\
\text { NAIL" }\end{array}$} & \multirow{2}{*}{\multicolumn{3}{|c|}{$\begin{array}{c}\text { FUERZA AXIAL DE TENSIÓN MÁXIMA [kN] } \\
\text { MODELO CONSTITUTIVO }\end{array}$}} \\
\hline & & & & \\
\hline & & Mohr Coulomb & Hardening Soil & HSsmall \\
\hline \multicolumn{5}{|c|}{ CONSTRUCCIÓN DE SÓTANO 3} \\
\hline 1 & 1 & 155.24 & 179.60 & 182.73 \\
\hline 2 & 2 & 117.66 & 202.31 & 197.41 \\
\hline 3 & 3 & 38.57 & 36.01 & 35.06 \\
\hline
\end{tabular}




\section{Excavación 4 - construcción de sótano 4}

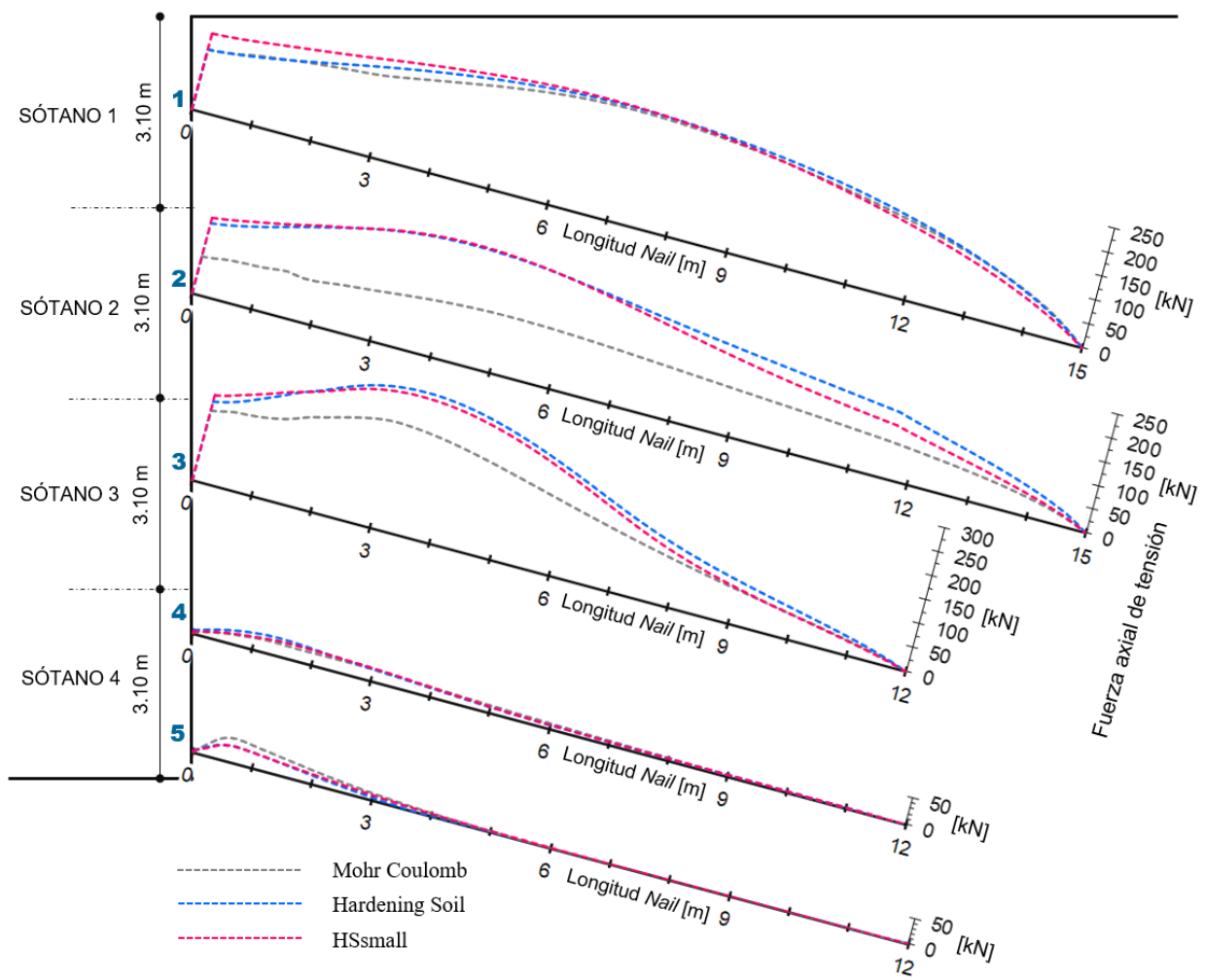

Fig. 5.52 Distribución de fuerzas axiales de tensión en "Soil Nails" inducidas por construcción de sótano 4 de Zaigen.

La Tabla 5.28 resume los valores de tensiones máximas para los "Soil Nails" del diagrama de la Fig. 5.52, generados por la construcción del sótano 4.

Tabla 5.28 Fuerzas de tensión máxima en "Soil Nails" por construcción de sótano 4 de Zaigen.

\begin{tabular}{|c|c|c|c|c|}
\hline \multirow{3}{*}{ SÓTANO } & \multirow{3}{*}{$\begin{array}{l}\text { "SOIL } \\
\text { NAIL" }\end{array}$} & \multicolumn{3}{|c|}{ FUERZA AXIAL DE TENSIÓN MÁXIMA [kN] } \\
\hline & & \multicolumn{3}{|c|}{ MODELO CONSTITUTIVO } \\
\hline & & Mohr Coulomb & Hardening Soil & HSsmall \\
\hline \multicolumn{5}{|c|}{ CONSTRUCCIÓN DE SÓTANO 4} \\
\hline 1 & 1 & 230.84 & 234.32 & 238.05 \\
\hline 2 & 2 & 122.07 & 243.19 & 244.49 \\
\hline 3 & 3 & 218.91 & 294.29 & 282.31 \\
\hline \multirow{2}{*}{4} & 4 & 23.09 & 32.55 & 28.21 \\
\hline & 5 & 44.96 & 30.11 & 31.15 \\
\hline
\end{tabular}


Excavación 5 - construcción de sótano 5

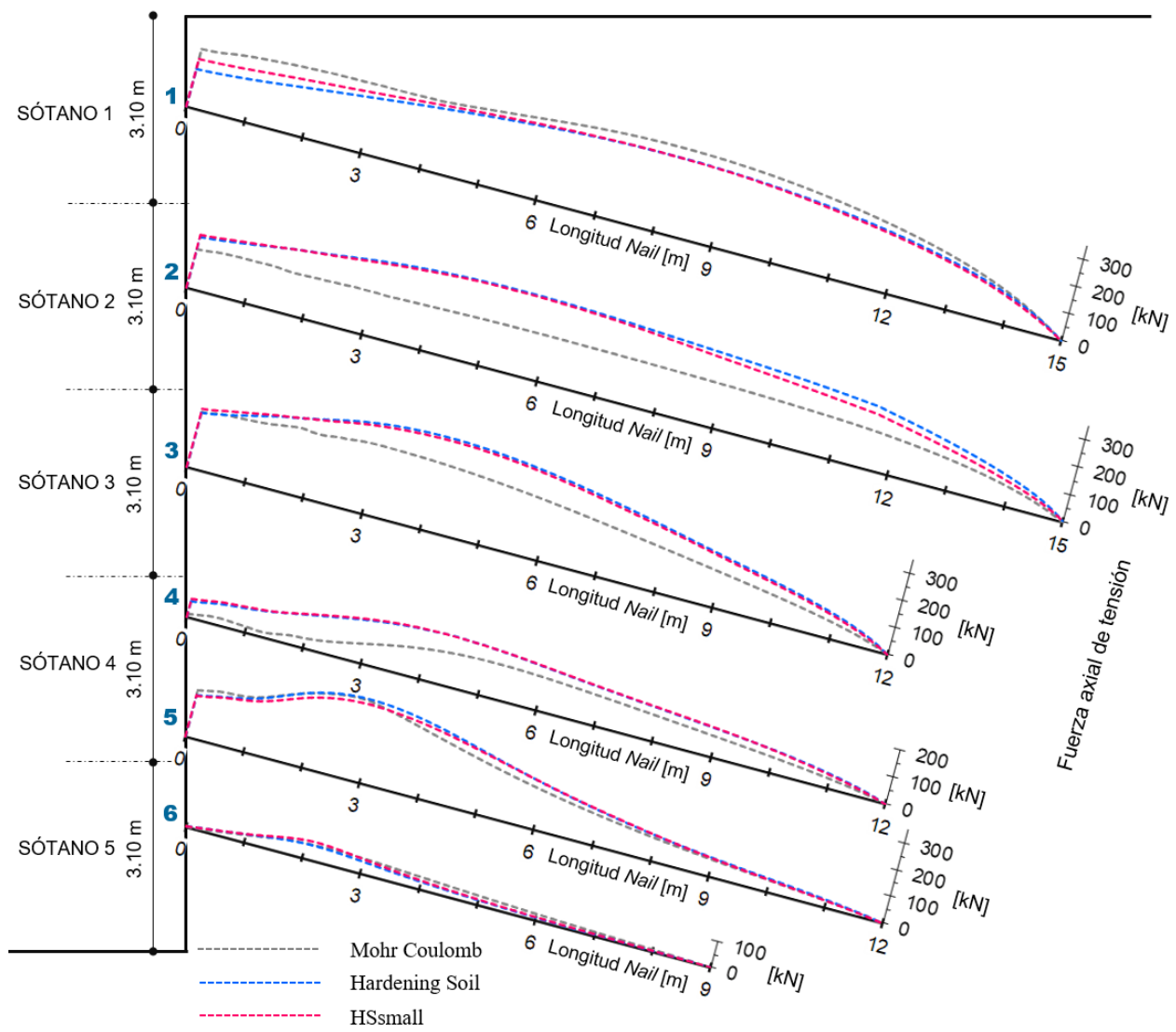

Fig. 5.53 Distribución de fuerzas axiales de tensión en "Soil Nails" inducidas por construcción de sótano 5 de Zaigen.

La Tabla 5.29 resume los valores de tensiones máximas para los "Soil Nails" del diagrama de la Fig. 5.53, inducidos por la construcción del sótano 5.

Tabla 5.29 Fuerzas de tensión máxima en "Soil Nails" por construcción de sótano 5 de Zaigen.

\begin{tabular}{|c|c|c|c|c|}
\hline \multirow{3}{*}{ SÓTANO } & \multirow{3}{*}{$\begin{array}{l}\text { "SOIL } \\
\text { NAIL" }\end{array}$} & \multirow{2}{*}{\multicolumn{3}{|c|}{$\begin{array}{c}\text { FUERZA AXIAL DE TENSIÓN MÁXIMA [kN] } \\
\text { MODELO CONSTITUTIVO }\end{array}$}} \\
\hline & & & & \\
\hline & & Mohr Coulomb & Hardening Soil & HSsmall \\
\hline \multicolumn{5}{|c|}{ CONSTRUCCIÓN DE SÓTANO 5} \\
\hline 1 & 1 & 314.93 & 279.75 & 276.99 \\
\hline 2 & 2 & 164.83 & 292.58 & 287.82 \\
\hline 3 & 3 & 250.06 & 341.45 & 331.81 \\
\hline \multirow{2}{*}{4} & 4 & 126.91 & 177.78 & 180.81 \\
\hline & 5 & 296.92 & 302.00 & 283.01 \\
\hline 5 & 6 & 59.36 & 56.20 & 69.07 \\
\hline
\end{tabular}




\section{Análisis sísmico pseudoestático}

Se ha incluido un análisis sísmico pseudoestático para la estructura de "Soil Nailing" de Zaigen para la altura total de $15.50 \mathrm{~m}$, que representa a los 5 niveles de sótano, y que constituye el caso más crítico.

En función de la zona sísmica de la ciudad de Quito, en este análisis se ha considerado la aceleración horizontal $\mathrm{a}_{\mathrm{h}}=0.20 \mathrm{~g}$ y la aceleración vertical $\mathrm{a}_{\mathrm{v}}=0.10$ g. La Fig. 5.54 muestra los diagramas de distribución de fuerzas de tensión en los "Soil Nails" por efecto del análisis sísmico pseudoestático para el caso de la excavación total para los 5 sótanos.

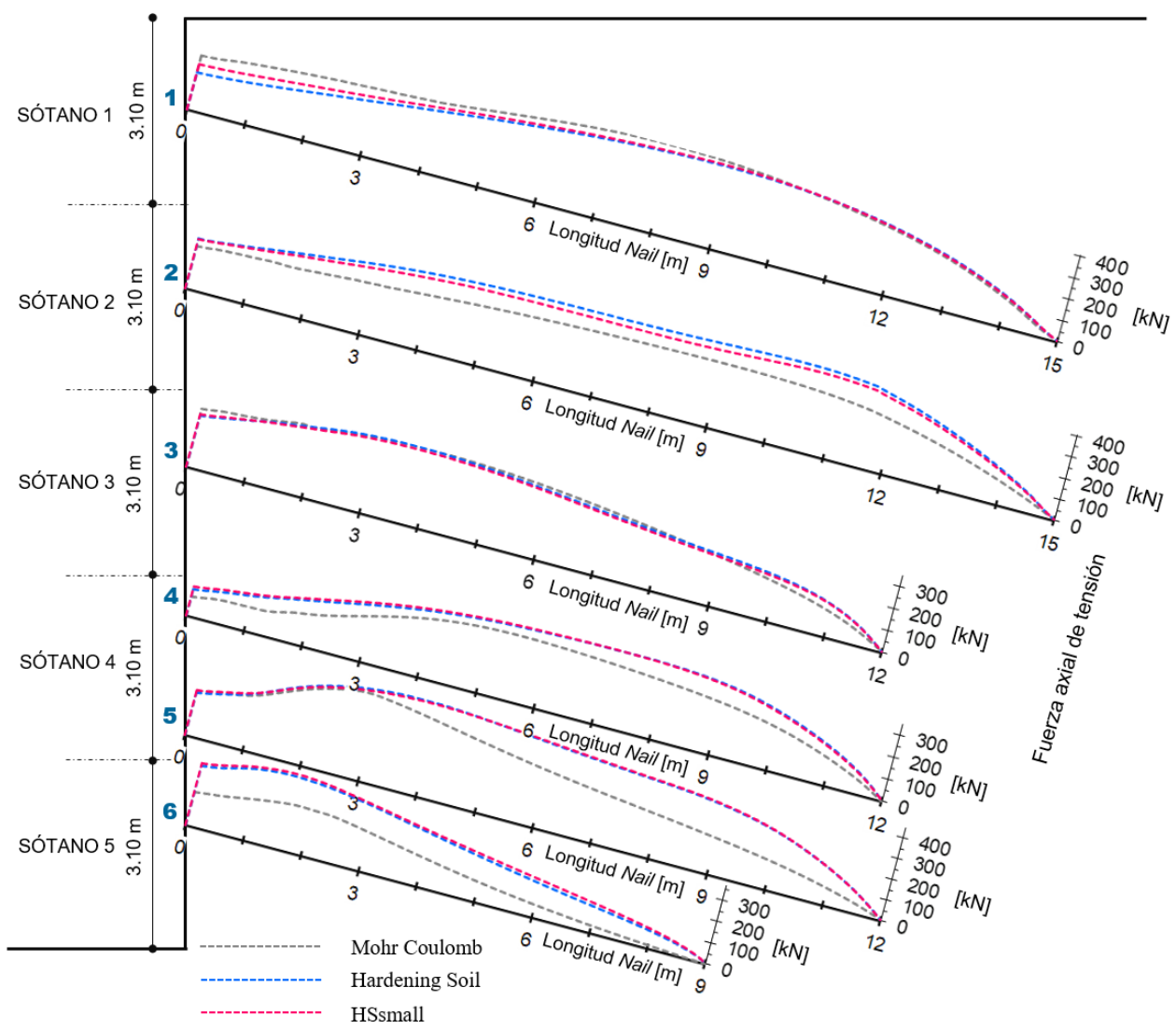

Fig. 5.54 Análisis sísmico pseudoestático: Distribución de fuerzas axiales de tensión en "Soil Nails" para la altura total de $15.50 \mathrm{~m}$ en estructura de Zaigen.

La Tabla 5.30 resume los valores de tensiones máximas para los "Soil Nails" del diagrama de la Fig. 5.54, generados por el enfoque sísmico pseudoestático, para el análisis con los 3 modelos constitutivos de suelo. 
Tabla 5.30 Fuerzas de tensión máxima en "Soil Nails" por enfoque sísmico pseudoestático en estructura de Zaigen.

\begin{tabular}{|c|c|c|c|c|}
\hline \multirow{3}{*}{ SÓTANO } & \multirow{3}{*}{$\begin{array}{l}\text { "SOIL } \\
\text { NAIL" }\end{array}$} & \multirow{2}{*}{\multicolumn{3}{|c|}{ FUERZA AXIAL DE TENSIÓN MÁXIMA [kN] }} \\
\hline & & & & \\
\hline & & Mohr Coulomb & Hardening Soil & HSsmall \\
\hline \multicolumn{5}{|c|}{ ANÁLISIS PSEUDOESTÁTICO } \\
\hline 1 & 1 & 405.47 & 380.05 & 385.29 \\
\hline 2 & 2 & 304.80 & 401.73 & 377.73 \\
\hline 3 & 3 & 342.95 & 345.69 & 332.17 \\
\hline \multirow{2}{*}{4} & 4 & 289.54 & 337.89 & 338.97 \\
\hline & 5 & 410.74 & 446.73 & 439.43 \\
\hline 5 & 6 & 218.51 & 344.07 & 353.27 \\
\hline
\end{tabular}

Evolución de tensiones con las fases constructivas según modelo de Mohr Coulomb

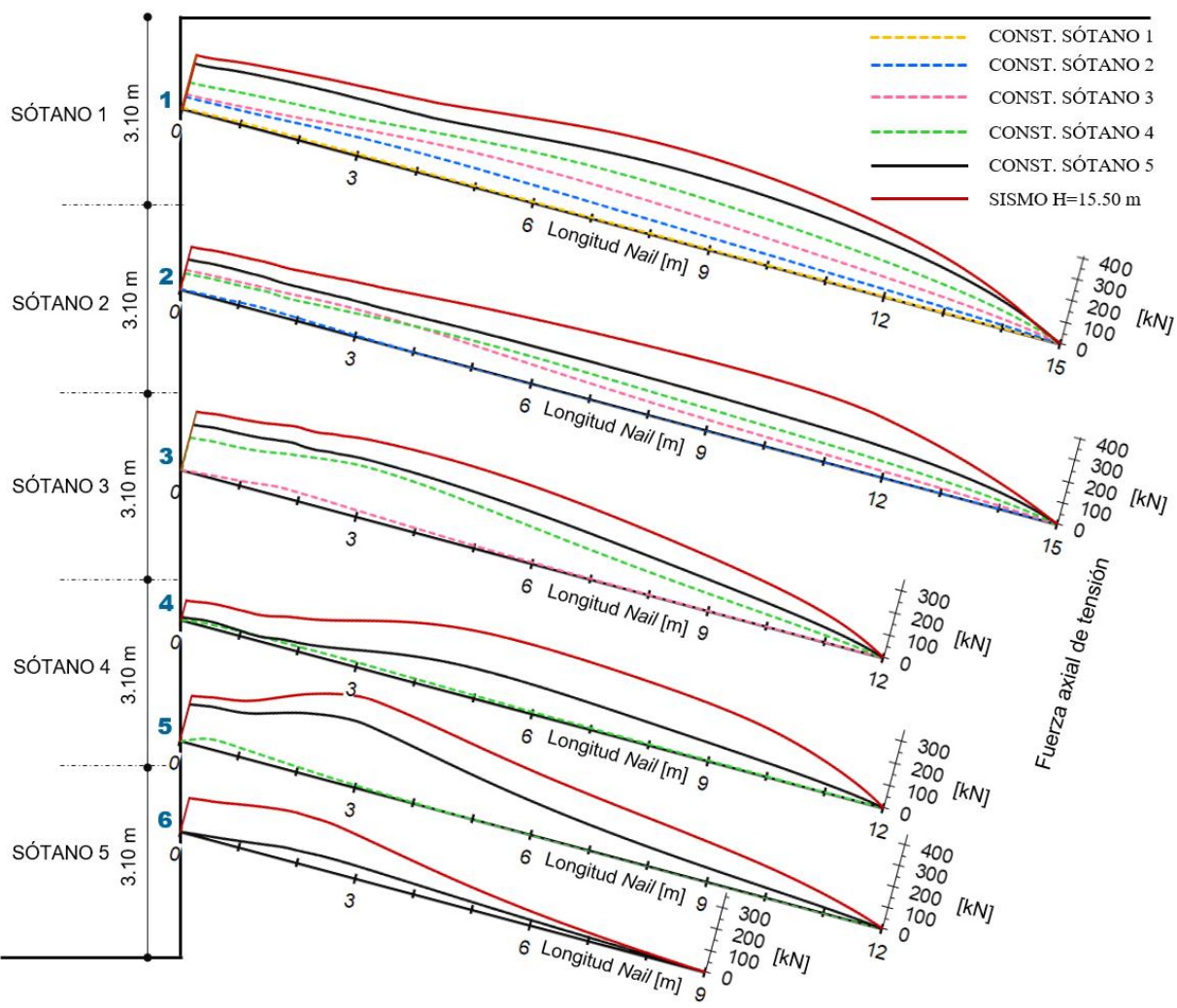

Fig. 5.55 Evolución de fuerzas de tensión en los "Soil Nails" con las fases constructivas según modelo constitutivo de Mohr Coulomb para estructura de Zaigen. 
La Fig. 5.55 muestra la evolución de las fuerzas de tensión en los "Soil Nails" con las fases constructivas según el modelo constitutivo de Mohr Coulomb. La Tabla 5.31 muestra el resumen de las tensiones máximas de los diagramas de la Fig. 5.55.

Tabla 5.31 Evolución de fuerzas de tensión máxima en "Soil Nails" según modelo de Mohr Coulomb.

\begin{tabular}{|c|c|c|c|c|c|c|}
\hline \multirow{3}{*}{ FASE } & \multicolumn{6}{|c|}{ FUERZA AXIAL DE TENSIÓN MÁXIMA [kN] } \\
\hline & & \multicolumn{5}{|c|}{ "SOIL NAILS" } \\
\hline & 1 & 2 & 3 & 4 & 5 & 6 \\
\hline CONST. SÓTANO 1 & 10.86 & $\overline{-}$ & - & - & - & - \\
\hline CONST. SÓTANO 2 & 84.78 & 14.60 & - & - & - & - \\
\hline CONST. SÓTANO 3 & 155.24 & 117.66 & 38.57 & - & - & - \\
\hline CONST. SÓTANO 4 & 230.84 & 122.07 & 218.91 & 23.09 & 44.96 & - \\
\hline CONST. SÓTANO 5 & 314.93 & 164.83 & 250.06 & 126.91 & 296.92 & 59.36 \\
\hline SISMO H= $15.50 \mathrm{~m}$ & 405.47 & 304.80 & 342.95 & 289.54 & 410.74 & 218.51 \\
\hline
\end{tabular}

\section{Evolución de tensiones con las fases constructivas según modelo de Hardening Soil}

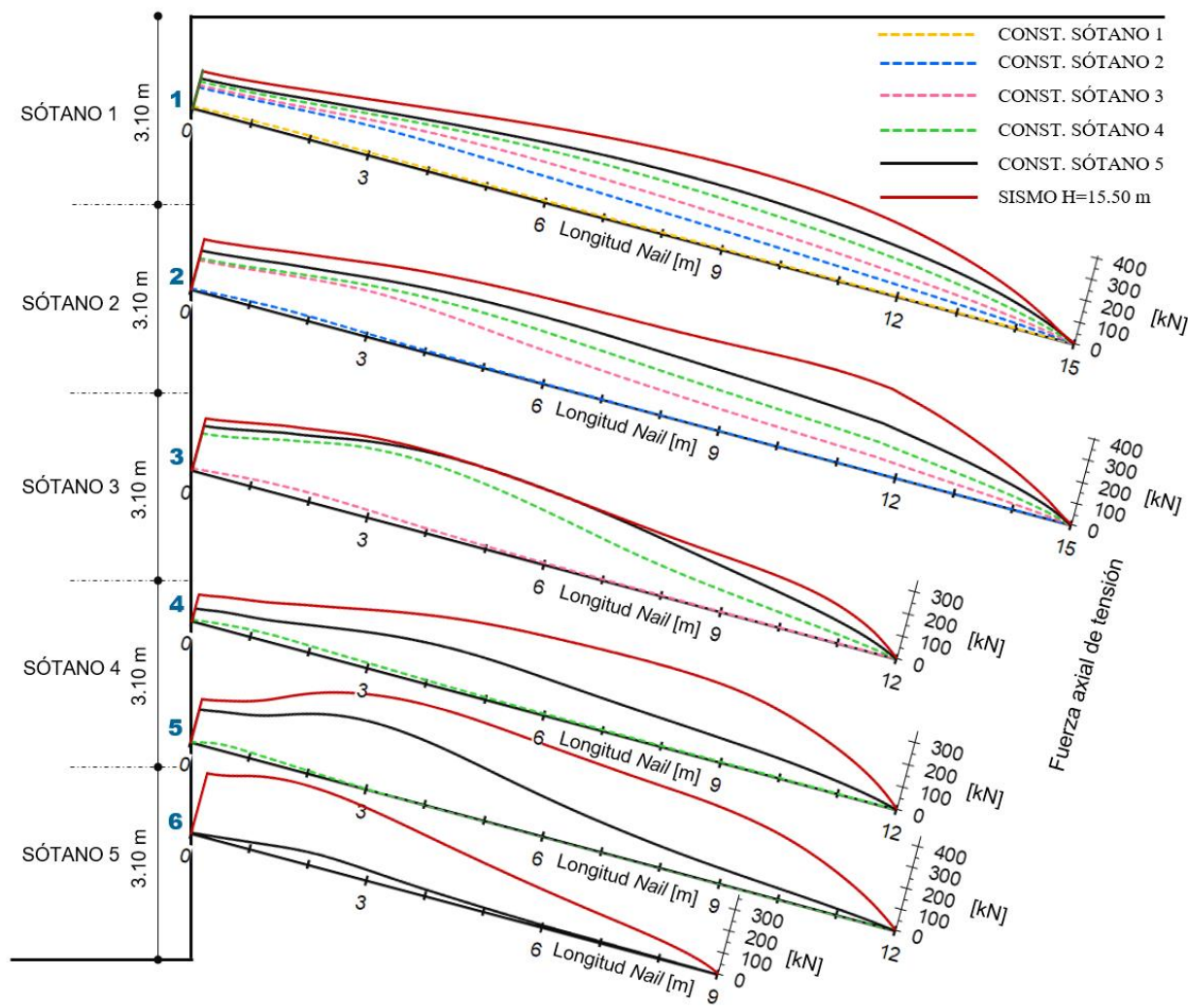

Fig. 5.56 Evolución de fuerzas de tensión en los "Soil Nails" con las fases constructivas según modelo constitutivo de Hardening Soil para estructura de Zaigen. 
La Fig. 5.56 presenta la evolución de las fuerzas de tensión en los "Soil Nails" con las fases constructivas según el modelo constitutivo de Hardening Soil. La Tabla 5.32 resume los valores de las tensiones máximas de los diagramas de la Fig. 5.56.

Tabla 5.32 Evolución de fuerzas de tensión máxima en "Soil Nails" según modelo de Hardening Soil.

\begin{tabular}{lcccccc}
\hline \multirow{2}{*}{ FASE } & \multicolumn{7}{c}{ FUERZA AXIAL DE TENSIÓN MÁXIMA [kN] } \\
\cline { 2 - 7 } & \multicolumn{7}{c}{1} & 2 & 3 & 4 & 5 & 6 \\
\cline { 2 - 6 } & 17.39 & - & - & - & - & - \\
\hline CONST. SÓTANO 1 & 129.03 & 24.44 & - & - & - & - \\
CONST. SÓTANO 2 & 179.60 & 202.31 & 36.01 & - & - & - \\
CONST. SÓTANO 3 & 174 NAILS" & 30.11 & - \\
CONST. SÓTANO 4 & 234.32 & 243.19 & 294.29 & 32.55 & 302.00 & 56.20 \\
CONST. SÓTANO 5 & 279.75 & 292.58 & 341.45 & 177.78 & 340 \\
SISMO H=15.50 m & 380.05 & 401.73 & 345.69 & 337.89 & 446.73 & 344.07 \\
\hline
\end{tabular}

\section{Evolución de tensiones con las fases constructivas según modelo de HSsmall}

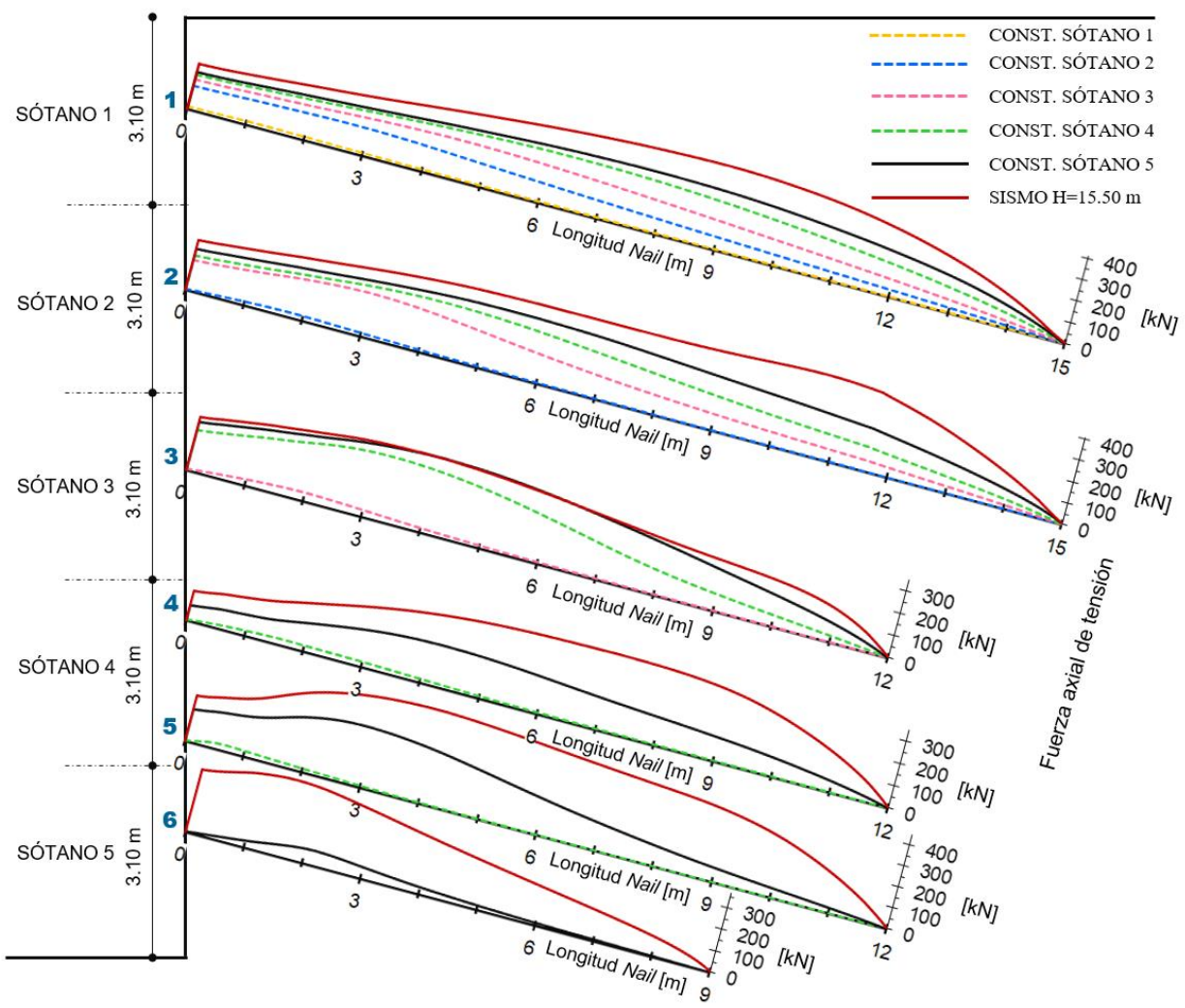

Fig. 5.57 Evolución de fuerzas de tensión en los "Soil Nails" con las fases constructivas según modelo constitutivo de HSsmall para estructura de Zaigen. 
La Fig. 5.57 detalla la evolución de las fuerzas de tensión en los "Soil Nails" con el avance de las fases constructivas según el modelo constitutivo de HSsmall. Por su parte, la Tabla 5.33 resume los valores de las fuerzas de tensión máximas de los diagramas de la Fig. 5.57.

Tabla 5.33 Evolución de fuerzas de tensión máxima en "Soil Nails" según modelo de HSsmall.

\begin{tabular}{lcccccc}
\hline \multirow{2}{*}{ FASE } & \multicolumn{7}{c}{ FUERZA AXIAL DE TENSIÓN MÁXIMA [kN] } \\
\cline { 2 - 7 } & 1 & 2 & 3 & 4 & 5 & 6 \\
\cline { 2 - 7 } & 16.67 & - & - & - & - & - \\
\hline CONST. SÓTANO 1 & 127.76 & 24.27 & - & - & - & - \\
CONST. SÓTANO 2 & 182.73 & 197.41 & 35.06 & - & - & - \\
CONST. SÓTANO 3 & 18.01 - & - & - \\
CONST. SÓTANO 4 & 238.05 & 244.49 & 282.31 & 28.21 & 31.15 & - \\
CONST. SÓTANO 5 & 276.99 & 287.82 & 331.81 & 180.81 & 283.01 & 69.07 \\
SISMO H=15.50 m & 385.29 & 377.73 & 332.17 & 338.97 & 439.43 & 353.27 \\
\hline
\end{tabular}

El análisis sísmico pseudoestático con los diferentes modelos constitutivos de suelo se lo realizó exclusivamente para la fase de altura total de la estructura $(\mathrm{H}=15.50 \mathrm{~m})$.

\subsubsection{Desplazamientos horizontales y verticales inducidos en Zaigen}

En esta sección se muestran los diagramas de desplazamientos horizontales en la pantalla y de desplazamientos verticales o asentamientos del terreno detrás de la pantalla, inducidos por las 5 excavaciones parciales para la construcción de cada sótano del proyecto Zaigen. Para una mejor comparación, en cada nivel de sótano se grafica simultáneamente la distribución de desplazamientos obtenidos aplicando los 3 modelos constitutivos de suelo: Mohr Coulomb, Hardening Soil y HSsmall.

La Fig. 5.58 presenta la evolución de los desplazamientos horizontales en la pantalla y verticales inducidos en el terreno por efectos de la excavación y construcción del sótano 1.
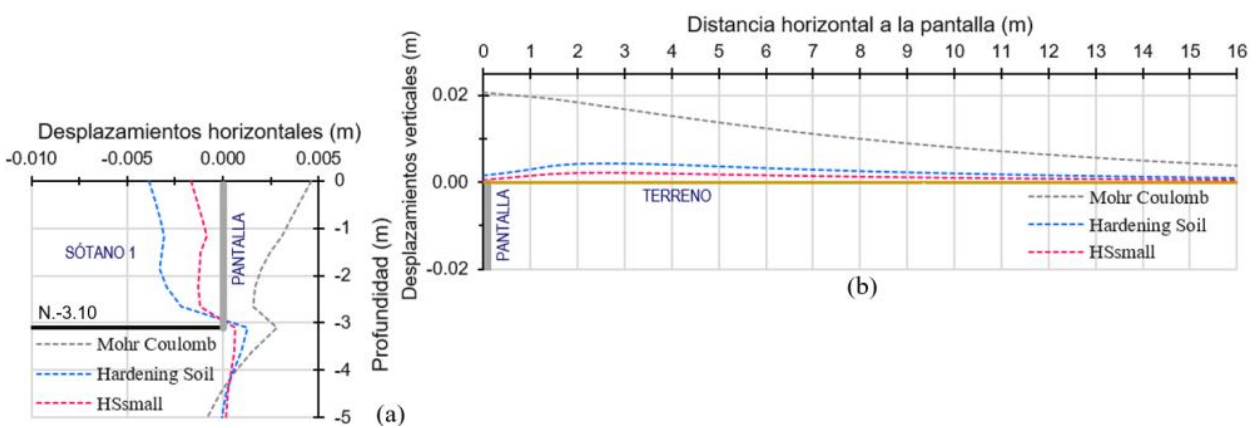

(b)

Fig. 5.58 Desplazamientos inducidos por construcción de sótano 1 de Zaigen: (a) desplazamientos horizontales en pantalla, y (b) asentamientos del terreno detrás de la pantalla. 
La Fig. 5.59 presenta la evolución de los desplazamientos horizontales y asentamientos inducidos en el terreno por la construcción del sótano 2.
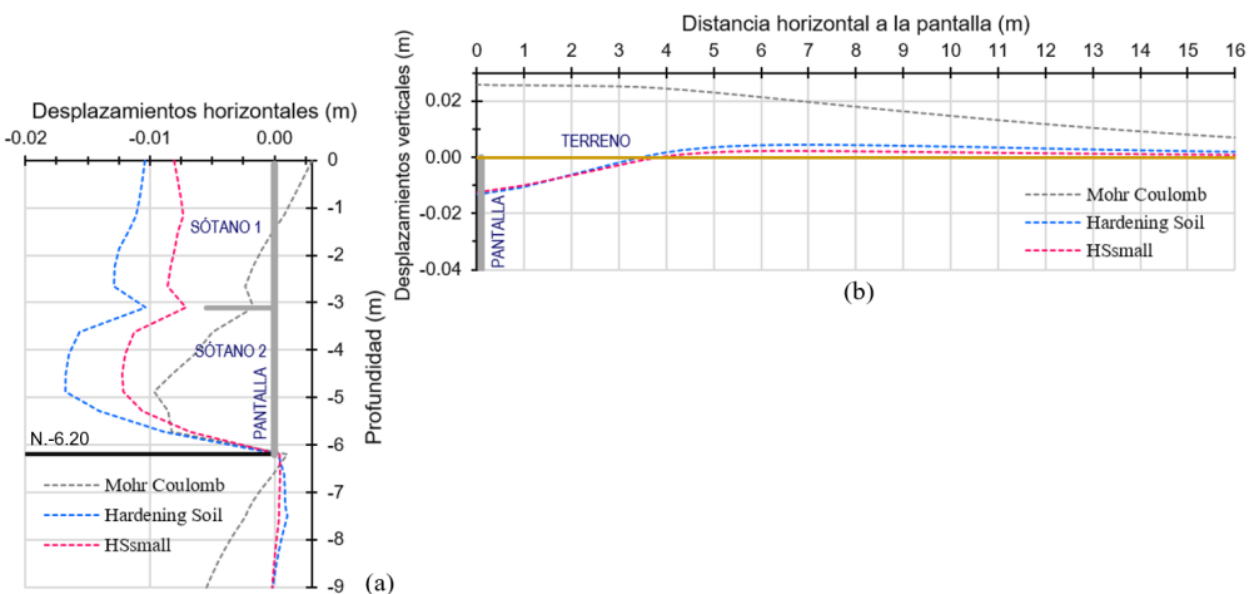

(b)

Fig. 5.59 Desplazamientos inducidos por construcción de sótano 2 de Zaigen: (a) desplazamientos horizontales en pantalla, y (b) asentamientos del terreno detrás de la pantalla.

La Fig. 5.60 muestra la evolución de los desplazamientos horizontales y asentamientos inducidos en el terreno por la construcción del sótano 3.
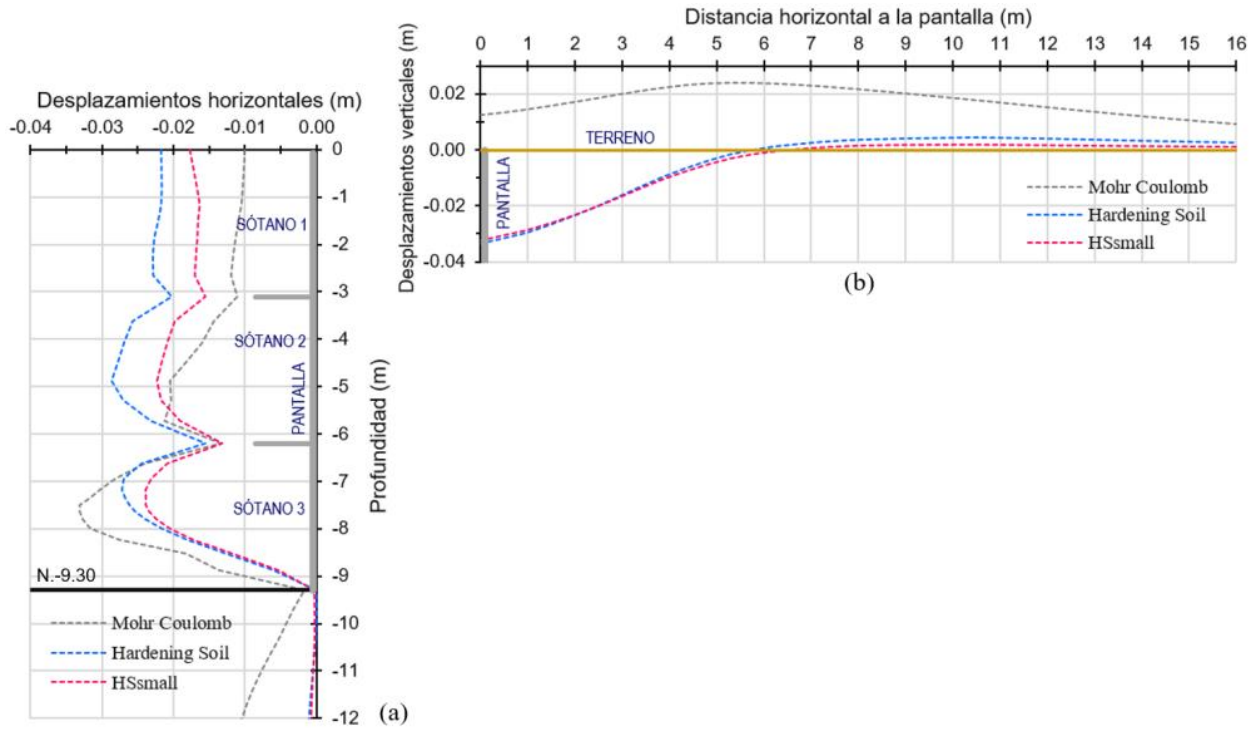

(a)

Fig. 5.60 Desplazamientos inducidos por construcción de sótano 3 de Zaigen: (a) desplazamientos horizontales en pantalla, y (b) asentamientos del terreno detrás de la pantalla.

Las Fig. 5.61 y 5.62 muestran la evolución de los desplazamientos horizontales en la pantalla y verticales en el suelo por la construcción de los sótanos 4 y 5, respectivamente. 

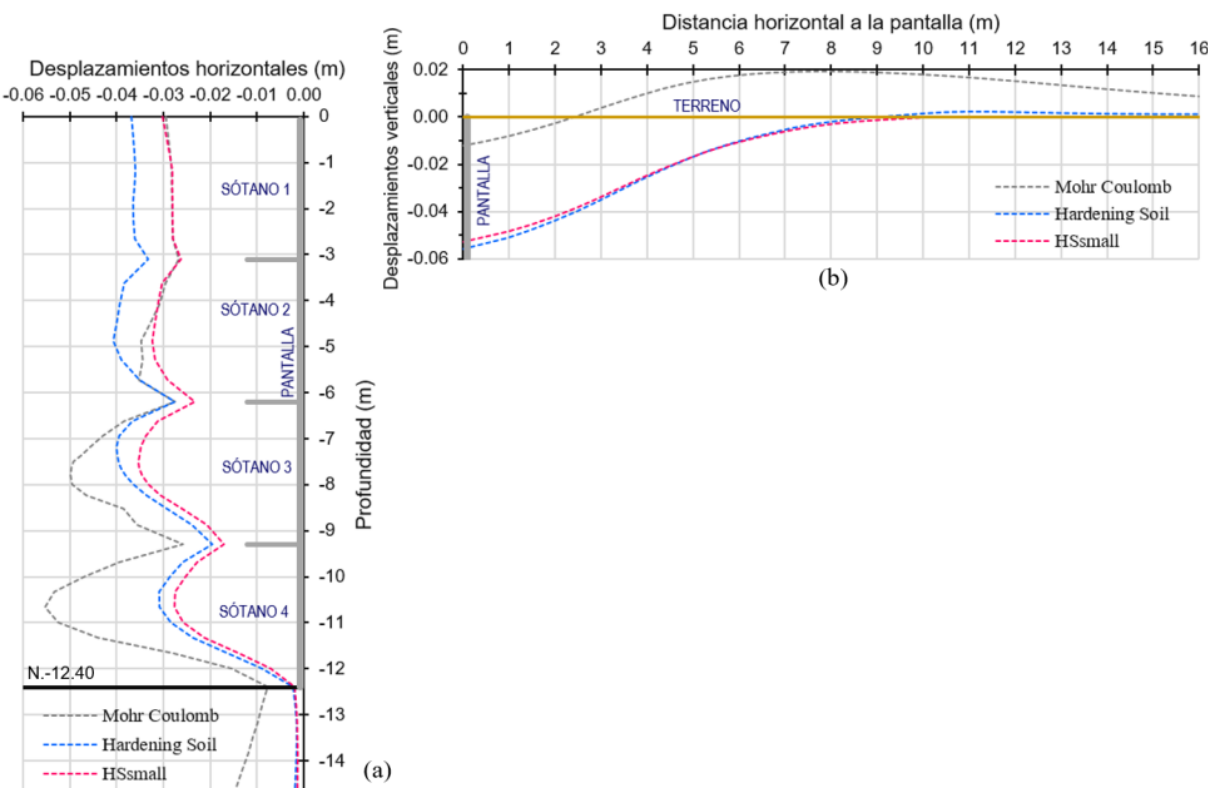

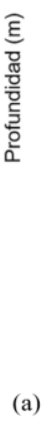

Fig. 5.61 Desplazamientos inducidos por construcción de sótano 4 de Zaigen: (a) desplazamientos horizontales en pantalla, y (b) asentamientos del terreno detrás de la pantalla.
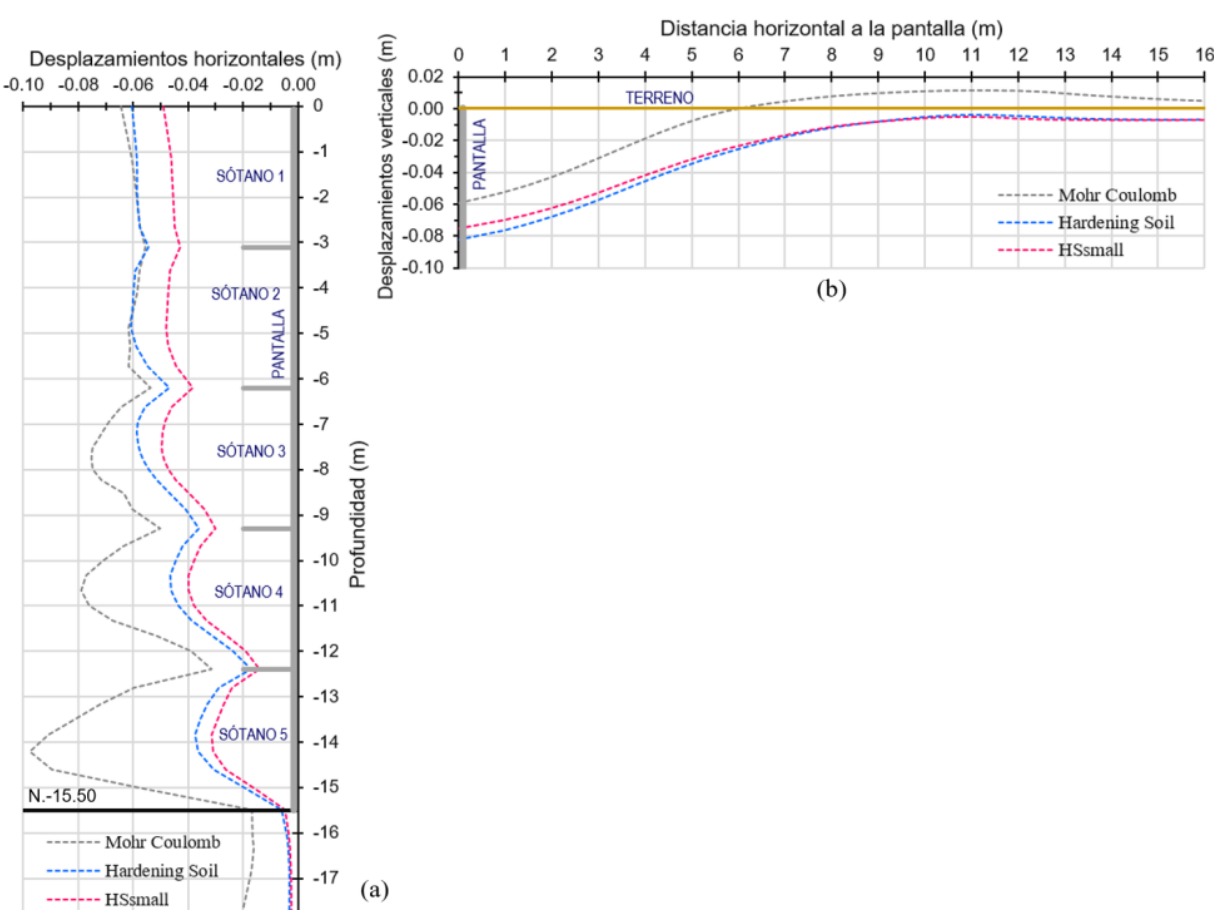

(b)

Fig. 5.62 Desplazamientos inducidos por construcción de sótano 5 de Zaigen: (a) desplazamientos horizontales en pantalla, y (b) asentamientos del terreno detrás de la pantalla. 
Por otra parte, en la Fig. 5.63 se presenta los diagramas de desplazamientos horizontales y verticales inducidos en el terreno por efectos del análisis sísmico pseudoestático para el caso de la excavación total para los 5 sótanos $(\mathrm{H}=15.50 \mathrm{~m})$.
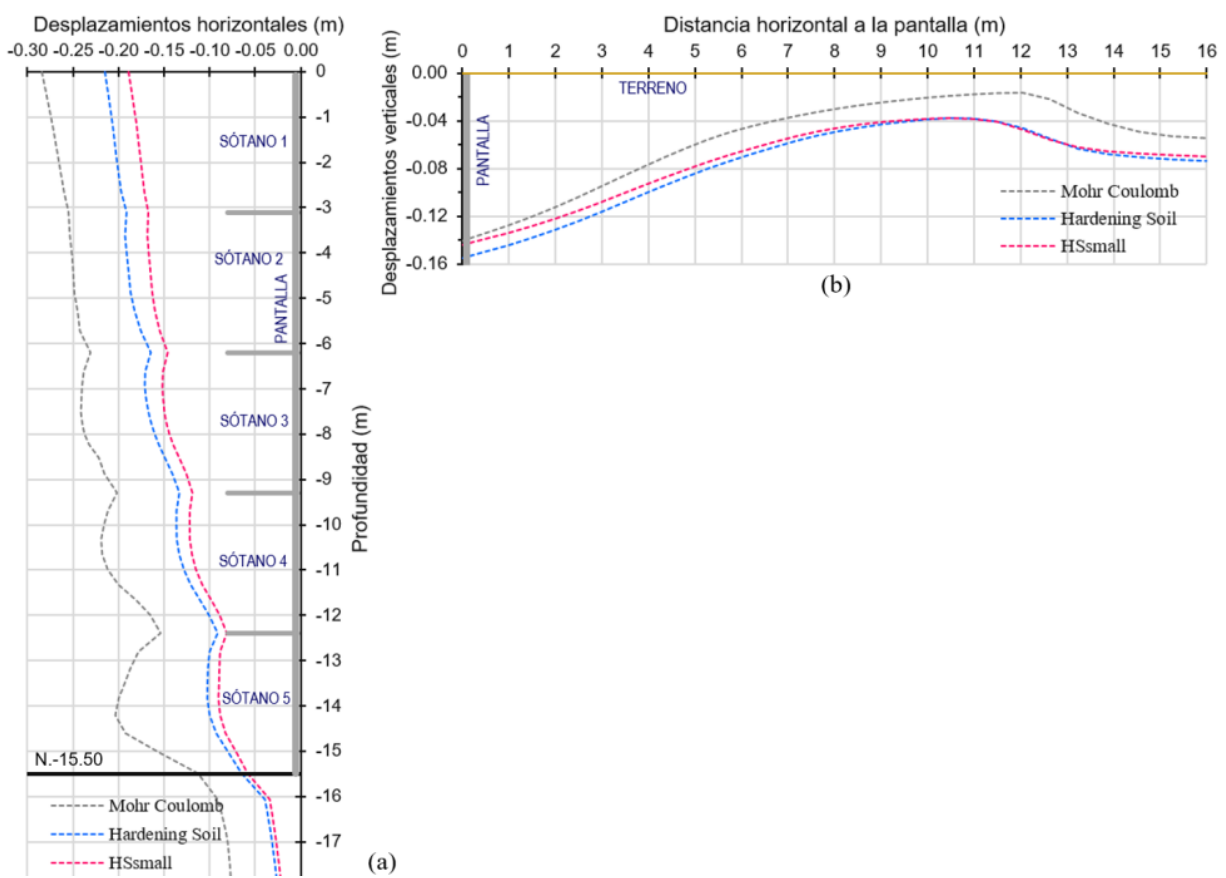

(b)

Fig. 5.63 Desplazamientos en Zaigen $(\mathrm{H}=15.50 \mathrm{~m})$ por análisis sísmico pseudoestático: (a) desplazamientos horizontales en pantalla, y (b) asentamientos del terreno detrás de la pantalla.

La Tabla 5.34 resume los valores máximos de desplazamientos horizontales en la pantalla y asentamientos inducidos en el terreno por la construcción de cada nivel de sótano.

Tabla 5.34 Desplazamientos máximos generados por construcción de sótanos de Zaigen.

\begin{tabular}{|c|c|c|c|c|c|c|c|c|}
\hline \multirow{4}{*}{ FASE } & \multirow{2}{*}{\multicolumn{2}{|c|}{ SÓTANO }} & \multicolumn{6}{|c|}{ DESPLAZAMIENTOS MÁXIMOS DEL TERRENO [m] } \\
\hline & & & \multicolumn{6}{|c|}{ MODELO CONSTITUTIVO } \\
\hline & \multirow{2}{*}{ No } & \multirow{2}{*}{$\begin{array}{c}\text { PROF. } \\
\text { ACUMULADA } \\
{[\mathrm{m}]}\end{array}$} & \multicolumn{2}{|c|}{ Mohr Coulomb } & \multicolumn{2}{|c|}{ Hardening Soil } & \multicolumn{2}{|c|}{ HSsmall } \\
\hline & & & Hor. & Ver. & Hor. & Ver. & Hor. & Ver. \\
\hline CONST. SÓTANO & 1 & -3.10 & 0.0046 & 0.0208 & -0.0038 & 0.0042 & -0.0017 & 0.0022 \\
\hline CONST. SÓTANO & 2 & -6.20 & -0.0097 & 0.0258 & -0.0168 & -0.0132 & -0.0123 & -0.0126 \\
\hline CONST. SÓTANO & 3 & -9.30 & -0.0331 & 0.0240 & -0.0286 & -0.0337 & -0.0240 & -0.0323 \\
\hline CONST. SÓTANO & 4 & -12.40 & -0.0554 & 0.0193 & -0.0408 & -0.0558 & -0.0353 & -0.0530 \\
\hline CONST. SÓTANO & 5 & -15.50 & -0.0975 & -0.0594 & -0.0608 & -0.0825 & -0.0496 & -0.0755 \\
\hline SISMO H=13.55 m & 5 & -15.50 & -0.2845 & -0.1405 & -0.2153 & -0.1555 & -0.1889 & -0.1444 \\
\hline
\end{tabular}



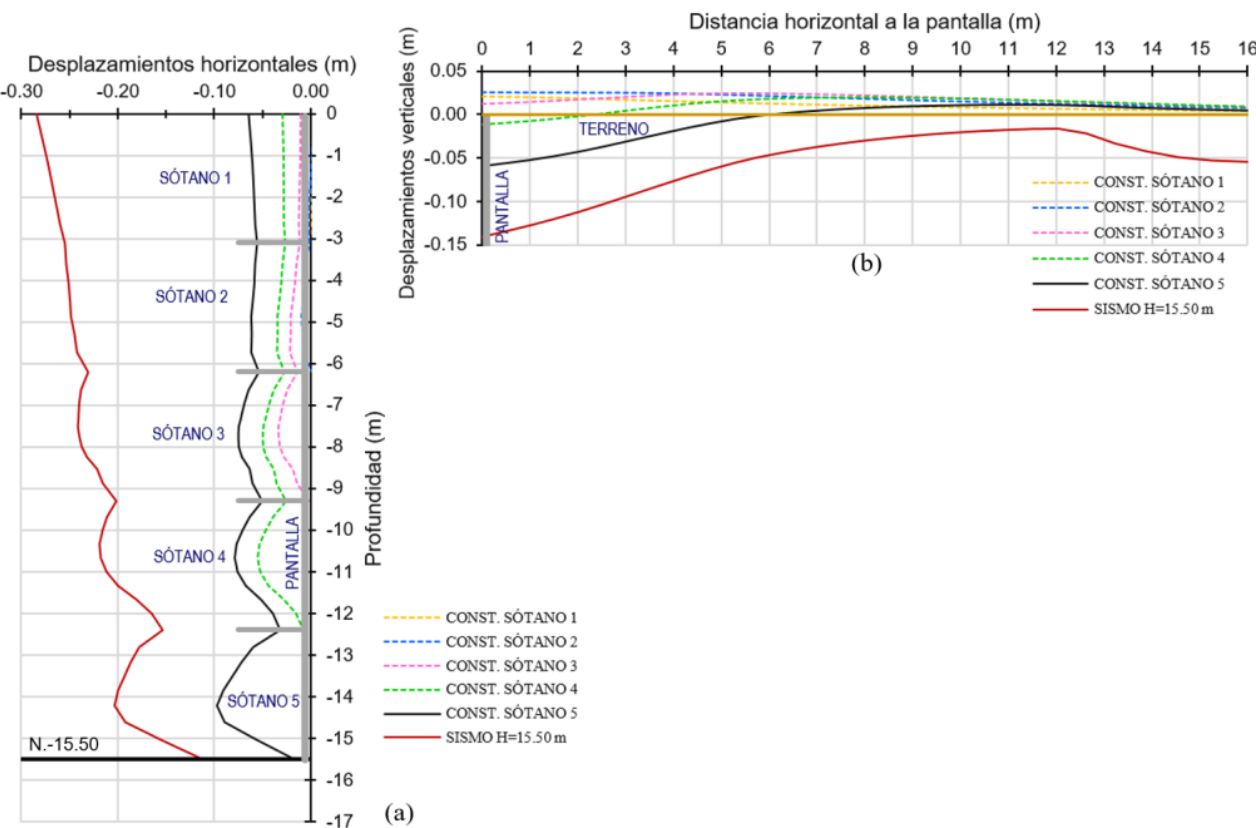

Fig. 5.64 Desplazamientos en Zaigen por construcción de sótanos (modelo de Mohr Coulomb): (a) desplazamientos horizontales en pantalla, y (b) asentamientos del terreno detrás de la pantalla.
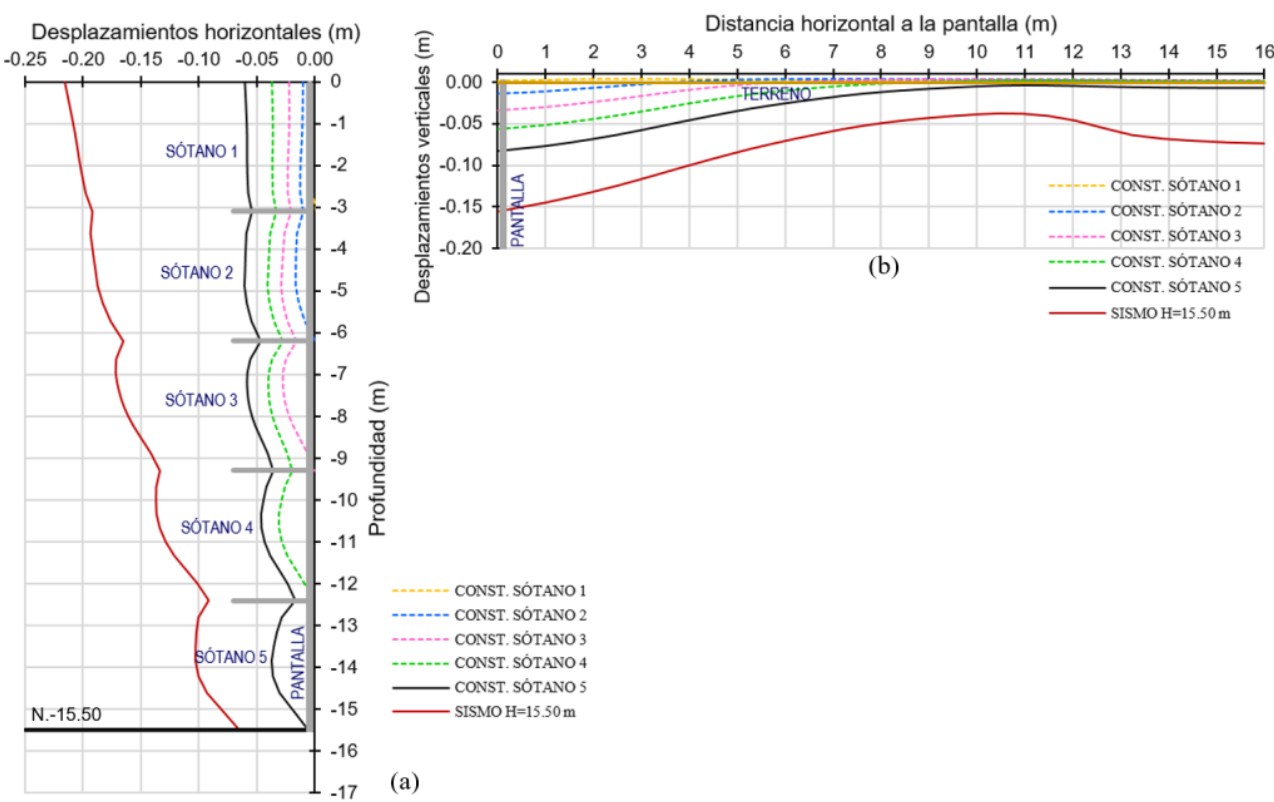

Fig. 5.65 Desplazamientos en Zaigen por construcción de sótanos (modelo de Hardening Soil): (a) desplazamientos horizontales en pantalla, y (b) asentamientos del terreno detrás de la pantalla. 
Las Fig. 5.64, 5.65 y 5.66 resumen la evolución de desplazamientos horizontales en la pantalla y asentamientos en el terreno, inducidos por la construcción de cada nivel de sótano de Zaigen y aplicando individualmente los modelos constitutivos de suelo de Mohr Coulomb, Hardening Soil y HSsmall, respectivamente.
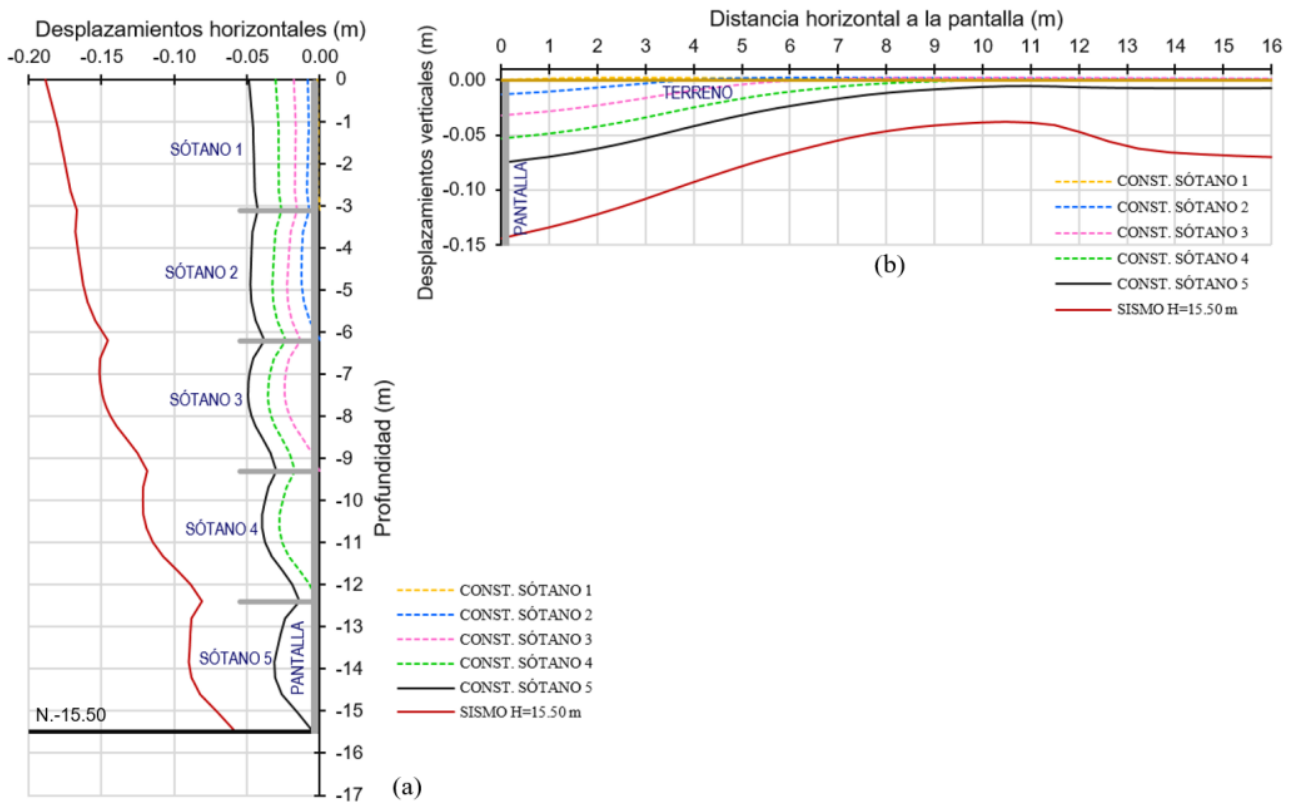

Fig. 5.66 Desplazamientos en Zaigen por construcción de sótanos (modelo de HSsmall): (a) desplazamientos horizontales en pantalla, y (b) asentamientos del terreno detrás de la pantalla.

\subsection{Análisis de estabilidad global de estructuras de "Soil Nailing"}

\subsubsection{Generalidades}

En esta sección se resumen los valores de factor de seguridad global obtenidos en el análisis de cada una de las estructuras. Dichos valores fueron determinados a través del método de los elementos finitos con aplicación de PLAXIS 2D y los modelos constitutivos de suelo de Mohr Coulomb, Hardening Soil y HSsmall.

También se determinaron los factores de seguridad a través de SLIDE2, que es un software de estabilidad de taludes 2D de equilibrio límite para evaluar el factor de seguridad o la probabilidad de falla de superficies de falla circulares o no circulares en el terreno (Rocscience, 2020). Dichos factores se evaluaron en todos los casos por los métodos de Bishop simplificado, Janbu simplificado, Morgenstern-Price y Spencer. Los factores de seguridad se obtuvieron para el proceso de construcción de cada nivel de sótano y adicionalmente para el análisis sísmico pseudoestático para la altura de los 5 sótanos, que corresponde a la altura mayor y por tanto al caso más crítico. 


\subsubsection{Análisis de estabilidad global de estructura de proyecto Torre Centre}

La Fig. 5.67 y la Tabla 5.35 muestran la variación de valores de factor de seguridad global (FS) con el avance constructivo de cada nivel de sótano para la estructura de Torre Centre. Por otra parte, la Fig. 5.68 muestra la determinación gráfica de factores de seguridad para el caso de análisis sísmico pseudoestático cuando $\mathrm{H}=13.55 \mathrm{~m}$.

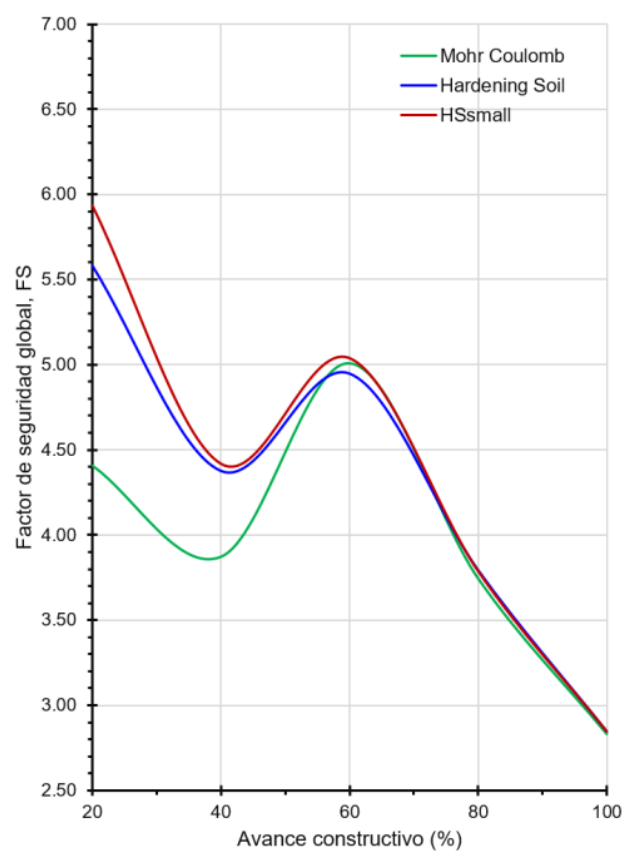

(a)

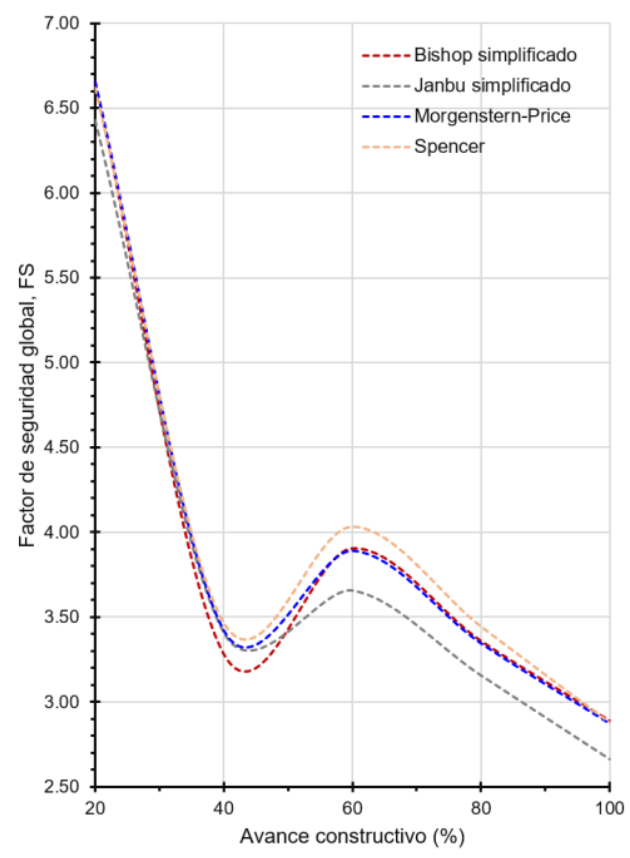

(b)

Fig. 5.67 Variación de factor de seguridad (FS) con avance constructivo de sótanos de Torre Centre: (a) Método de elementos finitos (PLAXIS 2D), y (b) Métodos de equilibrio límite (SLIDE2).

Del análisis mediante elementos finitos (PLAXIS 2D) y equilibrio límite (SLIDE2), existe una ligera variación de valores al inicio de la construcción. Sin embargo, los FS son similares al $100 \%$ de la construcción de los sótanos.

Tabla 5.35 Variación de factor de seguridad (FS) con avance constructivo de sótanos en Torre Centre.

\begin{tabular}{cccc|cccc}
\hline & \multicolumn{3}{c|}{ ELEMENTOS FINITOS } & \multicolumn{4}{c}{ EQUILIBRIO LÍMITE } \\
\cline { 2 - 7 } $\begin{array}{c}\text { SÓTANO } \\
\text { \% Const. }\end{array}$ & \multicolumn{3}{c}{ PLAXIS 2D V20 } & \multicolumn{4}{c}{ SLIDE2 } \\
\cline { 2 - 7 } & $\begin{array}{c}\text { Mohr } \\
\text { Coulomb }\end{array}$ & $\begin{array}{c}\text { Hardening } \\
\text { Soil }\end{array}$ & HSsmall & $\begin{array}{c}\text { Bishop } \\
\text { simplificado }\end{array}$ & $\begin{array}{c}\text { Janbu } \\
\text { simplificado }\end{array}$ & $\begin{array}{c}\text { Morgenstern } \\
\text { Price }\end{array}$ & Spencer \\
\hline $\mathbf{1}(20 \%)$ & 4.41 & 5.58 & 5.93 & 6.65 & 6.43 & 6.65 & 6.62 \\
$\mathbf{2}(40 \%)$ & 3.87 & 4.38 & 4.42 & 3.28 & 3.41 & 3.42 & 3.47 \\
$\mathbf{3}(60 \%)$ & 5.01 & 4.95 & 5.04 & 3.91 & 3.66 & 3.89 & 4.03 \\
$\mathbf{4}(80 \%)$ & 3.75 & 3.79 & 3.79 & 3.36 & 3.16 & 3.35 & 3.45 \\
$\mathbf{5}(100 \%)$ & 2.83 & 2.85 & 2.85 & 2.89 & 2.66 & 2.87 & 2.88 \\
Sismo & 2.01 & 2.01 & 2.01 & 2.19 & 1.82 & 2.17 & 2.25 \\
\hline
\end{tabular}




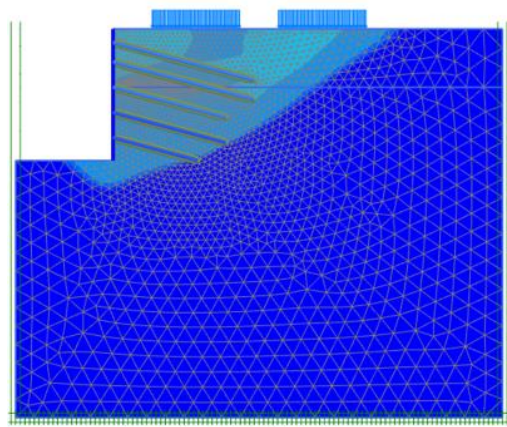

(a)

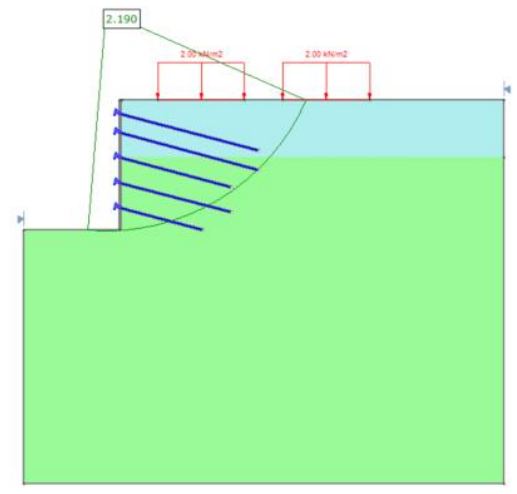

(b)

Fig. 5.68 Determinación de factor de seguridad (FS) de análisis sísmico pseudoestático en Torre Centre cuando H=13.55 m: (a) HSsmall - PLAXIS 2D, y (b) Bishop simplificado - SLIDE2.

\subsubsection{Análisis de estabilidad global de estructura de proyecto Zaigen}

La Fig. 5.69 y la Tabla 5.36 presentan la variación de valores de factor de seguridad global (FS) con el avance constructivo de cada nivel de sótano para la estructura de Zaigen. Por su parte, la Fig. 5.70 presenta la determinación gráfica de factores de seguridad para el caso de análisis sísmico pseudoestático cuando $\mathrm{H}=15.50 \mathrm{~m}$.

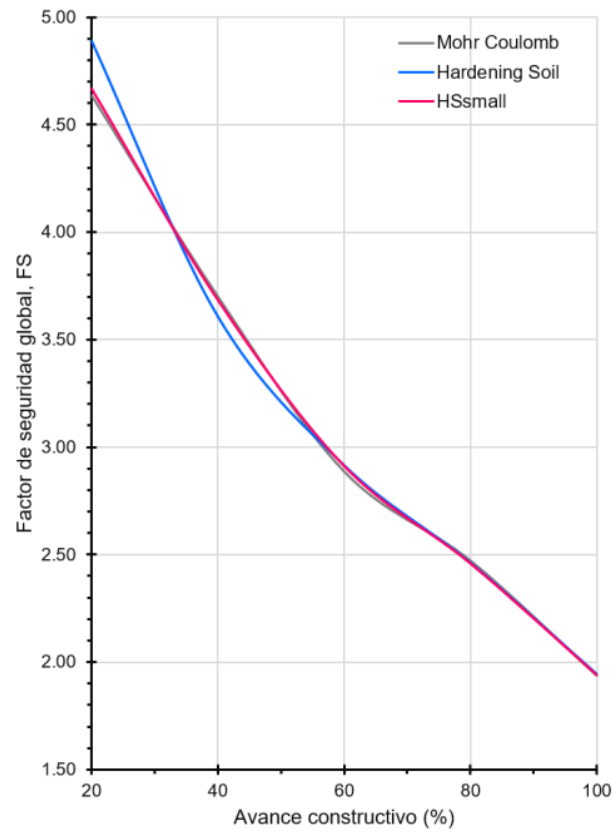

(a)

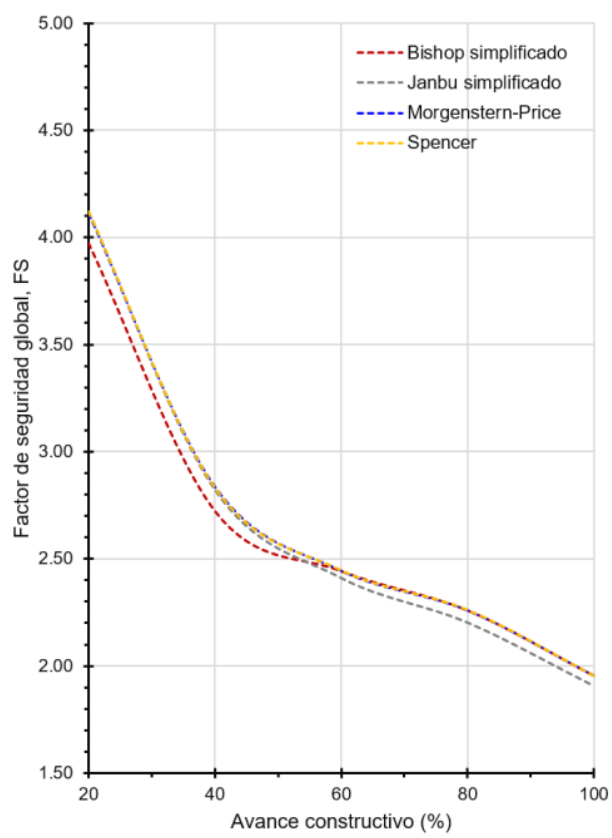

(b)

Fig. 5.69 Variación de factor de seguridad (FS) con avance constructivo de sótanos de Zaigen: (a) Método de elementos finitos (PLAXIS 2D), y (b) Métodos de equilibrio límite (SLIDE2). 
Tabla 5.36 Variación de factor de seguridad (FS) con el avance constructivo de sótanos en Zaigen.

\begin{tabular}{cccc|cccc}
\hline & \multicolumn{3}{c|}{ ELEMENTOS FINITOS } & \multicolumn{4}{c}{ EQUILIBRIO LÍMITE } \\
\cline { 2 - 7 } $\begin{array}{c}\text { SÓTANO } \\
\text { \% Const. }\end{array}$ & \multicolumn{3}{c|}{ PLAXIS 2D V20 } & \multicolumn{4}{c}{ SLIDE2 } \\
\cline { 2 - 7 } & $\begin{array}{c}\text { Mohr } \\
\text { Coulomb }\end{array}$ & $\begin{array}{c}\text { Hardening } \\
\text { Soil }\end{array}$ & HSsmall & $\begin{array}{c}\text { Bishop } \\
\text { simplificado }\end{array}$ & $\begin{array}{c}\text { Janbu } \\
\text { simplificado }\end{array}$ & $\begin{array}{c}\text { Morgenstern } \\
\text { Price }\end{array}$ & Spencer \\
\hline $\mathbf{1}(20 \%)$ & 4.64 & 4.89 & 4.67 & 3.97 & 4.12 & 4.11 & 4.12 \\
$\mathbf{2}(40 \%)$ & 3.70 & 3.61 & 3.69 & 2.72 & 2.82 & 2.84 & 2.83 \\
$\mathbf{3}(60 \%)$ & 2.89 & 2.92 & 2.91 & 2.44 & 2.41 & 2.44 & 2.45 \\
$\mathbf{4}(80 \%)$ & 2.47 & 2.46 & 2.46 & 2.26 & 2.20 & 2.26 & 2.26 \\
$\mathbf{5}(100 \%)$ & 1.94 & 1.94 & 1.94 & 1.95 & 1.91 & 1.95 & 1.95 \\
Sismo & 1.34 & 1.36 & 1.35 & 1.37 & 1.34 & 1.37 & 1.37 \\
\hline
\end{tabular}

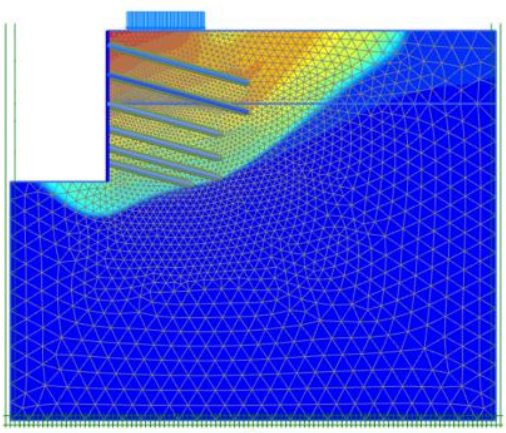

(a)

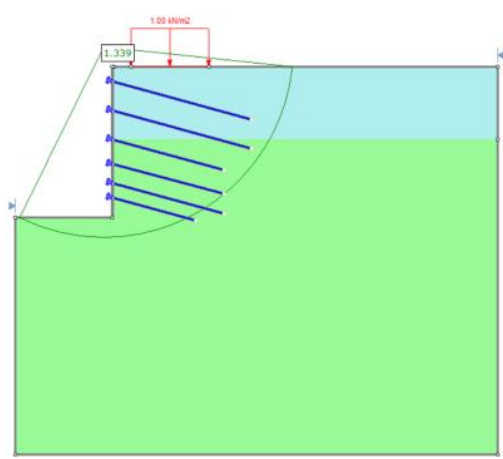

(b)

Fig. 5.70 Determinación de factor de seguridad (FS) de análisis sísmico pseudoestático en Zaigen cuando H=15.50 m: (a) HSsmall - PLAXIS 2D, y (b) Janbu simplificado - SLIDE2.

\subsection{Conclusiones relativas al análisis mediante elementos finitos $y$ equilibrio límite}

En este capítulo se realizaron análisis detallados de las estructuras de "Soil Nailing" de cada proyecto mediante el método de los elementos finitos y la aplicación del software Plaxis 2D V20. En este análisis numérico se consideraron los modelos constitutivos de suelo de Mohr Coulomb (MC), Hardening Soil (HS) y Hardening Soil with Small-Strain Stiffness (HSsmall). En general, el análisis por elementos finitos resulta ser práctico en la predicción de desplazamientos horizontales y verticales en el terreno, pero fundamentalmente muy útil en la predicción de la distribución de fuerzas axiales de tensión en las barras de los "Soil Nails".

En la primera parte de este capítulo se ha presentado a detalle la obtención de todos los parámetros geotécnicos a utilizarse en el análisis con los 3 modelos constitutivos de suelo, fundamentados en los ensayos de caracterización geotécnica (especialmente ensayos triaxiales $C U$ y $C D$ y ensayos edométricos) realizados y analizados en el Capítulo 3 de este estudio. Por tanto, los parámetros geotécnicos 
determinados en esta investigación son reales y no idealizados, a diferencia de gran parte de estudios numéricos existentes, en donde a manera de ejemplo se utilizan parámetros teóricos y hasta cierto punto perfectos.

De igual manera, en este capítulo se ha expuesto a detalle la obtención de los parámetros de rigidez axial EA y rigidez a flexión EI para los "Soil Nails" y pantallas de acuerdo a las propiedades de cada elemento estructural. Para el caso de los "Soil Nails" se determinó inicialmente un módulo de elasticidad equivalente según las propiedades compartidas por el acero y el "Grout".

Las magnitudes de las fuerzas de tensión determinadas en los "Soil Nails" con el modelo constitutivo de Mohr Coulomb en general son menores a las tensiones determinadas con los modelos de Hardening Soil y HSsmall. Sin embargo, las fuerzas obtenidas con Hardening Soil y HSsmall mantienen cierta similitud entre ellas en gran parte del proceso, siendo las tensiones de Hardening Soil ligeramente superiores en la mayoría de las fases constructivas (Ver Fig. 5.29 y Fig 5.53).

En gran parte de las etapas constructivas de ambas estructuras, los desplazamientos horizontales de las pantallas determinados con el modelo de Mohr Coulomb son menores, a diferencia de los desplazamientos horizontales obtenidos con Hardening Soil que son mayores al resto. Por su lado, los valores con HSsmall se mantienen en una posición intermedia.

Por otra parte, los desplazamientos verticales del terreno detrás de las pantallas determinados con el modelo de Mohr Coulomb en la mayoría de casos resultan estados de ascensión o levantamiento del suelo en lugar de asentamientos. De igual manera se puede apreciar valores altos de ascensión del suelo en el fondo de la excavación de cada etapa constructiva. Esto se debe a que el modelo constitutivo de Mohr Coulomb utiliza un solo módulo de elasticidad del suelo para la carga y la descarga. Por su parte, el análisis de desplazamientos verticales con los modelos constitutivos de suelo de Hardening Soil y HSsmall determina entre ellos valores similares de asentamientos inferidos por la construcción de los sótanos, siendo los asentamientos de Hardening Soil ligeramente superiores. Los asentamientos obtenidos con estos 2 modelos constitutivos serán, previsiblemente, más reales, ya que incluyen un módulo de rigidez de descarga/recarga, $E_{u r}$ que permite representar el comportamiento del suelo en condiciones de carga y descarga.

Para determinar los factores de seguridad global de las 2 estructuras se utilizó el método de los elementos finitos (Plaxis 2D V20) y varios métodos de equilibrio límite (SLIDE2). En este caso, ambas metodologías analizaron de manera satisfactoria la estabilidad de las pantallas claveteadas. Sin embargo, los FS determinados con elementos finitos y equilibrio límite presentan valores dispersos al inicio de la construcción de los sótanos, pero van convergiendo conforme avanza la construcción hasta presentar valores similares al término de la construcción del quinto nivel de sótano y con potenciales superficies de rotura similares. 
Estudio experimental y numérico del comportamiento de excavaciones ejecutadas mediante la técnica de suelo claveteado (Soil Nailing) en suelos de la ciudad de Quito (Ecuador) 


\section{Capítulo 6}

\section{RESULTADOS DEL ESTUDIO}

EXPERIMENTAL

\subsection{Introducción}

Este capítulo presenta los resultados del estudio experimental compuesto de las diferentes campañas de monitorización ejecutadas simultáneamente al proceso constructivo de las estructuras de "Soil Nailing" de Torre Centre y Zaigen. Según los procedimientos de instrumentación y monitorización detallados y explicados en el Capítulo 4 de este estudio, las variables investigadas fueron: las fuerzas axiales de tensión y su distribución a lo largo de la barra del anclaje, desplazamientos horizontales de las pantallas y desplazamientos verticales o asentamientos inferidos por las excavaciones para la construcción de cada nivel de sótano.

Por tanto, de acuerdo a los procedimientos de investigación utilizados, las fuerzas axiales de tensión se obtuvieron a través de lecturas periódicas en los "Strain Gauges" o galgas extensométricas (SG) instalados en las barras de acero de los "Soil Nails", los desplazamientos horizontales a través de lecturas topográficas durante las fases constructivas en las marcas metálicas o puntos de control de deformaciones instalados en las pantallas, en tanto que los desplazamientos verticales o asentamientos mediante lecturas topográficas periódicas en las bases de nivelación o puntos de control instalados en el terreno.

Para una mejor interpretación, en este capítulo los resultados de la monitorización se presentan superpuestos a los diagramas teóricos obtenidos del análisis numérico mediante elementos finitos con Plaxis 2D en el Capítulo 5. 


\subsection{Resultados experimentales por fases constructivas}

\subsubsection{Generalidades}

En función del avance constructivo de cada estructura de "Soil Nailing" se fueron obteniendo resultados parciales para las variables de fuerzas axiales de tensión y desplazamientos horizontales y verticales del terreno. Por tanto, la construcción de cada nivel de sótano implicó tareas simultáneas y oportunas de monitorización. Determinados "Strain Gauges" instalados en las barras de acero presentaron daños después de la construcción de los "Soil Nails" y no registraron información. Estos daños se deben probablemente a deficiencias en la adherencia sensor - barra de acero, afectaciones de humedad o algún golpe durante el proceso de instalación de la barra de acero en la perforación o en el proceso de inyección del "Grout".

\subsubsection{Fuerza axial en barras de acero de "Soil Nails"}

\subsubsection{Introducción}

Las fuerzas axiales de tensión se obtuvieron de manera indirecta a través de los "Strain Gauges" instalados en las barras de acero. Entonces para estimar la fuerza de tensión en cada barra de acero de los "Soil Nails" se aplicó la expresión 6.1.

$$
N=\sigma A=\varepsilon E A
$$

Donde:
$N \quad$ fuerza axial de tensión
$\sigma \quad$ esfuerzo axial de tensión
$A \quad$ área de la barra de acero
E módulo de elasticidad del acero
$\varepsilon \quad$ lectura de "Strain" en galga extensométrica o "Strain Gauge" (SG)

Por otra parte, no siempre las medidas obtenidas reflejan correctamente las fuerzas reales a las que está sometida la barra de acero, especialmente cuando el diámetro de la sección de "Grout" es grande (Hu y Lin, 2019). Esto se debe a que la sección de "Grout" también transporta fuerzas de tensión que no son registradas por las galgas, en la interfaz barra de acero - "Grout". Por tanto, las fuerzas de tensión registradas con las lecturas en los "Strain Gauges" sólo pueden ser consideradas como los límites inferiores de las fuerzas de tensión reales (Hu y Lin, 2019).

\subsubsection{Fuerza axial en barras de acero de "Soil Nails" de Torre Centre}

La Fig. 6.1 muestra la ubicación de las galgas extensométricas o "Strain Gauges" (SG) instalados en las barras de acero de los "Soil Nails" del proyecto Torre Centre. En esta figura se detalla la instrumentación completa para los 5 niveles de sótano, por tanto, en los puntos de medición indicados se realizaron las lecturas periódicas. 


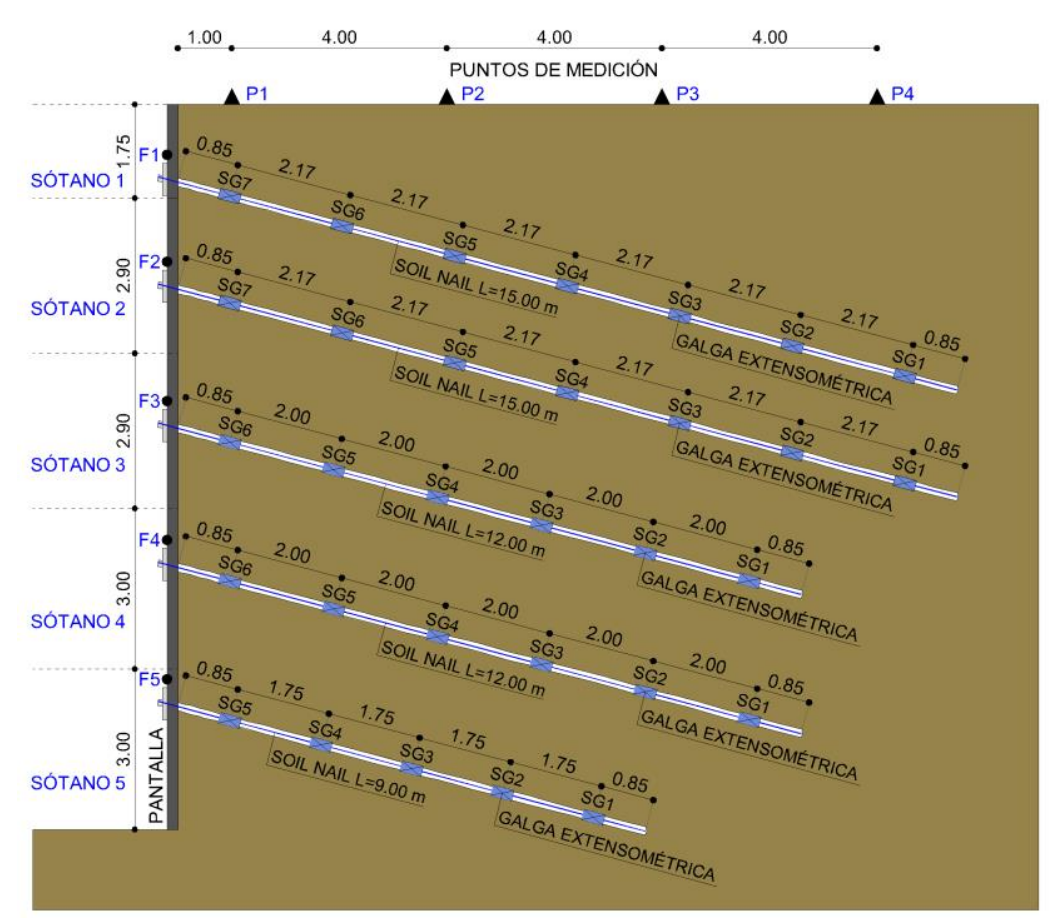

Fig. 6.1 Instrumentación completa de estructura de "Soil Nailing" de Torre Centre.

En las Fig. 6.2 a 6.6 se presenta la evolución de las fuerzas axiales de tensión en los "Soil Nails" inducidas por la construcción de cada nivel de sótano, determinadas de las lecturas en los "Strain Gauges" durante el proceso de monitorización. Para efectos de comparación, se han graficado simultáneamente con los diagramas del análisis numérico con elementos finitos y los modelos constitutivos de suelo de Mohr Coulomb, Hardening Soil y HSsmall, con Plaxis 2D.

\section{Excavación 1 - construcción de sótano 1}

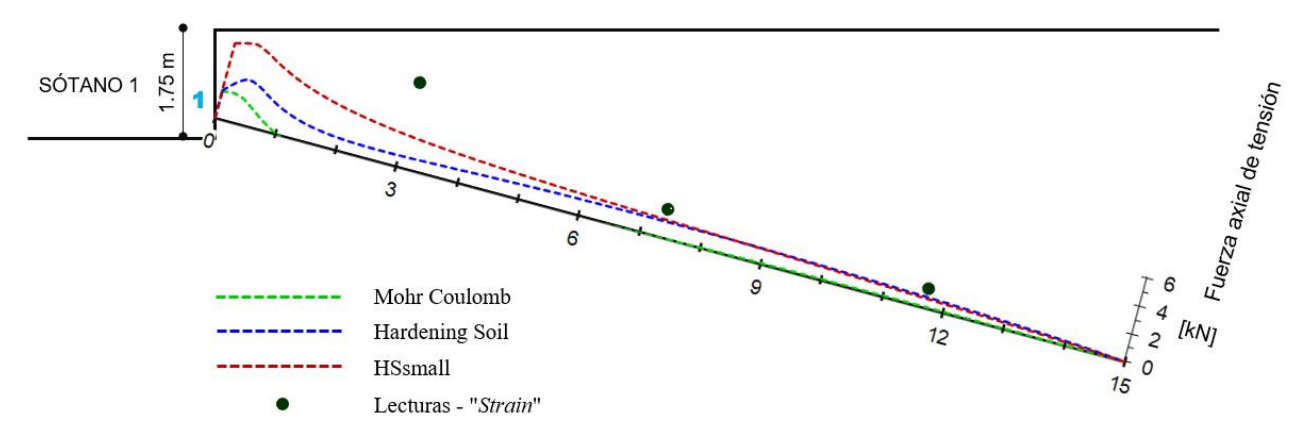

Fig. 6.2 Fuerzas axiales de tensión inducidas por construcción de sótano 1 de Torre Centre determinadas de lecturas en "Strain Gauges". Comparación con resultados de los modelos numéricos. 
En la Tabla 6.1 se resumen los valores de fuerzas axiales de tensión para los "Soil Nails" del diagrama de la Fig. 6.2, inducidos por la excavación y construcción del sótano 1, obtenidos por el análisis numérico mediante elementos finitos con Plaxis 2D y el enfoque con cada uno de los modelos constitutivos de suelo.

Por su parte, en la última fila de la Tabla 6.1 se exponen las fuerzas axiales de tensión deducidas de las lecturas de "Strain" en las galgas extensométricas durante el proceso de monitorización.

En el "Soil Nail" de la fila F1 se instalaron 7 galgas extensométricas y se distribuyeron según se muestra en la Fig. 6.1. Sin embargo, 4 de ellas presentaron daños y no reportaron información, según se puede observar en la tabla de resultados. Para efectos de comparación, las abscisas de los valores de fuerzas de tensión reportados del análisis numérico coinciden con las abscisas de posición de las galgas extensométricas del estudio experimental.

Tabla 6.1 Fuerzas axiales de tensión en "Soil Nails" por construcción de sótano 1 de Torre Centre.

\begin{tabular}{|c|c|c|c|c|c|c|c|c|}
\hline \multirow{4}{*}{$\begin{array}{c}\text { No. } \\
\text { SÓTANO / } \\
\text { FILA / } \\
\text { FECHA } \\
\text { LECTURA }\end{array}$} & \multirow{4}{*}{$\begin{array}{c}\text { MÉTODO } \\
\text { MODELO DE SUELO } \\
\text { / MONITORIZACIÓN }\end{array}$} & \multicolumn{7}{|c|}{ FUERZAS DE TENSIÓN EN UBIC. DE “STRAIN GAUGES” [kN] } \\
\hline & & SG7 & SG6 & SG5 & SG4 & SG3 & SG2 & SG1 \\
\hline & & \multicolumn{7}{|c|}{ Distancia en longitud de barra (desde pantalla) [m] } \\
\hline & & 0.85 & 3.02 & 5.19 & 7.36 & 9.53 & 11.70 & 13.87 \\
\hline \multirow{2}{*}{1} & Mohr Coulomb & 0.47 & 0.00 & 0.00 & 0.00 & 0.08 & 0.08 & 0.02 \\
\hline & Hardening Soil & 2.22 & 0.80 & 1.06 & 1.15 & 1.04 & 0.77 & 0.37 \\
\hline FILA F1 & HSsmall & 4.65 & 2.27 & 1.63 & 1.27 & 0.98 & 0.66 & 0.29 \\
\hline $25 / 07 / 2016$ & Lecturas - "Strain" & $(*)$ & 6.01 & $(*)$ & 1.93 & $(*)$ & 1.35 & $(*)$ \\
\hline
\end{tabular}

(*) "Strain Gauge" que no registró información.

Excavación 2 - construcción de sótano 2

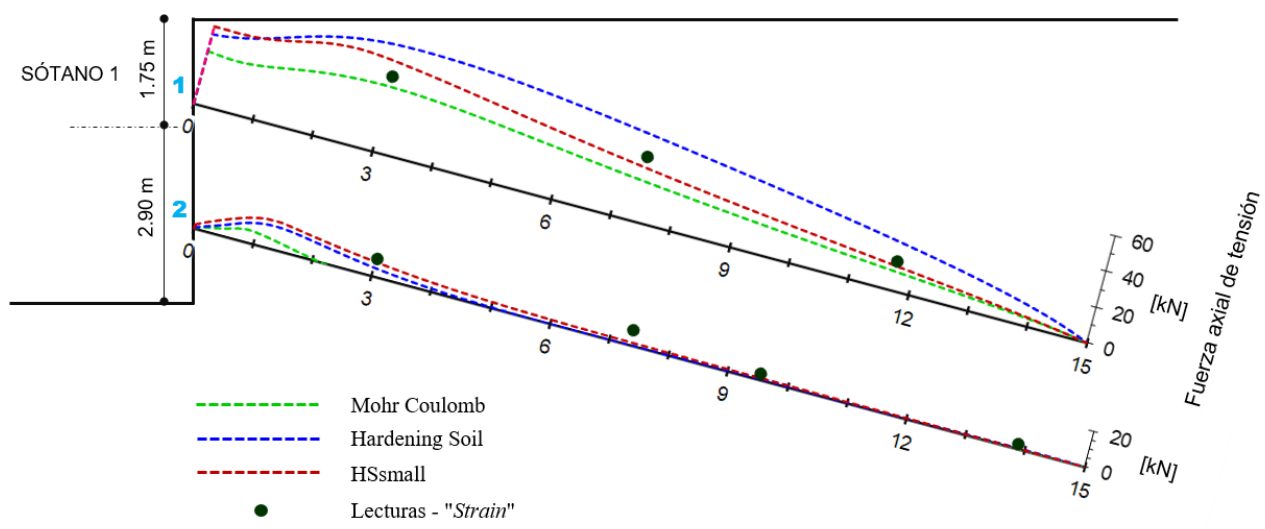

Fig. 6.3 Fuerzas axiales de tensión inducidas por construcción de sótano 2 de Torre Centre determinadas de lecturas en "Strain Gauges". Comparación con resultados de los modelos numéricos. 
La Tabla 6.2 resume las fuerzas de tensión del análisis numérico y experimental (Fig. 6.3) inducidas por la construcción del sótano 2. En el "Soil Nail" de la fila F2 se instalaron 7 galgas extensométricas, de las cuales 3 no reportaron información.

Tabla 6.2 Fuerzas axiales de tensión en "Soil Nails" por construcción de sótano 2 de Torre Centre.

\begin{tabular}{|c|c|c|c|c|c|c|c|c|}
\hline \multirow{4}{*}{$\begin{array}{c}\text { No. } \\
\text { SÓTANO / } \\
\text { FILA / } \\
\text { FECHA } \\
\text { LECTURA }\end{array}$} & \multirow{4}{*}{$\begin{array}{l}\text { MODELO DE SUELO } \\
\text { / MONITORIZACIÓN }\end{array}$} & \multicolumn{7}{|c|}{ FUERZAS DE TENSIÓN EN UBIC. DE “STRAIN GAUGES” [kN] } \\
\hline & & SG7 & SG6 & SG5 & SG4 & SG3 & SG2 & SG1 \\
\hline & & \multicolumn{7}{|c|}{ Distancia en longitud de barra (desde pantalla) [m] } \\
\hline & & 0.85 & 3.02 & 5.19 & 7.36 & 9.53 & 11.70 & 13.87 \\
\hline \multirow{2}{*}{1} & Mohr Coulomb & 28.91 & 36.39 & 30.51 & 22.66 & 16.22 & 10.54 & 4.99 \\
\hline & Hardening Soil & 44.02 & 59.69 & 56.46 & 47.90 & 37.93 & 26.34 & 12.52 \\
\hline FILA F1 & HSsmall & 43.91 & 50.21 & 39.95 & 29.84 & 21.34 & 13.47 & 5.66 \\
\hline 03/08/2016 & Lecturas - "Strain" & $(*)$ & 41.48 & $(*)$ & 35.45 & $(*)$ & 15.74 & $(*)$ \\
\hline \multirow{3}{*}{$\begin{array}{c}\text { SÓTANO / } \\
\text { FILA / } \\
\text { FECHA } \\
\text { LECTURA }\end{array}$} & \multirow{3}{*}{$\begin{array}{l}\text { MODELO DE SUELO } \\
\text { / MONITORIZACIÓN }\end{array}$} & SG7 & SG6 & SG5 & SG4 & SG3 & SG2 & SG1 \\
\hline & & \multicolumn{7}{|c|}{ Distancia en longitud de barra (desde pantalla) [m] } \\
\hline & & 0.85 & 3.02 & 5.19 & 7.36 & 9.53 & 11.70 & 13.87 \\
\hline \multirow{2}{*}{2} & Mohr Coulomb & 6.60 & 0.00 & 0.00 & 0.00 & 0.00 & 0.00 & 0.00 \\
\hline & Hardening Soil & 10.96 & 4.63 & 0.19 & 0.00 & 0.48 & 0.38 & 0.43 \\
\hline FILA F2 & HSsmall & 13.51 & 7.71 & 3.01 & 1.61 & 1.15 & 0.66 & 0.32 \\
\hline 03/08/2016 & Lecturas - "Strain" & $(*)$ & 9.23 & $(*)$ & 8.28 & 3.17 & $(*)$ & 2.15 \\
\hline
\end{tabular}

(*) "Strain Gauge" que no registró información.

\section{Excavación 3 - construcción de sótano 3}

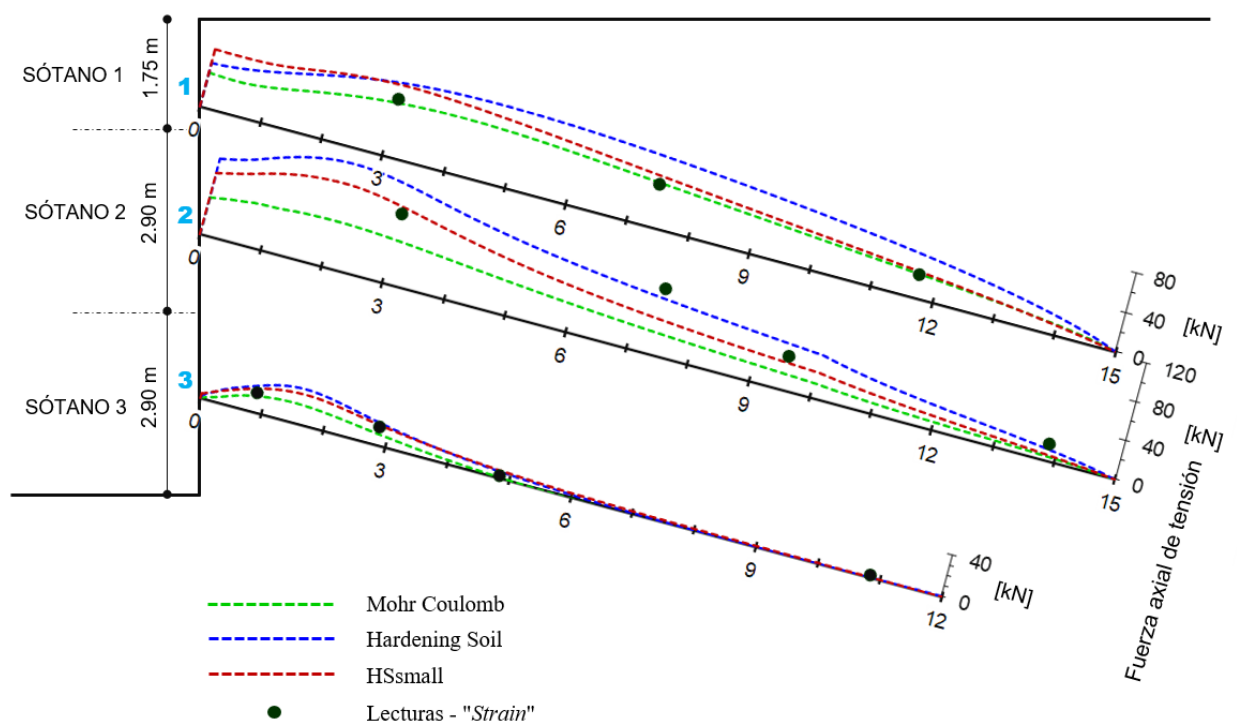

Fig. 6.4 Fuerzas axiales de tensión inducidas por construcción de sótano 3 de Torre Centre determinadas de lecturas en "Strain Gauges". Comparación con resultados de los modelos numéricos. 
La Tabla 6.3 presenta los valores de fuerzas axiales de tensión para los "Soil Nails" del diagrama de la Fig. 6.4, inducidos por la excavación y construcción del sótano 3, determinados por el análisis numérico mediante elementos finitos con Plaxis 2D y por el estudio experimental mediante las lecturas de "Strain" en las galgas extensométricas instaladas.

Como parte del estudio experimental, en el "Soil Nail" de la fila F3 correspondiente al sótano 3 se distribuyeron e instalaron en la longitud de la barra de acero 6 galgas extensométricas, conforme se muestra en la Fig. 6.1. Sin embargo, 2 de ellas presentaron daños y no reportaron valores de "Strain", según se detalla en la tabla de resultados.

En la última fila de cada sección de resultados por nivel de sótano de la Tabla 6.3 se muestran las fuerzas axiales de tensión deducidas de las lecturas de "Strain" en las galgas extensométricas durante el proceso de monitorización del estudio experimental.

Tabla 6.3 Fuerzas axiales de tensión en "Soil Nails" por construcción de sótano 3 de Torre Centre.

\begin{tabular}{|c|c|c|c|c|c|c|c|c|}
\hline \multirow{4}{*}{$\begin{array}{c}\text { No. } \\
\text { SÓTANO / } \\
\text { FILA / } \\
\text { FECHA } \\
\text { LECTURA }\end{array}$} & \multirow{4}{*}{$\begin{array}{c}\text { MÉTODO } \\
\text { MODELO DE SUELO } \\
\text { / MONITORIZACIÓN }\end{array}$} & \multicolumn{7}{|c|}{ FUERZAS DE TENSIÓN EN UBIC. DE “STRAIN GAUGES” [kN] } \\
\hline & & SG7 & SG6 & SG5 & SG4 & SG3 & SG2 & SG1 \\
\hline & & \multicolumn{7}{|c|}{ Distancia en longitud de barra (desde pantalla) [m] } \\
\hline & & 0.85 & 3.02 & 5.19 & 7.36 & 9.53 & 11.70 & 13.87 \\
\hline \multirow{2}{*}{1} & Mohr Coulomb & 34.26 & 53.45 & 53.64 & 44.31 & 34.12 & 23.75 & 12.02 \\
\hline & Hardening Soil & 49.09 & 73.35 & 76.97 & 70.19 & 58.53 & 42.57 & 20.96 \\
\hline FILA F1 & HSsmall & 57.40 & 70.71 & 63.20 & 50.66 & 38.52 & 25.81 & 11.35 \\
\hline $13 / 09 / 2016$ & Lecturas - "Strain" & $(*)$ & 56.45 & $(*)$ & 42.21 & $(*)$ & 22.68 & $(*)$ \\
\hline \multirow{3}{*}{$\begin{array}{l}\text { SÓTANO / } \\
\text { FILA / } \\
\text { FECHA } \\
\text { LECTURA }\end{array}$} & \multirow{3}{*}{$\begin{array}{l}\text { MODELO DE SUELO } \\
\text { / MONITORIZACIÓN }\end{array}$} & SG7 & $\overline{\text { SG6 }}$ & SG5 & SG4 & SG3 & SG2 & SG1 \\
\hline & & \multicolumn{7}{|c|}{ Distancia en longitud de barra (desde pantalla) [m] } \\
\hline & & 0.85 & 3.02 & 5.19 & 7.36 & 9.53 & 11.70 & 13.87 \\
\hline \multirow{2}{*}{2} & Mohr Coulomb & 45.18 & 45.33 & 33.02 & 23.43 & 16.68 & 9.25 & 4.64 \\
\hline & Hardening Soil & 92.81 & 99.85 & 73.60 & 57.60 & 46.27 & 26.83 & 11.62 \\
\hline FILA F2 & HSsmall & 77.47 & 78.70 & 52.46 & 37.09 & 28.00 & 15.71 & 6.22 \\
\hline $13 / 09 / 2016$ & Lecturas - "Strain" & $(*)$ & 71.21 & $(*)$ & 67.11 & 33.46 & $(*)$ & 16.46 \\
\hline \multirow{3}{*}{$\begin{array}{l}\text { SÓTANO / } \\
\text { FILA / } \\
\text { FECHA } \\
\text { LECTURA }\end{array}$} & \multirow{3}{*}{$\begin{array}{l}\text { MODELO DE SUELO } \\
\text { / MONITORIZACIÓN }\end{array}$} & SG6 & SG5 & SG4 & SG3 & SG2 & SG1 & \\
\hline & & \multicolumn{6}{|c|}{ Distancia en longitud de barra (desde pantalla) [m] } & \\
\hline & & 0.85 & 2.85 & 4.85 & 6.85 & 8.85 & 10.85 & \\
\hline \multirow{2}{*}{3} & Mohr Coulomb & 15.68 & 10.65 & 1.30 & 0.00 & 0.00 & 0.00 & \\
\hline & Hardening Soil & 24.65 & 19.62 & 5.53 & 0.52 & 0.00 & 0.00 & \\
\hline FILA F3 & HSsmall & 22.73 & 18.63 & 7.29 & 2.73 & 1.17 & 0.45 & \\
\hline $13 / 09 / 2016$ & Lecturas - "Strain" & 17.35 & 16.23 & 1.71 & $(*)$ & $(*)$ & 2.06 & \\
\hline
\end{tabular}

(*) "Strain Gauge" que no registró información. 


\section{Excavación 4 - construcción de sótano 4}

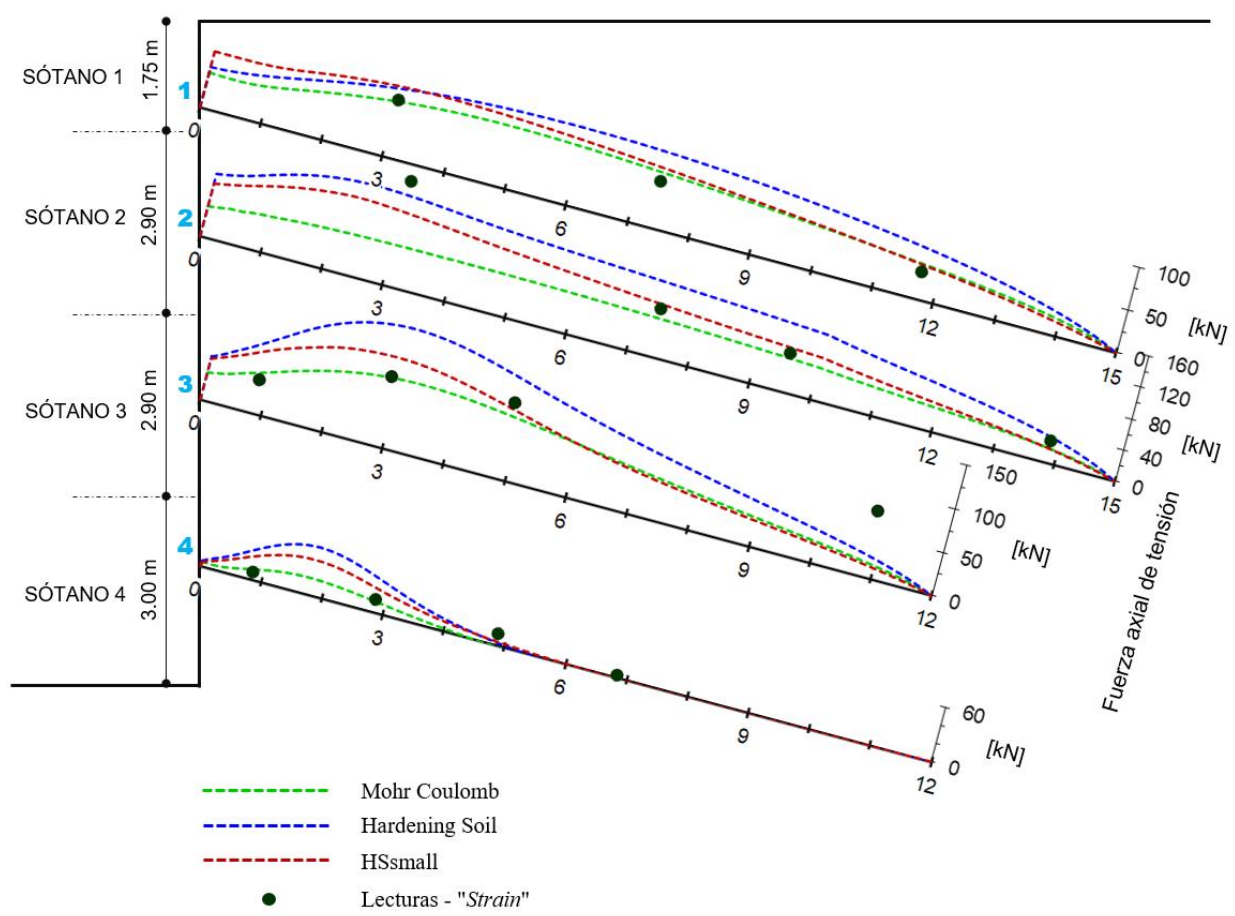

Fig. 6.5 Fuerzas axiales de tensión inducidas por construcción de sótano 4 de Torre Centre determinadas de lecturas en "Strain Gauges". Comparación con resultados de los modelos numéricos.

En la Tabla 6.4 se resumen los valores de fuerzas axiales de tensión para todos los "Soil Nails" del diagrama de la Fig. 6.5, generados por la excavación y construcción del sótano 4, determinados por el análisis numérico mediante elementos finitos con los 3 modelos constitutivos de suelo considerados en este estudio e incluidos en Plaxis 2D, y por las lecturas de "Strain" registradas de las galgas extensométricas durante la fase de monitorización del estudio experimental.

En el "Soil Nail" de la fila F4 correspondiente al sótano 4 se instalaron 6 "Strain Gauges", su posición y distribución en la longitud de la barra de acero se detalla en la Fig. 6.1. Sin embargo, 2 de los sensores instalados presentaron daños después de la construcción del anclaje y no emitieron ninguna información, según se puede observar en la tabla de reporte de resultados inferidos por la construcción de este nivel de sótano.

De igual manera, en la última fila de cada sección de resultados por nivel de sótano expuestos en la Tabla 6.4 se resumen las fuerzas axiales de tensión deducidas de las lecturas de "Strain" en las galgas extensométricas de cada fila de anclajes durante el proceso de monitorización del estudio experimental. 
Es notorio que cada excavación para la construcción de un nuevo nivel de sótano infiere nuevos valores de fuerzas de tensión en cada fila de "Soil Nails" de los niveles superiores de sótano construidos en las fases anteriores, los mismos que fueron registradas en el momento oportuno del proceso de monitorización de esta fase constructiva. El hecho de registrar los valores de "Strain" de los "Soil Nails" de todas las filas ya instaladas permite estudiar el comportamiento de cada fase de construcción.

Tabla 6.4 Fuerzas axiales de tensión en "Soil Nails" por construcción de sótano 4 de Torre Centre.

\begin{tabular}{|c|c|c|c|c|c|c|c|c|}
\hline \multirow{4}{*}{$\begin{array}{c}\text { No. } \\
\text { SÓTANO / } \\
\text { FILA / } \\
\text { FECHA } \\
\text { LECTURA }\end{array}$} & \multirow{4}{*}{$\begin{array}{c}\text { MÉTODO } \\
\text { MODELO DE SUELO } \\
\text { / MONITORIZACIÓN }\end{array}$} & \multicolumn{7}{|c|}{ FUERZAS DE TENSIÓN EN UBIC. DE “STRAIN GAUGES” [kN] } \\
\hline & & SG7 & SG6 & SG5 & SG4 & SG3 & SG2 & SG1 \\
\hline & & \multicolumn{7}{|c|}{ Distancia en longitud de barra (desde pantalla) [m] } \\
\hline & & 0.85 & 3.02 & 5.19 & 7.36 & 9.53 & 11.70 & 13.87 \\
\hline \multirow{2}{*}{1} & Mohr Coulomb & 41.13 & 64.37 & 70.11 & 64.00 & 53.68 & 40.32 & 21.85 \\
\hline & Hardening Soil & 52.73 & 79.63 & 89.63 & 87.72 & 77.20 & 58.55 & 29.72 \\
\hline FILA F1 & HSsmall & 65.36 & 81.38 & 79.17 & 68.97 & 55.67 & 39.07 & 17.91 \\
\hline $14 / 12 / 2016$ & Lecturas - "Strain" & $(*)$ & 65.26 & $(*)$ & 53.23 & $(*)$ & 31.35 & $(*)$ \\
\hline \multirow{3}{*}{$\begin{array}{l}\text { SÓTANO / } \\
\text { FILA / } \\
\text { FECHA } \\
\text { LECTURA }\end{array}$} & \multirow{3}{*}{$\begin{array}{l}\text { MODELO DE SUELO } \\
\text { / MONITORIZACIÓN }\end{array}$} & SG7 & SG6 & SG5 & SG4 & SG3 & SG2 & SG1 \\
\hline & & \multicolumn{7}{|c|}{ Distancia en longitud de barra (desde pantalla) [m] } \\
\hline & & 0.85 & 3.02 & 5.19 & 7.36 & 9.53 & 11.70 & 13.87 \\
\hline \multirow{2}{*}{2} & Mohr Coulomb & 45.49 & 57.24 & 51.74 & 48.48 & 42.71 & 36.67 & 18.11 \\
\hline & Hardening Soil & 95.63 & 126.07 & 101.90 & 93.43 & 84.62 & 73.09 & 31.49 \\
\hline FILA F2 & HSsmall & 81.45 & 104.12 & 78.53 & 66.03 & 55.51 & 46.53 & 17.71 \\
\hline $14 / 12 / 2016$ & Lecturas - "Strain" & $(*)$ & 132.57 & $(*)$ & 60.15 & 48.36 & $(*)$ & 26.56 \\
\hline \multirow{3}{*}{$\begin{array}{l}\text { SÓTANO / } \\
\text { FILA / } \\
\text { FECHA } \\
\text { LECTURA }\end{array}$} & \multirow{3}{*}{$\begin{array}{l}\text { MODELO DE SUELO } \\
\text { / MONITORIZACIÓN }\end{array}$} & SG6 & SG5 & SG4 & SG3 & SG2 & SG1 & \\
\hline & & \multicolumn{6}{|c|}{ Distancia en longitud de barra (desde pantalla) [m] } & \\
\hline & & 0.85 & 2.85 & 4.85 & 6.85 & 8.85 & 10.85 & \\
\hline \multirow{2}{*}{3} & Mohr Coulomb & 47.12 & 79.21 & 72.61 & 52.94 & 34.88 & 17.52 & \\
\hline & Hardening Soil & 82.56 & 137.26 & 115.42 & 80.57 & 53.00 & 25.65 & \\
\hline FILA F3 & HSsmall & 71.92 & 102.16 & 80.19 & 50.14 & 31.30 & 14.52 & \\
\hline $14 / 12 / 2016$ & Lecturas - "Strain" & 36.88 & 78.24 & 86.21 & $(*)$ & $(*)$ & 73.91 & \\
\hline \multirow{3}{*}{$\begin{array}{l}\text { SÓTANO / } \\
\text { FILA / } \\
\text { FECHA } \\
\text { LECTURA }\end{array}$} & \multirow{3}{*}{$\begin{array}{l}\text { MODELO DE SUELO } \\
\text { / MONITORIZACIÓN }\end{array}$} & SG6 & SG5 & SG4 & SG3 & SG2 & SG1 & \\
\hline & & \multicolumn{6}{|c|}{ Distancia en longitud de barra (desde pantalla) [m] } & \\
\hline & & 0.85 & 2.85 & 4.85 & 6.85 & 8.85 & 10.85 & \\
\hline \multirow{2}{*}{4} & Mohr Coulomb & 10.91 & 11.26 & 0.00 & 0.00 & 0.00 & 0.00 & \\
\hline & Hardening Soil & 32.74 & 34.45 & 3.32 & 0.00 & 0.00 & 0.00 & \\
\hline FILA F4 & HSsmall & 25.38 & 24.46 & 3.76 & 0.00 & 0.00 & 0.00 & \\
\hline $14 / 12 / 2016$ & Lecturas - "Strain" & 8.01 & 12.95 & 12.03 & 1.84 & $(*)$ & $(*)$ & \\
\hline
\end{tabular}

(*) "Strain Gauge" que no registró información. 
Excavación 5 - construcción de sótano 5

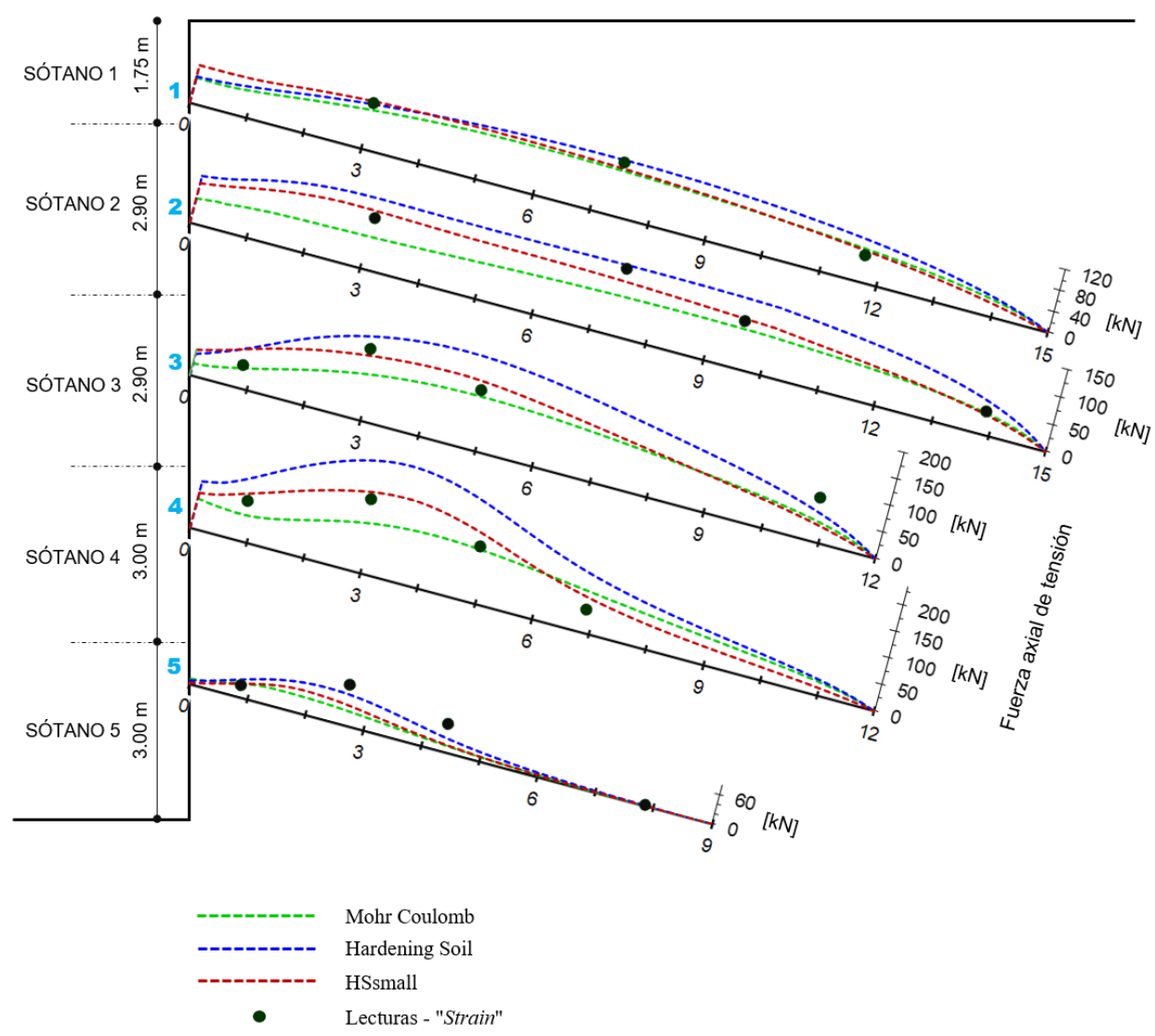

Fig. 6.6 Fuerzas axiales de tensión inducidas por construcción de sótano 5 de Torre Centre determinadas de lecturas en "Strain Gauges". Comparación con resultados de los modelos numéricos.

La Tabla 6.5 presenta las fuerzas axiales de tensión para los "Soil Nails" del diagrama de la Fig. 6.6, inducidas por la construcción del sótano 5, obtenidas por el análisis numérico mediante elementos finitos con Plaxis 2D y por las lecturas de "Strain" registradas de las galgas extensométricas durante la fase de monitorización del estudio experimental. En el "Soil Nail" de la fila F5 correspondiente al sótano 5 se instalaron 5 galgas extensométricas (SG), de las cuales una no registró información.

En esta estructura en total se instalaron 31 galgas extensométricas, de ellas 12 fueron identificadas con fallas, de las cuales algunas no reportaron datos desde el inicio, otras en cambio reportaron datos fuera de contexto, por lo que dichos resultados no fueron incluidos. En virtud de lo mencionado, en este proyecto se tuvo una "mortalidad" del $39 \%$ en lo que respecta al funcionamiento de "Strain Gauges". 
Tabla 6.5 Fuerzas axiales de tensión en "Soil Nails" por construcción de sótano 5 de Torre Centre.

\begin{tabular}{|c|c|c|c|c|c|c|c|c|}
\hline \multirow{4}{*}{$\begin{array}{c}\text { No. } \\
\text { SÓTANO / } \\
\text { FILA / } \\
\text { FECHA } \\
\text { LECTURA }\end{array}$} & \multirow{4}{*}{$\begin{array}{c}\text { MÉTODO } \\
\text { MODELO DE SUELO } \\
\text { / MONITORIZACIÓN }\end{array}$} & \multicolumn{7}{|c|}{ FUERZAS DE TENSIÓN EN UBIC. DE “STRAIN GAUGES” [kN] } \\
\hline & & SG7 & SG6 & SG5 & SG4 & SG3 & SG2 & SG1 \\
\hline & & \multicolumn{7}{|c|}{ Distancia en longitud de barra (desde pantalla) [m] } \\
\hline & & 0.85 & 3.02 & 5.19 & 7.36 & 9.53 & 11.70 & 13.87 \\
\hline \multirow{2}{*}{1} & Mohr Coulomb & 48.97 & 74.01 & 85.86 & 84.76 & 76.59 & 61.50 & 35.17 \\
\hline & Hardening Soil & 55.59 & 84.43 & 99.65 & 104.13 & 97.83 & 77.87 & 40.95 \\
\hline FILA F1 & HSsmall & 71.29 & 89.64 & 92.76 & 88.44 & 77.44 & 57.78 & 27.82 \\
\hline $18 / 01 / 2017$ & Lecturas - "Strain" & $(*)$ & 86.35 & $(*)$ & 99.87 & $(*)$ & 48.43 & $(*)$ \\
\hline $21 / 02 / 2017$ & Lecturas - "Strain" & $(*)$ & 91.48 & $(*)$ & 104.23 & $(*)$ & 54.25 & $(*)$ \\
\hline \multirow{3}{*}{$\begin{array}{l}\text { SÓTANO / } \\
\text { FILA / } \\
\text { FECHA } \\
\text { LECTURA }\end{array}$} & \multirow{3}{*}{$\begin{array}{l}\text { MODELO DE SUELO } \\
\text { / MONITORIZACIÓN }\end{array}$} & SG7 & SG6 & SG5 & SG4 & SG3 & SG2 & SG1 \\
\hline & & \multicolumn{7}{|c|}{ Distancia en longitud de barra (desde pantalla) [m] } \\
\hline & & 0.85 & 3.02 & 5.19 & 7.36 & 9.53 & 11.70 & 13.87 \\
\hline \multirow{2}{*}{2} & Mohr Coulomb & 50.99 & 57.24 & 64.40 & 70.14 & 70.45 & 61.49 & 37.66 \\
\hline & Hardening Soil & 101.65 & 126.07 & 124.63 & 126.06 & 124.37 & 105.56 & 58.40 \\
\hline FILA F2 & HSsmall & 86.38 & 104.12 & 100.14 & 97.55 & 88.88 & 68.84 & 35.07 \\
\hline $18 / 01 / 2017$ & Lecturas - "Strain" & $(*)$ & 90.98 & $(*)$ & 119.99 & 84.27 & $(*)$ & 39.67 \\
\hline $21 / 02 / 2017$ & Lecturas - "Strain" & $(*)$ & 95.68 & $(*)$ & 124.36 & 86.39 & $(*)$ & 44.37 \\
\hline \multirow{3}{*}{$\begin{array}{l}\text { SÓTANO / } \\
\text { FILA / } \\
\text { FECHA } \\
\text { LECTURA }\end{array}$} & \multirow{3}{*}{$\begin{array}{l}\text { MODELO DE SUELO } \\
\text { / MONITORIZACIÓN }\end{array}$} & SG6 & SG5 & SG4 & SG3 & SG2 & SG1 & \\
\hline & & \multicolumn{6}{|c|}{ Distancia en longitud de barra (desde pantalla) [m] } & \\
\hline & & 0.85 & 2.85 & 4.85 & 6.85 & 8.85 & 10.85 & \\
\hline \multirow{2}{*}{3} & Mohr Coulomb & 37.13 & 83.90 & 98.27 & 88.88 & 69.32 & 39.58 & \\
\hline & Hardening Soil & 75.40 & 155.44 & 171.23 & 146.09 & 107.47 & 56.66 & \\
\hline FILA F3 & HSsmall & 73.71 & 119.55 & 127.53 & 101.91 & 69.98 & 34.22 & \\
\hline $18 / 01 / 2017$ & Lecturas - "Strain" & 41.22 & 129.45 & 109.54 & $(*)$ & $(*)$ & 78.77 & \\
\hline $21 / 02 / 2017$ & Lecturas - "Strain" & 46.78 & 134.58 & 113.47 & $(*)$ & $(*)$ & 81.45 & \\
\hline \multirow{3}{*}{$\begin{array}{l}\text { SÓTANO / } \\
\text { FILA / } \\
\text { FECHA } \\
\text { LECTURA }\end{array}$} & \multirow{3}{*}{$\begin{array}{l}\text { MODELO DE SUELO } \\
\text { / MONITORIZACIÓN }\end{array}$} & SG6 & SG5 & SG4 & SG3 & SG2 & SG1 & \\
\hline & & \multicolumn{6}{|c|}{ Distancia en longitud de barra (desde pantalla) [m] } & \\
\hline & & 0.85 & 2.85 & 4.85 & 6.85 & 8.85 & 10.85 & \\
\hline \multirow[t]{2}{*}{4} & Mohr Coulomb & 48.24 & 91.18 & 98.00 & 75.86 & 51.20 & 27.58 & \\
\hline & Hardening Soil & 117.72 & 208.43 & 180.12 & 107.07 & 63.72 & 32.40 & \\
\hline FILA F4 & HSsmall & 87.49 & 148.64 & 126.53 & 65.25 & 34.02 & 16.19 & \\
\hline $18 / 01 / 2017$ & Lecturas - "Strain" & 72.59 & 135.25 & 102.56 & 42.43 & $(*)$ & $(*)$ & \\
\hline $21 / 02 / 2017$ & Lecturas - "Strain" & 76.89 & 139.56 & 105.67 & 43.39 & $(*)$ & $(*)$ & \\
\hline \multirow{3}{*}{$\begin{array}{l}\text { SÓTANO / } \\
\text { FILA / } \\
\text { FECHA } \\
\text { LECTURA }\end{array}$} & \multirow{3}{*}{$\begin{array}{l}\text { MODELO DE SUELO } \\
\text { / MONITORIZACIÓN }\end{array}$} & SG5 & SG4 & SG3 & SG2 & SG1 & & \\
\hline & & \multicolumn{5}{|c|}{ Distancia en longitud de barra (desde pantalla) [m] } & & \\
\hline & & 0.85 & 2.60 & 4.35 & 6.10 & 7.85 & & \\
\hline \multirow[t]{2}{*}{5} & Mohr Coulomb & 27.70 & 29.07 & 12.94 & 3.10 & 0.00 & & \\
\hline & Hardening Soil & 38.16 & 62.40 & 28.31 & 8.67 & 1.27 & & \\
\hline FILA F5 & HSsmall & 29.31 & 41.86 & 15.51 & 4.32 & 0.52 & & \\
\hline 18/01/2017 & Lecturas - "Strain" & 23.62 & 79.33 & 54.25 & $(*)$ & 1.64 & & \\
\hline $21 / 02 / 2017$ & Lecturas - "Strain" & 28.79 & 84.38 & 56.39 & (*) & 3.57 & & \\
\hline
\end{tabular}

(*) "Strain Gauge" que no registró información.

Al final de la construcción del sótano 5, se realizó una campaña de monitorización en una fecha posterior, en donde se distinguen incrementos en las fuerzas de tensión. Por tanto, las tensiones desarrolladas en los "Soil Nails" son una función del tiempo. 


\subsubsection{Fuerza axial en barras de acero de "Soil Nails" de Zaigen}

En la Fig. 6.7 se indica la ubicación de las galgas extensométricas o "Strain Gauges" (SG) instalados en la longitud de las barras de acero de los "Soil Nails" del proyecto Zaigen. En esta figura se muestra la instrumentación completa para los 5 niveles de sótano, los cuales fueron construidos de manera secuencial por niveles desde arriba hacia abajo. Por tanto en los puntos de medición y control indicados en este esquema de instrumentación se llevaron a cabo las mediciones periódicas del estudio experimental.

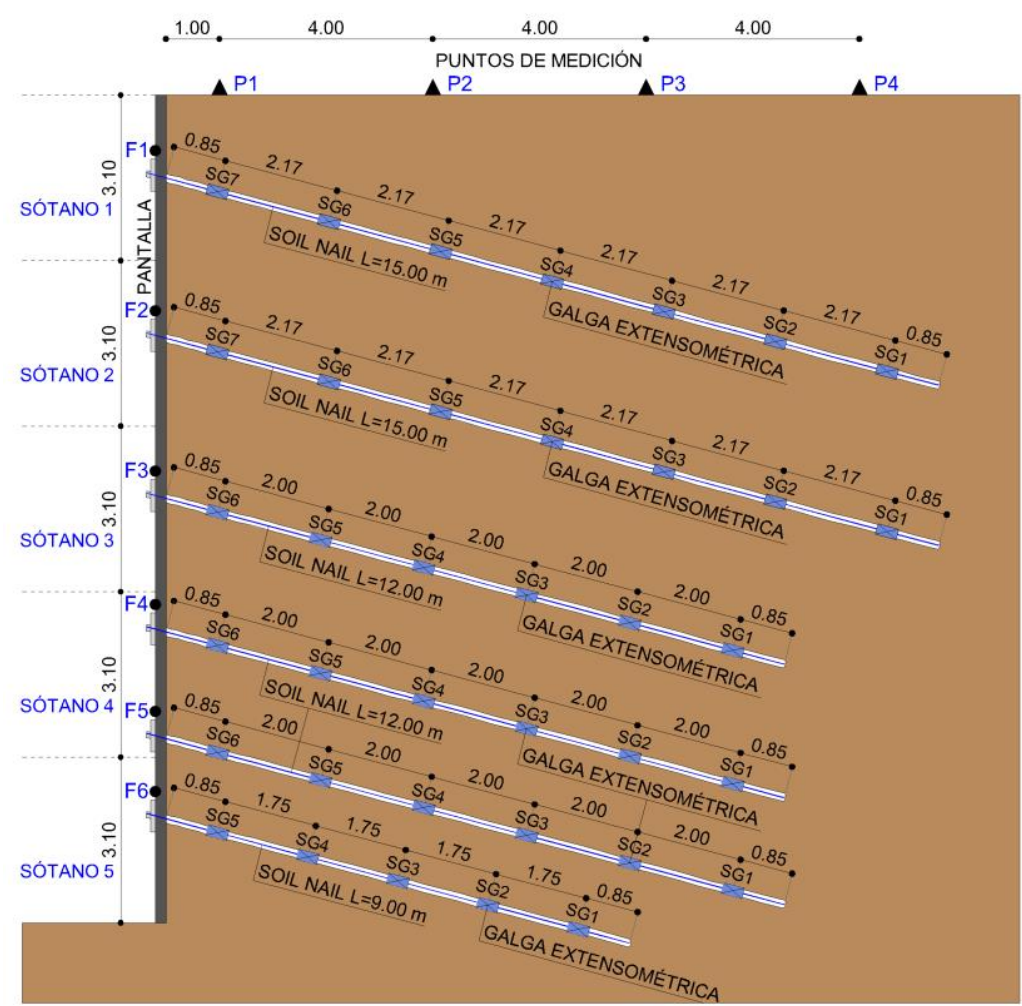

Fig. 6.7 Instrumentación completa de estructura de "Soil Nailing" de Zaigen.

Las Fig. 6.8 a 6.12 muestran la evolución de las fuerzas axiales de tensión en los "Soil Nails" del proyecto Zaigen, generadas por la construcción de cada nivel de sótano, deducidas de las lecturas de "Strain" en las galgas extensométricas durante el proceso de monitorización. Para efectos de comparación, se han graficado simultáneamente con los diagramas del enfoque numérico con elementos finitos y los modelos constitutivos de suelo de Mohr Coulomb, Hardening Soil y HSsmall, analizados con Plaxis 2D. 


\section{Excavación 1 - construcción de sótano 1}

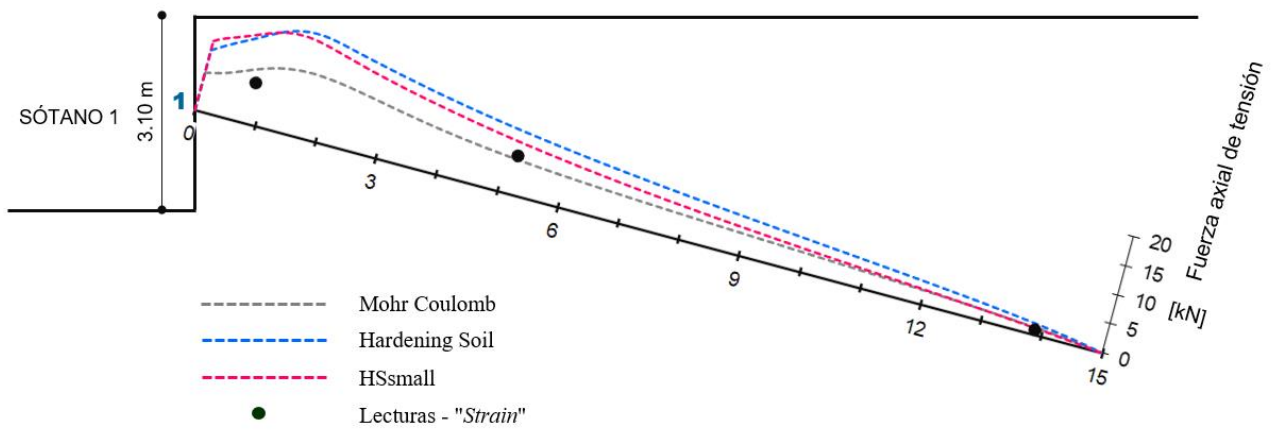

Fig. 6.8 Fuerzas axiales de tensión inducidas por construcción de sótano 1 de Zaigen determinadas de lecturas en "Strain Gauges". Comparación con resultados de los modelos numéricos.

La Tabla 6.6 presenta los valores de fuerzas axiales de tensión para los "Soil Nails" del diagrama de la Fig. 6.8, generados por la excavación y construcción del sótano 1 , determinados por el análisis numérico mediante elementos finitos con Plaxis 2D y la aplicación de cada uno de los modelos constitutivos de suelo considerados en este estudio.

En la última fila de la Tabla 6.6 se resumen las fuerzas axiales de tensión deducidas de las lecturas de "Strain" en las galgas extensométricas durante las tareas de monitorización del estudio experimental.

Tabla 6.6 Fuerzas axiales de tensión en "Soil Nails" por construcción de sótano 1 de Zaigen.

\begin{tabular}{|c|c|c|c|c|c|c|c|c|}
\hline \multirow{4}{*}{$\begin{array}{c}\text { No. } \\
\text { SÓTANO / } \\
\text { FILA / } \\
\text { FECHA } \\
\text { LECTURA }\end{array}$} & \multirow{4}{*}{$\begin{array}{c}\text { MÉTODO } \\
\text { MODELO DE SUELO } \\
\text { / MONITORIZACIÓN }\end{array}$} & \multicolumn{7}{|c|}{ FUERZAS DE TENSIÓN EN UBIC. DE “STRAIN GAUGES” [kN] } \\
\hline & & SG7 & SG6 & SG5 & SG4 & SG3 & SG2 & SG1 \\
\hline & & \multicolumn{7}{|c|}{ Distancia en longitud de barra (desde pantalla) [m] } \\
\hline & & 0.85 & 3.02 & 5.19 & 7.36 & 9.53 & 11.70 & 13.87 \\
\hline \multirow{2}{*}{1} & Mohr Coulomb & 9.26 & 8.84 & 5.87 & 4.48 & 3.54 & 2.55 & 1.31 \\
\hline & Hardening Soil & 14.99 & 14.40 & 10.60 & 8.01 & 6.02 & 4.10 & 1.95 \\
\hline FILA F1 & HSsmall & 15.49 & 12.78 & 8.80 & 6.18 & 4.34 & 2.77 & 1.21 \\
\hline $23 / 03 / 2017$ & Lecturas - "Strain" & 6.92 & $(*)$ & 6.31 & $(*)$ & (*) & $(*)$ & 0.83 \\
\hline
\end{tabular}

(*) "Strain Gauge" que no registró información.

Por temas de comparación, las abscisas de los valores de fuerzas de tensión reportados del análisis numérico coinciden con las abscisas de posición de las galgas extensométricas del estudio experimental.

En el "Soil Nail" de la fila F1 correspondiente al sótano 1 se instalaron 7 galgas extensométricas. Estos sensores se distribuyeron en la longitud de la barra de acero según se muestra en la Fig. 6.7. Sin embargo, 4 "Strain Gauges" presentaron daños y no registraron información, según se puede observar en la Tabla 6.6. 
Excavación 2 - construcción de sótano 2

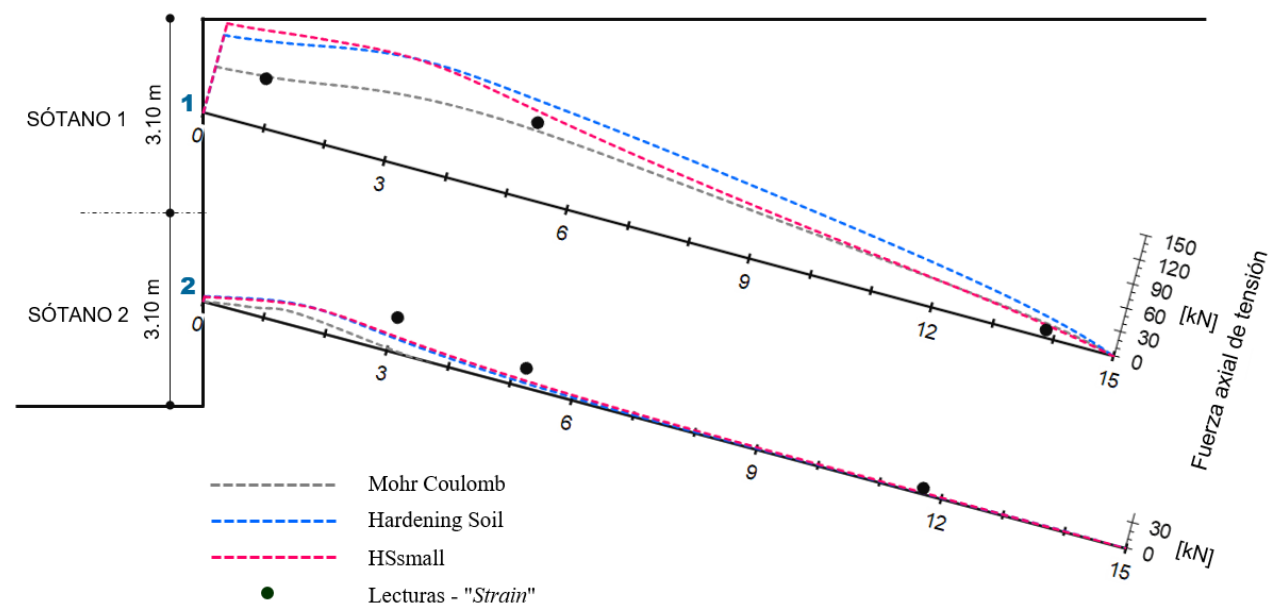

Fig. 6.9 Fuerzas axiales de tensión inducidas por construcción de sótano 2 de Zaigen determinadas de lecturas en "Strain Gauges". Comparación con resultados de los modelos numéricos.

La Tabla 6.7 resume los valores de fuerzas axiales de tensión para los "Soil Nails" del diagrama de la Fig. 6.9, inducidos por la construcción del sótano 2, obtenidos por el análisis numérico mediante elementos finitos con Plaxis 2D y por las lecturas de "Strain" registradas de las galgas extensométricas durante la fase de monitorización del estudio experimental. En el "Soil Nail" de la fila F2 correspondiente al sótano 2 se instalaron 7 galgas extensométricas (SG), de las cuales 3 no registraron información.

Tabla 6.7 Fuerzas axiales de tensión en "Soil Nails" por construcción de sótano 2 de Zaigen.

\begin{tabular}{|c|c|c|c|c|c|c|c|c|}
\hline \multirow{4}{*}{$\begin{array}{c}\text { No. } \\
\text { SÓTANO / } \\
\text { FILA / } \\
\text { FECHA } \\
\text { LECTURA }\end{array}$} & \multirow{4}{*}{$\begin{array}{c}\text { MÉTODO } \\
\text { MODELO DE SUELO } \\
\text { / MONITORIZACIÓN }\end{array}$} & \multicolumn{7}{|c|}{ FUERZAS DE TENSIÓN EN UBIC. DE “STRAIN GAUGES” [kN] } \\
\hline & & SG7 & SG6 & SG5 & SG4 & SG3 & SG2 & SG1 \\
\hline & & \multicolumn{7}{|c|}{ Distancia en longitud de barra (desde pantalla) [m] } \\
\hline & & 0.85 & 3.02 & 5.19 & 7.36 & 9.53 & 11.70 & 13.87 \\
\hline \multirow{2}{*}{1} & Mohr Coulomb & 60.86 & 82.29 & 81.51 & 67.28 & 51.44 & 35.34 & 17.56 \\
\hline & Hardening Soil & 104.59 & 128.80 & 117.81 & 99.54 & 78.57 & 54.58 & 26.14 \\
\hline FILA F1 & HSsmall & 115.87 & 127.44 & 104.07 & 78.23 & 56.51 & 36.23 & 15.74 \\
\hline 08/04/2017 & Lecturas - "Strain" & 57.02 & $(*)$ & 90.28 & $(*)$ & $(*)$ & (*) & 8.96 \\
\hline \multirow{3}{*}{$\begin{array}{l}\text { SÓTANO / } \\
\text { FILA / } \\
\text { FECHA } \\
\text { LECTURA }\end{array}$} & \multirow{3}{*}{$\begin{array}{l}\text { MODELO DE SUELO } \\
\text { / MONITORIZACIÓN }\end{array}$} & SG7 & SG6 & SG5 & SG4 & SG3 & SG2 & SG1 \\
\hline & & \multicolumn{7}{|c|}{ Distancia en longitud de barra (desde pantalla) [m] } \\
\hline & & 0.85 & 3.02 & 5.19 & 7.36 & 9.53 & 11.70 & 13.87 \\
\hline \multirow{2}{*}{2} & Mohr Coulomb & 9.44 & 2.79 & 0.00 & 0.00 & 0.00 & 0.00 & 0.00 \\
\hline & Hardening Soil & 19.05 & 15.76 & 4.82 & 1.67 & 1.35 & 1.44 & 0.82 \\
\hline FILA F2 & HSsmall & 17.65 & 17.77 & 7.48 & 3.55 & 2.22 & 1.68 & 0.77 \\
\hline 08/04/2017 & Lecturas - "Strain" & $(*)$ & 37.99 & 19.63 & $(*)$ & $(*)$ & 4.67 & $(*)$ \\
\hline
\end{tabular}

(*) "Strain Gauge" que no registró información. 
Excavación 3 - construcción de sótano 3

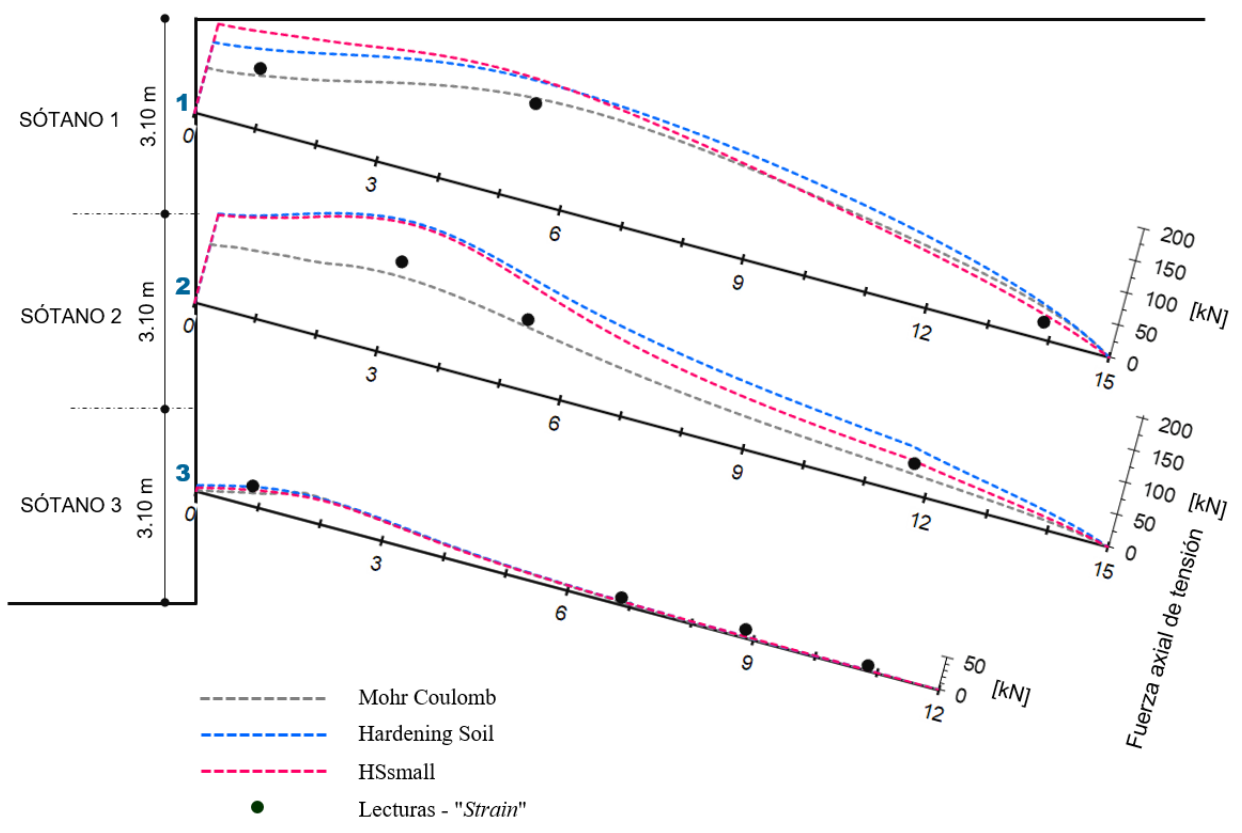

Fig. 6.10 Fuerzas axiales de tensión inducidas por construcción de sótano 3 de Zaigen determinadas de lecturas en "Strain Gauges". Comparación con resultados de los modelos numéricos.

En la Tabla 6.8 se presentan los valores de fuerzas axiales de tensión para todos los "Soil Nails" del diagrama de la Fig. 6.10, inducidos por la excavación y construcción del sótano 3, determinados por el enfoque numérico realizado mediante elementos finitos con los 3 modelos constitutivos de suelo considerados en este estudio y analizados con Plaxis 2D, y por las lecturas de "Strain" registradas de las galgas extensométricas durante la fase de monitorización del estudio experimental de este proyecto.

En el "Soil Nail" de la fila F3 correspondiente al sótano 3 se instalaron 6 "Strain Gauges". La posición y distribución de los sensores en la longitud de la barra de acero se detalla en la Fig. 6.7.

Por otra parte, del total de sensores instalados en la fila de anclaje F3 de este nivel de sótano, 2 "Strain Gauges" presentaron daños después de la construcción del "Soil Nail", por lo que no registraron ninguna información, según se puede observar en la tabla de reporte de resultados inferidos por la construcción de este nivel de sótano de Zaigen. 
Tabla 6.8 Fuerzas axiales de tensión en "Soil Nails" por construcción de sótano 3 de Zaigen.

\begin{tabular}{|c|c|c|c|c|c|c|c|c|}
\hline \multirow{4}{*}{$\begin{array}{c}\text { No. } \\
\text { SÓTANO / } \\
\text { FILA / } \\
\text { FECHA } \\
\text { LECTURA }\end{array}$} & \multirow{4}{*}{$\begin{array}{c}\text { MÉTODO } \\
\text { MODELO DE SUELO } \\
\text { / MONITORIZACIÓN }\end{array}$} & \multicolumn{7}{|c|}{ FUERZAS DE TENSIÓN EN UBIC. DE “STRAIN GAUGES” [kN] } \\
\hline & & SG7 & SG6 & SG5 & SG4 & SG3 & SG2 & SG1 \\
\hline & & \multicolumn{7}{|c|}{ Distancia en longitud de barra (desde pantalla) [m] } \\
\hline & & 0.85 & 3.02 & 5.19 & 7.36 & 9.53 & 11.70 & 13.87 \\
\hline \multirow{2}{*}{1} & Mohr Coulomb & 78.68 & 123.66 & 153.48 & 148.65 & 124.82 & 91.70 & 47.97 \\
\hline & Hardening Soil & 119.56 & 161.76 & 179.60 & 168.91 & 144.28 & 105.86 & 52.23 \\
\hline FILA F1 & HSsmall & 144.59 & 172.79 & 181.13 & 158.33 & 124.35 & 84.29 & 38.05 \\
\hline 22/04/2017 & Lecturas - "Strain" & 88.77 & $(*)$ & 143.59 & $(*)$ & $(*)$ & $(*)$ & 24.57 \\
\hline \multirow{3}{*}{$\begin{array}{l}\text { SÓTANO / } \\
\text { FILA / } \\
\text { FECHA } \\
\text { LECTURA }\end{array}$} & \multirow{3}{*}{$\begin{array}{l}\text { MODELO DE SUELO } \\
\text { / MONITORIZACIÓN }\end{array}$} & SG7 & SG6 & SG5 & SG4 & SG3 & SG2 & SG1 \\
\hline & & \multicolumn{7}{|c|}{ Distancia en longitud de barra (desde pantalla) [m] } \\
\hline & & 0.85 & 3.02 & 5.19 & 7.36 & 9.53 & 11.70 & 13.87 \\
\hline \multirow{2}{*}{2} & Mohr Coulomb & 99.97 & 117.64 & 93.52 & 63.90 & 44.10 & 30.59 & 14.85 \\
\hline & Hardening Soil & 159.23 & 202.31 & 163.27 & 119.78 & 90.99 & 68.72 & 28.94 \\
\hline FILA F2 & HSsmall & 154.57 & 197.41 & 151.97 & 99.24 & 68.47 & 49.51 & 19.99 \\
\hline 22/04/2017 & Lecturas - "Strain" & $(*)$ & 138.48 & 104.66 & $(*)$ & $(*)$ & 44.21 & $(*)$ \\
\hline \multirow{3}{*}{$\begin{array}{l}\text { SÓTANO / } \\
\text { FILA / } \\
\text { FECHA } \\
\text { LECTURA }\end{array}$} & \multirow{3}{*}{$\begin{array}{l}\text { MODELO DE SUELO } \\
\text { / MONITORIZACIÓN }\end{array}$} & SG6 & SG5 & SG4 & SG3 & SG2 & SG1 & \\
\hline & & \multicolumn{6}{|c|}{ Distancia en longitud de barra (desde pantalla) [m] } & \\
\hline & & 0.85 & 2.85 & 4.85 & 6.85 & 8.85 & 10.85 & \\
\hline \multirow{2}{*}{3} & Mohr Coulomb & 18.20 & 29.45 & 12.61 & 3.51 & 0.00 & 0.00 & \\
\hline & Hardening Soil & 27.22 & 30.95 & 13.55 & 5.64 & 2.39 & 0.86 & \\
\hline FILA F3 & HSsmall & 23.18 & 29.47 & 12.78 & 5.60 & 2.67 & 1.08 & \\
\hline $22 / 04 / 2017$ & Lecturas - "Strain" & 28.32 & $(*)$ & $(*)$ & 10.62 & 12.95 & 5.78 & \\
\hline
\end{tabular}

(*) "Strain Gauge" que no registró información.

Por su parte, en la última fila de cada sección de resultados por nivel de sótano de la Tabla 6.8 se presentan las fuerzas axiales de tensión deducidas de las lecturas de "Strain" en las galgas extensométricas durante el proceso de monitorización del estudio experimental de este proyecto.

Es claro que cada excavación para la construcción de un nuevo nivel de sótano genera nuevos valores de fuerzas de tensión en cada fila de "Soil Nails" de los niveles de sótano superiores construidos en las fases previas.

Durante las tareas periódicas de monitorización, el hecho de registrar los valores de "Strain" de todas las filas de "Soil Nails" correspondientes a todos los niveles de sótano ya construidos permite estudiar el comportamiento y evolución de las fuerzas axiales de tensión a través de cada fase constructiva de nivel de sótano. Es muy notorio que los valores de fuerzas axiales de tensión en los "Soil Nails" presentan un incremento con respecto a la fase anterior conforme avanzan las etapas constructivas del proyecto. 


\section{Excavación 4 - construcción de sótano 4}

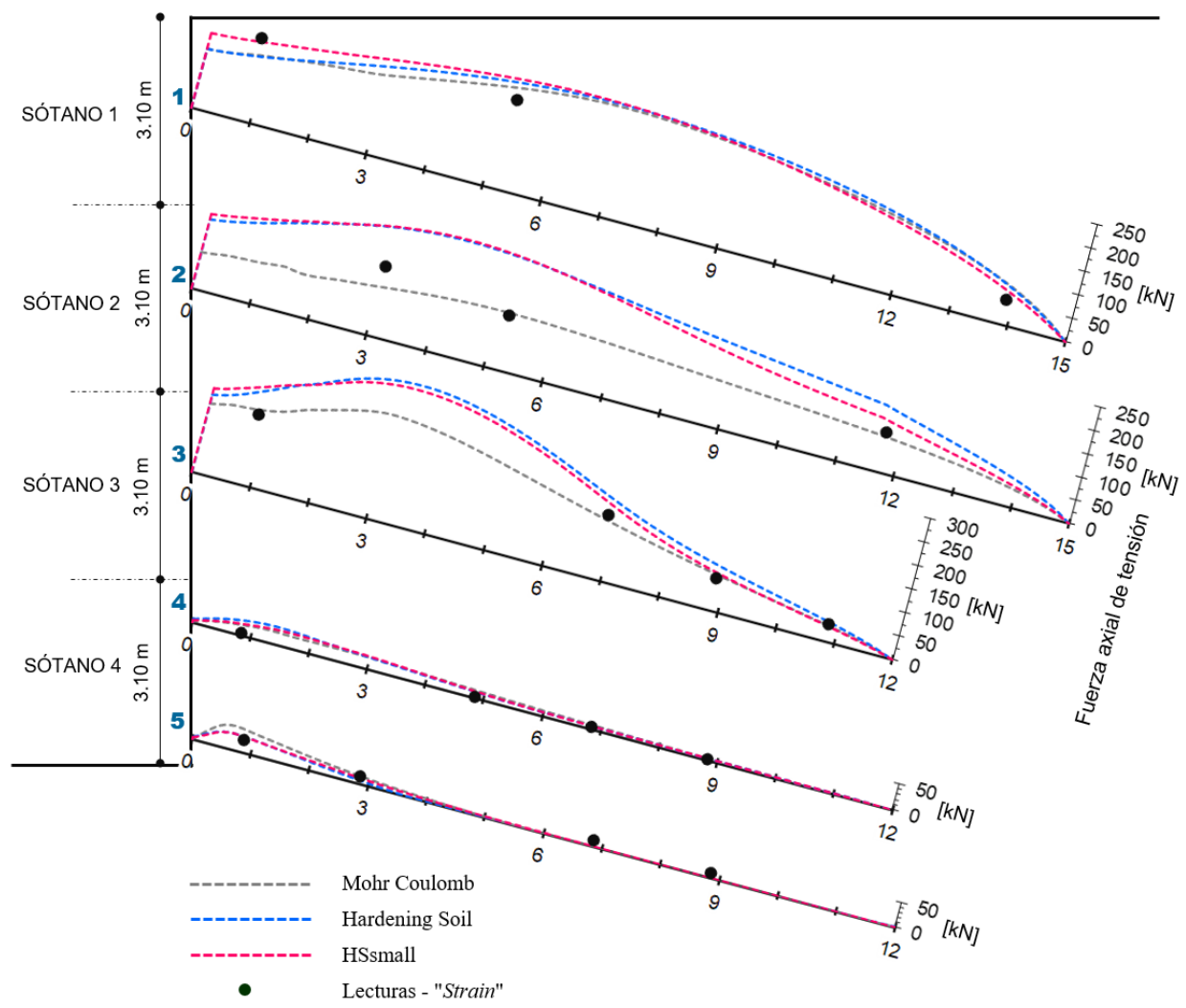

Fig. 6.11 Fuerzas axiales de tensión inducidas por construcción de sótano 4 de Zaigen determinadas de lecturas en "Strain Gauges". Comparación con resultados de los modelos numéricos.

Los valores de fuerzas axiales de tensión para todos los "Soil Nails" del diagrama de la Fig. 6.11, generados por la excavación y construcción del sótano 4, se resumen en la Tabla 6.9. Estos valores de tensiones fueron obtenidos por el análisis numérico mediante elementos finitos con los 3 modelos constitutivos de suelo considerados en esta investigación e incluidos en el análisis con Plaxis 2D y por las lecturas de "Strain" registradas de las galgas extensométricas durante las tareas de monitorización.

En los "Soil Nails" de las filas F4 y F5 correspondientes al sótano 4 se instalaron 6 "Strain Gauges" en cada fila, su posición y distribución en las longitudes de las barras de acero se detalla en la Fig. 6.7.

Del total de "Strain Gauges" instalados, 2 sensores presentaron daños en cada fila. Estas fallas fueron evidentes después de la construcción de los anclajes, por lo que 
no emitieron ninguna información, según se puede observar en la tabla de reporte resultados inferidos por la construcción de este nivel de sótano.

En la última fila de cada sección de resultados por nivel de sótano expuestos en la Tabla 6.9 se muestran las fuerzas axiales de tensión deducidas de las lecturas de "Strain" en las galgas extensométricas de cada fila de anclajes durante el proceso de monitorización del estudio experimental de este proyecto.

Tabla 6.9 Fuerzas axiales de tensión en "Soil Nails" por construcción de sótano 4 de Zaigen.

\begin{tabular}{|c|c|c|c|c|c|c|c|c|}
\hline \multirow{4}{*}{$\begin{array}{c}\text { No. } \\
\text { SÓTANO / } \\
\text { FILA / } \\
\text { FECHA } \\
\text { LECTURA }\end{array}$} & \multirow{4}{*}{$\begin{array}{c}\text { MÉTODO } \\
\text { MODELO DE SUELO } \\
\text { / MONITORIZACIÓN }\end{array}$} & \multicolumn{7}{|c|}{ FUERZAS DE TENSIÓN EN UBIC. DE “STRAIN GAUGES” [kN] } \\
\hline & & SG7 & SG6 & SG5 & SG4 & SG3 & SG2 & SG1 \\
\hline & & \multicolumn{7}{|c|}{ Distancia en longitud de barra (desde pantalla) [m] } \\
\hline & & 0.85 & 3.02 & 5.19 & 7.36 & 9.53 & 11.70 & 13.87 \\
\hline \multirow{2}{*}{1} & Mohr Coulomb & 139.92 & 170.25 & 214.86 & 230.33 & 208.24 & 160.96 & 86.75 \\
\hline & Hardening Soil & 136.26 & 187.09 & 223.99 & 233.66 & 214.18 & 166.21 & 84.65 \\
\hline FILA F1 & HSsmall & 167.59 & 202.84 & 232.11 & 235.47 & 208.06 & 153.20 & 74.04 \\
\hline $13 / 05 / 2017$ & Lecturas - "Strain" & 174.32 & $(*)$ & 185.56 & $(*)$ & $(*)$ & $(*)$ & 51.47 \\
\hline \multirow{3}{*}{$\begin{array}{l}\text { SÓTANO / } \\
\text { FILA / } \\
\text { FECHA } \\
\text { LECTURA }\end{array}$} & \multirow{3}{*}{$\begin{array}{l}\text { MODELO DE SUELO } \\
\text { / MONITORIZACIÓN }\end{array}$} & SG7 & SG6 & SG5 & SG4 & SG3 & SG2 & SG1 \\
\hline & & \multicolumn{7}{|c|}{ Distancia en longitud de barra (desde pantalla) [m] } \\
\hline & & 0.85 & 3.02 & 5.19 & 7.36 & 9.53 & 11.70 & 13.87 \\
\hline \multirow{2}{*}{2} & Mohr Coulomb & 88.32 & 105.00 & 122.06 & 111.09 & 94.33 & 76.05 & 41.01 \\
\hline & Hardening Soil & 170.29 & 232.17 & 237.93 & 204.64 & 170.14 & 136.15 & 62.83 \\
\hline FILA F2 & HSsmall & 177.81 & 232.21 & 237.93 & 194.40 & 145.03 & 108.91 & 48.06 \\
\hline $13 / 05 / 2017$ & Lecturas - "Strain" & $(*)$ & 146.26 & 115.87 & $(*)$ & $(*)$ & 82.16 & $(*)$ \\
\hline \multirow{3}{*}{$\begin{array}{l}\text { SÓTANO / } \\
\text { FILA / } \\
\text { FECHA } \\
\text { LECTURA }\end{array}$} & \multirow{3}{*}{$\begin{array}{l}\text { MODELO DE SUELO } \\
\text { / MONITORIZACIÓN }\end{array}$} & SG6 & SG5 & SG4 & SG3 & SG2 & SG1 & \\
\hline & & \multicolumn{6}{|c|}{ Distancia en longitud de barra (desde pantalla) [m] } & \\
\hline & & 0.85 & 2.85 & 4.85 & 6.85 & 8.85 & 10.85 & \\
\hline \multirow{2}{*}{3} & Mohr Coulomb & 158.81 & 218.57 & 184.43 & 125.42 & 75.73 & 33.57 & \\
\hline & Hardening Soil & 200.71 & 290.93 & 264.85 & 173.44 & 95.34 & 41.77 & \\
\hline FILA F3 & HSsmall & 208.28 & 280.09 & 252.70 & 160.56 & 79.82 & 32.50 & \\
\hline $13 / 05 / 2017$ & Lecturas - "Strain" & 146.37 & $(*)$ & $(*)$ & 135.28 & 66.00 & 34.56 & \\
\hline \multirow{3}{*}{$\begin{array}{l}\text { SÓTANO / } \\
\text { FILA / } \\
\text { FECHA } \\
\text { LECTURA }\end{array}$} & \multirow{3}{*}{$\begin{array}{l}\text { MODELO DE SUELO } \\
\text { / MONITORIZACIÓN }\end{array}$} & SG6 & SG5 & SG4 & SG3 & SG2 & SG1 & \\
\hline & & \multicolumn{6}{|c|}{ Distancia en longitud de barra (desde pantalla) [m] } & \\
\hline & & 0.85 & 2.85 & 4.85 & 6.85 & 8.85 & 10.85 & \\
\hline \multirow{2}{*}{4} & Mohr Coulomb & 19.24 & 22.01 & 14.50 & 8.18 & 4.08 & 1.51 & \\
\hline & Hardening Soil & 27.94 & 22.99 & 11.45 & 6.08 & 3.73 & 1.89 & \\
\hline FILA F4 & HSsmall & 21.74 & 24.79 & 12.35 & 6.19 & 3.85 & 1.92 & \\
\hline $13 / 05 / 2017$ & Lecturas - "Strain" & 2.31 & $(*)$ & 1.70 & 2.76 & 1.67 & $(*)$ & \\
\hline \multirow{2}{*}{4} & Mohr Coulomb & 42.89 & 13.46 & 1.01 & 0.00 & 0.00 & 0.00 & \\
\hline & Hardening Soil & 29.32 & 5.20 & 0.00 & 0.00 & 0.00 & 0.00 & \\
\hline FILA F5 & HSsmall & 30.21 & 10.71 & 2.20 & 0.18 & 0.00 & 0.00 & \\
\hline $13 / 05 / 2017$ & Lecturas - "Strain" & 23.78 & 12.42 & $(*)$ & 9.47 & 8.67 & $(*)$ & \\
\hline
\end{tabular}

(*) "Strain Gauge" que no registró información. 
Excavación 5 - construcción de sótano 5

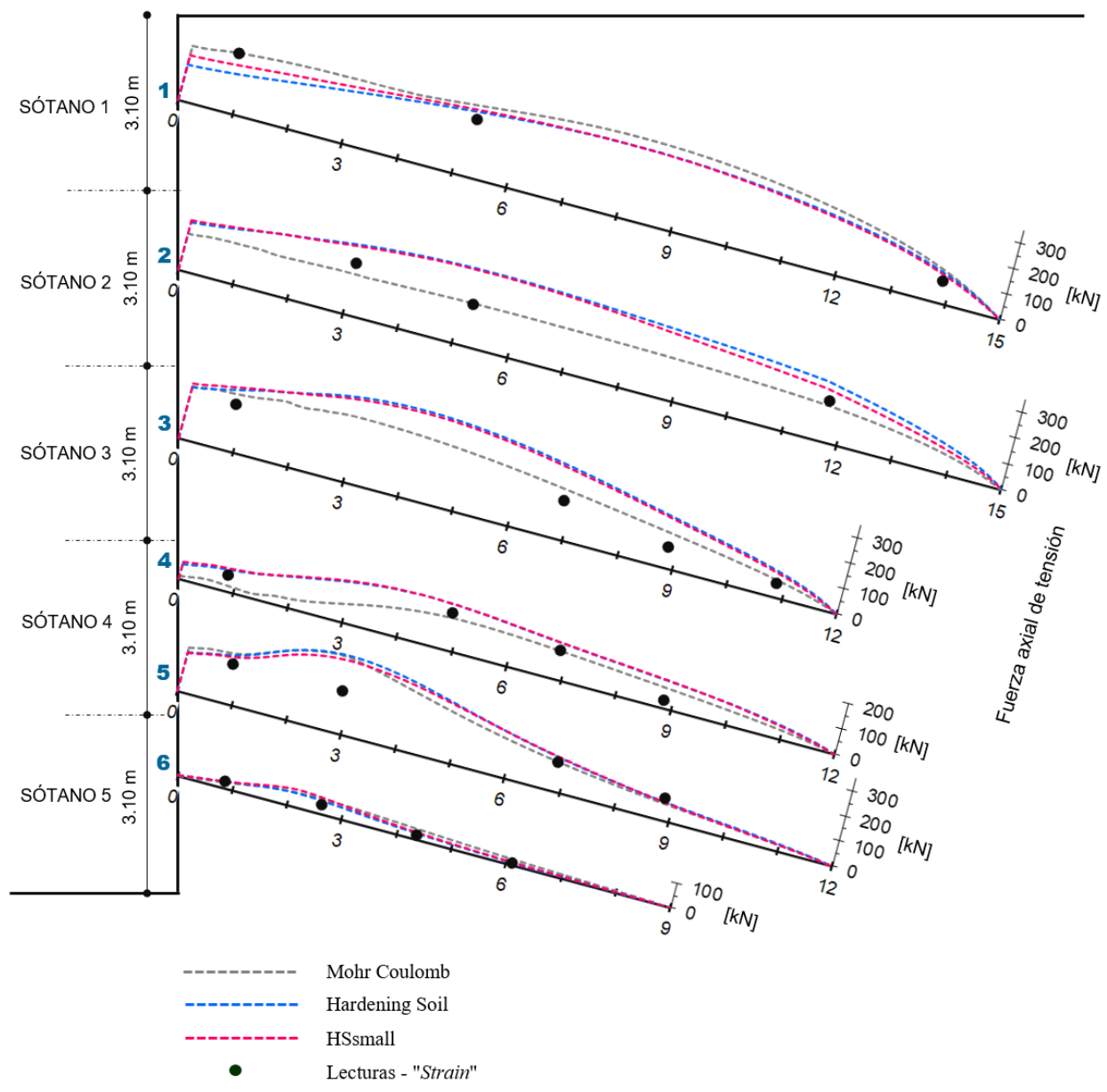

Fig. 6.12 Fuerzas axiales de tensión inducidas por construcción de sótano 5 de Zaigen determinadas de lecturas en "Strain Gauges". Comparación con resultados de los modelos numéricos.

Las fuerzas axiales de tensión para todos los "Soil Nails" del diagrama de la Fig. 6.12 , inducidas por la excavación y construcción del sótano 5, se muestran en la Tabla 6.10. Estas fuerzas axiales de tensión fueron obtenidas por el análisis numérico mediante elementos finitos con los 3 modelos constitutivos de suelo con Plaxis 2D y por las lecturas de "Strain" registradas de los "Strain Gauges" durante los trabajos de monitorización.

Para facilitar la comparación de datos, las abscisas de los valores de fuerzas de tensión reportados del análisis numérico coinciden con las abscisas de posición de las galgas extensométricas del estudio experimental. 
Tabla 6.10 Fuerzas axiales de tensión en "Soil Nails" por construcción de sótano 5 de Zaigen.

\begin{tabular}{|c|c|c|c|c|c|c|c|c|}
\hline \multirow{4}{*}{$\begin{array}{c}\text { No. } \\
\text { SÓTANO / } \\
\text { FILA / } \\
\text { FECHA } \\
\text { LECTURA }\end{array}$} & \multirow{4}{*}{$\begin{array}{c}\text { MÉTODO } \\
\text { MODELO DE SUELO } \\
\text { / MONITORIZACIÓN }\end{array}$} & \multicolumn{7}{|c|}{ FUERZAS DE TENSIÓN EN UBIC. DE “STRAIN GAUGES” [kN] } \\
\hline & & SG7 & SG6 & SG5 & SG4 & SG3 & SG2 & SG1 \\
\hline & & \multicolumn{7}{|c|}{ Distancia en longitud de barra (desde pantalla) [m] } \\
\hline & & 0.85 & 3.02 & 5.19 & 7.36 & 9.53 & 11.70 & 13.87 \\
\hline \multirow{2}{*}{1} & Mohr Coulomb & 230.71 & 251.02 & 275.14 & 312.09 & 304.08 & 245.73 & 129.96 \\
\hline & Hardening Soil & 151.51 & 205.72 & 251.64 & 278.14 & 270.42 & 220.99 & 120.66 \\
\hline FILA F1 & HSsmall & 183.95 & 220.82 & 256.23 & 276.38 & 265.81 & 212.52 & 112.36 \\
\hline 20/05/2017 & Lecturas - "Strain" & 228.96 & $(*)$ & 216.45 & $(*)$ & $(*)$ & $(*)$ & 82.45 \\
\hline 21/07/2017 & Lecturas - "Strain" & 233.11 & $(*)$ & 219.36 & $(*)$ & $(*)$ & $(*)$ & 85.23 \\
\hline \multirow{3}{*}{$\begin{array}{l}\text { SÓTANO / } \\
\text { FILA / } \\
\text { FECHA } \\
\text { LECTURA } \\
\end{array}$} & \multirow{3}{*}{$\begin{array}{l}\text { MODELO DE SUELO } \\
\text { / MONITORIZACIÓN }\end{array}$} & SG7 & SG6 & SG5 & SG4 & SG3 & SG2 & SG1 \\
\hline & & \multicolumn{7}{|c|}{ Distancia en longitud de barra (desde pantalla) [m] } \\
\hline & & 0.85 & 3.02 & 5.19 & 7.36 & 9.53 & 11.70 & 13.87 \\
\hline \multirow[t]{2}{*}{2} & Mohr Coulomb & 151.69 & 155.01 & 163.99 & 163.63 & 156.89 & 137.83 & 75.60 \\
\hline & Hardening Soil & 205.27 & 265.57 & 292.38 & 280.92 & 256.85 & 219.09 & 108.27 \\
\hline FILA F2 & HSsmall & 209.51 & 259.34 & 287.52 & 272.77 & 235.74 & 192.63 & 91.06 \\
\hline 20/05/2017 & Lecturas - "Strain" & $(*)$ & 192.45 & 156.30 & $(*)$ & $(*)$ & 153.56 & $(*)$ \\
\hline 21/07/2017 & Lecturas - "Strain" & $(*)$ & 196.12 & 159.27 & $(*)$ & $(*)$ & 156.12 & $(*)$ \\
\hline \multirow{3}{*}{$\begin{array}{l}\text { SÓTANO / } \\
\text { FILA / } \\
\text { FECHA } \\
\text { LECTURA } \\
\end{array}$} & \multirow{3}{*}{$\begin{array}{l}\text { MODELO DE SUELO } \\
\text { / MONITORIZACIÓN }\end{array}$} & SG6 & SG5 & SG4 & SG3 & SG2 & SG1 & \\
\hline & & \multicolumn{6}{|c|}{ Distancia en longitud de barra (desde pantalla) [m] } & \\
\hline & & 0.85 & 2.85 & 4.85 & 6.85 & 8.85 & 10.85 & \\
\hline \multirow[t]{2}{*}{3} & Mohr Coulomb & 217.24 & 249.69 & 235.00 & 190.82 & 133.50 & 66.58 & \\
\hline & Hardening Soil & 237.05 & 325.02 & 335.61 & 280.43 & 194.67 & 100.27 & \\
\hline FILA F3 & HSsmall & 245.34 & 315.93 & 326.68 & 270.96 & 187.68 & 93.01 & \\
\hline 20/05/2017 & Lecturas - "Strain" & 176.35 & $(*)$ & $(*)$ & 144.67 & 78.43 & 52.78 & \\
\hline 21/07/2017 & Lecturas - "Strain" & 180.15 & $(*)$ & $(*)$ & 147.18 & 82.51 & 56.12 & \\
\hline \multirow{3}{*}{$\begin{array}{l}\text { SÓTANO / } \\
\text { FILA / } \\
\text { FECHA } \\
\text { LECTURA } \\
\end{array}$} & \multirow{3}{*}{$\begin{array}{l}\text { MODELO DE SUELO } \\
\text { / MONITORIZACIÓN }\end{array}$} & SG6 & SG5 & SG4 & SG3 & SG2 & SG1 & \\
\hline & & \multicolumn{6}{|c|}{ Distancia en longitud de barra (desde pantalla) [m] } & \\
\hline & & 0.85 & 2.85 & 4.85 & 6.85 & 8.85 & 10.85 & \\
\hline \multirow[t]{2}{*}{4} & Mohr Coulomb & 24.09 & 68.40 & 125.94 & 112.00 & 78.68 & 40.58 & \\
\hline & Hardening Soil & 82.47 & 152.77 & 175.17 & 139.70 & 104.58 & 58.80 & \\
\hline FILA F4 & HSsmall & 89.01 & 159.13 & 177.91 & 143.53 & 107.95 & 56.32 & \\
\hline 20/05/2017 & Lecturas - "Strain" & 60.32 & $(*)$ & 141.37 & 111.45 & 26.87 & $(*)$ & \\
\hline 21/07/2017 & Lecturas - "Strain" & 64.28 & $(*)$ & 145.18 & 116.37 & 29.39 & $(*)$ & \\
\hline \multirow{2}{*}{4} & Mohr Coulomb & 196.12 & 293.95 & 195.44 & 116.64 & 64.82 & 28.96 & \\
\hline & Hardening Soil & 189.34 & 301.96 & 229.36 & 134.60 & 71.87 & 33.31 & \\
\hline FILA F5 & HSsmall & 182.08 & 283.01 & 224.02 & 136.03 & 70.16 & 29.25 & \\
\hline 20/05/2017 & Lecturas - "Strain" & 152.56 & 159.04 & (*) & 112.45 & 85.68 & $(*)$ & \\
\hline 21/07/2017 & Lecturas - "Strain" & 156.37 & 162.45 & $(*)$ & 115.89 & 89.32 & $(*)$ & \\
\hline \multirow{3}{*}{$\begin{array}{l}\text { SÓTANO / } \\
\text { FILA / } \\
\text { FECHA } \\
\text { LECTURA } \\
\end{array}$} & \multirow{3}{*}{$\begin{array}{l}\text { MODELO DE SUELO } \\
\text { / MONITORIZACIÓN }\end{array}$} & SG5 & SG4 & SG3 & SG2 & SG1 & & \\
\hline & & \multicolumn{5}{|c|}{ Distancia en longitud de barra (desde pantalla) [m] } & & \\
\hline & & 0.85 & 2.60 & 4.35 & 6.10 & 7.85 & & \\
\hline \multirow{2}{*}{5} & Mohr Coulomb & 25.60 & 59.23 & 41.06 & 23.90 & 9.92 & & \\
\hline & Hardening Soil & 29.24 & 52.88 & 24.90 & 10.57 & 4.56 & & \\
\hline FILA F6 & HSsmall & 29.37 & 63.94 & 28.08 & 12.51 & 5.03 & & \\
\hline 20/05/2017 & Lecturas - "Strain" & 26.38 & 35.13 & 16.80 & 4.83 & $(*)$ & & \\
\hline 21/07/2017 & Lecturas - "Strain" & 31.56 & 39.37 & 20.78 & 8.67 & (*) & & \\
\hline
\end{tabular}

(*) "Strain Gauge" que no registró información. 
En el estudio experimental, en el "Soil Nail" de la fila F6 correspondiente al sótano 5 se instalaron 5 "Strain Gauges", según se muestra en la Fig. 6.7. Sin embargo, un sensor presentó daños después de la construcción del anclaje y no registró información, según se presenta en la Tabla 6.10.

En general, en la estructura de "Soil Nailing" de Zaigen se instalaron en total 37 galgas extensométricas, de ellas 15 fueron identificadas con fallas después de la construcción de los anclajes, de las cuales algunas no reportaron datos desde el inicio, otras en cambio registraron datos fuera de contexto, por lo que dichos resultados no fueron considerados en este análisis. Entonces, por lo mencionado anteriormente en este proyecto se tuvo una "mortalidad" del $41 \%$ en lo que respecta al funcionamiento de "Strain Gauges".

Después de la construcción del sótano 5 se realizó una campaña adicional de monitorización, en donde se distinguen incrementos en las fuerzas de tensión. Por tanto, las tensiones desarrolladas en los "Soil Nails" son una función del tiempo y no necesariamente se mantienen constantes al final del proceso constructivo.

\subsubsection{Efectos de la temperatura en las lecturas de "Strain"}

Para estudiar y estimar la posible afectación de la temperatura en las lecturas periódicas de los valores de "Strain" en las galgas extensométricas instaladas en las barras de acero, se introdujo en el terreno de una zona cercana a las estructuras de "Soil Nailing" una pequeña barra de acero de $1.00 \mathrm{~m}$ de longitud con un "Strain Gauge" instalado adecuadamente. Se tuvo cuidado en elegir una zona de suelo que no esté afectada por variaciones significativas de esfuerzos del terreno.

Se realizaron lecturas periódicas de "Strain" en la galga durante cada tarea periódica de monitorización y se pudo verificar mínimas variaciones en las lecturas, por lo que no se consideraron correcciones por temperatura.

\subsubsection{Desplazamientos horizontales y verticales medidos en excavaciones}

\subsubsection{Introducción}

De manera simultánea al avance constructivo se realizaron medidas topográficas en las marcas metálicas colocadas en las pantallas a la altura de las placas de los "Soil Nails" monitorizados y en las bases de nivelación instaladas en el terreno, para obtener las variaciones de desplazamientos horizontales en las pantallas y desplazamientos verticales o asentamientos en el terreno, respectivamente.

Para una mejor comparación, los desplazamientos horizontales y verticales obtenidos durante todas las fases de la monitorización se han graficado simultáneamente con los diagramas de deformaciones del análisis numérico con elementos finitos y los modelos constitutivos de suelo de Mohr Coulomb, Hardening Soil y HSsmall, con Plaxis 2D. 


\subsubsection{Desplazamientos horizontales y verticales medidos en Torre Centre}

Las Fig. 6.13 a 6.17 presentan la evolución de los desplazamientos horizontales en la pantalla y desplazamientos verticales o asentamientos en el terreno medidos en el proyecto Torre Centre, los cuales fueron inducidos por la construcción de cada nivel de sótano.

\section{Excavación 1 - construcción de sótano 1}

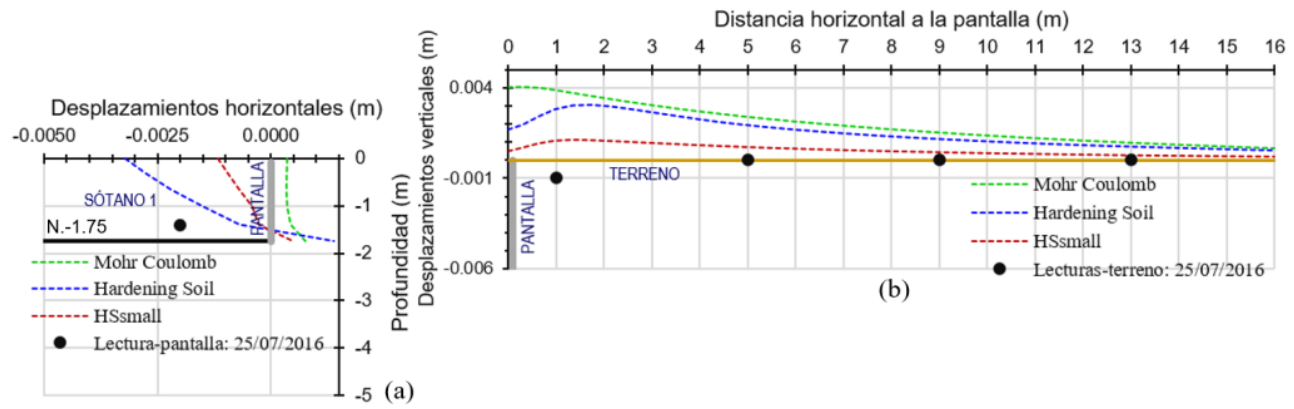

Fig. 6.13 Medidas topográficas de desplazamientos por construcción de sótano 1 de Torre Centre: (a) desplazamientos horizontales en pantalla, y (b) asentamientos del terreno detrás de la pantalla. Comparación con resultados de los modelos numéricos.

La Tabla 6.11 muestra los valores de desplazamientos horizontales en la pantalla determinados por el análisis numérico y por las medidas topográficas. En tanto que la Tabla 6.12 presenta los valores de asentamientos inducidos en el terreno que se encuentra detrás de la pantalla, por efectos de la construcción del nivel de sótano 1.

Tabla 6.11 Desplazamientos horizontales en pantalla por construcción de sótano 1 de Torre Centre.

\begin{tabular}{ccccccc}
\hline \multirow{3}{*}{ SÓTANO } & MARCA & \multicolumn{3}{c}{ DESPLAZAMIENTOS HORIZONTALES EN PANTALLA [m] } \\
\cline { 3 - 6 } & METÁLICA & \multicolumn{2}{c}{ MODELO CONSTITUTIVO } & $\begin{array}{c}\text { Medidas topográficas en } \\
\text { pantalla }\end{array}$ \\
\cline { 2 - 6 } & "SOIL & $\begin{array}{c}\text { Prof. } \\
{[\mathrm{m}]}\end{array}$ & $\begin{array}{c}\text { Mohr } \\
\text { Coulomb }\end{array}$ & $\begin{array}{c}\text { Hardening } \\
\text { Soil }\end{array}$ & HSsmall & $25 / 07 / 2016$ \\
\hline 1 & F1 & -1.40 & 0.0004 & -0.0007 & -0.0003 & -0.0020 \\
\hline
\end{tabular}

Tabla 6.12 Asentamientos en terreno detrás de pantalla por construcción de sótano 1 de Torre Centre.

\begin{tabular}{ccccc}
\hline MÉTODO & \multicolumn{4}{c}{ ASENTAMIENTOS EN TERRENO DETRÁS DE PANTALLA [m] } \\
\cline { 2 - 4 } MODELO DE SUELO / & $\mathrm{P} 1$ & $\mathrm{P} 2$ & $\mathrm{P} 3$ & $\mathrm{P} 4$ \\
\cline { 2 - 4 } MONITORIZACIÓN & \multicolumn{4}{c}{ Distancia desde la pantalla [m] } \\
\cline { 2 - 4 } & 0.0039 & 0.0024 & 0.0015 & 0.0009 \\
\hline Mohr Coulomb & 0.0028 & 0.0019 & 0.0011 & 0.0007 \\
Hardening Soil & 0.0011 & 0.0007 & 0.0004 & 0.0003 \\
HSsmall & -0.0010 & 0.0000 & 0.0000 & 0.0000 \\
\hline Lecturas-terreno: 25/07/2016 & & & &
\end{tabular}




\section{Excavación 2 - construcción de sótano 2}
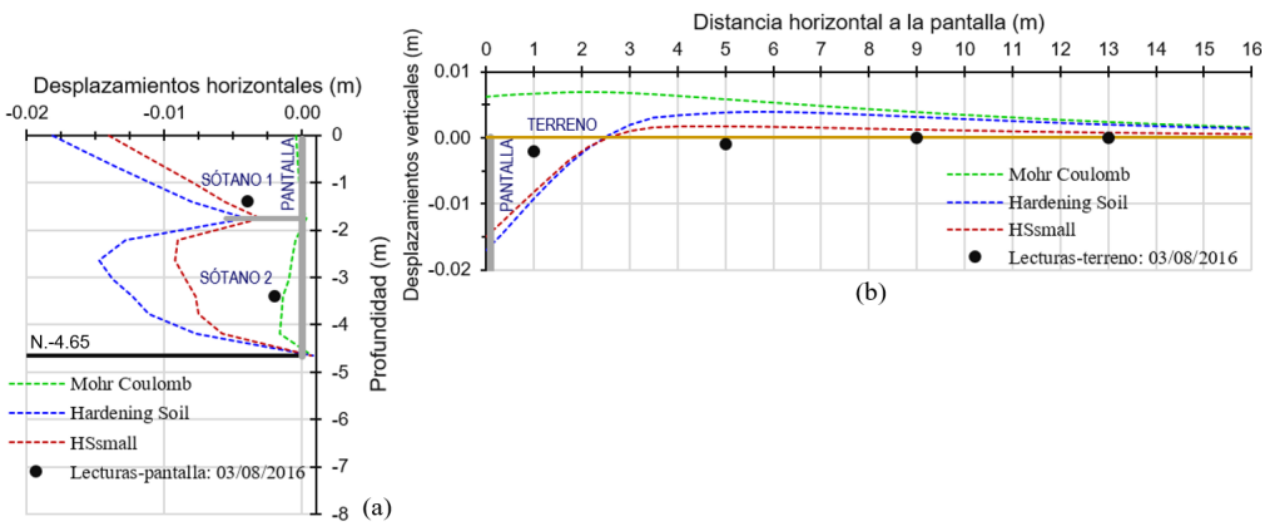

(b)

Fig. 6.14 Medidas topográficas de desplazamientos por construcción de sótano 2 de Torre Centre: (a) desplazamientos horizontales en pantalla, y (b) asentamientos del terreno detrás de la pantalla. Comparación con resultados de los modelos numéricos.

En la Tabla 6.13 se presentan los valores de desplazamientos horizontales en la pantalla obtenidos por el análisis numérico y también por las lecturas topográficas durante las tareas de monitorización. Por otra parte, en la Tabla 6.14 se muestran los valores de asentamientos inducidos en el terreno por la construcción del nivel de sótano 2.

Tabla 6.13 Desplazamientos horizontales en pantalla por construcción de sótano 2 de Torre Centre.

\begin{tabular}{ccccccc}
\hline \multirow{2}{*}{ SÓtANO } & \multicolumn{2}{c}{ MARCA } & \multicolumn{2}{c}{ DESPLAZAMIENTOS HORIZONTALES EN PANTALLA [m] } \\
\cline { 3 - 6 } & \multicolumn{2}{c}{ METÁLICA } & \multicolumn{2}{c}{ MODELO CONSTITUTIVO } & $\begin{array}{c}\text { Medidas topográficas en } \\
\text { pantalla }\end{array}$ \\
\cline { 2 - 6 } & $\begin{array}{c}\text { "SOIL } \\
\text { NAIL" }\end{array}$ & $\begin{array}{c}\text { Prof. } \\
{[\mathrm{m}]}\end{array}$ & $\begin{array}{c}\text { Mohr } \\
\text { Coulomb }\end{array}$ & $\begin{array}{c}\text { Hardening } \\
\text { Soil }\end{array}$ & HSsmall & $03 / 08 / 2016$ \\
\hline 1 & F1 & -1.40 & -0.0001 & -0.0080 & -0.0056 & -0.0040 \\
2 & F2 & .3 .40 & -0.0014 & -0.0123 & -0.0077 & -0.0020 \\
\hline
\end{tabular}

Tabla 6.14 Asentamientos en terreno detrás de pantalla por construcción de sótano 2 de Torre Centre.

\begin{tabular}{ccccc}
\hline MÉTODO & \multicolumn{4}{c}{ ASENTAMIENTOS EN TERRENO DETRÁS DE PANTALLA [m] } \\
\cline { 2 - 4 } MODELO DE SUELO / & $\mathrm{P} 1$ & $\mathrm{P} 2$ & $\mathrm{P} 3$ \\
\cline { 2 - 4 } MONITORIZACIÓN & \multicolumn{4}{c}{ Distancia desde la pantalla [m] } \\
\cline { 2 - 4 } & 0.0067 & 5.00 & 9.00 & P4 \\
\hline Mohr Coulomb & -0.0094 & 0.0059 & 0.0038 & 0.0024 \\
Hardening Soil & -0.0083 & 0.0017 & 0.0031 & 0.0020 \\
HSsmall & -0.0020 & -0.0010 & 0.0012 & 0.0007 \\
\hline Lecturas-terreno: 03/08/2016 & & & 0.0000 & 0.0000 \\
\hline
\end{tabular}




\section{Excavación 3 - construcción de sótano 3}

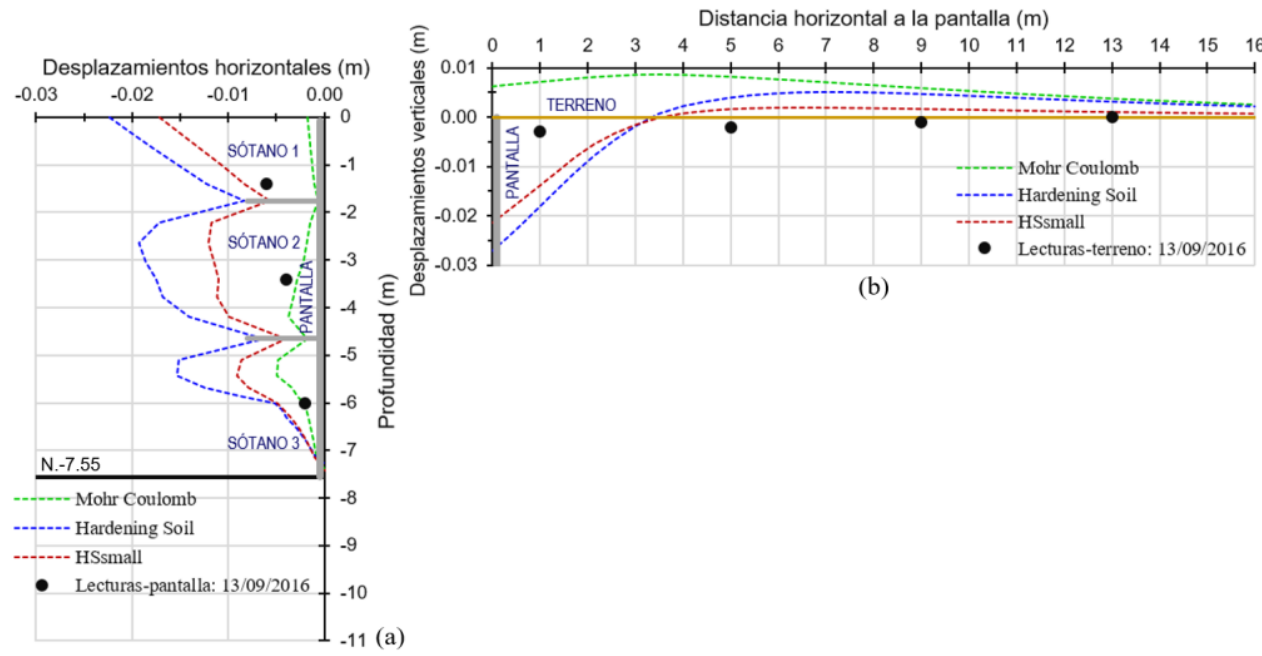

Fig. 6.15 Medidas topográficas de desplazamientos por construcción de sótano 3 de Torre Centre: (a) desplazamientos horizontales en pantalla, y (b) asentamientos del terreno detrás de la pantalla. Comparación con resultados de los modelos numéricos.

La Tabla 6.15 resume los desplazamientos horizontales en la pantalla determinados por el análisis numérico y por las medidas topográficas. La Tabla 6.16 muestra los asentamientos en el terreno detrás de la pantalla, por la construcción del sótano 3.

Tabla 6.15 Desplazamientos horizontales en pantalla por construcción de sótano 3 de Torre Centre.

\begin{tabular}{ccccccc}
\hline \multirow{2}{*}{ SótANO } & \multicolumn{2}{c}{ MARCA } & \multicolumn{2}{c}{ DESPLAZAMIENTOS HORIZONTALES EN PANTALLA [m] } \\
\cline { 3 - 6 } & \multicolumn{2}{c}{ METÁLICA } & \multicolumn{2}{c}{ MODELO CONSTITUTIVO } & $\begin{array}{c}\text { Medidas topográficas en } \\
\text { pantalla }\end{array}$ \\
\cline { 2 - 6 } & "SOIL & $\begin{array}{c}\text { Prof. } \\
\text { NAIL" }\end{array}$ & $\begin{array}{c}\text { Mohr } \\
\text { Coulomb }\end{array}$ & $\begin{array}{c}\text { Hardening } \\
\text { Soil }\end{array}$ & HSsmall & $13 / 09 / 2016$ \\
\hline 1 & F1 & -1.40 & -0.0011 & -0.0123 & -0.0083 & -0.0060 \\
2 & F2 & .3 .40 & -0.0029 & -0.0175 & -0.0110 & -0.0040 \\
3 & F3 & -6.00 & -0.0021 & -0.0051 & -0.0049 & -0.0020 \\
\hline
\end{tabular}

Tabla 6.16 Asentamientos en terreno detrás de pantalla por construcción de sótano 3 de Torre Centre.

\begin{tabular}{ccccc}
\hline MÉTODO & \multicolumn{4}{c}{ ASENTAMIENTOS EN TERRENO DETRÁS DE PANTALLA [m] } \\
\cline { 2 - 4 } MODELO DE SUELO / & $\mathrm{P} 1$ & $\mathrm{P} 2$ & $\mathrm{P} 3$ & $\mathrm{P} 4$ \\
\cline { 2 - 4 } MONITORIZACIÓN & \multicolumn{4}{c}{ Distancia desde la pantalla [m] } \\
\cline { 2 - 4 } & 1.00 & 5.00 & 9.00 & 13.00 \\
\hline Mohr Coulomb & 0.0072 & 0.0083 & 0.0058 & 0.0038 \\
Hardening Soil & -0.0183 & 0.0039 & 0.0047 & 0.0032 \\
HSsmall & -0.0139 & 0.0017 & 0.0017 & 0.0011 \\
\hline Lecturas-terreno: 13/09/2016 & -0.0030 & -0.0020 & -0.0010 & 0.0000 \\
\hline
\end{tabular}




\section{Excavación 4 - construcción de sótano 4}
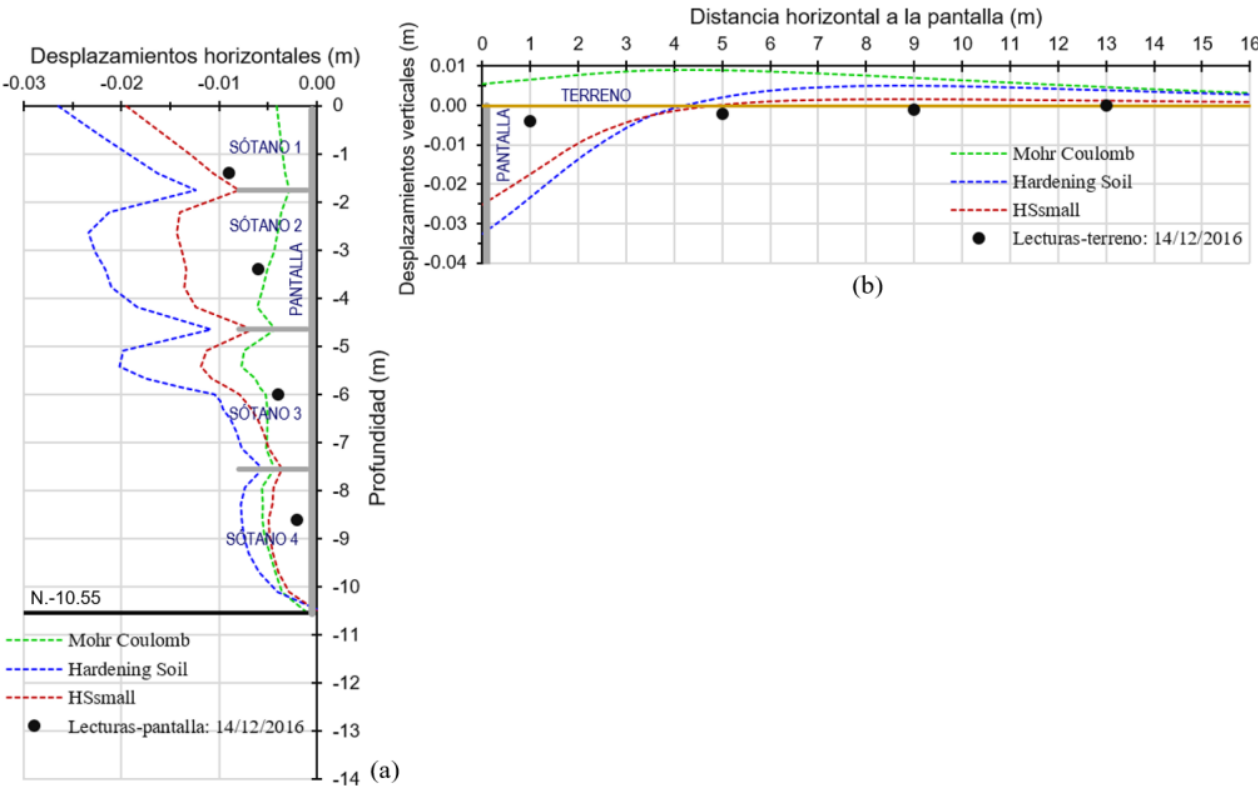

Fig. 6.16 Medidas topográficas de desplazamientos por construcción de sótano 4 de Torre Centre: (a) desplazamientos horizontales en pantalla, y (b) asentamientos del terreno detrás de la pantalla. Comparación con resultados de los modelos numéricos.

Tabla 6.17 Desplazamientos horizontales en pantalla por construcción de sótano 4 de Torre Centre.

\begin{tabular}{ccccccc}
\hline \multirow{2}{*}{ SótANO } & \multicolumn{2}{c}{ MARCA } & \multicolumn{2}{c}{ DESPLAZAMIENTOS HORIZONTALES EN PANTALLA [m] } \\
\cline { 3 - 6 } & \multicolumn{2}{c}{ METÁLICA } & \multicolumn{2}{c}{ MODELO CONSTITUTIVO } & $\begin{array}{c}\text { Medidas topográficas en } \\
\text { pantalla }\end{array}$ \\
\cline { 2 - 6 } & $\begin{array}{c}\text { "SOIL } \\
\text { NAIL" }\end{array}$ & $\begin{array}{r}\text { Prof. } \\
{[\mathrm{m}]}\end{array}$ & $\begin{array}{c}\text { Mohr } \\
\text { Coulomb }\end{array}$ & $\begin{array}{c}\text { Hardening } \\
\text { Soil }\end{array}$ & HSsmall & $14 / 12 / 2016$ \\
\hline 1 & F1 & -1.40 & -0.0032 & -0.0163 & -0.0106 & -0.0090 \\
2 & F2 & .3 .40 & -0.0051 & -0.0217 & -0.0134 & -0.0060 \\
3 & F3 & -6.00 & -0.0052 & -0.0105 & -0.0080 & -0.0040 \\
4 & F4 & -8.60 & -0.0056 & -0.0077 & -0.0049 & -0.0020 \\
\hline
\end{tabular}

Tabla 6.18 Asentamientos en terreno detrás de pantalla por construcción de sótano 4 de Torre Centre.

\begin{tabular}{|c|c|c|c|c|}
\hline MÉTODO & \multicolumn{4}{|c|}{ ASENTAMIENTOS EN TERRENO DETRÁS DE PANTALLA [m] } \\
\hline \multirow{3}{*}{$\begin{array}{l}\text { MODELO DE SUELO / } \\
\text { MONITORIZACIÓN }\end{array}$} & P1 & $\mathrm{P} 2$ & P3 & $\mathrm{P} 4$ \\
\hline & \multicolumn{4}{|c|}{ Distancia desde la pantalla $[\mathrm{m}]$} \\
\hline & 1.00 & 5.00 & 9.00 & 13.00 \\
\hline Mohr Coulomb & 0.0066 & 0.0091 & 0.0069 & 0.0046 \\
\hline Hardening Soil & -0.0235 & 0.0020 & 0.0051 & 0.0039 \\
\hline HSsmall & -0.0175 & 0.0002 & 0.0017 & 0.0013 \\
\hline Lecturas-terreno: 14/12/2016 & -0.0040 & -0.0020 & -0.0010 & 0.0000 \\
\hline
\end{tabular}


La Tabla 6.17 muestra los valores de desplazamientos horizontales en la pantalla obtenidos por el análisis numérico y por las lecturas topográficas. Por su parte la Tabla 6.18 presenta los asentamientos generados en el terreno que se encuentra detrás de la pantalla, por la construcción del nivel de sótano 4.

\section{Excavación 5 - construcción de sótano 5}
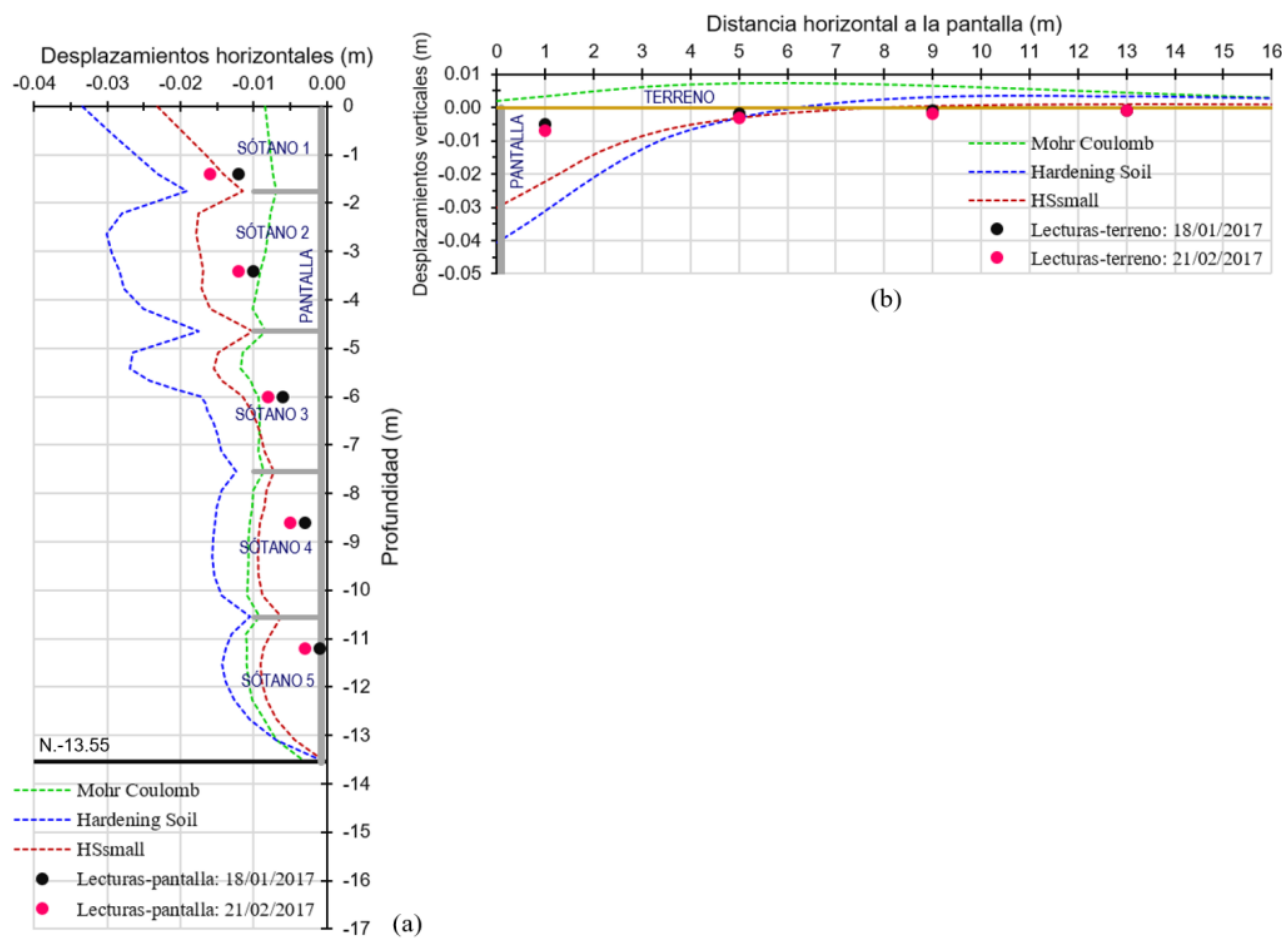

(b)

Fig. 6.17 Medidas topográficas de desplazamientos por construcción de sótano 5 de Torre Centre: (a) desplazamientos horizontales en pantalla, y (b) asentamientos del terreno detrás de la pantalla. Comparación con resultados de los modelos numéricos.

Tabla 6.19 Desplazamientos horizontales en pantalla por construcción de sótano 5 de Torre Centre.

\begin{tabular}{cccccccc}
\hline \multirow{2}{*}{ SótANO } & \multicolumn{2}{c}{ MARCA } & \multicolumn{2}{c}{ DESPLAZAMIENTOS HORIZONTALES EN PANTALLA [m] } \\
\cline { 3 - 7 } & \multicolumn{2}{c}{ METÁLICA } & \multicolumn{2}{c}{ MODELO CONSTITUTIVO } & $\begin{array}{c}\text { Medidas topográficas en } \\
\text { pantalla }\end{array}$ \\
\cline { 2 - 7 } & $\begin{array}{c}\text { "SOIL } \\
\text { NAIL" }\end{array}$ & $\begin{array}{c}\text { Prof. } \\
{[\mathrm{m}]}\end{array}$ & $\begin{array}{c}\text { Mohr } \\
\text { Coulomb }\end{array}$ & $\begin{array}{c}\text { Hardening } \\
\text { Soil }\end{array}$ & HSsmall & $18 / 01 / 2017$ & $21 / 02 / 2017$ \\
\hline 1 & F1 & -1.40 & -0.0074 & -0.0231 & -0.0141 & -0.0120 & -0.0160 \\
2 & F2 & -3.40 & -0.0091 & -0.0283 & -0.0169 & -0.0100 & -0.0120 \\
3 & F3 & -6.00 & -0.0094 & -0.0172 & -0.0115 & -0.0060 & -0.0080 \\
4 & F4 & -8.60 & -0.0105 & -0.0153 & -0.0092 & -0.0030 & -0.0050 \\
5 & F5 & -11.20 & -0.0110 & -0.0138 & -0.0087 & -0.0010 & -0.0030 \\
\hline
\end{tabular}


En la Tabla 6.19 se muestran los valores de desplazamientos horizontales en la pantalla obtenidos por el análisis numérico y por las lecturas topográficas durante las tareas de monitorización. Mientras tanto, en la Tabla 6.20 se presentan los valores de asentamientos generados en el terreno por la construcción del nivel de sótano 5.

Tabla 6.20 Asentamientos en terreno detrás de pantalla por construcción de sótano 5 de Torre Centre.

\begin{tabular}{ccccc}
\hline MÉTODO & \multicolumn{4}{c}{ ASENTAMIENTOS EN TERRENO DETRÁS DE LA PANTALLA [m] } \\
\cline { 2 - 4 } MODELO DE SUELO / & $\mathrm{P} 1$ & $\mathrm{P} 2$ & $\mathrm{P} 3$ & $\mathrm{P} 4$ \\
\cline { 2 - 4 } MONITORIZACIÓN & \multicolumn{4}{c}{ Distancia desde la pantalla [m] } \\
\cline { 2 - 4 } & 0.0033 & 0.0074 & 0.0065 & 0.0045 \\
\hline Mohr Coulomb & -0.0313 & -0.0034 & 0.0031 & 0.0032 \\
Hardening Soil & -0.0224 & -0.0033 & 0.0004 & 0.0009 \\
HSsmall & -0.0050 & -0.0020 & -0.0010 & -0.0010 \\
\hline Lecturas-terreno: 18/01/2017 & -0.0070 & -0.0030 & -0.0020 & -0.0010 \\
\hline Lecturas-terreno: 21/02/2017 & & & & \\
\hline
\end{tabular}

\subsubsection{Desplazamientos horizontales y verticales medidos en Zaigen}

Las Fig. 6.18 a 6.22 muestran la evolución de los desplazamientos horizontales en la pantalla y desplazamientos verticales o asentamientos en el terreno medidos en el proyecto Zaigen, los cuales fueron generados por la construcción de cada nivel de sótano.

Excavación 1 - construcción de sótano 1
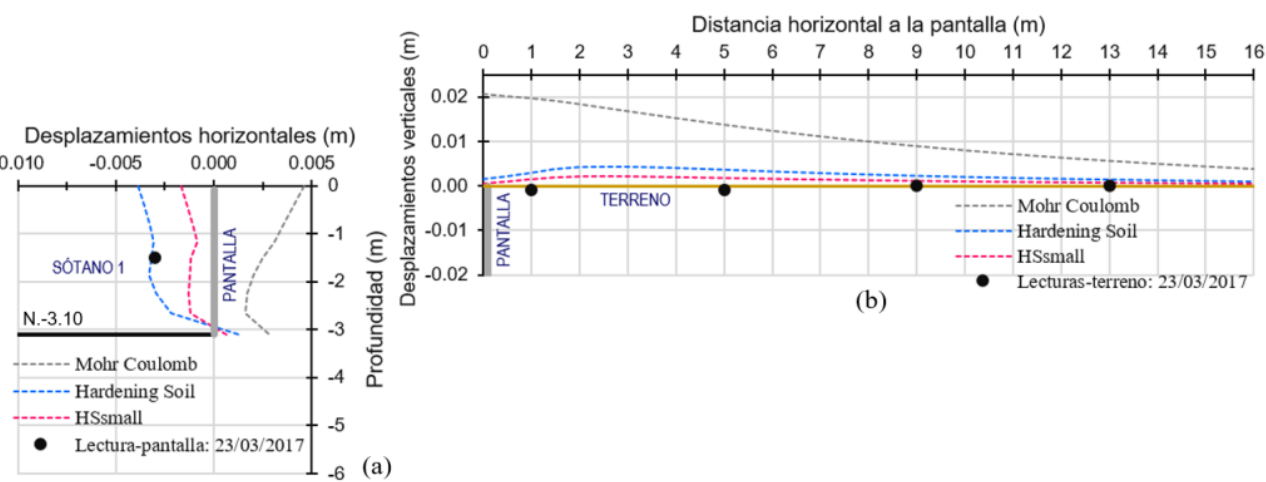

Fig. 6.18 Medidas topográficas de desplazamientos por construcción de sótano 1 de Zaigen: (a) desplazamientos horizontales en pantalla, y (b) asentamientos del terreno detrás de la pantalla. Comparación con resultados de los modelos numéricos.

En la Tabla 6.21 se resumen los valores de desplazamientos horizontales en la pantalla obtenidos por el análisis numérico y también por las lecturas topográficas durante las tareas de monitorización. Por su parte, en la Tabla 6.22 se presentan los valores de asentamientos inducidos en el terreno por la construcción del nivel de sótano 1. 
Tabla 6.21 Desplazamientos horizontales en pantalla por construcción de sótano 1 de Zaigen.

\begin{tabular}{ccccccc}
\hline \multirow{2}{*}{ SÓtANO } & \multicolumn{2}{c}{ MARCA } & \multicolumn{4}{c}{ DESPLAZAMIENTOS HORIZONTALES EN PANTALLA [m] } \\
\cline { 3 - 6 } & METÁLICA & \multicolumn{2}{c}{ MODELO CONSTITUTIVO } & $\begin{array}{c}\text { Medidas topográficas en } \\
\text { pantalla }\end{array}$ \\
\cline { 2 - 6 } & $\begin{array}{c}\text { NOIL } \\
\text { NAIL" }\end{array}$ & $\begin{array}{c}\text { Prof. } \\
{[\mathrm{m}]}\end{array}$ & $\begin{array}{c}\text { Mohr } \\
\text { Coulomb }\end{array}$ & $\begin{array}{c}\text { Hardening } \\
\text { Soil }\end{array}$ & HSsmall & $23 / 03 / 2017$ \\
\hline 1 & $\mathrm{~F} 1$ & -1.50 & 0.0025 & -0.0032 & -0.0012 & -0.0030 \\
\hline
\end{tabular}

Tabla 6.22 Asentamientos en terreno detrás de pantalla por construcción de sótano 1 de Zaigen.

\begin{tabular}{ccccc}
\hline MÉTODO & \multicolumn{4}{c}{ ASENTAMIENTOS EN TERRENO DETRÁS DE PANTALLA [m] } \\
\cline { 2 - 4 } MODELO DE SUELO / & $\mathrm{P} 1$ & $\mathrm{P} 2$ & $\mathrm{P} 3$ & $\mathrm{P} 4$ \\
\cline { 2 - 4 } MONITORIZACIÓN & \multicolumn{4}{c}{ Distancia desde la pantalla [m] } \\
\cline { 2 - 4 } & 0.0198 & 0.0141 & 0.00 & 13.00 \\
\hline Mohr Coulomb & 0.0028 & 0.0036 & 0.0022 & 0.0054 \\
Hardening Soil & 0.0015 & 0.0019 & 0.0011 & 0.0007 \\
HSsmall & -0.0010 & -0.0010 & 0.0000 & 0.0000 \\
\hline Lecturas-terreno: 23/03/2017 & & & & 0.0000 \\
\hline
\end{tabular}

\section{Excavación 2 - construcción de sótano 2}

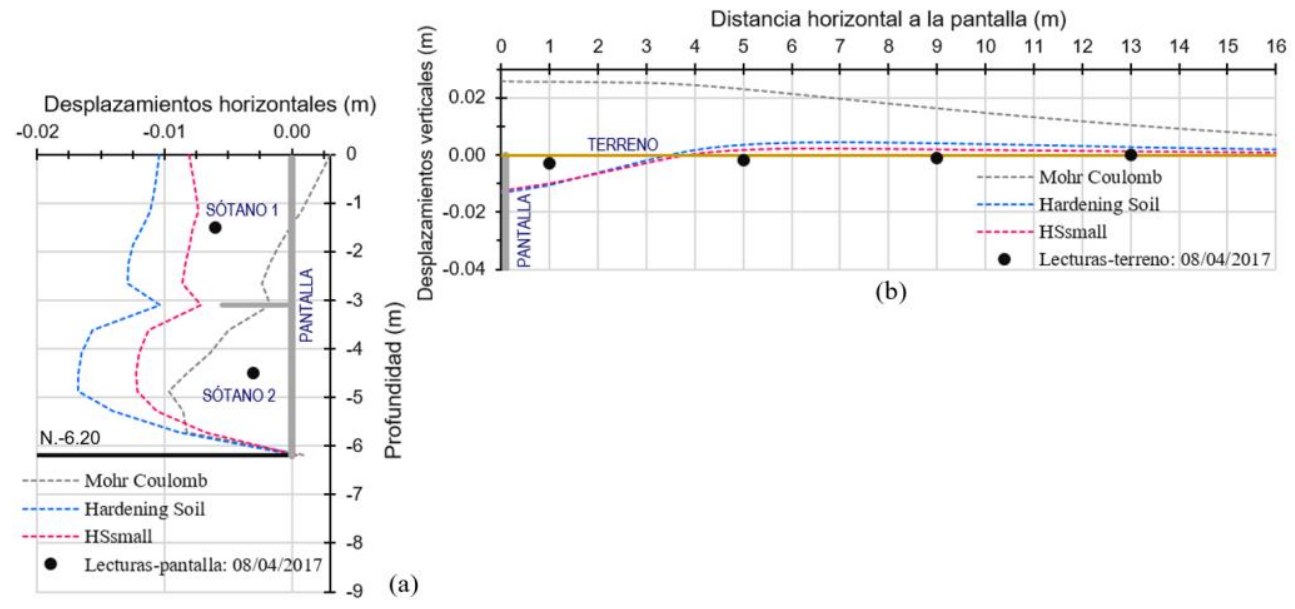

Fig. 6.19 Medidas topográficas de desplazamientos por construcción de sótano 2 de Zaigen: (a) desplazamientos horizontales en pantalla, y (b) asentamientos del terreno detrás de la pantalla. Comparación con resultados de los modelos numéricos.

En la Tabla 6.23 se resumen los valores de desplazamientos horizontales en la pantalla determinados por el análisis numérico y también por las lecturas topográficas durante las tareas de monitorización. Por su parte, en la Tabla 6.24 se muestran los valores de asentamientos generados en el terreno por la construcción del nivel de sótano 2. 
Estudio experimental y numérico del comportamiento de excavaciones ejecutadas mediante la técnica de suelo claveteado (Soil Nailing) en suelos de la ciudad de Quito (Ecuador)

Tabla 6.23 Desplazamientos horizontales en pantalla por construcción de sótano 2 de Zaigen.

\begin{tabular}{ccccccc}
\hline \multirow{2}{*}{ SÓTANO } & \multicolumn{2}{c}{ MARCA } & \multicolumn{3}{c}{ DESPLAZAMIENTOS HORIZONTALES EN PANTALLA [m] } \\
\cline { 3 - 7 } & \multicolumn{2}{c}{ METÁLICA } & \multicolumn{3}{c}{ MODELO CONSTITUTIVO } & $\begin{array}{c}\text { Medidas topográficas en } \\
\text { pantalla }\end{array}$ \\
\cline { 2 - 7 } & $\begin{array}{c}\text { "SOIL } \\
\text { NAIL" }\end{array}$ & $\begin{array}{c}\text { Prof. } \\
{[\mathrm{m}]}\end{array}$ & $\begin{array}{c}\text { Mohr } \\
\text { Coulomb }\end{array}$ & $\begin{array}{c}\text { Hardening } \\
\text { Soil }\end{array}$ & HSsmall & $08 / 04 / 2017$ \\
\hline 1 & F1 & -1.50 & -0.0002 & -0.0117 & -0.0078 & -0.0060 \\
2 & F2 & -4.50 & -0.0082 & -0.0168 & -0.0123 & -0.0030 \\
\hline
\end{tabular}

Tabla 6.24 Asentamientos en terreno detrás de pantalla por construcción de sótano 2 de Zaigen.

\begin{tabular}{ccccc}
\hline MÉTODO & \multicolumn{4}{c}{ ASENTAMIENTOS EN TERRENO DETRÁS DE PANTALLA [m] } \\
\cline { 2 - 4 } MODELO DE SUELO / & $\mathrm{P} 1$ & $\mathrm{P} 2$ & $\mathrm{P} 3$ \\
\cline { 2 - 4 } MONITORIZACIÓN & \multicolumn{4}{c}{ Distancia desde la pantalla [m] } \\
\cline { 2 - 4 } & 0.0256 & 0.0233 & 0.00 & 13.00 \\
\hline Mohr Coulomb & -0.0106 & 0.0033 & 0.0041 & 0.0102 \\
Hardening Soil & -0.0101 & 0.0017 & 0.0020 & 0.0013 \\
HSsmall & -0.0030 & -0.0020 & -0.0010 & 0.0000 \\
\hline Lecturas-terreno: 08/04/2017 & & & &
\end{tabular}

\section{Excavación 3 - construcción de sótano 3}

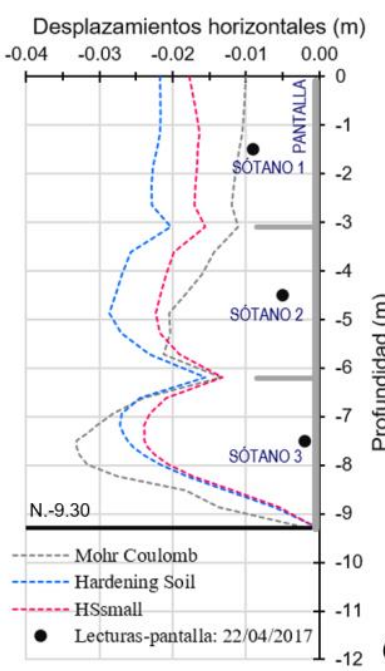

(a)

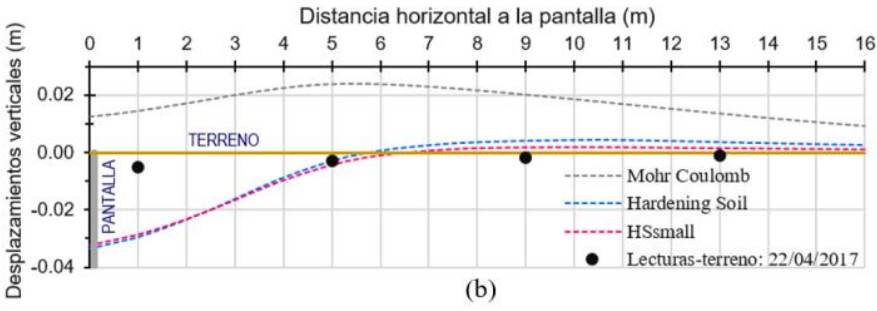

(b)

Fig. 6.20 Medidas topográficas de desplazamientos por construcción de sótano 3 de Zaigen: (a) desplazamientos horizontales en pantalla, y (b) asentamientos del terreno detrás de la pantalla. Comparación con resultados de los modelos numéricos.

Las Tablas 6.25 y 6.26 muestran los desplazamientos horizontales en la pantalla y los asentamientos en el terreno por la construcción del sótano 3, respectivamente. 
Tabla 6.25 Desplazamientos horizontales en pantalla por construcción de sótano 3 de Zaigen.

\begin{tabular}{|c|c|c|c|c|c|c|}
\hline \multirow{3}{*}{ SÓTANO } & \multirow{2}{*}{\multicolumn{2}{|c|}{$\begin{array}{c}\text { MARCA } \\
\text { METÁLICA }\end{array}$}} & \multicolumn{4}{|c|}{ DESPLAZAMIENTOS HORIZONTALES EN PANTALLA [m] } \\
\hline & & & \multicolumn{3}{|c|}{ MODELO CONSTITUTIVO } & \multirow{2}{*}{$\begin{array}{c}\begin{array}{c}\text { Medidas topográficas en } \\
\text { pantalla }\end{array} \\
22 / 04 / 2017\end{array}$} \\
\hline & $\begin{array}{l}\text { "SOIL } \\
\text { NAIL" }\end{array}$ & $\begin{array}{c}\text { Prof. } \\
{[\mathrm{m}]}\end{array}$ & $\begin{array}{c}\text { Mohr } \\
\text { Coulomb }\end{array}$ & $\begin{array}{l}\text { Hardening } \\
\quad \text { Soil }\end{array}$ & HSsmall & \\
\hline & \multicolumn{6}{|c|}{ CONSTRUCCIÓN DE SÓTANO 3} \\
\hline 1 & F1 & -1.50 & -0.0109 & -0.0221 & -0.0166 & -0.0090 \\
\hline 2 & $\mathrm{~F} 2$ & .4 .50 & -0.0183 & -0.0278 & -0.0217 & -0.0050 \\
\hline 3 & F3 & -7.50 & -0.0331 & -0.0261 & -0.0239 & -0.0020 \\
\hline
\end{tabular}

Tabla 6.26 Asentamientos en terreno detrás de pantalla por construcción de sótano 3 de Zaigen.

\begin{tabular}{ccccc}
\hline MÉTODO & \multicolumn{4}{c}{ ASENTAMIENTOS EN TERRENO DETRÁS DE PANTALLA [m] } \\
\cline { 2 - 4 } MODELO DE SUELO / & $\mathrm{P} 1$ & $\mathrm{P} 2$ & $\mathrm{P} 3$ & $\mathrm{P} 4$ \\
\cline { 2 - 4 } MONITORIZACIÓN & \multicolumn{4}{c}{ Distancia desde la pantalla [m] } \\
\cline { 2 - 4 } & 0.0143 & 0.0237 & 0.0200 & 0.0131 \\
\hline Mohr Coulomb & -0.0298 & -0.0040 & 0.0040 & 0.0035 \\
Hardening Soil & -0.0286 & -0.0051 & 0.0019 & 0.0016 \\
HSsmall & -0.0050 & -0.0030 & -0.0020 & -0.0010 \\
\hline Lecturas-terreno: 22/04/2017 & & & & \\
\hline
\end{tabular}

\section{Excavación 4 - construcción de sótano 4}

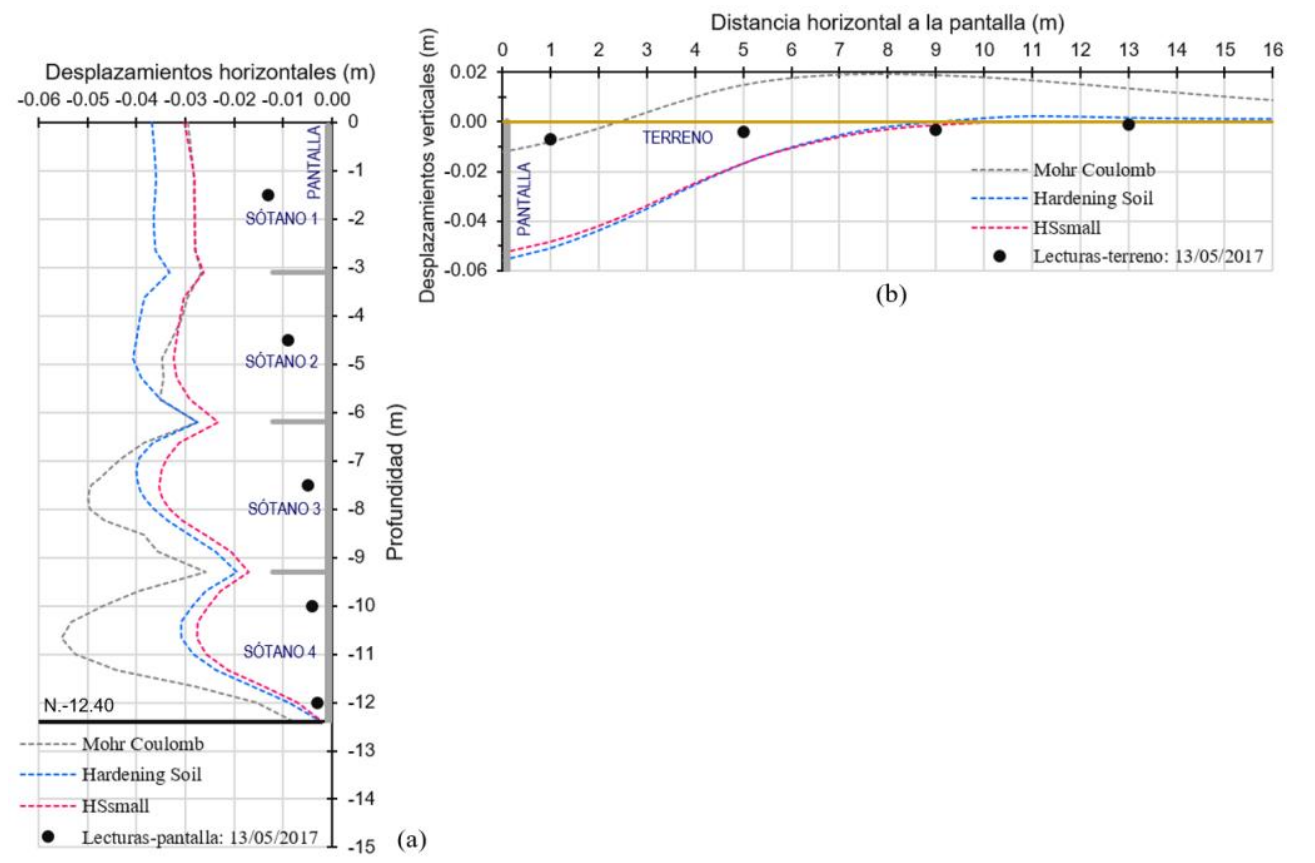

Fig. 6.21 Medidas topográficas de desplazamientos por construcción de sótano 4 de Zaigen: (a) desplazamientos horizontales en pantalla, y (b) asentamientos del terreno detrás de la pantalla. Comparación con resultados de los modelos numéricos. 
Las Tablas 6.27 y 6.28 resumen los desplazamientos horizontales en la pantalla y los asentamientos en el terreno por la construcción del sótano 4, respectivamente.

Tabla 6.27 Desplazamientos horizontales en pantalla por construcción de sótano 4 de Zaigen.

\begin{tabular}{ccccccc}
\hline \multirow{2}{*}{ SótANO } & \multicolumn{2}{c}{ MARCA } & \multicolumn{2}{c}{ DESPLAZAMIENTOS HORIZONTALES EN PANTALLA [m] } \\
\cline { 3 - 6 } & \multicolumn{2}{c}{ METÁLICA } & \multicolumn{2}{c}{ MODELO CONSTITUTIVO } & $\begin{array}{c}\text { Medidas topográficas en } \\
\text { pantalla }\end{array}$ \\
\cline { 2 - 6 } & "SOIL & $\begin{array}{c}\text { Prof. } \\
{[\mathrm{m}]}\end{array}$ & $\begin{array}{c}\text { Mohr } \\
\text { Coulomb }\end{array}$ & $\begin{array}{c}\text { Hardening } \\
\text { Soil }\end{array}$ & HSsmall & $13 / 05 / 2017$ \\
\hline \multirow{2}{*}{1} & F1 & -1.50 & -0.0282 & -0.0362 & -0.0281 & -0.0130 \\
2 & F2 & -4.50 & -0.0329 & -0.0401 & -0.0318 & -0.0090 \\
3 & F3 & -7.50 & -0.0493 & -0.0396 & -0.0353 & -0.0050 \\
& F4 & -10.00 & -0.0468 & -0.0286 & -0.0252 & -0.0040 \\
& F5 & -12.00 & -0.0154 & -0.0089 & -0.0071 & -0.0030 \\
\hline
\end{tabular}

Tabla 6.28 Asentamientos en terreno detrás de pantalla por construcción de sótano 4 de Zaigen.

\begin{tabular}{ccccc}
\hline MÉTODO & \multicolumn{4}{c}{ ASENTAMIENTOS EN TERRENO DETRÁS DE PANTALLA [m] } \\
\cline { 2 - 4 } MODELO DE SUELO / & $\mathrm{P} 1$ & $\mathrm{P} 2$ & $\mathrm{P} 3$ \\
\cline { 2 - 4 } MONITORIZACIÓN & \multicolumn{4}{c}{ Distancia desde la pantalla [m] } \\
\cline { 2 - 4 } & -0.0081 & 0.0142 & 0.00 & 13.00 \\
\hline Mohr Coulomb & -0.0511 & -0.0182 & 0.0188 & 0.0131 \\
Hardening Soil & -0.0486 & -0.0181 & -0.0012 & 0.0017 \\
HSsmall & -0.0070 & -0.0040 & -0.0030 & -0.0001 \\
\hline Lecturas-terreno: 13/05/2017 & & &
\end{tabular}

\section{Excavación 5 - construcción de sótano 5}

Las Tablas 6.29 y 6.30 resumen los valores de desplazamientos horizontales en la pantalla y los asentamientos en el terreno por la construcción del sótano 5, respectivamente. Por su parte, la Fig. 6.22 muestra gráficamente la evolución de estos desplazamientos.

Tabla 6.29 Desplazamientos horizontales en pantalla por construcción de sótano 5 de Zaigen.

\begin{tabular}{|c|c|c|c|c|c|c|c|}
\hline \multirow{3}{*}{ SÓTANO } & \multirow{2}{*}{\multicolumn{2}{|c|}{$\begin{array}{c}\text { MARCA } \\
\text { METÁLICA }\end{array}$}} & \multicolumn{5}{|c|}{ DESPLAZAMIENTOS HORIZONTALES EN PANTALLA [m] } \\
\hline & & & \multicolumn{3}{|c|}{ MODELO CONSTITUTIVO } & \multicolumn{2}{|c|}{$\begin{array}{c}\text { Medidas topográficas en } \\
\text { pantalla }\end{array}$} \\
\hline & $\begin{array}{l}\text { "SOIL } \\
\text { NAIL" }\end{array}$ & $\begin{array}{l}\text { Prof. } \\
{[\mathrm{m}]}\end{array}$ & $\begin{array}{c}\text { Mohr } \\
\text { Coulomb }\end{array}$ & $\begin{array}{l}\text { Hardening } \\
\quad \text { Soil }\end{array}$ & HSsmall & $20 / 05 / 2017$ & $21 / 07 / 2017$ \\
\hline & \multicolumn{7}{|c|}{ CONSTRUCCIÓN DE SÓTANO 5} \\
\hline 1 & F1 & -1.50 & -0.0596 & -0.0585 & -0.0459 & -0.0230 & -0.0390 \\
\hline 2 & $\mathrm{~F} 2$ & -4.50 & -0.0600 & -0.0602 & -0.0476 & -0.0170 & -0.0320 \\
\hline 3 & F3 & -7.50 & -0.0746 & -0.0579 & -0.0496 & -0.0090 & -0.0260 \\
\hline \multirow{2}{*}{4} & F4 & -10.00 & -0.0707 & -0.0444 & -0.0377 & -0.0050 & -0.0210 \\
\hline & F5 & -12.00 & -0.0389 & -0.0237 & -0.0191 & -0.0040 & -0.0200 \\
\hline 5 & F6 & -13.50 & -0.0811 & -0.0355 & -0.0292 & -0.0020 & -0.0150 \\
\hline
\end{tabular}


Desplazamientos horizontales $(\mathrm{m})$ $\begin{array}{llllll}-0.10 & -0.08 & -0.06 & -0.04 & -0.02 & 0.00\end{array}$
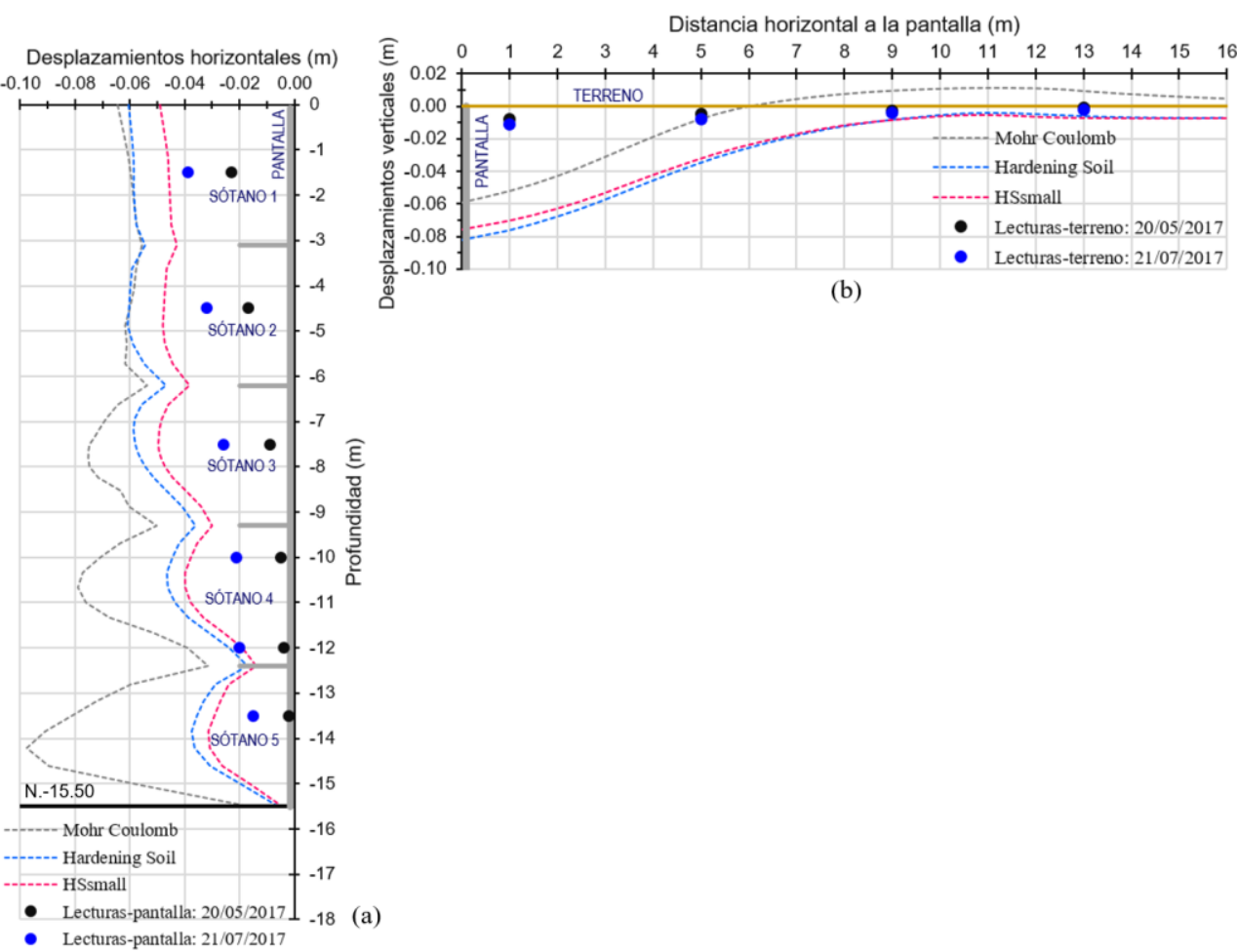

(b)

Fig. 6.22 Medidas topográficas de desplazamientos por construcción de sótano 5 de Zaigen: (a) desplazamientos horizontales en pantalla, y (b) asentamientos del terreno detrás de la pantalla. Comparación con resultados de los modelos numéricos.

Tabla 6.30 Asentamientos en terreno detrás de pantalla por construcción de sótano 5 de Zaigen.

\begin{tabular}{ccccc}
\hline MÉTODO & \multicolumn{4}{c}{ ASENTAMIENTOS EN TERRENO DETRÁS DE LA PANTALLA [m] } \\
\cline { 2 - 4 } MODELO DE SUELO / & $\mathrm{P} 1$ & $\mathrm{P} 2$ & $\mathrm{P} 3$ & $\mathrm{P} 4$ \\
\cline { 2 - 4 } MONITORIZACIÓN & \multicolumn{4}{c}{ Distancia desde la pantalla [m] } \\
\cline { 2 - 4 } & -0.0525 & -0.0096 & 9.00 & 13.00 \\
\hline Mohr Coulomb & -0.0766 & -0.0365 & -0.0098 & 0.0090 \\
Hardening Soil & -0.0702 & -0.0336 & -0.0081 & -0.0061 \\
HSsmall & -0.0080 & -0.0050 & -0.0030 & -0.0070 \\
\hline Lecturas-terreno: 20/05/2017 & -0.0110 & -0.0080 & -0.0040 & -0.0020 \\
Lecturas-terreno: 21/07/2017 & &
\end{tabular}

Posterior a la construcción del último nivel de sótano, se llevó a cabo una campaña adicional de tareas de monitorización, en donde se identificaron claramente, incrementos en los valores de desplazamientos horizontales y asentamientos. Lo que determina que, los desplazamientos son una función del tiempo y varían a través del mismo. 


\subsection{Comparación de resultados experimentales y numéricos}

\subsubsection{Generalidades}

En esta sección se comparan los valores de las tres variables investigadas: fuerzas axiales de tensión, desplazamientos horizontales en las pantallas y asentamientos del terreno en el trasdós de las pantallas, obtenidos de los estudios experimentales y numéricos para los proyectos Torre Centre y Zaigen. La comparación efectuada, evalúa la diferencia en valor absoluto entre las mediciones experimentales y los valores del análisis numérico con los modelos constitutivos de Mohr Coulomb, Hardening Soil y HSsmall. Esta diferencia entre los valores experimentales y numéricos determina la aproximación entre los mismos, se presenta como error porcentual [\%] y se muestra para cada una de las fases de construcción de los diferentes niveles de sótano. Por obvias razones, la comparación se lleva a cabo únicamente en los puntos de medición en donde se disponen de datos experimentales.

\subsubsection{Comparación de fuerza axial en barras de acero de "Soil Nails"}

\subsubsection{Introducción}

En esta parte, se compara y determina la aproximación o diferencia entre resultados experimentales y numéricos y el error porcentual [\%] para los valores de fuerzas axiales de tensión de los anclajes de los proyectos Torre Centre y Zaigen.

\subsubsection{Comparación de fuerza axial en barras de acero de "Soil Nails" de Torre Centre}

La Tabla 6.31 muestra detalladamente la comparación de valores experimentales y numéricos, inferidos en los "Soil Nails" por la construcción del sótano 1.

Tabla 6.31 Comparación de tensiones en "Soil Nails" por construcción de sótano 1 de Torre Centre.

\begin{tabular}{|c|c|c|c|c|c|c|c|c|}
\hline \multicolumn{9}{|c|}{ FUERZAS DE TENSIÓN EN UBIC. DE “STRAIN GAUGES” [kN] } \\
\hline \multicolumn{9}{|c|}{ SÓTANO 1 - FILA F1 (INDUCIDAS POR CONSTRUCCIÓN DE SÓTANO 1) } \\
\hline \multirow{3}{*}{$\begin{array}{l}\text { MONITORIZACIÓN / } \\
\text { MODELO DE SUELO }\end{array}$} & SG7 & SG6 & SG5 & SG4 & SG3 & SG2 & SG1 & \multirow{3}{*}{ TOTAL } \\
\hline & \multicolumn{7}{|c|}{ Distancia en longitud de barra (desde pantalla) [m] } & \\
\hline & 0.85 & 3.02 & 5.19 & 7.36 & 9.53 & 11.70 & 13.87 & \\
\hline "Strain" 25/07/2016 & - & 6.01 & - & 1.93 & - & 1.35 & - & 9.29 \\
\hline MOHR COULOMB & 0.47 & 0.00 & 0.00 & 0.00 & 0.08 & 0.08 & 0.02 & \\
\hline |Error| [kN] & - & 6.01 & - & 1.93 & - & 1.27 & - & 9.21 \\
\hline |Error| [\%] & - & 64.69 & - & 20.78 & - & 13.67 & - & 99.14 \\
\hline HARDENING SOIL & 2.22 & 0.80 & 1.06 & 1.15 & 1.04 & 0.77 & 0.37 & \\
\hline |Error| [kN] & - & 5.21 & - & 0.78 & - & 0.58 & - & 6.57 \\
\hline |Error| [\%] & - & 56.08 & - & 8.40 & - & 6.24 & - & 70.72 \\
\hline HSSMALL & 4.65 & 2.27 & 1.63 & 1.27 & 0.98 & 0.66 & 0.29 & \\
\hline |Error| [kN] & - & 3.74 & - & 0.66 & - & 0.69 & - & 5.09 \\
\hline |Error| [\%] & - & 40.26 & - & 7.10 & - & 7.43 & - & 54.79 \\
\hline
\end{tabular}


En la construcción del sótano 1 del proyecto Torre Centre, los valores del modelo de HSsmall, se ajustan con el menor porcentaje de error a los resultados experimentales, a diferencia de los valores del modelo de Mohr Coulomb, que presentan menos aproximación y por tanto, un mayor error.

Por su parte, la Tabla 6.32 expone a detalle la comparación de valores de fuerzas de tensión, inferidos en los "Soil Nails" por la construcción del sótano 2.

Tabla 6.32 Comparación de tensiones en "Soil Nails" por construcción de sótano 2 de Torre Centre.

\begin{tabular}{|c|c|c|c|c|c|c|c|c|}
\hline \multicolumn{9}{|c|}{ FUERZAS DE TENSIÓN EN UBIC. DE “STRAIN GAUGES” [kN] } \\
\hline \multicolumn{9}{|c|}{ SÓTANO 1 - FILA F1 (INDUCIDAS POR CONSTRUCCIÓN DE SÓTANO 2) } \\
\hline \multirow{3}{*}{$\begin{array}{l}\text { MONITORIZACIÓN / } \\
\text { MODELO DE SUELO }\end{array}$} & SG7 & SG6 & SG5 & SG4 & SG3 & SG2 & SG1 & \multirow{3}{*}{ TOTAL } \\
\hline & \multicolumn{7}{|c|}{ Distancia en longitud de barra (desde pantalla) [m] } & \\
\hline & 0.85 & 3.02 & 5.19 & 7.36 & 9.53 & 11.70 & 13.87 & \\
\hline "Strain" 03/08/2016 & - & 41.48 & - & 35.45 & - & 15.74 & - & 92.67 \\
\hline MOHR COULOMB & 28.91 & 36.39 & 30.51 & 22.66 & 16.22 & 10.54 & 4.99 & \multirow{3}{*}{$\begin{array}{l}23.08 \\
\mathbf{2 4 . 9 1}\end{array}$} \\
\hline |Error $\mid[\mathrm{kN}]$ & - & 5.09 & - & 12.79 & - & 5.20 & - & \\
\hline |Error| [\%] & - & 5.49 & - & 13.80 & - & 5.61 & - & \\
\hline HARDENING SOIL & 44.02 & 59.69 & 56.46 & 47.90 & 37.93 & 26.34 & 12.52 & \multirow{3}{*}{$\begin{array}{l}41.26 \\
\mathbf{4 4 . 5 4}\end{array}$} \\
\hline |Error| [kN] & - & 18.21 & - & 12.45 & - & 10.60 & - & \\
\hline |Error| [\%] & - & 19.65 & - & 13.43 & - & 11.44 & - & \\
\hline HSSMALL & 43.91 & 50.21 & 39.95 & 29.84 & 21.34 & 13.47 & 5.66 & \multirow{3}{*}{$\begin{array}{l}16.61 \\
\mathbf{1 7 . 9 2}\end{array}$} \\
\hline |Error| [kN] & - & 8.73 & - & 5.61 & - & 2.27 & - & \\
\hline |Error| $[\%]$ & - & 9.42 & - & 6.05 & - & 2.45 & - & \\
\hline \multicolumn{9}{|c|}{ SÓTANO 2 - FILA F2 (INDUCIDAS POR CONSTRUCCIÓN DE SÓTANO 2) } \\
\hline \multirow{3}{*}{$\begin{array}{l}\text { MONITORIZACIÓN / } \\
\text { MODELO DE SUELO }\end{array}$} & SG7 & SG6 & SG5 & SG4 & SG3 & SG2 & SG1 & \multirow{3}{*}{ TOTAL } \\
\hline & \multicolumn{7}{|c|}{ Distancia en longitud de barra (desde pantalla) [m] } & \\
\hline & 0.85 & 3.02 & 5.19 & 7.36 & 9.53 & 11.70 & 13.87 & \\
\hline "Strain" 03/08/2016 & - & 9.23 & - & 8.28 & 3.17 & - & 2.15 & 22.83 \\
\hline MOHR COULOMB & 6.60 & 0.00 & 0.00 & 0.00 & 0.00 & 0.00 & 0.00 & \multirow{3}{*}{$\begin{array}{c}22.83 \\
\mathbf{1 0 0 . 0 0}\end{array}$} \\
\hline |Error $\mid[\mathrm{kN}]$ & - & 9.23 & - & 8.28 & 3.17 & - & 2.15 & \\
\hline | Error| [\%] & - & 40.43 & - & 36.27 & 13.89 & - & 9.42 & \\
\hline HARDENING SOIL & 10.96 & 4.63 & 0.19 & 0.00 & 0.48 & 0.38 & 0.43 & \multirow{3}{*}{$\begin{array}{l}17.29 \\
\mathbf{7 5 . 7 3}\end{array}$} \\
\hline |Error| [kN] & - & 4.60 & - & 8.28 & 2.69 & - & 1.72 & \\
\hline |Error| [\%] & - & 20.15 & - & 36.27 & 11.78 & - & 7.53 & \\
\hline HSSMALL & 13.51 & 7.71 & 3.01 & 1.61 & 1.15 & 0.66 & 0.32 & \\
\hline |Error| [kN] & - & 1.52 & - & 6.67 & 2.02 & - & 1.83 & 12.04 \\
\hline |Error| [\%] & - & 6.66 & - & 29.22 & 8.85 & - & 8.02 & 52.74 \\
\hline
\end{tabular}

En la construcción del sótano 2 del proyecto Torre Centre, los valores del modelo de HSsmall, se acoplan a los resultados experimentales con el menor error, a diferencia de los valores de los modelos de Hardening Soil y Mohr Coulomb, que denotan menos aproximación.

Por su lado, la Tabla 6.33 presenta de manera detallada la comparación de valores de fuerzas axiales de tensión inferidos en los "Soil Nails" por la construcción del sótano 3. 
Tabla 6.33 Comparación de tensiones en "Soil Nails" por construcción de sótano 3 de Torre Centre.

\begin{tabular}{|c|c|c|c|c|c|c|c|c|}
\hline \multicolumn{9}{|c|}{ FUERZAS DE TENSIÓN EN UBIC. DE “STRAIN GAUGES” [kN] } \\
\hline \multicolumn{9}{|c|}{ SÓTANO 1 - FILA F1 (INDUCIDAS POR CONSTRUCCIÓN DE SÓTANO 3) } \\
\hline \multirow{3}{*}{$\begin{array}{l}\text { MONITORIZACIÓN / } \\
\text { MODELO DE SUELO }\end{array}$} & SG7 & SG6 & SG5 & SG4 & SG3 & SG2 & SG1 & \multirow{3}{*}{ TOTAL } \\
\hline & \multicolumn{7}{|c|}{ Distancia en longitud de barra (desde pantalla) [m] } & \\
\hline & 0.85 & 3.02 & 5.19 & 7.36 & 9.53 & 11.70 & 13.87 & \\
\hline "Strain" 13/09/2016 & - & 56.45 & - & 42.21 & - & 22.68 & - & 121.34 \\
\hline MOHR COULOMB & 34.26 & 53.45 & 53.64 & 44.31 & 34.12 & 23.75 & 12.02 & \multirow{3}{*}{$\begin{array}{l}6.17 \\
\mathbf{5 . 0 8}\end{array}$} \\
\hline |Error| [kN] & - & 3.00 & - & 2.10 & - & 1.07 & - & \\
\hline |Error| [\%] & - & 2.47 & - & 1.73 & - & 0.88 & - & \\
\hline HARDENING SOIL & 49.09 & 73.35 & 76.97 & 70.19 & 58.53 & 42.57 & 20.96 & \multirow{3}{*}{$\begin{array}{l}64.77 \\
\mathbf{5 3 . 3 8}\end{array}$} \\
\hline |Error| [kN] & - & 16.90 & - & 27.98 & - & 19.89 & - & \\
\hline |Error| [\%] & - & 13.93 & - & 23.06 & - & 16.39 & - & \\
\hline HSSMALL & 57.40 & 70.71 & 63.20 & 50.66 & 38.52 & 25.81 & 11.35 & \multirow{3}{*}{$\begin{array}{l}25.84 \\
\mathbf{2 1 . 3 0}\end{array}$} \\
\hline |Error| [kN] & - & 14.26 & - & 8.45 & - & 3.13 & - & \\
\hline |Error| [\%] & - & 11.75 & - & 6.96 & - & 2.58 & - & \\
\hline \multicolumn{9}{|c|}{ SÓTANO 2 - FILA F2 (INDUCIDAS POR CONSTRUCCIÓN DE SÓTANO 3) } \\
\hline \multirow{3}{*}{$\begin{array}{l}\text { MONITORIZACIÓN / } \\
\text { MODELO DE SUELO }\end{array}$} & SG7 & SG6 & SG5 & SG4 & SG3 & SG2 & SG1 & \multirow{3}{*}{ TOTAL } \\
\hline & \multicolumn{7}{|c|}{ Distancia en longitud de barra (desde pantalla) [m] } & \\
\hline & 0.85 & 3.02 & 5.19 & 7.36 & 9.53 & 11.70 & 13.87 & \\
\hline "Strain" 13/09/2016 & - & 71.21 & - & 67.11 & 33.46 & - & 16.46 & 188.24 \\
\hline MOHR COULOMB & 45.18 & 45.33 & 33.02 & 23.43 & 16.68 & 9.25 & 4.64 & \multirow{3}{*}{$\begin{array}{l}98.16 \\
\mathbf{5 2 . 1 5}\end{array}$} \\
\hline |Error| [kN] & - & 25.88 & - & 43.68 & 16.78 & - & 11.82 & \\
\hline |Error| [\%] & - & 13.75 & - & 23.20 & 8.91 & - & 6.28 & \\
\hline HARDENING SOIL & 92.81 & 99.85 & 73.60 & 57.60 & 46.27 & 26.83 & 11.62 & \multirow{3}{*}{$\begin{array}{l}55.80 \\
\mathbf{2 9 . 6 4}\end{array}$} \\
\hline |Error| [kN] & - & 28.64 & - & 9.51 & 12.81 & - & 4.84 & \\
\hline |Error| [\%] & - & 15.21 & - & 5.05 & 6.81 & - & 2.57 & \\
\hline \multirow{3}{*}{$\begin{array}{r}\text { HSSMALL } \\
\text { |Error| }[\mathrm{kN}] \\
\mid \text { Error| }[\%]\end{array}$} & 77.47 & 78.70 & 52.46 & 37.09 & 28.00 & 15.71 & 6.22 & \multirow{3}{*}{$\begin{array}{l}53.21 \\
\mathbf{2 8 . 2 7}\end{array}$} \\
\hline & - & 7.49 & - & 30.02 & 5.46 & - & 10.24 & \\
\hline & - & 3.98 & - & 15.95 & 2.90 & - & 5.44 & \\
\hline \multicolumn{8}{|c|}{ SÓTANO 3 - FILA F3 (INDUCIDAS POR CONSTRUCCIÓN DE SÓTANO 3) } & \\
\hline \multirow{3}{*}{$\begin{array}{l}\text { MONITORIZACIÓN / } \\
\text { MODELO DE SUELO }\end{array}$} & SG6 & SG5 & SG4 & SG3 & SG2 & SG1 & \multirow{3}{*}{ TOTAL } & \\
\hline & \multicolumn{6}{|c|}{ Distancia en longitud de barra (desde pantalla) [m] } & & \\
\hline & 0.85 & 2.85 & 4.85 & 6.85 & 8.85 & 10.85 & & \\
\hline "Strain" 13/09/2016 & 17.35 & 16.23 & 1.71 & - & - & 2.06 & 37.35 & \\
\hline MOHR COULOMB & 15.68 & 10.65 & 1.30 & 0.00 & 0.00 & 0.00 & & \\
\hline |Error| [kN] & 1.67 & 5.58 & 0.41 & - & - & 2.06 & 9.72 & \\
\hline |Error| [\%] & 4.47 & 14.94 & 1.10 & - & - & 5.52 & 26.02 & \\
\hline HARDENING SOIL & 24.65 & 19.62 & 5.53 & 0.52 & 0.00 & 0.00 & & \\
\hline |Error| [kN] & 7.30 & 3.39 & 3.82 & - & - & 2.06 & 16.57 & \\
\hline |Error| [\%] & 19.54 & 9.08 & 10.23 & - & - & 5.52 & 44.36 & \\
\hline HSSMALL & 22.73 & 18.63 & 7.29 & 2.73 & 1.17 & 0.45 & & \\
\hline |Error| [kN] & 5.38 & 2.40 & 5.58 & - & - & 1.61 & 14.97 & \\
\hline |Error| [\%] & 14.40 & 6.43 & 14.94 & - & - & 4.31 & 40.08 & \\
\hline
\end{tabular}

En la construcción del sótano 3 de Torre Centre, los modelos de HSsmall y Mohr Coulomb, presentan mejor ajuste y aproximación a los resultados experimentales. 
De igual manera, la Tabla 6.34 expone a detalle la comparación de valores de fuerzas de tensión, inferidos en los "Soil Nails" por la construcción del sótano 4.

Tabla 6.34 Comparación de tensiones en "Soil Nails" por construcción de sótano 4 de Torre Centre.

\begin{tabular}{|c|c|c|c|c|c|c|c|c|}
\hline \multicolumn{9}{|c|}{ FUERZAS DE TENSIÓN EN UBIC. DE “STRAIN GAUGES” [kN] } \\
\hline \multicolumn{9}{|c|}{ SÓTANO 1 - FILA F1 (INDUCIDAS POR CONSTRUCCIÓN DE SÓTANO 4) } \\
\hline \multirow{3}{*}{$\begin{array}{l}\text { MONITORIZACIÓN / } \\
\text { MODELO DE SUELO }\end{array}$} & SG7 & SG6 & SG5 & SG4 & SG3 & SG2 & SG1 & \multirow{3}{*}{ TOTAL } \\
\hline & \multicolumn{7}{|c|}{ Distancia en longitud de barra (desde pantalla) [m] } & \\
\hline & 0.85 & 3.02 & 5.19 & 7.36 & 9.53 & 11.70 & 13.87 & \\
\hline "Strain" 14/12/2016 & - & 65.26 & - & 53.23 & - & 31.35 & - & 149.84 \\
\hline MOHR COULOMB & 41.13 & 64.37 & 70.11 & 64.00 & 53.68 & 40.32 & 21.85 & \multirow{3}{*}{$\begin{array}{l}20.63 \\
13.77\end{array}$} \\
\hline |Error $\mid[\mathrm{kN}]$ & - & 0.89 & - & 10.77 & - & 8.97 & - & \\
\hline |Error| [\%] & - & 0.59 & - & 7.19 & - & 5.99 & - & \\
\hline HARDENING SOIL & 52.73 & 79.63 & 89.63 & 87.72 & 77.20 & 58.55 & 29.72 & \multirow{3}{*}{$\begin{array}{l}76.06 \\
\mathbf{5 0 . 7 6}\end{array}$} \\
\hline |Error $\mid[\mathrm{kN}]$ & - & 14.37 & - & 34.49 & - & 27.20 & - & \\
\hline |Error| [\%] & - & 9.59 & - & 23.02 & - & 18.15 & - & \\
\hline \multirow{3}{*}{$\begin{array}{l}\text { HSSMALL } \\
\qquad \begin{array}{l}\text { Error } \mid[\mathrm{kN}] \\
\mid \text { Error } \mid[\%]\end{array}\end{array}$} & 65.36 & 81.38 & 79.17 & 68.97 & 55.67 & 39.07 & 17.91 & \multirow{3}{*}{$\begin{array}{l}39.58 \\
\mathbf{2 6 . 4 1}\end{array}$} \\
\hline & - & 16.12 & - & 15.74 & - & 7.72 & - & \\
\hline & - & 10.76 & - & 10.50 & - & 5.15 & - & \\
\hline \multicolumn{9}{|c|}{ SÓTANO 2 - FILA F2 (INDUCIDAS POR CONSTRUCCIÓN DE SÓTANO 4) } \\
\hline \multirow{3}{*}{$\begin{array}{l}\text { MONITORIZACIÓN / } \\
\text { MODELO DE SUELO }\end{array}$} & SG7 & SG6 & SG5 & SG4 & SG3 & SG2 & SG1 & \multirow{3}{*}{ TOTAL } \\
\hline & \multicolumn{7}{|c|}{ Distancia en longitud de barra (desde pantalla) [m] } & \\
\hline & 0.85 & 3.02 & 5.19 & 7.36 & 9.53 & 11.70 & 13.87 & \\
\hline "Strain" 14/12/2016 & - & 132.57 & - & 60.15 & 48.36 & - & 26.56 & 267.64 \\
\hline MOHR COULOMB & 45.49 & 57.24 & 51.74 & 48.48 & 42.71 & 36.67 & 18.11 & \multirow{3}{*}{$\begin{array}{c}101.10 \\
\mathbf{3 7 . 7 7}\end{array}$} \\
\hline |Error| [kN] & - & 75.33 & - & 11.67 & 5.65 & - & 8.48 & \\
\hline |Error $\mid[\%]$ & - & 28.15 & - & 4.36 & 2.11 & - & 3.16 & \\
\hline \multirow{3}{*}{$\begin{array}{r}\text { HARDENING SOIL } \\
\text { |Error } \mid[\mathrm{kN}] \\
\text { |Error } \mid[\%]\end{array}$} & 95.63 & 126.07 & 101.90 & 93.43 & 84.62 & 73.09 & 31.49 & \multirow{3}{*}{$\begin{array}{l}80.97 \\
\mathbf{3 0 . 2 5}\end{array}$} \\
\hline & - & 6.50 & - & 33.28 & 36.26 & - & 4.93 & \\
\hline & - & 2.43 & - & 12.43 & 13.55 & - & 1.84 & \\
\hline \multirow{3}{*}{$\begin{array}{r}\text { HSSMALL } \\
\text { |Error } \mid[\mathrm{kN}] \\
\mid \text { Error } \mid[\%]\end{array}$} & 81.45 & 104.12 & 78.53 & 66.03 & 55.51 & 46.53 & 17.71 & \multirow{3}{*}{$\begin{array}{l}50.33 \\
\mathbf{1 8 . 8 1}\end{array}$} \\
\hline & - & 28.45 & - & 5.88 & 7.15 & - & 8.85 & \\
\hline & - & 10.63 & - & 2.20 & 2.67 & - & 3.31 & \\
\hline \multicolumn{8}{|c|}{ SÓTANO 3 - FILA F3 (INDUCIDAS POR CONSTRUCCIÓN DE SÓTANO 4) } & \\
\hline \multirow{3}{*}{$\begin{array}{l}\text { MONITORIZACIÓN / } \\
\text { MODELO DE SUELO }\end{array}$} & SG6 & SG5 & SG4 & SG3 & SG2 & SG1 & \multirow{3}{*}{ TOTAL } & \\
\hline & \multicolumn{6}{|c|}{ Distancia en longitud de barra (desde pantalla) [m] } & & \\
\hline & 0.85 & 2.85 & 4.85 & 6.85 & 8.85 & 10.85 & & \\
\hline "Strain" 14/12/2016 & 36.88 & 78.24 & 86.21 & - & - & 73.91 & 275.24 & \\
\hline MOHR COULOMB & 47.12 & 79.21 & 72.61 & 52.94 & 34.88 & 17.52 & & \\
\hline |Error| [kN] & 10.24 & 0.97 & 13.60 & - & - & 56.39 & 81.20 & \\
\hline |Error| [\%] & 3.72 & 0.35 & 4.94 & - & - & 20.49 & 29.50 & \\
\hline HARDENING SOIL & 82.56 & 137.26 & 115.42 & 80.57 & 53.00 & 25.65 & & \\
\hline |Error| [kN] & 45.68 & 59.02 & 29.21 & - & - & 48.26 & 182.17 & \\
\hline |Error| [\%] & 16.60 & 21.44 & 10.61 & - & - & 17.53 & 66.19 & \\
\hline HSSMALL & 71.92 & 102.16 & 80.19 & 50.14 & 31.30 & 14.52 & & \\
\hline |Error| [kN] & 35.04 & 23.92 & 6.02 & - & - & 59.39 & 124.37 & \\
\hline |Error| [\%] & 12.73 & 8.69 & 2.19 & - & - & 21.58 & 45.19 & \\
\hline
\end{tabular}


Continuación de Tabla 6.34

\begin{tabular}{|c|c|c|c|c|c|c|c|}
\hline \multicolumn{8}{|c|}{ SÓTANO 4 - FILA F4 } \\
\hline \multirow{3}{*}{$\begin{array}{l}\text { MONITORIZACIÓN / } \\
\text { MODELO DE SUELO }\end{array}$} & SG6 & SG5 & SG4 & SG3 & SG2 & SG1 & \multirow{3}{*}{ TOTAL } \\
\hline & \multicolumn{6}{|c|}{ Distancia en longitud de barra (desde pantalla) [m] } & \\
\hline & 0.85 & 2.85 & 4.85 & 6.85 & 8.85 & 10.85 & \\
\hline "Strain" 14/12/2016 & 8.01 & 12.95 & 12.03 & 1.84 & - & - & 34.83 \\
\hline MOHR COULOMB & 10.91 & 11.26 & 0.00 & 0.00 & 0.00 & 0.00 & \\
\hline |Error| [kN] & 2.90 & 1.69 & 12.03 & 1.84 & - & - & 18.46 \\
\hline |Error $[\%]$ & 8.33 & 4.85 & 34.54 & 5.28 & - & - & 53.00 \\
\hline HARDENING SOIL & 32.74 & 34.45 & 3.32 & 0.00 & 0.00 & 0.00 & \\
\hline |Error| [kN] & 24.73 & 21.50 & 8.71 & 1.84 & - & - & 56.78 \\
\hline |Error| [\%] & 71.00 & 61.73 & 25.01 & 5.28 & - & - & 163.02 \\
\hline HSSMALL & 25.38 & 24.46 & 3.76 & 0.00 & 0.00 & 0.00 & \\
\hline |Error| [kN] & 17.37 & 11.51 & 8.27 & 1.84 & - & - & 38.99 \\
\hline |Error| [\%] & 49.87 & 33.05 & 23.74 & 5.28 & - & - & 111.94 \\
\hline
\end{tabular}

En la construcción del sótano 4 del proyecto Torre Centre, los valores de los modelos de Mohr Coulomb y HSsmall, presentan mejor ajuste y aproximación a los resultados experimentales, a diferencia de los valores obtenidos con el modelo de Hardening Soil, que muestran un mayor error.

Finalmente, la Tabla 6.35 muestra a detalle la comparación de valores de fuerzas de tensión generados en los "Soil Nails" por la construcción del sótano 5.

Tabla 6.35 Comparación de tensiones en "Soil Nails" por construcción de sótano 5 de Torre Centre.

\begin{tabular}{|c|c|c|c|c|c|c|c|c|}
\hline \multicolumn{9}{|c|}{ FUERZAS DE TENSIÓN EN UBIC. DE “STRAIN GAUGES” [kN] } \\
\hline \multicolumn{9}{|c|}{ SÓTANO 1 - FILA F1 (INDUCIDAS POR CONSTRUCCIÓN DE SÓTANO 5) } \\
\hline \multirow{3}{*}{$\begin{array}{l}\text { MONITORIZACIÓN / } \\
\text { MODELO DE SUELO }\end{array}$} & SG7 & SG6 & SG5 & SG4 & SG3 & SG2 & SG1 & \multirow{3}{*}{ TOTAL } \\
\hline & \multicolumn{7}{|c|}{ Distancia en longitud de barra (desde pantalla) [m] } & \\
\hline & 0.85 & 3.02 & 5.19 & 7.36 & 9.53 & 11.70 & 13.87 & \\
\hline "Strain" 18/01/2017 & - & 86.35 & - & 99.87 & - & 48.43 & - & 234.65 \\
\hline "Strain" 21/02/2017 & - & 91.48 & - & 104.23 & - & 54.25 & - & 249.96 \\
\hline MOHR COULOMB & 48.97 & 74.01 & 85.86 & 84.76 & 76.59 & 61.50 & 35.17 & \\
\hline Error| 18/01/2017 [kN] & - & 12.34 & - & 15.11 & - & 13.07 & - & 40.52 \\
\hline Error $\mid \%]$ & - & 5.26 & - & 6.44 & - & 5.57 & - & 17.27 \\
\hline |Error| 21/02/2017 [kN] & - & 17.47 & - & 19.47 & - & 7.25 & - & 44.19 \\
\hline |Error| [\%] & - & 6.99 & - & 7.79 & - & 2.90 & - & 17.68 \\
\hline HARDENING SOIL & 55.59 & 84.43 & 99.65 & 104.13 & 97.83 & 77.87 & 40.95 & \\
\hline |Error| 18/01/2017 [kN] & - & 1.92 & - & 4.26 & - & 29.44 & - & 35.62 \\
\hline |Error| [\%] & - & 0.82 & - & 1.82 & - & 12.55 & - & 15.18 \\
\hline |Error| 21/02/2017 [kN] & - & 7.05 & - & 0.10 & - & 23.62 & - & 30.77 \\
\hline |Error| [\%] & - & 2.82 & - & 0.04 & - & 9.45 & - & 12.31 \\
\hline HSSMALL & 71.29 & 89.64 & 92.76 & 88.44 & 77.44 & 57.78 & 27.82 & \\
\hline |Error| 18/01/2017 [kN] & - & 3.29 & - & 11.43 & - & 9.35 & - & 24.07 \\
\hline |Error| [\%] & - & 1.40 & - & 4.87 & - & 3.98 & - & 10.26 \\
\hline |Error| 21/02/2017 [kN] & - & 1.84 & - & 15.79 & - & 3.53 & - & 21.16 \\
\hline |Error| [\%] & - & 0.74 & - & 6.32 & - & 1.41 & - & 8.47 \\
\hline
\end{tabular}


Continuación de Tabla 6.35

\begin{tabular}{|c|c|c|c|c|c|c|c|c|}
\hline \multicolumn{9}{|c|}{$\begin{array}{ll}\text { SÓTANO 2- FILA F2 (INDUCIDAS POR CONSTRUCCIÓN DE SÓT } t \\
\end{array}$} \\
\hline \multirow{3}{*}{$\begin{array}{l}\text { MONITORIZACIÓN I } \\
\text { MODELO DE SUELO }\end{array}$} & SG7 & SG6 & SG5 & SG4 & SG3 & SG2 & SG1 & \multirow{3}{*}{ TOTAL } \\
\hline & \multicolumn{7}{|c|}{ Distancia en longitud de barra (desde pantalla) [m] } & \\
\hline & 0.85 & 3.02 & 5.19 & 7.36 & 9.53 & 11.70 & 13.87 & \\
\hline "Strain" 18/01/2017 & - & 90.98 & - & 119.99 & 84.27 & - & 39.67 & 334.91 \\
\hline "Strain" 21/02/2017 & - & 95.68 & - & 124.36 & 86.39 & - & 44.37 & 350.80 \\
\hline MOHR COULOMB & 50.99 & 57.24 & 64.40 & 70.14 & 70.45 & 61.49 & 37.66 & \\
\hline |Error| 18/01/2017 [kN] & - & 33.74 & - & 49.85 & 13.82 & - & 2.01 & 99.42 \\
\hline |Error| [\%] & - & 10.07 & - & 14.88 & 4.13 & - & 0.60 & 29.69 \\
\hline |Error| 21/02/2017 [kN] & - & 38.44 & - & 54.22 & 15.94 & - & 6.71 & 115.31 \\
\hline |Error| [\%] & - & 10.96 & - & 15.46 & 4.54 & - & 1.91 & 32.87 \\
\hline HARDENING SOIL & 101.65 & 126.07 & 124.63 & 126.06 & 124.37 & 105.56 & 58.40 & \\
\hline |Error| 18/01/2017 [kN] & - & 35.09 & - & 6.07 & 40.10 & - & 18.73 & 99.99 \\
\hline |Error| [\%] & - & 10.48 & - & 1.81 & 11.97 & - & 5.59 & 29.86 \\
\hline |Error| 21/02/2017 [kN] & - & 30.39 & - & 1.70 & 37.98 & - & 14.03 & 84.10 \\
\hline |Error $\mid[\%]$ & - & 8.66 & - & 0.48 & 10.83 & - & 4.00 & 23.97 \\
\hline HSSMALL & 86.38 & 104.12 & 100.14 & 97.55 & 88.88 & 68.84 & 35.07 & \\
\hline |Error| 18/01/2017 [kN] & - & 13.14 & - & 22.44 & 4.61 & - & 4.60 & 44.79 \\
\hline |Error| [\%] & - & 3.92 & - & 6.70 & 1.38 & - & 1.37 & 13.37 \\
\hline Error| 21/02/2017 [kN] & - & 8.44 & - & 26.81 & 2.49 & - & 9.30 & 47.04 \\
\hline |Error| [\%] & - & 2.41 & - & 7.64 & 0.71 & - & 2.65 & 13.41 \\
\hline \multicolumn{9}{|c|}{ SÓTANO 3 - FILA F3 (INDUCIDAS POR CONSTRUCCIÓN DE SÓTANO 5) } \\
\hline \multirow{3}{*}{$\begin{array}{l}\text { MONITORIZACIÓN / } \\
\text { MODELO DE SUELO }\end{array}$} & SG6 & SG5 & SG4 & SG3 & SG2 & SG1 & \multirow{3}{*}{ TOTAL } & \\
\hline & \multicolumn{6}{|c|}{ Distancia en longitud de barra (desde pantalla) [m] } & & \\
\hline & 0.85 & 2.85 & 4.85 & 6.85 & 8.85 & 10.85 & & \\
\hline "Strain" 18/01/2017 & 41.22 & 129.45 & 109.54 & - & - & 78.77 & 358.98 & \\
\hline "Strain" 21/02/2017 & 46.78 & 134.58 & 113.47 & - & - & 81.45 & 376.28 & \\
\hline MOHR COULOMB & 37.13 & 83.90 & 98.27 & 88.88 & 69.32 & 39.58 & & \\
\hline Error 18/01/2017 [kN] & 4.09 & 45.55 & 11.27 & - & - & 39.19 & 100.10 & \\
\hline |Error| [\%] & 1.14 & 12.69 & 3.14 & - & - & 10.92 & 27.88 & \\
\hline |Error| 21/02/2017 [kN] & 9.65 & 50.68 & 15.20 & - & - & 41.87 & 117.40 & \\
\hline Error| [\%] & 2.56 & 13.47 & 4.04 & - & - & 11.13 & 31.20 & \\
\hline HARDENING SOIL & 75.40 & 155.44 & 171.23 & 146.09 & 107.47 & 56.66 & & \\
\hline |Error| 18/01/2017 [kN] & 34.18 & 25.99 & 61.69 & - & - & 22.11 & 143.97 & \\
\hline |Error| [\%] & 9.52 & 7.24 & 17.18 & - & - & 6.16 & 40.11 & \\
\hline |Error| 21/02/2017 [kN] & 28.62 & 20.86 & 57.76 & - & - & 24.79 & 132.03 & \\
\hline |Error $\mid[\%]$ & 7.61 & 5.54 & 15.35 & - & - & 6.59 & 35.09 & \\
\hline HSSMALL & 73.71 & 119.55 & 127.53 & 101.91 & 69.98 & 34.22 & & \\
\hline |Error| 18/01/2017 [kN] & 32.49 & 9.90 & 17.99 & - & - & 44.55 & 104.93 & \\
\hline |Error| $[\%]$ & 9.05 & 2.76 & 5.01 & - & - & 12.41 & 29.23 & \\
\hline |Error| 21/02/2017 [kN] & 26.93 & 15.03 & 14.06 & - & - & 47.23 & 103.25 & \\
\hline |Error| [\%] & 7.16 & 3.99 & 3.74 & - & - & 12.55 & 27.44 & \\
\hline
\end{tabular}


Continuación de Tabla 6.35

\begin{tabular}{|c|c|c|c|c|c|c|c|}
\hline \multicolumn{8}{|c|}{ (INDUCIDAS POR CONSTRUCCIÓN DE SÓTANO 5) } \\
\hline \multirow{3}{*}{$\begin{array}{l}\text { MONITORIZACIÓN / } \\
\text { MODELO DE SUELO }\end{array}$} & SG6 & SG5 & SG4 & SG3 & SG2 & SG1 & \multirow{3}{*}{ TOTAL } \\
\hline & \multicolumn{6}{|c|}{ Distancia en longitud de barra (desde pantalla) [m] } & \\
\hline & 0.85 & 2.85 & 4.85 & 6.85 & 8.85 & 10.85 & \\
\hline "Strain" 18/01/2017 & 72.59 & 135.25 & 102.56 & 42.43 & - & - & 352.83 \\
\hline "Strain" 21/02/2017 & 76.89 & 139.56 & 105.67 & 43.39 & - & - & 365.51 \\
\hline MOHR COULOMB & 48.24 & 91.18 & 98.00 & 75.86 & 51.20 & 27.58 & \\
\hline |Error| 18/01/2017 [kN] & 24.35 & 44.07 & 4.56 & 33.43 & - & - & 106.41 \\
\hline |Error| [\%] & 6.90 & 12.49 & 1.29 & 9.47 & - & - & 30.16 \\
\hline |Error| 21/02/2017 [kN] & 28.65 & 48.38 & 7.67 & 32.47 & - & - & 117.17 \\
\hline |Error| [\%] & 7.84 & 13.24 & 2.10 & 8.88 & - & - & 32.06 \\
\hline HARDENING SOIL & 117.72 & 208.43 & 180.12 & 107.07 & 63.72 & 32.40 & \\
\hline |Error| 18/01/2017 [kN] & 45.13 & 73.18 & 77.56 & 64.64 & - & - & 260.51 \\
\hline |Error| [\%] & 12.79 & 20.74 & 21.98 & 18.32 & - & - & 73.83 \\
\hline |Error| 21/02/2017 [kN] & 40.83 & 68.87 & 74.45 & 63.08 & - & - & 247.83 \\
\hline |Error| [\%] & 11.17 & 18.84 & 20.37 & 17.42 & - & - & 67.80 \\
\hline HSSMALL & 87.49 & 148.64 & 126.53 & 65.25 & 34.02 & 16.19 & \\
\hline Error| 18/01/2017 [kN] & 14.90 & 13.39 & 23.97 & 22.82 & - & - & 75.08 \\
\hline |Error| [\%] & 4.22 & 3.80 & 6.79 & 6.47 & - & - & 21.28 \\
\hline |Error| 21/02/2017 [kN] & 10.60 & 9.08 & 20.86 & 21.86 & - & - & 62.40 \\
\hline |Error| [\%] & 2.90 & 2.48 & 5.71 & 5.98 & - & - & 17.07 \\
\hline \multicolumn{8}{|c|}{ SÓTANO 5 - FILA F5 (INDUCIDAS POR CONSTRUCCIÓN DE SÓTANO 5) } \\
\hline \multirow{3}{*}{$\begin{array}{l}\text { MONITORIZACIÓN / } \\
\text { MODELO DE SUELO }\end{array}$} & SG5 & SG4 & SG3 & SG2 & SG1 & \multirow{3}{*}{ TOTAL } & \\
\hline & \multicolumn{5}{|c|}{ Distancia en longitud de barra (desde pantalla) [m] } & & \\
\hline & 0.85 & 2.60 & 4.35 & 6.10 & 7.85 & & \\
\hline "Strain" 18/01/2017 & 23.62 & 79.33 & 54.25 & - & 1.64 & 158.84 & \\
\hline "Strain" 21/02/2017 & 28.79 & 84.38 & 56.39 & - & 3.57 & 173.13 & \\
\hline MOHR COULOMB & 27.70 & 29.07 & 12.94 & 3.10 & 0.00 & & \\
\hline Error 18/01/2017 [kN] & 4.08 & 50.26 & 41.31 & - & 1.64 & 97.29 & \\
\hline |Error $\mid[\%]$ & 2.57 & 31.64 & 26.01 & - & 1.03 & 61.25 & \\
\hline |Error| 21/02/2017 [kN] & 1.09 & 55.31 & 43.45 & - & 3.57 & 103.42 & \\
\hline |Error| [\%] & 0.63 & 31.95 & 25.10 & - & 2.06 & 59.74 & \\
\hline HARDENING SOIL & 38.16 & 62.40 & 28.31 & 8.67 & 1.27 & & \\
\hline Error| 18/01/2017 [kN] & 14.54 & 16.93 & 25.94 & - & 0.37 & 57.78 & \\
\hline |Error| $[\%]$ & 9.15 & 10.66 & 16.33 & - & 0.23 & 36.38 & \\
\hline |Error| 21/02/2017 [kN] & 9.37 & 21.98 & 28.08 & - & 2.30 & 61.73 & \\
\hline |Error| $[\%]$ & 5.41 & 12.70 & 16.22 & - & 1.33 & 35.66 & \\
\hline HSSMALL & 29.31 & 41.86 & 15.51 & 4.32 & 0.52 & & \\
\hline |Error| 18/01/2017 [kN] & 5.69 & 37.47 & 38.74 & - & 1.12 & 83.02 & \\
\hline |Error| [\%] & 3.58 & 23.59 & 24.39 & - & 0.71 & 52.27 & \\
\hline Error| 21/02/2017 [kN] & 0.52 & 42.52 & 40.88 & - & 3.05 & 86.97 & \\
\hline Error $[\%]$ & 0.30 & 24.56 & 23.61 & - & 1.76 & 50.23 & \\
\hline
\end{tabular}

En la construcción del sótano 5 del proyecto Torre Centre, los valores del modelo de HSsmall, presentan la mejor aproximación a los valores experimentales, en 
consecuencia muestran el menor error porcentual. En el presente caso, el error de aplicación del modelo constitutivo de HSsmall oscila entre el $8 \%$ y el $50 \%$.

En este apartado se comparan los resultados de fuerzas axiales de tensión para los "Soil Nails" de cada nivel de sótano en las diferentes etapas constructivas del proyecto Torre Centre, obtenidos del estudio experimental y del análisis numérico mediante elementos finitos con Plaxis 2D. La comparación realizada determina la aproximación de resultados y establece el margen de error para cada modelo constitutivo de suelo.

6.3.2.3. Comparación de fuerza axial en barras de acero de "Soil Nails" de Zaigen

La Tabla 6.36 presenta la comparación de valores experimentales y numéricos de fuerzas axiales de tensión generados en los "Soil Nails" por la construcción del sótano 1 de Zaigen. Como parte de esta comparación, se establece la aproximación entre los mismos y se determina el error porcentual [\%].

Tabla 6.36 Comparación de tensiones en "Soil Nails" por construcción de sótano 1 de Zaigen.

\begin{tabular}{|c|c|c|c|c|c|c|c|c|}
\hline \multicolumn{9}{|c|}{ FUERZAS DE TENSIÓN EN UBIC. DE “STRAIN GAUGES” [kN] } \\
\hline \multicolumn{9}{|c|}{ SÓTANO 1 - FILA F1 (INDUCIDAS POR CONSTRUCCIÓN DE SÓTANO 1) } \\
\hline \multirow{3}{*}{$\begin{array}{l}\text { MONITORIZACIÓN / } \\
\text { MODELO DE SUELO }\end{array}$} & SG7 & SG6 & SG5 & SG4 & SG3 & SG2 & SG1 & \multirow{3}{*}{ TOTAL } \\
\hline & \multicolumn{7}{|c|}{ Distancia en longitud de barra (desde pantalla) [m] } & \\
\hline & 0.85 & 3.02 & 5.19 & 7.36 & 9.53 & 11.70 & 13.87 & \\
\hline "Strain" 23/03/2017 & 6.92 & - & 6.31 & - & - & - & 0.83 & 14.06 \\
\hline MOHR COULOMB & 9.26 & 8.84 & 5.87 & 4.48 & 3.54 & 2.55 & 1.31 & \\
\hline |Error| [kN] & 2.34 & - & 0.44 & - & - & - & 0.48 & 3.26 \\
\hline |Error| [\%] & 16.64 & - & 3.13 & - & - & - & 3.41 & 23.19 \\
\hline HARDENING SOIL & 14.99 & 14.40 & 10.60 & 8.01 & 6.02 & 4.10 & 1.95 & \\
\hline |Error| [kN] & 8.07 & - & 4.29 & - & - & - & 1.12 & 13.48 \\
\hline |Error| [\%] & 57.40 & - & 30.51 & - & - & - & 7.97 & 95.87 \\
\hline HSSMALL & 15.49 & 12.78 & 8.80 & 6.18 & 4.34 & 2.77 & 1.21 & \\
\hline |Error| [kN] & 8.57 & - & 2.49 & - & - & - & 0.38 & 11.44 \\
\hline |Error $\mid[\%]$ & 60.95 & - & 17.71 & - & - & - & 2.70 & 81.37 \\
\hline
\end{tabular}

En la construcción del sótano 1 del proyecto Zaigen, los valores de fuerzas axiales de tensión obtenidos con el modelo constitutivo de suelo de Mohr Coulomb se ajustan con el menor porcentaje de error a los resultados experimentales, a diferencia de los valores del modelo constitutivo de suelo de Hardening Soil, que presentan menos aproximación y consecuentemente, un mayor error. Por su parte, el error obtenido con el modelo constitutivo de HSsmall se mantiene en una posición intermedia.

Por otro lado, la Tabla 6.37 muestra a detalle la comparación de valores experimentales y numéricos inferidos en los "Soil Nails" por la construcción del sótano 2. 
Tabla 6.37 Comparación de tensiones en "Soil Nails" por construcción de sótano 2 de Zaigen.

\begin{tabular}{|c|c|c|c|c|c|c|c|c|}
\hline \multicolumn{9}{|c|}{ FUERZAS DE TENSIÓN EN UBIC. DE “STRAIN GAUGES” [kN] } \\
\hline \multicolumn{9}{|c|}{ SÓTANO 1 - FILA F1 (INDUCIDAS POR CONSTRUCCIÓN DE SÓTANO 2) } \\
\hline \multirow{3}{*}{$\begin{array}{l}\text { MONITORIZACIÓN / } \\
\text { MODELO DE SUELO }\end{array}$} & SG7 & SG6 & SG5 & SG4 & SG3 & SG2 & SG1 & \multirow{3}{*}{ TOTAL } \\
\hline & \multicolumn{7}{|c|}{ Distancia en longitud de barra (desde pantalla) [m] } & \\
\hline & 0.85 & 3.02 & 5.19 & 7.36 & 9.53 & 11.70 & 13.87 & \\
\hline "Strain" 08/04/2017 & 57.02 & - & 90.28 & - & - & - & 8.96 & 156.26 \\
\hline MOHR COULOMB & 60.86 & 82.29 & 81.51 & 67.28 & 51.44 & 35.34 & 17.56 & \multirow{3}{*}{$\begin{array}{l}21.21 \\
\mathbf{1 3 . 5 7}\end{array}$} \\
\hline |Error| [kN] & 3.84 & - & 8.77 & - & - & - & 8.60 & \\
\hline |Error| [\%] & 2.46 & - & 5.61 & - & - & - & 5.50 & \\
\hline HARDENING SOIL & 104.59 & 128.80 & 117.81 & 99.54 & 78.57 & 54.58 & 26.14 & \multirow{3}{*}{$\begin{array}{l}92.28 \\
\mathbf{5 9 . 0 6}\end{array}$} \\
\hline |Error| [kN] & 47.57 & - & 27.53 & - & - & - & 17.18 & \\
\hline |Error| [\%] & 30.44 & - & 17.62 & - & - & - & 10.99 & \\
\hline HSSMALL & 115.87 & 127.44 & 104.07 & 78.23 & 56.51 & 36.23 & 15.74 & \multirow{3}{*}{$\begin{array}{l}79.42 \\
\mathbf{5 0 . 8 3}\end{array}$} \\
\hline |Error| [kN] & 58.85 & - & 13.79 & - & - & - & 6.78 & \\
\hline |Error| [\%] & 37.66 & - & 8.83 & - & - & - & 4.34 & \\
\hline \multicolumn{9}{|c|}{ SÓTANO 2 - FILA F2 (INDUCIDAS POR CONSTRUCCIÓN DE SÓTANO 2) } \\
\hline \multirow{3}{*}{$\begin{array}{l}\text { MONITORIZACIÓN / } \\
\text { MODELO DE SUELO }\end{array}$} & SG7 & SG6 & SG5 & SG4 & SG3 & SG2 & SG1 & \multirow{3}{*}{ TOTAL } \\
\hline & \multicolumn{7}{|c|}{ Distancia en longitud de barra (desde pantalla) [m] } & \\
\hline & 0.85 & 3.02 & 5.19 & 7.36 & 9.53 & 11.70 & 13.87 & \\
\hline "Strain" 08/04/2017 & - & 37.99 & 19.63 & - & - & 4.67 & - & 62.29 \\
\hline MOHR COULOMB & 9.44 & 2.79 & 0.00 & 0.00 & 0.00 & 0.00 & 0.00 & \\
\hline |Error| [kN] & - & 35.20 & 19.63 & - & - & 4.67 & - & 59.50 \\
\hline | Error| [\%] & - & 56.51 & 31.51 & - & - & 7.50 & - & 95.52 \\
\hline HARDENING SOIL & 19.05 & 15.76 & 4.82 & 1.67 & 1.35 & 1.44 & 0.82 & \\
\hline |Error| [kN] & - & 22.23 & 14.81 & - & - & 3.23 & - & 40.27 \\
\hline |Error| [\%] & - & 35.69 & 23.78 & - & - & 5.19 & - & 64.65 \\
\hline HSSMALL & 17.65 & 17.77 & 7.48 & 3.55 & 2.22 & 1.68 & 0.77 & \\
\hline |Error| [kN] & - & 20.22 & 12.15 & - & - & 2.99 & - & 35.36 \\
\hline |Error| [\%] & - & 32.46 & 19.51 & - & - & 4.80 & - & 56.77 \\
\hline
\end{tabular}

En la construcción del sótano 2 del proyecto Zaigen, los valores de fuerzas axiales de tensión obtenidos del análisis numérico con los modelos constitutivos de suelo de HSsmall y Mohr Coulomb, se acoplan a los resultados del estudio experimental con el menor error, a diferencia de los valores de fuerzas axiales de tensión determinados con el modelo constitutivo de suelo de Hardening Soil, que denotan menos aproximación.

De igual manera, la Tabla 6.38 presenta de manera detallada la comparación de valores de fuerzas axiales de tensión determinados de los estudios experimental y numérico, y que fueron inferidos en los "Soil Nails" por la construcción del sótano 3. 
Tabla 6.38 Comparación de tensiones en "Soil Nails" por construcción de sótano 3 de Zaigen.

\begin{tabular}{|c|c|c|c|c|c|c|c|c|}
\hline \multicolumn{9}{|c|}{ FUERZAS DE TENSIÓN EN UBIC. DE “STRAIN GAUGES” [kN] } \\
\hline \multicolumn{9}{|c|}{ SÓTANO 1 - FILA F1 (INDUCIDAS POR CONSTRUCCIÓN DE SÓTANO 3) } \\
\hline \multirow{3}{*}{$\begin{array}{l}\text { MONITORIZACIÓN / } \\
\text { MODELO DE SUELO }\end{array}$} & SG7 & SG6 & SG5 & SG4 & SG3 & SG2 & SG1 & \multirow{3}{*}{ TOTAL } \\
\hline & \multicolumn{7}{|c|}{ Distancia en longitud de barra (desde pantalla) [m] } & \\
\hline & 0.85 & 3.02 & 5.19 & 7.36 & 9.53 & 11.70 & 13.87 & \\
\hline "Strain" 22/04/2017 & 88.77 & - & 143.59 & - & - & - & 24.57 & 256.93 \\
\hline MOHR COULOMB & 78.68 & 123.66 & 153.48 & 148.65 & 124.82 & 91.70 & 47.97 & \multirow{3}{*}{$\begin{array}{l}43.38 \\
\mathbf{1 6 . 8 8}\end{array}$} \\
\hline |Error| [kN] & 10.09 & - & 9.89 & - & - & - & 23.40 & \\
\hline |Error| [\%] & 3.93 & - & 3.85 & - & - & - & 9.11 & \\
\hline HARDENING SOIL & 119.56 & 161.76 & 179.60 & 168.91 & 144.28 & 105.86 & 52.23 & \multirow{3}{*}{$\begin{array}{l}94.46 \\
\mathbf{3 6 . 7 6}\end{array}$} \\
\hline |Error| [kN] & 30.79 & - & 36.01 & - & - & - & 27.66 & \\
\hline |Error| [\%] & 11.98 & - & 14.02 & - & - & - & 10.77 & \\
\hline HSSMALL & 144.59 & 172.79 & 181.13 & 158.33 & 124.35 & 84.29 & 38.05 & \multirow{3}{*}{$\begin{array}{c}106.84 \\
\mathbf{4 1 . 5 8} \\
\end{array}$} \\
\hline |Error| [kN] & 55.82 & - & 37.54 & - & - & - & 13.48 & \\
\hline |Error| [\%] & 21.73 & - & 14.61 & - & - & - & 5.25 & \\
\hline \multicolumn{9}{|c|}{ SÓTANO 2 - FILA F2 (INDUCIDAS POR CONSTRUCCIÓN DE SÓTANO 3) } \\
\hline \multirow{3}{*}{$\begin{array}{l}\text { MONITORIZACIÓN / } \\
\text { MODELO DE SUELO }\end{array}$} & SG7 & SG6 & SG5 & SG4 & SG3 & SG2 & SG1 & \multirow{3}{*}{ TOTAL } \\
\hline & \multicolumn{7}{|c|}{ Distancia en longitud de barra (desde pantalla) [m] } & \\
\hline & 0.85 & 3.02 & 5.19 & 7.36 & 9.53 & 11.70 & 13.87 & \\
\hline "Strain" 22/04/2017 & - & 138.48 & 104.66 & - & - & 44.21 & - & 287.35 \\
\hline MOHR COULOMB & 99.97 & 117.64 & 93.52 & 63.90 & 44.10 & 30.59 & 14.85 & \multirow{3}{*}{$\begin{array}{l}45.60 \\
15.87\end{array}$} \\
\hline |Error| [kN] & - & 20.84 & 11.14 & - & - & 13.62 & - & \\
\hline |Error| [\%] & - & 7.25 & 3.88 & - & - & 4.74 & - & \\
\hline HARDENING SOIL & 159.23 & 202.31 & 163.27 & 119.78 & 90.99 & 68.72 & 28.94 & \multirow{3}{*}{$\begin{array}{c}146.95 \\
\mathbf{5 1 . 1 4}\end{array}$} \\
\hline |Error| [kN] & - & 63.83 & 58.61 & - & - & 24.51 & - & \\
\hline |Error| [\%] & - & 22.21 & 20.40 & - & - & 8.53 & - & \\
\hline \multirow{3}{*}{$\begin{array}{l}\text { HSSMALL } \\
\text { |Error } \mid[\mathrm{kN}] \\
\mid \text { Error } \mid[\%]\end{array}$} & 154.57 & 197.41 & 151.97 & 99.24 & 68.47 & 49.51 & 19.99 & \multirow{3}{*}{$\begin{array}{c}111.54 \\
\mathbf{3 8 . 8 2}\end{array}$} \\
\hline & - & 58.93 & 47.31 & - & - & 5.30 & - & \\
\hline & - & 20.51 & 16.46 & - & - & 1.84 & - & \\
\hline \multicolumn{8}{|c|}{ SÓTANO 3 - FILA F3 (INDUCIDAS POR CONSTRUCCIÓN DE SÓTANO 3) } & \\
\hline \multirow{3}{*}{$\begin{array}{l}\text { MONITORIZACIÓN / } \\
\text { MODELO DE SUELO }\end{array}$} & SG6 & SG5 & SG4 & SG3 & SG2 & SG1 & \multirow{3}{*}{ TOTAL } & \\
\hline & \multicolumn{6}{|c|}{ Distancia en longitud de barra (desde pantalla) [m] } & & \\
\hline & 0.85 & 2.85 & 4.85 & 6.85 & 8.85 & 10.85 & & \\
\hline "Strain" 22/04/2017 & 28.32 & - & - & 10.62 & 12.95 & 5.78 & 57.67 & \\
\hline MOHR COULOMB & 18.20 & 29.45 & 12.61 & 3.51 & 0.00 & 0.00 & & \\
\hline |Error| $[\mathrm{kN}]$ & 10.12 & - & - & 7.11 & 12.95 & 5.78 & 35.96 & \\
\hline |Error| [\%] & 17.55 & - & - & 12.33 & 22.46 & 10.02 & 62.35 & \\
\hline HARDENING SOIL & 27.22 & 30.95 & 13.55 & 5.64 & 2.39 & 0.86 & & \\
\hline |Error| [kN] & 1.10 & - & - & 4.98 & 10.56 & 4.92 & 21.56 & \\
\hline |Error| [\%] & 1.91 & - & - & 8.64 & 18.31 & 8.53 & 37.39 & \\
\hline HSSMALL & 23.18 & 29.47 & 12.78 & 5.60 & 2.67 & 1.08 & & \\
\hline |Error| [kN] & 5.14 & - & - & 5.02 & 10.28 & 4.70 & 25.14 & \\
\hline |Error| [\%] & 8.91 & - & - & 8.70 & 17.83 & 8.15 & 43.59 & \\
\hline
\end{tabular}

En la construcción del sótano 3 de Zaigen, los modelos de Mohr Coulomb y Hardening Soil, muestran mejor aproximación a los resultados experimentales. 
Por su parte, la Tabla 6.39 presenta a detalle la comparación de valores de fuerzas de tensión inferidos en los "Soil Nails" por la construcción del sótano 4.

Tabla 6.39 Comparación de tensiones en "Soil Nails" por construcción de sótano 4 de Zaigen.

\begin{tabular}{|c|c|c|c|c|c|c|c|c|}
\hline \multicolumn{9}{|c|}{ FUERZAS DE TENSIÓN EN UBIC. DE “STRAIN GAUGES” [kN] } \\
\hline \multicolumn{9}{|c|}{ SÓTANO 1 - FILA F1 (INDUCIDAS POR CONSTRUCCIÓN DE SÓTANO 4) } \\
\hline \multirow{3}{*}{$\begin{array}{l}\text { MONITORIZACIÓN / } \\
\text { MODELO DE SUELO }\end{array}$} & SG7 & SG6 & SG5 & SG4 & SG3 & SG2 & SG1 & \multirow{3}{*}{ TOTAL } \\
\hline & \multicolumn{7}{|c|}{ Distancia en longitud de barra (desde pantalla) [m] } & \\
\hline & 0.85 & 3.02 & 5.19 & 7.36 & 9.53 & 11.70 & 13.87 & \\
\hline "Strain" 13/05/2017 & 174.32 & & 185.56 & & & & 51.47 & 411.35 \\
\hline MOHR COULOMB & 139.92 & 170.25 & 214.86 & 230.33 & 208.24 & 160.96 & 86.75 & \multirow{3}{*}{$\begin{array}{l}98.98 \\
\mathbf{2 4 . 0 6}\end{array}$} \\
\hline |Error $\mid[\mathrm{kN}]$ & 34.40 & - & 29.30 & - & - & - & 35.28 & \\
\hline |Error $[\%]$ & 8.36 & - & 7.12 & - & - & - & 8.58 & \\
\hline HARDENING SOIL & 136.26 & 187.09 & 223.99 & 233.66 & 214.18 & 166.21 & 84.65 & \multirow{3}{*}{$\begin{array}{c}109.67 \\
\mathbf{2 6 . 6 6} \\
\end{array}$} \\
\hline |Error| [kN] & 38.06 & - & 38.43 & - & - & - & 33.18 & \\
\hline |Error| [\%] & 9.25 & - & 9.34 & - & - & - & 8.07 & \\
\hline \multirow{3}{*}{$\begin{array}{r}\text { HSSMALL } \\
\text { |Error } \mid[\mathrm{kN}] \\
\mid \text { Error } \mid[\%] \\
\end{array}$} & 167.59 & 202.84 & 232.11 & 235.47 & 208.06 & 153.20 & 74.04 & \multirow{3}{*}{$\begin{array}{l}75.85 \\
18.44\end{array}$} \\
\hline & 6.73 & & 46.55 & - & - & - & 22.57 & \\
\hline & 1.64 & & 11.32 & - & - & - & 5.09 & \\
\hline \multicolumn{9}{|c|}{ SÓTANO 2 - FILA F2 $\quad$ (INDUCIDAS POR CONSTRUCCIÓN DE SÓTANO 4) } \\
\hline \multirow{3}{*}{$\begin{array}{l}\text { MONITORIZACIÓN / } \\
\text { MODELO DE SUELO }\end{array}$} & SG7 & SG6 & SG5 & SG4 & SG3 & SG2 & SG1 & \multirow{3}{*}{ TOTAL } \\
\hline & \multicolumn{7}{|c|}{ Distancia en longitud de barra (desde pantalla) [m] } & \\
\hline & 0.85 & 3.02 & 5.19 & 7.36 & 9.53 & 11.70 & 13.87 & \\
\hline "Strain" 13/05/2017 & - & 146.26 & 115.87 & - & - & 82.16 & - & 344.29 \\
\hline MOHR COULOMB & 88.32 & 105.00 & 122.06 & 111.09 & 94.33 & 76.05 & 41.01 & \multirow{3}{*}{$\begin{array}{l}53.56 \\
\mathbf{1 5 . 5 6}\end{array}$} \\
\hline |Error| $[\mathrm{kN}]$ & - & 41.26 & 6.19 & - & - & 6.11 & - & \\
\hline |Error $[\%]$ & - & 11.98 & 1.80 & - & - & 1.77 & - & \\
\hline HARDENING SOIL & 170.29 & 232.17 & 237.93 & 204.64 & 170.14 & 136.15 & 62.83 & \multirow{3}{*}{$\begin{array}{c}261.96 \\
\mathbf{7 6 . 0 9}\end{array}$} \\
\hline $\mid$ Error $\mid[\mathrm{kN}]$ & - & 85.91 & 122.06 & - & - & 53.99 & - & \\
\hline |Error| [\%] & - & 24.95 & 35.45 & - & - & 15.68 & - & \\
\hline \multirow{3}{*}{$\begin{array}{r}\text { HSSMALL } \\
\qquad \text { |Error } \mid[\mathrm{kN}] \\
\mid \text { Error } \mid[\%]\end{array}$} & 177.81 & 232.21 & 237.93 & 194.40 & 145.03 & 108.91 & 48.06 & \multirow{3}{*}{$\begin{array}{c}234.76 \\
\mathbf{6 8 . 1 9}\end{array}$} \\
\hline & - & 85.95 & 122.06 & - & - & 26.75 & - & \\
\hline & - & 24.96 & 35.45 & - & - & 7.77 & - & \\
\hline \multicolumn{8}{|c|}{ SÓTANO 3 - FILA F3 (INDUCIDAS POR CONSTRUCCIÓN DE SÓTANO 4) } & \\
\hline \multirow{3}{*}{$\begin{array}{l}\text { MONITORIZACIÓN / } \\
\text { MODELO DE SUELO }\end{array}$} & SG6 & SG5 & SG4 & SG3 & SG2 & SG1 & \multirow{3}{*}{ TOTAL } & \\
\hline & \multicolumn{6}{|c|}{ Distancia en longitud de barra (desde pantalla) [m] } & & \\
\hline & 0.85 & 2.85 & 4.85 & 6.85 & 8.85 & 10.85 & & \\
\hline "Strain" 13/05/2017 & 146.37 & - & - & 135.28 & 66.00 & 34.56 & 382.21 & \\
\hline MOHR COULOMB & 158.81 & 218.57 & 184.43 & 125.42 & 75.73 & 33.57 & & \\
\hline |Error| $[\mathrm{kN}]$ & 12.44 & - & - & 9.86 & 9.73 & 0.99 & 33.02 & \\
\hline |Error| [\%] & 3.25 & - & - & 2.58 & 2.55 & 0.26 & 8.64 & \\
\hline HARDENING SOIL & 200.71 & 290.93 & 264.85 & 173.44 & 95.34 & 41.77 & & \\
\hline |Error $\mid[\mathrm{kN}]$ & 54.34 & - & - & 38.16 & 29.34 & 7.21 & 129.05 & \\
\hline |Error| [\%] & 14.22 & - & - & 9.98 & 7.68 & 1.89 & 33.76 & \\
\hline HSSMALL & 208.28 & 280.09 & 252.70 & 160.56 & 79.82 & 32.50 & & \\
\hline |Error| [kN] & 61.91 & - & - & 25.28 & 13.82 & 2.06 & 103.07 & \\
\hline |Error| [\%] & 16.20 & - & - & 6.61 & 3.62 & 0.54 & 26.97 & \\
\hline
\end{tabular}


Continuación de Tabla 6.39

\begin{tabular}{|c|c|c|c|c|c|c|c|}
\hline \multicolumn{8}{|c|}{ IDAS POR CONSTRUCCIÓ } \\
\hline \multirow{3}{*}{$\begin{array}{l}\text { MONITORIZACIÓN / } \\
\text { MODELO DE SUELO }\end{array}$} & SG6 & SG5 & SG4 & SG3 & SG2 & SG1 & \multirow{3}{*}{ TOTAL } \\
\hline & \multicolumn{6}{|c|}{ Distancia en longitud de barra (desde pantalla) [m] } & \\
\hline & 0.85 & 2.85 & 4.85 & 6.85 & 8.85 & 10.85 & \\
\hline "Strain" 13/05/2017 & 2.31 & - & 1.70 & 2.76 & 1.67 & - & 8.44 \\
\hline MOHR COULOMB & 19.24 & 22.01 & 14.50 & 8.18 & 4.08 & 1.51 & \multirow{3}{*}{$\begin{array}{c}37.56 \\
\mathbf{4 4 5 . 0 2}\end{array}$} \\
\hline |Error $\mid[\mathrm{kN}]$ & 16.93 & & 12.80 & 5.42 & 2.41 & - & \\
\hline |Error| [\%] & 200.59 & & 151.66 & 64.22 & 28.55 & - & \\
\hline HARDENING SOIL & 27.94 & 22.99 & 11.45 & 6.08 & 3.73 & 1.89 & \multirow{3}{*}{$\begin{array}{c}40.76 \\
\mathbf{4 8 2 . 9 4}\end{array}$} \\
\hline |Error| [kN] & 25.63 & - & 9.75 & 3.32 & 2.06 & - & \\
\hline |Error| [\%] & 303.67 & - & 115.52 & 39.34 & 24.41 & - & \\
\hline HSSMALL & 21.74 & 24.79 & 12.35 & 6.19 & 3.85 & 1.92 & \multirow{3}{*}{$\begin{array}{c}35.69 \\
\mathbf{4 2 2 . 8 7}\end{array}$} \\
\hline |Error| [kN] & 19.43 & - & 10.65 & 3.43 & 2.18 & - & \\
\hline |Error| [\%] & 230.21 & - & 126.18 & 40.64 & 25.83 & - & \\
\hline \multicolumn{8}{|c|}{ SÓTANO 4 - FILA F5 (INDUCIDAS POR CONSTRUCCIÓN DE SÓTANO 4) } \\
\hline \multirow{3}{*}{$\begin{array}{l}\text { MONITORIZACIÓN / } \\
\text { MODELO DE SUELO }\end{array}$} & SG6 & SG5 & SG4 & SG3 & SG2 & SG1 & \multirow{3}{*}{ TOTAL } \\
\hline & \multicolumn{6}{|c|}{ Distancia en longitud de barra (desde pantalla) [m] } & \\
\hline & 0.85 & 2.85 & 4.85 & 6.85 & 8.85 & 10.85 & \\
\hline "Strain" 13/05/2017 & 23.78 & 12.42 & - & 9.47 & 8.67 & - & 54.34 \\
\hline MOHR COULOMB & 42.89 & 13.46 & 1.01 & 0.00 & 0.00 & 0.00 & \\
\hline |Error $\mid[\mathrm{kN}]$ & 19.11 & 1.04 & - & 9.47 & 8.67 & - & 38.29 \\
\hline |Error| [\%] & 35.17 & 1.91 & - & 17.43 & 15.96 & - & 70.46 \\
\hline HARDENING SOIL & 29.32 & 5.20 & 0.00 & 0.00 & 0.00 & 0.00 & \\
\hline |Error| [kN] & 5.54 & 7.22 & - & 9.47 & 8.67 & - & 30.90 \\
\hline |Error| [\%] & 10.20 & 13.29 & - & 17.43 & 15.96 & - & 56.86 \\
\hline HSSMALL & 30.21 & 10.71 & 2.20 & 0.18 & 0.00 & 0.00 & \\
\hline |Error| [kN] & 6.43 & 1.71 & - & 9.29 & 8.67 & - & 26.10 \\
\hline |Error| [\%] & 11.83 & 3.15 & - & 17.10 & 15.96 & - & 48.03 \\
\hline
\end{tabular}

En la construcción del sótano 4 del proyecto Zaigen, los valores de fuerzas axiales de tensión determinados del análisis numérico con los modelos constitutivos de suelo de HSsmall y Mohr Coulomb se ajustan en su orden, a los resultados del estudio experimental con el menor porcentaje de error. Por su parte, los valores de fuerzas axiales de tensión obtenidos con el modelo constitutivo de suelo de Hardening Soil, denotan una menor aproximación a los resultados experimentales y en consecuencia un mayor error porcentual. 
Finalmente, la Tabla 6.40 presenta detalladamente la comparación de valores de fuerzas de tensión generados en los "Soil Nails" por la construcción del sótano 5.

Tabla 6.40 Comparación de tensiones en "Soil Nails" por construcción de sótano 5 de Zaigen.

\begin{tabular}{|c|c|c|c|c|c|c|c|c|}
\hline \multicolumn{9}{|c|}{ FUERZAS DE TENSIÓN EN UBIC. DE “STRAIN GAUGES” [kN] } \\
\hline \multicolumn{9}{|c|}{ SÓTANO 1 - FILA F1 (INDUCIDAS POR CONSTRUCCIÓN DE SÓTANO 5) } \\
\hline \multirow{3}{*}{$\begin{array}{l}\text { MONITORIZACIÓN / } \\
\text { MODELO DE SUELO }\end{array}$} & SG7 & SG6 & SG5 & SG4 & SG3 & SG2 & SG1 & \multirow{3}{*}{ TOTAL } \\
\hline & \multicolumn{7}{|c|}{ Distancia en longitud de barra (desde pantalla) [m] } & \\
\hline & 0.85 & 3.02 & 5.19 & 7.36 & 9.53 & 11.70 & 13.87 & \\
\hline "Strain" 20/05/2017 & 228.96 & - & 216.45 & - & - & - & 82.45 & 527.86 \\
\hline "Strain" 21/07/2017 & 233.11 & - & 219.36 & - & - & - & 85.23 & 537.70 \\
\hline MOHR COULOMB & 230.71 & 251.02 & 275.14 & 312.09 & 304.08 & 245.73 & 129.96 & \multirow{5}{*}{$\begin{array}{c}107.95 \\
\mathbf{2 0 . 4 5} \\
102.91 \\
\mathbf{1 9 . 1 4}\end{array}$} \\
\hline |Error| 20/05/2017 [kN] & 1.75 & - & 58.69 & - & - & - & 47.51 & \\
\hline |Error| [\%] & 0.33 & - & 11.12 & - & - & - & 9.00 & \\
\hline Error| 21/07/2017 [kN] & 2.40 & - & 55.78 & - & - & - & 44.73 & \\
\hline |Error| $[\%]$ & 0.45 & - & 10.37 & - & - & - & 8.32 & \\
\hline HARDENING SOIL & 151.51 & 205.72 & 251.64 & 278.14 & 270.42 & 220.99 & 120.66 & \\
\hline |Error| 20/05/2017 [kN] & 77.45 & - & 35.19 & - & - & - & 38.21 & 150.85 \\
\hline |Error| [\%] & 14.67 & - & 6.67 & - & - & - & 7.24 & 28.58 \\
\hline |Error| 21/07/2017 [kN] & 81.60 & - & 32.28 & - & - & - & 35.43 & 149.31 \\
\hline |Error| [\%] & 15.18 & - & 6.00 & - & - & - & 6.59 & 27.77 \\
\hline HSSMALL & 183.95 & 220.82 & 256.23 & 276.38 & 265.81 & 212.52 & 112.36 & \\
\hline |Error| 20/05/2017 [kN] & 45.01 & - & 39.78 & - & - & - & 29.91 & 114.70 \\
\hline |Error| $[\%]$ & 8.53 & - & 7.54 & - & - & - & 5.67 & 21.73 \\
\hline |Error| 21/07/2017 [kN] & 49.16 & - & 36.87 & - & - & - & 27.13 & 113.16 \\
\hline |Error| $[\%]$ & 9.14 & - & 6.86 & - & - & - & 5.05 & 21.05 \\
\hline \multicolumn{9}{|c|}{ SÓTANO 2 - FILA F2 (INDUCIDAS POR CONSTRUCCIÓN DE SÓTANO 5) } \\
\hline \multirow{3}{*}{$\begin{array}{l}\text { MONITORIZACIÓN / } \\
\text { MODELO DE SUELO }\end{array}$} & SG7 & SG6 & SG5 & SG4 & SG3 & SG2 & SG1 & \multirow{3}{*}{ TOTAL } \\
\hline & \multicolumn{7}{|c|}{ Distancia en longitud de barra (desde pantalla) [m] } & \\
\hline & 0.85 & 3.02 & 5.19 & 7.36 & 9.53 & 11.70 & 13.87 & \\
\hline "Strain" 20/05/2017 & - & 192.45 & 156.30 & - & - & 153.56 & - & 502.31 \\
\hline "Strain" 21/07/2017 & - & 196.12 & 159.27 & - & - & 156.12 & - & 511.51 \\
\hline MOHR COULOMB & 151.69 & 155.01 & 163.99 & 163.63 & 156.89 & 137.83 & 75.60 & \\
\hline |Error| 20/05/2017 [kN] & - & 37.44 & 7.69 & - & - & 15.73 & - & 60.86 \\
\hline |Error| [\%] & - & 7.45 & 1.53 & - & - & 3.13 & - & 12.12 \\
\hline |Error| 21/07/2017 [kN] & - & 41.11 & 4.72 & - & - & 18.29 & - & 64.12 \\
\hline |Error| [\%] & - & 8.04 & 0.92 & - & - & 3.58 & - & 12.54 \\
\hline HARDENING SOIL & 205.27 & 265.57 & 292.38 & 280.92 & 256.85 & 219.09 & 108.27 & \\
\hline |Error| 20/05/2017 [kN] & - & 73.12 & 136.08 & - & - & 65.53 & - & 274.73 \\
\hline |Error| [\%] & - & 14.56 & 27.09 & - & - & 13.05 & - & 54.69 \\
\hline |Error| 21/07/2017 [kN] & - & 69.45 & 133.11 & - & - & 62.97 & - & 265.53 \\
\hline |Error| [\%] & - & 13.58 & 26.02 & - & - & 12.31 & - & 51.91 \\
\hline HSSMALL & 209.51 & 259.34 & 287.52 & 272.77 & 235.74 & 192.63 & 91.06 & \\
\hline |Error| 20/05/2017 [kN] & - & 66.89 & 131.22 & - & - & 39.07 & - & 237.18 \\
\hline |Error| $[\%]$ & - & 13.32 & 26.12 & - & - & 7.78 & - & 47.22 \\
\hline |Error| 21/07/2017 [kN] & - & 63.22 & 128.25 & - & - & 36.51 & - & 227.98 \\
\hline |Error| $[\%]$ & - & 12.36 & 25.07 & - & - & 7.14 & - & 44.57 \\
\hline
\end{tabular}




\begin{tabular}{|c|c|c|c|c|c|c|c|}
\hline \multicolumn{8}{|c|}{ SÓTANO 3 - FILA F3 } \\
\hline \multirow{3}{*}{$\begin{array}{l}\text { MONITORIZACIÓN / } \\
\text { MODELO DE SUELO }\end{array}$} & SG6 & SG5 & SG4 & SG3 & SG2 & SG1 & \multirow{3}{*}{ TOTAL } \\
\hline & \multicolumn{6}{|c|}{ Distancia en longitud de barra (desde pantalla) [m] } & \\
\hline & 0.85 & 2.85 & 4.85 & 6.85 & 8.85 & 10.85 & \\
\hline "Strain" 20/05/2017 & 176.35 & - & - & 144.67 & 78.43 & 52.78 & 452.23 \\
\hline "Strain" 21/07/2017 & 180.15 & - & - & 147.18 & 82.51 & 56.12 & 465.96 \\
\hline MOHR COULOMB & 217.24 & 249.69 & 235.00 & 190.82 & 133.50 & 66.58 & \\
\hline |Error| 20/05/2017 [kN] & 40.89 & - & - & 46.15 & 55.07 & 13.80 & 155.91 \\
\hline |Error| [\%] & 9.04 & - & - & 10.20 & 12.18 & 3.05 & 34.48 \\
\hline Error| 21/07/2017 [kN] & 37.09 & - & - & 43.64 & 50.99 & 10.46 & 142.18 \\
\hline |Error| [\%] & 7.96 & - & - & 9.37 & 10.94 & 2.24 & 30.51 \\
\hline HARDENING SOIL & 237.05 & 325.02 & 335.61 & 280.43 & 194.67 & 100.27 & \\
\hline |Error| 20/05/2017 [kN] & 60.70 & - & - & 135.76 & 116.24 & 47.49 & 360.19 \\
\hline |Error| [\%] & 13.42 & - & - & 30.02 & 25.70 & 10.50 & 79.65 \\
\hline |Error| 21/07/2017 [kN] & 56.90 & - & - & 133.25 & 112.16 & 44.15 & 346.46 \\
\hline |Error $\mid[\%]$ & 12.21 & - & - & 28.60 & 24.07 & 9.48 & 74.35 \\
\hline HSSMALL & 245.34 & 315.93 & 326.68 & 270.96 & 187.68 & 93.01 & \\
\hline Error| 20/05/2017 [kN] & 68.99 & - & - & 126.29 & 109.25 & 40.23 & 344.76 \\
\hline |Error| [\%] & 15.26 & - & - & 27.93 & 24.16 & 8.90 & 76.24 \\
\hline |Error| 21/07/2017 [kN] & 65.19 & - & - & 123.78 & 105.17 & 36.89 & 331.03 \\
\hline $\mid$ Error $\mid[\%]$ & 13.99 & - & - & 26.56 & 22.57 & 7.92 & 71.04 \\
\hline \multicolumn{8}{|c|}{ SÓTANO 4 - FILA F4 } \\
\hline \multirow{3}{*}{$\begin{array}{l}\text { MONITORIZACIÓN / } \\
\text { MODELO DE SUELO }\end{array}$} & SG6 & SG5 & SG4 & SG3 & SG2 & SG1 & \multirow{3}{*}{ TOTAL } \\
\hline & \multicolumn{6}{|c|}{ Distancia en longitud de barra (desde pantalla) [m] } & \\
\hline & 0.85 & 2.85 & 4.85 & 6.85 & 8.85 & 10.85 & \\
\hline "Strain" 20/05/2017 & 60.32 & - & 141.37 & 111.45 & 26.87 & - & 340.01 \\
\hline "Strain" 21/07/2017 & 64.28 & - & 145.18 & 116.37 & 29.39 & - & 355.22 \\
\hline MOHR COULOMB & 24.09 & 68.40 & 125.94 & 112.00 & 78.68 & 40.58 & \\
\hline |Error| 20/05/2017 [kN] & 36.23 & - & 15.43 & 0.55 & 51.81 & - & 104.02 \\
\hline |Error| [\%] & 10.66 & - & 4.54 & 0.16 & 15.24 & - & 30.59 \\
\hline |Error| 21/07/2017 [kN] & 40.19 & - & 19.24 & 4.37 & 49.29 & - & 113.09 \\
\hline |Error| [\%] & 11.31 & - & 5.42 & 1.23 & 13.88 & - & 31.84 \\
\hline HARDENING SOIL & 82.47 & 152.77 & 175.17 & 139.70 & 104.58 & 58.80 & \\
\hline |Error| 20/05/2017 [kN] & 22.15 & - & 33.80 & 28.25 & 77.71 & - & 161.91 \\
\hline |Error| [\%] & 6.51 & - & 9.94 & 8.31 & 22.86 & - & 47.62 \\
\hline |Error| 21/07/2017 [kN] & 18.19 & - & 29.99 & 23.33 & 75.19 & - & 146.70 \\
\hline |Error| [\%] & 5.12 & - & 8.44 & 6.57 & 21.17 & - & 41.30 \\
\hline HSSMALL & 89.01 & 159.13 & 177.91 & 143.53 & 107.95 & 56.32 & \\
\hline |Error| 20/05/2017 [kN] & 28.69 & - & 36.54 & 32.08 & 81.08 & - & 178.39 \\
\hline |Error| [\%] & 8.44 & - & 10.75 & 9.44 & 23.85 & - & 52.47 \\
\hline Error| 21/07/2017 [kN] & 24.73 & - & 32.73 & 27.16 & 78.56 & - & 163.18 \\
\hline |Error| [\%] & 6.96 & - & 9.21 & 7.65 & 22.12 & - & 45.94 \\
\hline
\end{tabular}


Continuación de Tabla 6.40

\begin{tabular}{|c|c|c|c|c|c|c|c|}
\hline \multicolumn{8}{|c|}{ (INDUCIDAS POR CONSTRUCCIÓN DE SÓ' } \\
\hline \multirow{3}{*}{$\begin{array}{l}\text { MONITORIZACIÓN / } \\
\text { MODELO DE SUELO }\end{array}$} & SG6 & SG5 & SG4 & SG3 & SG2 & SG1 & \multirow{3}{*}{ TOTAL } \\
\hline & \multicolumn{6}{|c|}{ Distancia en longitud de barra (desde pantalla) [m] } & \\
\hline & 0.85 & 2.85 & 4.85 & 6.85 & 8.85 & 10.85 & \\
\hline "Strain" 20/05/2017 & 152.56 & 159.04 & - & 112.45 & 85.68 & - & 509.73 \\
\hline "Strain" 21/07/2017 & 156.37 & 162.45 & - & 115.89 & 89.32 & - & 524.03 \\
\hline MOHR COULOMB & 196.12 & 293.95 & 195.44 & 116.64 & 64.82 & 28.96 & \\
\hline |Error| 20/05/2017 [kN] & 43.56 & 134.91 & - & 4.19 & 20.86 & - & 203.52 \\
\hline |Error| [\%] & 8.55 & 26.47 & - & 0.82 & 4.09 & - & 39.93 \\
\hline Error| 21/07/2017 [kN] & 39.75 & 131.50 & - & 0.75 & 24.50 & - & 196.50 \\
\hline |Error| [\%] & 7.59 & 25.09 & - & 0.14 & 4.68 & - & $\mathbf{3 7 . 5 0}$ \\
\hline HARDENING SOIL & 189.34 & 301.96 & 229.36 & 134.60 & 71.87 & 33.31 & \\
\hline |Error| 20/05/2017 [kN] & 36.78 & 142.92 & - & 22.15 & 13.81 & - & 215.66 \\
\hline |Error| [\%] & 7.22 & 28.04 & - & 4.35 & 2.71 & - & 42.31 \\
\hline |Error| 21/07/2017 [kN] & 32.97 & 139.51 & - & 18.71 & 17.45 & - & 208.64 \\
\hline |Error| [\%] & 6.29 & 26.62 & - & 3.57 & 3.33 & - & 39.81 \\
\hline HSSMALL & 182.08 & 283.01 & 224.02 & 136.03 & 70.16 & 29.25 & \\
\hline |Error| 20/05/2017 [kN] & 29.52 & 123.97 & - & 23.58 & 15.52 & - & 192.59 \\
\hline |Error| $[\%]$ & 5.79 & 24.32 & - & 4.63 & 3.04 & - & 37.78 \\
\hline |Error| 21/07/2017 [kN] & 25.71 & 120.56 & - & 20.14 & 19.16 & - & 185.57 \\
\hline |Error $\mid[\%]$ & 4.91 & 23.01 & - & 3.84 & 3.66 & - & 35.41 \\
\hline \multicolumn{8}{|c|}{ SÓTANO 5 - FILA F6 (INDUCIDAS POR CONSTRUCCIÓN DE SÓTANO 5) } \\
\hline \multirow{3}{*}{$\begin{array}{l}\text { MONITORIZACIÓN / } \\
\text { MODELO DE SUELO }\end{array}$} & SG5 & SG4 & SG3 & SG2 & SG1 & \multirow{3}{*}{ TOTAL } & \\
\hline & \multicolumn{5}{|c|}{ Distancia en longitud de barra (desde pantalla) [m] } & & \\
\hline & 0.85 & 2.60 & 4.35 & 6.10 & 7.85 & & \\
\hline "Strain" 20/05/2017 & 26.38 & 35.13 & 16.80 & 4.83 & - & 83.14 & \\
\hline "Strain" 21/07/2017 & 31.56 & 39.37 & 20.78 & 8.67 & - & 100.38 & \\
\hline MOHR COULOMB & 25.60 & 59.23 & 41.06 & 23.90 & 9.92 & & \\
\hline Error| 20/05/2017 [kN] & 0.78 & 24.10 & 24.26 & 19.07 & - & 68.21 & \\
\hline |Error| [\%] & 0.94 & 28.99 & 29.18 & 22.94 & - & 82.04 & \\
\hline |Error| 21/07/2017 [kN] & 5.96 & 19.86 & 20.28 & 15.23 & - & 61.33 & \\
\hline |Error| [\%] & 5.94 & 19.78 & 20.20 & 15.17 & - & 61.10 & \\
\hline HARDENING SOIL & 29.24 & 52.88 & 24.90 & 10.57 & 4.56 & & \\
\hline Error 20/05/2017 [kN] & 2.86 & 17.75 & 8.10 & 5.74 & - & 34.45 & \\
\hline |Error| [\%] & 3.44 & 21.35 & 9.74 & 6.90 & - & 41.44 & \\
\hline |Error| 21/07/2017 [kN] & 2.32 & 13.51 & 4.12 & 1.90 & - & 21.85 & \\
\hline |Error| [\%] & 2.31 & 13.46 & 4.10 & 1.89 & - & 21.77 & \\
\hline HSSMALL & 29.37 & 63.94 & 28.08 & 12.51 & 5.03 & & \\
\hline |Error| 20/05/2017 [kN] & 2.99 & 28.81 & 11.28 & 7.68 & - & 50.76 & \\
\hline |Error| [\%] & 3.60 & 34.65 & 13.57 & 9.24 & - & 61.05 & \\
\hline Error| 21/07/2017 [kN] & 2.19 & 24.57 & 7.30 & 3.84 & - & 37.90 & \\
\hline |Error| [\%] & 2.18 & 24.48 & 7.27 & 3.83 & - & 37.76 & \\
\hline
\end{tabular}

En la construcción del sótano 5 del proyecto Zaigen, los valores de fuerzas axiales de tensión del análisis numérico con los modelos constitutivos de suelo de Mohr Coulomb y HSsmall, muestran en su orden, la mejor aproximación a los valores del 
estudio experimental. Para el caso de Mohr Coulomb, el error varía entre el $13 \%$ y el $61 \%$, en tanto que para $H S$ small el error oscila entre el $21 \%$ y el $71 \%$. Por su parte, el error porcentual determinado con el modelo constitutivo de suelo de Hardening Soil es ligeramente mayor al determinado con el modelo constitutivo de HSsmall.

Este apartado compara los valores de fuerzas axiales de tensión para los "Soil Nails" de cada nivel de sótano en las diferentes fases constructivas del proyecto Zaigen, determinados del estudio experimental y del análisis numérico mediante elementos finitos con Plaxis 2D.

\subsubsection{Comparación de desplazamientos horizontales en pantallas}

\subsubsection{Introducción}

En esta parte, se comparan los valores experimentales y numéricos obtenidos para los desplazamientos horizontales en las pantallas de los proyectos Torre Centre y Zaigen. Por tanto, la comparación determina la diferencia en valor absoluto entre mediciones experimentales y valores numéricos, para obtener su aproximación y establecer un error porcentual [\%]. El nivel de aproximación entre estos valores se determina para cada modelo constitutivo de suelo y para las fases de construcción de todos los niveles de sótano.

6.3.3.2. Comparación de desplazamientos horizontales en pantalla de Torre Centre

La Tabla 6.41 muestra detalladamente la comparación entre valores de desplazamientos horizontales, experimentales y numéricos, inferidos en la pantalla por la construcción de cada nivel de sótano.

Tabla 6.41 Comparación de desplazamientos horizontales por construcción de sótanos de Torre Centre

\begin{tabular}{|c|c|c|c|c|c|c|}
\hline \multicolumn{7}{|c|}{ DESPLAZAMIENTOS HORIZONTALES EN PANTALLA [m] } \\
\hline \multicolumn{7}{|c|}{ INDUCIDOS POR CONSTRUCCIÓN DE SÓTANO 1} \\
\hline \multirow{3}{*}{$\begin{array}{l}\text { MONITORIZACIÓN / } \\
\text { MODELO DE SUELO }\end{array}$} & F1 & $\mathrm{F} 2$ & F3 & F4 & F5 & \multirow{3}{*}{ |TOTAL } \\
\hline & \multicolumn{5}{|c|}{ Profundidad $[\mathrm{m}]$} & \\
\hline & -1.40 & -3.40 & -6.00 & -8.60 & -11.20 & \\
\hline "Lecturas" 25/07/2016 & -0.0020 & - & - & - & - & 0.0020 \\
\hline MOHR COULOMB & 0.0004 & - & - & - & - & \\
\hline |Error| [m] & 0.0024 & - & - & - & - & 0.0024 \\
\hline |Error| [\%] & 120.00 & - & - & - & - & 120.00 \\
\hline HARDENING SOIL & -0.0007 & - & - & - & - & \\
\hline |Error| [m] & 0.0013 & - & - & - & - & 0.0013 \\
\hline |Error| [\%] & 65.00 & - & - & - & - & 65.00 \\
\hline HSSMALL & -0.0003 & - & - & - & - & \\
\hline |Error| [m] & 0.0017 & - & - & - & - & 0.0017 \\
\hline |Error| [\%] & 85.00 & - & - & - & - & 85.00 \\
\hline
\end{tabular}


Estudio experimental y numérico del comportamiento de excavaciones ejecutadas mediante la técnica de suelo claveteado (Soil Nailing) en suelos de la ciudad de Quito (Ecuador)

Continuación de Tabla 6.41

\begin{tabular}{|c|c|c|c|c|c|c|}
\hline \multicolumn{7}{|c|}{ INDUCIDOS POR CONSTRUCCIÓN DE SÓTANO 2} \\
\hline \multirow{3}{*}{$\begin{array}{l}\text { MONITORIZACIÓN / } \\
\text { MODELO DE SUELO }\end{array}$} & F1 & $\mathrm{F} 2$ & F3 & $\mathrm{F} 4$ & F5 & \multirow{3}{*}{ |TOTAL } \\
\hline & \multicolumn{5}{|c|}{ Profundidad $[\mathrm{m}]$} & \\
\hline & -1.40 & -3.40 & -6.00 & -8.60 & -11.20 & \\
\hline "Lecturas" 03/08/2016 & -0.0040 & -0.0020 & - & - & - & 0.0060 \\
\hline MOHR COULOMB & -0.0001 & -0.0014 & - & - & - & \multirow{3}{*}{$\begin{array}{c}0.0045 \\
\mathbf{7 5 . 0 0}\end{array}$} \\
\hline |Error| [m] & 0.0039 & 0.0006 & - & - & - & \\
\hline |Error| [\%] & 65.00 & 10.00 & - & - & - & \\
\hline HARDENING SOIL & -0.0080 & -0.0123 & - & - & - & \multirow{3}{*}{$\begin{array}{l}0.0143 \\
\mathbf{2 3 8 . 3 3}\end{array}$} \\
\hline |Error| [m] & 0.0040 & 0.0103 & - & - & - & \\
\hline |Error| [\%] & 66.67 & 171.67 & - & - & - & \\
\hline HSSMALL & -0.0056 & -0.0077 & - & - & - & \multirow{3}{*}{$\begin{array}{l}0.0073 \\
\mathbf{1 2 1 . 6 7}\end{array}$} \\
\hline |Error| [m] & 0.0016 & 0.0057 & - & - & - & \\
\hline |Error| [\%] & 26.67 & 95.00 & - & - & - & \\
\hline \multicolumn{7}{|c|}{ INDUCIDOS POR CONSTRUCCIÓN DE SÓTANO 3} \\
\hline \multirow{3}{*}{$\begin{array}{l}\text { MONITORIZACIÓN / } \\
\text { MODELO DE SUELO }\end{array}$} & F1 & $\mathrm{F} 2$ & $\bar{F} 3$ & $\mathrm{~F} 4$ & F5 & \multirow{3}{*}{ |TOTAL | } \\
\hline & \multicolumn{5}{|c|}{ Profundidad [m] } & \\
\hline & -1.40 & -3.40 & -6.00 & -8.60 & -11.20 & \\
\hline \multirow{2}{*}{ MOHR COULOMB } & -0.0060 & -0.0040 & -0.0020 & - & - & 0.0120 \\
\hline & -0.0011 & -0.0029 & -0.0021 & - & - & \multirow{3}{*}{$\begin{array}{c}0.0061 \\
\mathbf{5 0 . 8 3}\end{array}$} \\
\hline \multirow{2}{*}{$\begin{array}{l}\mid \text { Error } \mid[\mathrm{m}] \\
\text { |Error } \mid[\%]\end{array}$} & 0.0049 & 0.0011 & 0.0001 & - & - & \\
\hline & 40.83 & 9.17 & 0.83 & - & - & \\
\hline \multirow{4}{*}{$\begin{array}{l}\text { HARDENING SOIL } \\
\text { |Error| [m] } \\
\text { |Error| [\%] }\end{array}$} & -0.0123 & -0.0175 & -0.0051 & - & - & \multirow{3}{*}{$\begin{array}{l}0.0229 \\
\mathbf{1 9 0 . 8 3}\end{array}$} \\
\hline & 0.0063 & 0.0135 & 0.0031 & - & - & \\
\hline & 52.50 & 112.50 & 25.83 & - & - & \\
\hline & -0.0083 & -0.0110 & -0.0049 & - & - & \\
\hline \multirow{2}{*}{ HSSMALL } & 0.0023 & 0.0070 & 0.0029 & - & - & 0.0122 \\
\hline & 19.17 & 58.33 & 24.17 & - & - & 101.67 \\
\hline INDU & $\overline{\mathrm{OS}}$ & $\overline{\mathrm{ON}}$ & CIÓN & SÓT & & \\
\hline & F1 & $\mathrm{F} 2$ & F3 & $\mathrm{F} 4$ & F5 & \\
\hline MODELO DE SUELO & & & undidad & & & |TOTAL $\mid$ \\
\hline & -1.40 & -3.40 & -6.00 & -8.60 & -11.20 & \\
\hline "Lecturas" 14/12/2016 & -0.0090 & -0.0060 & -0.0040 & -0.0020 & - & 0.0210 \\
\hline MOHR COULOMB & -0.0032 & -0.0051 & -0.0052 & -0.0056 & - & \\
\hline |Error| [m] & 0.0058 & 0.0009 & 0.0012 & 0.0036 & - & 0.0115 \\
\hline Error [\%] & 27.62 & 4.29 & 5.71 & 17.14 & - & 54.76 \\
\hline HARDENING SOIL & -0.0163 & -0.0217 & -0.0105 & -0.0077 & - & \\
\hline |Error| [m] & 0.0073 & 0.0157 & 0.0065 & 0.0057 & - & 0.0352 \\
\hline |Error| [\%] & 34.76 & 74.76 & 30.95 & 27.14 & - & 167.62 \\
\hline HSSMALL & -0.0106 & -0.0134 & -0.0080 & -0.0049 & - & \\
\hline |Error| $[\mathrm{m}]$ & 0.0016 & 0.0074 & 0.0040 & 0.0029 & - & 0.0159 \\
\hline |Error| [\%] & 7.62 & 35.24 & 19.05 & 13.81 & - & 75.71 \\
\hline
\end{tabular}


Continuación de Tabla 6.41

\begin{tabular}{|c|c|c|c|c|c|c|}
\hline \multicolumn{7}{|c|}{ INDUCIDOS POR CONSTRUCCIÓN DE SÓTANO 5} \\
\hline \multirow{3}{*}{$\begin{array}{l}\text { MONITORIZACIÓN / } \\
\text { MODELO DE SUELO }\end{array}$} & F1 & $\mathrm{F} 2$ & F3 & $\mathrm{F} 4$ & F5 & \multirow{3}{*}{ |TOTAL } \\
\hline & \multicolumn{5}{|c|}{ Profundidad $[\mathrm{m}]$} & \\
\hline & -1.40 & -3.40 & -6.00 & -8.60 & -11.20 & \\
\hline "Lecturas"18/01/2017 & -0.0120 & -0.0100 & -0.0060 & -0.0030 & -0.0010 & 0.0320 \\
\hline "Lecturas" 21/02/2017 & -0.0160 & -0.0120 & -0.0080 & -0.0050 & -0.0030 & 0.0440 \\
\hline MOHR COULOMB & -0.0074 & -0.0091 & -0.0094 & -0.0105 & -0.0110 & \\
\hline |Error| 18/01/2017 [m] & 0.0046 & 0.0009 & 0.0034 & 0.0075 & 0.0100 & 0.0264 \\
\hline |Error| [\%] & 14.38 & 2.81 & 10.63 & 23.44 & 31.25 & 82.50 \\
\hline |Error| 21/02/2017 [m] & 0.0086 & 0.0029 & 0.0014 & 0.0055 & 0.0080 & 0.0264 \\
\hline Error [\%] & 19.55 & 6.59 & 3.18 & 12.50 & 18.18 & 60.00 \\
\hline HARDENING SOIL & -0.0231 & -0.0283 & -0.0172 & -0.0153 & -0.0138 & \\
\hline |Error| 18/01/2017 [m] & 0.0111 & 0.0183 & 0.0112 & 0.0123 & 0.0128 & 0.0657 \\
\hline |Error| [\%] & 34.69 & 57.19 & 35.00 & 38.44 & 40.00 & 205.31 \\
\hline |Error| 21/02/2017 [m] & 0.0071 & 0.0163 & 0.0092 & 0.0103 & 0.0108 & 0.0537 \\
\hline |Error| [\%] & 16.14 & 37.05 & 20.91 & 23.41 & 24.55 & 122.05 \\
\hline HSSMALL & -0.0141 & -0.0169 & -0.0115 & -0.0092 & -0.0087 & \\
\hline |Error| 18/01/2017 [m] & 0.0021 & 0.0069 & 0.0055 & 0.0062 & 0.0077 & 0.0284 \\
\hline Error [\%] & 6.56 & 21.56 & 17.19 & 19.38 & 24.06 & 88.75 \\
\hline |Error| 21/02/2017 [m] & 0.0019 & 0.0049 & 0.0035 & 0.0042 & 0.0057 & 0.0202 \\
\hline |Error| [\%] & 4.32 & 11.14 & 7.95 & 9.55 & 12.95 & 45.91 \\
\hline
\end{tabular}

La comparación realizada resume la variación de error para los valores de cada modelo constitutivo de suelo del análisis numérico y en función de los datos de desplazamientos horizontales del estudio experimental.

Generalmente, en las primeras etapas constructivas de este tipo de estructuras, se tienen pequeñas variaciones de desplazamientos horizontales, que demandan de una mayor precisión en su medición y que pueden posibilitar una pérdida notable de apreciación. En el presente caso, la aproximación entre valores experimentales y numéricos en la construcción de los sótanos 1 a 4, es variable con la aplicación de cada uno de los modelos constitutivos de suelo. Sin embargo, en la construcción del sótano 5, se tiene la etapa en la cual se presentan las mayores deformaciones, al tener la pantalla su mayor altura. En esta fase constructiva, los desplazamientos horizontales determinados con el modelo constitutivo de HSsmall muestran la mejor aproximación a los resultados experimentales, por tanto, presentan el menor error porcentual, en este caso cercano al $46 \%$.

\subsubsection{Comparación de desplazamientos horizontales en pantalla de Zaigen}

La Tabla 6.42 presenta a detalle la comparación de valores de desplazamientos horizontales, experimentales y numéricos, inferidos en la pantalla por la construcción de todos los niveles de sótano. 
Estudio experimental y numérico del comportamiento de excavaciones ejecutadas mediante la técnica de suelo claveteado (Soil Nailing) en suelos de la ciudad de Quito (Ecuador)

Tabla 6.42 Comparación de desplazamientos horizontales por construcción de sótanos de Zaigen.

\begin{tabular}{|c|c|c|c|c|c|c|c|}
\hline \multicolumn{8}{|c|}{ DESPLAZAMIENTOS HORIZONTALES EN PANTALLA [m] } \\
\hline \multicolumn{8}{|c|}{ INDUCIDOS POR CONSTRUCCIÓN DE SÓTANO 1} \\
\hline \multirow{3}{*}{$\begin{array}{l}\text { MONITORIZACIÓN } \\
\text { MODELO DE SUELO }\end{array}$} & F1 & $\mathrm{F} 2$ & F3 & F4 & F5 & F6 & \multirow{3}{*}{ |TOTAL } \\
\hline & \multicolumn{6}{|c|}{ Profundidad $[\mathrm{m}]$} & \\
\hline & -1.50 & -4.50 & -7.50 & -10.00 & -12.00 & -13.50 & \\
\hline "Lecturas" 23/03/2017 & -0.0030 & - & - & - & - & - & 0.0030 \\
\hline MOHR COULOMB & 0.0025 & - & - & - & - & - & \multirow{3}{*}{$\begin{array}{l}0.0055 \\
\mathbf{1 8 3 . 3 3}\end{array}$} \\
\hline |Error $\mid[\mathrm{m}]$ & 0.0055 & - & - & - & - & - & \\
\hline |Error| [\%] & 183.33 & - & - & - & - & - & \\
\hline HARDENING SOIL & -0.0032 & - & - & - & - & - & \multirow{3}{*}{$\begin{array}{c}0.0002 \\
\mathbf{6 . 6 7}\end{array}$} \\
\hline |Error| [m] & 0.0002 & - & - & - & - & - & \\
\hline |Error| [\%] & 6.67 & - & - & - & - & - & \\
\hline HSSMALL & -0.0012 & - & - & - & - & - & \multirow{3}{*}{$\begin{array}{c}0.0018 \\
\mathbf{6 0 . 0 0}\end{array}$} \\
\hline |Error| [m] & 0.0018 & - & - & - & - & - & \\
\hline |Error| [\%] & 60.00 & - & - & - & - & - & \\
\hline \multicolumn{8}{|c|}{ INDUCIDOS POR CONSTRUCCIÓN DE SÓTANO 2} \\
\hline \multirow{3}{*}{$\begin{array}{l}\text { MONITORIZACIÓN } \\
\text { MODELO DE SUELO }\end{array}$} & F1 & $\mathrm{F} 2$ & F3 & $\mathrm{F} 4$ & F5 & F6 & \multirow{3}{*}{ |TOTAL $\mid$} \\
\hline & \multicolumn{6}{|c|}{ Profundidad $[\mathrm{m}]$} & \\
\hline & -1.50 & -4.50 & -7.50 & -10.00 & -12.00 & -13.50 & \\
\hline "Lecturas" 08/04/2017 & -0.0060 & -0.0030 & - & - & - & - & 0.0090 \\
\hline MOHR COULOMB & -0.0002 & -0.0082 & - & - & - & - & \multirow{3}{*}{$\begin{array}{l}0.0110 \\
\mathbf{1 2 2 . 2 2}\end{array}$} \\
\hline |Error| $[\mathrm{m}]$ & 0.0058 & 0.0052 & - & - & - & - & \\
\hline |Error| [\%] & 64.44 & 57.78 & - & - & - & - & \\
\hline HARDENING SOIL & -0.0117 & -0.0168 & - & - & - & - & \multirow{3}{*}{$\begin{array}{l}0.0195 \\
\mathbf{2 1 6 . 6 7}\end{array}$} \\
\hline |Error| [m] & 0.0057 & 0.0138 & - & - & - & - & \\
\hline |Error| [\%] & 63.33 & 153.33 & - & - & - & - & \\
\hline HSSMALL & -0.0078 & -0.0123 & - & - & - & - & \multirow{3}{*}{$\begin{array}{l}0.0111 \\
\mathbf{1 2 3 . 3 3}\end{array}$} \\
\hline |Error| $[\mathrm{m}]$ & 0.0018 & 0.0093 & - & - & - & - & \\
\hline |Error| [\%] & 20.00 & 103.33 & - & - & - & - & \\
\hline \multicolumn{8}{|c|}{ INDUCIDOS POR CONSTRUCCIÓN DE SÓTANO 3} \\
\hline \multirow{3}{*}{$\begin{array}{l}\text { MONITORIZACIÓN } \\
\text { MODELO DE SUELO }\end{array}$} & F1 & $\mathrm{F} 2$ & $\mathrm{~F} 3$ & $\mathrm{~F} 4$ & F5 & F6 & \multirow{3}{*}{ |TOTAL $\mid$} \\
\hline & \multicolumn{6}{|c|}{ Profundidad $[\mathrm{m}]$} & \\
\hline & -1.50 & -4.50 & -7.50 & -10.00 & -12.00 & -13.50 & \\
\hline "Lecturas" 22/04/2017 & -0.0090 & -0.0050 & -0.0020 & - & - & - & 0.0160 \\
\hline MOHR COULOMB & -0.0109 & -0.0183 & -0.0331 & - & - & - & \multirow{3}{*}{$\begin{array}{l}0.0463 \\
\mathbf{2 8 9 . 3 8}\end{array}$} \\
\hline |Error| $[\mathrm{m}]$ & 0.0019 & 0.0133 & 0.0311 & - & - & - & \\
\hline |Error| [\%] & 11.88 & 83.13 & 194.38 & - & - & - & \\
\hline HARDENING SOIL & -0.0221 & -0.0278 & -0.0261 & - & - & - & \\
\hline |Error| [m] & 0.0131 & 0.0228 & 0.0241 & - & - & - & 0.0600 \\
\hline |Error| [\%] & 81.88 & 142.50 & 150.63 & - & - & - & 375.00 \\
\hline HSSMALL & -0.0166 & -0.0217 & -0.0239 & - & - & - & \\
\hline |Error| [m] & 0.0076 & 0.0167 & 0.0219 & - & - & - & 0.0462 \\
\hline |Error| [\%] & 47.50 & 104.38 & 136.88 & - & - & - & 288.75 \\
\hline
\end{tabular}


Continuación de Tabla 6.42

\begin{tabular}{|c|c|c|c|c|c|c|c|}
\hline \multicolumn{8}{|c|}{ INDUCIDOS POR CONSTRUCCIÓN DE SÓTANO 4} \\
\hline \multirow{3}{*}{$\begin{array}{l}\text { MONITORIZACIÓN } \\
\text { MODELO DE SUELO }\end{array}$} & F1 & $\mathrm{F} 2$ & F3 & F4 & F5 & F6 & \multirow{3}{*}{ |TOTAL $\mid$} \\
\hline & \multicolumn{6}{|c|}{ Profundidad $[\mathrm{m}]$} & \\
\hline & -1.50 & -4.50 & -7.50 & -10.00 & -12.00 & -13.50 & \\
\hline "Lecturas" 13/05/2017 & -0.0130 & -0.0090 & -0.0050 & -0.0040 & -0.0030 & - & 0.0340 \\
\hline MOHR COULOMB & -0.0282 & -0.0329 & -0.0493 & -0.0468 & -0.0154 & - & \multirow{3}{*}{$\begin{array}{l}0.1386 \\
\mathbf{4 0 7 . 6 5}\end{array}$} \\
\hline |Error| [m] & 0.0152 & 0.0239 & 0.0443 & 0.0428 & 0.0124 & - & \\
\hline |Error| [\%] & 44.71 & 70.29 & 130.29 & 125.88 & 36.47 & - & \\
\hline HARDENING SOIL & -0.0362 & -0.0401 & -0.0396 & -0.0286 & -0.0089 & - & \multirow{3}{*}{$\begin{array}{l}0.1194 \\
\mathbf{3 5 1 . 1 8}\end{array}$} \\
\hline |Error| [m] & 0.0232 & 0.0311 & 0.0346 & 0.0246 & 0.0059 & - & \\
\hline |Error| [\%] & 68.24 & 91.47 & 101.76 & 72.35 & 17.35 & - & \\
\hline HSSMALL & -0.0281 & -0.0318 & -0.0353 & -0.0252 & -0.0071 & - & \multirow{3}{*}{$\begin{array}{l}0.0935 \\
\mathbf{2 7 5 . 0 0}\end{array}$} \\
\hline |Error| [m] & 0.0151 & 0.0228 & 0.0303 & 0.0212 & 0.0041 & - & \\
\hline |Error| [\%] & 44.41 & 67.06 & 89.12 & 62.35 & 12.06 & - & \\
\hline \multicolumn{8}{|c|}{ INDUCIDOS POR CONSTRUCCIÓN DE SÓTANO 5} \\
\hline \multirow{3}{*}{$\begin{array}{l}\text { MONITORIZACIÓN } \\
\text { MODELO DE SUELO }\end{array}$} & $\mathrm{F} 1$ & $\mathrm{~F} 2$ & F3 & $\mathrm{F} 4$ & F5 & F6 & \multirow{3}{*}{ |TOTAL| } \\
\hline & \multicolumn{6}{|c|}{ Profundidad [m] } & \\
\hline & -1.50 & -4.50 & -7.50 & -10.00 & -12.00 & -13.50 & \\
\hline "Lecturas" 20/05/2017 & -0.0230 & -0.0170 & -0.0090 & -0.0050 & -0.0040 & -0.0020 & 0.0600 \\
\hline "Lecturas" 21/07/2017 & -0.0390 & -0.0320 & -0.0260 & -0.0210 & -0.0200 & -0.0150 & 0.1530 \\
\hline MOHR COULOMB & -0.0596 & -0.0600 & -0.0746 & -0.0707 & -0.0389 & -0.0811 & \\
\hline |Error| 20/05/2017 [m] & 0.0366 & 0.0430 & 0.0656 & 0.0657 & 0.0349 & 0.0791 & 0.3249 \\
\hline |Error| [\%] & 61.00 & 71.67 & 109.33 & 109.50 & 58.17 & 131.83 & 541.50 \\
\hline |Error| 21/07/2017 [m] & 0.0206 & 0.0280 & 0.0486 & 0.0497 & 0.0189 & 0.0661 & 0.2319 \\
\hline |Error| [\%] & 13.46 & 18.30 & 31.76 & 32.48 & 12.35 & 43.20 & 151.57 \\
\hline HARDENING SOIL & -0.0585 & -0.0602 & -0.0579 & -0.0444 & -0.0237 & -0.0355 & \\
\hline |Error| 20/05/2017 [m] & 0.0355 & 0.0432 & 0.0489 & 0.0394 & 0.0197 & 0.0355 & 0.2202 \\
\hline |Error| [\%] & 59.17 & 72.00 & 81.50 & 65.67 & 32.83 & 55.83 & 367.00 \\
\hline |Error| 21/07/2017 [m] & 0.0195 & 0.0282 & 0.0319 & 0.0234 & 0.0037 & 0.0205 & 0.1272 \\
\hline |Error| [\%] & 12.75 & 18.43 & 20.85 & 15.29 & 2.42 & 13.40 & 83.14 \\
\hline HSSMALL & -0.0459 & -0.0476 & -0.0496 & -0.0377 & -0.0191 & -0.0292 & \\
\hline |Error| 20/05/2017 [m] & 0.0229 & 0.0306 & 0.0406 & 0.0327 & 0.0151 & 0.0272 & 0.1691 \\
\hline |Error| [\%] & 38.17 & 51.00 & 67.67 & 54.50 & 25.17 & 45.33 & 281.83 \\
\hline |Error| 21/07/2017 [m] & 0.0069 & 0.0156 & 0.0236 & 0.0167 & 0.0009 & 0.0142 & 0.0779 \\
\hline |Error| [\%] & 4.51 & 10.20 & 15.42 & 10.92 & 0.59 & 9.28 & 50.92 \\
\hline
\end{tabular}

En este proyecto, la aproximación entre valores experimentales y numéricos de desplazamientos horizontales en la pantalla, en las fases de construcción de los niveles de sótano 1 a 3, es variable con la aplicación de cada uno de los modelos constitutivos de suelo. Sin embargo, en la construcción del sótano 5, al tener la pantalla la altura mayor, se presentan las mayores deformaciones. En esta etapa constructiva, los desplazamientos horizontales determinados con el modelo constitutivo de HSsmall muestran la mejor aproximación a los resultados 
experimentales, por tanto, presentan el menor porcentaje de error, siendo para el presente caso cercano al $51 \%$.

\subsubsection{Comparación de asentamientos en el terreno detrás de pantallas}

\subsubsection{Introducción}

En esta parte, se lleva a cabo, la comparación de los valores de las mediciones del estudio experimental y los resultados del análisis numérico con los diferentes modelos constitutivos de suelo, determinados para los desplazamientos verticales o asentamientos del terreno que se encuentra detrás de las pantallas de los proyectos Torre Centre y Zaigen.

La comparación determina la diferencia en valor absoluto entre mediciones experimentales y valores numéricos, para obtener su aproximación y establecer un error porcentual [\%]. El nivel de aproximación entre estos valores se determina para cada modelo constitutivo de suelo y para las fases de construcción de todos los niveles de sótano.

\subsubsection{Comparación de asentamientos en el terreno detrás de pantalla de Torre Centre}

La Tabla 6.43 muestra de manera detallada la comparación de resultados de desplazamientos verticales o asentamientos, obtenidos de las lecturas y mediciones del estudio experimental y del análisis numérico, y que fueron inferidos progresivamente en el terreno que se encuentra detrás de la pantalla del proyecto Torre Centre, por la construcción de los diferentes niveles de sótano.

Tabla 6.43 Comparación de asentamientos por construcción de sótanos de Torre Centre.

\begin{tabular}{|c|c|c|c|c|c|}
\hline \multirow{2}{*}{\multicolumn{6}{|c|}{$\begin{array}{c}\text { ASENTAMIENTOS EN TERRENO DETRÁS DE PANTALLA } \\
\text { INDUCIDOS POR CONSTRUCCIÓN DE SÓTANO } 1\end{array}$}} \\
\hline & & & & & \\
\hline \multirow{3}{*}{$\begin{array}{l}\text { MONITORIZACIÓN / } \\
\text { MODELO DE SUELO }\end{array}$} & P1 & $\mathrm{P} 2$ & P3 & $\mathrm{P} 4$ & \multirow{3}{*}{ |TOTAL $\mid$} \\
\hline & \multicolumn{4}{|c|}{ Distancia desde la pantalla [m] } & \\
\hline & 1.00 & 5.00 & 9.00 & 13.00 & \\
\hline "Lecturas" 25/07/2016 & -0.0010 & 0.0000 & 0.0000 & 0.0000 & 0.0010 \\
\hline MOHR COULOMB & 0.0039 & 0.0024 & 0.0015 & 0.0009 & \\
\hline |Error| [m] & 0.0049 & 0.0024 & 0.0015 & 0.0009 & 0.0097 \\
\hline |Error| [\%] & 490.00 & 240.00 & 150.00 & 90.00 & 970.00 \\
\hline HARDENING SOIL & 0.0028 & 0.0019 & 0.0011 & 0.0007 & \\
\hline |Error| [m] & 0.0038 & 0.0019 & 0.0011 & 0.0007 & 0.0075 \\
\hline |Error| [\%] & 380.00 & 190.00 & 110.00 & 70.00 & 750.00 \\
\hline HSSMALL & 0.0011 & 0.0007 & 0.0004 & 0.0003 & \\
\hline |Error| [m] & 0.0021 & 0.0007 & 0.0004 & 0.0003 & 0.0035 \\
\hline |Error| [\%] & 210.00 & 70.00 & 40.00 & 30.00 & 350.00 \\
\hline
\end{tabular}


Continuación de Tabla 6.43

\begin{tabular}{|c|c|c|c|c|c|}
\hline \multicolumn{6}{|c|}{ INDUCIDOS POR CONSTRUCCIÓN DE SÓTANO 2} \\
\hline \multirow{3}{*}{$\begin{array}{l}\text { MONITORIZACIÓN / } \\
\text { MODELO DE SUELO }\end{array}$} & $\mathrm{P} 1$ & $\mathrm{P} 2$ & P3 & $\mathrm{P} 4$ & \multirow{3}{*}{ |TOTAL $\mid$} \\
\hline & \multicolumn{4}{|c|}{ Distancia desde la pantalla [m] } & \\
\hline & 1.00 & 5.00 & 9.00 & 13.00 & \\
\hline "Lecturas" 03/08/2016 & -0.0020 & -0.0010 & 0.0000 & 0.0000 & 0.0030 \\
\hline MOHR COULOMB & 0.0067 & 0.0059 & 0.0038 & 0.0024 & \multirow{3}{*}{$\begin{array}{l}0.0218 \\
\mathbf{7 2 6 . 6 7}\end{array}$} \\
\hline |Error| [m] & 0.0087 & 0.0069 & 0.0038 & 0.0024 & \\
\hline |Error| [\%] & 290.00 & 230.00 & 126.67 & 80.00 & \\
\hline HARDENING SOIL & -0.0094 & 0.0038 & 0.0031 & 0.0020 & \multirow{3}{*}{$\begin{array}{l}0.0173 \\
\mathbf{5 7 6 . 6 7}\end{array}$} \\
\hline |Error| [m] & 0.0074 & 0.0048 & 0.0031 & 0.0020 & \\
\hline |Error| [\%] & 246.67 & 160.00 & 103.33 & 66.67 & \\
\hline HSSMALL & -0.0083 & 0.0017 & 0.0012 & 0.0007 & \multirow{3}{*}{$\begin{array}{l}0.0109 \\
\mathbf{3 6 3 . 3 3}\end{array}$} \\
\hline |Error| [m] & 0.0063 & 0.0027 & 0.0012 & 0.0007 & \\
\hline |Error| [\%] & 210.00 & 90.00 & 40.00 & 23.33 & \\
\hline \multicolumn{6}{|c|}{ INDUCIDOS POR CONSTRUCCIÓN DE SÓTANO 3} \\
\hline \multirow{3}{*}{$\begin{array}{l}\text { MONITORIZACIÓN / } \\
\text { MODELO DE SUELO }\end{array}$} & $\mathrm{P} 1$ & $\mathrm{P} 2$ & $\mathrm{P} 3$ & $\mathrm{P} 4$ & \multirow{3}{*}{ |TOTAL $\mid$} \\
\hline & \multicolumn{4}{|c|}{ Distancia desde la pantalla [m] } & \\
\hline & 1.00 & 5.00 & 9.00 & 13.00 & \\
\hline "Lecturas" 13/09/2016 & -0.0030 & -0.0020 & -0.0010 & 0.0000 & 0.0060 \\
\hline MOHR COULOMB & 0.0072 & 0.0083 & 0.0058 & 0.0038 & \multirow{3}{*}{$\begin{array}{l}0.0311 \\
\mathbf{5 1 8 . 3 3}\end{array}$} \\
\hline |Error| [m] & 0.0102 & 0.0103 & 0.0068 & 0.0038 & \\
\hline |Error| [\%] & 170.00 & 171.67 & 113.33 & 63.33 & \\
\hline HARDENING SOIL & -0.0183 & 0.0039 & 0.0047 & 0.0032 & \multirow{3}{*}{$\begin{array}{l}0.0301 \\
\mathbf{5 0 1 . 6 7}\end{array}$} \\
\hline |Error| [m] & 0.0153 & 0.0059 & 0.0057 & 0.0032 & \\
\hline |Error| [\%] & 255.00 & 98.33 & 95.00 & 53.33 & \\
\hline \multirow[t]{3}{*}{ HSSMALL } & -0.0139 & 0.0017 & 0.0017 & 0.0011 & \multirow{3}{*}{$\begin{array}{l}0.0184 \\
\mathbf{3 0 6 . 6 7}\end{array}$} \\
\hline & 0.0109 & 0.0037 & 0.0027 & 0.0011 & \\
\hline & 181.67 & 61.67 & 45.00 & 18.33 & \\
\hline \multicolumn{6}{|c|}{ INDUCIDOS POR CONSTRUCCIÓN DE SÓTANO 4} \\
\hline \multirow{3}{*}{$\begin{array}{l}\text { MONITORIZACIÓN / } \\
\text { MODELO DE SUELO }\end{array}$} & $\mathrm{P} 1$ & $\mathrm{P} 2$ & P3 & $\mathrm{P} 4$ & \multirow{3}{*}{ |TOTAL $\mid$} \\
\hline & \multicolumn{4}{|c|}{ Distancia desde la pantalla [m] } & \\
\hline & 1.00 & 5.00 & 9.00 & 13.00 & \\
\hline "Lecturas" 14/12/2016 & -0.0040 & -0.0020 & -0.0010 & 0.0000 & 0.0070 \\
\hline MOHR COULOMB & 0.0066 & 0.0091 & 0.0069 & 0.0046 & \\
\hline |Error| [m] & 0.0106 & 0.0111 & 0.0079 & 0.0046 & 0.0342 \\
\hline |Error| [\%] & 151.43 & 158.57 & 112.86 & 65.71 & 488.57 \\
\hline HARDENING SOIL & -0.0235 & 0.0020 & 0.0051 & 0.0039 & \\
\hline |Error $\mid[\mathrm{m}]$ & 0.0195 & 0.0040 & 0.0061 & 0.0039 & 0.0335 \\
\hline |Error| [\%] & 278.57 & 57.14 & 87.14 & 55.71 & 478.57 \\
\hline$H S S M A L L$ & -0.0175 & 0.0002 & 0.0017 & 0.0013 & \\
\hline |Error| [m] & 0.0135 & 0.0022 & 0.0027 & 0.0013 & 0.0197 \\
\hline |Error| [\%] & 192.86 & 31.43 & 38.57 & 18.57 & 281.43 \\
\hline
\end{tabular}


Continuación de Tabla 6.43

\begin{tabular}{|c|c|c|c|c|c|}
\hline \multicolumn{6}{|c|}{ INDUCIDOS POR CONSTRUCCIÓN DE SÓTANO 5} \\
\hline \multirow{3}{*}{$\begin{array}{l}\text { MONITORIZACIÓN / } \\
\text { MODELO DE SUELO }\end{array}$} & P1 & $\mathrm{P} 2$ & $\mathrm{P} 3$ & $\mathrm{P} 4$ & \multirow{3}{*}{ |TOTAL } \\
\hline & \multicolumn{4}{|c|}{ Distancia desde la pantalla [m] } & \\
\hline & 1.00 & 5.00 & 9.00 & 13.00 & \\
\hline "Lecturas" 18/01/2017 & -0.0050 & -0.0020 & -0.0010 & -0.0010 & 0.0090 \\
\hline "Lecturas" 21/02/2017 & -0.0070 & -0.0030 & -0.0020 & -0.0100 & 0.0130 \\
\hline MOHR COULOMB & 0.0033 & 0.0074 & 0.0065 & 0.0045 & \\
\hline |Error| 18/01/2017 [m] & 0.0083 & 0.0094 & 0.0075 & 0.0055 & 0.0307 \\
\hline |Error| [\%] & 92.22 & 104.44 & 83.33 & 61.11 & 341.11 \\
\hline |Error| 21/02/2017 [m] & 0.0103 & 0.0104 & 0.0085 & 0.0055 & 0.0347 \\
\hline |Error| [\%] & 79.23 & 80.00 & 65.38 & 42.31 & 266.92 \\
\hline HARDENING SOIL & -0.0313 & -0.0034 & 0.0031 & 0.0032 & \\
\hline |Error| 18/01/2017 [m] & 0.0263 & 0.0014 & 0.0041 & 0.0042 & 0.0360 \\
\hline |Error| [\%] & 292.22 & 15.56 & 45.56 & 46.67 & 400.00 \\
\hline |Error| 21/02/2017 [m] & 0.0243 & 0.0004 & 0.0051 & 0.0042 & 0.0340 \\
\hline |Error| [\%] & 186.92 & 3.08 & 39.23 & 32.31 & 261.54 \\
\hline HSSMALL & -0.0224 & -0.0033 & 0.0004 & 0.0009 & \\
\hline |Error| 18/01/2017 [m] & 0.0174 & 0.0013 & 0.0014 & 0.0019 & 0.0220 \\
\hline |Error| [\%] & 193.33 & 14.44 & 15.56 & 21.11 & 244.44 \\
\hline Error| 21/02/2017 [m] & 0.0154 & 0.0003 & 0.0024 & 0.0019 & 0.0200 \\
\hline |Error| [\%] & 118.46 & 2.31 & 18.46 & 14.62 & 153.85 \\
\hline
\end{tabular}

Por lo general, en las primeras fases constructivas de este tipo de estructuras, se tienen pequeñas variaciones de desplazamientos verticales en el terreno, que requieren de una mayor precisión en su lectura experimental y que pueden ocasionar una pérdida notable de apreciación.

En este proyecto, en la construcción de todos los niveles de sótano, los valores del modelo constitutivo de suelo de HSsmall muestran el mejor ajuste o aproximación a los valores experimentales, y por tanto, el menor error porcentual. Por su parte, los valores del modelo constitutivo de Mohr Coulomb, presentan el mayor porcentaje de error, a diferencia de los valores del modelo constitutivo de Hardening Soil, que se mantienen en una posición intermedia. Finalmente, a pesar que el modelo de HSsmall presenta el mejor ajuste, sin embargo, se tienen porcentajes de error arriba del $300 \%$ en las fases iniciales, y un error cercano al $154 \%$ en la construcción del sótano 5, lo que determina, que los valores del análisis numérico tienden a ser superiores a los valores reales del estudio experimental.

\subsubsection{Comparación de asentamientos en el terreno detrás de pantalla de Zaigen}

La Tabla 6.44 muestra detalladamente la comparación de valores de desplazamientos verticales o asentamientos, experimentales y numéricos, inferidos en el terreno que se encuentra detrás de la pantalla, por la construcción de cada nivel de sótano. 
Tabla 6.44 Comparación de asentamientos por construcción de sótanos de Zaigen.

\begin{tabular}{|c|c|c|c|c|c|}
\hline \multicolumn{6}{|c|}{ ASENTAMIENTOS EN TERRENO DETRÁS DE PANTALLA [m] } \\
\hline \multicolumn{6}{|c|}{ INDUCIDOS POR CONSTRUCCIÓN DE SÓTANO 1} \\
\hline \multirow{3}{*}{$\begin{array}{l}\text { MONITORIZACIÓN / } \\
\text { MODELO DE SUELO }\end{array}$} & $\mathrm{P} 1$ & $\mathrm{P} 2$ & P3 & $\mathrm{P} 4$ & \multirow{3}{*}{ |TOTAL } \\
\hline & \multicolumn{4}{|c|}{ Distancia desde la pantalla $[\mathrm{m}]$} & \\
\hline & 1.00 & 5.00 & 9.00 & 13.00 & \\
\hline "Lecturas" 23/03/2017 & -0.0010 & -0.0010 & 0.0000 & 0.0000 & 0.0020 \\
\hline MOHR COULOMB & 0.0198 & 0.0141 & 0.0089 & 0.0054 & \multirow{3}{*}{$\begin{array}{c}0.0502 \\
\mathbf{2 5 1 0 . 0 0}\end{array}$} \\
\hline |Error $\mid[\mathrm{m}]$ & 0.0208 & 0.0151 & 0.0089 & 0.0054 & \\
\hline |Error| [\%] & 1040.00 & 755.00 & 455.00 & 270.00 & \\
\hline HARDENING SOIL & 0.0028 & 0.0036 & 0.0022 & 0.0014 & \multirow{3}{*}{$\begin{array}{l}0.0120 \\
\mathbf{6 0 0 . 0 0}\end{array}$} \\
\hline |Error| [m] & 0.0038 & 0.0046 & 0.0022 & 0.0014 & \\
\hline |Error| [\%] & 190.00 & 230.00 & 110.00 & 70.00 & \\
\hline$H S S M A L L$ & 0.0015 & 0.0019 & 0.0011 & 0.0007 & \multirow{3}{*}{$\begin{array}{l}0.0072 \\
\mathbf{3 6 0 . 0 0}\end{array}$} \\
\hline |Error| [m] & 0.0025 & 0.0029 & 0.0011 & 0.0007 & \\
\hline |Error| [\%] & 125.00 & 145.00 & 55.00 & 35.00 & \\
\hline \multicolumn{6}{|c|}{ INDUCIDOS POR CONSTRUCCIÓN DE SÓTANO 2} \\
\hline \multirow{3}{*}{$\begin{array}{l}\text { MONITORIZACIÓN / } \\
\text { MODELO DE SUELO }\end{array}$} & $\mathrm{P} 1$ & $\mathrm{P} 2$ & P3 & $\mathrm{P} 4$ & \multirow{3}{*}{ |TOTAL $\mid$} \\
\hline & \multicolumn{4}{|c|}{ Distancia desde la pantalla $[\mathrm{m}]$} & \\
\hline & 1.00 & 5.00 & 9.00 & 13.00 & \\
\hline "Lecturas" 08/04/2017 & -0.0030 & -0.0020 & -0.0010 & 0.0000 & 0.0060 \\
\hline MOHR COULOMB & 0.0256 & 0.0233 & 0.0163 & 0.0102 & \multirow{3}{*}{$\begin{array}{c}0.0814 \\
\mathbf{1 3 5 6 . 6 7}\end{array}$} \\
\hline |Error| [m] & 0.0286 & 0.0256 & 0.0173 & 0.0102 & \\
\hline |Error| [\%] & 476.67 & 421.67 & 288.33 & 170.00 & \\
\hline HARDENING SOIL & -0.0106 & 0.0033 & 0.0041 & 0.0027 & \multirow{3}{*}{$\begin{array}{l}0.0207 \\
\mathbf{3 4 5 . 0 0}\end{array}$} \\
\hline |Error $\mid[\mathrm{m}]$ & 0.0076 & 0.0053 & 0.0051 & 0.0027 & \\
\hline |Error| [\%] & 126.67 & 88.33 & 85.00 & 45.00 & \\
\hline HSSMALL & -0.0101 & 0.0017 & 0.0020 & 0.0013 & \multirow{3}{*}{$\begin{array}{l}0.0151 \\
\mathbf{2 5 1 . 6 7}\end{array}$} \\
\hline |Error| [m] & 0.0071 & 0.0037 & 0.0030 & 0.0013 & \\
\hline Error $[\%]$ & 118.33 & 61.67 & 50.00 & 21.67 & \\
\hline \multicolumn{6}{|c|}{ INDUCIDOS POR CONSTRUCCIÓN DE SÓTANO 3} \\
\hline \multirow{3}{*}{$\begin{array}{l}\text { MONITORIZACIÓN / } \\
\text { MODELO DE SUELO }\end{array}$} & $\mathrm{P} 1$ & $\mathrm{P} 2$ & P3 & $\mathrm{P} 4$ & \multirow{3}{*}{ |TOTAL $\mid$} \\
\hline & \multicolumn{4}{|c|}{ Distancia desde la pantalla $[\mathrm{m}]$} & \\
\hline & 1.00 & 5.00 & 9.00 & 13.00 & \\
\hline "Lecturas" 22/04/2017 & -0.0050 & -0.0030 & -0.0020 & -0.0010 & 0.0110 \\
\hline MOHR COULOMB & 0.0143 & 0.0237 & 0.0200 & 0.0131 & \multirow{3}{*}{$\begin{array}{l}0.0821 \\
\mathbf{7 4 6 . 3 6}\end{array}$} \\
\hline |Error| [m] & 0.0193 & 0.0267 & 0.0220 & 0.0141 & \\
\hline |Error| [\%] & 175.45 & 242.73 & 200.00 & 128.18 & \\
\hline \multirow{3}{*}{$\begin{array}{l}\text { HARDENING SOIL } \\
\qquad \text { |Error| }[\mathrm{m}] \\
\text { |Error } \mid[\%]\end{array}$} & -0.0298 & -0.0040 & 0.0040 & 0.0035 & \multirow{3}{*}{$\begin{array}{l}0.0363 \\
\mathbf{3 3 0 . 0 0}\end{array}$} \\
\hline & 0.0248 & 0.0010 & 0.0060 & 0.0045 & \\
\hline & 225.45 & 9.09 & 54.55 & 40.91 & \\
\hline \multirow[t]{3}{*}{ HSSMALL } & -0.0286 & -0.0051 & 0.0019 & 0.0016 & \\
\hline & 0.0236 & 0.0021 & 0.0039 & 0.0026 & 0.0322 \\
\hline & 214.55 & 19.09 & 35.45 & 23.64 & 292.73 \\
\hline
\end{tabular}


Continuación de Tabla 6.44

\begin{tabular}{|c|c|c|c|c|c|}
\hline \multicolumn{6}{|c|}{ INDUCIDOS POR CONSTRUCCIÓN DE SÓTANO 4} \\
\hline \multirow{3}{*}{$\begin{array}{l}\text { MONITORIZACIÓN / } \\
\text { MODELO DE SUELO }\end{array}$} & P1 & $\mathrm{P} 2$ & $\mathrm{P} 3$ & $\mathrm{P} 4$ & \multirow{3}{*}{ |TOTAL } \\
\hline & \multicolumn{4}{|c|}{ Distancia desde la pantalla [m] } & \\
\hline & 1.00 & 5.00 & 9.00 & 13.00 & \\
\hline "Lecturas" 13/05/2016 & -0.0070 & -0.0040 & -0.0030 & -0.0010 & 0.0150 \\
\hline MOHR COULOMB & -0.0081 & 0.0142 & 0.0188 & 0.0131 & \multirow{3}{*}{$\begin{array}{l}0.0552 \\
\mathbf{3 6 8 . 0 0}\end{array}$} \\
\hline |Error| $[\mathrm{m}]$ & 0.0011 & 0.0182 & 0.0218 & 0.0141 & \\
\hline |Error| [\%] & 7.33 & 121.33 & 145.33 & 94.00 & \\
\hline HARDENING SOIL & -0.0511 & -0.0182 & 0.0002 & 0.0017 & \multirow{3}{*}{$\begin{array}{l}0.0642 \\
\mathbf{4 2 8 . 0 0}\end{array}$} \\
\hline |Error| [m] & 0.0441 & 0.0142 & 0.0032 & 0.0027 & \\
\hline |Error| [\%] & 294.00 & 94.67 & 21.33 & 18.00 & \\
\hline HSSMALL & -0.0486 & -0.0181 & -0.0012 & -0.0001 & \multirow{3}{*}{$\begin{array}{l}0.0584 \\
\mathbf{3 8 9 . 3 3}\end{array}$} \\
\hline |Error| [m] & 0.0416 & 0.0141 & 0.0018 & 0.0009 & \\
\hline |Error| [\%] & 277.33 & 94.00 & 12.00 & 6.00 & \\
\hline \multicolumn{6}{|c|}{ INDUCIDOS POR CONSTRUCCIÓN DE SÓTANO 5} \\
\hline \multirow{3}{*}{$\begin{array}{l}\text { MONITORIZACIÓN / } \\
\text { MODELO DE SUELO }\end{array}$} & $\mathrm{P} 1$ & $\mathrm{P} 2$ & $\mathrm{P} 3$ & $\mathrm{P} 4$ & \multirow{3}{*}{ |TOTAL $\mid$} \\
\hline & \multicolumn{4}{|c|}{ Distancia desde la pantalla [m] } & \\
\hline & 1.00 & 5.00 & 9.00 & 13.00 & \\
\hline "Lecturas" 20/05/2017 & -0.0080 & -0.0050 & -0.0030 & -0.0010 & 0.0170 \\
\hline “Lecturas" 21/07/2017 & -0.0110 & -0.0080 & -0.0040 & -0.0020 & 0.0250 \\
\hline MOHR COULOMB & -0.0525 & -0.0096 & 0.0098 & 0.0090 & \\
\hline |Error| 20/05/2017 [m] & 0.0445 & 0.0046 & 0.0128 & 0.0100 & 0.0719 \\
\hline |Error| [\%] & 261.76 & 27.06 & 75.29 & 58.82 & 422.94 \\
\hline |Error| 21/07/2017 [m] & 0.0415 & 0.0016 & 0.0138 & 0.0110 & 0.0679 \\
\hline |Error| [\%] & 166.00 & 6.40 & 55.20 & 44.00 & 271.60 \\
\hline HARDENING SOIL & -0.0766 & -0.0365 & -0.0079 & -0.0061 & \\
\hline |Error| 20/05/2017 [m] & 0.0686 & 0.0315 & 0.0049 & 0.0051 & 0.1101 \\
\hline |Error $\mid[\%]$ & 403.53 & 185.29 & 28.82 & 30.00 & 647.65 \\
\hline |Error| 21/07/2017 [m] & 0.0656 & 0.0285 & 0.0039 & 0.0041 & 0.1021 \\
\hline |Error| [\%] & 262.40 & 114.00 & 15.60 & 16.40 & 408.40 \\
\hline HSSMALL & -0.0702 & -0.0336 & -0.0081 & -0.0070 & \\
\hline |Error| 20/05/2017 [m] & 0.0622 & 0.0286 & 0.0051 & 0.0060 & 0.1019 \\
\hline |Error $\mid[\%]$ & 365.88 & 168.24 & 30.00 & 35.29 & 599.41 \\
\hline |Error| 21/07/2017 [m] & 0.0592 & 0.0256 & 0.0041 & 0.0050 & 0.0939 \\
\hline |Error| [\%] & 236.80 & 102.40 & 16.40 & 20.00 & 375.60 \\
\hline
\end{tabular}

En la construcción de los niveles de sótano de este proyecto, los valores de desplazamientos verticales del terreno, del modelo constitutivo de suelo de HSsmall muestran la mejor aproximación a los valores del estudio experimental. Sin embargo, a pesar que este modelo de suelo presenta el mejor ajuste, se evidencian porcentajes de error arriba del $250 \%$, lo que demuestra que los resultados del análisis numérico tienden a ser superiores a los valores reales del estudio experimental. 


\subsection{Conclusiones relativas a los resultados del estudio experimental}

En este capítulo se exponen los valores de fuerzas de tensión en los "Soil Nails", desplazamientos horizontales en las pantallas y los asentamientos del terreno detrás de las pantallas, obtenidos del estudio experimental de las estructuras de "Soil Nailing" de los proyectos Torre Centre y Zaigen.

Como parte del estudio experimental, para determinar las fuerzas de tensión en los "Soil Nails" de la estructura de "Soil Nailing" de Torre Centre se instalaron 31 galgas extensométricas, de las cuales 12 no registraron información, que representa una "mortalidad" del $39 \%$ en lo referente al funcionamiento de "Strain Gauges". Por su parte, en la estructura de "Soil Nailing" de Zaigen se instalaron 37 galgas extensométricas, de las cuales 15 no reportaron información, que equivale a una "mortalidad" del $41 \%$ en lo que respecta al funcionamiento de "Strain Gauges".

De manera general y simplificada, los valores de fuerzas de tensión en los "Soil Nails", los desplazamientos horizontales en las pantallas y los asentamientos del terreno registrados en el estudio experimental de ambos proyectos resultan inferiores a aquellos determinados en el estudio numérico con elementos finitos y los modelos constitutivos de suelo de Mohr Coulomb (MC), Hardening Soil (HS) y Hardening Soil with Small-Strain Stiffness (HSsmall). Sin embargo, los valores de estas 3 variables: fuerzas de tensión, desplazamientos horizontales y asentamientos constituyen una función del tiempo, pues mientras la estructura de "Soil Nailing" conserve su altura libre y no se realicen apuntalamientos constructivos con las losas de entrepiso o forjados, estas variables sufren incrementos, los cuales fueron registrados y fue notorio en las lecturas de "Strain" y las mediciones topográficas después de la última fase constructiva (Ver Tabla 6.35 y Tabla 6.40).

Del análisis comparativo de los resultados del estudio experimental con los resultados del análisis numérico con cada modelo constitutivo de suelo, se tiene que el modelo de HSsmall se ajusta mejor a los datos experimentales de fuerzas de tensión, desplazamientos horizontales y asentamientos, ya que reflejan el menor porcentaje de error en comparación con los valores de los modelos constitutivos de Mohr Coulomb y Hardening Soil. El mejor ajuste es más notorio durante la fase constructiva del último nivel de sótano, que es cuando se han inducido los valores más altos de "Strain" y de deformaciones en el terreno. Por el contrario, en las primeras etapas constructivas se maneja en el rango de pequeños valores de "Strain" y desplazamientos, que requieren de una mayor precisión y que da opción a una pérdida notable de apreciación.

Sin embargo, el modelo de Mohr Coulomb, al momento de estimar las fuerzas de tensión en determinadas etapas constructivas iniciales se ajusta de manera aceptable a los resultados del estudio experimental. Por lo que este modelo de suelo que se caracteriza por su simplicidad de manejo puede utilizarse como una opción de estimación rápida y somera de las fuerzas de tensión en los "Soil Nails". 
Por su parte, los desplazamientos horizontales de las pantallas determinados con el modelo de HSsmall se ajustan mejor a los obtenidos en las lecturas del estudio experimental. Esta apreciación resulta más evidente al término de la monitorización de la construcción del último nivel de sótano de cada proyecto.

De igual manera, en la mayoría de casos los asentamientos del terreno determinados con el modelo de HSsmall se ajustan con el menor error porcentual a los asentamientos obtenidos en el estudio experimental, en comparación a los modelos constitutivos de Mohr Coulomb y Hardening Soil.

Es importante mencionar que los desplazamientos verticales del terreno obtenidos del análisis numérico con el modelo de Mohr Coulomb en gran parte de casos resultan estados de ascensión o levantamiento del suelo en lugar de asentamientos, como en la mayoría de casos con los modelos numéricos de HSsmall y Hardening Soil y las lecturas del estudio experimental. Esto se debe a que el modelo de Mohr Coulomb utiliza un solo módulo de elasticidad del suelo para la carga y la descarga, a diferencia de los modelos de Hardening Soil y HSsmall que incluyen un módulo de rigidez de descarga/recarga, $E_{u r}$ que permite representar el comportamiento del suelo en condiciones de carga y descarga. Por tanto, el modelo constitutivo de Mohr Coulomb no es el más adecuado para estimar los asentamientos del terreno inferidos por las excavaciones para la construcción de los diferentes niveles de sótano. 


\section{Capítulo 7}

\section{CONCLUSIONES Y FUTURAS LÍNEAS DE INVESTIGACIÓN}

\subsection{Conclusiones}

En la ciudad de Quito, la aplicación de la técnica de "Soil Nailing" ha resultado ser efectiva al momento de reforzar el terreno durante las etapas de excavación para la construcción de los diferentes niveles de estructuras de sótano en edificaciones de proyectos inmobiliarios y de altura. Es así que, esta técnica de refuerzo del terreno ha ganado un reconocido espacio de confiabilidad en su aplicación en la mayoría de estructuras subterráneas de sótano. Pero, por el contrario, "Soil Nailing" en la capital ecuatoriana, a pesar de su uso extendido, cuenta con escasos estudios locales experimentales y numéricos basados en estructuras teóricas y reales; y el análisis de su comportamiento suele estar apegado a casos de estudios y normativas características de otros medios, o en su defecto a experiencias de construcciones exitosas de estructuras vecinas similares.

Esta Tesis Doctoral se ha centrado en el estudio experimental y numérico del comportamiento de excavaciones ejecutadas con la técnica de "Soil Nailing" para construcción de sótanos de aparcamiento vehicular de cinco niveles de dos importantes edificios localizados en el sector centro-norte de la ciudad de Quito. Pero para lograr este objetivo general, de manera específica y obligatoria se han determinado a detalle los parámetros geotécnicos para diferentes modelos constitutivos de suelo de esta zona en particular, para ser utilizados en el análisis numérico. Adicionalmente, el desarrollo de la investigación del comportamiento de 
las estructuras, permitió verificar la validez y el nivel de aproximación entre los resultados experimentales y valores numéricos de fuerzas axiales de tensión y deformaciones. Por tanto, la obtención detallada de los parámetros geotécnicos de los suelos volcánicos de la zona centro-norte de la ciudad de Quito y la comparación y validación de los resultados del estudio experimental y del análisis numérico con los diferentes modelos constitutivos de suelo, constituyen los aportes principales de esta Tesis Doctoral.

El primer paso de esta investigación constituyó el estudio de caracterización geotécnica del terreno del sitio en donde se emplazan las estructuras, para en función de este estudio determinar los parámetros geotécnicos para cada uno de los modelos constitutivos de suelo para el análisis numérico con elementos finitos.

El estudio de caracterización geotécnica realizado en la zona centro-norte de la ciudad de Quito determinó principalmente las siguientes conclusiones:

- El subsuelo en la zona centro-norte de la ciudad de Quito está constituido por suelos volcánicos compuestos principalmente por limos y acillas de baja a alta plasticidad e integrados básicamente por anortita, augita, tremolita, cristobalita, albita, diópsido, cuarzo, clinoenstatita y clorita. Sin embargo, también se identificaron en menores proporciones pirita, calcita, biotita, montmorillonita y caolinita.

- Algunas imágenes de ensayos de microscopía electrónica (SEM) mostraron presencia de burbujas de gas, lo cual podría ser la razón principal de los valores bajos de densidad y de gravedad específica y por el contrario valores altos de relación de vacíos y de porosidad de determinados estratos de suelo, en concordancia con los estudios de suelos volcánicos analizados por otros investigadores.

- Se determinó estratos de suelos ligeramente sobreconsolidados, con relaciones de sobreconsolidación $(O C R)$ en el rango de 1.29 y 1.69 para perfiles hasta la profundidad de $15.0 \mathrm{~m}$. Por tanto, los valores obtenidos de $O C R$ fueron incluidos en el análisis numérico en todos los modelos constitutivos de suelo.

- En general, se identificaron de manera clara dos grupos de estratos de suelos con parámetros de resistencia al corte no drenada. Entre $3.5 \mathrm{~m}$ y $7.5 \mathrm{~m}$ de profundidad, los valores del ángulo de fricción pico $\left(\emptyset_{\text {peak }}^{\prime}\right)$ medidos variaron entre $33.7^{\circ}$ a $34.8^{\circ}$, mientras que entre $9.0 \mathrm{~m}$ y $14.5 \mathrm{~m}$ los valores de $\emptyset_{\text {peak }}^{\prime}$ medidos estuvieron en el rango de $37.1^{\circ}$ y $38.0^{\circ}$. Por su parte, el ángulo de fricción pico $\left(\emptyset^{\prime}\right.$ peak $)$ obtenido en los ensayos de compresión triaxial consolidados drenados presentaron valores entre $36.1^{\circ}$ y $36.9^{\circ}$ para profundidades entre $8.0 \mathrm{~m}$ y $13.5 \mathrm{~m}$.

- Los valores de cohesión obtenidos en el presente estudio estuvieron en el rango de $5 \mathrm{kPa}$ y $69 \mathrm{kPa}$, como puede verse en las Tablas 3.2 y 3.3 . 
Los diferentes parámetros para cada modelo constitutivo de suelo utilizados en el análisis numérico se determinaron a partir de los resultados de los ensayos de laboratorio del estudio de caracterización geotécnica. En resumen, los parámetros de resistencia al corte (cohesión c' y ángulo de fricción $\varnothing^{\prime}$ ) se tomaron directamente de los ensayos triaxiales consolidados no drenados $(C U)$ y consolidados drenados $(C D)$. Por otra parte, los parámetros de rigidez $\left(E_{50}^{r e f}\right.$ y $\left.E_{u r}^{r e f}\right)$ para los modelos de Hardening Soil y HSsmall por principio y requerimiento básico de estos modelos constitutivos fueron determinados exclusivamente de los ensayos triaxiales consolidados drenados $(C D)$, mientras que los parámetros del módulo de rigidez tangente $E_{\text {oed }}^{\text {ref fueron }}$ obtenidos de los ensayos edométricos. Es importante recalcar que para determinar los parámetros de rigidez de los modelos de Hardening Soil y HSsmall se requiere obligadamente de ensayos triaxiales consolidados drenados $(C D)$; sin embargo, pueden ser estimados de una manera superficial a través de correlaciones a partir de la rigidez no drenada.

Del análisis numérico de las estructuras de "Soil Nailing" con los diferentes modelos constitutivos de suelo mediante elementos finitos se determinaron las siguientes conclusiones:

- Las fuerzas de tensión obtenidas en los "Soil Nails" con el modelo de Mohr Coulomb en general son menores a las tensiones estimadas con los modelos de Hardening Soil y HSsmall. No obstante, las tensiones obtenidas con Hardening Soil y HSsmall guardan cierta similitud entre ellas en varias fases constructivas, siendo las tensiones del modelo de Hardening Soil ligeramente mayores en gran parte del proceso constructivo.

- Los desplazamientos horizontales de las pantallas obtenidos con el modelo de Mohr Coulomb son menores en gran parte de las fases constructivas a los valores de los otros modelos constitutivos. Por su parte, los desplazamientos horizontales determinados con Hardening Soil resultan superiores al resto, a diferencia de los valores obtenidos con HSsmall que se encajan en una posición intermedia.

- Los valores de asentamientos del terreno detrás de las pantallas inferidos por la construcción de los sótanos y obtenidos con los modelos constitutivos de suelo de Hardening Soil y HSsmall resultan similares, siendo los asentamientos de Hardening Soil ligeramente superiores. Por otro lado, los desplazamientos verticales del terreno detrás de las pantallas obtenidos con el modelo de Mohr Coulomb en gran parte de los casos resultaron estados de levantamiento del suelo en lugar de asentamientos.

Por otra parte, del análisis de estabilidad global, los factores de seguridad (FS) determinados con elementos finitos y métodos de equilibrio límite mostraron valores dispersos al inicio de la construcción de los sótanos, pero fueron convergiendo progresivamente con el avance de las etapas constructivas hasta presentar valores 
similares con la construcción del quinto nivel de sótano equivalente $100 \%$ de la construcción.

En lo referente al estudio experimental, como parte de esta investigación en los "Soil Nails" de ambas estructuras de "Soil Nailing" se instalaron en total 68 galgas extensométricas, de las cuales 27 no registraron valores coherentes de "Strain", que representa una "mortalidad" del $40 \%$ en lo que respecta al funcionamiento de "Strain Gauges". Los daños en este porcentaje de galgas extensométricas afectadas probablemente se debieron a deficiencias en la adherencia sensor - barra de acero, problemas de humedad o algún golpe durante los procedimientos de instalación de la barra de acero en todo el tramo de la perforación o en el proceso de inyección del "Grout".

Del estudio experimental de las estructuras de "Soil Nailing" fundamentado principalmente en los procesos de instrumentación y monitorización se determinaron las siguientes conclusiones:

- Los valores de fuerzas axiales de tensión en las barras de acero de los "Soil Nails", de desplazamientos horizontales en las pantallas y de asentamientos del terreno detrás de las pantallas obtenidos del estudio experimental, de manera general son inferiores a aquellos del análisis numérico con elementos finitos con los modelos constitutivos de suelo de Mohr Coulomb, Hardening Soil y HSsmall.

- Los valores experimentales de fuerzas de tensión, desplazamientos horizontales y asentamientos no permanecen constantes al final de una etapa constructiva y por el contrario sufren incrementos, por lo que son una función del tiempo. Esto resulta más notorio después de la última fase constructiva, siempre y cuando la estructura de "Soil Nailing" conserve su altura libre y no se realicen apuntalamientos constructivos con las losas de entrepiso o forjados, que alteren las condiciones de comparación. En esta investigación, se pudo ejecutar una comparación inicial que sirvió como referencia y no fue posible realizar un estudio completo de variación a través del tiempo, ya que al tratarse de proyectos de edificación reales y de inversión privada, los procesos constructivos de los niveles de forjados se dieron en el lapso de poco tiempo, por parte de la empresa constructora.

- Los valores de fuerzas axiales de tensión, desplazamientos horizontales y asentamientos, obtenidos con el modelo constitutivo de HSsmall se ajustan con el menor error porcentual a los obtenidos en el estudio experimental. Resulta más notorio el mejor acople de valores de los estudios experimental y numérico, en la construcción del último nivel de sótano o al $100 \%$ de la construcción, que es cuando se han generado los valores mayores de "Strain" en las barras de acero $\mathrm{y}$ de deformaciones en el terreno.

- La aplicación del modelo constitutivo de Mohr Coulomb resulta aceptable en este caso al momento de estimar de manera simplificada o a manera de una 
primera aproximación los valores de las fuerzas axiales de tensión, en ausencia de ensayos de laboratorio que permitan determinar los parámetros geotécnicos para aplicación del modelo constitutivo de HSsmall. Sin embargo, Mohr Coulomb, al ser un modelo de suelo básico resulta inapropiado para estimar los asentamientos del terreno generados por las excavaciones de cada fase constructiva, es evidente que en gran parte de los casos se obtienen estados de ascensión o levantamiento del suelo exagerados, en lugar de asentamientos. Por tanto, los modelos de HSsmall y Hardening Soil, en su orden, resultan más convenientes y prácticos para estimar las deformaciones verticales del terreno, puesto que incluyen un módulo de rigidez de descarga/recarga, $E_{u r}$ que permite representar el comportamiento del suelo en condiciones de carga y descarga.

\subsection{Futuras líneas de investigación}

A raíz de las investigaciones de esta Tesis Doctoral, surge la necesidad de realizar estudios adicionales para complementar la investigación ya iniciada dentro del comportamiento de estructuras de "Soil Nailing". Por lo tanto, se plantean las siguientes líneas de investigación:

- Estudio de ajuste de parámetros geotécnicos en base a los resultados del análisis numérico y del estudio experimental, de manera de calibrar los modelos teóricos de las estructuras.

- Estudio experimental y numérico de la variación de los valores de fuerzas de tensión en los "Soil Nails", desplazamientos horizontales en la pantalla y asentamientos del terreno a través del tiempo después del $100 \%$ de la construcción. Se ha verificado que estas variables son una función del tiempo y por tanto sufren incrementos, especialmente al final de la construcción de la estructura.

- Desarrollo de un método simplificado de análisis de este tipo de estructuras claveteadas con enfoque en la estimación de las fuerzas axiales en las barras de los "Soil Nails" y la magnitud de los desplazamientos horizontales en la pantalla y los asentamientos del terreno inferidos por la ejecución de cada fase constructiva.

- Estudio de la resistencia a la extracción (pull-out) en los "Soil Nails" en la interfaz del suelo con el "Grout" o en el contacto "Grout" con la barra de acero o bulón. La resistencia a la extracción o "pull-out" es un parámetro fundamental de incidencia directa en la estabilidad global de la estructura de "Soil Nailing" y que depende de factores incidentes, como las condiciones del terreno, el método de perforación, la sobrecarga/presión del suelo y el método de inyección del "Grout" o mortero líquido en condiciones de presión o bajo acción de la gravedad. 
- Estudio de la falla estructural en la cabeza de los "Soil Nails" o en la pantalla, la misma puede ser falla de flexión, punzonamiento o falla en la conexión de la pantalla con la cabeza del "Soil Nail".

- Estudio del comportamiento sísmico de estructuras de "Soil Nailing" considerando los efectos de sitio. Para este análisis es necesario estudiar detalladamente la zona de ubicación de la estructura en base a un estudio de caracterización sísmica del terreno para generar un espectro sísmico de sitio e incluirlo en el análisis numérico de la estructura con diferentes modelos constitutivos de suelo avanzados. 


\section{REFERENCIAS}

ACI 318 (2019). Building Code Requirements for Structural Concrete ACI 318-19. American Concrete Institute. Farmington Hills, USA.

AENOR (1999). Asociación Española de Normalización y Certificación. Geotecnia. Ensayos de campo y de laboratorio, AENOR, Madrid, Spain. [In Spanish].

Ardakani, A., Bayat, M., Javanmard, M. (2014). Numerical modeling of soil nail walls considering Mohr Coulomb, hardening soil and hardening soil with smallstrain stiffness effect models. Geomechanics and Engineering, Vol. 6, No. 4 (2014) 391-401.

ASTM (2011). American Society for Testing and Materials. Annual Book of ASTM Standards, Vol 4.08, Soil and Rock (I): D420-D5876. ASTM International, West Conshohocken.

ASTM D1586 (2011). Standard Test Method for Standard Penetration Test (SPT) and Split-Barrel Sampling of Soils. Annual Book of ASTM Standards, Vol 4.08. ASTM International, West Conshohocken.

ASTM D2435 (2011). Standard Test Methods for One-Dimensional Consolidation Properties of Soils Using Incremental Loading. Annual Book of ASTM Standards, Vol 4.08. ASTM International, West Conshohocken.

ASTM D2487 (2011). Standard Practice for Classification of Soils for Engineering Purposes (Unified Soil Classification System). Annual Book of ASTM Standards, Vol 4.08. ASTM International, West Conshohocken. 
ASTM D2850 (2015). Standard Test Method for Unconsolidated-Undrained Triaxial Compression Test on Cohesive Soils. Annual Book of ASTM Standards, Vol 4.08. ASTM International, West Conshohocken.

ASTM D4767 (2011). Standard Test Method for Consolidated Undrained Triaxial Compression Test for Cohesive Soils. Annual Book of ASTM Standards, Vol 4.08. ASTM International, West Conshohocken.

Avşar, E., Ulusay, R., Mutlutürk, M. (2015). An experimental investigation of the mechanical behavior and microstructural features of a volcanic soil (Isparta, Turkey) and stability of cut slopes in this soil. Engineering Geology 189, 68-83.

Belloni, L., Morris, D. (1991). Earthquake-induced shallow slides in volcanic debris soils. Géotechnique 41, No. 4, 539-551.

Bommer, J.J., Rolo, R., Mitroulia, A., Berdousis, P. (2002). Geotechnical properties and seismic slope stability of volcanic soils. 12th European Conference on Earthquake Engineering, Elsevier, Paper No. 695.

Benz, T. (2007). Small-Strain Stiffness of Soils and its Numerical Consequences. $\mathrm{PhD}$ Thesis. Institut für Geotechnik der Universität Stuttgart, Germany.

Brandes, H.G., Nakayama, D.D. (2010). Creep, strength and other characteristics of Hawaiian volcanic soils. Géotechnique 60, No. 4, 235-245.

Burland, J.B. (1990). On the compressibility and shear strength of natural clays. Géotechnique 40, No. 3, 329-378.

Caltrans (1991). A User's Manual for the SNAIL Program, Version 2.02 - Updated PC Version. California Department of Transportation, Division of New Technology, Material and Research, Office of Geotechnical Engineering, Sacramento, California.

Coltorti, M., Ollier, C.D. (1999). Geomorphic and tectonic evolution of the Ecuadorian Andes. Geomorphology 32 (2000) 1-19.

Clouterre (1991). Recommendations CLOUTERRE 1991 - Soil Nailing Recommendations 1991, English Translation, Presses de l'Ecole Nationale des Ponts et Chaussées, Paris, France.

Crosta, G.B., Imposimato, S., Roddeman, D., Chiesa, S., Moia, F. (2005). Small fastmoving flow-like landslides in volcanic deposits: The 2001 Las Colinas Landslide (El Salvador). Engineering Geology 79 (2005) 185-214.

Courant, R. (1943). Variational methods for the solution of problems of equilibrium and vibrations. Bull Am Math Soc 49:1-23.

del Potro, R., Hürlimann, M. (2008). Geotechnical classification and characterisation of materials for stability analyses of large volcanic slopes. Engineering Geology 98 (2008) 1-17. 
DGGM (1980). Dirección General de Geología y Minas. Hoja Geológica Sangolquí. Escala: 1:50000.

Duncan, J.M. (2000). Factors of Safety and Reliability in Geotechnical Engineering. Journal of Geotechnical and Geoenvironmental Engineering 126(4): 307-316.

Duncan, J.M., Chang, C.Y. (1970). Non-linear analysis of stress and strain in soils. Journal of the Soil Mechanics and Foundation Division, ASCE 96-SM5, 1629-1653.

Duncan, J.M., Wright, S.G. (2005). Soil Strength and Slope Stability. Wiley, Jersey city, NJ, USA.

Ehrlich, M., Silva, R.C. (2015). Behavior of a $31 \mathrm{~m}$ high excavation supported by anchoring and nailing in residual soil of gneiss. Engineering Geology 191 (2015), 48-60.

El Howayek, A., Bobet, A., Santagata, M. (2016). Geologic origin effects on mineralogy, index properties and fabric of a fine-grained carbonatic deposit. Engineering Geology 216, 108-121.

EPMMQ (2016). Empresa Pública Metropolitana Metro de Quito. Estudio Geológico Geotécnico para la Línea 1 del Metro de la Ciudad de Quito, Ecuador.

Fan, C.C., Luo, J.H. (2008). Numerical study on the optimum layout of soil-nailed slopes. Computers and Geotechnics 35 (2008) 585-599.

FHWA (2015). Federal Highway Administration. Soil Nail Walls. Reference Manual. Washington, USA.

Garzón, J., Capa, V.E., Torrijo, F.J., Company, J. (2019). Designing Soil-Nailed Walls Using the Amherst Wall Considering Problematic Issues during Execution and Service Life. International Journal of Geomechanics 2019, 19(7):05019006.

GEO (2008). Guide to Soil Nail Design and Construction (Geoguide 7). Geotechnical Engineering Office, Civil Engineering and Development Department. The Government of the Hong Kong.

González de Vallejo, L.I., Jiménez Salas, J.A., Legy Jiménez, S. (1981). Engineering geology of the tropical volcanic soils of La Laguna, Tenerife. Engineering Geology 1981 17:1-17.

González de Vallejo, L.I., Hijazo, T., Ferrer, M. (2008). Engineering Geological Properties of the Volcanic Rocks and Soils of the Canary Islands. Soils Rocks 31 (1), 3-13.

Griffiths, D.V., Lane, P.A. (1999). Slope stability analysis by finite elements. Géotechnique 49, No. 3, 387-403.

Gylland, A., Long, M., Emdal, A., Sandven, R. (2013). Characterisation and engineering properties of Tiller clay. Engineering Geology 164, 86-100. 
Hall, M.L., Samaniego, P., Le Pennec, J.L., Johnson J.B. (2008). Ecuadorian Andes volcanism: A review of Late Pliocene to present activity. Journal of Volcanology and Geothermal Research 176 (2008) 1-6.

Hardin, B.O., Black, W.L. (1969). Closure to vibration modulus of normally consolidated clays. Proc. ASCE: Journal of the Soil Mechanics and Foundations Division, 95(SM6), 1531-1537.

Head, K.H., Epps, R.J. (2014). Manual of Soil Laboratory Testing, Volume III: Effective Stress Tests, 3rd edition. Whittles Publishing. Scotland, UK.

Holman, T.P., Tuozzolo, T.J. (2009). Load Development in Soil Nails from a StrainGauge Instrumented Wall. Contemporary Topics in Ground Modification, Problem Soils, and Geo-Support, 2009 International Foundation Congress and Equipment Expo, Orlando, USA, 25-32.

Hong, C., Yin, J., Pei, H. (2013). Comparative study on pullout behaviour of pressure grouted soil nails from field and laboratory tests. J. Cent. South Univ. (2013) 20: 2285-2292.

Hu, H., Lin, P. (2019). Model Uncertainty in Predicting Facing Tensile Forces of Soil Nail Walls Using Bayesian Approach. Mathematical Problems in Engineering, Hindawi, Volume 2019, Article ID 5076438.

Hürlimann, M., Ledesma, A., Martí, J. (2001). Characterisation of a volcanic residual soil and its implications for large landslide phenomena: application to Tenerife, Canary Islands. Engineering Geology 59, 115-132.

ICE (2012). Institution of Civil Engineers. ICE manual of geotechnical engineering. Geotechnical Design, Construction and Verification. Volume II. Chapter 74: Design of soil nails by Whitbread, M.J. London, United Kingdom.

Kempfert, H.G., Gebreselassie, B. (2006). Excavations and Foundations in Soft Soils. Springer. Netherlands.

Konkol, J., Międlarz, K., Bałachowski, L. (2019). Geotechnical characterization of soft soil deposits in Northern Poland. Engineering Geology 259 105187, doi.org/10.1016/j.enggeo.2019.105187.

Kumar, R., Bhargava, K., Choudhury, D. (2016). Estimation of Engineering Properties of Soils from Field SPT Using Random Number Generation. INAE Lett (2016) 1:77-84, doi 10.1007/s41403-016-0012-6.

Ladd, C.C., DeGroot, D.J. (2003). Recommended practice for soft ground site characterization: Arthur Casagrande Lecture. 12th Panamerican Conference on Soil Mechanics and Geotechnical Engineering.

Lang, T.A. (1961). Theory and Practice of Rock Bolting. Transactions of the American Institute of Mining Engineers, Vol. 220, 333-348. Englewood, CO. 
Leroueil, S., Magnan, J.P., Tavernas, F. (1990). Embankments on soft clays. Tran. By Wood, D.M. Ellis Horwood, New York.

Lin, P., Liu, J. (2016). Analysis of resistance factors for LFRD of soil nail walls against external stability failures. Acta Geotechnica (2017) 12:157-169.

Low, H.E., Landon Maynard, M., Randolph, M.F., DeGroot, D.J. (2011). Geotechnical characterization and engineering properties of Burswood clay. Géotechnique 61, No. 7, 575-591.

Martin-Gombojav, N., Winkler, W. (2008). Recycling of Proterozoic crust in the Andean Amazon foreland of Ecuador: implications for orogenic development of the Northern Andes. Terra Nova, 20, 22-31.

Mayne, P.W., Kulhawy, F.H. (1982). Ko-OCR Relationships in Soils. Journal of the Geotechnical Engineering Division ASCE. Vol. 108 No. GT6 851-872.

Menkiti, C.O., Long., M. (2008). Performance of soil nails in Dublin glacial till. Canadian Geotechnical Journal 45: 1685-1698.

Menkiti, C.O., Long, M., Milligan, G.W.E., Higgins, P. (2013). Soil Nailing in Dublin Boulder Clay. Geotech Geol Eng (2014) 32:1427-1438.

Mujtaba, H., Farooq, K., Sivakugan, N., Das, B. (2017). Evaluation of Relative Density and Friction Angle Base on SPT-N Values. KSCE Journal of Civil Engineering, 22(2), 572-581.

NEC (2015). Norma Ecuatoriana de la Construcción. Estructuras de Hormigón Armado. Código NEC-SE-HM. MIDUVI, CAMICON. Quito, Ecuador.

O'Rourke, T.D., Crespo, E. (1988). Geotechnical Properties of Cemented Volcanic Soils. J. Geotech. Eng. 114(10), 1126-1147.

Ortigao, J.A.R, Sayao, A.S.F.J. (2004). Handbook of Slope Stabilisation. Chapter 13: Soil Nailing by Ortigao and Palmeira. Springer, Berlin, Heidelberg.

Pilecki, T.J. (1990). Geotechnical Properties of Cemented Volcanic Soils (Discussion). J. Geotech. Engrg. 116(2): 349-352.

PLAXIS (2020). PLAXIS Material Models. Connect Edition V20. Delft, The Netherlands.

PLAXIS (2020). PLAXIS 2D Reference Manual. Connect Edition V20. Delf, The Netherlands.

Pineda, J.A., Suwal, L.P., Kelly, R.B., Bates, L., Sloan, W. (2016). Characterisation of Ballina clay. Géotechnique 66, No. 7, 556-577. 
Pradhan, S.P., Vishal, V., Singh, T.N. (2018). Finite element modelling of landslide prone slopes around Rudraprayag and Agastyamuni in Uttarakhand Himalayan terrain. Natural Hazards (2018) 94:181-200.

Pradhan, S.P., Vishal, V., Singh, T.N. (2019). Landslides: Theory, Practice and Modelling. Chapter 9: Soil Nailing: An Effective Slope Stabilization Technique by Sharma M., Samanta M. and Sarkar S. Springer, Cham.

Rabcewicz, L. (1964a). The New Austrian Tunnelling Method. Part I, Water Power 16 (11):453-457.

Rabcewicz, L. (1964b). The New Austrian Tunnelling Method. Part II, Water Power 16 (12):511-515.

Rabcewicz, L. (1965). The New Austrian Tunnelling Method. Part III, Water Power 17(1):19-24.

Rabejac, S., Toudic, P. (1974). Construction d'un mur de soutènement entre Versailles-Chantiers et Versailles-Matelots. (Trans: Construction of a retaining wall between Versailles-Chantiers and Versailles-Matelots). Revue générale des chemins de fer, Vol. 93, Paris, France, 232-237.

Rabie, M. (2014). Comparison study between traditional and finite element methods for slopes under heavy rainfall. HBRC Journal (2014) 10, 160-168.

Rabie, M. (2016). Performance of hybrid MSE/Soil Nail walls using numerical analysis and limit equilibrium approaches. HBRC Journal (2016) 12, 63-70.

Rawat, S., Gupta, A.K. (2016). Analysis of a Nailed Soil Slope Using Limit Equilibrium and Finite Element Methods. Int. J. of Geosynth. and Ground Eng. (2016) 2:34.

Rocscience (2020). Slide2 Modeler, 2D Limit Equilibrium Analysis for Slopes. Toronto, Canadá.

Rodríguez-Peces, M.J., Gordón-Pérez, D. (2015). Análisis automático de la susceptibilidad de las inestabilidades de laderas provocadas por terremotos en un sector de la Cordillera de Los Andes, Ecuador. Revista de la Sociedad Geológica de España 28(1): 91-104.

Ruiz, G.M.H., Seward, D., Winkler, W. (2007). Evolution of the Amazon Basin in Ecuador with special reference to hinterland tectonics: Data from zircon fission-track and heavy mineral analysis. Developments in Sedimentology, Vol. 58, 907-934.

Schanz, T., Vermeer, P.A., Bonnier, P.G. (1999). The hardening soil model: Formulation and verification. Beyond 2000 in Computational Geotechnics - 10 years of PLAXIS. 
Sheahan, T. (2000). A field study of soil nails in clay at the UMass NGES. National Geotechnical Experimentation Sites, Geotechnical Special Publication 93, edited by J. Benoit and A. J. Lutenegger, 250-263. Reston, VA: ASCE.

Shiu, Y.K., Chang, G.W.K., Cheung, W.M. (2007). Review of Limit Equilibrium Methods for Soil Nail Design (GEO Report No. 208). Geotechnical Engineering Office, Civil Engineering and Development Department, Hong Kong.

Singh, V.P., Sivakumar Babu, G.L. (2009). 2D Numerical Simulations of Soil Nail Walls. Geotech Geol Eng (2010) 28:299-309.

Sivakumar Babu, G.L., Singh, V.P. (2009). Simulation of Soil Nail Structures using PLAXIS 2D. Plaxis Bulletin. Spring issue 2009.

Spikings, R., Simpson G. (2014). Rock uplift and exhumation of continental margins by the collision, accretion, and subduction of buoyant and topographically prominent oceanic crust. Tectonics, 33, doi:10.1002/2013TC003425.

Stocker, M.F., Korber, G.W., Gässler, G., Gudehus, G. (1979). Soil Nailing. International Conference on Soil Reinforcement I. Paris, France, Vol. 2, 469-474.

Surarak, C., Likitlersuang, S., Wanatowski, D., Balasubramaniam, A., Oh, E., Guan, H. (2012). Stiffness and strength parameters for hardening soil model of soft and stiff Bangkok clays. Soils and Foundations 2012; 52(4): 682-697.

Tan, D., Sarma, S.K. (2008). Finite element verification of an enhanced limit equilibrium method for slope analysis. Géotechnique 58, No. 6, 481-487.

Teo, P.L., Wong, K.S. (2012). Application of the Hardening Soil model in deep excavation analysis. The IES Journal Part A: Civil \& Structural Engineering, 5:3, 152-165.

Turner, J.P., Jensen, W.G. (2005). Landslide Stabilization Using Soil Nail and Mechanically Stabilized Earth Walls: Case Study. Journal of Geotechnical and Geoenvironmental Engineering 131(2): 141-150.

Vezzoli, L., Apuani, T., Corazzato, C., Uttini, A. (2017). Geological and geotechnical characterization of the debris avalanche and pyroclastic deposits of Cotopaxi Volcano (Ecuador). A contribute to instability-related hazard studies. Journal of Volcanology and Geothermal Research 332 (2017) 51-70.

Villalobos, S.A., Oróstegui, P.L., Villalobos, F.A. (2013). Re-assessing a soil nailing design in heavily weathered granite after a strong earthquake. Bull Eng Geol Envirom (2013) 72: 203-212.

Wei, W.B., Cheng, Y.M. (2010). Soil nailed slope by strength reduction and limit equilibrium methods. Computers and Geotechnics 37 (2010) 602-618. 
Wesley, L.D. (1973). Some basic engineering properties of halloysite and allophane clays in Java, Indonesia. Géotechnique 23, No. 4, 471-494.

Wesley, L.D. (1990). Influence of structure and composition on residual soils. Journal of Geotechnical Engineering, Vol. 116, No. 4.

Wright, S.G., Duncan, J.M. (1991). Limit equilibrium stability analyses for reinforced slopes. Transp Res Rec 1330:40-46.

Wroth, C.P., Houlsby, G.T. (1985). Soil mechanics - Property characterization and analysis procedures. Proc. $11^{\text {th }}$ ICSMFE, San Francisco, 1-55.

Wu, J.T.H., Tung, C.-Y. (2019). Determination of Model Parameters for the Hardening Soil Model. Transportation Infrastructure Geotechnology, doi.org/10.1007/s40515-019-00085-8.

Wu, X., El Naggar, H., Valsangkar, A.J. (2017). Finite-element and limit equilibrium analyses of a stabilised natural high slope. Ground Improvement 170 May 2017 Issue GI2, pages 89-101.

Zhu, D.Y., Lee, C.F., Jiang, H.D. (2003). Generalised framework of limit equilibrium methods for slope stability analysis. Géotechnique 53, No. 4, 377-395.

Zhu, F., Miao, L., Gu, H., Cheng, Y. (2013). A case study on behaviors of composite soil nailed wall with bored piles in a deep excavation. J. Cent. South Univ. (2013) 20: 2017-2024. 


\section{APÉNDICE}

\section{A.1. Ensayos de difracción de rayos $X$}

En esta sección se presentan los difractogramas de los ensayos de difracción de rayos $\mathrm{X}(X R D)$ realizados en las muestras de los sondeos JAPl y $A M A 1$, como parte del estudio de caracterización geotécnica, llevados a cabo en el Laboratorio de Geología de la Universitat de València (Valencia, España). 


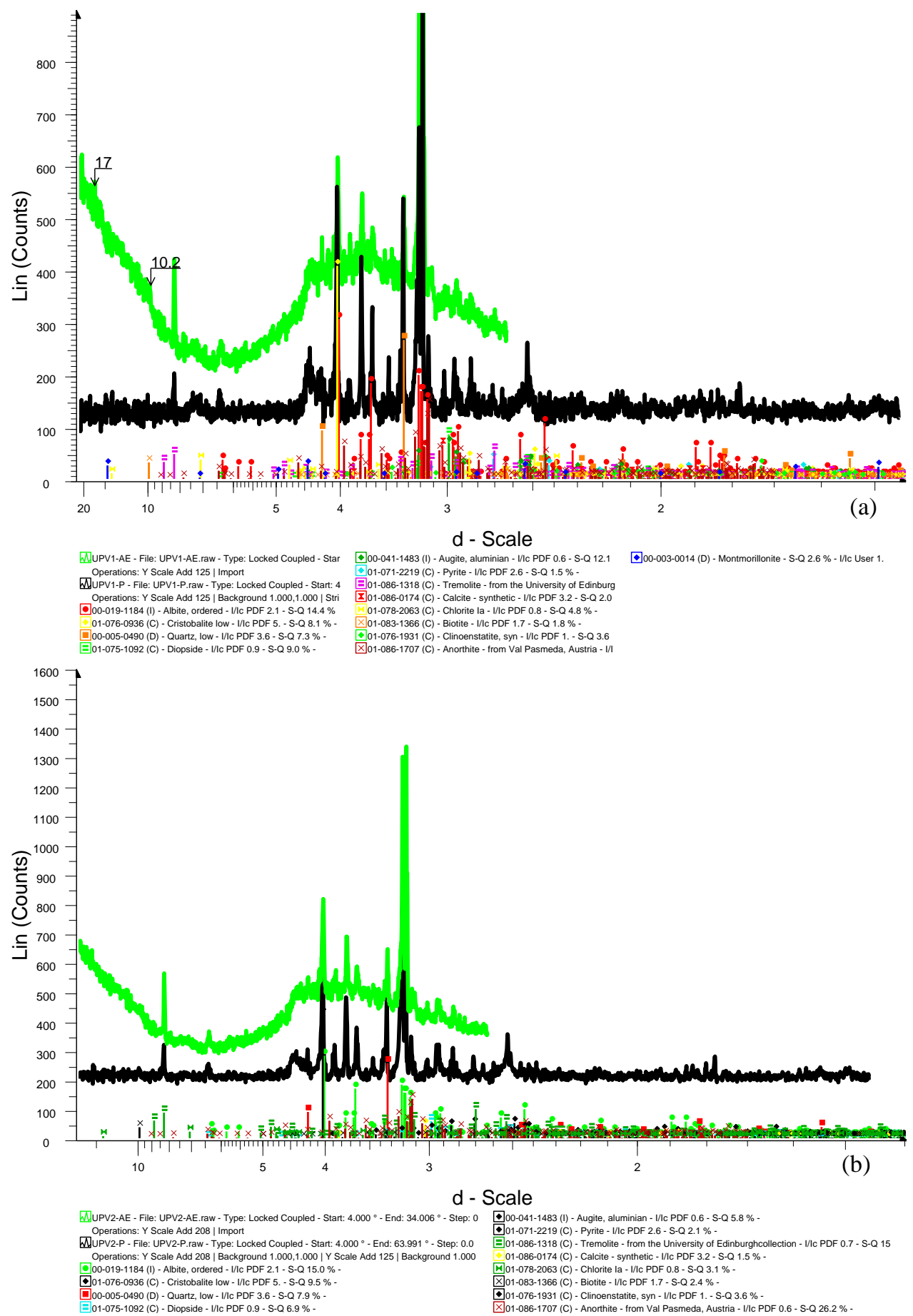

Fig. A.1 Difractogramas de ensayos de difracción de rayos X: (a) JAP1 $3.50 \mathrm{~m}$, (b) JAP1 $7.50 \mathrm{~m}$. 


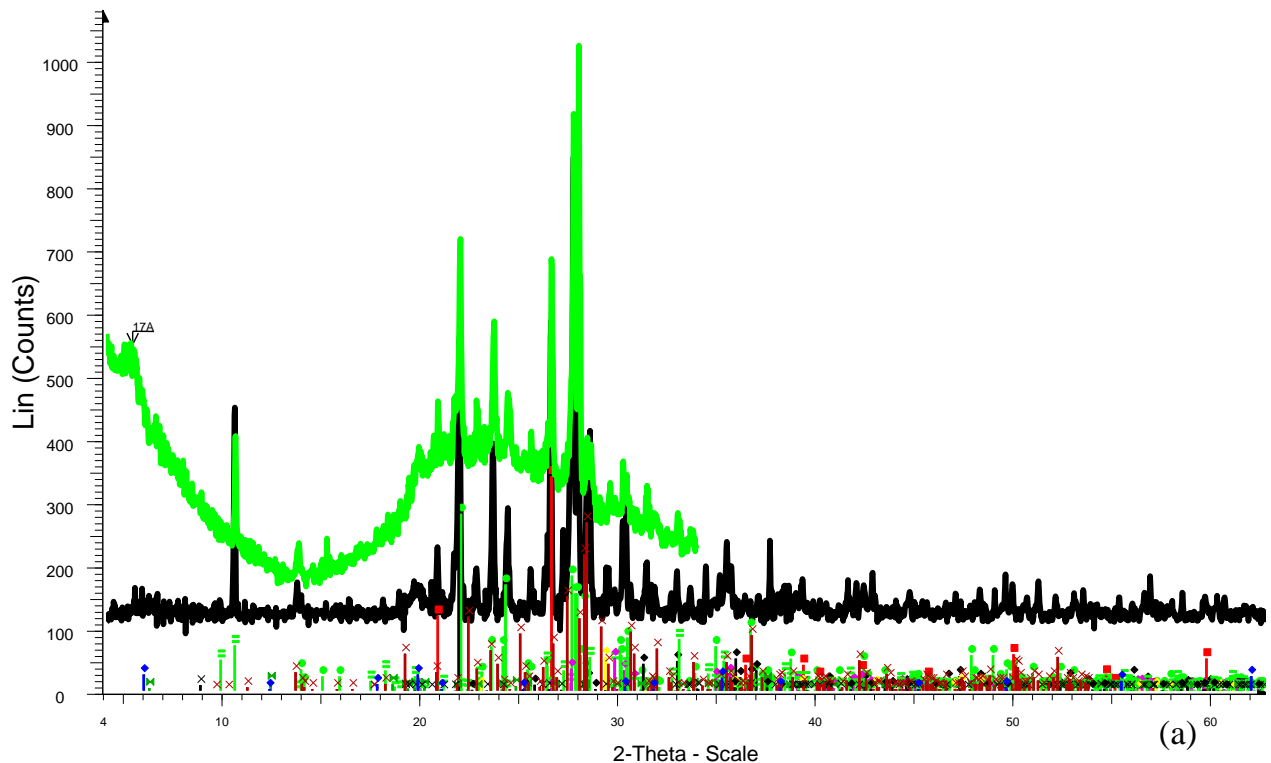

WuPV3-P - File: UPV3-P.raw - Type: Locked Coupled - Start: 4 00-041-1483 (I) - Augite, aluminian - I//c PDF 0.6 - S-Q $8.1 \quad \square 00-003-0014$ (D) - Montmorillonite - S-Q $2.2 \%$ - I//c User 1 Operations: Y Scale Add 125 | Background 1.000,1.000 |YS 01-071-2219 (C) - Pyrite - 1//c PDF 2.6 - S-Q $1.6 \%$

MUPV3-AE - File: UPV3-AE.raw - Type: Locked Coupled - Star E01-086-1318 (C) - Tremolite - from the University of Edinburg

Operations: Y Scale Add 83 / Import

00-019-1184 (I) - Albite, ordered - ///C PDF 2.1 - S-Q $11.6 \%$ 01-078-2063 (C) - Chlorite la - I//C PDF 0.8 - S-Q $1.6 \%$ -

01-076-0936 (C) - Cristobalite low- MC PDF 5. - S-Q $7.4 \%$ - $01-083-1366$ (C) - Biotite - Mc PDF 1.7 - S-Q $0.4 \%$ -

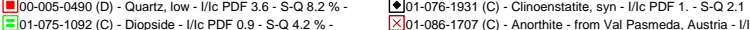

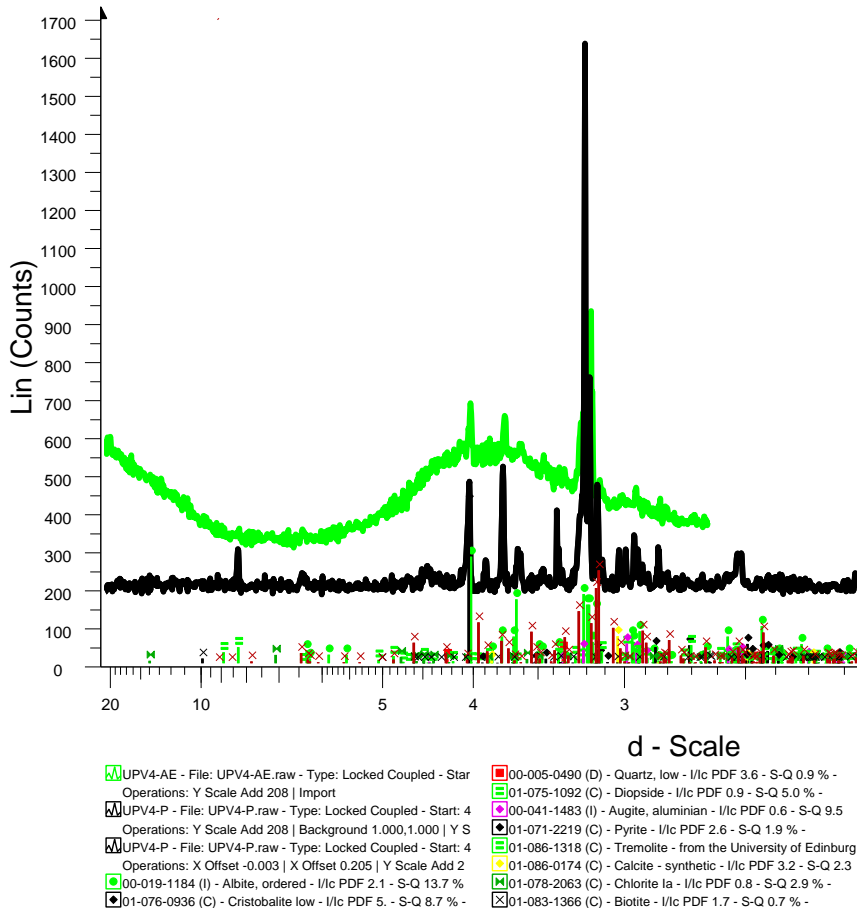

Fig. A.2 Difractogramas de ensayos de difracción de rayos X: (a) JAP1 9.00 m, (b) JAP1 $11.00 \mathrm{~m}$. 

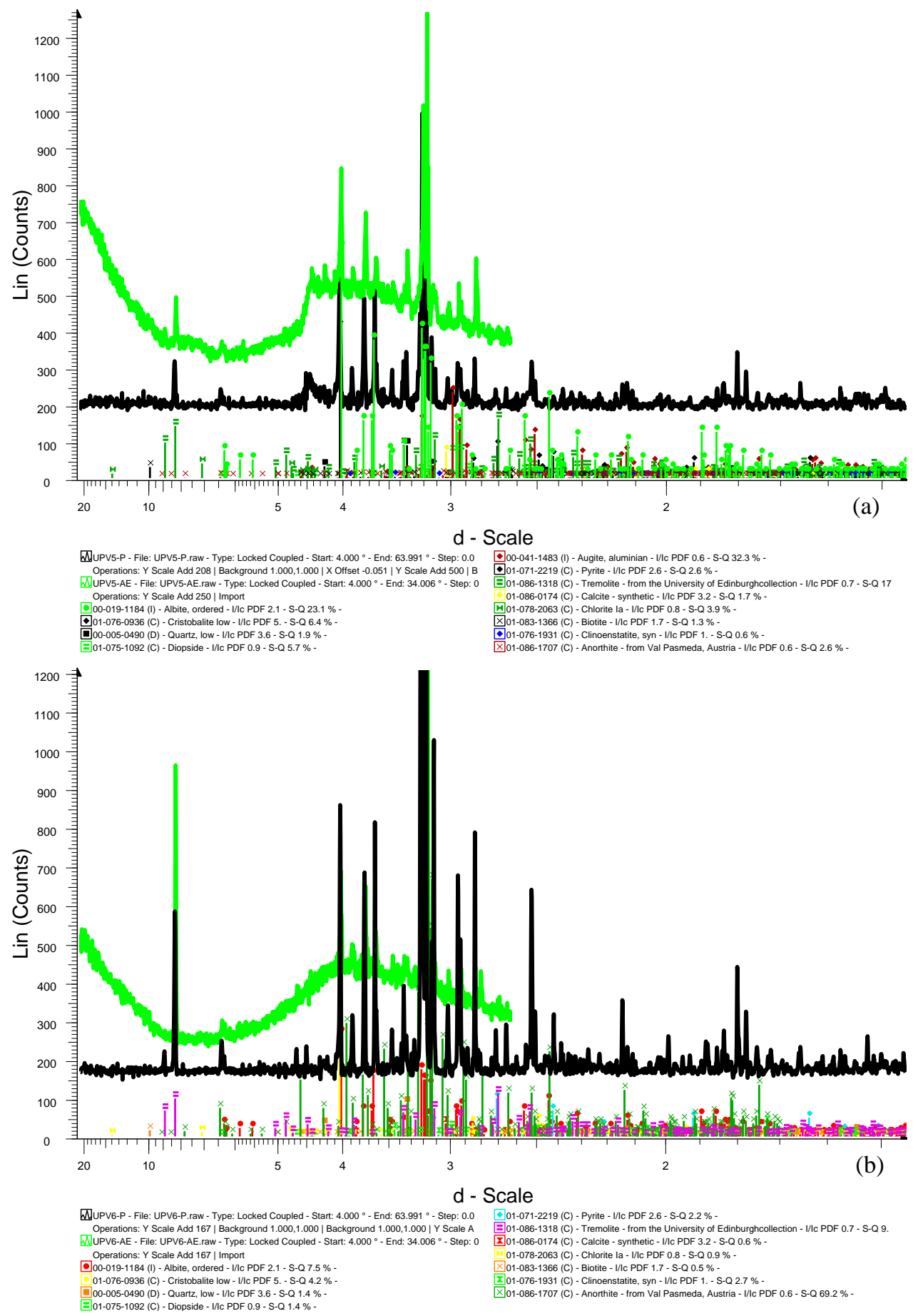

Fig. A.3 Difractogramas de ensayos de difracción de rayos X: (a) JAPl 14.50 m, (b) AMA1 $1.80 \mathrm{~m}$. 


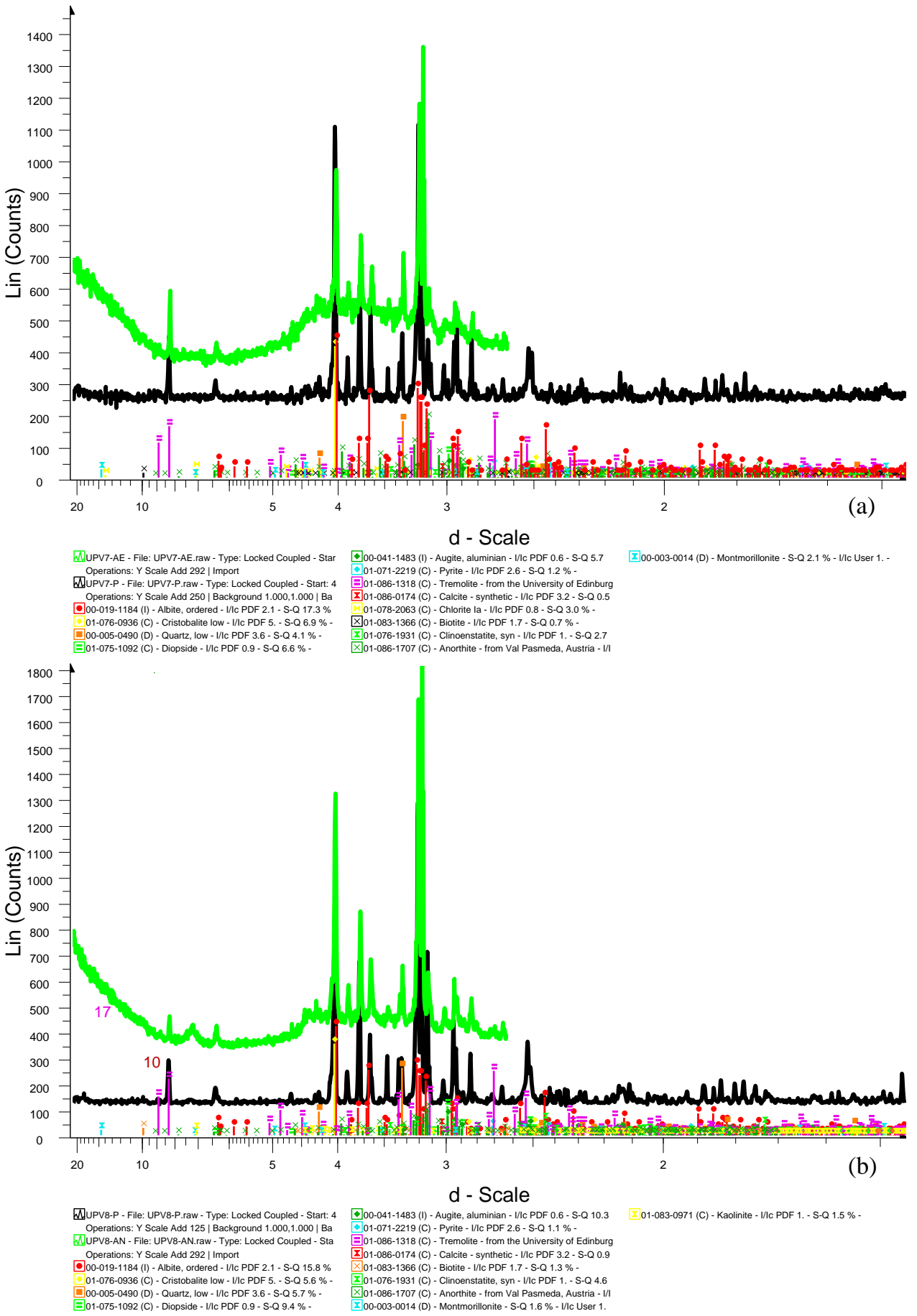

Fig. A.4 Difractogramas de ensayos de difracción de rayos X: (a) AMA1 4.50 m, (b) AMA1 8.00 m. 


\section{A.2. Ensayos de consolidación unidimensional}

En esta sección se presentan las curvas, relación de vacíos - esfuerzo efectivo vertical, e- $\sigma$ 'v, de los ensayos de consolidación unidimensional realizados en las muestras de los sondeos JAPl y AMA1, como parte del estudio de caracterización geotécnica.

Los esfuerzos de sobrecarga fueron incrementados de $5 \mathrm{kPa}$ hasta $1000 \mathrm{kPa}$, aunque algunos especímenes fueron cargados hasta $2000 \mathrm{kPa}$. Cada escalón de incremento de carga se mantuvo durante 24 horas.

Estos ensayos se llevaron a cabo en el Laboratorio de Mecánica de Suelos del Departamento de Ingeniería del Terreno de la Universitat Politècnica de València (Valencia, España).

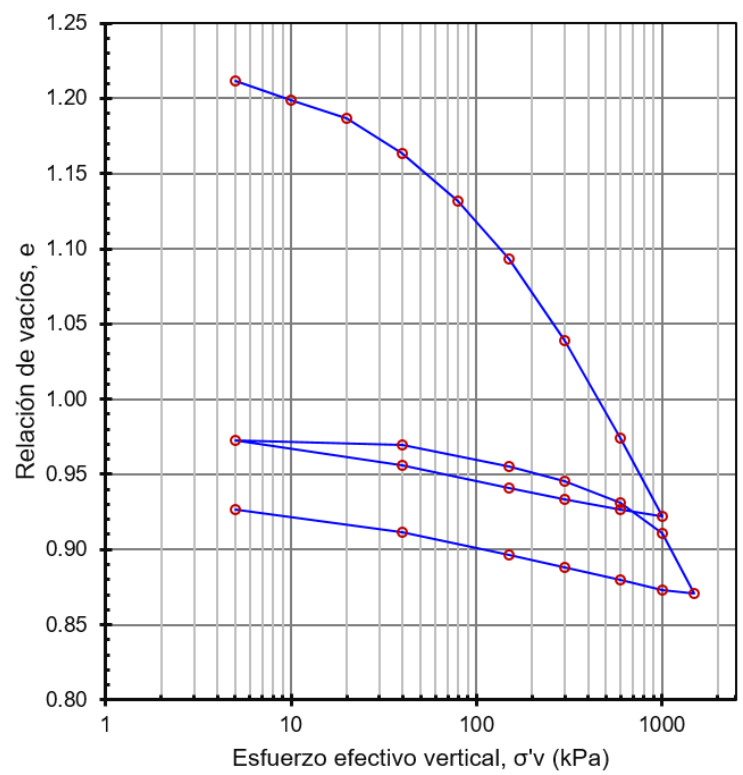

Fig. A.5 Curva relación de vacíos-esfuerzo efectivo vertical, de ensayo de consolidación unidimensional realizado en muestra JAP1 $3.50 \mathrm{~m}$. 


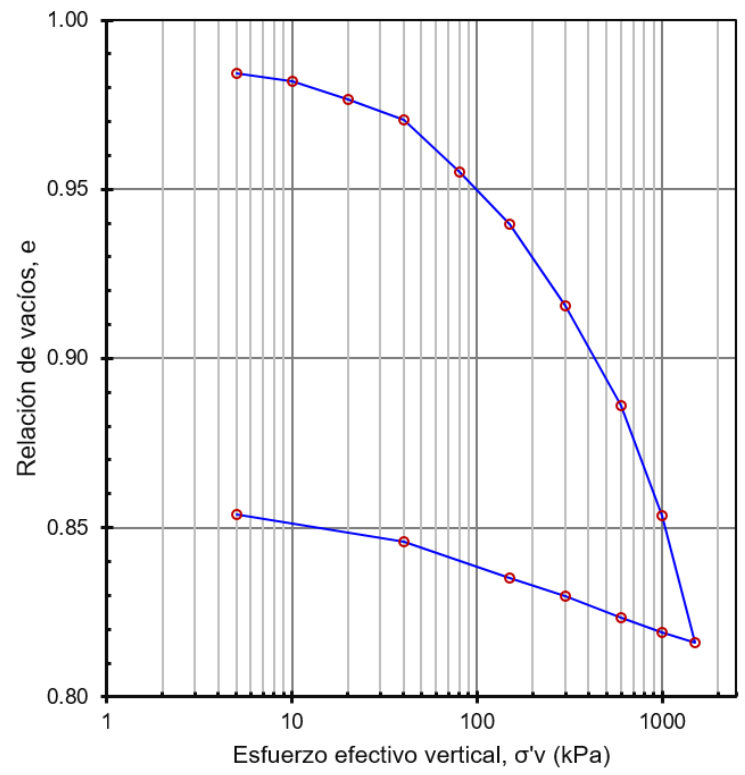

Fig. A.6 Curva relación de vacíos-esfuerzo efectivo vertical, de ensayo de consolidación unidimensional realizado en muestra JAPl $6.50 \mathrm{~m}$.

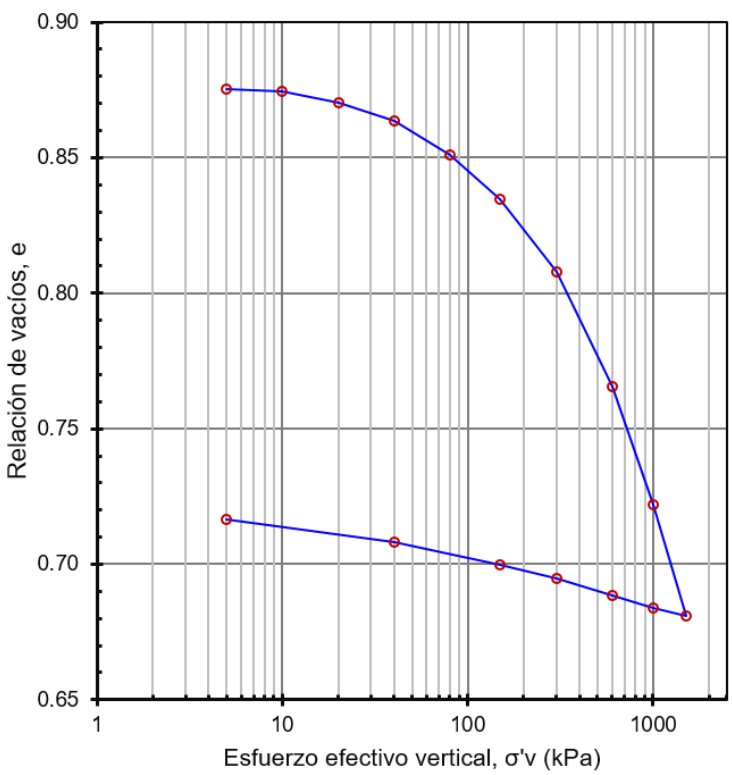

Fig. A.7 Curva relación de vacíos-esfuerzo efectivo vertical, de ensayo de consolidación unidimensional realizado en muestra JAP1 $9.00 \mathrm{~m}$. 


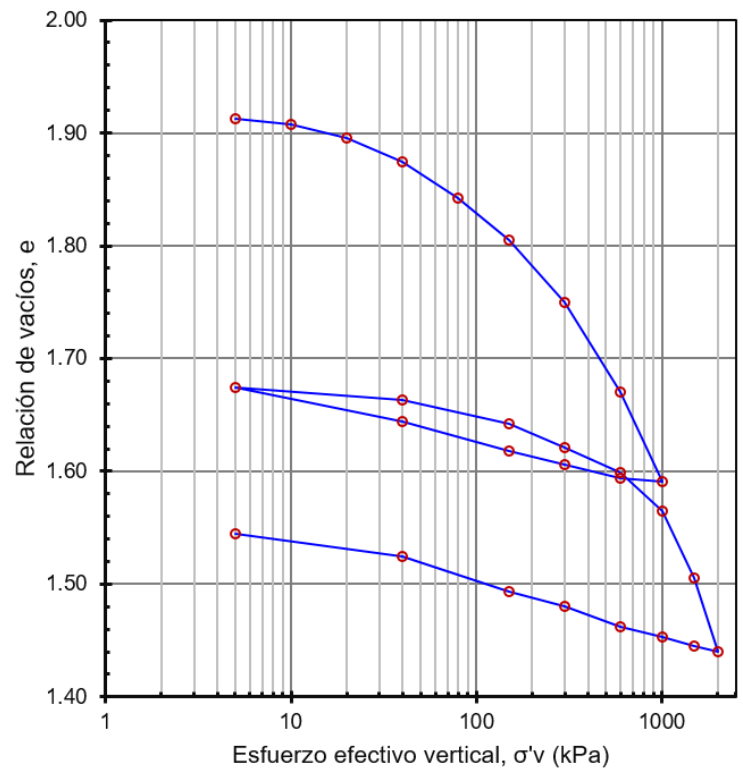

Fig. A.8 Curva relación de vacíos-esfuerzo efectivo vertical, de ensayo de consolidación unidimensional realizado en muestra JAPl $11.00 \mathrm{~m}$.

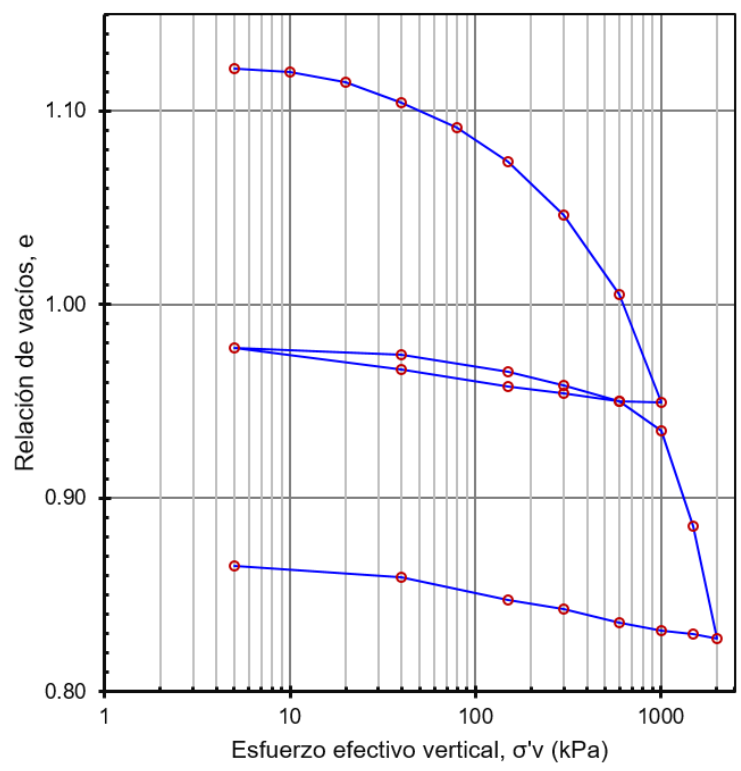

Fig. A.9 Curva relación de vacíos-esfuerzo efectivo vertical, de ensayo de consolidación unidimensional realizado en muestra JAP1 $14.50 \mathrm{~m}$. 


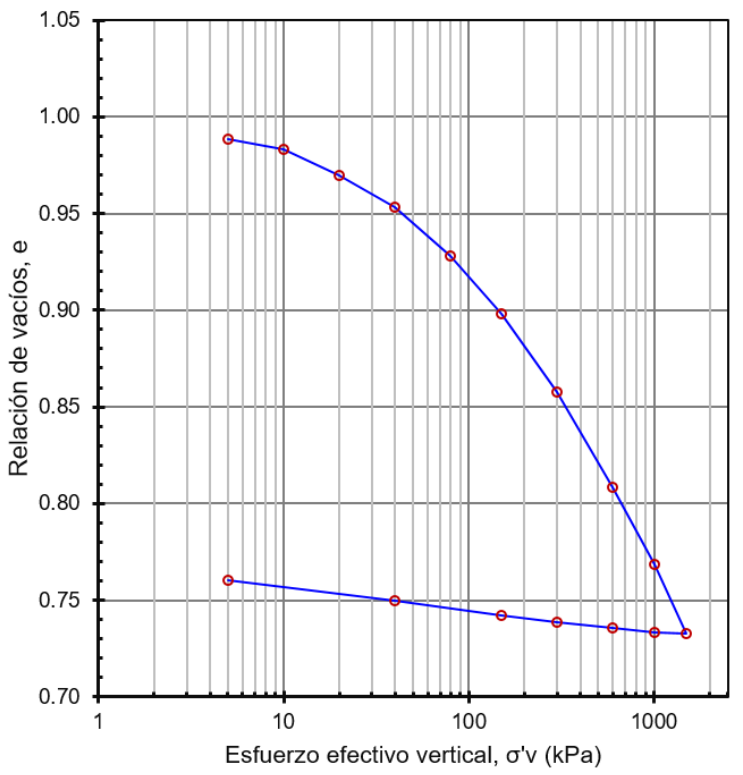

Fig. A.10 Curva relación de vacíos-esfuerzo efectivo vertical, de ensayo de consolidación unidimensional realizado en muestra AMA1 $1.50 \mathrm{~m}$.

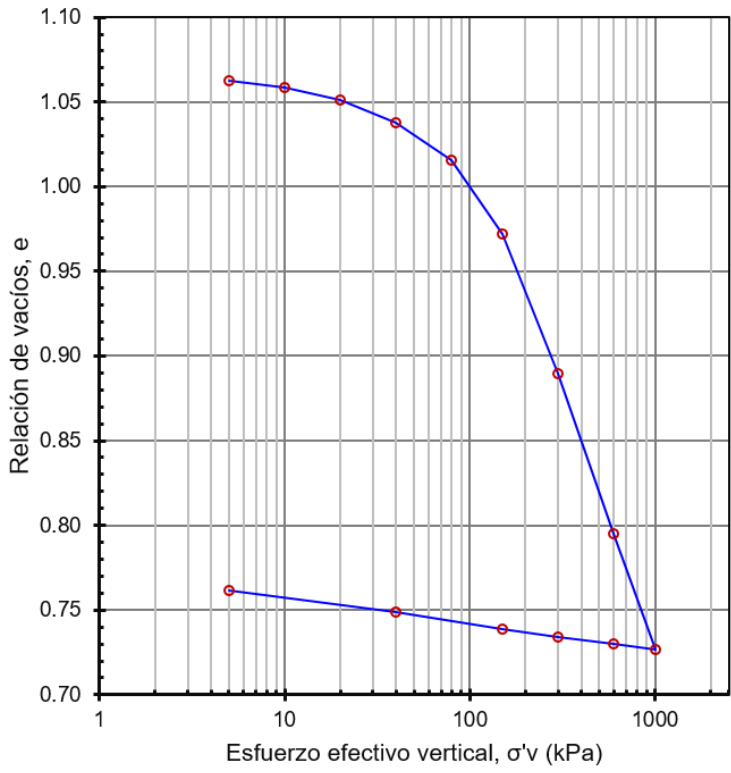

Fig. A.11 Curva relación de vacíos-esfuerzo efectivo vertical, de ensayo de consolidación unidimensional realizado en muestra AMA1 $2.00 \mathrm{~m}$. 


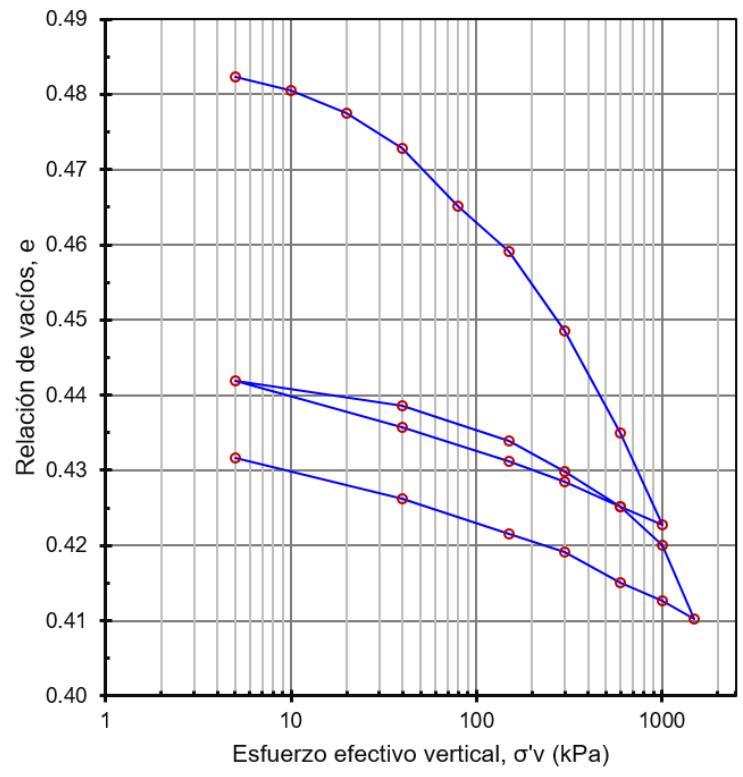

Fig. A.12 Curva relación de vacíos-esfuerzo efectivo vertical, de ensayo de consolidación unidimensional realizado en muestra AMA1 $6.00 \mathrm{~m}$.

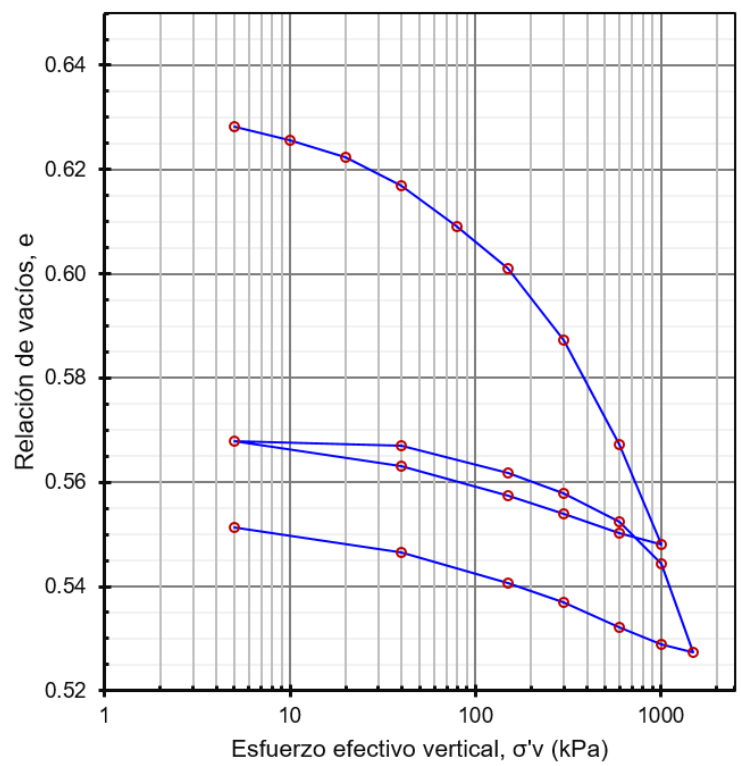

Fig. A.13 Curva relación de vacíos-esfuerzo efectivo vertical, de ensayo de consolidación unidimensional realizado en muestra AMA1 $7.50 \mathrm{~m}$. 


\section{A.3. Trayectorias de tensiones efectivas en ensayos triaxiales tipo $C U$}

En esta sección se presentan las curvas de trayectorias de tensiones efectivas obtenidas de los ensayos triaxiales consolidados no drenados con medida de presión de poros, en las muestras de los sondeos JAPl y AMAl, como parte del estudio de caracterización geotécnica. Estos ensayos se realizaron en el Laboratorio de Mecánica de Suelos del Departamento de Ingeniería del Terreno de la Universitat Politècnica de València (Valencia, España).

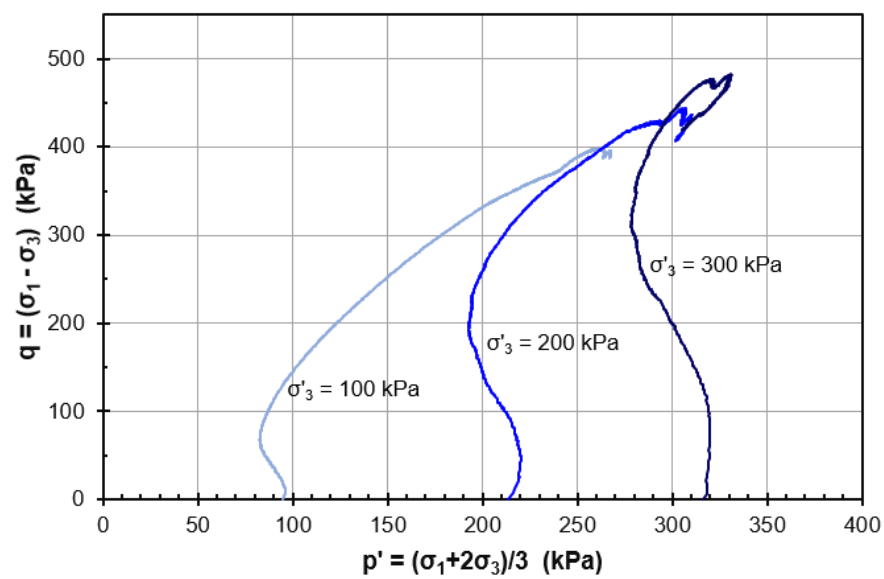

Fig. A.14 Trayectorias de tensiones efectivas de ensayo triaxial tipo $C U$ realizado en muestra $J A P 1$ $3.50 \mathrm{~m}$.

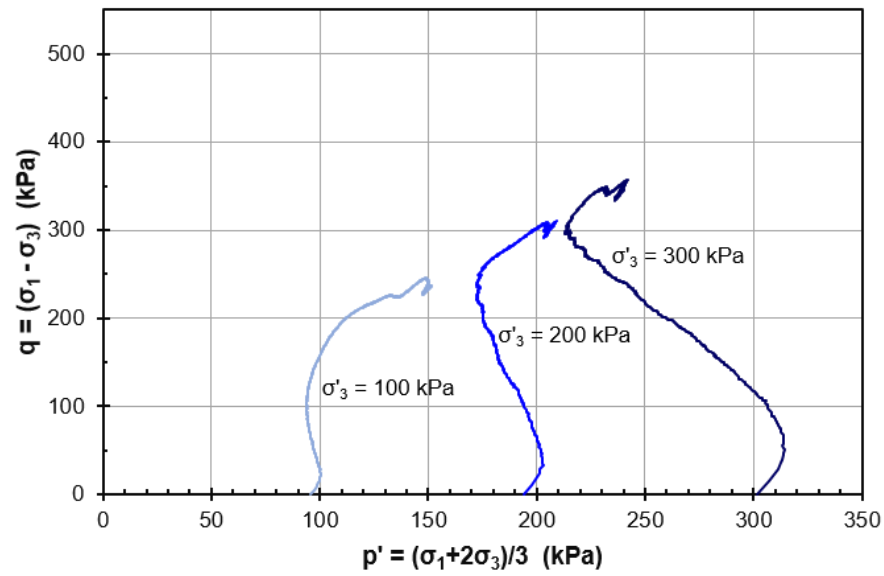

Fig. A.15 Trayectorias de tensiones efectivas de ensayo triaxial tipo $C U$ realizado en muestra JAP1 $7.50 \mathrm{~m}$. 


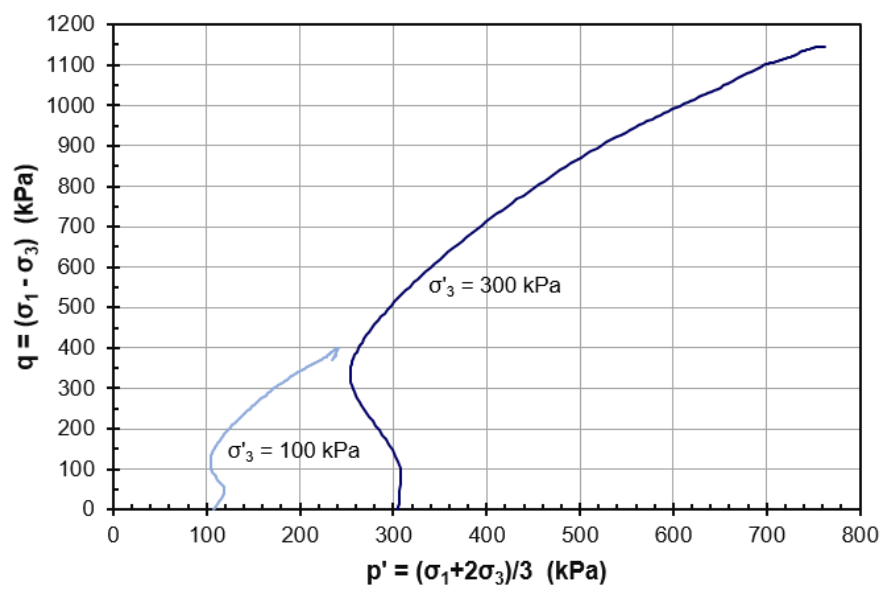

Fig. A.16 Trayectorias de tensiones efectivas de ensayo triaxial tipo $C U$ realizado en muestra JAP1 $9.00 \mathrm{~m}$.

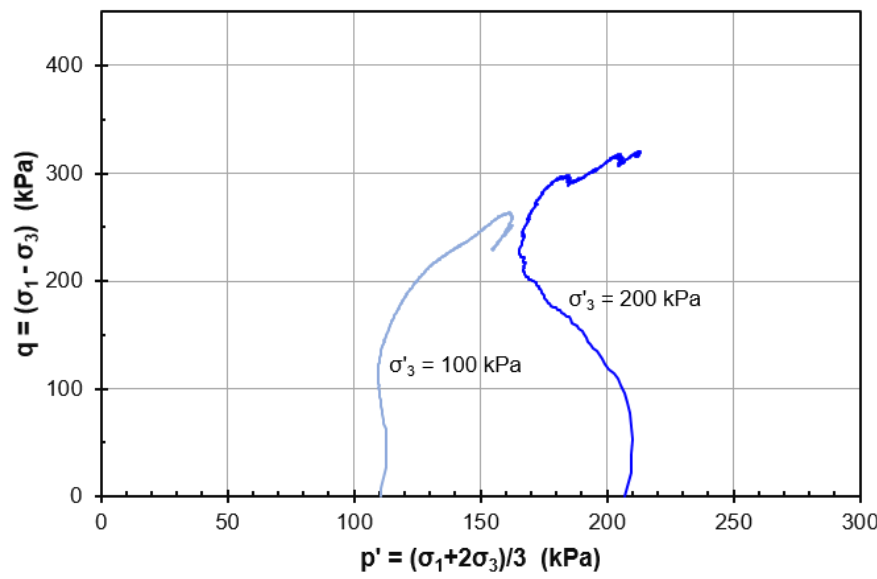

Fig. A.17 Trayectorias de tensiones efectivas de ensayo triaxial tipo $C U$ realizado en muestra JAP1 $11.00 \mathrm{~m}$. 


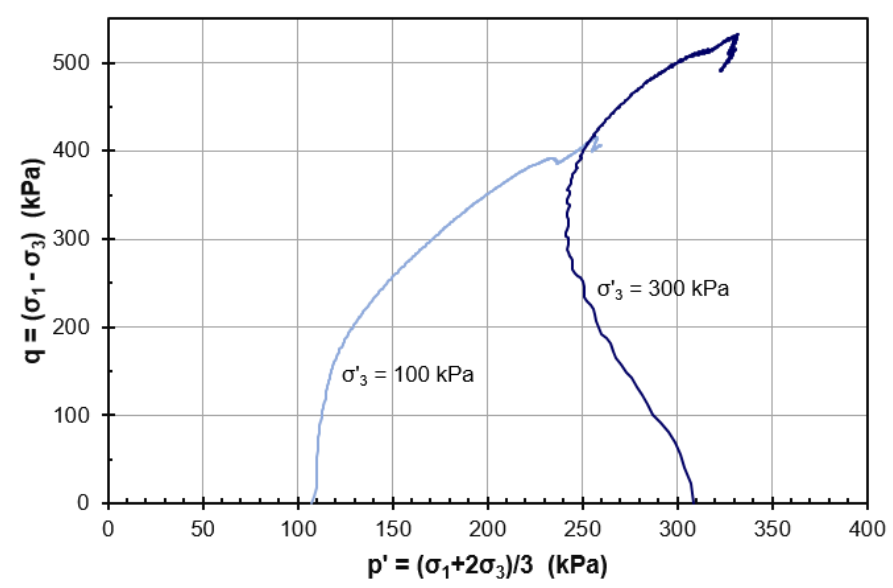

Fig. A.18 Trayectorias de tensiones efectivas de ensayo triaxial tipo $C U$ realizado en muestra JAP1 $14.50 \mathrm{~m}$.

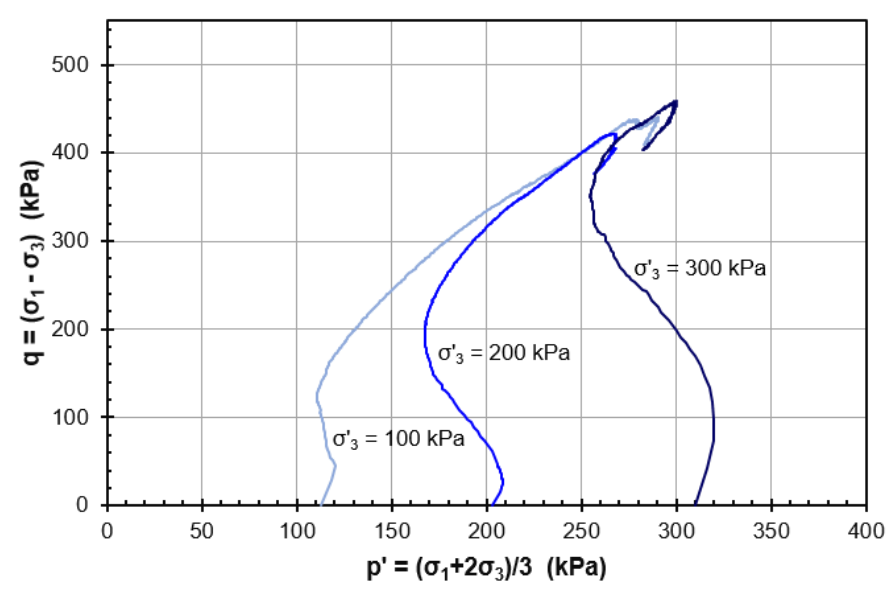

Fig. A.19 Trayectorias de tensiones efectivas de ensayo triaxial tipo $C U$ realizado en muestra $A M A 1$ $4.50 \mathrm{~m}$. 


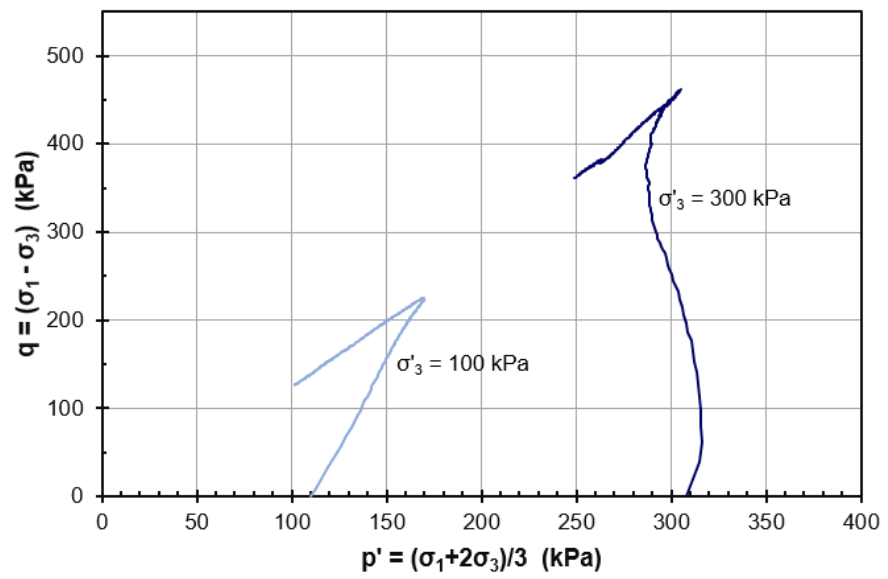

Fig. A.20 Trayectorias de tensiones efectivas de ensayo triaxial tipo $C U$ realizado en muestra $A M A 1$ $6.00 \mathrm{~m}$. 